\title{
SKILLS DEVELOPMENT, THE ENABLING ENVIRONMENT AND INFORMAL MICRO-ENTERPRISE IN GHANA
}

\author{
Robert Palmer
}

PhD

The University of Edinburgh 
This thesis is dedicated to

\section{John Albert Durrad 1917-2005}




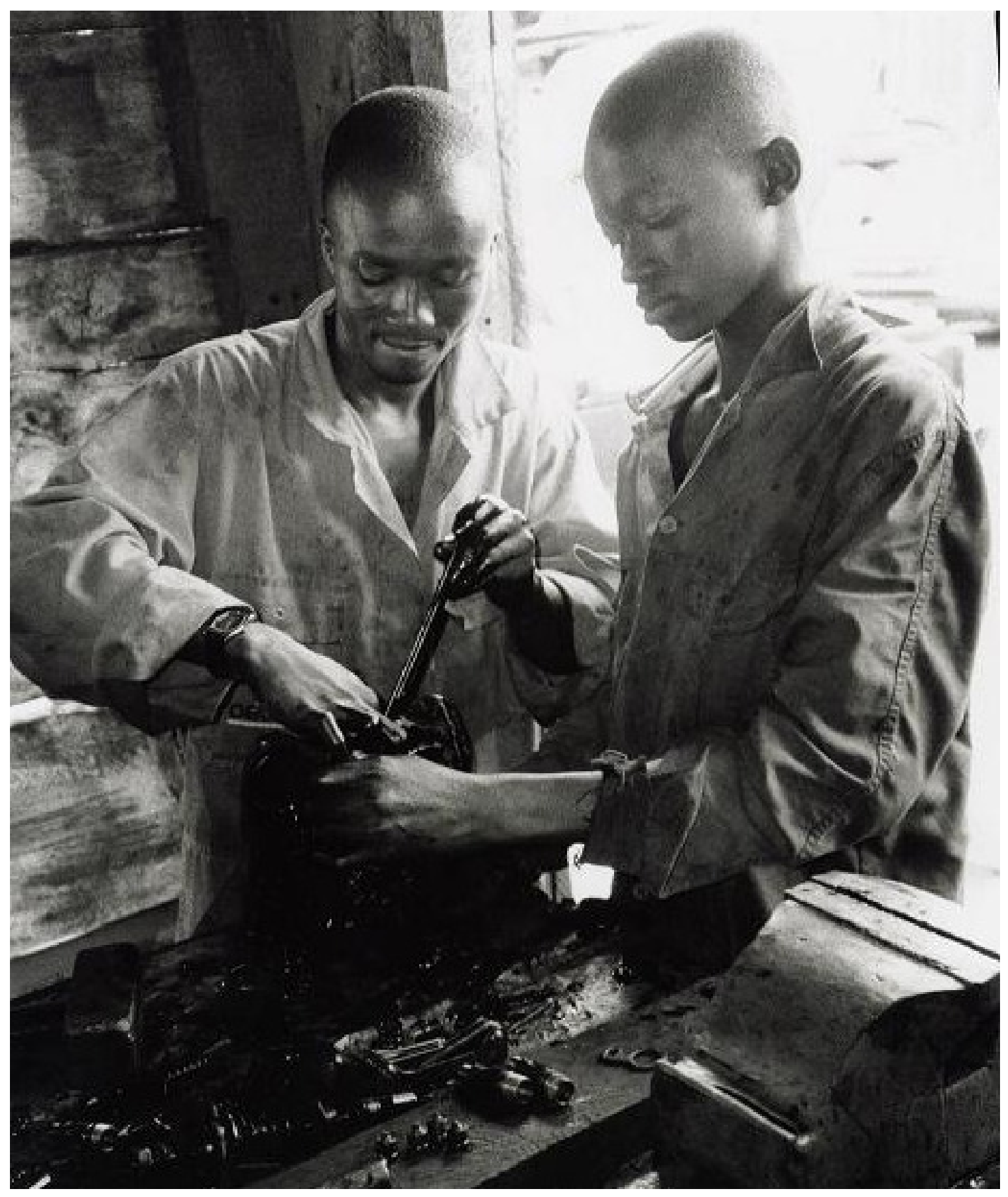

Photo 1. Master George (left) and his apprentice, Suame Magazine (Kumasi), August 2003 


\section{Declaration}

This thesis has been composed by myself from results of my own work, except where stated otherwise. It has not been submitted in any previous application for a degree.

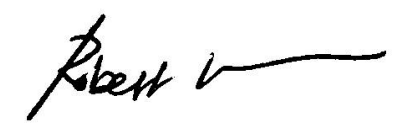

Robert Palmer

December 2006 


\begin{abstract}
Unemployment and underemployment, particularly among the youth, are serious concerns to governments across Sub-Saharan Africa (SSA). Fifteen years on from the World Conference on Education For All (EFA) in Jomtien, EFA policies have started to result in some of the largest cohorts of primary school leavers ever witnessed in many parts of SSA. This is occurring at a time when SSA's formal sector is unable to generate sufficient formal employment and income opportunities. The great majority of all school leavers, therefore, are obliged to enter the informal, micro-enterprise economy, urban and rural, and receive informal training in traditional apprenticeships and/or through other on-the-job means.
\end{abstract}

However the links between education, training and enterprise are still poorly understood. This study presents an investigation into how young people construct and are able to navigate these pathways to informal self-employment in rural Ghana by acquiring skills and schooling from multiple sources, and through seeking assistance from informal networks. It makes a contribution not only to understanding the transition from training to self-employment, but also to the nature of the rural informal sector in Ghana.

This study examines three types of skills training provision; on-the-job apprenticeship training, short-term modular training and longer-term pre-employment training, examining both the delivery context of these different training modalities, as well as the graduates' labour market outcomes. The analysis is based on 12 months fieldwork in rural Ghana in 2004 and 2005 during which time multiple approaches were used to uncover these skill-to-work pathways; tracer studies with 162 vocational training graduates, semi-structured interviews with 160 apprentices and a household survey capturing data on 147 youth. Furthermore, retrospective interviews with 114 enterprise owners were conducted to better understand pathways to informal self-employment and the multiple occupational realities, or occupational pluralism, of many of those in this rural African economy. This data suggests that the school-skill-enterprise relationship is highly dependent on the delivery context of training as well as the type of enabling or disabling environments within which the training is translated into employment outcomes.

This study also includes an analysis of the long history of Ghana's skills development policies and practice - up to 2006. This is integrated with a discussion on the wider environment within which skills are delivered, particularly the labour market, and how this impacts on the employment opportunities of technical and vocational education and training graduates in Ghana. 


\section{Acknowledgements}

I should start by thanking Kenneth King and Simon McGrath for producing Enterprise in Africa. On returning from my first 11 month visit to Ghana in December 2001, it was this book which drew my attention to the Centre of African Studies (CAS) in Edinburgh.

In CAS my thanks go to my two supervisors, Professors Kenneth King and Paul Nugent. Both of these master-craftsmen have been very helpful in providing comments, feedback and encouragement to me at every stage of this $\mathrm{PhD}$ apprenticeship. Doing my Masters degree then $\mathrm{PhD}$ at CAS has been thoroughly rewarding and I would also thank Pravina King and, lately, Grace Owens for their support and encouragement.

I would like to thank my principal $\mathrm{PhD}$ supervisor, Kenneth King, again for encouraging me to get involved in a good deal of analytical work beyond the PhD. I believe this has been as important as doing the $\mathrm{PhD}$ itself.

I would also like to acknowledge the Economic and Social Research Council for the funding to undertake this exercise, without which none of it would have been possible.

In Ghana my thanks go especially to Nana Anthony Boateng and his wife Mary, Osei Tutu Abbabio (Assembly!) and his expanding family, James Ojawuri Nsiah, Charles Akroboto and the Otaakromhene, Nana Yaw Owusu, as well as the other sub-chiefs. I would also like to thank Will Guest for his hospitality on my visits to Accra.

I thank my parents and other Palmer and Durrad family members for their support. Also thanks go to the Nusair family in Irbid.

My largest debt and biggest thanks are owed to Lama and, more recently, to our baby Laith. Both have been a constant reminder that there are far more important things in life than writing all day long. 


\section{Table of Contents}

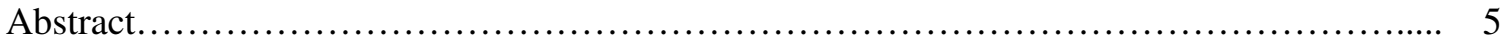

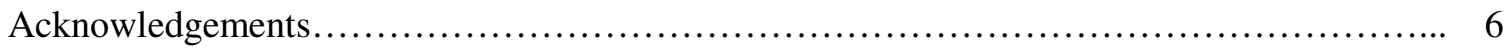

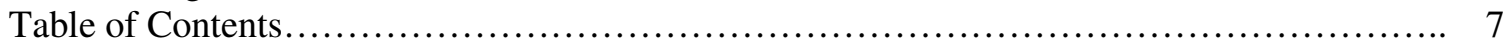

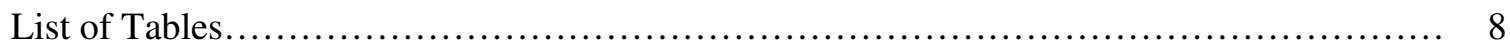

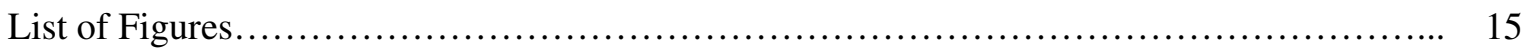

Abbreviations and Acronyms........................................................... 16

Indigenous Terms (Akan Twi) ...................................................... 19

Chapter 1: Research Context and Approach.......................................... 21

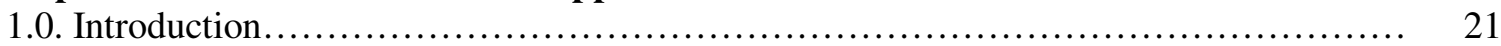

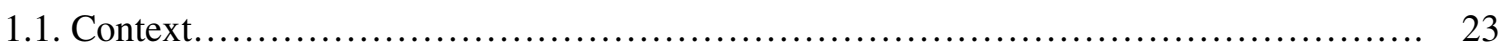

1.1.1. Skills development policy in Sub-Saharan Africa: a brief history................. 23

1.1.2. Education for all, formal jobs for some and informal micro-enterprise for most in Sub-Saharan Africa.............................................................. 25

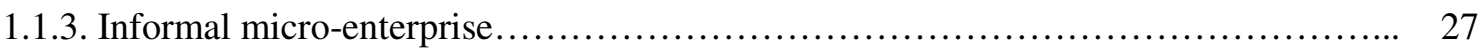

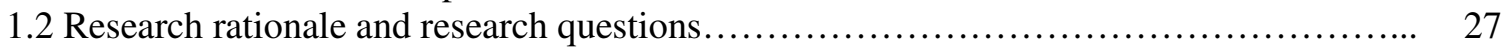

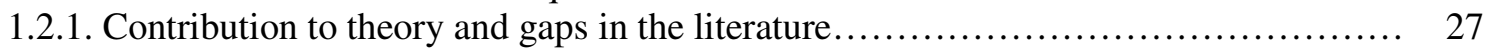

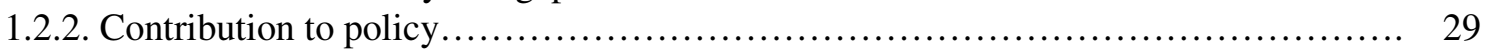

1.2.3. Research questions, objectives and structure of thesis......................... 30

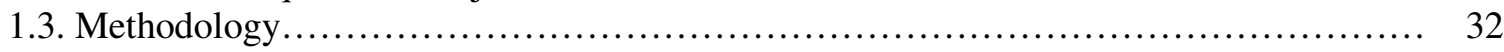

1.3.1. Literature reviews and balancing consultancy and academic research............... 33

1.3.2. Choice and description of location............................................. 34

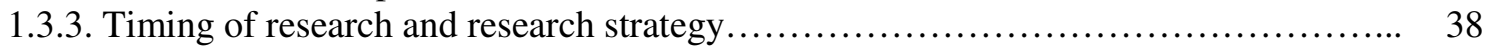

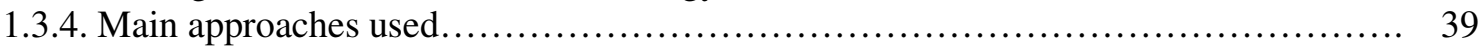

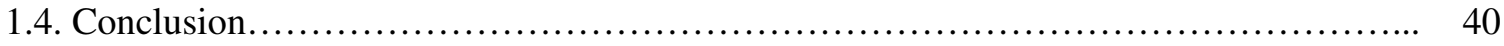

Chapter 2: Micro-Enterprise and Occupational Pluralism: Rethinking Urban Bias and the Farm-Nonfarm Divide in Sub-Saharan Africa..................................... 41

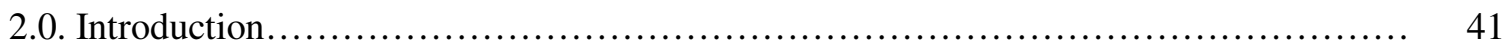

2.1. The history of the informal sector concept..................................... 41

2.1.1. The primary school leaver problem and the internationalisation of the informal sector concept by the ILO/UNDP employment mission to Kenya.......................... 44

2.1.2. The informal sector, the informal economy and informal employment: the

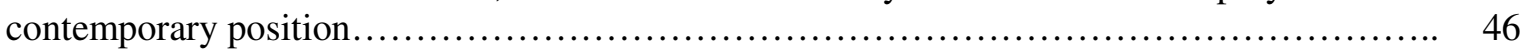

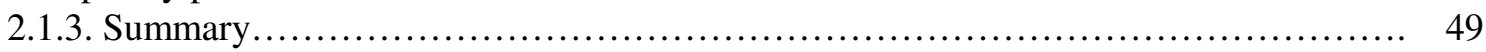

2.2. The informal sector in rural areas................................................... 50

2.2.1. The initial urban bias...................................................... 50

2.2.2. The farm-nonfarm divide and defining the rural informal sector................... 52

2.2.3. The changing composition of the rural informal sector: de-agrarianisation............ 56

2.2 .4 . Summary ............................................................. 58

2.3. Re-conceptualising work in SSA as a result of occupational pluralism................ 59

2.3.1. Tinker, tailor, farmer, trader: occupational pluralism and the fallacy of dichotomous

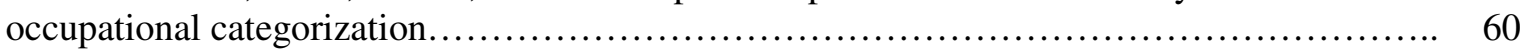

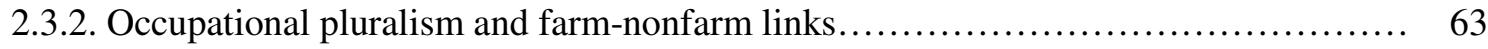

2.3.3. Occupational pluralism: an illustration from rural Ashanti (Ghana)................ 64

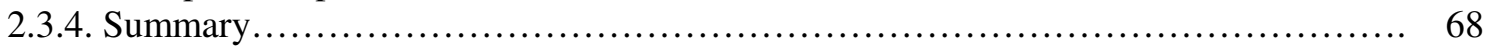

2.4. Conclusion: implications for the skill-to-enterprise link beyond the farm-nonfarm divide 68 
Chapter 3: Skills Development, the Enabling Environment and Pathways to Informal Micro-Enterprise in Sub-Saharan Africa..

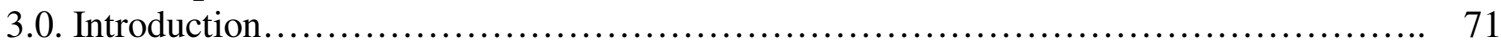

3.1. Translating skills development into employment outcomes.......................... 73

3.1.1. The delivery environment for skill acquisition................................. 74

3.1.2. The transformative environment for skills utilization........................... 75

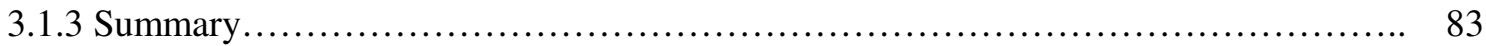

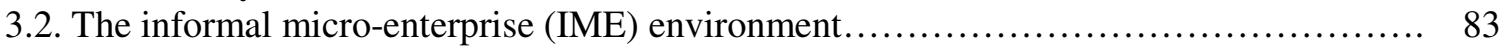

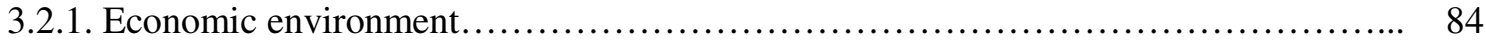

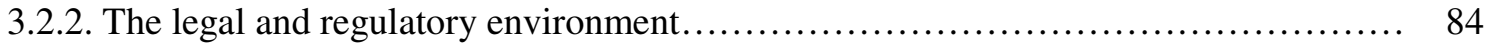

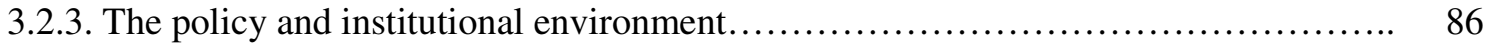

3.2.4. The social environment; networks, associations and gender...................... 86

3.2.5. The post-training environment: finance, follow-up and technology................ 88

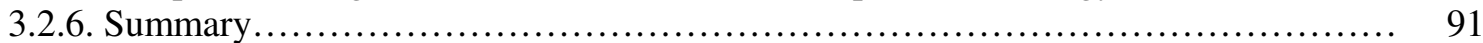

3.3. Pathways to self-employment in micro-enterprise ................................. 91

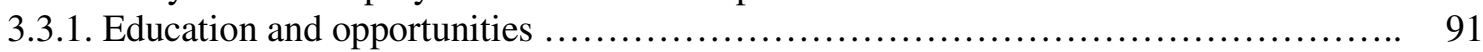

3.3.2. Typical pathways to micro-enterprise self-employment.......................... 93

3.3.3. Enterprise and entrepreneur lifecycles...................................... 103

3.3.4. Summary ............................................................ 108

3.4. Conclusion: assumptions and challenges of the school-skill-enterprise link............. 108

Chapter 4: Ghana's Policies on Skills Development, Work and Enterprise in relation to the Economic, Social, Historical and Political Environments, early Nineteenth Century to 2000 .

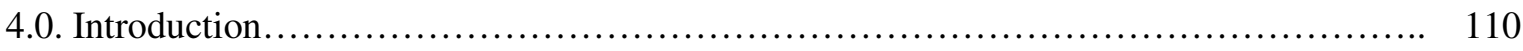

4.1. Gold Coast policies on skills development in relation to the economic and social

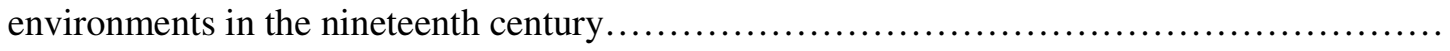

4.1.1. Early skills and schooling: artisans, castles, merchants and missionaries..............

4.1.2. Government and missionary attempts to provide technical, vocational and

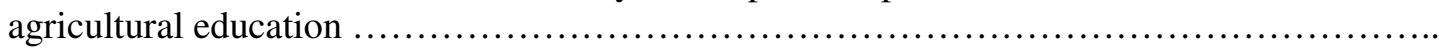

4.1.3. The early development of the colonial exchange and informal economies..............

4.1.4. Summary: the difficulty of establishing TVET during the nineteenth century............

4.2. Gold Coast policies on skills development in relation to the economic and social

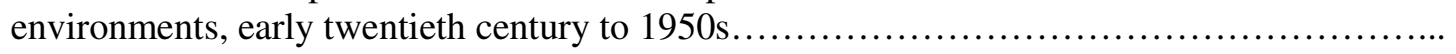

4.2.1. Changes in the labour market and economic environment up to World War One

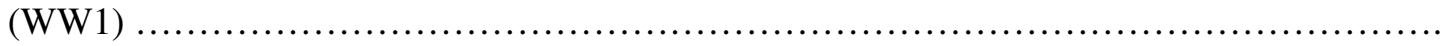

4.2.2. From Guggisberg's 'Ten Year Development Plan' and renewed push for TVET during the 1920s, to the 1930s-40s depression, retrenchment and war.......................

4.2.3. The demise of TVET, the rise of academic schooling and the re-emergence of the

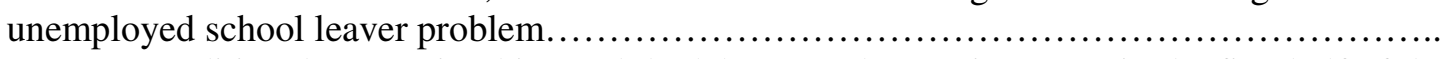

4.2.4. Traditional apprenticeships and the labour market environment in the first half of the

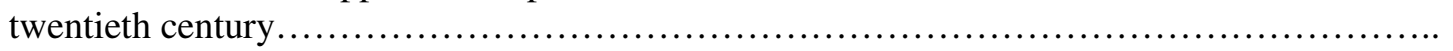

4.2.5. Summary .............................................................

4.3. Ghana's policies on skills development in relation to the economic, social, historical and

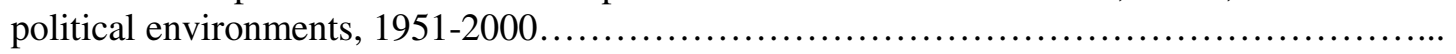

4.3.1. Education, training and the environment in the new Ghana, 1951-1965 ...............

4.3.2. Education and training policies and practice, 1960s - 1970s: coups, political unrest and education policy repetitiveness in the face of 'old problems' ......................... 135

4.3.3. Schooling, skills and the environment: from crisis to reform, 1980 s to $2000 \ldots \ldots \ldots \ldots .139$

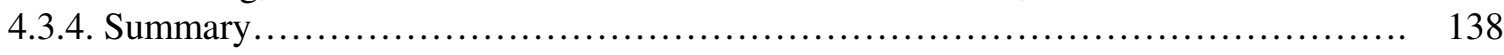


4.4. Concluding remarks on 150 years of skills training, work, enterprise and the enabling environment, 1850s-2000.

Chapter 5: Skills Development and Informal Micro-Enterprise in Ghana's New Political Context, 2001-2006.

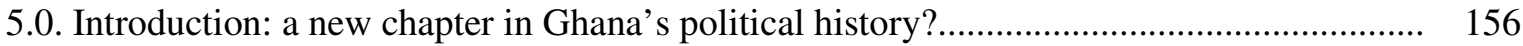

5.1. Skills development policy, 2001-2006: the vision and the reality ................... 156

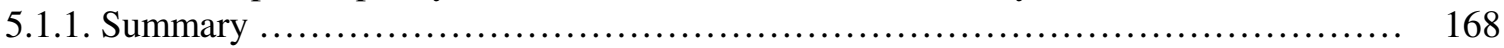

5.2. Informal micro-enterprise, youth employment and the enabling environment: policy

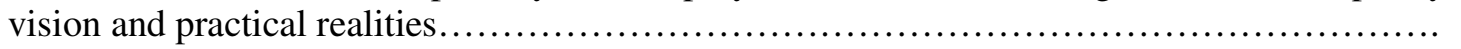

5.2 .1 . Summary $\ldots \ldots \ldots \ldots \ldots \ldots \ldots \ldots \ldots \ldots \ldots \ldots \ldots \ldots \ldots \ldots \ldots \ldots \ldots \ldots \ldots \ldots \ldots \ldots \ldots \ldots \ldots \ldots \ldots \ldots \ldots$
5.3. From skills acquisition to skills utilisation: enabling and disabling contexts in Ghana's

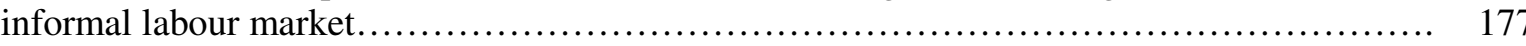

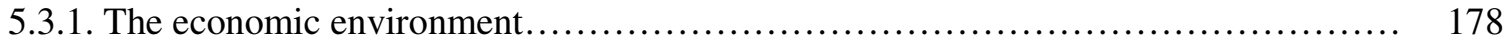

5.3.2. The infrastructural environment............................................ 178

5.3.3. The legal and regulatory environment........................................ 180

5.3.4. The policy and institutional environment................................... 180

5.3.5. The social environment (politics, networks, associations and gender)............... 183

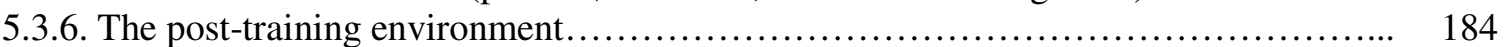

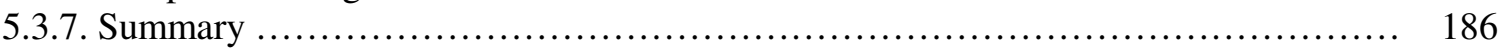

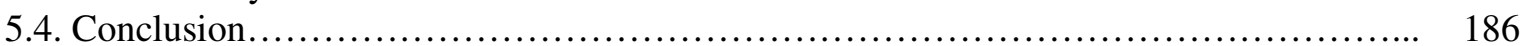

Chapter 6: Institution-Based Pre-Employment Skills Training in Ghana at the Integrated Community Centres for Employable Skills (ICCES): The Training Environment and Pathways to Informal Micro-Enterprise ................................. 188

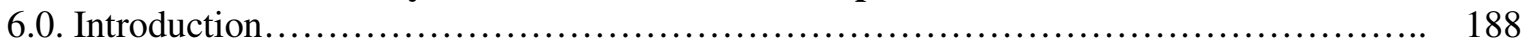

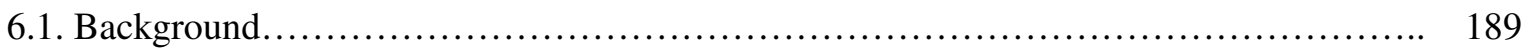

6.1.1. ICCES as part of GoG strategy ........................................... 190

6.1.2. Curriculum, enrolments, fees and dropouts................................. 191

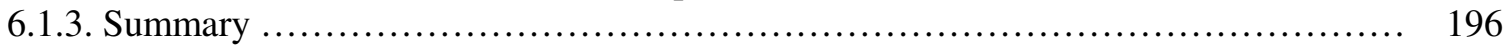

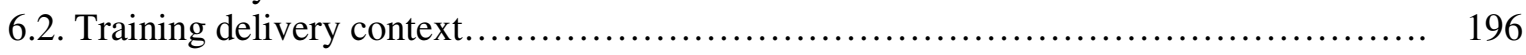

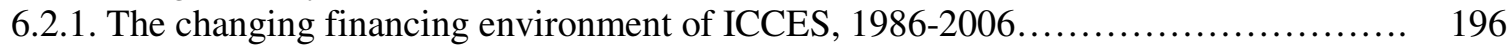

6.2.2. Salaries and condition of service........................................... 201

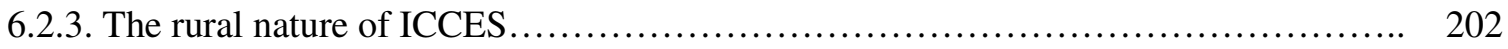

6.2.4. Community-supported training and kobewo.................................. 202

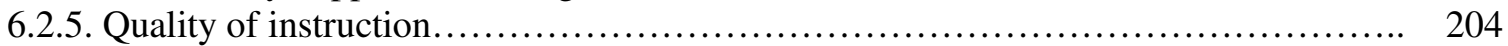

6.2.6. Pressure for more academic and examination-orientated teaching................. 206

6.2.7. Weak centre-level management capacity....................................... 207

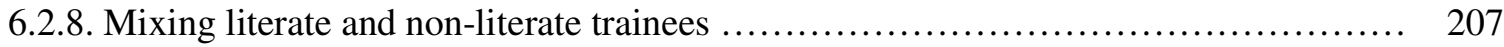

6.2.9. General meetings and training of centre managers .............................. 207

6.2.10 Poor public perception of vocational training.................................. 208

6.2.11. The social composition of ICCES trainees and the centre managers' dilemma........ 209

6.2.12 The gender composition of training ............................................ 212

6.2.13 Regional coordination issues................................................. 212

6.2.14. National coordination issues............................................... 213

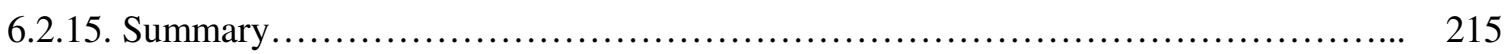

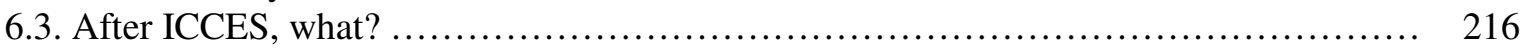

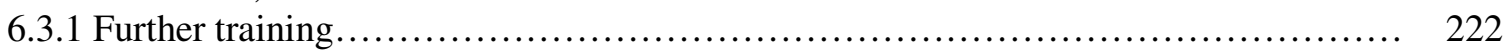

6.3.2 Employment activities of ICCES graduates in the labour market.................... 227

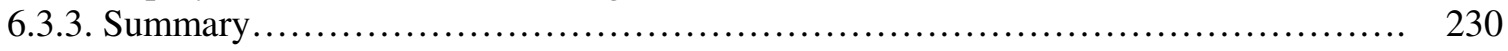


Chapter 7: Short-Duration Skills Training and Enterprise-Based Training in Traditional Apprenticeships: Training and Post-training Environments in Ghana.........

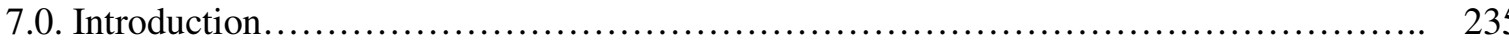

7.1. Section one: the short-duration skills training modality ........................... 236

7.2. Background and objectives of STEP............................................. 236

7.3. The training delivery context of STEP.......................................... 241

7.3.1. Skills training delivered through vocational training providers: the case of ICCES.... 241

7.3.2. Skills enhancement for master-craftspeople and skills training delivered through apprenticeship placements......................................................... 242

7.3.3. Lack of demand for these types of skills..................................... 243

7.3.4. Lack of coordination and weak management................................... 244

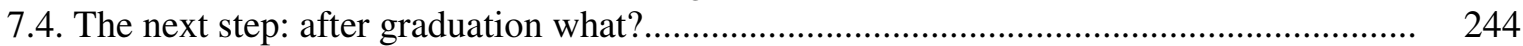

7.4.1. Micro-finance provision...................................................... 245

7.4.2. Employment outcomes unknown . ........................................ 247

7.5. Concluding comments on STEP: training delivery in a highly politicised environment... 248

7.6. Section two: the traditional apprenticeship training modality......................... 250

7.7. Traditional apprenticeship training in Ghana..................................... 251

7.8. Traditional apprenticeship training in rural Ashanti (Ghana)........................ 252

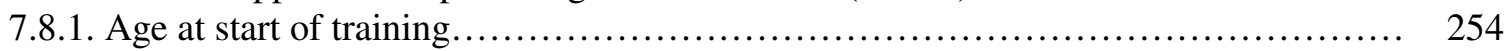

7.8.2. Duration of apprenticeship ................................................ 255

7.8.3. Education level of apprentices.............................................. 256

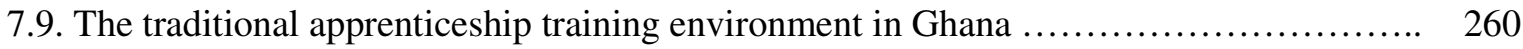

7.9.1. Access, apprenticeship fees and the poor..................................... 264

7.10. Entering into self-employment after apprenticeship.................................. 268

7.10.1. Expected source of start-up capital for rural apprentices in Ashanti................ 268

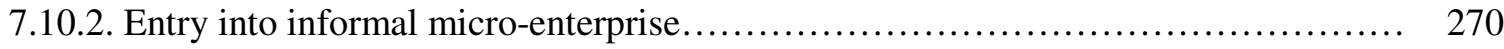

7.11. Concluding comments on traditional apprenticeship training in Ghana................ 273

Chapter 8: Mastering the Trade - Creating Pathways to Rural Informal MicroEnterprise............................................................................. 274

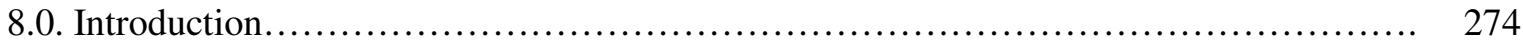

8.1. Becoming skilled, becoming networked.

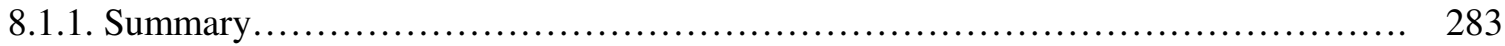

8.2. Becoming financed: overcoming the financial barrier to start-up ................... 283

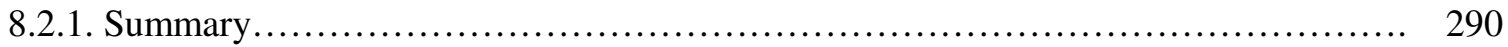

8.3. Becoming established: strategies for sustaining self-employment activities and ongoing

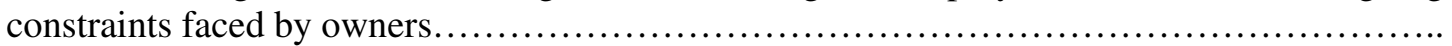

8.3.1. Occupational pluralism among rural masters..................................... 299

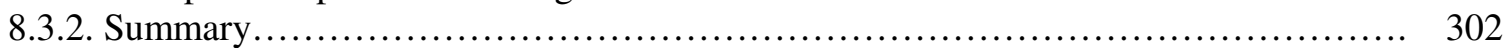

8.4. Conclusion: typical pathways to self-employment in rural Ghana.................. 303

Chapter 9: Skills Development, Enabling Environments and Informal Micro-Enterprise in Ghana............................................................................. 315

9.0. The study's contribution to knowledge ......................................... 315

9.1. Limitations of the study and generalisability $\ldots \ldots \ldots \ldots \ldots \ldots \ldots \ldots \ldots \ldots \ldots \ldots \ldots \ldots \ldots . \ldots \ldots$ 
9.2. The Ghanaian skills development agenda..................................... 319

9.2.1. Underlying assumptions of the Ghanaian skills development agenda................ 319

9.2.2. The Ghanaian skills development agenda: access and equity ..................... 322

9.2.3. The skills development agenda in relation to larger macro-economic dynamics........ 323

9.3. Skills development and pathways to informal micro-enterprise in rural Ghana.......... 325

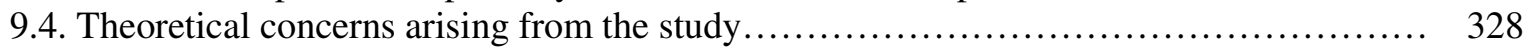

9.4.1. The years of schooling variable ............................................ 328

9.4.2. Occupational classifications: interrogating the farm-nonfarm and formal-informal

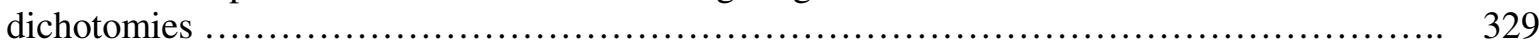

9.4.3. The transformative context .................................................... 330

Appendix A: Background on master-craftsperson and apprentice interviews............ 333

A.0. Introduction................................................................. 333

A.1. Background data on enterprises......................................... 333

A.1.1. Occupational pluralism................................................. 336

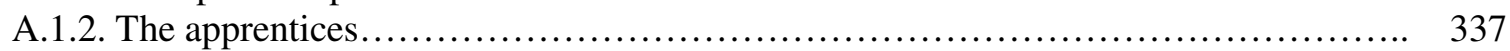

A.2. Semi-structured questionnaire for masters: interview guide....................... 338

A.3. Semi-structured questionnaire for apprentices: interview guide................... 339

Appendix B: ICCES questionnaires................................................... 340

B.1. ICCES tracer questionnaire (06.01.05) - filled in by graduates themselves............. 340

B.2. ICCES questionnaire for centre managers and instructors regarding the current activity of 2003 graduates........................................................... 344

Appendix C: Household survey in Otaakrom village. Methodology and background data..................................................................................... 345

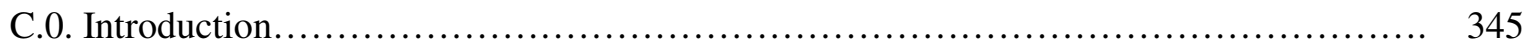

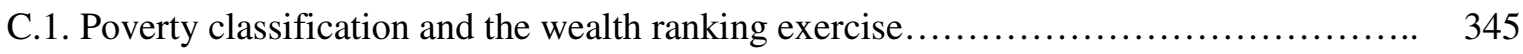

C.2. Household mapping exercise .............................................. 351

C.3. Random sampling and questionnaires

352

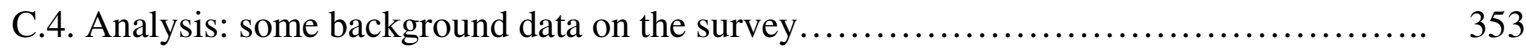

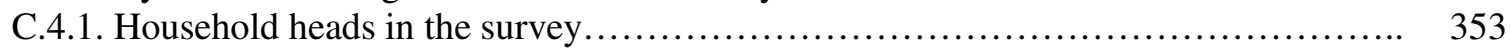

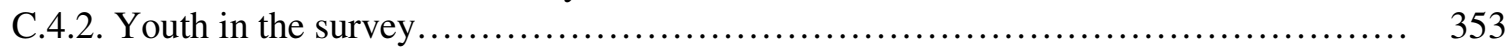

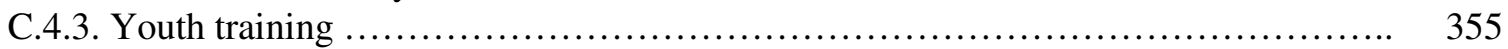

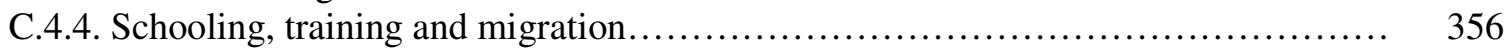

C.5. Household questionnaire: Otaakrom...................................... 358

Appendix D: Methodological choices, approach and considerations................... 361

D.0. Introduction: the research design .............................................. 361

D.1. Choices made: why Ghana, why this research and why this approach?....................... 362

D.1.1. Why investigate skills development and MSEs in Ghana's informal economy?......... 362

D.1.2. Why look at the rural informal economy? ................................... 362

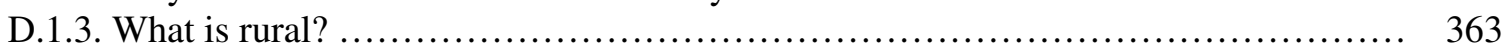

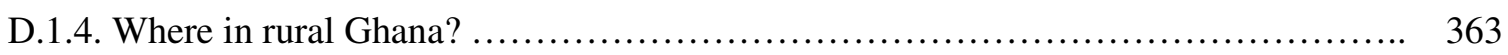

D.2. Methodological approach................................................ 364

D.2.1. Interviews with other key informants .................................. 364

D.2.2. Informal (participant) observation of education, skills and enterprises in rural

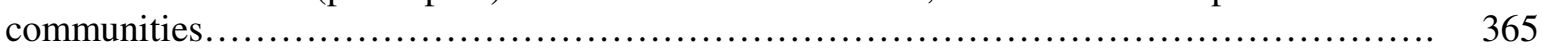

D.2.3. The case study approach and issues of triangulation........................... 365 


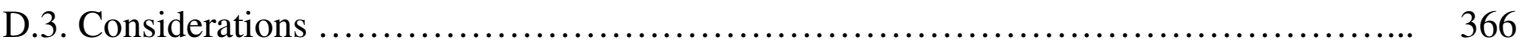

D.3.1. Epistemological considerations........................................ 366

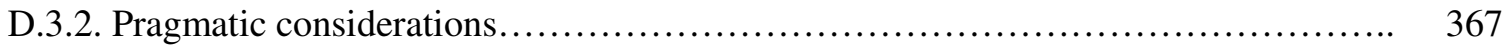

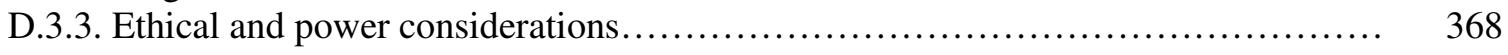

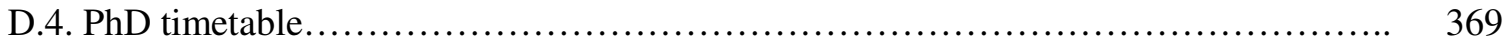

Appendix E: Photographs................................................................. 370

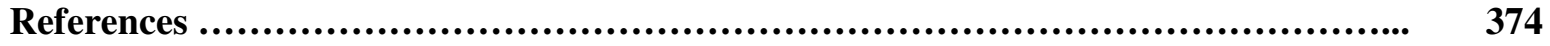




\section{List of Tables}

Table 1.1. Primary school enrolment figures in Ghana, 1986-2005.............................. 23

Table 2.1. Occupational pluralism among 80 households in Otaakrom by wealth category............. 65

Table 2.2. Enterprises in Nkawie-Kuma: households engaging in income-generating activities in addition to their main enterprise activity........................................... 67

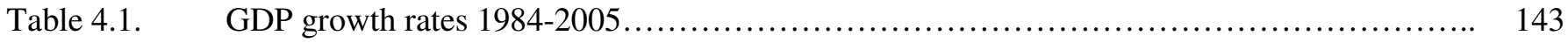

Table 4.2. Trends in formal sector employment, 1960 to 1991 (thousands)......................................... 144

Table 4.3. Labour force status: percentages of individuals by category of employment................ 145

Table 4.4. Employment and unemployment, by gender and rural/urban (1998/99).................... 146

Table 5.1. Doing business in Ghana, Kenya, South Africa, Tanzania, China and India.................. 171

Table 6.1. Total enrolment figures for ICCES in Ashanti Region, 2001-2006...................... 191

Table 6.2. $\quad$ Enrolment in ICCES centres, by sex, Ashanti Region, January 2006...................... 192

Table 6.3. Enrolment in ICCES centres, by trade, Ashanti Region, January 2006.................... 193

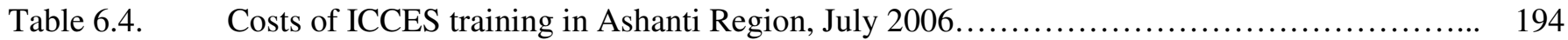

Table 6.5. Dropout rates for Otaakrom, Konkoma, Amoawi and Akutuase ICCES centres, 2003-2005... 195

Table 6.6. Percentage of 'needy' students in selected ICCES centres in Ashanti Region, according to

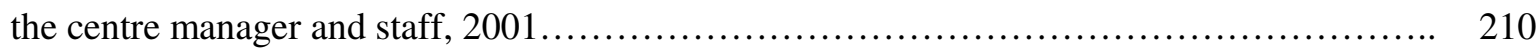

Table 6.7. NVTI exam results for Nerebehi, Baworo, Ofuase-Kokoben, Akutuase, Konkoma, Asiwa and Otaakrom ICCES centres, Ashanti Region (May/June 2005)................... 216

Table 6.8. Compostion of focus group 1 (FG1), ICCES graduates, Tetrefu ICCES, 09.10.05........... 221

Table 6.9. Compostion of focus group 2 (FG2), ICCES graduates, Tetrefu ICCES, 09.10.05........... 221

Table 6.10. Compostion of focus group 3 (FG3), final year ICCES trainees, Tetrefu ICCES, 09.10.05..... 222

Table 6.11. Further training received by ICCES trainees, from a sample of 2000-2004 cohorts from Tetrefu, Nerebehi, Bawro, Dweaso Praso, Twedie, Otaakrom and Ofoase ICCES............ 225

Table 6.12. Current employment activity of graduates from a sample of 2000-2004 cohorts from Tetrefu, Nerebehi, Bawro, Dweaso Praso, Twedie, Otaakrom and Ofoase ICCES .................. 230

Table 7.1. Responses from the 2001 unemployment registration exercise (aspirations of respondents)... 238

Table 7.2. Distribution of apprentices by main trade learnt, by sex and locality (\%).................. 253

Table 7.3. Distribution of rural apprentices, by trade and sex (Ashanti)............................. 254

Table 7.4. Age range at start of rural apprenticeship training (Ashanti) ............................ 255

Table 7.5. Duration of rural apprenticeship training, by trade (Ashanti) $\quad$........................... 256

Table 7.6. Average length of apprenticeship training, by trade, sex and locality (months) (Ghana)....... 256

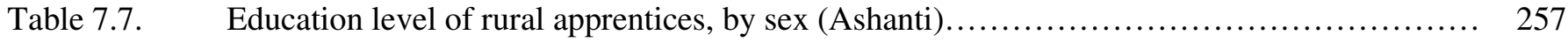

Table 7.8. Education level of rural apprentices, by trade (Ashanti) ............................... 257

Table 7.9. Educational background of apprentices, by trade (percent) from a 2001 survey in Ghana...... 258

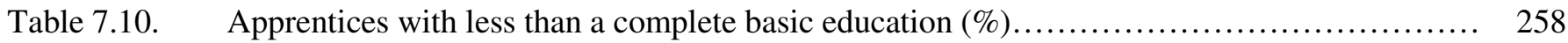

Table 7.11. Comparison of highest education level of apprentices and their masters in rural Ashanti....... 260 


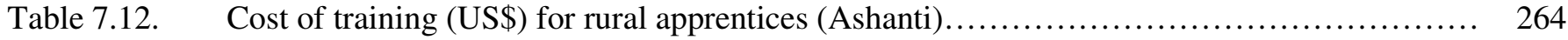

Table 7.13. Cost of rural apprenticeship, by trade (Ashanti)..................................... 266

Table 7.14. 'Chop money’ received by rural apprentices, by trade (Ashanti)........................ 267

Table 7.15. 'Chop money’ received by rural apprentices, by gender (Ashanti) ......................... 267

Table 7.16. Expected source of start-up capital of rural apprentices by gender (Ashanti)................ 268

Table 7.17. Expected source of start-up capital of rural apprentices, by trade (Ashanti).................. 269

Table 7.18. Expected versus actual sources of start-up capital in rural Ashanti......................... 270

Table 7.19. Activities of apprentices after apprenticeship.................................... 270

Table 8.1. Types of enterprise among those interviewed........................................ 275

Table 8.2. Size of enterprises among those interviewed..................................... 276

Table 8.3. Location of enterprises among those interviewed.................................... 276

Table 8.4. Highest education level of master-craftspeople among those interviewed................... 277

Table 8.5. Highest education level of masters in Ghana: evidence from three studies.................. 279

Table 8.6. Source of master-craftspeople training among those interviewed........................... 281

Table 8.7. Duration of apprenticeship training of the master-craftspeople among those interviewed...... 282

Table 8.8. $\quad$ Source of start-up capital for enterprise owners (by sex) among those interviewed............ 286

Table 8.9. Source of start-up capital for enterprise owners according to trade and gender among those interviewed................................................................ 287

Table 8.10. Main source of start-up capital: a comparison of Ghanaian findings, urban and rural......... 288

Table 8.11. Average age of enterprise owners at start-up according to sex among those interviewed....... 292

Table 8.12. Average number of apprentices by sex of enterprise owner among those interviewed......... 294

Table 8.13. Average number of apprentices per enterprise by type of enterprise among those interviewed. 295

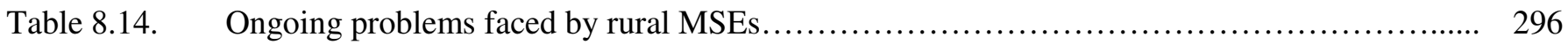

Table 8.15. Factors considered as 'major ongoing problems' by rural MSE owners in Ghana............. 297

Table 8.16. Ongoing problems faced by rural MSEs (by selected trade area).......................... 298

Table 8.17. Primary additional income-generating enterprise activity of master-craftspeople............. 299

Table 8.18. Primary additional income-generating enterprise activity, by trade and sex, among those interviewed.................................................................. 300

Table 8.19. Source of start-up capital and later incidence of occupational pluralism.................... 301

Table 8.20. Pluri-activity (occupational pluralism) of owners by age of their enterprise.................. 302

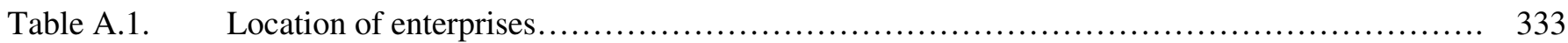

Table A.2. Structure of enterprises, by type of enterprise and sex of master......................... 335

Table C.1. Social groupings in the informal sector according to the National Health Insurance Scheme 348

Table C.2. Education level of household heads in the survey..................................... 353

Table C.3. Age of youth in Otaakrom survey............................................. 354

Table C.4. Location of Otaakrom's youth at time of survey (Oct.05-Jan.06).......................... 354

Table C.5. Highest formal education level of youth that have left school............................. 355

Table C.6. Percentage of youth in Otaakrom engaged in post school skills training.................... 355

Table C.7. Current activity of Otaakrom youth $(\mathrm{n}=205)$, by place of current residence and household

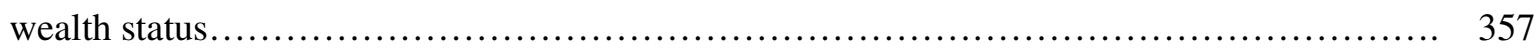




\section{List of Figures}

Fig.1.1. $\quad$ Ashanti Region, showing Atwima Mponua District................................. 35

Fig.1.2. $\quad$ Map of Atwima Mponua District, Ashanti.......................................... 36

Fig.2.1. Components of the informal sector and of informal employment....................... 49

Fig.2.2. $\quad$ Estimated proportions of formal and informal sector employment in SSA................ 54

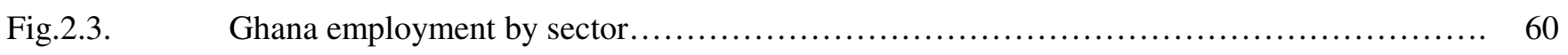

Fig.3.1. Translating skills development into employment outcomes........................... 82

Fig.3.2. The positions of the two 'growth ceilings' present in the lifecycle of an enterprise........... 105

Fig.4.1. The political environment in Ghana (to 2000)..................................... 149

Fig.4.2. The policy and legislative environment for skills development in Ghana (to 2000).......... 152

Fig.4.3. The policy and legislative environment for work in Ghana (to 2000)....................... 153

Fig.4.4. The institutional environment for micro- and small-enterprise in Ghana (to 2000)........... 154

Fig.6.1. Post-ICCES training pathways (male graduates)........................................ 224

Fig.6.2. Post-ICCES training pathways (female graduates) ..................................... 225

Fig.6.3. Post-ICCES pathways to training, employment and enterprise............................ 234

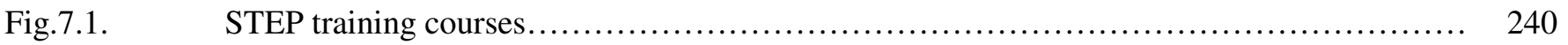

Fig.7.2. Advantages of the traditional training modality in Ghana............................. 261

Fig.7.3. Disadvantages of the traditional training modality in Ghana............................ 262

Fig.7.4. The work environment in Ghanaian MSEs........................................ 263

Fig.8.1. Reasons why getting access to formal credit is difficult for rural micro-enterprises.......... 284

Fig.8.2. Strategies adopted to finance enterprise start-up costs in rural Ghana....................... 290

Fig.8.3. Strategies adopted to finance working capital costs................................. 298

Fig.8.4.-8.9 Typical pathways to self-employment in rural Ghana.................................. 304-9

Fig.8.10. Typical pathway to self-employment in a rural hairdressing enterprise (females)............ 310

Fig.8.11. Typical pathway to self-employment in a rural dressmaking enterprise (females)........... 311

Fig.8.12. Typical pathway to self-employment in a rural tailoring enterprise (males)................. 312

Fig.8.13. Typical pathway to self-employment in a rural carpentry enterprise (males)............... 313

Fig.9.1. Some main pathways to employment through education and skills training in Ghana......... 327

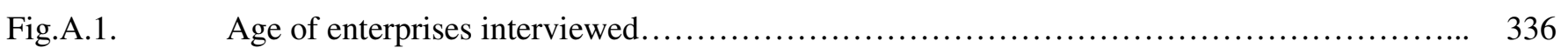




\section{Abbreviations and Acronyms}

\begin{tabular}{|c|c|}
\hline AFRC & Armed Forces Revolutionary Council \\
\hline ARB & Association of Rural Banks \\
\hline BAB & Bibiani-Anhwiaso-Bekwai District \\
\hline BAC & Business Advisory Centre \\
\hline BDS & Business Development Services \\
\hline BECE & Basic Education Certificate Examination \\
\hline BESO & British Executive Service Overseas, now part of VSO \\
\hline $\mathrm{C} \& \mathrm{G}$ & City and Guild \\
\hline CAS & Centre of African Studies, University of Edinburgh \\
\hline CIDA & Canadian International Development Agency \\
\hline COTVET & Council for Technical and Vocational Education and Training \\
\hline $\mathrm{CPP}$ & Convention People's Party \\
\hline CTC & Craft Technician Certificate \\
\hline DA & District Assembly \\
\hline DACF & District Assembly Common Fund \\
\hline DFID & Department for International Development, UK \\
\hline DP & Development partner \\
\hline EFA & Education For All \\
\hline EMPRETEC & $\begin{array}{l}\text { An SME support programme under UNCTAD - from the Spanish acronym for } \\
\text { emprendedores (entrepreneurs) and tecnología (technology). }\end{array}$ \\
\hline ERP & Educational Recovery Programme \\
\hline EU & European Union \\
\hline FCUBE & Free Compulsory Universal Basic Education \\
\hline FUSMED & Fund for Small and Medium Enterprise Development (Bank of Ghana) \\
\hline GDP & Gross Domestic Product \\
\hline GEDC & Ghana Enterprise Development Commission (now merged with NBSSI) \\
\hline GES & Ghana Education Service \\
\hline GETFund & Ghana Education Trust Fund \\
\hline GISDC & Ghana Industrial Skills Development Centre \\
\hline GLSS & Ghana Living Standards Survey \\
\hline GPRS & Ghana Poverty Reduction Strategy \\
\hline GRATIS & Ghana Regional Appropriate Technology Industrial Service \\
\hline GSS & Ghana Statistical Service \\
\hline GNA & Ghana News Agency \\
\hline
\end{tabular}




\begin{tabular}{|c|c|}
\hline GoG & $\begin{array}{l}\text { Government of Ghana } \\
\text { Deutsche Gesellschaft für Technische Zusammenarbeit (German Agency for } \\
\text { Technical Cooperation) }\end{array}$ \\
\hline HIPC & Heavily Indebted Poor Country \\
\hline ICCES & Integrated Community Centres for Employable Skills \\
\hline ICLS & International Conference of Labour Statisticians \\
\hline ICT & Information and Communication Technology \\
\hline IDB & Inter-American Development Bank \\
\hline IFAD & International Fund for Agricultural Development \\
\hline ILO & International Labour Organisation \\
\hline IME & Informal Micro-Enterprise \\
\hline IMF & International Monetary Fund \\
\hline ISA & Informal Sector Association \\
\hline JICA & Japanese International Cooperation Agency \\
\hline JOCV & Japanese Overseas Cooperation Volunteer \\
\hline JSS & Junior Secondary School \\
\hline $\mathrm{KG}$ & Kindergarten \\
\hline MDAs & Ministries, Departments and Agencies \\
\hline MDGs & Millennium Development Goals \\
\hline MESE & Micro-Entrepreneurial Self-Employment \\
\hline MFI & Micro-Finance Institution \\
\hline MoE & Ministry of Education (now MoESS) \\
\hline MoEYS & Ministry of Education Youth and Sports (now MoESS) \\
\hline MoES & Ministry of Education and Sports (now MoESS) \\
\hline MoESS & Ministry of Education, Science and Sports \\
\hline MoESW & Ministry of Employment and Social Welfare (now MoMYE) \\
\hline MoEMD & Ministry of Employment and Manpower Development (now MoMYE) \\
\hline MoF & Ministry of Finance \\
\hline MoMDE & Ministry of Manpower Development and Employment (now MoMYE) \\
\hline MoMDYE & Ministry of Manpower Development, Youth and Employment (now MoMYE) \\
\hline MoMYE & Ministry of Manpower, Youth and Employment \\
\hline MoTIPP & Ministry of Trade, Industry, Private Sector and Presidential Special Initiatives \\
\hline MSE & Micro and small enterprise \\
\hline MSLC & Middle School Leaving Certificate \\
\hline MSME & Micro, Small and Medium Enterprise \\
\hline NACVET & National Coordinating Committee for TVET \\
\hline NARE & Non-Agricultural Rural Employment \\
\hline NBSSI & National Board for Small-Scale Industries \\
\hline NDC & National Democratic Congress \\
\hline NDPC & National Development Planning Commission \\
\hline NGO & Non-governmental Organisation \\
\hline
\end{tabular}




\begin{tabular}{|c|c|}
\hline NHIS & National Health Insurance Scheme \\
\hline NLC & National Liberation Council \\
\hline NPP & New Patriotic Party \\
\hline NQF & National Qualifications Framework \\
\hline NRC & National Redemption Council \\
\hline NSP & National Service Personnel \\
\hline NVTI & National Vocational Training Institute \\
\hline NYEP & National Youth Employment Programme \\
\hline PAMSCAD & Programme of Action to Mitigate the Social Cost of Adjustment \\
\hline PNDC & Provisional National Defence Council \\
\hline PRSP & Poverty Reduction Strategy Paper \\
\hline PSD & Private Sector Development \\
\hline REP & Rural Enterprise Project (IFAD, 1995-ongoing) \\
\hline ROSCA & Rotating Savings and Credit Association \\
\hline SAP & Structural Adjustment Policy \\
\hline SME & Small and Medium Enterprise \\
\hline SSA & Sub-Saharan Africa \\
\hline SSS & Senior Secondary School \\
\hline SSNIT & Social Security and National Insurance Trust \\
\hline STEP & Skills Training and Entrepreneurship Programme \\
\hline TAT & Traditional Apprenticeship Training \\
\hline TVET & Technical and Vocational Education and Training \\
\hline TVETS & TVET Support Project, JICA (2006-2009) \\
\hline UN & United Nations \\
\hline UNDP & United Nations Development Programme \\
\hline UNESCO & United Nations Educational, Scientific and Cultural Organisation \\
\hline UNICEF & United Nations Children's Fund \\
\hline UPE & Universal Primary Education \\
\hline USAID & United States Agency for International Development \\
\hline VOTEC & Vocational and Technical Education Centre \\
\hline VSME & Very Small and Micro-Enterprise \\
\hline VSO & Voluntary Service Overseas \\
\hline VSP & Vocational Skills and Informal Sector support project, World Bank (1995-01) \\
\hline VTI & Vocational Training Institute \\
\hline WCEFA & World Conference on Education For All \\
\hline WEP & World Employment Programme \\
\hline WGICSD & Working Group for International Cooperation in Skills Development \\
\hline WWBG & Women's World Banking Ghana \\
\hline
\end{tabular}

NB. The exchange rate at the time of the research (2005) was approximately 9,025 cedis per US\$ or 15,500 cedis per GBP. 


\section{Indigenous Terms (Akan Twi)}

$\begin{array}{ll}\text { Adantemo } & \text { - average (wealth category) } \\ \text { Adepamni barimaa } & \text { - tailoring } \\ \text { Adua dwumayefuo } & \text { - carpentry } \\ \text { Akpeteshie } & \text { - local alcohol/gin (usually made from distilled palm wine) } \\ \text { Afidiesiesiefuo } & \text { - mechanic } \\ \text { Arpanpamu } & \text { - lit. 'a store on top of the head', referring to those in the informal sector } \\ & \text { that carry goods around on their head for sale. } \\ \text { Asante } & \text { - the Ashanti people who speak a dialect of Akan } \\ \text { Asantehene } & \text { - the paramount chief of the Asante } \\ \text { Asikafoo } & \text { - rich people (above average wealth category) } \\ \text { Bogyuwa-bogyuwa } & \text { - people who sell minor items in bits or simply 'petty trading' } \\ \text { Kobswo } & \text { - an expression that refers to students who continue their education or } \\ & \text { training in the same community after completing JSS } \\ \text { Galamsay } & \text { - illegal gold mining. } \\ \text { Meyeyie / meya ayeyie } & \text { - on the way to becoming rich (above average wealth category) } \\ \text { Mmoatia } & \text { - dwarfs (also called fairies) believed to live in the forests of Ashanti } \\ \text { Nitrinsa } & \text { - apprenticeship joining fee } \\ \text { Nsanodwuma suafuo } & \text { - traditional apprenticeship training } \\ \text { Oburuni } & \text { - 'white man' } \\ \text { Oburuni waawu } & \text { - imported second-hand clothing (lit. 'a white man has died') } \\ \text { Odansifuo } & \text { - masonry } \\ \text { Odefuo } & \text { - very well off (wealth category) } \\ \text { Ohia ye edam bo } & \text { - poverty is madness (very poor) } \\ \text { Ohiabubroo } & \text { - miserably poor (very poor) } \\ \text { Ohiani / ohiafoo } & \text { - the poor } \\ \text { Okuani } & \text { - small-scale farmer } \\ \text { Oteneho } & \text { - lit. 'I live on my own' (very poor) } \\ \text { Panpanmu } & \text { - lit. 'a store on a tray' } \\ \text { Pito } & \text { - a locally brewed alcoholic drink (usually made from distilled guinea } \\ \text { Sikawur } & \text { corn) } \\ \text { Susu } & \text { - lit. 'owner of money' (very well off wealth category) } \\ \text { Trotro } & \text { - traditional mobile banker or ROSCA } \\ & \text { - minibus }\end{array}$




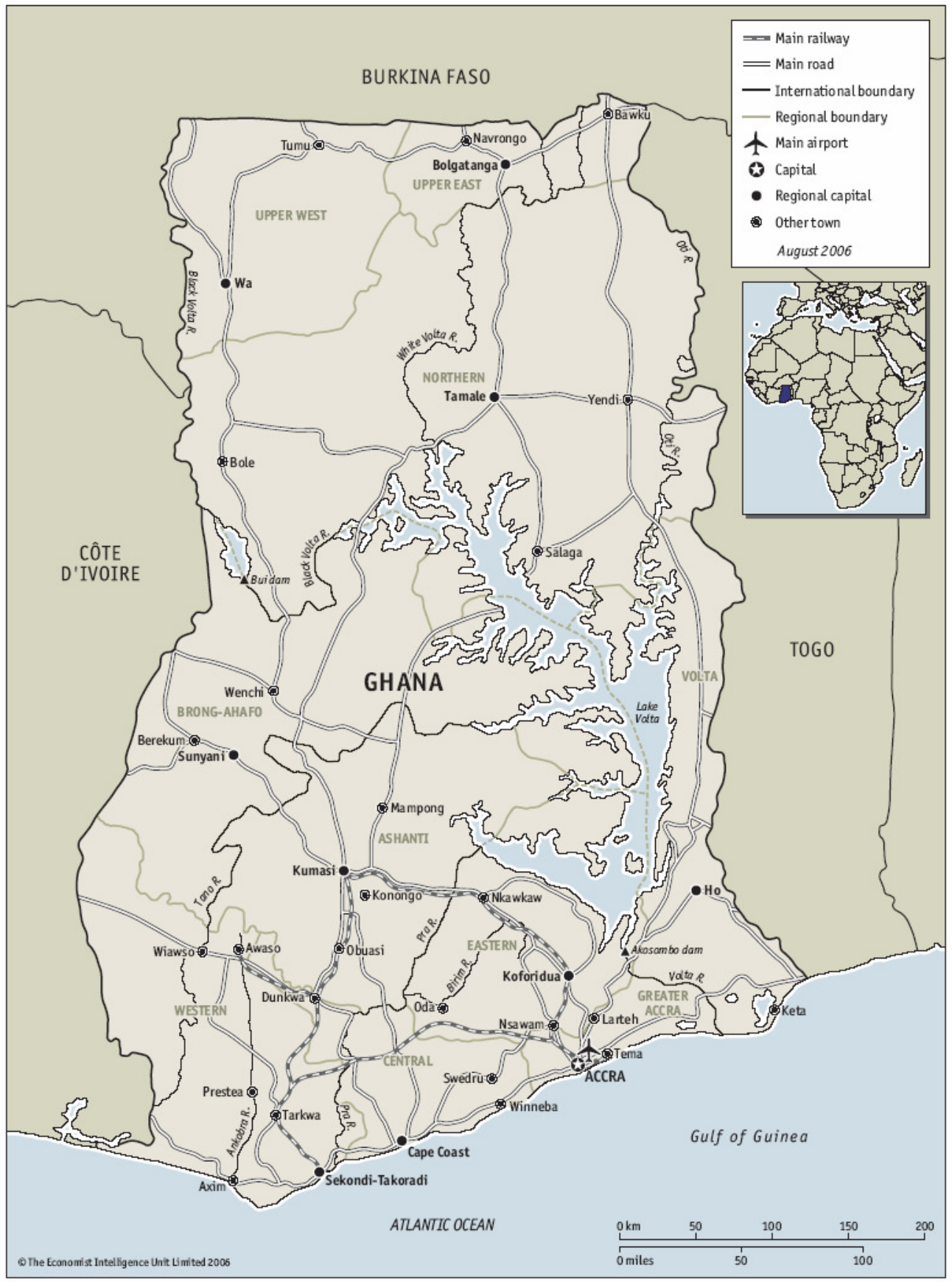

Kindly supplied by the Economist Intelligence Unit. (c) 2006. 


\section{Chapter 1: Research Context and Approach}

\subsection{Introduction}

Africa's young majority (King, McGrath, Nugent and Trudell, 2002) means that youth employment in Sub-Saharan Africa (SSA) is a critical issue for governments, civil society and development partners alike (Guarcello, Manacorda, Rosati, Fares, Lyon and Valdivia, 2005; World Bank, 2006b). Failure to address this issue will have far-reaching ramifications for the economy and society (Guarcello et al., 2005).

Fifteen years on from the World Conference on Education for All (EFA) in Jomtien, EFA policies have started to result in some of the largest cohorts of primary school leavers ever witnessed in a substantial numbers of countries. This is occurring at a time when the formal sector in SSA is unable to generate employment and income opportunities (indeed the formal economy in Africa is stagnating), in part a result of structural adjustment ${ }^{1}$ and the loss of what Ronald Dore once termed real jobs (Dore, 1976). The dilemma that most countries in SSA have following EFA is that there is "no possibility of offering employment for all" (King, 1997: 1). Therefore, the great majority of all school leavers are obliged to enter the informal, micro-enterprise economy, urban and rural. Furthermore the growth of the informal economy has been quickened by the increased rate of rural-urban migration and enlarging labour force (Blunch, Canagarajah and Raju, 2001). Governments, increasingly concerned with spiralling youth unemployment and the lack of postschool opportunities, are looking to expand their technical and vocational education and training (TVET) sector (in school, in vocational training institutions (VTIs) and on-the-job) as a means to facilitate the transition to work. Indeed, a senior advisor of a large development partner (DP) ${ }^{2}$ commented that of

the initial drafts of the 10 year plans produced by 15 partner countries in SSA... [a]ll of them included expansion of TVET primarily at the post-primary level. If this becomes a reality we might be seeing the biggest expansion of TVET since the 60s. (personal communication to King, 19.09.06)

\footnotetext{
${ }^{1}$ The Structural Adjustment Policies (SAPs), implemented throughout Africa in the 1980s (starting in Ghana in 1983), led to government spending cut backs resulting in a stagnation of formal sector employment opportunities and the concomitant explosion of informal activities (chap.4).

${ }^{2} \mathrm{DP}$ is the new name for a donor agency.
} 
Therefore, one of the most critical issues facing both African youth and policy makers across the continent is the school-skill-enterprise relationship. But it is likely this relationship is highly dependent on context, or rather, on the factors that impact on how skills development is translated into skills utilisation and hence employment creation. Analytically this can be divided into two types of context: ${ }^{3}$

- The delivery environment for skill acquisition - refers to factors that will ensure or inhibit the sustainable provision of a quality education and training system itself (e.g. the financing of education; availability of teachers and equipment);

- The transformative environment for skills utilisation - refers to the enabling environment, outside of the education and training system, that is required to transform education and skills training into developmental outcomes (e.g. growth in the economy and availability of employment opportunities).

Ghana represents an excellent case study of this trend: about $40 \%$ of the population was under 15 years in 2003 (UNDP, 2005); the primary-level cohorts are increasing in size (table 1.1) and each year about 300,000 youth exit lower secondary school, with about a third of these progressing to further education; ${ }^{4}$ Ghana lacks formal employment prospects, with nine-tenths of the population working in the informal enterprise (farm and nonfarm) ${ }^{5}$ the government is increasingly seeing skills training (in school, in VTIs, in short-duration programmes and on-the-job) and the need to create an enabling environment for private sector development as critical areas.

\footnotetext{
${ }^{3}$ The origin of this framework can be traced to discussions between the author, Kenneth King and Ruth Wedgwood about critical systems and the enabling environment for a research application to DFID in November 2003.

${ }^{4}$ Education specialist, World Bank Ghana, personal communication 27.07.06.

${ }^{5}$ It was research in Ghana by Keith Hart that first used the term 'the informal sector' (chap.2.1).
} 
Table 1.1. Primary school enrolment figures in Ghana, 1986-2005

\begin{tabular}{|r|r|}
\hline Year & $\begin{array}{l}\text { Primary school enrolment } \\
\text { (public and private) }\end{array}$ \\
\hline 1986 & $1,679,072$ \\
1990 & $1,945,422$ \\
1991 & $2,011,062$ \\
1992 & $2,047,293$ \\
1993 & $2,138,635$ \\
1994 & $2,154,676$ \\
1995 & $2,197,172$ \\
1996 & $2,333,347$ \\
1997 & $2,445,353$ \\
1998 & $2,562,229$ \\
1999 & $2,684,689$ \\
2000 & $2,477,990^{*}$ \\
2001 & $2,723,300$ \\
2002 & $2,857,535$ \\
2003 & $2,957,491$ \\
2004 & $3,077,489$ \\
2005 & $3,239,462$ \\
\hline
\end{tabular}

* A World Bank (2004c: 145-147) report suggests the drop in enrolment in 2000 is due to the non-inclusion that year of private school enrolments.

Source: GoG, 2005b: 17; GoG, 2006b: 23; World Bank, 2004c: 145

\subsection{Context}

\subsubsection{Skills development policy in Sub-Saharan Africa: a brief history ${ }^{6}$}

During the 1960s and early 1970s, TVET was a high priority for many bilateral and multilateral agencies (King, 1991; Jones, 1992). From the very first World Bank education loan in 1963 up until the mid-1980s, funding diversified secondary education with prevocational streams became a high priority for the Bank - as a result of their view about the need to promote TVET in order to train people for jobs. Indeed during this period it "became the norm of education operations" (Psacharopoulos, 2006: 330).

However, the mid-1980s marked a turning point in Bank policy regarding the usefulness of diversified education. Firstly the new rate-of-return studies claimed to show that primary education provided the highest returns (e.g. Psacharopoulos, 1980). And secondly, a study on World Bank-supported attempts to diversify secondary education in Columbia and Tanzania

\footnotetext{
${ }^{6}$ For a more detailed history of World Bank and ILO support to skills training, see King and Palmer (2006b).
} 
found that the higher costs of such education were not reflected in higher private or social returns (cf. Psacharopoulos and Loxley, 1985). The evidence suggested that diversified schooling was "no more effective than academic secondary education in enabling graduates to enter wage or self-employment" (World Bank, 1991: 9). ${ }^{7}$

While Bank policy remained critical of vocationalised secondary education, it remained popular for many national governments during the late eighties and nineties - e.g. Kenya, Ghana and South East Asia (King and Palmer, 2006b).

In the 1980s, the ILO began to emphasise the importance of training for the informal sector (cf. Fluitman, 1989; ILO, 1985; 1988; 1990). However, since 1990 and the World Conference on EFA the attention of international development agencies has become increasingly focused on primary education, a focus that has become set in the time-bound targets of the MDGs. The focus on basic, and especially primary, education has contributed to the neglect of post-basic education and training (King and Palmer, 2006c; Palmer, 2005b; c; World Bank, 2004a). Interest in skills development has suffered as a result of the focus on other development goals (Fluitman, 2005). Indeed, the international neglect of skills development in developing countries is underlined by its absence in the MDGs. Similarly, the neglect of skills development is seen in many poverty reduction strategy papers (PRSPs) where, as far as education and training are concerned, UPE is prioritised (Bennell, 1999; Caillods, 2003; ILO, 2003a).

In spite of this focus on basic education during the 1990s, the World Bank did produce an influential policy paper on TVET in 1991 (World Bank, 1991) and a related book in 1993 (Middleton, Ziderman, and Adams, 1993). But between 1993 and 2004, when the World Bank published its Skills Development in Sub-Saharan Africa (2004a), there was a relative absence of research in this area.

In the last few years, however, there is growing concern among DPs that the MDGs are being interpreted in a more restrictive way than what was agreed at Dakar and Jomtien (e.g. UNESCO-

\footnotetext{
${ }^{7}$ There have been serious reservations about both Psacharopoulos and Loxley's original research and their subsequent generalisations. Jain (1991) argued that Psacharopoulos's methodology and data can support a significantly different conclusion. McGrath, King, Leach and Carr-Hill (1995) point out that Psacharopoulos and Loxley's research applies only to the weak version (King, 1987) of school-based vocational education. This weak version of vocationalisation involves an orientation to vocational trades as part of general education, as compared to the strong version which involves heavy specialization in vocational subjects in separate schools or streams (McGrath et al., 1995).
} 
IIEP, 2004). The Dakar, and especially the Jomtien, agreements made skills development a much more explicit priority. The six Dakar goals included the goal of "ensuring that the learning needs of all young people and adults are met through equitable access to appropriate learning and lifeskills programmes" (UNESCO, 2000). At Jomtien, the World Declaration included "skills training, apprenticeships, and formal and non-formal education programmes" (WCEFA, 1990: article 5). ${ }^{8}$

Indeed, "[c]urrent international policy debates demonstrate the need for an expanded vision of EFA, closer to the spirit of Jomtien" (UNESCO-IIEP, 2004: 78). For example, the World Summit (September 2005) sees a widening of the MDGs to include TVET, secondary, and higher education (UN, 2005: 11). Moreover, a whole series of international documents (e.g. Commission for Africa, 2005; UN Millennium Project, 2005; World Bank, 2002, 2004a, 2005a) point towards the importance of a holistic, inter-sectoral approach to the whole of the education and training domain if countries are to reach the MDGs (Beveridge, King, Palmer and Wedgwood, 2005).

Even agencies that have long been associated with supporting primary education are increasingly of the view that "there is also a growing need to invest in secondary and higher education and vocational skills training" (DFID, 2006b: 76; cf. DFID, 2006a).

\subsubsection{Education for all, formal jobs for some and informal micro-enterprise for most in Sub-Saharan Africa}

Post-independence history indicates that parental commitment to primary school attendance for all their children will depend on some clear evidence of improved opportunities for skills development and/or formal post-basic access on the one hand, and equally evidence of a relationship between basic education and decent work through increased income generation in micro- and small-enterprises (MSEs) on the other. The sustainability of the current unparalleled investments in basic education will be determined by such evidence. The next few years' experience of the quality and outcomes of EFA will determine whether the massive numbers of poor, first generation school-attenders and their families will continue their new commitment to schooling.

\footnotetext{
${ }^{8}$ None of the EFA Global Monitoring Reports have focused on skills training to date.
} 
While basic education discourse in SSA has focused on quantity and quality of service provision, there has not been sufficient discussion of labour market outcomes. But the issue of what happens next to these school graduates is crucial. Politically the massive costs of universal primary education (UPE) and EFA need to be able to answer the question: EFA for what? That is not to say that the EFA-for-what question is new (King and McGrath, 1999b), but simply that the urgency of the question is becoming more of a concern for governments and development partners alike. Indeed, the inescapable interconnectedness of the Millennium Development Goals (MDGs) on Poverty (Target 1), Education (Target 3) and Decent and Productive Work (Target 16), point both to the urgent need to examine possible synergies between these areas, and to the immediate post-school outcomes of EFA cohorts. However, the MDGs offer only a narrow agenda for combating these critical employment issues - over-emphasising primary education and making no mention of the crucially important informal employment activities or skills training initiatives.

In SSA it is estimated that the informal micro-enterprise (IME) sector is responsible for over $90 \%$ of all new jobs (Chen, 2001; Commission for Africa, 2005), or as much as 85\% of total employment, according to the World Bank (2004a; 2005a).

In the past these MSEs were often seen as largely characterised by low productivity and poverty (Kilby, 1969; Ninsin, 1991) and there were doubts about their ability to continue to create employment (House, 1984; Simon, 1984; ILO/JASPA, 1985; Preston-Whyte, 1991). ${ }^{9}$

In the last two decades there has been a rapid growth in IME sector, especially in rural areas (Jeans, 1999; Kilby, 1986 in Livingstone, 1997; King and McGrath, 1999a; Liedholm and Mead, 1999), and since the 1990s a concomitant heightened interest in its potential to assist in poverty reduction. The dominant contemporary view of governments, planners, donors and academics is that IMEs are "the backbone of many developing economies" (Haan, 2001: 167). ${ }^{10}$ Indeed empirical evidence suggests that the informal sector in SSA is important for economic growth (ILO, 2002; Livingstone, 1997; Xaba, Horn and Motala, 2002) and it is now directly linked to the main objectives of development; increased production, employment and wealth creation, and as a key ingredient in poverty reduction (Afrisat, 1997; Akpalu and Bhasin, 2001; Bagachwa, 1997;

\footnotetext{
${ }^{9}$ See Palmer (2004b: 29-31) for a discussion on the origins of this negative perception of the informal economy.

${ }^{10}$ See Palmer (2004b: 31-33) for a discussion on the positive perception of the informal economy.
} 
Commission for Africa, 2005; Daniels, 1999; DFID, 2000; Dijk, 1997; ILO, 1972; King and McGrath, 1999a; Livingstone, 1991; 1997; Mamman, 2003; Webster and Fidler, 1996; World Bank, 2004a). The importance of informal MSEs to the economic and social development of Africa is "almost undisputed" (Rogerson, 2001: 115).

\subsubsection{Informal micro-enterprise (IME)}

Micro-enterprises in developing countries, including Ghana, are usually defined as comprising less than 10 workers (Aryeetey, Baah-Nuakoh, Duggleby, Hettige and Steel, 1994; Aryeetey, 1996; Boapeah, 1996; Liedholm, 1991; Liedholm and Mead, 1999; Livingstone, 1991; Rhyne and Otero, 1994).

The working definition of IME for this research is that they are any farm or nonfarm incomegenerating activity (full-time or part-time), operated from the home (cf. Chen, Sebstad, and O'Connell, 1999) or outside (from a stall, on the street or on the farm), constituting 1-9 workers (inclusive of the owner-worker and apprentices), who are either paid or non-paid (cf. Livingstone, 1991). The micro-enterprise spectrum is defined as a continuum between the more survivalist trading (bogyuwa-bogyuwa), ${ }^{11}$ manufacturing and farming activities at one end and the more dynamic enterprises at the other (cf. McGrath, et al., 1995).

The IME sector can be further subdivided into micro-manufacturing, trading, repair, transport, financial, ICT and agricultural enterprises (chap.2.2.2).

The emphasis of this study will be on micro-manufacturing enterprises, though occupational pluralism (chap.2.3.1) is also investigated.

\subsection{Research rationale and research questions}

\subsubsection{Contribution to theory and gaps in the literature}

This research will contribute to the informal sector literature. Firstly, it contributes to the knowledge about (training for, and pathways to) IME in rural areas (work on this still suffers from

\footnotetext{
${ }^{11}$ In Ghana, trading micro-enterprises are sometimes referred to as bogyuwa-bogyuwa (petty trading).
} 
urban bias, e.g. Haan, 2006). Secondly, since the informal sector is often conceptualised as a decontextualised phenomenon - without reference to "the context of the specific historical, political and social aspects of the country or region in question" (Blunch et al., 2001: 8) - this study will contribute to the contextualisation of the informal sector in Ghana. Thirdly it will emphasise the importance of occupational pluralism as an element of the informal sector, a concept which challenges the traditional proliferation of dualisms, or oppositional categories: e.g. employed/unemployed; farm/nonfarm; formal/informal.

There is a large amount of the literature on rural nonfarm activities (Bagachwa, 1997; Canagarajaha, Newman, and Bhattamishra, 2001; Ellis, 1998; FAO, 1998; Haggblade and Liedholm, 1991; Lanjouw and Lanjouw, 2001; Newman, and Sudharshan, 2000; Reardon, 1997; Reardon, Berdegue and Escobar, 2001; Start, 2001) and their role in rural employment and deagrarianisation (Bryceson, 1996, 1997a, 1997b, 2002a, 2004). This rural nonfarm literature is usually taken as synonymous with the literature on the rural informal economy (Bagachwa, 1997). While there is a literature on farm activities and farm-nonfarm relationships (Kilby, Liedholm and Meyer, 1984; Livingstone, 1991), the importance of occupational pluralism (pluriactivity) and its relationship with the farm-nonfarm divide has not been sufficiently stressed despite it not being a new concept (see Mureithi, 1973). This research contributes to the understanding of occupational pluralism.

There is a long running (and heavily contested, e.g. Bennell, 1996a) literature examining quantitatively the relationship between education and incomes in wage-employment in developing countries (e.g. Psacharopoulos and Patrinos, 2002). Similarly, quantitative studies regarding the effects of schooling on farm outcomes are common (e.g. Lockheed, Jamison and Lau, 1980). However, such studies regarding the effects of schooling on nonfarm outcomes are less so (but see Moock, Musgrove and Stelcner, 1990; Vijverberg, 1995; 1999) and even fewer quantitatively-orientated authors look simultaneously at effects of schooling on both farm and nonfarm activities (but see Jolliffe, 1996; 2002; 2004). ${ }^{12}$ It is not within the scope of this thesis to review these kinds of studies for Ghana. In fact, this has been done earlier (Palmer, 2006a). On the qualitative side, there is quite a well developed literature examining the impact of education on nonfarm informal employment (e.g. Afenyadu, King, McGrath, Oketch, Rogerson and Visser, 1999; Aryee, 1976; King, 1977, 1980, 1996; McGrath et al., 1995; Muskin, 1997). However, the

\footnotetext{
${ }^{12}$ This is, in part, due to the methodological difficulties associated with calculating income for those selfemployed in nonfarm enterprise (see Glewwe, 2002).
} 
issue of formal schooling followed by (multiple forms of) vocational skills acquisition and the subsequent link from skills training to enterprise has hardly been developed in the literature. This study aims to fill this gap.

Moreover, in much of the quantitative literature, the standard years of schooling measure says nothing about the quality of the delivery context of education and training. And yet this is a crucial issue (UNESCO, 2004). This research will examine in detail the delivery context of training programmes and, in so doing, disaggregate this environment and emphasise the importance of knowing more than simply how many years of training an individual received.

The research also contributes to the understanding of the transition from training to selfemployment which, at present "remains unclear" (Haan, 2006: 3).

\subsubsection{Contribution to policy}

For development partners, researching the outcomes beyond EFA is becoming more of a priority area as 2015 approaches. USAID is increasingly talking more about school-to-career transitions and DFID, in late 2005, set up three Education Research Programme Consortia (RPCs) one of which is examining educational outcomes. ${ }^{13}$ DFID is now actively thinking about the link between education, training and work and is keen for more information in this area (Desmond Birmingham, Head of Profession, DFID, personal communication 14.09.05). ${ }^{14}$

In most of SSA, poverty is most prevalent in rural areas and hence there is an ongoing need to better understand how to meet the needs of the rural poor (IFAD, 2004; World Bank, 2003). The focus of this thesis on training and IME in rural areas will contribute to this understanding.

The GoG has stated its desire to create an enabling environment for private sector development (GoG, 2003a; GoG, 2005a) and has been increasingly involved in financing skills training and youth employment programmes (chap.5). Moreover in 2005 the President announced the intention to formalise the informal sector and an informal sector survey is underway during 2006-

\footnotetext{
${ }^{13}$ See http://www.educ.cam.ac.uk/RECOUP/index.html

${ }^{14}$ As a contributor to the RPC on Outcomes (see below) I am in a good position to feed my thesis findings into the RPC, and through that to DFID.
} 
07. My thesis, therefore, is timely and will further the understanding of these highly topical issues.

\subsubsection{Research questions, objectives and structure of thesis}

This thesis examines the interaction amongst school, skill and enterprise in rural Ghana; though focus is on the relationship between skills training and informal micro-enterprise. With the research rationale in mind (chap.1.2.1\&1.2.2), the main research questions, therefore, are:

1. What has been the history of the interaction amongst school, skills development and informal micro-enterprise policy and practice in Ghana?

2. How do Ghanaian youth, especially those in rural areas, acquire vocational skills and create pathways to informal micro-enterprise?

3. How does the delivery environment for skill acquisition and the transformative environment for skills utilisation relate to 1 . and 2. above?

4. How can an examination of these questions add to the theoretical understanding of these matters?

In order to answer these questions, this study pursues the following objectives:

- To revisit a conceptualisation of the informal economy, and to rethink this debate that has hitherto been focused on an urban perspective;

- To analyse the dynamic relationship between schooling, skills training and work in historical context in Ghana;

- To analyse the delivery environment of three kinds of skills development programmes - all aimed at informal micro-enterprise (especially in rural areas): informal enterprise-based training in apprenticeship, short-term modular training and longer-term pre-employment training;

- To analyse the pathways to work in informal micro-enterprise from these three kinds of skills development programmes;

- To assess the extent to which skills acquired by graduates of these training programmes are utilised in the labour market and the types of enabling and disabling environments that impact on these labour market outcomes.

This chapter sets the context for the thesis and explores the methodological approach used. 
Chapter two focuses on the enterprise component of the school-skill-enterprise link and rethinks some traditional conceptualisations in light of the occupational pluralism, or pluri-activity, of large segments of Africa's population, for example with regard to the farm-nonfarm divide. It also examines the urban bias that has characterised the literature on the informal sector.

Chapter three examines some of the assumptions and challenges of the school-skill-enterprise link arising from current thinking in the areas of skills development, enabling environments and pathways to self-employment.

Chapter four explores the history of policy and practice vis-à-vis skills development, work and enterprise in the Gold Coast/Ghana from the early nineteenth century to 2000. It examines the remarkable consistency in the way TVET has been revived as the solution to un/underemployment over the decades from the early colonial period to the present.

Chapter five explores skills development and informal micro-enterprise policy and practice within the new political context, 2001-2006.

Chapter six, using a case study of an institution-based pre-employment skills training programme (the Integrated Community Centres for Employable Skills, ICCES), analyses both the delivery context of training and graduates' pathway to work.

Chapter seven examines two other types of skills acquisition modalities and presents new evidence on these programmes: traditional apprenticeship training in rural areas and a shortduration modular skills programme.

Chapter eight analyses retrospective interviews with MSE owners, looking at their education and training pathways and their entry into self-employment.

Chapter nine concludes the thesis by covering three major issues: first, it re-examines the assumptions of Ghanaian skills development agenda (chapters 4 and 5) and positions this both in relation to access and equity issues, but also to the larger macro-economic dynamics; second, it comments on the skills development programmes and pathways to rural informal microenterprise identified in chapters 6,7 and 8; lastly, it outlines some theoretical concerns arising 
from the study (particularly in relation to chapters 2 and 3) and the new research challenges that this study's findings suggest.

\subsection{Methodology}

I first went to Ghana in 2001 as a volunteer, having requested to the volunteer agency that I be placed 'with a tree-planting NGO, somewhere rural, with no electricity or running water'. On arrival I found myself in a vocational training centre (ICCES) in rural Ashanti but, having had three out of my four requests granted I saw no reason to move. And so my interest in rural vocational training began.

It was by chance that my first arrival in Ghana, in January 2001, coincided with a change of government (chap.5) and the taking up of office of the New Patriotic Party (NPP). Trotro (minibus) passengers were alive with the expected 'positive change' that many believed would be seen quickly. ${ }^{15}$

In early 2002, just after returning from my first 11-month visit to Ghana, I visited the Centre of African Studies (CAS) in Edinburgh to discuss my application for the MSc/PhD. Having been working closely with ICCES I was keen to understand more about what the youth that had received this type of skills training were doing after they left. While aware of the problems faced by ICCES, at that time I had never heard of Philip Foster and was largely uncritical of the idea that pre-employment training might not be the best way for youth to acquire 'employable' skills. I later returned to Ghana in 2002 (for 3 months work with ICCES) and 2003 (for 2 months MSc fieldwork on IME financing - see Palmer, 2004a). Prior to starting the PhD, therefore, I had some sixteen months of experience in rural Ashanti. The focus area for my $\mathrm{PhD}$ developed both from my work experience in ICCES and from my MSc research.

For research of this type, that involved a year of fieldwork with multiple questionnaires, interviews, impromptu discussions and secondary analysis, it is impossible to briefly discuss the methodology used since much essential information would be lost. Due to the desire that the thesis would flow clearly, it was considered necessary to include a methodology overview in the main text, and allow for a more detailed discussion of some aspects of the research in Appendices A-D.

15 'Positive change' is the slogan of the NPP. 
The research was based on twelve months fieldwork in rural Ashanti (2004-05), during which time multiple approaches were used to uncover skill-to-work pathways: i) retrospective interviews with 114 masters in rural manufacturing enterprises (chap.8); ii) interviews with 160 traditional apprentices (chap.7); iii) questionnaires, interviews and focus groups with 162 graduates from 7 vocational training centres (chap.6); iv) a basic household survey (81 households) in one rural community (involving a wealth-ranking and mapping exercise) that captured data on 147 youth in the labour market (Appendix C); v) interviews with other key informants (e.g. village, district and national officials, as well as DP officials); and, vi) informal (participant) observation of education, skills and enterprises in rural communities.

The research design adopted a multi-disciplinary approach and was intentionally as reflexive as possible. This allowed the design to evolve as both ideas and thoughts changed and as unforeseen constraints arose.

Despite the difficulty of collecting quantitative data regarding the informal sector and the unreliability of official data, the research design chose to combine both quantitative and qualitative methods (questionnaires, interviews and discussions), an approach that proved highly successful during previous MSc fieldwork in Ghana (Palmer, 2004a). This triangulation of data has a number of well-known strengths and weaknesses that should be noted (Appendix D.2.3).

\subsubsection{Literature reviews and balancing consultancy and academic research}

A comprehensive review was undertaken of two sets of relevant literature concerned with: i) education and skills development; ii) informal sector, livelihoods and MSE development. This

allowed for initial choices to be made that had to satisfy audiences the research was robust and valid.

This resulted in an early paper (pp.105) on the informal economy (Palmer, 2004b) which, together with the author's revised Masters' dissertation on rural IME financing (Palmer, 2004a) provided a solid foundation for this thesis.

Between 2004-2006, I was involved in some consultancy research directly related to the topic of this thesis. The largest of these was a DFID-funded project examining the contribution of post- 
basic education and training to poverty reduction (Palmer, Wedgwood, Hayman, King and Thin, 2007). ${ }^{16}$ As a result of this project I (co-)wrote a number of papers related to skills and education (King and Palmer, 2006a, b, c; King, Palmer and Hayman, 2005; Palmer, 2005a, b, c - see bibliography). In 2006, I become involved in a DFID-funded RPC examining the outcomes of education and have produced some papers connected to this (see Ayamdoo, Casely-Hayford, Palmer and Thompson (2006) and Palmer (2006a, b)). ${ }^{17}$

It has been difficult at times to maintain an appropriate balance between consultancy research and the demands of academic doctoral research, but the opportunity to be part of these research exercises on highly relevant topics - and the opportunity to publish and co-author both policyorientated and academic papers, in addition to the access to key policy and academic personnel that these research exercises have offered - has undoubtedly enriched my own thesis. Whilst the consultancy research has been on similar topics, I have consistently been careful not to include in these papers fieldwork from my $\mathrm{PhD}$. While the depth of my knowledge has increased significantly as a result of doing these extra pieces of research, my thesis is, of course, an entirely new piece of work. Moreover I have been careful to ensure that this consultancy research complements my academic focus (McGrath, 1995).

\subsubsection{Choice and description of location}

As noted above, before starting my Masters or PhD, I worked for fourteen months for a rural skills training programme in Ghana (ICCES), based primarily at village level in Atwima District. ${ }^{18}$ Given the difficulty of researching the informal sector, as well as the financial constraints $\mathrm{PhD}$ fieldwork operates within, I considered it far better to return to an area where I had excellent access, excellent contacts and over 14 months of prior experience. These contacts and my ability to demonstrate previous insider status allowed me to gain greater access to individuals, situations, events, places and documents (Agar 1996). This prior knowledge also improved the efficiency with which I was able to undertake the fieldwork, and it gave me the advantage of knowing about the socio-cultural framework of the communities - even before I commenced my fieldwork. With this background, the study sites were chosen as I knew that the

\footnotetext{
${ }^{16}$ See http://www.cas.ed.ac.uk/research/projects.html

${ }^{17}$ Palmer (2006a) is essentially a review and critique of the economic literature that links education, skills and labour market outcomes.

${ }^{18}$ During this time I worked mainly in one rural ICCES centre, but also did work at the regional level in Ashanti. In 2004 Atwima District split into two and became Atwima Mponua and Atwima Nwabiagya Districts.
} 
different skill modalities I intended to investigate in this research (informal enterprise-based training in apprenticeship, short-term modular training and longer-term pre-employment training), as well as numerous MSEs, could all be found in these locations.

The bulk of the research was conducted in Atwima Mponua District (fig.1.1) in Otaakrom village and the district capital, Nyinahin. A third site was the (neighbouring) district capital of Bibiani just 10km from Otaakrom (fig.1.2). The interviews with masters and apprentices took place in all three locations, while the household survey was only in Otaakrom. Much of the detailed understanding of ICCES came from Otaakrom, though this was supplemented with data from six other centres.

\section{Fig.1.1. Ashanti Region, showing Atwima Mponua District}

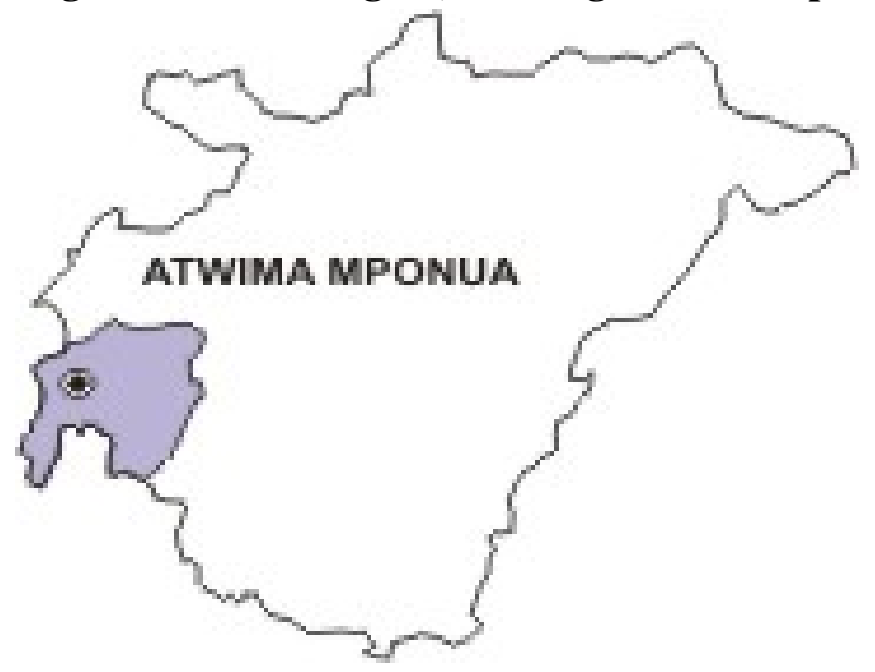

Source: www.ghanadistricts.com 


\section{Fig.1.2. Map of Atwima Mponua District, Ashanti}

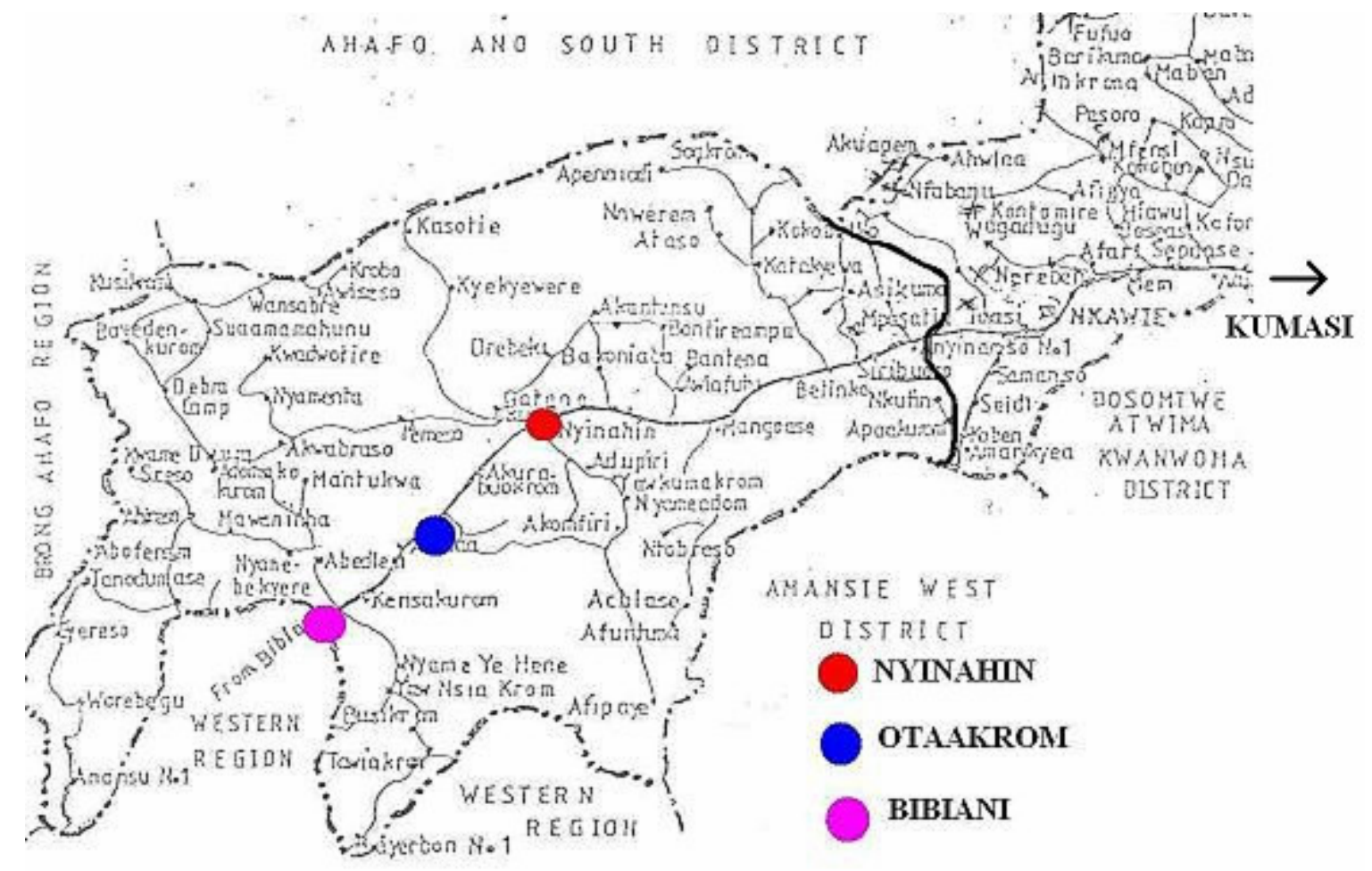

Source: Atwima District Assembly, 2003

Nyinahin ${ }^{19}$

Nyinahin is the capital of the newly created (August 2004) Atwina Mponua District and has a population of about 8000 . The main occupation is agriculture; both cash crops (cocoa, oil palm) and Chop(food)-crops (yam, coco-yam, plantain, cassava, maize). Wage-employment opportunities exist in the district assembly, the hospital, post-office and schools. Nyinahin has large bauxite deposits and a mine is expected to open before 2010 which will offer youth with National Vocational Training Institute (NVTI) certificates (or higher) increased wageemployment opportunities. Nyinahin has both electricity (since 1999) and pipe-borne-water (a new water pumping station was installed in the late 1990s), though sanitation remains a problem. Electricity allowed new types of enterprises to start-up (e.g. in telecommunications, welding etc.). Nyinahin's health centre was upgraded to a hospital in the late 1990s and it is served by a rural bank and post-office. There is a senior secondary school (SSS) (though it suffers from a lack of teachers) as well as numerous junior secondary (JSS) and primary schools and kindergartens

\footnotetext{
${ }^{19}$ The data in the following three paragraphs draws both on personal experience (2001-2004), fieldwork (2005/6) and UNDP/NDPC (2004).
} 
(KG). Apprenticeship training in informal enterprises is also common. The roads within Nyinahin have been rehabilitated and the main road to Kumasi has been resurfaced with asphalt (completed 2006). About $25 \%$ of households in Nyinahin are classified as poor.

\section{Otaakrom}

The population of Otaakrom is approximately 2000 . It is located about $75 \mathrm{~km}$ west of Kumasi. The village is predominantly reliant on agricultural produce; both cash crops (principally cocoa) and chop-crops (see above). The only waged-employment in Otaakrom consists of the teachers, an agricultural officer, the nurse and a few logging-company employees. It is not a well-off area: the author's household survey conducted in 2005 suggested that over $40 \%$ of households can be regarded as poor/very-poor (chap.2.3.3). ${ }^{20}$ Educational facilities include: two public JSS, two public primary schools, two private KGs, and a public VTI (ICCES). The nearest SSSs are in Nyinahin and Bibiani. There are also a number of local artisans that train youths within a traditional apprenticeship framework. There is no pipe-borne-water, bank or post-office. However, Otaakrom has good transport links (located on a new (2006) asphalt road between Kumasi and Bibiani and is served by a public bus service and private trotro minibuses) and in 2003 got mains electricity. In addition, it has a small clinic and public communication centre (and mobile space-to-space telephone) ${ }^{21}$ As a result of the electricity new enterprises are opening up in the village (e.g. a radio repairer) and existing enterprises are able to use new types of equipment (e.g. hairdressers using an electric dryer).

\section{Bibiani}

Bibiani is the capital of Bibiani-Anhwiaso-Bekwai (BAB) District. It has a population of about 22,000 and is located $88 \mathrm{~km}$ west of Kumasi. Agriculture is the main occupation (principally cassava, yam, plantain, cocoyam) though petty-trading and artisanal enterprises are widespread in Bibiani. Wage-employment exists in the gold mine (Ashanti Goldfields Bibiani Ltd.), various logging companies, as well as in the district assembly, hospital and schools. Educational facilities include a public Secondary Technical School, JSSs, primary schools, KGs and apprenticeship training in informal enterprises. Bibiani has had both electricity and pipe-borne-water for the last decade and has a government hospital, post-office and telecommunications facilities. Road links

\footnotetext{
${ }^{20}$ This is similar to the rural average of $38 \%$ for this district (UNDP/NDPC, 2004). See Appendix C for a description of what poor means in Otaakrom and more information on the household survey.

${ }^{21}$ See chap.2.2.2.
} 
around Bibiani are good (due to the presence of the gold mine), but in BAB District as a whole most roads are unpaved.

\section{The three sites}

This area has, over the last thirty years, seen a considerable decline in the percentage of the population working in agriculture. While it continues to be the main source of livelihood for the majority, for many of the youth it is no longer their primary activity. Nonfarm activities are increasing among the youth, and migration to larger settlements in search of employment or education/training is also a common strategy. Poverty indicators suggest that this area lags behind the national situation (UNDP/NDPC, 2004).

Bibiani is the most dynamic enterprise setting out of the three. This can be seen, for example, in the average number of apprentices per enterprise: while Bibiani has, on average, 4.2 apprentices per enterprise, Nyinahin only has 2.3 and Otaakrom 1.5. While one-person enterprises make up $62 \%$ of all enterprises in Otaakrom, in Nyinahin and Bibiani $33 \%$ and $4 \%$ respectively are oneperson ventures. The presence of electricity for the last decade in Bibiani has meant that, compared to Nyinahin, more enterprises requiring electricity can be found here compared to Nyinahin or Otaakrom (Appendix A).

\subsubsection{Timing of research and research strategy}

The research took place for twelve months between 2005/06. To avoid development tourism (Chambers, 1983: 11), the phenomenon of a brief rural visit, I lived in Otaakrom village for the duration of the fieldwork. This was convenient since it was between Nyinahin and Bibiani (fig.1.2). This meant finding somewhere to live in town, taking time to talk to people, going to funerals with friends and, as Dingwall (1997) puts it, "hanging out" (p.53). The impromptu discussions that resulted allowed a more holistic understanding of rural livelihoods. This was invaluable since it is not possible to study anything in isolation (Tripp, 1997). Moreover, I was able to continue to work in the village ICCES centre and hence participated in, and observed, day to day events. 


\subsubsection{Main approaches used (see Appendix D for supplementary approaches used)}

The enterprise data (see also chap.7 and 8)

i) Retrospective interviews with 114 masters in different rural manufacturing enterprises. Retrospective interviews were chosen as they allowed me to trace the life-history of the owner backwards and to find out about the type of education and skills acquired and how they made the transition into self-employment. In the three localities, enterprises were mapped with the assistance of local VTI instructors. These local actors were able to point out the majority of store, street and home-based enterprises. Since I wanted to look at training enterprises and trade areas that were also taught in the ICCES, the focus was on dressmaking and carpentry enterprises, though other enterprises were also included. For example, it soon became apparent that large numbers of hairdressing enterprises were operating in these localities, training large numbers of apprentices. Basic semi-structured questionnaires (Appendix A.2) were used to guide the interviews, and space was given for additional probing questions. Each interview lasted about 30 minutes.

ii) Interviews with 160 traditional apprentices. Traditional apprenticeship training was chosen for examination since it represents the most widespread skills training modality in Ghana. In each enterprise a maximum of 2 apprentices were interviewed (again using a semi-structured questionnaire, Appendix A.3). While some enterprises had no apprentices, overall the 114 enterprises had a total of 347 apprentices making the sample of 160 almost $50 \%$ of the total number of apprentices.

\section{The data on skills training providers}

iii) Questionnaires, interviews and focus groups with 162 graduates from 7 vocational training centres. Two types of questionnaires were used (Appendix B) to collect data: one was answered directly by ICCES graduates, while in the other centre managers and instructors were asked about the current activity of graduates. This approach is discussed elsewhere (chap.6). ICCES was selected as a case study as it has, as a central concept, the idea of training youth for selfemployment using pre-employment training in formal VTIs. This is unusual. Moreover, it has not been studied by other researchers before and the author's strong contact with ICCES since January 2001 made it an obvious choice. 


\section{The household survey data}

iv) A basic household survey ( 81 households) in one rural community (involving a wealthranking and mapping exercise) that captured data on 147 youth in the labour market. This survey sought to get information on: youth in Otaakrom (aged 14-25) regarding their education/skills background, their current activities and migration patterns; the occupational pluralism of households; and, the poverty/wealth categories of households in order to look for trends. This household survey involved multiple stages (Appendix C): i) interviews in 21 households to establish poverty/wealth categories; ii) household mapping of the entire village by agreed poverty/wealth categories; iii) random sampling of 81 households and basic questionnaire (Appendix C.5) administered in each household.

\subsection{Conclusion}

This chapter has set the context and questions for the thesis. The following two chapters examine the international literature and interrogate some of the concepts and theoretical concerns related to the school-skill-enterprise link. The next chapter (2) focuses on the enterprise component of the school-skill-enterprise link, while chapter 3 focuses on the skill-enterprise transition. 


\section{Chapter 2: Micro-Enterprise and Occupational Pluralism: Rethinking Urban Bias and the Farm-Nonfarm Divide in Sub-Saharan Africa}

\subsection{Introduction 22}

This chapter focuses on the enterprise component of the school-skill-enterprise link and rethinks the farm-nonfarm conceptualisation in light of the occupational pluralism, or pluri-activity, of large segments of the Africa's population. Furthermore it examines the rural dimension to the informal sector.

The first section examines the informal sector in historical perspective, examining how the concept became shaped by key actors and events and noting briefly the way it is currently defined. The second section focuses on the rural informal sector, examining the farm-nonfarm divide and how the composition of the rural informal sector is changing as a result of deagrarianisation. The final section explores a re-conceptualisation of work in SSA; it argues that, as a result of occupational pluralism, the dichotomous occupational categorisation so common in labour market statistics is misleading. It concludes with implications for the skill-to-enterprise link beyond the farm-nonfarm divide.

\subsection{The history of the informal sector concept}

Given that the concept of the informal sector is over thirty years old, it is not surprising that it has been used to mean different things by different analysts (Mead and Morrisson, 1996). This is evidenced in the large number of terms that have been used to describe the informal economy (cf. Palmer, 2004b): e.g. the unregulated or unenumerated sector; the Jua Kali sector (King, 1996); or the micro-enterprise sector (Bagachwa, 1997; Livingstone, 1991; Webster and Fidler, 1996).

It has been claimed (e.g. Bromley, 1978) that the informal/formal economy dualism was simply a spin-off of the dual economy literature of the 1950s (cf. Lewis, 1954). But the idea also has origins in research work done in numerous countries: for example Kenya, Nigeria and Ghana.

\footnotetext{
${ }^{22}$ For more detail on the history and conceptualisation of the informal economy see the occasional paper (pp.105) that was written as part of this doctoral research (Palmer, 2004b).
} 
In Kenya the East African Royal Commission (EARC) of 1953-55 recognised the clusters of small enterprise activities on the outskirts of Nairobi - that would later fall under the informal sector concept - as "important as centres of African trade" (EARC, 1955, cited in King, 1996: 4). The African businessmen (Marris and Somerset, 1971), based on fieldwork 1966-1967, also highlighted the importance of small enterprises in Kenya. ${ }^{23}$ Later the 1966 Report to the Kericho Conference in Kenya described what would later be termed that informal sector as a sector where the unemployed "eke out an existence as casual labourers, stall-holders, beggars and petty thieves" (Harbison, 1967, cited in King, 1996: 5) with activities also including "petty barter trade and traditional crafts" (ibid.). This negative view contrasts with the positive view of the ILO (1972) a few years later.

In 1972, just before the publication of the ILO Kenya report, Steele presented his idea of an intermediate sector (Steele, 1972) in Kenya at a conference at the University of Edinburgh. Steele noted that

an unknown portion of... service [sic] and manufacturing [African business] is not registered in the big towns or the rural areas for factory, social insurance, minimum wage, or statistics collecting legislation. Yet there are indications... that it is a significant zone for entrepreneurial activity. Policy does very little to assist and the sector as a whole fits only piecemeal into development theory. (ibid.: 206)

Steele's colleagues at the university of Sussex included the two main authors of the ILO Kenya report: Hans Singer and Richard Jolly. Since the ILO Kenya report was not submitted in draft form until early July 1972 and published until November 1972, it is likely that some of Steele's ideas filtered into the thinking of the ILO Kenya report write-up.

Meanwhile, about the same time that the ILO Mission started in Kenya, Kenneth King - without knowing about the ILO Mission - started research work in July 1972 interviewing informal machine makers (published as King, 1977) (cf. McGrath, Jedrej, King and Thompson, 1997).

In Nigeria in the early 1960s, Callaway's research (Callaway, 1963; 1964) highlighted a number of key elements that would later be described as characteristic of the informal sector. For example, Callaway (1963) highlights the case of a typical school leaver who goes to search for work in Ibadan and might end up becoming an apprentice after exhausting the limited options for

\footnotetext{
${ }^{23}$ Somerset was also a member of the 1972 ILO Mission to Kenya (see below).
} 
entry into the modern sector. ${ }^{24} \mathrm{He}$ then goes on to discuss the "whole array of indigenous enterprises [that] represents the only really competitive element in these economies" (p.359).

In Ghana apprenticeship training had long been recognised as an important means of skills acquisition (Foster, 1965a; Hart, 1973; Peil, 1970; Quartey-Papafio, 1914). For example, Foster's research in the mid-1960s (1965a), like Callaway's in Nigeria just mentioned, brings up the issue of informal apprenticeship. ${ }^{25}$ Foster, moreover, throughout his classic Education and Social Change in Ghana frequently uses the distinction between exchange and subsistence economies (Foster, 1965a).

It was Keith Hart's work in Ghana, of course, that is acknowledged as discovering the informal sector. Hart conducted doctoral fieldwork between 1965-68 exploring the informal economic activities of the northern Frafra migrants in a poor area of Accra, Nima. ${ }^{26}$ In September 1971 Hart first discussed his preliminary findings on informal economic activities, later published as his 1973 article (Hart, 1973), at a conference on Urban unemployment in Africa at the university of Sussex. Present at this conference were ten members of the later ILO Employment Mission to Kenya including the two leaders of the mission, Singer and Jolly. This early interaction with the concept of informal economic activities discussed by Hart, will have undoubtedly shaped some of the later ILO findings in Kenya the following year (cf. Bromley, 1978; Cruise O'Brien, 1972). ${ }^{27}$ Tony Somerset, a member of the informal sector working party for the ILO Kenya Mission, confirmed this - while also noting the urban bias of the Kenyan Mission - and commented that:

it's something of a puzzle that the ILO Mission considered the informal sector to be mainly an urban phenomenon... As I recall it, we were strongly influenced by Keith Hart's paper... and also by the preoccupation at the time with rural-urban migration as a precursor to jobseeking (in Mike Todaro's work, for instance). (Somerset to Kenneth King, by email 11.04.05)

Hart's presentation at this conference is likely to have been an important factor securing his name as the discoverer of the informal sector idea. However, as noted above, Hart's work was preceded by a wealth of research that was effectively looking at the same phenomenon, in all but name.

\footnotetext{
${ }^{24}$ See also his 1964 article on Nigeria's apprenticeship system (Callaway, 1964).

${ }^{25}$ Quartey-Papafio (1914) provides an earlier account of apprenticeship training in the Gold Coast.

${ }^{26}$ In his doctoral thesis, Hart also examines the economic activities of the Frafra in rural areas in northern Ghana, see Palmer (2004b).

${ }^{27}$ A later member of the Kenya ILO team, John Weeks, also presented at this conference a paper on the unenumerated sector, a cousin idea to the informal sector.
} 
Hart would have had access to much of the literature noted above that explored many of the main aspects of the informal sector-to-be such as: low-cost informal apprenticeship (Callaway, 1963; Foster, 1965a); enterprise activities (Callaway, 1963; Harbison, 1967); labour intensive activities (Callaway, 1963); diversification of enterprises (Bauer, 1954); not to mention the dual economy literature of the 1950s. Thus Hart being attributed the role of discoverer of the informal sector seems an exaggeration and it is most likely that he was in the right place at the right time. ${ }^{28}$

Nonetheless, Hart's two early articles (Hart, 1970; 1973) were important pieces: e.g. Hart's view was that the informal sector served a productive role in the economy and he also discussed the issue of multiple occupations. ${ }^{29}$

\subsubsection{The primary school leaver problem and the internationalisation of the informal sector concept by the ILO/UNDP employment mission to Kenya}

Associated with the three UNESCO meetings - Addis, Santiago and Karachi - the early push for UPE in the 1960s resulted, by the end of that decade, in a growing concern for unemployed school leavers and the search for employment opportunities for these youth. The unemployed school leaver problem was made more pressing for some as a result of warnings about forthcoming political instability that were believed to be the result of large numbers of unemployed educated youth (Gutkind, 1969).

This concern for unemployed school leavers at the time also laid the foundations for the internationalisation of the informal sector concept in the 1970s and potentially its link to schooling.

The 1961 conference in Addis Ababa on the development of education in Africa (noted above) set a target to achieve UPE by 1980. A few years after this conference Callaway (1963) noted that the advance towards UPE "reveals itself as an opportunity - but also a dilemma" (p.354). He goes on to say that "only a few parents - most of whom are farmers - want their school children to become farmers" (ibid.). By the mid-1960s the dilemma was apparent as it became clear that an

\footnotetext{
${ }^{28}$ The fact is that Hart's earliest published use of the term informal sector is after the ILO Mission had used it. He used it in his unpublished paper in 1971 which may even have been an oral presentation.

${ }^{29}$ See Palmer (2004b) for a detailed discussion on Hart's early papers and his PhD.
} 
insufficient number of modern jobs were being created that were needed to absorb the people wanting to fill them (Bangasser, 2000). It was becoming clear that:

increasingly large numbers of people were obviously economically active; but what they were doing did not appear in the [national development] plan and so, de facto, neither did they. (ibid.: 4)

As a response to this problem the ILO launched the World Employment Programme (WEP) in 1969 in an attempt to bring the issue of employment creation to the forefront of developmental efforts. The first employment missions, to Colombia (1970) and Sri Lanka (1971), both recommended a full employment strategy involving major structural and institutional reforms, for example with land and fiscal reforms and the development of labour intensive employment schemes. In Colombia the report noted the necessity to create five million new jobs between 1970-1985 but was soon criticised for being far too unrealistic and only likely to be adopted through a revolutionary process (Urrutia, in Moser, 1978).

The ILO mission to Kenya, the first comprehensive employment mission to Africa, differed from earlier missions in identifying the key problem not as unemployment per se, but employment of the working poor (ILO, 1972). The report positively described a sector apart from the modern/formal sector, an informal sector that was "economically efficient and profit-making" (ibid.: 5) characterised by ease of entry, labour intensive activities and providing skills training outside of the formal system. This interpretation of the informal sector would have fitted well with those concerned with the primary school leaver or youth employment problems of this time. ${ }^{30}$ Moreover, it would have fitted well with those thinking about the outcomes of UPE: since it was clear there were insufficient jobs created in formal employment, this informal sector seemed a viable alternative with regard to job creation and employment opportunities for the products of UPE. Indeed the Kenya report explicitly noted this in commenting that the "[informal] sector can be a source of future growth as an integral part of an employment strategy" (ibid.: 229).

However, the ILO Kenya report was criticised for laying too much emphasis on the employment/unemployment problem and not enough emphasis on economic growth, while at the same time making rapid economic growth a necessity for solving the problem (Moser, 1978). Indeed, Leys (1973) described "the recommendations... as utopian" (p.421).

\footnotetext{
${ }^{30}$ See King (1991) for a history of the thinking about education and employment.
} 


\subsubsection{The informal sector, the informal economy and informal employment: the contemporary position ${ }^{31}$}

The informal sector is now widely viewed as heterogeneous and as consisting of three segments, each having their own specific set of constraints and requiring their own particular support strategies (Haan, 2001: 169; cf. World Bank, 2004a: 51):

- Pre-entrepreneurial subsistence types of self-employment characterized by part-time (seasonal) operations, traditional technologies, local materials, and local markets, a particularly important source of income for poor rural women.

- Micro-enterprises of up to 10 workers, mostly family members or apprentices using a mix of technologies, serving rural markets, and often operating in rural centers.

- Small-scale enterprises with 10 to 50 workers, using some modern technologies, semiformalized, and with some growth potential.

A thread running through this thesis is the acknowledgement that the informal sector is heterogeneous but that, for analytical purposes it is useful to examine specific segments of it. Since, the focus of this thesis is on self-employment in micro-enterprises, the discussion will largely relate to the first two of the segments outlined above and, following King (1980) and McGrath et al. (1995), will largely adopt a two-fold distinction between subsistence orientated self-employment, on the one hand, and entrepreneurship self-employment one the other. ${ }^{32}$

While some have traditionally viewed the informal sector as comprised of subsistence-orientated activities, the dominant view now is that due to its heterogeneous nature the informal sector is both survivalist and dynamic (Mead, 1999). The informal sector encompasses both microenterprises struggling to survive at one end and much better off enterprises (often moving into high-tech business such as internet cafes), showing innovative and expansive tendencies, at the other. Interestingly Hart (1969), in his doctoral thesis, analysed the need:

to distinguish between those [in trading and self-employment] who look on these activities as a source of subsistence income equivalent or additional to a wage or farming (i.e. full-time and part-time petty traders and small artisans) and those to whom these are small beginnings to a cumulative process (i.e. "entrepreneurs proper"). (p.273)

\footnotetext{
${ }^{31}$ See also Palmer (2004b).

${ }^{32}$ But see chap.3.3.2 that introduces a third category: micro-entrepreneurial self-employment (MESE).
} 
King (1980) also made a distinction between types of employment within the informal sector: in his case between subsistence self-employment and entrepreneurial self-employment. In a later coauthored paper, it was made clear that the informal sector should not be used as a catch all phrase. Instead there is the need to be specific about which group is being discussed at any given time (cf. McGrath et al., 1995). Further, there is the need to be clear, when using the distinction between subsistence self-employment and entrepreneurial self-employment, that this does not imply that "there is something static about the situation" (ibid.: 15). Informal enterprise activities can and do move between these different types over the course of an enterprise's life-cycle. ${ }^{33}$

However, a word of caution should be added when viewing the informal sector as a continuum between subsistence and entrepreneurial enterprise activities, at the same time as recognising the need to discuss different types of enterprise within this continuum. The use of a conceptual continuum that will highlight the transition of enterprises along it, as Bromley (1978) noted, implies that informal operators can graduate to the formal sector (Liedholm, 1991; Meghir, 1991). However, evidence suggests that this graduation is uncommon since numerous constraints exist to keep informal operators at the same level (cf. Blunch et al., 2001: 8; Buckley, 1997: 1091; King and McGrath, 1999a: 6; chap.5.3, this thesis). The existence of certain barriers to growth has been highlighted by others (e.g. Palmer, 2004a: 47-50). ${ }^{34}$

Many of the characteristics of urban informal micro-enterprise (IME) are shared by their rural counterparts, though there are some distinct differences. Some shared characteristics include (Palmer, 2004b: 39-59):

- Smallness of size;

- Often alegal status and lack of regulations; ${ }^{35}$

- Members are mostly law-abiding and often pay some form of license or tax;

- Informal finance predominates;

- Few formal business records are kept;

- There is a general low-level of education, but this is rising following EFA policies;

- Skills training occurs on-the-job;

\footnotetext{
${ }^{33}$ See chap.3.3.3.

${ }^{34}$ See chap.3.3.3.

${ }^{35}$ Alegal activities refer to activities that are legitimate in nature (i.e. differentiated from illegal activities like corruption, theft, coercion or bribery) but which are not officially sanctioned by law and therefore not legal in the strictest sense.
} 
- Low level of technology;

- Low price of informal sector products and services;

- Ease of entry to activities at the lower end of the MSE continuum;

- Occupational pluralism is widespread;

- Enterprises operate within geographically-constrained markets and often in saturated and income-constrained markets;

- There is a high birth and death rate of enterprises.

The January 1993 15th International Conference of Labour Statisticians (ICLS) definition of the informal sector was that it consisted of economic units (enterprises) engaged in the production of goods or services. Since 2002 it has become common to also use the term informal economy as a broader concept that incorporates "the whole of informality" (ILO, 2002: 11). In the expanded conceptual framework the informal economy is seen as comprised of informal employment (without secure contracts, worker benefits, or social protection) both inside and outside informal enterprises (based on ILO, 2002: 12):

- Informal Employment in Informal Enterprises (small unregistered or unincorporated enterprises), including: employers, employees, own account operators, and unpaid family workers in informal enterprises;

- Informal Employment outside Informal Enterprises (for formal enterprises, for households, or with no fixed employer), including: domestic workers, casual or day labourers, temporary or part-time workers, industrial outworkers (including homeworkers), and unregistered or undeclared workers.

In 2003 the $17^{\text {th }}$ ICLS (ILO, 2003 cited in Charmes, 2005: 218) defined informal employment as comprising all jobs carried out in informal enterprises as well as those carried out in formal enterprises by employees "whose employment relationship is, in law or in practice, not subject to national labour legislation, income taxation, social protection or entitlement to certain employment benefits (advance notice of dismissal, severance pay, paid annual or sick leave...) because of non declaration of the jobs or the employees, casual or short duration jobs, jobs with hours or wages below a specified threshold, (...), place of work outside premises of employer's enterprise (outworkers), jobs for which labour regulations are not applied, not enforced, or not complied with for any other reason". The $17^{\text {th }}$ ICLS considered that employment in the informal sector (based on the enterprise as the unit of observation) and informal employment (based on jobs as units of observation) were two concepts which refer to different aspects of the informalisation of employment and to different targets for policy-making (ILO, 2004). 
The distinction between informal sector employment and informal employment can be made clearer: Ralf Hussmanns (2001, in Charmes, 2005: 219-220) proposed a framework to understand the coverage and meaning of the two concepts (fig.2.1).

Fig.2.1. Components of the informal sector and of informal employment

\begin{tabular}{|l|c|c|c|}
\hline \multicolumn{2}{|c|}{} & \multicolumn{2}{c|}{ Individuals/Jobs } \\
\cline { 3 - 4 } Economic units / Enterprises & Informal & Informal & Formal \\
\cline { 2 - 4 } & Formal & $(3)$ & $(2)$ \\
\hline
\end{tabular}

The two cells in grey cover the informal sector while the two cells in double line cover informal employment. Cell (2) means that in the informal sector some individuals may have a formal job (it may happen where the criteria of non-registration of the unit or of the employees is not used in the definition). Such a category is assumed to be small. Cell (3) represents informal jobs outside the informal sector and in the formal sector. This category is assumed to be huge and growing up. Nonetheless, it is important to remember that multiple employment and straddling between these categories is also increasing (e.g. formal sector teachers also having part-time IMEs) which complicates any neat distinction (chap.2.3).

Recognising the long-standing urban bias in informal sector research and analysis, the $15^{\text {th }}$ ICLS definition specifically mentioned that the informal sector should be measured in both urban and rural areas (ICLS, 1993: sect.15).

\subsubsection{Summary}

The informal sector might have been popularised by the ILO's Mission to Kenya in the early 1970s, but it is somewhat of an exaggeration to attribute to Hart the discovery of it: while his work influenced the ILO Mission it undoubtedly drew upon earlier research from Ghana, Kenya, Nigeria and elsewhere.

The current view of the informal sector sees it as made up of enterprises of different sizes: a common distinction made is between lower-end subsistence enterprises and more dynamic, 
entrepreneurial ventures. The term informal employment is also used and refers to informal-type work either in informal enterprises or in the formal sector.

While the informal sector concept has traditionally been urban-focused, there is growing acknowledgement that the concept can also include rural areas. This is the focus of the following section.

\subsection{The informal sector in rural areas}

This section will start where the last left off: by noting the long-standing urban bias in the informal sector literature, despite the fact that the two main early studies by Hart and the ILO did acknowledge a rural informal sector (2.2.1.). The next section (2.2.2.) looks at the farm-nonfarm divide and characteristics that define the rural informal sector. The last section (2.2.3.) looks at the changing composition of the rural informal sector as a result of de-agrarianisation.

\subsubsection{The initial urban bias}

It is surely not possible to deny the existence of similar enterprises (artisans, petty traders, peasant farmers etc.)... in rural areas. The 'rural informal sector' should logically receive at least as much attention as the 'urban informal sector'. (Bromley, 1978: 1034)

As noted in the previous section, since Hart's concentration on "the urban sub-proletariat" in Accra (Hart, 1973: 61), ${ }^{36}$ and the ILO Kenya Mission and later urban informal sector studies conducted by the ILO, the informal sector has for the most part been considered part of the dualistic nature of urban economies (Aboagye and Gozo, 1986).

The ILO Kenya mission, whose report internationalised the informal sector concept, described "two urban sectors" as the formal and informal sectors (ILO, 1972: 503), directly placing the informal sector idea into an urban framework, largely excluding discussion of an informal sector in rural areas. ${ }^{37}$ This urban bias in informal sector studies was noticed six years later (e.g. Bromley, 1978: see the quotation above).

\footnotetext{
${ }^{36}$ Not only did the informal sector become seen largely as an urban phenomenon, but Hart's research in Nima, a poor area of Accra, cast the concept into the slums as well.

${ }^{37}$ However, the ILO Kenya report did state that the informal sector idea was applicable to rural areas, mentioning a dichotomy between official, large-scale plantation agriculture and unofficial, subsistence
} 
However the initial urban bias was compounded by divisions within the World Employment Programme (WEP): informal sector work in the WEP was largely confined to the Urbanisation and employment programme, while a parallel division - the Rural poverty, employment and development division - "had virtually no informal sector concerns" (King, 1991: 120). Hence research by the Urbanisation and employment programme subsequently "cast the notion of informality into an exclusively urban context" (Bangasser, 2000: 11). Consequently there was much written on the urban informal sector in the 1970s/1980s and very little discussion of how relevant the concept was to rural areas.

Both Hart (1973) and the ILO (1972) study mentioned agriculture as part of the informal sector, ${ }^{38}$ but both their final products definitely cast the informal sector into an urban framework. Both Hart and the ILO also made mention of rural non-agricultural enterprises.

For example Hart's doctoral thesis contained a chapter mentioning rural nonfarm enterprise activity and the issue of multiple occupations:

blacksmiths, potters, tailors of smocks, drummers and barbers earn sizeable cash incomes from occupations which are usually only secondary to the main business of farming. (Hart, 1969: 144)

He also mentioned that some activities were taken up during the agricultural off-season and notes, for example, that as the

farming season has always been short - a matter of some six months from late April to early October... [farmers]... have traditionally supplemented their income by specializing in certain crafts and skilled occupations. (ibid.: 143)

However, this discussion of rural informal economic activities never found its way either into his presentation at the University of Sussex in 1971 or his two early pieces (Hart, 1970, 1973).

Similarly, the ILO (1972) Kenya report noted, in its famous chapter 13, that although the chapter would

agriculture (ILO, 1972). This distinction failed to fully discuss other nonfarm enterprises in rural areas, but see ILO (1972: 223).

${ }^{38}$ See Palmer (2004b, chap.10.38). 
concentrate on the urban informal sector... it should be noted that in 1969, in what was certainly an under-count, there were found to be almost 190,000 men, women and children working in non-agricultural activities in rural areas. (p.223)

However, despite this acknowledgement of rural enterprise, the ILO's decision to "concentrate on the urban" (ILO, 1972: 223), Hart's research in urban Ghana (1970, 1973) and divisions within the WEP set the stage for urban bias in informal sector work. Consequent research focused on larger cities, with little information on small or intermediate cities (Trager, 1987) or rural areas. Indeed, this urban bias still prevails (Xaba et al., 2002).

\subsubsection{The farm-nonfarm divide and defining the rural informal sector}

What, then, is the rural informal sector? This section examines this question, noting that traditionally it has been associated with nonfarm enterprise and has excluded agriculture. Since the late 1990s, however, agriculture has increasingly been considered part of the rural informal sector. In research and policy literature there has often been a tendency to discuss the impact of schooling or skills on farm activities without mention of nonfarm activities, or vice-versa. ${ }^{39}$ This section discusses this farm-nonfarm divide and argues that this artificial divide is not only fallacious, but that it disguises an essential characteristic of African livelihoods, especially in rural areas: occupational pluralism. In doing this the enterprise component of the school-skillenterprise link is highly simplified.

Livingstone (1991) notes that "defining the rural informal sector is even more problematic than in the urban case" (p.652). He comments that "it is often taken as synonymous with the non-farm activities" (ibid.). For example, Bagachwa (1997) identifies the rural informal sector as comprising

non-farm or non-agricultural small-scale activities, including manufacturing, construction, mining, fishing, transport, commerce and other services... irrespective of whether they are carried out as main or secondary activities. (p.141)

King (2005a) goes on to note that when the term informal sector was

\footnotetext{
${ }^{39}$ Though there is obviously a literature that examines farm-nonfarm links.
} 
finally used of Africa's rural areas, there was a very strong tendency to consider that the informal small enterprise economy was 'off-farm'... Only relatively recently has the term been broadened to accept that "small farms are also small businesses"' (p.440).

By conceptualising the informal sector in rural areas as nonfarm or off-farm, "the informal sector was set aside from the regular urban (formal) sector and the regular 'enterprise' of running a small farm" (King, 1996: 194; Tribe, 1995).

King points out, for example, that the Kenyan sessional paper on the development of micro and small enterprises for employment creation and poverty reduction argues strongly that "small farms are also small businesses" (Kenya Government 2003, cited in King, 2005a: 440). King adds that the latest draft of this same paper "boldly redefines the sector finally to cut across the farm/non-farm divide" (ibid.).

Nonetheless the distinction between farm and nonfarm is still commonly made. ${ }^{40}$ For example neither the UN Millennium Project (2005), the UK's Commission for Africa (2005) nor the Bank's Skills Development in Sub-Saharan Africa (World Bank, 2004a) completely abandons the farm-nonfarm divide. This said, the Commission for Africa Report does acknowledge that: "[t]he primary source of jobs in Africa is small enterprises, the most important of which is the family farm" (Commission for Africa, 2005: 51). While the Bank did include smallholder agriculture as part of the informal economy (World Bank, 2004a: 3), the study specifically excluded skills for agriculture from their remit - as it was thought that this issue was so large and complex as to merit a separate study (World Bank, 2004a: 33). Indeed a separate Bank study on skills for agriculture is forthcoming. ${ }^{41}$ However the World Bank, by proposing separate studies on skills development for agricultural and for nonfarm employment, has helped to maintain the traditional farm-nonfarm divide. This is unhelpful since it perpetuates the artificial construction of neat employment realities of the (rural) poor. Nonetheless, the Bank's inclusion of agriculture as part of the informal economy and the recognition of a "rural informal sector" (World Bank, 2004a: 48) are positive steps forward.

The rural informal sector, therefore, is made up of both non-agricultural and agricultural activities. It has been accepted that, conceptually, the informal economy can include agricultural

\footnotetext{
${ }^{40}$ Carter and Rosa (1998) argue that small business analysts overlook the UK farm sector.

${ }^{41}$ The initial intention was for the World Bank to produce a counterpart study on agricultural education and training. Johanson (2005) has written a draft study outline which was further discussed by Saint (2005) at the Rome Meeting of the WGICSD.
} 
activities (Afrisat, 1997). The $15^{\text {th }}$ and $17^{\text {th }}$ ICLS definitions of the informal sector and informal employment respectively do not exclude farm activities and "a strict application of the definitions would include agriculture (and more generally primary activities: agriculture, animal husbandry, forestry, fishery)" (Charmes, 2005: 218). However for "practical reasons" (ICLS, 1993: sect.16), which are not mentioned but presumably pertain to the collection of information, when it comes to measurement the $15^{\text {th }}$ ICLS definition of the informal sector excludes agricultural activities (ibid.: sect.20), being limited to "household enterprises engaged in non-agricultural activities" (ibid.: sect.16). Instead of including agriculture as part of the informal economy the $15^{\text {th }}$ ICLS notes that "agricultural activities... may be identified as separate categories outside the distinction between the informal and formal sectors" (ibid.: sect.20). This, as Charmes (2005) notes, is not only due to methodological and measurement issues, but also so that the proportion of farm and nonfarm activities would not be hidden if the concept mixed both farm and nonfarm components.

Indeed there is now an increasingly widespread view that the informal sector includes agriculture (e.g. Commission for Africa, 2005; World Bank, 2004a) and that farms should be regarded as enterprises too.

When agriculture is included as part of the informal sector, the informal sector becomes a very rural phenomenon, since farm activities predominate in rural areas of developing countries. ${ }^{42}$ In SSA, rural informal sector employment (farm/nonfarm) accounts for about two-thirds of all employment (fig.2.2).

\section{Fig.2.2. Estimated proportions of formal and informal sector employment in SSA}

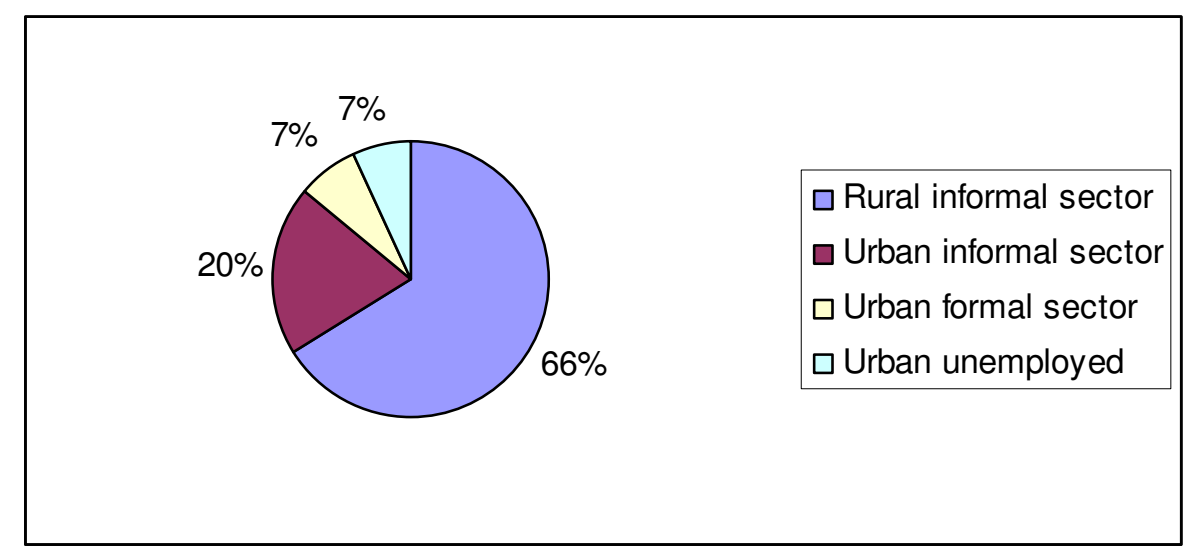

Source: World Bank, 2004a: 48

\footnotetext{
${ }^{42}$ In fact the majority of studies note the predominance of nonfarm enterprises in rural areas (Mead, 1999). But see Adams and Pischke (1992).
} 
In Ghana (Ashanti) the rural informal sector comprises myriad IME activities:

- Agricultural enterprises (both pastoral and arable) 43 $^{43}$ predominantly small-scale farming units (okuani) and small-scale rearing of animals (e.g. goats, chickens);

- Fishing and fish-processing enterprises - found mostly along Ghana's coastline;

- Rural agro-based processing enterprises - e.g. corn-milling; processing cassava into gari; palm, palm kernel, groundnut and copra oils; alcohol production (palm wine, pito, akpeteshie); ${ }^{44}$ and traditional soap-making;

- Trading enterprises - food traders and processors (e.g. food sellers in the market, itinerant wholesalers and retailers, bakers, caterers and cooked-food sellers), building suppliers, pharmacy/cosmetic stores, spots (local bars), and charcoal, mineral (soft drink) and wood sellers etc.;

- Manufacturing/construction enterprises - e.g. masonry (odansifuo), blacksmithing, carpentry (adua dwumayefuo), tailoring (adepamni barimaa), dressmaking, weaving and small-scale gold mining (galamsay);

- Repair enterprises - e.g. refrigerator, bicycle, mechanic (afidiesiesiefuo);

- Information and communication technology (ICT)-based enterprises, e.g. Space-to-Space wireless telephone enterprises, ${ }^{45}$ mobile phone repair/unlocking enterprises, internet cafés;

- Service enterprises - e.g. barbering, hair-dressing and shoe-shining;

- Transport enterprises - e.g. minibuses (trotro);

- Finance-providing enterprises - e.g. door-to-door money collectors (susu).

More so than in urban areas, the rural informal sector in SSA contains a large hidden element. In rural Ashanti, for example, charcoal makers, water carriers, traditional healers and fetish/juju men and women ${ }^{46}$ are difficult for surveys to identify. ${ }^{47}$ Many rural informal economic activities

\footnotetext{
${ }^{43}$ See Palmer (2004b, chap.11.4).

${ }^{44}$ See Bryceson (2002b; 2004) and Hart (1969). Pito is distilled guinea corn. Akpeteshie is a strong spirit made from distilled palm wine.

${ }^{45}$ Areeba (formally Spacefon) is a large mobile phone provider in Ghana who built a wireless, battery powered, telephone handset that can be used wherever there is a mobile signal. The space-to-space machines are purchased from the Areeba company and are then operated by private owners and are now commonplace in rural Ghana. The owners sell airtime by the minute to customers wanting to make a phone call. These machines have undoubtedly dramatically changed access to telecommunications in rural Ghana.

${ }^{46}$ Juju (wo)men are believed to be able to harness the power of good and evil spirits (including the mmoatia, dwarfs believed by many to live in the forests of Ashanti). Sometimes people visit them to ensure their new enterprise start-up will be successful, or go if their enterprise is going badly (cf. Buckley, 1996).
} 
are conducted by women, in the home or as mobile enterprises, often from a head-pan (аграпрати), or from a tray (рапрапти) or moveable cart. Moreover occupational pluralism, or pluri-activity, is more widespread in rural areas. ${ }^{48}$ These factors make the rural informal sector even more difficult to measure than its urban counterpart. ${ }^{49}$

Like the composition of the informal economy more generally, ${ }^{50}$ trade represents the most common type of nonfarm activity in the rural informal sector (Bagachwa, 1997; ILO, 1972; Livingstone, 1991). For example, Palmer's (2004a) research in Nkawie-Kuma, a rural town in Ghana, noted that only $21 \%$ of the sample of 109 rural MSEs were manufacturing enterprises, with 53\% retail enterprises. The Ghana Living Standards Survey (GLSS) 4 (1998/99) revealed that over 56\% (1.3 million) of all nonfarm enterprises were trading ventures, $24 \%(550,000)$ were manufacturing, and the remaining $20 \%$ in other activities. Many of these would have forward and backward linkages to agriculture (ILO, 2003b).

This illustration of the different kinds of rural informal sector activities shows that what is often subsumed under the amorphous heading of informal sector activities, is highly diverse.

\subsubsection{The changing composition of the rural informal sector: de-agrarianisation}

It could be argued that the concept of a rural informal sector has been strengthened over the last twenty years, since the introduction of SAPs and neo-liberal policies (Bryceson, 2002a; 2004), by the increasing recognition given to the process of de-agrarianisation in SSA (Bryceson, 1996). ${ }^{51}$

De-agrarianisation is defined by Bryceson (1996) as a long term process of: i) economic activity reorientation (livelihood); ii) occupational adjustment (work activity) and; iii) spatial realignment of human settlement (residence) away from strictly agricultural patterns. She comments that, while in the 1950s to 1970s the idea of a move away from agriculture was understood as a move

In addition to taking items like baby chickens, lizards, leaves, string, akpeteshie (local gin) there is usually a financial payment required for this type of informal service ( $\$ 30-40,000$ in 2005 , c.US\$3-4).

${ }^{47}$ Though obviously note that these activities may well be present in urban areas, even if they have previously not been mentioned in the literature or research documents.

${ }^{48}$ See chap.2.3.1 on occupational pluralism.

${ }^{49}$ See Palmer (2004b, section 10) on measurement.

${ }^{50}$ See Palmer (2004b, section 7.2).

${ }^{51}$ This refers to research conducted as part of the de-agrarianisation and rural employment (DARE) project, co-ordinated by Deborah Bryceson of the Centre of African Studies, Leiden. The countries in the DARE project were Ethiopia, Nigeria, Tanzania, Zimbabwe and South Africa. 
from rural to urban areas, the process of de-agrarianisation conceptualises a move away from agriculture to happen in situ, in the rural areas themselves (Bryceson, 2004).

Bryceson (1996) points to research since 1980 that illustrates the increasing importance of nonagricultural rural employment (NARE) in SSA. She notes that the increased significance of NARE relates to the growing role it plays in rural livelihood strategies. This is shown by the increase in total labour time spent on NARE activities and the increasing part it plays in contributing to overall household income.

In terms of contribution to overall rural household income, rural nonfarm activities have previously been estimated to make-up about $40 \%$ of the overall income in SSA (Bagachwa, 1997; Ellis, 1998; Haggblade, Hazel, and Brown, 1989; Reardon, 1997). However, research by Bryceson suggested rural nonfarm activities make a higher contribution to overall income, between $60-80 \%$ (Bryceson, 2002a: 730). It is clear, therefore, that with respect to household income, nonfarm activities are increasingly becoming the most important part of the rural informal sector. This being said, there are obviously differences across countries. For example, Livingstone (1991: 654) revealed that in Kenya (1981-2), on average, nonfarm activities accounted for just over $50 \%$ of total income: of this only $17 \%$ of income came from nonfarm enterprise activity (Kenyan Central Bureau of Statistics, in Livingstone, 1991). ${ }^{52}$

Bryceson (1996) notes that although NARE has received a centre-stage position in development project work, it has traditionally been seen as largely supplementary to, rather than operating independently of, farming activities. She notes that, increasingly, NARE is being seen as an "alternative to farming for certain categories of people in a number of places" (ibid.: 97, original emphasis). However, Bryceson (2004) comments that de-agrarianisation does not suggest that the rural poor are turning their backs on agriculture altogether, since subsistence agriculture is frequently retained as a fall-back option.

Bryceson (1996; 2002a; 2004) points to causal factors responsible for an increase in NARE: i) increasing population densities in many rural areas, causing people to increasingly turn to nonfarm activities due to lack of land (e.g. parts of Nigeria and Ethiopia); ii) a contraction of urban employment opportunities for potential migrants as a result of SAPs; iii) an increased need to acquire cash on a daily basis as a result of SAPs (and removal of government subsidies on

\footnotetext{
${ }^{52}$ The rest was made up of salary and wages (21\%) and other sources (remittances, gifts etc) (14\%).
} 
education and health); iv) the reduction of farm incomes in many cases due to the government cessation of paying subsidies on agriculture under SAPs; v) the decrease in public sector wages (due to SAPs) that forced greater livelihood diversification and increased participation in informal economic activities; vi) the increased investment in primary education resulting in a generation of rural inhabitants becoming more dissatisfied with a strictly agrarian way of life; vii) the increase in rural people charging for traditional services that were previously given for free (e.g. village midwifery). ${ }^{53}$

With reference to point vi) above, it might be interesting to consider what affect the current EFA policy will have on speeding up de-agrarianisation. Will the expansion of formal (basic) education mean that more and more rural youth enter into primarily non-agricultural livelihood strategies? If this is the case, there will need to be more policy focus than there is now on promoting and assisting MSE development, including the creation of enabling environments and business development services (BDS) that can assist enterprise start-ups. ${ }^{54}$

As noted above (and explained below), one overriding characteristic of rural livelihoods is occupational pluralism ${ }^{55}$ and the notion of de-agrarianisation, confirms this (Bryceson, 2002a).

\subsubsection{Summary}

The urban focus of early informal sector research by Hart and the ILO during the 1970s set the stage for an urban bias in the informal sector literature. This is in spite of the fact that both Hart and the ILO Kenya Mission discussed rural informal enterprise.

Where the informal sector has been discussed in relation to rural areas, it is usually taken as synonymous with nonfarm enterprise. There is a growing view, however, that farms should also be treated as enterprises, and that agriculture should be included as part of the rural informal sector. In fact the farm-nonfarm distinction, so frequently used in the literature, fails to

\footnotetext{
${ }^{53}$ This has been mentioned before. Hart (1969), for example, mentions that many traditional roles, such as roofing expert, hut-builder and ritual diviners "now [1969] have an open market value and some Frafra have turned to these roles as a major supplementary source of cash income, where before they were part of the nexus of kinship obligations which linked the inhabitants of a particular settlement" (p.144).

${ }^{54}$ The attention paid to enabling environments in many of the PRSPs, for example, is a step forward. But in many cases enabling environments for IMEs are not improving. BDS includes market information, management and business advice as well as vocational skills training. See Sievers and Vandenberg (2004).

${ }^{55}$ Occupational pluralism is also a common feature of the informal economic activities in urban and periurban settings (Palmer, 2004b).
} 
adequately capture the notion of occupational pluralism; that individuals/households frequently operate across the farm-nonfarm divide in multiple enterprise ventures.

The process of de-agrarianisation in SSA means that rural enterprise is increasing in importance. The next section re-examines the notion of work in SSA by discussing more about occupational pluralism.

\subsection{Re-conceptualising work in SSA as a result of occupational pluralism}

This section re-examines concepts of work in SSA, arguing that occupational pluralism contributes to the blurring of the usual categories: e.g. farm/nonfarm, wage-/self-employment.

Employment classification in developing countries is beset with problems (cf. Harbison, 1967). Since "many censuses rely on the informants' own identification of their employment status" (Scott, 1979: 107), with many informants receiving no guidance as to what criteria they should use in answering (ibid.: 108), the definition of employment is subjective and open to myriad interpretation.

Imagine an announcement of a forthcoming unemployment census in the media of a country in SSA that had just elected a new government whose election campaign had highlighted job creation as a key area. This might lead those in informal employment (including farmers) to register as unemployed in the hope of gaining a job. This was exactly what happened in Ghana. The present ruling political party, the New Patriotic Party (NPP), came to power in January 2001 with, among other election promises, the pledge to create employment for the youth. As a result when the employment census was announced, telling the unemployed to register there were many incidences of "unemployed" people registering who were in most senses of the word, employed. "There are yet some who do not recognise farming as a job and came to register as unemployed persons" (GNA, 2001c). Many were registering specifically with the idea that by doing so they would benefit with a job or at least some kind of training. ${ }^{56}$

The problems associated with measuring unemployment in Ghana, and other developing countries with large informal economies, mean that it is hard to take official unemployment figures seriously. And yet many do. For example, Teal (2001) reports the unemployment rates for

\footnotetext{
${ }^{56}$ See chap.7.2.
} 
Ghana were around 2-3.5\% (1989-1999) which he comments are "very low" and "stand in marked contrast to those observed in other African countries" (p.5). ${ }^{57}$

\subsubsection{Tinker, tailor, farmer, trader: occupational pluralism and the fallacy of dichotomous occupational categorisation}

It has long been regarded as misleading to talk of 'unemployment' in the SSA situation (Hart, 1973, 1976; Weeks, 1973). Indeed a joint ILO/UNICEF/World Bank funded paper comments that "the traditional labour market concepts such as jobs, employment, unemployment, participation, wages, and earnings are difficult to apply to Africa" (Guarcello et al., 2005: 2).

However, occupational statistics from developing countries frequently make these kinds of categorisation that grossly over-simplify reality: individuals and sometimes households are classified as either farm or nonfarm, or as being self- or wage-employed, as working in the formal or informal sector, or even as being rural or urban. ${ }^{58}$

Such pigeon-holing and use of these neat dichotomies are misleading and disguise complex realities regarding the nature of work in SSA, especially in rural areas. For example Teal's presentation of the GLSS data (table 4.3, chap.4) and the ILO diagram below (fig.2.3.) disguise a lot of information concerning the Ghanaian labour market.

\section{Fig.2.3.}

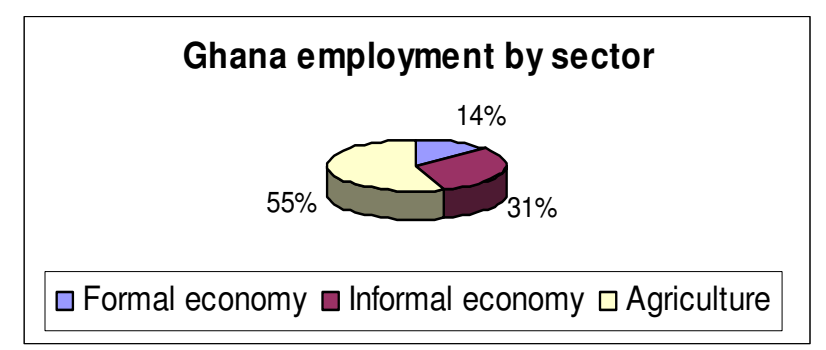

Source: ILO, 2003c

Teal's diagram, with the categories wage employee, farmer, non-agricultural self-employment and unemployed, does not reveal whether some of those that are recorded as working outside of agriculture actually work part-time in agriculture and part time in nonfarm activities (ILO,

\footnotetext{
${ }^{57}$ See table 4.3 , chap. 4 .

${ }^{58}$ The rural-urban dimension is complicated where households are located in rural areas but get a proportion of their income from family members' enterprise or jobs in urban areas (Livingstone, 1991).
} 
2003b). The ILO diagram (fig.2.3.) makes a neat, but very crude, division between formal, informal and agricultural sectors - a division that does not exist in peoples' everyday livelihoods.

Classifications such as employed or unemployed disguise the great problem of underemployment (Heintz, 2004). Categorising an individual or household as working in either farm or nonfarm activities fails to capture the possibility of multiple occupations and hence farm-nonfarm relationships.

Occupational pluralism, pluri-activity or enterprise diversification - involving working across sectors and between activities is increasingly the norm in SSA, especially in rural areas, but is not a new issue (cf. Barrett, Reardon and Webb, 2001; Bryceson, 2002a, c; Buckley, 1997; Ellis, 2000, 1998; Hart, 1973; Kilby et al., 1984; King, 1996; Long and Richardson, 1978; Mureithi, 1973; Palmer, 2004a, b). For example in Kenya in the 1970s, Mureithi (1973) commented that: "a characteristic of rural dwellers is occupational pluralism... [in other words] many have more than one job" (p.130). Hart (1973), commenting on Ghana in the late 1960s/early 1970s, noted the "widespread incidence of multiple income sources" (p.83).

Income diversification through occupational pluralism is becoming more widespread in SSA (Barrett et al., 2001) and is determined by multiple factors (Ellis, 2000). For example, enterprise owners near the level of subsistence are more likely to follow strategies which reduce risk, even if these strategies result in less overall profit for those involved (Scott, 1976). In this context, one strategy that is followed is livelihood and income diversification, which has its roots in the traditional risk aversion strategy utilised by peasants living in situations of extreme uncertainty (Long and Richardson, 1978: 200; cf. Hugon, 1990: 75). In this context Scott (1976) notes that some traders pursue "several minor occupations to minimize the danger of ever being entirely out of work" (p.24). In other words, enterprises might expand not by increasing investment in their successful enterprise, but by investing in the start-up of another enterprise or in farming activities (Long and Richardson, 1978). Alternatively, those owners engaged in entrepreneurial selfemployment who are looking to expand might be more willing to accept the risk of investing in a new, higher end, enterprise.

Moreover the issue of occupational pluralism complicating occupational quantification has been noted before. For example Canagarajah and Mazumdar (1997) note that: 
The quantification of the different segments of the labour market in an economy like that of Ghana is complicated because of the prevalence of multiple occupations. The same household would be involved in more than one sector, or as different working members are involved in activities in different sectors, or the same individual earner divides his time between different activities. (p.2)

In fact, over 50 years ago Bauer (1954) commented on the deficiency in occupational categorisation in Gold Coast statistics:

In the Northern Territories of the Gold Coast many farmers spend a substantial part of their time in non-agricultural activities... [in] the colony area of the Gold Coast, the great bulk of the population has other occupations, generally some form of trading, in addition to their main activity. (p.11)

This imperfect specialization and the importance of secondary activities carried on by members of the household greatly diminish the value and relevance of the conventional occupational classifications of statistical compilations. This fact has not been sufficiently recognized. (p.12)

As noted, however, the notion of occupational pluralism, at both the individual and household level, is frequently sidestepped in research and policy documents - and, fifty years after Bauer's warning, is still not sufficiently recognised. Bauer also noted the issue of what is now termed occupational straddling - long before the term was used - and that it was not only so-called farmers that had other occupations, but "Government employees are also frequently part-time traders" (ibid.).

Indeed many of those working in SSA, particularly those in rural areas, can be said to not simply have one occupational or income-generating activity, rather their employment portfolio is complex, and likely to be made up of two, three or more income-generating activities pursued simultaneously, the composition of which changes at different times of the year. Many activities are highly opportunistic, "involving quick responses to market demand and supply" (Bryceson, 2002a: 732). Further, those in the formal sector may have informal employment activities as an increasingly necessary side-line. Thus while some have multiple activities in the informal sector, some have multiple activities in the formal sector, others straddle the formal-informal divide taking up employment in both. For example, it is increasingly recognised that informal income opportunities play a large role in the income portfolio of many teachers (Kerr, 2006; King, 2001). The traditional view of the informal sector being synonymous with self-employment or non-wage 
employment no longer prevails. ${ }^{59}$ Indeed it was recognised early that self- and wage-employment can exist in both informal and formal sectors (cf. Bromley, 1978; Davies, 1979).

\subsubsection{Occupational pluralism and farm-nonfarm links}

Farm-nonfarm links are an important element of occupational pluralism, and have been well documented in the literature (e.g. Haggblade et al., 1989; Reardon, Crawford and Kelly, 1994; Reardon et al., 2001). For example, Reardon et al. (1994) discuss the important relationship between farm productivity and nonfarm income of rural households. Forward linkages are evident from agriculture to MSEs, especially with regard to agro-processing and trade in both the rural and urban areas, for both large and micro-enterprises. Farming inputs such as farm tools or simple machinery are often sold, manufactured, repaired or sharpened in rural nonfarm enterprise. Other agricultural inputs, like fertilisers, insecticides or weed-killer are traded in rural nonfarm enterprises.

Agriculture stimulates the demand for transportation in rural areas especially at harvest time when goods need to be transported to market. More transportation in rural areas increases the demand for repair workshops, vulcanisers, fitters and mechanics in rural localities. Moreover, the demand for the rural production of consumer goods and services is related to (seasonal) agricultural earnings (Livingstone, 1991).

Another important aspect of occupational pluralism is cross-financing. This refers to the use of profits from one (farm or nonfarm) enterprise as an input for another (farm or nonfarm) enterprise. The relationship is two-way, with farm activities cross-financing nonfarm activities and vice-versa. Cross-financing occurs between household and enterprise, enterprise and enterprise and vice-versa. It is also noted that, particularly in rural areas, households and enterprises are one and the same (Meghir, 1991; Rhyne and Otero, 1994). Thus in the same household someone might be a carpenter, while at the same time raising poultry or grass-cutters, ${ }^{60}$ meanwhile the wife and children tend to the farm, with the wife also having a part-time activity brewing and/or selling alcohol to the neighbours at night. Many such cases like this exist and it should be clear that micro-enterprises do not operate as autonomous units. For example, evidence from research in a rural town in Ghana (Palmer, 2004a) indicates that a significant percentage of

\footnotetext{
${ }^{59}$ But some, like Blunch et al. (2001: 3) still make this distinction to "provide some semblance of order".

${ }^{60}$ Grass-cutters are large rodents that are bred for meat in Ghana.
} 
enterprises (farm/nonfarm) cross-finance each other - particularly at the start-up phase, but also with respect to working capital needs. This concurs with other research (Rhyne and Otero, 1994). Indeed, the ILO (1972) Kenya report also noted the cross-financing of farming and nonfarm activities.

\subsubsection{Occupational pluralism: an illustration from rural Ashanti (Ghana)}

In order to explore the farm-nonfarm issues in more depth, a household survey conducted as part of this doctoral research examined the extent of occupational pluralism in one rural community, Otaakrom (Ashanti) (table 2.1). It also examined whether the dimensions of occupational pluralism varied according to the wealth status of the household to investigate whether enterprise owners in this area tended to diversify for profit or out of necessity. ${ }^{61}$

\footnotetext{
${ }^{61}$ For a description of the methodology of this household survey and of the detailed wealth ranking and household mapping exercises that preceded it, see Appendix C.
} 
Table 2.1. Occupational pluralism among 80 households in Otaakrom by wealth category

\begin{tabular}{|l|r|r|r|r|r|r|}
\hline & $\begin{array}{r}\text { Very } \\
\text { poor }\end{array}$ & Poor & Average & $\begin{array}{r}\text { Above } \\
\text { average }\end{array}$ & $\begin{array}{r}\text { Well- } \\
\text { off }\end{array}$ & Total \\
\hline None & 0 & 0 & 3 & 0 & 0 & 3 \\
Farming only (1) & 0 & 0 & 1 & 0 & 0 & 1 \\
Farming only (2) & 1 & 5 & 4 & 0 & 0 & 10 \\
Farming only (3) & 0 & 16 & 12 & 0 & 0 & 28 \\
Farming (1) + ISE (1) & 0 & 1 & 1 & 0 & 1 & 3 \\
Farming (2) + ISE (1) & 1 & 2 & 6 & 0 & 0 & 9 \\
Farming (3 or more) + ISE (1) & 1 & 2 & 4 & 0 & 0 & 7 \\
Farming (2) + ISE (2) & 0 & 0 & 1 & 0 & 0 & 1 \\
Farming (2) + WE & 0 & 1 & 2 & 0 & 0 & 3 \\
Farming (3 or more) + WE & 0 & 0 & 2 & 0 & 0 & 2 \\
Farming (2) + ISE (1) + WE & 0 & 1 & 0 & 0 & 0 & 1 \\
Farming (3 or more) + ISE (1) + WE & 0 & 0 & 1 & 0 & 0 & 1 \\
ISE only (1) & 0 & 1 & 4 & 1 & 0 & 6 \\
ISE only (2) & 0 & 2 & 0 & 0 & 0 & 2 \\
WE only & 0 & 1 & 2 & 0 & 0 & 3 \\
\hline Totals & 3 & 32 & 43 & 1 & 1 & 80 \\
\hline Farming only & & & & & & \\
ISE only & 1 & 21 & 17 & 0 & 0 & 39 \\
WE only & 0 & 3 & 4 & 1 & 0 & 8 \\
Farming and nonfarm & 0 & 1 & 2 & 0 & 0 & 3 \\
Farming total & 2 & 7 & 17 & 0 & 1 & 27 \\
Source: A & 3 & 28 & 34 & 0 & 1 & 66 \\
\hline
\end{tabular}

Source: Author's fieldwork, 2005

Legend:

ISE - Informal (nonfarm) self-employment

WE - Formal (nonfarm) wage employment

(1)(2)(3) refers to number of farming or non-farm activities

Otaakrom (Ashanti Region) is one of the field sites for this doctoral research. For background information on

Otaakrom, see chap.1.3.2. The total number of households in the sample was 81, but data on income generating

activities was missing for one household.

Respondents were asked to name all income generating occupational activities that their household engaged in at any time in the year. ${ }^{62}$ The main findings can be summarised as follows:

${ }^{62}$ Since respondents were asked to name income generating activities, the degree to which subsistence farming (or chop-cropping) was also practiced was not captured by this survey. However, the distinction between chop-crops and crops grown for sale is often blurred. In this part of Ghana, yams, cassava and corn are the three main staple crops grown and, depending on daily household demand for cash, these crops can either be consumed by the household or sold in the market for a few thousand cedis. In practice most households tend to sell some and eat the majority of so-called chop-crops (fieldwork, 2001-2006). Despite the respondents being asked about income generating activities during the whole year, the amount of nonfarm activity is likely to be under-reported in this household survey: since the data collection period (October 2005 to January 2006) covered the main cocoa harvesting time, it is possible that many households were concentrating on farming at this time. It would be interesting to conduct this same exercise around March/April time which is regarded as the low-point in the year when cocoa money has 
- Of all households in the sample:

○ $83 \%$ (66/80) engaged in farming enterprises;

- $38 \%$ (30/80) engaged in informal sector nonfarm self-employment (of these $80 \%$ (24/30) were involved in one or more additional income-generating ventures, farm or nonfarm);

○ $13 \%(10 / 80)$ engaged in wage-employment.

- $84 \%(67 / 80)$ of all households were engaged in multiple income generating ventures (either multiple farm, multiple nonfarm or farm and nonfarm). A further 13\% (10/80) of households were engaged in only one income generating activity, ${ }^{63}$ while $4 \%$ (3/80) of households had no-one earning an income. ${ }^{64}$

- $34 \%(27 / 80)$ of all households engaged in both farm and nonfarm activities. This figure is similar to other estimates from rural Africa. Haggblade et al. (1989), for example, estimate that in rural Africa between $20-40 \%$ of the labour force works in both farm and nonfarm activities. $26 \%$ of poor/very poor households (9/35), compared to $40 \%$ (17/43) of average households were engaged in both farm and nonfarm activities.

- $49 \%$ (39/80) of all households engaged only in farming activities: of these only $3 \%(1 / 39)$ of solely farming households practiced just one farming venture. The rest of these farming households undertook at least two different kinds of farming ventures. Diversification in farming enterprises, therefore, appears to be the norm.

- $14 \%(11 / 80)$ of all households engaged only in nonfarm activities: of these $10 \%(8 / 80)$ were in informal self-employment, and 4\% (3/80) were in wage-employment.

- Poorer households appeared to be less likely to be undertaking nonfarm activities and, those that did, appeared less likely to be engaged simultaneously in both farm and nonfarm ventures: $37 \%$ (13/35) of poor/very poor households in the sample were engaged in nonfarm activities (of these $26 \%$ (9/35) were engaged in both farm and nonfarm

been spent and the next harvest is not due for some time. Hence there might be more nonfarm activity at this point.

${ }^{63}$ Of these only $1 \%(1 / 80)$ of households undertook only one farm activity. $11 \%$ (9/80) of households had only one informal self-employment activity (6/80) or one wage-employment activity (3/80).

${ }^{64}$ These three households were all female headed. 
activities); 60\% (26/43) of average households were engaged in nonfarm activities (of these $40 \%$ (17/43) were engaged in both farm and nonfarm activities).

Earlier research (Palmer, 2004a) on informal MSE owners conducted in another rural town in Ashanti (Nkawie-Kuma) in 2003 had similar findings and the results can be compared to the findings above (for those households engaged in informal enterprise, $n=30$ ). ${ }^{65}$ The Nkawie-Kuma survey found that $86 \%$ of all enterprise owners $(n=109)$ indicated that their household was involved in one or more additional income-generating activities (table 2.2). This compares well to the survey results above which found that $80 \%$ of all those engaged in IME were also involved in one or more additional income-generating ventures, farm or nonfarm.

In the survey above, $73 \%$ (22/30) of those engaged in IME indicated that farming was one of their additional activities. Similarly, Palmer (2004a) found that $67 \%$ of enterprise owners indicated that farming was one of their additional activities. ${ }^{66}$

Table 2.2. Enterprises in Nkawie-Kuma: households engaging in incomegenerating activities in addition to their main enterprise activity

\begin{tabular}{l|r|r} 
& $\begin{array}{r}\text { MSE } \\
\text { respondents }\end{array}$ & \% \\
\hline No income-generating activities in addition to main enterprise & 15 & $\mathbf{1 4}$ \\
Farming activities in addition to main enterprise & 30 & $\mathbf{2 8}$ \\
Farming activities and other activity* in addition to main enterprise & 43 & $\mathbf{3 9}$ \\
Other activity* in addition to main enterprise & 21 & $\mathbf{1 9}$ \\
\hline & 109 & $\mathbf{1 0 0}$
\end{tabular}

Source: Palmer (2004a)

* 'other activity' included; 1] Waged-employment: security work, teacher, nurse, prison office, mining, logging, police, agricultural officer, clerk, accountant, cooperative agent, government driver, forestry; 2] Self-employment: any other informal sector enterprise, such as carpentry or retail.

Put together these two surveys highlight the extent of occupational pluralism in rural Ashanti. Only a few households rely on only one enterprise activity, farm or nonfarm, and about one third of all households are engaged in both farm and nonfarm activities. Most IME activity in rural

\footnotetext{
${ }_{66}^{65}$ For details on the methodology of this survey see Palmer (2004a).

${ }^{66}$ This figure of $67 \%$ is likely to be an under-estimate since, although the questionnaire specifically stated that farming should be included as an enterprise activity, some respondents may have not considered that their farming was significant enough to mention.
} 
Ashanti appears to form part of a wider household enterprise strategy: more than $80 \%$ of IME owners also receive income from other sources. Better-off households in Otaakrom appear to be both more likely to be engaged in nonfarm enterprises and more likely to be involved in both farm and nonfarm enterprises simultaneously.

\subsubsection{Summary}

Despite the fact that the issue of multiple employment has been raised before, standard occupational categorisation usually characterises individuals and activities into distinct and exclusive categories (e.g. farm/nonfarm, wage-/self-employed) which disguises occupational pluralism. There are signs though that this might be changing. For example, Heintz (2004) outlines a set of possible indicators for tracking employment outcomes in Ghana, based on questions that have been asked in the GLSS 4: one of these was 'percentage of the employed who work in two jobs or more'.

The concept of occupational pluralism, however, cuts across the farm-nonfarm divide, across the wage-/self-employment distinction, acknowledges cross-financing and the complex linkages between farm and nonfarm work.

As a concluding word to this section, Hart (1973) makes this point:

Spurious attempts at quantification [of unemployment] obscure the truth of the matter, which is that very few of those peddling such information have any idea of how the majority of Africans make a living. Moreover, government policies are framed in the light of analysis using information of this kind! (p.493)

\subsection{Conclusion: implications for the school-skill-enterprise link beyond the farm- nonfarm divide}

Discussion in this chapter has resulted in a number of implications for rethinking the school-skillenterprise interaction.

Recognising occupational pluralism in SSA means that an individual's employment is often not in one activity, or one enterprise, but in multiple activities, or multiple enterprises: multiple farm, 
multiple nonfarm or farm and nonfarm. Moreover, the issue of straddling formal and informal occupations further complicates employment realities.

While the issue of occupational pluralism, or enterprise diversification, is discussed in the literature, the straightforward occupational classifications continue to be used. The implications such an acknowledgement of occupational pluralism has for the school-skill-enterprise relationship have not been acted upon.

It is too simplistic to examine the effects of schooling and/or skills training on enterprise outcomes, where enterprise outcomes are measured from only one activity - either farm or nonfarm. Studies regarding the effects of schooling on farm outcomes are common (e.g. Lockheed et al., 1980), but those regarding effects of schooling on nonfarm outcomes are less so (but see Vijverberg, 1995; 1999). Very few authors look at effects of schooling on both farm and nonfarm activities (Jolliffe, 1996; 2002; 2004), and the issue of schooling, skills and occupational pluralism needs to be more developed in the literature. Given the widespread, and growing, nature of occupational pluralism in SSA, studies that only look at the effects of schooling or skills on individuals' farm or nonfarm activities are missing a lot.

Similarly, it is too crude to categorise an individual as only self- or wage-employed. Secondary and tertiary enterprise activities or occupations need to be considered.

The implications of occupational pluralism and straddling are that skills needs are diverse and changing, and that skills development has to be flexible enough to contribute to diverse livelihood strategies. Training should enhance individual capability to move from one type of work to another.

The occupational pluralism of households or individuals, that results in an often simultaneous combination of formal and informal employment, in addition to the importance of cross-financing between these activities, suggests that any sharp distinction between the formal and informal sectors is a fallacy (cf. King, 1977; Rimmer, 1992).

Given the large number of links between formal/informal economies and that they both exhibit characteristics of each other, the relationship between the formal and informal becomes blurred; for example wage duplication takes place, where formal sector employees have informal sector 
sidelines, or informal sector participants have multiple informal employment; some waged jobs are unrecorded (Rimmer, 1992); others make rational decisions to move from the formal to informal areas of the economy and, by doing so, bring a formal background, up-to-date information and access to formal support mechanisms (i.e. training, modern banking, extension services) to the informal economy; others use informal activities to finance a period of formal sector unemployment; in addition many informal activities act as service/material providers for both the informal/formal economy. Further, since the activities exhibit both modern and traditional features, this clear-cut dualistic categorization is inappropriate (Aboagye and Gozo, 1986).

Once it is recognised that the informal sector is both urban and rural, is often characterised by occupational pluralism (individuals/households with multiple occupations and strong farmnonfarm links) and accounts for some $90 \%$ of all employment in some developing countries, surely the time has come to stop seeing it as a sector at all, or as something special in an economy. King (1990a; 1996; 2005a) argues that it is not an informal economy, it is the ordinary economy of most developing countries; it is one that is dominated by micro-enterprise. 


\section{Chapter 3: Skills Development, the Enabling Environment and Pathways to Informal Micro-Enterprise in Sub-Saharan Africa}

\subsection{Introduction}

The education-enterprise link is not well understood (King and McGrath, 1999a), though UNESCO and the ILO have been "making the connection between education and the acquisition of skills for a productive working life" (ILO, 2003a: 8).

The previous chapter focused on the enterprise component of the school-skill-enterprise interaction and re-visited some traditional conceptualisations in light of the occupational pluralism of large segments of the Africa's population. This chapter will mainly focus on the skill-enterprise link.

As noted in chapter 1, since the EFA initiative in 1990 the school leaver crisis, emerging due to the massive increase in numbers completing basic education, has led to questions concerning the scale of post-basic education and skills training, and ultimately, to questions about EFA for what type of employment outcome. Politicians and policy makers in many countries in SSA are concerned on the one hand about these large numbers of youth exiting the school system and, on the other hand, about the knowledge that there are insufficient formal jobs for these youth. The bulk of school graduates enter the informal micro-enterprise (IME) economy, both rural and urban, in farm and nonfarm enterprises. In a number of countries across SSA attention has turned to delivering skills training as a means to make these school graduates employable and hence facilitate their entry into enterprise. Hence knowing more about the education-enterprise link, and especially the skill-enterprise pathway is important both from a political and a policy-making position. Moreover, to maintain commitment to primary school enrolment there is need for parents to see further training or employment opportunities for their children after school.

Skills training is said to be beneficial to labour market outcomes. The standard approach, popular among economists, has been to link years of schooling with outcomes: increases in productivity, incomes or higher returns. Much of this literature, however, has not looked at the returns to TVET (but see Bennell, 1996b). ${ }^{67}$

\footnotetext{
${ }^{67}$ See also King and Palmer (2006b).
} 
Skills learnt though TVET are often linked with positive developmental outcomes including the alleged positive impact skills have on the nature of employment outcomes in an economy. In a general analysis the ILO (1998) saw training as being important for workers in the informal economy. The ILO (2003a: 8) stresses that "skills are essential to improve productivity, incomes and access to employment opportunities". Skills training is often said to be beneficial to IME operatives in a number of ways.

Firstly, it is widely assumed that skills training increases productivity, quality, diversity and occupational safety and improves health, thereby increasing incomes and hence leading to reductions in poverty levels for these workers and their families (Fluitman and Haan, 2002; World Bank, 1991; 2000a; 2004a; 2005a).

Secondly, it has been argued that on-the-job skills training helps to develop social capital and enterprise networks (Assad, 1993).

Thirdly, skills training can help develop business skills and experience, crucial to apprentices' future survival as independent entrepreneurs (Fluitman, 1994).

Fourthly, given that increasing numbers of people in SSA are engaging in occupational pluralism, any increase in productivity resulting from nonfarm skills training has positive knock-on effects to agricultural enterprises, principally through cross-financing (Palmer, 2004b).

Fifthly, traditional apprenticeship training represents the most accessible source of training for the poor and an important source of technical skills for those who cannot access formal training. ${ }^{68}$

These claims about the beneficial results of skills acquired through TVET or so many years of schooling perpetuate the assumption that this training leads to economic growth and poverty reduction. ${ }^{69}$ But there is no automatic relationship between acquiring skills and obtaining these outcomes above. Skills development outcomes, at all levels, are obviously determined many other things such as the quality of the education and training and the state of the enabling environment surrounding skills development (King and Palmer, 2006c). The years of schooling

\footnotetext{
${ }^{68}$ However, the poor can still have trouble financing apprenticeship (see chap.7.9.1).

${ }^{69}$ See chap.9.
} 
measure fails to say anything about the quality of the learning or about the type of environment in which graduates find themselves. ${ }^{70}$

This is something that is perhaps very obvious but which had been missing in much of the longrunning debate about the developmental outcomes of education and skills training - that education and training needs to be embedded in a series of particular contexts or environments if it is to have the powerful effects that are so often claimed for it. Hence, skills training on its own may be a key variable, but it is not a determinant of poverty reduction, growth or of job creation.

The first section of this chapter examines two types of environment which are crucial in the skillto-work link: i) the delivery environment for skill acquisition; ii) the transformative environment for skills utilisation. ${ }^{71}$ The second section examines one aspect of this transformative environment: the micro-enterprise environment in developing countries. Lastly, this chapter examines some of the pathways to IME.

\subsection{Translating skills development into employment outcomes}

The quantity and quality of human resources produced depend on both the delivery capacity of the formal and informal education and skills system, and on the demand for these resources in a given country. It is not simply a case of increasing the supply of educated and skilled workers through investing heavily in expanding the provision of education and training. Education and training, alone, do not result in increased productive capacity in the form of employment. Nor, by the same token, do they, alone, result in poverty reduction/growth. If skills cannot be put to use, potential capacity may be increased, but productive capacity will not be (King and Palmer, 2006a). There is a difference between skills development (the capacities acquired) and skills utilisation. Not only do the skills acquired need to be of good quality, but they need to be produced in a positive climate for their adoption (World Bank, 2004b).

\footnotetext{
${ }^{70}$ For a critique of the economics of education literature for Ghana, see Palmer (2006a). See also Bennell (1996a) who has been a vocal critic of rate-of-return to education estimates.

${ }^{71}$ The framework for the delivery and transformative context were also discussed in King and Palmer (2006c) and Palmer et al. (2007), but in both cases it was the author who wrote that part of the papers.
} 


\subsubsection{The delivery environment for skill acquisition}

This refers to the context in which skills are acquired and is made up of three distinct environments: the formal education environment (skills delivered through schools or formal VTIs); the informal enterprise-based training environment (e.g. traditional apprenticeship training); and, the formal enterprise-based training environment.

In the formal education environment the delivery of skills is affected by factors such as: the availability and quality of, and incentives for, teachers; text books and other learning materials (e.g. tools, equipment); management/governance; curriculum; instruction time; language of instruction; school infrastructure (including workshops) (World Bank, 2005a). These quality aspects of school- or institution-based training are absolutely critical (UNESCO, 2004).

Informal enterprise-based training is intimately linked to the nature of informal enterprise itself and to the associated challenges that most of these enterprises face. Training in this environment is well known to have a number of advantages and disadvantages (Palmer, 2005a; World Bank, 2004a). ${ }^{72}$ This type of training is also affected both by policies related to the informal private sector, but also by government skills strategies that might include apprenticeship training in their remit.

Meanwhile formal enterprise-based training is affected by the policies and environment related to formal private sector development (and in some countries which have skills levies, by government skills strategies). ${ }^{73}$

This delivery environment exerts a major influence on the degree to which quality skills are developed. But the delivery environment is, itself, affected by other factors. For example: user fees/other direct costs; indirect and opportunity costs; household income; distance to school; student health/ vulnerability; perceived returns (World Bank, 2005a).

\footnotetext{
${ }^{72}$ See chap.7.9.

${ }^{73}$ See World Bank (2004a) on training in formal enterprises.
} 


\subsubsection{The transformative environment for skills utilisation}

For skills to translate into productive employment outcomes there needs to be the development of other factors, external to the education and training system. The extent to which the traditional skills learnt through basic education and traditional forms of TVET can contribute to the development of a county's productive capacity are influenced both by the development and utilisation of a country's higher-level skills, and by the development of a supportive enabling environment that allows skills to be utilised productively (fig.3.1) (King and Palmer, 2006a; Palmer et al., 2007).

In 2005 three documents highlighted the crucial importance of seeing the expected outcomes and quality of education and training within such wider enabling contexts: the UN Millennium Project Report (UN Millennium Project, 2005), the Commission for Africa (Commission for Africa, 2005), and the World Bank's policy paper on education (World Bank, 2005a). ${ }^{74}$ Likewise UNESCO (2004) highlights the importance of external contextual factors that impact on the quality of an education system. These include: the economic and labour market conditions; sociocultural and religious factors; aid strategies; educational knowledge and support infrastructure; public resources available for education; parental support; labour demands.

Similarly the World Bank (2004a) sees no automatic connection between skills development and employment: "[t]raining, by itself, will not create jobs and will achieve its objectives only where the conditions are right for economic growth" (p.188). The Inter-American Development Bank (IDB) further adds that there is no tangible evidence that training alone creates jobs (IDB, 2000: 17 , italics in original) and notes that

Training requires an enabling environment... [T]raining by itself will not be effective unless the conditions for the deployment of learned skills are favorable. This includes the political and economic climate... The first and foremost precondition is the creation of jobs. Unless jobs are being created, training runs a high risk of being ineffective. (p.7, italics in original)

Among the most critical factors in such a transformative environment, therefore, are the macroeconomy, work and employment.

\footnotetext{
${ }^{74}$ For a full discussion of each of these, see King and Palmer, 2006c and Palmer et al., 2007.
} 
The essential first step with regard to skills development remains getting the macroeconomic context right (World Bank, 2004a: xv). The World Bank made a similar point ten years earlier that for skills training to result in increased productivity and earnings, the economic and labour market environment had to first be reformed so that it was supportive of skills utilisation:

Progress along this road [improvement in productivity and earnings of the poor] initially requires not training, but reform of policies that discourage economic and employment growth. (Middleton et al., 1993: 217)

The 1991 Bank TVET paper further acknowledged that training alone was a necessary, but insufficient factor in improving informal sector productivity:

Training in the rural and urban informal sectors can improve the productivity of the poor if it is used to complement broader strategies to generate income, but training alone has not been very effective. (World Bank, 1991: 58)

In the field of agriculture, skills development is recognised as "a vital part of the package needed to advance farm productivity, raise incomes, reduce poverty and make the transition to a more productive non-farm sector" (Johanson, 2005: 17). However, as with our discussion above concerning skills learnt though traditional TVET, "support for the educational needs of rural populations... is unlikely to foster the improvements in rural incomes and living standards... without the support of other reinforcing initiatives" (Saint, 2005: 1, emphasis added). These reinforcing initiatives include, for example: a proper macro-economic and regulatory framework; innovative private firms and NGOs; and adequate communication and transport infrastructure (ibid.). Similarly, Kodithuwakku and Rosa (2002) argue that knowledge utilisation is dependent on resource availability:

[A]ny increase in knowledge must be matched with equivalent and relevant resource mobilisation. Learning about fertilizers and farm machinery, for example, can only be useful if fertilizer and machinery for spreading is affordable, can be obtained, and maintained. (p.435)

The widely used claim in policy documents about how education increases agricultural very seldom notes the central caveat to the original research this claim is based on - that the impact of skills on agricultural productivity acquired through education is dependent on the state of the enabling environment for farming. Lockheed et al. (1980) showed that four years of education for 
farmers makes a difference to agricultural productivity of about $10 \%$ in a modernising environment. This modernising environment referred to a context where there were

new crop varieties, innovative planting methods, erosion control, and the availability of capital inputs such as insecticides, fertilisers, and tractors or machines. Some other indicators of [a modern] environment were market-orientated production and exposure to extension services. (ibid.: 129)

Education makes virtually no difference, the research argued, if the environment is nonmodern (ibid.). ${ }^{75}$

The labour market environment includes, for example: the growth in the economy and availability of more and better employment opportunities; the advancement, accessibility and adoption of technological capabilities; the development of an equitable infrastructure for formal and informal enterprises; the presence of meritocratic access to both the formal and informal labour markets; and the availability of financial capital.

The macro-economic environment includes, for example: civil service reform; good governance (with policy predictability, transparency and accountability) and action on corruption; poverty reduction and inclusion; social cohesion; decentralisation; political economy of reform; knowledge economy goals; resource mobilisation and utilisation (Commission for Africa, 2005; UNDP, 2004; World Bank, 2005a).

The interaction between education and economic development has been the subject of long debate. In fact, it was in Ghana in the late 1950s, that one of the most influential pieces of research was done concerning the role of the school in the economic development of a country: Philip Foster's Vocational School Fallacy in Development Planning (Foster, 1965b). Briefly put, Foster argued that it was a fallacy to think that it was possible to change the aspirations of (rural and urban) youth in favour of farming (and staying in the rural areas) by changing the curriculum to include vocational education. This was because, he continued, youths' aspirations are determined largely by what happens outside the education and training system - in the labour market. ${ }^{76}$ Foster argued that in general, pupils and parents value academic education much more than vocational education and training because it promises to offer better employment

\footnotetext{
${ }^{75}$ For an extended analysis of this see King and Palmer (2006c) and King et al. (2005).

${ }^{76}$ Foster's research was not, of course, in VTIs, but in middle and secondary schools.
} 
opportunities in the future. Foster argued therefore that, in many respects, academic education is more vocational than vocational education proper.

Even though Foster (1965b) was able persuasively to show that "the idea that children's vocational aspirations can be altered by massive changes in curriculum is no more than a piece of folklore with little empirical justification" (p.149), the belief that a vocationalised curriculum can largely alter pupils' occupational aspirations held sway in the Bank until the mid 1980s and continues amongst national policy-makers up to the present (chap.1.2.1).

While Foster (1965b) argued that the curriculum made no difference to the aspirations of students with regard to occupation, a later study in Ghana by King and Martin (2002) suggests "that there could, very possibly, be an identifiable school influence or school effect on attitudes towards employment and self-employment" (p.6). ${ }^{77}$ Nonetheless, King and Martin agree with Foster that "clearly pupils are directly affected by their perceptions of the opportunity structure outside the schools" (p.23) and that one should be aware of the limitations of any attempt "to use schools to deliver massive changes in attitude and aspiration in the absence of any parallel initiatives in the larger economic environment" (p.24).

The view in the 1960s - concerning the role of school in development - which Foster was so concerned with was this: in largely agricultural societies, where formal employment is small and cannot absorb the vast majority of school leavers, it is "essential... [that] large scale technical and agricultural programmes [are developed] within the schools" (Foster, 1965b: 142) ${ }^{78}$ that would prepare school leavers with vocational, agricultural and technical skills needed to transform their society. The British economist, Thomas Balogh, commented that: ${ }^{79}$

Present educational facilities constitute an obstacle to rural progress because people are not trained for agriculture, and academic systems of formal education are the chief determinant of attitudes hostile to the practice of rural agriculture. Schools are regarded as primarily responsible for the flight from rural areas to the towns. (Balogh in Foster, 1965b: 142)

However, in the Vocational School Fallacy, Foster (1965b) argued that such views are "generally fallacious and ignore a series of crucial variables" (p.143). Foster's concerns, which are still of

\footnotetext{
${ }^{77}$ See also Foster (2002).

${ }^{78}$ Here, Foster is paraphrasing the views of Balogh (see fn. 79).

${ }^{79}$ Balogh made a series of observations on the conclusions of the 1961Conference of African Ministers of Education (Addis Ababa).
} 
critical relevance to today's Ghana - e.g. vis-à-vis the proposed education reform (chap.5.1) relate to the need to understand the limitations of what education alone can do for economic development. He argued that the solution to the problem of unemployment is not the school, or the school curriculum, since it is relatively easy to expand student enrolments, but if the economy is not growing sufficiently to absorb the increased influx of school graduates then the unemployment situation will worsen.

Educating and training large numbers of people "does not... create employment opportunities for them" (Foster, 1965b: 153). Foster argued that the solution to the problem of unemployment lies outwith the school, and children's aspirations - and the occupations that they end up in - "are almost exclusively determined by factors which lie outside of the schools" (p.152). He notes that it is the institutional environment outside the school which is critical:

the crucial variables lie... in the structure of incentives within the economic system and in the degree to which the institutional milieu is supportive of entrepreneurial activity. Without such a milieu no amount of vocational instruction can be effective since the skills acquired will not be utilized. (ibid.: 153 , emphasis added) ${ }^{80}$

In a later paper, Foster (1975) continues to make the point that providing formal education, without concomitant developments in the rural economy (e.g. in markets, infrastructure etc.) will not lead to economic development and the expected outcomes of education.

[F]ormal education alone must not be regarded as the primary engine of rural transformation, for literacy and schooling become effective only when they operate in conjunction with other changes in the rural economy...

the priorities for rural improvement are the provision of incentives for peasant farmers; the development of markets; the extension of transport facilities; and increase in input supplies; and basic research on agriculture. Without these, the rural economy will not grow and educational efforts will be partly wasted. (p.385, italics in original)

It is clear, therefore, that Foster's concerns related to the outcomes of education and the need for other enabling factors to be in place - job opportunities, infrastructure etc. - are directly related to the concerns regarding the importance of the transformative environment.

\footnotetext{
${ }^{80}$ For an analysis of the institutional environment for enterprise activity in Ghana, see chap.5.3.
} 
In fact, Foster was not alone in his scepticism of the role that education, alone, could play in the economic development and transformation of a country. Both Callaway's Nigerian research and Peil's Ghanaian research in the 1960s/70s led them to similar conclusions.

Callaway noted that it was not schools that affected student perceptions, but, rather the wider external social and economic environment:

The fact is that school leavers' views of their vocation in life are determined largely by what happens outside the school, in the society and economy. (Callaway, 1963: 362, emphasis added)

Peil was also of this view. During the discussion at the conference on urban unemployment in Africa in 1971, she commented that:

... it is the influences from the wider social environment and not just education which are crucial in shaping attitudes towards the labour market. (Cruise O'Brien, 1972: 111-112, emphasis added)

In 2002 Foster commented again on the limitations that should be placed on expectations of what education can do for economic development:

...education is only one of the factors associated with economic development. Over the last thirty years a formidable body of evidence has been generated to emphasize that it plays a major role. But I would contend that education is not the "prime mover" in economic change but it is a powerful accelerator given an appropriate structural and institutional environment. This caveat is absent from much of the current policyorientated literature... (Foster, 2002: 28, emphasis in original)

In addition to the macro-economic and labour market environment there are a number of other environments which all serve to enable or disable the translation of skills acquisition to skills utilisation (fig.3.1): cross-sectoral linkages; the historical, social and cultural environment; and the international environment.

The cross-sectoral linkages (physical and social infrastructure) include, for example: water and sanitation; transport; health; energy; social protection; youth; agriculture; education; private sector development (labour market environment) (Commission for Africa, 2005; UNDP, 2004; World Bank, 2005a). Investment in infrastructure is increasingly regarded as being absolutely critical for development (DFID, 2006b: 61). For example, Hettige (2006) finds that the poor and 
very poor benefit substantially from rural roads through access to state services in areas such as health, education, agricultural extension, and provision of information. Lack of access to basic infrastructure and services, for example electrical, telephonic and transport infrastructures can inhibit successful production, trade and networking among MSEs (King and McGrath, 2002b).

The historical, socio-cultural and political environment includes, for example: the development of social capital; cultural values and attitudes; societal values and norms.

The international environment impacts on the different kinds of national enabling environments: the cross-sectoral linkages; macro-economic linkages; historical, social and cultural environment; the labour market environment; and, as noted above, the national delivery environment of education and training. This international environment includes, for example, open markets and international trade regulations; international aid policy and framework; global geo-politics; and, debt (UNDP, 2004).

Fig.3.1 tries to show visually that which has been discussed above. The key point to note here is the distinction between skills development and skills utilisation. Developing skills in a labour force is one thing, but if people cannot utilise these skills because other supportive measures are absent, then skills development cannot lead to productive employment outcomes.

The relationship between the development of the transformative environment and the different levels of skills development (fig.3.1) is, of course, two-way: particularly at the post-basic level skills development assists in the creation of the transformative environment (see King and Palmer, 2006c).

Many of the environments that have been discussed above come close to what the World Bank refers to as the investment climate - defined as the "opportunities and incentives for firms to invest productively, create jobs and expand" (World Bank, 2004b: 19). The Bank also makes the useful point that many aspects of a good investment climate - courts, finance markets and infrastructure - improve the lives of the population whether they are working in private sector enterprise or not (ibid.). 


\section{Fig.3.1.Translating skills development into employment outcomes}

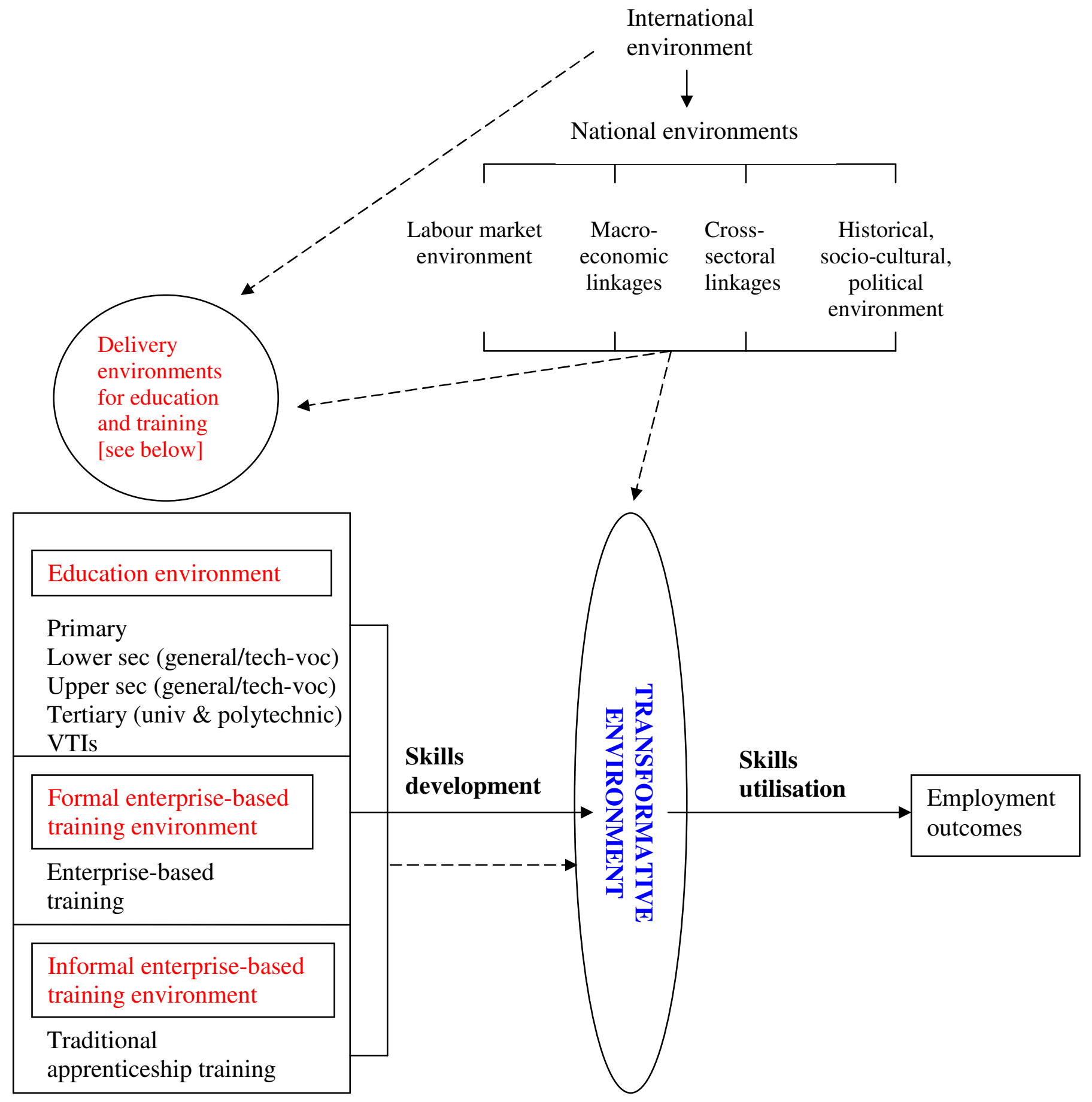

Source: Author

VTIs - vocational and technical institutes/centres

An earlier version of this diagram was drawn by the author for King and Palmer, 2006b and also appears in Palmer et al., 2007. 


\subsubsection{Summary}

This section questioned the straightforward linking of skills training with outcomes and highlighted the importance of both the context in which skills are delivered - the delivery environment for skill acquisition - and the context in which trainees find themselves upon graduating - the transformative environment for skills utilisation. The labour market environment is among the most critical elements of this transformative environment, and this is examined in the following section in relation to the informal sector.

\subsection{The informal micro-enterprise (IME) environment}

African IMEs face a host of challenges and there is a wide literature discussing the kinds of enabling factors which influence the success of these ventures (Commission for Africa, 2005; Grierson, 1997; King and McGrath, 1999a; 2002b; McGrath, 2005b; McGrath et al., 1995; Trager, 1987; UNDP, 2004; World Bank, 1991; 2004a).

Both the 2004 and 1993 World Bank publications on TVET (Middleton et al., 1993; World Bank, 2004a) underlined the need to support skills training with other interventions if self-employment outcomes were to occur. The 1991 Bank paper also made this point:

Successful entry into self-employment and the establishment of small businesses require much more than vocational skills; access to capital and markets and business management competence are also needed. (World Bank, 1991: 27)

Grierson (1997) also highlighted the importance of an enabling environment for enterprise development:

The clearest lesson learned about enterprise development in recent years is that all types of business are easier to establish and ultimately more successful if framework conditions are positive - that is, if there is an "enabling environment" (p.43)

In addition to the more general aspects of the transformative context, noted above, it is worth briefly outlining components of the micro-enterprise environment that serves both to enable and disable skill-to-enterprise outcomes. These include the:

- economic environment;

- legal and regulatory environment; 
- policy and institutional environment;

- $\quad$ social environment (networks, associations and gender);

- post training environment.

\subsubsection{The economic environment}

The key macro-economic linkages that impact on the overall informal sector labour market environment were noted above. But it is worth taking this discussion a little further at this point.

Firstly, in most of SSA the informal sector represents the dominant source of employment. Countries in SSA that have experienced economic growth appear to have largely done so without concomitant job growth; GDP growth, in other words, is often jobless (Altman, 2003). It is therefore important that the growth in economies is complemented by the availability of more and better employment opportunities. In the absence of formal job creation and supportive policies for informal MSE development, it is difficult for skills learnt to be used.

Secondly, the nature of informal economies in SSA suppresses demand for skills training or upgrading. Informal economies effectively operate as income-constrained markets - meaning that people's buying power is weak overall. ${ }^{81}$ This restricts not only overall demand for products and services, but reduces the demand for training to improve quality since the market could not purchase better quality, more expensive, goods and services anyway (Palmer, 2005a; World Bank, 2004a: 135). ${ }^{82}$

\subsubsection{The legal and regulatory environment}

The legal and regulatory environment can also serve both to enable and disable enterprise outcomes. The UNDP (2004) notes that "[p]erhaps most important in allowing entrepreneurship and the private sector to blossom is a level playing field... with fair rules, fairly enforced" (p.17). These rules are laid down in a sound legal framework, consisting of written rules and laws followed by every citizen, and are enforced by a professional bureaucracy in a fair and

\footnotetext{
${ }^{81}$ Markets may also be saturated or dispersed which further constrains entrepreneurial activity.

${ }^{82}$ Hence, skills development interventions need to improve quality and efficiency without resulting in too great a price rise for the final product/service.
} 
transparent manner (UNDP, 2004). In the private sector the rule of law manifests itself in, among others, commercial laws, custom laws and contract laws (ibid.).

However "[r]ules, if excessively complex and incorrectly applied, can turn into significant barriers for enterprises... [t]his applies to rules for entry, operating, market and exit" (UNDP, 2004: 17). Too many complex or inaccessible procedures associated with formally registering and running a business will serve to disable enterprise outcomes.

In developing countries a key constraint to the informal economy remains the lack of rights over land and commercial assets (Commission for Africa, 2005). The need for enforceable contracts in relation to property rights is crucial (Commission for Africa, 2005; UNDP, 2004). Many in the informal economy find it hard to utilise their assets, which largely remain "dead capital" (De Soto, 2001). Dead capital is capital in the form of informal assets that lack value as collateral for securing the interests of creditors. To become live capital, these assets must be formalised so that ownership can be traced and validated and exchanges can be governed by a legally recognisable set of rules (ibid.).

Other regulations and standards (e.g. health and safety issues) and social protection (e.g. labour protection) that exist in developing countries largely ignore the informal economy, especially in rural areas (Commission for Africa, 2005).

Nonetheless, since the vast majority of MSEs in the informal economy are alegal (Blunch et al., 2001; Hugon, 1990: 73), "it does not appear that the legal and regulatory framework has been a serious hindrance to the establishment of most enterprises" (Liedholm and Mead, 1999: 85; cf. Mead, 1999).

In spite of the fact that the IME economy contains the largest proportion of workers in many developing countries, preferential treatment for their formal sector colleagues still occurs (McGrath et al., 1995). While governments are now becoming generally less openly hostile towards informal economic activities, constraints still arise in many countries from often contradictory policies of local, state and central government policy, in relation to tax collection, harassment and official procedures concerning MSE registration and start-up. 


\subsubsection{The policy and institutional environment}

IMEs can be constrained by: weak, contradictory or absent government policy vis-à-vis IME; lack of coordination between, and lack of capacity of ministries and agencies concerned with education, skills and private sector development. These are obviously interrelated: a lack of an overall strategic policy framework contributes to weak institutional linkages and hence a disabling policy environment for IMEs.

\subsubsection{The social environment; networks, associations and gender}

Grierson (1997) notes that social barriers to entry present a "formidable challenge to the prospective self-employed" (p.57). For example, despite the fact that "women play a pivotal role in the informal economy... women entrepreneurs in Africa face huge discrimination with regard to economic and social assets, including land rights" (Commission for Africa, 2005: 239), credit and other aspects. The difficulty of female access to such basic assets constrains their ability to enter dynamic self-employment activities when compared to their male counterparts. The traditional roles of women in many developing countries often restrict and discourage female involvement in activities outside of what women traditionally do: dressmaking, hairdressing, trading etc.

Social networks, enterprise networks and other informal sector associations (ISAs) are vital for self-employment promotion (cf. Kodithuwakku and Rosa, 2002) and the extent to which aspiring self-employed youths can access these social networks may affect their start-up success. Some groups, especially women, the young, poor or disadvantaged find it difficult to obtain access to these networks needed to start and sustain enterprises (Chigunta, Schnurr, James-Wilson and Torres, 2005; Grierson, 1997). Grierson (1997) comments that:

ease of entry to self-employment is related to the ability to access or create the social networks needed to provide information about self-employment opportunities and access to the resources and skills needed to take advantage of these skills. (p.57)

As noted below, the majority of those entering self-employment in SSA get financial assistance from family or other social networks. This takes the form of social relationships between people assisting relatives/friends financially or helping them find employment - or might be more 
structured in the form of informal savings, funeral or social welfare groups ${ }^{83}$ However, the role that family plays in enterprise start-up can both be a help and a hindrance (Buckley, 1996; Palmer, 2004a).

In addition to the importance of family and social networks, those entering self-employment activities need to develop good enterprise networks made up of trainees' own enterprises, their competitors, their suppliers, their creditors and their customers. Enterprise networks don't only provide advice to new starts, but can also assist financially (e.g. some enterprises might offer supplier credit to new starts). There is often quite a degree of overlap between social and enterprise networks; since other owners might also be in an individual's social network the boundary between social and enterprise networks can often be blurred. Moreover, social contacts can act as intermediaries to bring enterprise owners together.

Grierson (1997) argues that two distinct types of network ${ }^{84}$ need to be stimulated for selfemployment promotion: i) enterprise networks; and ii) institutional networks - comprised of training programmes, complementary support institutions, banks and other financial and nonfinancial support institutions that have the aim of supporting self-employment. These institutional networks relate directly to the point made below about the need for strong collaboration between those agencies concerned with education and skills training, and those concerned with selfemployment creation.

A study by Gibb and Manu (1990, cited in Grierson, 1997) of 57 projects in Africa, Asia, Latin America and Europe concluded that effective small enterprise development institutions linked training with other support services not as part of a bureaucratic service, but through stimulating network and linkage creation. Coordination between institutions is therefore vital as is the strengthening of networks and associations that can facilitate this coordination process.

Furthermore, informal sector associations (ISAs) can be an important means not only to link owners of similar enterprises together so that they might support each other informally, but also to act as a single voice to get the views of thier members felt in policy dialogue, and as a means to strengthen these institutional networks. The Commission for Africa Report (2005) noted that, in

\footnotetext{
${ }^{83}$ These types of informal savings and insurance associations have been well documented (see Ardener and Burman, 1996).

${ }^{84}$ Given what has been said above about the importance of family and ethnic connections, it is noted that a third type of network could be added to these two: the family and ethnic network (see chap.8.1).
} 
order to develop a private sector strategy for the informal economy, small enterprises have to be given a voice in the policy process.

\subsubsection{The post-training environment: finance, follow-up and technology}

\section{Finance}

It is widely acknowledged that lack of, or difficulty in obtaining, credit is a major problem to enterprise development in Africa, especially for MSEs (ApT, 1993; Aryeetey, 1996; Commission for Africa, 2005; ILO, 2003a; UNDP, 2004).

Youth wishing to start-up a small enterprise find it especially difficult to access formal credit, and informal credit markets are usually insufficient to meet their needs at this stage (Palmer, 2004a: 12-28). ${ }^{85}$ Participation in informal credit markets often relies on social capital (informal networks and trust), an asset that newly trained young people generally have not yet had time to develop. Furthermore, young people find it difficult to participate fully in the informal credit market since suppliers and customers often exploit their need for credit to get a cheaper price (customer) or a bigger profit (supplier) for themselves. Consequently, new start-ups have to rely heavily on their own savings (ibid.). ${ }^{86}$

In general, informal economic activities have long been characterised by their ease of entry (ILO, 1972). Webster and Fidler (1996) note that "low entry barriers facilitate relatively easy enterprise start-up" (p.13). Others note that the "capital intensity in this sector is low" (Barwa, 1995: 9), meaning that those wishing to establish informal economic activities do not require much capital.

However, once the construct of the informal economic self-employment is broken down into the distinction between subsistence and entrepreneurial self-employment, noted earlier (chap.2.1.2), then pathways to enterprise appear to be different: it seems that the more subsistence-orientated enterprises are generally charcterised by ease of entry, whereas more dynamic enterprises, like micro-communications enterprises, are harder to enter.

This distinction between entry into different types of enterprise was recognised early by Hart $(1969,1973)$ who noted that while there was a general ease of entry, this was less true for the

\footnotetext{
${ }^{85}$ For a detailed discussion of MSE financing in Africa (using Ghana as a case study) see Palmer (2004a).

${ }^{86}$ See chap.8.2.
} 
more dynamic, profit-making enterprises. More dynamic informal activities require more financing and, where start-up capital is difficult to come by, entry is harder. Hart (1973) noted that an essential prerequisite for entry into more profitable activities was that savings had been accumulated. A later ILO/JASPA (1985) report noted that:

the ease of entry argument about the informal sector has to be qualified substantively: entry [can be]... quite selective. (p.43)

Bryceson (2002a) points to a number of studies from SSA that suggest entry into more lucrative non-agricultural activities requires high levels of starting capital, that results in the exclusion of "farmers from more modest means" (p.734).

Thus, while it may be true to describe pathways to the more subsistence-orientated enterprises as an "erratic, iterative process" (Grierson, 1997: 45), or as rapid, incremental and unplanned (Aldrich, Rosen and Woodward, 1987, in Grierson, 1997), it would be less true to say the same of pathways to more dynamic, entrepreneurial, enterprises.

In addition to problems associated with formal credit, formal savings and insurance programmes are difficult to access by young, often poor, individuals, especially those in rural areas.

Some researchers (e.g. Adams and von Pischke, 1992; Buckley, 1997; Dawson, 1997; Gockel and Akoena, 2002) have come to the conclusion that micro-enterprises may face more important constraints than lack of working or fixed capital. Buckley (1997) adds that the real problems facing micro-entrepreneurs "cannot be tackled solely by capital injections but require fundamental structural changes of the socioeconomic conditions that define the informal sector activity" (p.1081, emphasis added). The importance of market demand (low purchasing power), market access, lack of diversification, inadequate infrastructure, and poor access to raw materials are seen as critical points for MSE intervention, moving non-financial support services back on the policy agenda (Rogerson, 2001).

Indeed evidence suggests that once artisans obtain credit they soon start to demand training as well (Oketch, 1993). This is particularly the case for expanding MSEs where the managerial competence of the owner is often out-stripped by the speed the enterprise is expanding (postcredit), leading to default on repayments (Harper, 1984). This suggests that the relative importance of credit (e.g. compared to training) is higher for enterprises at the lower end of the 
MSE spectrum than it is for expanding MSEs that are in need of more entrepreneurialmanagement skills training to accompany credit (McGrath et al., 1995; Palmer, 2004a).

\section{Business skills, entrepreneurship development, follow-up and extension}

The Commission for Africa Report (2005) notes that "[s]mall enterprises [in SSA] are also constrained by a lack of access to business services, including training and planning" (p.240). A number of programmes exist in developing countries aimed at providing enterprises with business training. These are usually aimed at the more dynamic enterprises, and less so at the more subsistence-orientated enterprises (McGrath et al., 1995).

Non-financial BDS are infrequently received by informal MSEs, especially in rural areas though there exist innovative possibilities to extend BDS to these clients. ${ }^{87}$ Agricultural education, extension and training services are weak in many developing countries (Johanson, 2005). This contributes to a general lack of access to technology, especially in rural areas, which further disables education and skill outcomes.

\section{Technology}

It is widely acknowledged that a technically dynamic environment enhances the benefits to education and general skills as more educated individuals are better able to make decisions and evaluate information in changing economic conditions (see King and Palmer, 2006a; King et al., 2005 for a discussion).

Reliance on out-dated or traditional technological practices is seen as a constraint to enterprise development in the informal economy (McGrath et al., 1995). The apprenticeship literature, in particular, frequently cites perpetuation of traditional technology as a major disadvantage of this type of training (World Bank, 2004a). NGOs and other agencies have attempted, in various countries, to improve productivity, diversity or product quality by improving technology among MSEs (Jeans, 1999; Smillie, 1986). Of course the technology environment is not uniform in the informal economies of SSA: many of the more dynamic MSEs are able to access modern technologies or their enterprise itself might be based on modern technology such as microcommunications enterprises (cf. Molony, 2006).

\footnotetext{
${ }^{87}$ See chap.5.3.6.
} 
Another point of view is that one of the strengths of the informal sector is its ability to use and develop appropriate technologies.

\subsubsection{Summary}

This section has briefly examined some of the key components of the labour market environment for IME: factors that enable or disable the utilisation of education and skills in the labour market.

While the difficulty of accessing financial resources is commonly cited as the main constraint to IME, the non-financial environment - infrastructure, market demand, the legal environment and access to social networks are also critical factors in determining ease of entry into IME.

\subsection{Pathways to self-employment in micro-enterprise}

\subsubsection{Education and opportunities}

The absolutely critical nature of the enabling environment in the translation of skills acquisition to skills utilisation and employment outcomes has involved discussion both of the specific microenterprise environment (itself part of the transformative environment), and also the delivery environment. But what does the literature say about pathways to enterprise self-employment in developing countries, especially in SSA? What typical pathways through education and skills to self-employment can be inferred from the literature?

There is a strong consensus that the acquisition of education and skills is "an important building block for new entrepreneurs in the informal sector" (World Bank, 2004a: 54). Caillods (1993) stresses the diversity of pathways towards employment through a variety of different skill training modalities:

Such surveys carried out in developed and in developing countries consistently show that there is not one single way of acceding to skilled occupations: workers and employees acquire their skills in a variety of ways, through on-the-job training and experience, through short training courses in enterprises, vocational centres, or private institutions. (p.3) 
McGrath et al. (1995) also stress the multiple pathways to self-employment through these different providers. This thesis concurs with this position but would add that the multiple skills routes to self-employment are complicated when youth combine multiple types of skills acquisition. It is not uncommon, for example, for youth to undertake traditional apprenticeship training either before or after receiving training in a VTI. Indeed Haan (2001) notes that "[t]here are... ample examples of persons who engage in apprenticeship training after a first period of formal VTI training" (p.24).

Research in West Africa (Birks, Fluitman, Oudin and Sinclair, 1994; Fluitman, 2001) points to education as a critical factor facilitating entry into self-employment, especially in a range of more dynamic, attractive, economic activities (including: radio and TV repair, car mechanics, secretarial services, cybercafés, tailoring and women's hairdressing).

Entrepreneurs in the informal sector with a higher level of education were found more likely to obtain pre-employment training, to benefit more from apprenticeship training and to need less time to enter into self-employment (Birks et al., 1994; Haan, 2001). Birks et al. (1994: 64) distinguish two career paths: one to more subsistence-orientated self-employment and the other to more-entrepreneurial self-employment:

(i) Entry to the more attractive, higher technology activities typically involves 7 years at school, followed by some technical vocational training (or period at technical school), and nearly 4.5 years of apprenticeship, followed by a limited period (less than 3 years) of wage-employment before embarking on self-employment; the median age for these entrepreneurs is 25 years at the start of self-employment;

(ii) Entrepreneurs in less attractive activities have only 3.4 years of schooling, less propensity to undertake technical or vocational training and, if any (only 55\% of them), a shorter period of apprenticeship (3.2 years).

Increasingly, entry into informal self-employment is becoming the preferred option for some and not only the fall-back option for those who could not make it into formal employment (World Bank, 2004a). New opportunities at the more dynamic end of the MSE spectrum are opening up in developing countries, not least as a result of the spread of ICT. It is now common place in many urban, and increasingly rural parts of West Africa to have micro-communications enterprises, either selling air time from a mobile handset or from a specially designed machine (chap.2.2.2) - sold to private owners and used in the informal economy (fieldwork, 2001-2005). 
Pathways to entrepreneurial self-employment, more so than to subsistence self-employment, are constrained or hindered by the existence of entry barriers. The whole series of factors that make up the micro-enterprise environment are all relevant here (chap.3.2).

The following section looks at a series of typical pathways to self-employment.

\subsubsection{Typical pathways to micro-enterprise self-employment}

A study by McGrath et al. (1995) outlines a number of typical pathways to self-employment. In analysing these pathways below, it is necessary to expand the range of possible other pathways not covered by these authors. The intention is that the following diagrams show possible transitions to first employment or training and hence do not reflect occupational pluralism, which tends to occur later.

Foster's critique of the provision of skills training in schools in the mid-1960s (Foster, 1965a; b) and the acknowledgement in the mid-1980s that providing vocational training as part of a diversified school curriculum was no more effective than providing academic education in terms of preparing youth for self-employment, led to the World Bank viewing a good general education followed by enterprise-based training as the most likely path to self-employment. The World Bank (1991; 2004a) has made it clear, as was pointed out above, that it considers a general basic education as an essential building block for self-employment:

A solid basic education is the best preparation for a wide range of jobs and often will shorten the length of training required. (World Bank, 2004a: 27)

Hence the pathway to self-employment implied here is one where a youth completes general education, then enters into some form of formal or, more likely, informal training in an enterprise, and subsequently establishes their own enterprise (Model A).

Nonetheless, Model A "is less explicit about what happens after training. It appears to be assumed that many graduates of both formal and informal sector enterprise based training will 
become self-employed" (McGrath et al., 1995: 109, emphasis added). This assumption, as noted later, is common. ${ }^{88}$

\section{Model A}

General Education

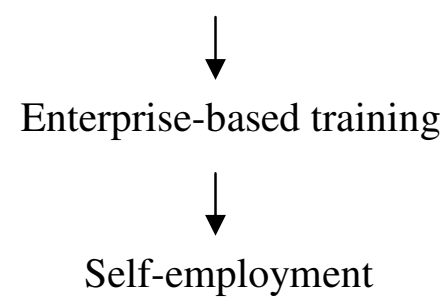

Source: McGrath et al., 1995: 108

Model B, based on Grierson (1997) who takes up this issue at the post-school point, examines further the link between post-school enterprise-based training and self-employment. In this model, the youth, after completing a period of (mostly) informal enterprise-based training pursues wage-employment. The importance of time is stressed in this model: in order to ultimately become self-employed a period of wage-employment will allow an individual, over time, to accumulate savings, develop social networks and gain experience all of which are crucial in order to enter self-employment. Indeed, "work experience is a known asset and useful predictor of selfemployment potential" (Mead, Mukwenha and Reed, 1993). Earlier, Hart (1973) noted that acquiring capital alone was not sufficient, but that experience was required to establish informal activities:

Artisans need not only small capital sums in order to set up their own sewing machine, bench and tools... but also a considerable amount of learned expertise. (p.70)

${ }^{88}$ See chap.9. 


\section{Model B}

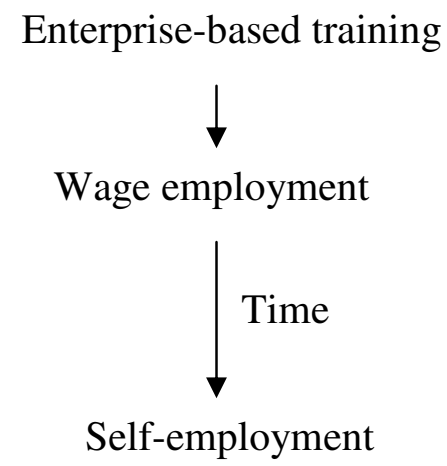

Source: McGrath et al., 1995: 109

Of course, what Model B does not make clear is the type of wage-employment that youth might pursue after their period of enterprise-based training. Indeed if the enterprise-based training was an informal apprenticeship it is more likely that the period of wage-employment would be in the informal economy, perhaps working for their previous master or doing other ad hoc wage work than it is that a newly qualified apprentice would get a job in the formal sector.

Haan (2001) adds that, as a mechanism to accumulate start-up capital, the importance of wageemployment would diminish if there was an accessible credit scheme that could provide this capital. Indeed, as shown later, as a mechanism to accumulate personal savings, wageemployment, particularly of the informal kind, is but one of many strategies used in rural Ghana. ${ }^{89}$

Palmer (2004a) shows that rural enterprises in Ghana utilise multiple sources of start-up capital. One of these sources involves, what might be termed, micro-entrepreneurial self-employment (MESE); that is working on very micro, often ad hoc, income generating activities as a means to save money to start up a more permanent self-employment venture - e.g. micro-scale cash cropping; a graduate tailor doing ad hoc clothing repair work door-to-door; a graduate carpenter doing ad hoc furniture work.

\footnotetext{
${ }^{89}$ See chap.8.2.
} 
The analytical distinction used so far has been between subsistence and entrepreneurial selfemployment, or between what has also been termed: subsistence activities and lucrative segments (Blunch et al., 2001) or survivalist and dynamic activities (Mead, 1999). But it may be that it is useful to make a distinction between two kinds of entrepreneurial self-employment: on the one hand there is what has just been termed MESE, and on the other entrepreneurial self-employment proper. MESE, as noted above, might refer to micro-scale entrepreneurial activities that do succeed in making a small profit - and so are distinct from subsistence self-employment (which is defined by its inability to move beyond the mere replication of current activities $)^{90}$ - but could not yet be termed dynamic or lucrative.

Thus the seemingly paradoxical conclusion is that another typical pathway to self-employment is through self-employment (Model C).

\section{Model C}

Enterprise Based

Training

(Informal Sector)

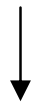

Micro-entrepreneurial

Self-employment

Time

Entrepreneurial

Self-employment

Source: Author

\footnotetext{
${ }^{90}$ Subsistence enterprise activities provide only enough profit to satisfy some of the basic needs of the owner, and enough to reinvest in the enterprise to maintain its current position. No profit is left over for the expansion of the enterprise, or for savings.
} 
Model D represents a common pathway to self-employment in developing countries, illustrating both the common phenomenon of youth not completing education and the general lack of postschool training opportunities (McGrath et al., 1995).

\section{Model D}

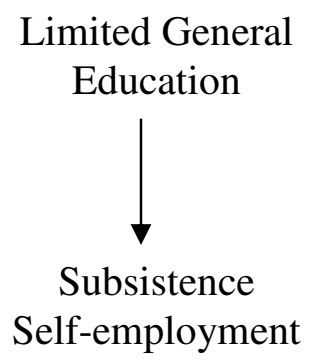

Source: McGrath et al., 1995: 111

Indeed, 'limited general education' (Model D) might well be replaced by 'no formal education' since many youth move into the labour market in developing countries with no formal schooling. Ghana, for example, despite 15 years of attention to EFA has more than one million primary school-age children not enrolled at the primary level (UNESCO, 2004) and 3.3 million (aged 15 and above in 1998/99) people in the population with no education (GSS, 2000).

A further model (Model E), therefore, starts with the premise that in many developing countries children start their education and training not in school, but in the home, in the market and on the farm (Palmer, 2005a). ${ }^{91}$

\footnotetext{
${ }^{91}$ King and Postlethwaite (1975) examine combining general education with work on the farm.
} 


\section{Model E}

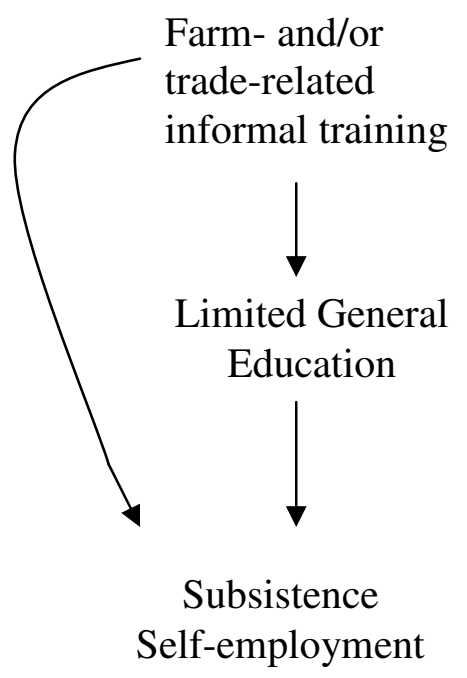

Source: Author

From a very early age children in rural areas are taken to the farm, usually by their mother. Starting with basic weeding, children acquire farming skills informally from their parents, engaging in progressively more complex tasks. Similarly many children, from an early age, assist their parents in selling farm produce or trading in local markets (Clark, 1994). This highly informalised training that children receive usually continues as the child attends school. Rural youth, therefore, regardless of whether they finish, drop out of, or even attend formal schooling in the first place usually already possess a basic knowledge of, and experience in, farming and/or trading (Palmer, 2005a).

Model F represents typical pathways to entrepreneurial self-employment through three different kinds of training. This model fits with the view that "general education... provides [youth with] the foundation for later acquisition of vocational skills" (World Bank, 2006b: 111). It assumes that a good basic education "is the foundation of most individuals' success in achieving access to enterprise self-employment, although it does not make assumptions about the form and content of the basic cycle" (McGrath et al., 1995: 112). It also acknowledges that, in light of the stagnation of many formal economies in developing countries, the traditional skills pathways to formal sector employment - such as VTIs and formal enterprise-based training - are "increasingly becoming pathways to enterprise self-employment" (ibid.: 113). After the training period, Model F follows Model B, emphasising the importance of wage-employment for entry into entrepreneurial self-employment. Again, wage-employment here is more likely to be of the 
informal kind. This model seems to fit with the typical pathway to self-employment outlined in a World Bank (2004a) study:

A typical sequence in becoming an entrepreneur is to acquire a basic education, then develop skills through a variety of means (formal training, informal training, on-the-job training), then obtain wage-employment, and finally enter into self-employment. (p.54)

\section{Model F}

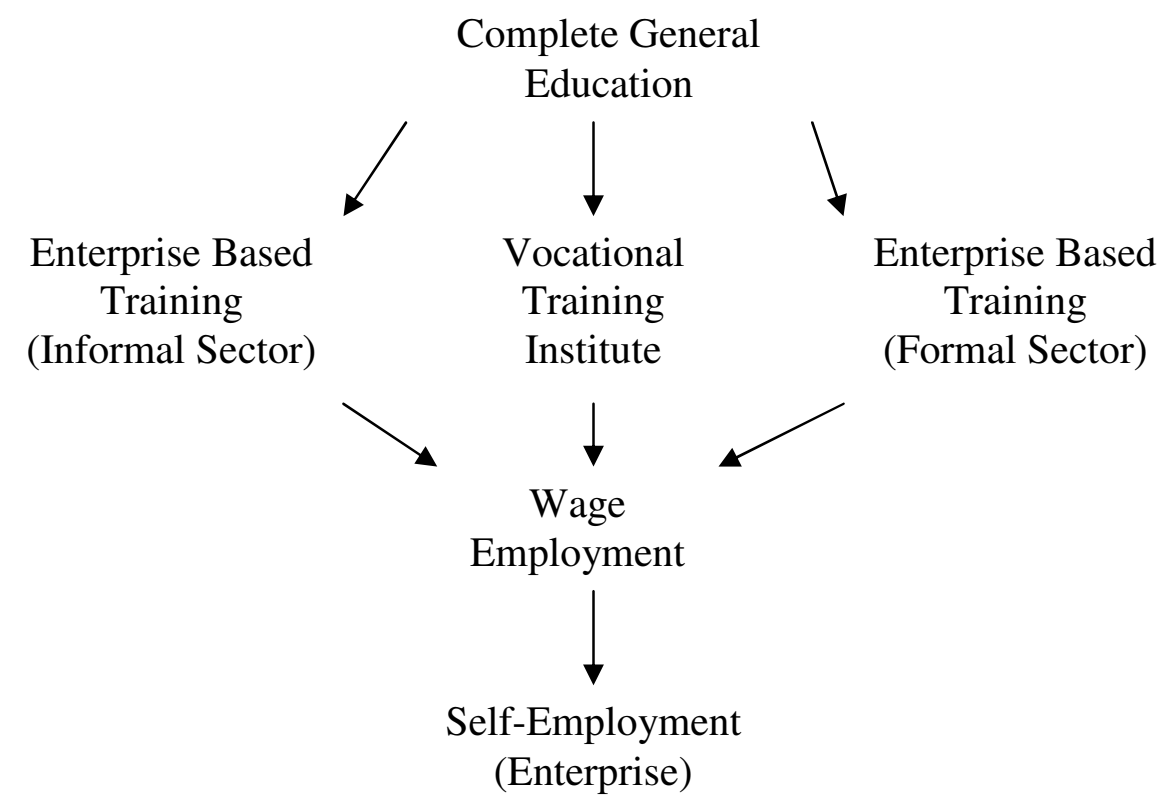

Source: McGrath et al., 1995: 112

McGrath et al. (1995) emphasise the issue of the enabling environment: that "education-andtraining pathways are situated within a particular legal and macroeconomic framework which very often constrains or supports them" (p.117). They illustrate this with a further model (Model G) intended, on the one hand, to illustrate the enabling environment and, on the other, to illustrate the kinds of interventions that have been considered as important for facilitating access to entrepreneurial self-employment. However, McGrath et al. (1995) note that these kinds of interventions are more effective if delivered after someone has started in self-employment. They also note that the support services in Model $\mathrm{G}$ are rarely seen by the many millions who engage in self-employment around the world. 


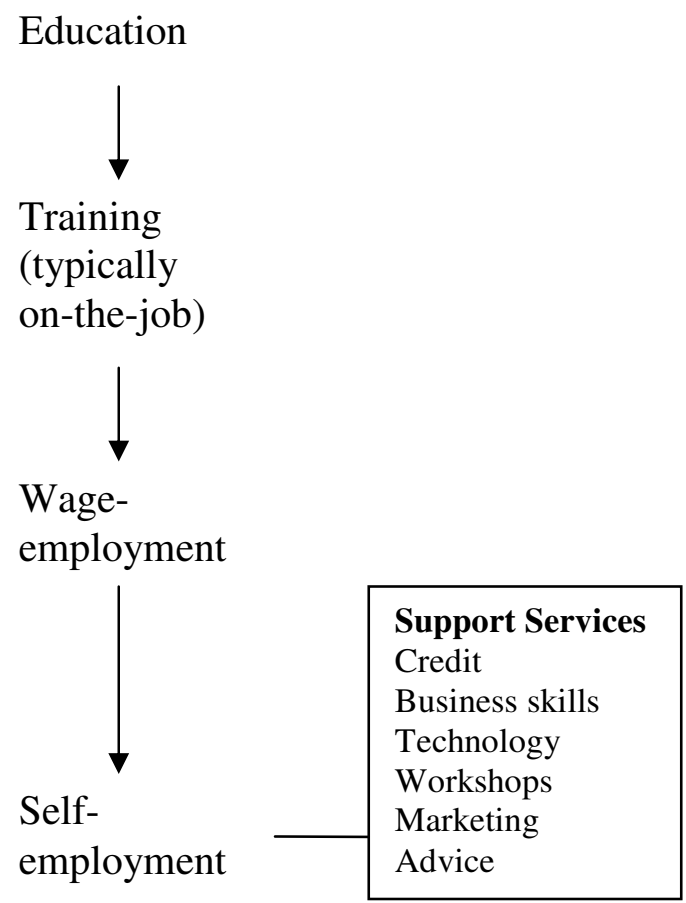

Source: McGrath et al., 1995: 118

A summary model $(\mathrm{H})$ attempts to incorporate all previous models, or pathways to entrepreneurial self-employment. It illustrates the multiple skills pathways that might be followed: from no, limited or complete formal education; through three types of skills training (or none) - including the possibility of movement between training and acquisition of skills from multiple sources; from the acquisition of skills to informal/formal wage-employment or MESE; and from here to entrepreneurial self-employment. As noted earlier, access to formal wageemployment is more likely for those who have completed formal enterprise-based training or formal VTI training - as opposed to informal apprenticeship training. Moreover, the MESE route incorporates those who, after finishing skills training are able to get support from family to establish an enterprise - without having to go through informal/formal wage-employment as a precursor to self-employment. Those that follow this route have little or no experience and are likely to learn through their own mistakes, from copying or observing others, or from getting advice from a family member or friend. A further aspect that Model $\mathrm{H}$ does not clearly illustrate is the route from no, incomplete or complete education to MESE, often with the support of family, described above. This route, that bypasses enterprise or VTI training altogether, is likely to be more common for those entering retail or farming enterprises, rather than manufacturing 
enterprises. Model $\mathrm{H}$ also suggests that there is movement, or pathways, from subsistence selfemployment to entrepreneurial self-employment. While very many entrepreneurs become entrenched in, what might be termed, a subsistence-entrepreneurship equilibrium, others - given the right support, advice and time - are able to access entrepreneurial self-employment. There are, in fact, very many examples of highly successful self-employed entrepreneurs in developing countries who have received no formal education or (formal/informal) skills training. 


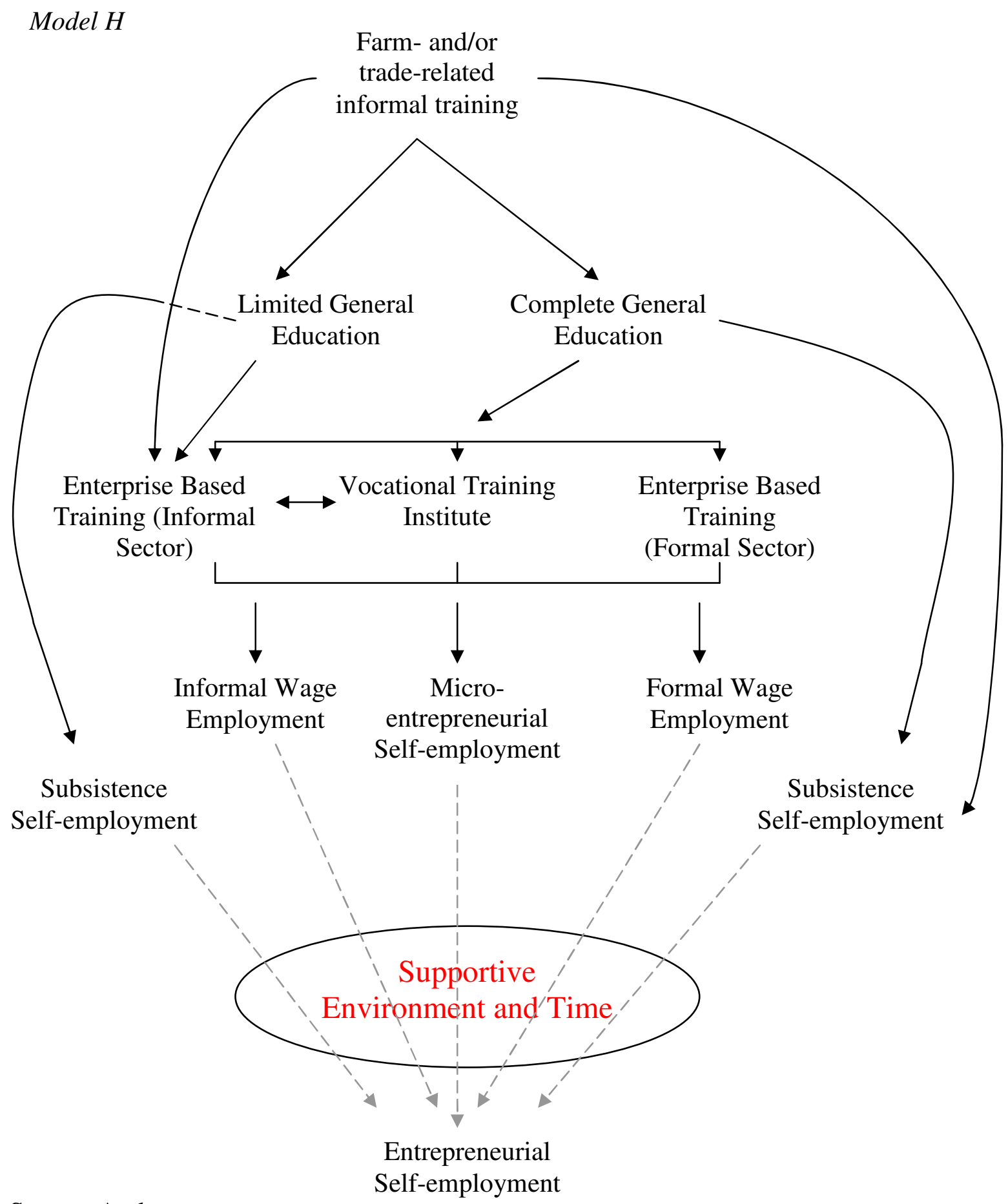

Source: Author

Model $\mathrm{H}$, however, does not show all the possible movements that can take place between different kinds of employment activity. For example, two-way movement can occur between subsistence self-employment and MESE; or between informal wage-employment and MESE. 
The, now, threefold distinction between self-employment activities (subsistence, MESE and entrepreneurial) should not, as has been emphasised, lead to the assumption that these types of activity should be seen as static (chap.3.3.3). These three types of self-employment coexist and movement clearly takes places - in both directions; successful entrepreneurs may find the market turns against them and they end up in more MESE activities, or their enterprise might head towards collapse via a subsistence-type existence; similarly, movement may occur in the other direction. Movement from subsistence to entrepreneurial self-employment is constrained by the types of economic and social barriers noted above. Changes in both the entrepreneur (e.g. skill level) and the environment affect the entrepreneurial process (Gibb and Ritchie, 1982).

King (1996), in a longitudinal study of informal sector operators in Kenya covering a twenty-year period, observes the co-existence of survival/subsistence and entrepreneurial activities at different stages of the lives of entrepreneurs. The life histories of King's sample revealed that many of those who had now established themselves as entrepreneurs would have looked very much more like subsistence self-employed in the 1970s when they often engaged in casual (kibarua) work. This has led King to conclude that subsistence activities should sometimes be seen as a stage towards a more enterprise-oriented modality. Furthermore, according to Hoppers (1994), shortterm or casual income-generating activities often function as stepping-stones for young people to a more substantive business effort. This view - that, for some, MESE activities can be seen as a step towards a more entrepreneurial, dynamic, stage of self-employment, is confirmed by data and interviews from this doctoral research in Ghana: many current micro-enterprise owners interviewed who were all engaging in some form of artisanal or service enterprise, revealed that a common strategy used to obtain start-up capital for their more dynamic enterprise was through starting off in MESE activities (chap.8.2).

The coexistence of subsistence and entrepreneurial self-employment activities in the informal economy, and of the mobility between these types, brings us onto a discussion of the life-cycle of enterprises and issues of graduation.

\subsubsection{Enterprise and entrepreneur lifecycles}

To understand micro-enterprise development it is necessary to adopt a dynamic perspective (Liedholm, 1991; Meghir, 1991). Enterprise dynamics refer to the inception of enterprise start- 
ups, through growth and/or survival eventually to enterprise disappearance/closure. Liedholm and Mead (1999) found it useful to examine MSE dynamics through four main categories: ${ }^{92}$

1. New starts. These enterprises are just getting underway. The needs of this group for support are significantly different from those of enterprises that have been in existence for some time and that have managed to overcome many of their start-up problems.

2. Non-growing enterprises. These are enterprises that have survived the perils of start-up but have not added to their employment since they were first established.

3. Small growers. These are enterprises that have been in existence for some time and have added to their work force since starting, but have grown only in small amounts.

4. Graduates. These are enterprises that started from a very small base and have made a transition to reach at least the middle ranges of the small enterprise spectrum.

It is often suggested that informal MSEs will eventually graduate to the formal sector, gaining access to formalised credit during the life-cycle of their enterprise (Liedholm 1991; Meghir 1991). Liedholm (1991) outlines a typical picture:

The firm originates as a tiny enterprise... [then has] three years of struggle, a high probability of failure, and little growth. If it survives... it is likely to experience a sudden spurt of growth that will typically project it into one of the larger size categories of micro-enterprises. (p.3)

In this view the lifecycle of an enterprise is characterised by a relatively static existence, punctuated by sudden growth spurts as "they... jump to a larger-size category" (Meghir, 1991: 103). While Meghir (1991) seems more optimistic that this type of graduation to the formal sector will happen given time, Leidholm (1991) cautions that "relatively few... micro-enterprises... ultimately graduate or transform themselves into more complex modern small and medium enterprises" (p.3). Indeed he later noted that "only about 1 percent of all MSEs starting out very small succeed in "graduating" to an enterprise with ten or more workers" (Liedholm and Mead, 1999: 94). Mead (1999) notes that the "number of enterprises that graduate from the survivalist end is not as many as we would like, but it is not insignificant" (p.69). Liedholm (1991) adds that "an important issue is to what extent inadequate access to finance, informal or formal, may have impeded this graduation process" (p.3). While it may be true that relatively few micro-enterprises are able to graduate into modern small and medium enterprises in the formal sector, it seems

\footnotetext{
${ }^{92}$ A fifth category not covered in Liedholm and Mead's typology might obviously be the examination of dead enterprises - those that have closed. See, for example, Tellegen (1997) who includes in her study of rural enterprises in Malawi ex-entrepreneurs, or those that have stopped running an enterprise.
} 
more likely that those engaged in MESE will be able to graduate into entrepreneurial selfemployment proper (fig.3.2).

This being said, very large numbers of micro-enterprises at the more subsistence end of the enterprise continuum will remain unable to overcome the barriers that inhibit graduation to a more successful, dynamic, IME activity.

Palmer (2004a) outlined a theoretical lifecycle of an enterprise and how graduation is impeded by two main growth ceilings (fig.3.2.) which serve to keep very large numbers of owners as what Liedholm and Mead (1999: 84) call "non-growing enterprises".

\section{Fig.3.2. The positions of the two 'growth ceilings' present in the lifecycle of an enterprise}

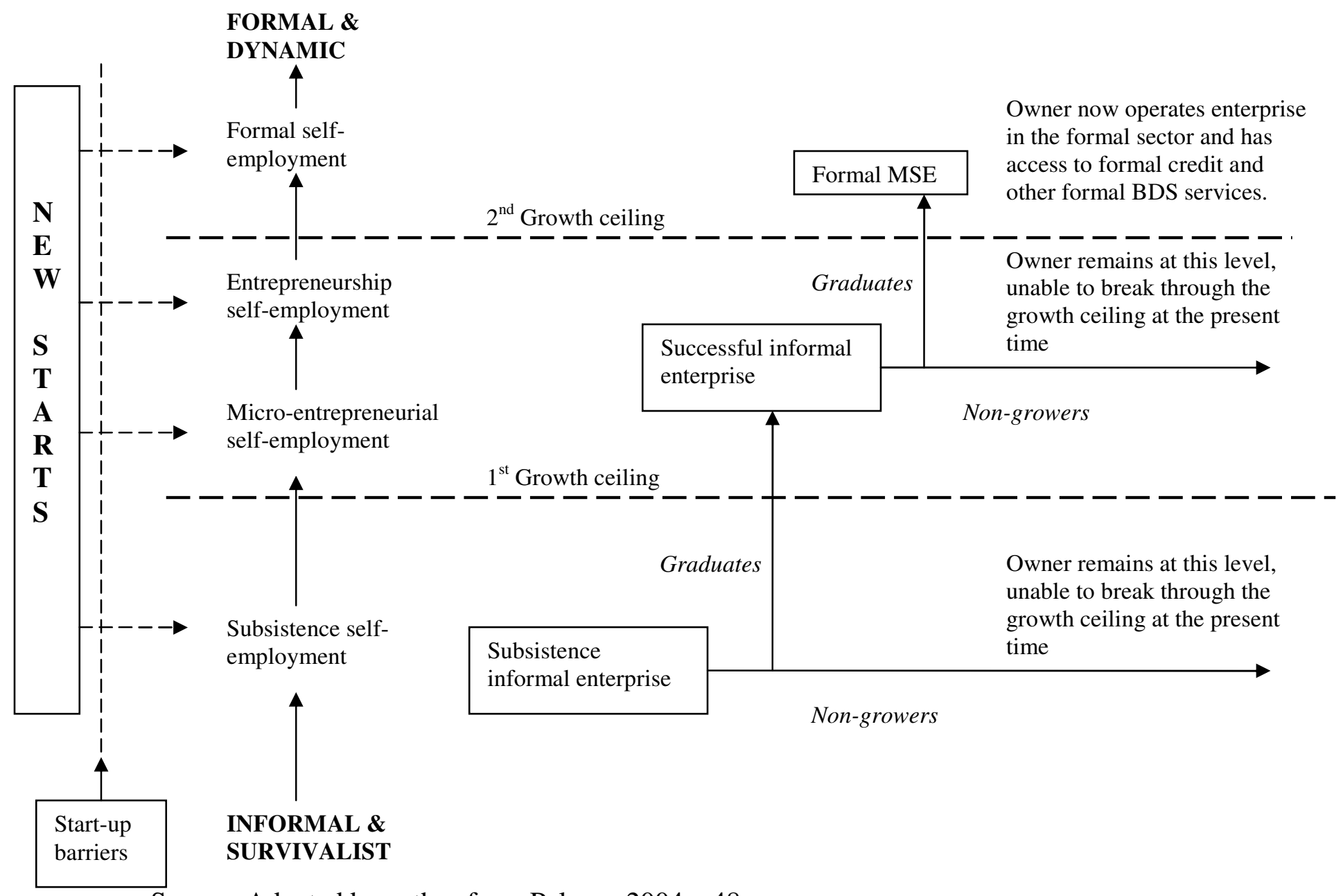

Source: Adapted by author from Palmer, 2004a: 48. 
In developing countries the vast majority of new-starts enter enterprise self-employment towards the lower end of the MSE continuum in the informal economy. However, depending on personal/family background, access to financial and social capital, some new-starts may be more able than others to overcome start-up barriers, and hence start self-employment activities from a higher level (fig.3.2.). ${ }^{93}$ Indeed the age of a potential enterprise owner often determines their ability to overcome start-up barriers and to participate in entrepreneurship (Chigunta et al., 2005; Hoppers, 1994). Hoppers (1994) comments that age has implications for the professional maturity, outlook on life and general experience of male and female youth in the urban informal sector. Chigunta et al. (2005: 29) add that "younger youth are less likely to have the resources, social networks, business contacts, and work experience needed to engage in enterprise activities." The two (financial) growth ceilings identified by Palmer (2004a: 49-50) include:

\section{Graduating past subsistence type self-employment $-1^{\text {st }}$ Growth ceiling}

Growth past subsistence level is constrained by saturated, low-income or dispersed markets, by the lack of access to social and enterprise networks, and the (partly related) difficulty of getting fixed or working capital (Palmer, 2004a; b). Typically owners might underestimate the amount of working capital that the enterprise will require or overestimate the amount of profit it will generate. Often new enterprise owners might give up small-scale commercial farming for their new activity and not invest wisely the higher than normal profits they are likely to receive during the first year or so of the enterprises existence. ${ }^{94}$ Since enterprise owners of this sort permanently have financial problems, suppliers are likely to be less keen to advance credit to them. In order to attract business to their enterprises new owners often extend credit to customers and, in so doing, tie up substantial parts of their dwindling working capital. Moreover, customers often take advantage of owners' needs to make a sale by forcing down the price. Thus not only do these owners have very little working capital, but the profits they make are too small to reinvest in enterprise expansion/diversification.

\footnotetext{
${ }^{93}$ Fig.3.2. concerns start-up, non-growth and graduation. However, enterprises and owners can obviously move in the opposite direction; enterprises can shrink, can move from the formal to informal sectors, or more from more dynamic to subsistence types, or close down altogether!

${ }^{94}$ Enterprise owners in rural Ghana talk of an enterprise honeymoon period (Palmer, 2004a). "This is approximately a year-long period following the inception of the enterprise in the rural community when people are more interested in the new enterprise and hence profits for this period are atypically high when compared to future years" (ibid.: 45).
} 
There are two main reasons why many enterprises experience a ceiling to grow beyond the subsistence stage, including:

- Their inability to participate fully in the informal credit market since suppliers and customers often exploit the owners need for credit to get a cheaper price (customer) or a bigger profit (supplier) for themselves. Often the owners have exhausted their own initial savings through mis-management or short-sighted planning;

- Subsistence-type enterprises are usually unwilling to take the risk of trying something new (such as expanding) that might cause their enterprise to fail. From their perspective it is better to be sure of a little profit, than try to get more profit but risk losing all. Buckley (1997) suggests that the closer an enterprise owner is to "the margin of basic survival the harder it is to be entrepreneurial because risk of failure increases" (p.1091).

\section{Graduating from the top tier of the micro-enterprise spectrum to the formal sector $-2^{\text {nd }}$ Growth ceiling}

The second ceiling to further growth is typically experienced by those at the higher end of the IME spectrum, those enterprises that have expanded as much as they can using mostly informal financial means. At this stage they reach a credit ceiling.

As enterprises grow, informal lending bodies become less able to satisfy their financial demands: larger loans over longer periods (Duggleby, Aryeetey and Steel, 1992; Liedholm 1991; Meghir 1991). Aryeetey (1996) notes that the type of credit that many small borrowers desire in growing economies (a loan of about $\$ 1000$, with interest rates much less that $30 \%$ pa and a maturity of about 18 months) cannot be met by informal intermediaries and hence this leads to "an obvious gap in the credit market... [as this group of potential borrowers] become too big for informal finance and yet too small for formal lenders" (p.12). Palmer (2004a) adds that in Ghana more dynamic MSE owners are not too small for formal lenders since they can access rural bank loans for example. Rather the rules that surround formal lending inhibit MSEs from getting access to loans of useful size. 


\subsubsection{Summary}

This section discussed IME start-up and growth in relation to the various types of enabling and disabling environments which were discussed earlier in this chapter. A series of models representing typical pathways to self-employment were described.

\subsection{Conclusion: assumptions and challenges of the school-skill-enterprise link}

As a result of discussion in this chapter, implications arise for the way that the school-skillenterprise link in SSA should be conceptualised. These include that:

Multiple pathways, differentiated by gender and poverty status, through education and skills training to enterprise exist and youth often combine both a period of formal schooling with (multiple forms of) skills training and experience. These multiple skill pathways are likely to be different for the rich and poor alike. This implies that the usual years of schooling measure used in econometric studies of education fails on two main counts: ${ }^{95}$ firstly it fails to pick up the effect of how formal schooling combines with other (multiple) skills acquisition strategies; and, secondly, from a poverty reduction perspective, the usual studies do not differentiate between youth wealth categories which means that there is a dearth of information related to how the poor and nonpoor access and utilise multiple skills acquisition strategies. The outcomes resulting from an education and training pathway of formal education followed by formal or informal skills training needs to be examined in more depth.

The recognition that the development of skills depends to a large degree on the delivery context of the training means that the quality variable needs to be given high priority. Moreover, the quality of education and training can vary significantly during any of the multiple stages a youth pursues, and is certainly not uniform for the rich and poor. The standard years of education measure, therefore, further fails to take account of the quality of education and training received prior to enterprise.

\footnotetext{
${ }^{95}$ For a review and critique of these approaches (e.g. the rate of returns to education estimates) see King and Palmer (2006b), Palmer et al. (2007) and for a review and critique of this quantitative material specifically related to Ghana see Palmer (2006a).
} 
The recognition that the utilisation of skills is enabled or disabled by other factors, external to the education and training system, implies that studies have to take much more account of contextual issues. Again, the standard years of schooling measure says nothing about the wider context in which the education or training was delivered. Some earlier studies of education and farm productivity made the distinction between modern and nonmodern environments (e.g. Lockheed et al., 1980), but it is not routine practice to discuss the possible impact that different sociocultural, historical, economic and political environments may have on skills utilisation (or skills development for that matter). It is likely that school-skill-enterprise interaction is highly dependent on context, or rather, on the type of internal and external enabling environments within which the training occurs and through which it is translated into employment outcomes.

Recognising the informal economy as a heterogeneous entity, that can, analytically, be divided into subsistence-orientated enterprises and entrepreneurial-enterprises, ${ }^{96}$ implies that skill needs are different for different parts of the informal economy. The types of work that the poor have are more likely to be of the subsistence type, rather than of a more dynamic kind. Ease of entry into informal economic activities is only true at the more subsistence-orientated end of the informal economy spectrum. It is likely, therefore, that the poor construct a portfolio of multiple low-profit informal activities. There remain considerable barriers to entering the more profitable informal activities. Understanding the social and economic barriers to enterprise start-up is therefore crucial. The nature of employment - for the majority - in developing countries further complicates a neat school-skill-enterprise link. Informal economy employment has traditionally been seen as an urban phenomenon, and has usually been examined in the context of individuals engaging in distinct types of work (in farm or nonfarm work), or in distinct types of activities (e.g. carpenters, dressmakers etc). However the nature of enterprise in developing countries means that the assumption of one man, one job/enterprise does not hold true for many, especially the poor.

The first three chapters have covered the international literature, especially on Africa. The following chapters examine the interaction amongst school, skill and enterprise in the context of enabling/disabling environments in Ghana.

\footnotetext{
${ }^{96}$ Self-employment in more entrepreneurial enterprises might be further sub-divided - as noted above - into MESE activities and entrepreneurial self-employment proper.
} 


\section{Chapter 4: Ghana's Policies on Skills Development, Work and Enterprise in relation to the Economic, Social, Historical and Political Environments, early Nineteenth Century to 2000}

\subsection{Introduction}

This chapter explores the history of policy and practice vis-à-vis skills development, work and enterprise in the Gold Coast ${ }^{97} /$ Ghana from the early nineteenth century to 2000. It is divided into three sections; the nineteenth century; early twentieth century to 1950s; and post-independence to 2000. Each section examines policy and practice of skills development in relation to the economic (especially the labour market), political and social environments at the time. It explores the remarkable consistency in the way TVET has been reworked as the solution to un/underemployment over the decades from the early colonial period to the present.

\subsection{Gold Coast Policies on skills development in relation to the economic and social environments in the nineteenth century}

\subsubsection{Early skills and schooling: artisans, castles, merchants and missionaries}

Early formal schooling in the Gold Coast became, for a time, a subsidiary function of the large merchant companies who operated schools usually attached to castle chaplaincies which preceded the main mission activity in the Gold Coast by nearly a hundred years. ${ }^{98}$ In 1821 provision was made from Crown funds to set up a series of government schools, though these were later absorbed by missions.

It was not until the late-nineteenth century, with the rise of European missionary societies, that the development of educational facilities really took off. ${ }^{99}$ Two of the most important missions were the Wesleyan Methodist Missionary Society and the Basel Mission Society.

\footnotetext{
${ }^{97}$ The term 'Gold Coast' subsumes the Ashanti Region and the Northern Territories (which were both administered separately until 1936), Togoland (after 1922) and the Gold Coast Colony (established 1874).

${ }^{98}$ It was the Portuguese who established the first school at Elmina Castle (mid-sixteenth century). Other castle schools were opened by the Dutch (Elmina 1644), Danes (Christianborg 1722) and British (Cape Coast 1751).

${ }^{99}$ In fact, at the turn of the twentieth century most schools were still Mission-run "to such an extent that Christians were commonly called sukul-fo, "people of the school"” (Kimble, 1963: 74).
} 
The arrival of the first Wesleyan missionaries in 1835 led to a number of educational institutes being established, ${ }^{100}$ with a largely academic focused curriculum (Kimble, 1963).

The Basel Mission Society, a Swiss missionary group (Gannon, 1983), arrived in Accra in 1828 seven years before the first Wesleyans. ${ }^{101}$ The Basel Mission took a different approach to schooling than the Wesleyans, focusing on agricultural and industrial training (Ayandele, 1971 in Ahadzie, 2003; Kimble, 1963). ${ }^{102}$ A nineteenth century representative of the mission remarked:

The Basel Mission, recognizing the fact that industrial training is a most important factor in the education of a heathen un-civilised nation, tried to exercise an every-day influence on the people, making the spade and other instruments go hand-in-hand with the Bible. (Rottmann, 1905 cited in Foster, 1965a: 87)

Outside of these early formal schools, skills formation and replication among the early occupational specialists - e.g. the goldsmiths, weavers and wood-carvers - took place through informal apprenticeship learning. Silver (1981) describes the activities of carvers in Asante and notes the growth of this trade in response to the massive commissions of wooden ceremonial objects by the Asantehene. Apprenticeship in the pre-colonial period existed largely as a means to reproduce skills among kin or communities, though occasionally outsiders came to train in communities known for specific trades. Silver (1981) notes that the duration of apprenticeship for outsiders took longer than for children from the carving community since "they had had no informal exposure" (p.43). Moreover the "fees for training nonvillagers were substantial... [and] the entire town council had to vote to accept the recruit before his apprenticeship could begin" (ibid.). Communities, therefore, often had an effective monopoly over certain trades, like carving, and the associated reproduction of skill through apprenticeship training.

While carvers "certainly received prestige for their work... there was no indication of outright payment for services rendered" (ibid.). Carving work during pre-colonial times, therefore, was likely to have largely been non-commerical regalia production. But with the defeat of the Asante Kingdom at the end of the eighteenth century, combined with the increased monetisation of the colonial economy and the emergence of a free labour market, artisanal production was to shift from a largely non-commercial to commercial function.

\footnotetext{
${ }^{100}$ By 1858 there were 29 schools, mostly along the coast, with 1,130 pupils ( $80 \%$ boys) (Kimble, 1963).

${ }^{101}$ The high mortality among the Basel missionaries meant that by 1841 they had failed to establish a single school. It was not until 1843 that the first school was opened after the mission relocated inland.

${ }^{102}$ By 1858, the Basel Mission had 13 day and 4 boarding schools with about 250 pupils (Kimble, 1963).
} 


\subsubsection{Government and missionary attempts to provide technical, vocational and agricultural education}

In the early 1840s "an oversupply of graduates" (Foster, 1965a: 89) from castle and mission schools had become visible and, by 1850 there were indications that this "supply of literates was already exceeding... demand" (ibid.: 67). As a response to this, the idea of creating agricultural and industrial institutions became more popular. From this point on, the view that school-based TVET could ease or solve the problem of unemployed school leavers was to remain a recurring theme in the minds of Gold Coast, and later Ghanaian, officials and politicians.

The literature of the mid-nineteenth century comments extensively on the bookish character of African education and on the need to re-orientate this towards work through the provision of technical, vocational and agricultural education. The most systematic expression of this view came in the 1847 report by the Education Committee of the Privy Council to the Colonial Office.

The 1847 report outlined the principal objectives of education in colonial areas and included specific mention of the need to provide practical training in handicrafts and agriculture. It was one of the earliest explicit expressions of the belief that the provision of school-based TVET was the key to economic development in the British colonial territories.

As a response to criticism of their bookish curriculum, the Wesleyan missionaries, in the 1850s, experimented in agricultural education through the creation of several farm schools in Fanti territory. However within ten years every one of these institutions had closed through lack of support.

In contrast, by the end of the nineteenth century, the Basel Mission had made great efforts to develop a system of technical, vocational and agricultural institutions in the southern interior areas.

The mission activity in the Gold Coast, particularly that of the Basel Mission, is likely to have been the main source of training for the first carpenters and tailors and may well have contributed to the development of such a varied, vibrant and widespread apprenticeship system in Ghana. While apprenticeship in more traditional trades (carving, weaving, gold-/black-smithing, beadmaking) had been around for hundreds of years, the TVET provided by the Basel Mission 
undoubtedly introduced new trades into Ghana (Agbodeka, 1992; Akyeampong, 2002; Peil, 1970; Quartey-Papafio, 1914).

In 1882 an Education Ordinance in the Gold Coast tried to establish a series of industrial schools in which pupils were meant to spend no less than 10 hours per week in practical classes on handicrafts, manufacturing processes and agriculture (Foster, 1965a). Government grants were offered to encourage educational establishments to teach technical and agricultural subjects. ${ }^{103}$

\subsubsection{The early development of the colonial exchange ${ }^{104}$ and informal economies}

In order to understand the relationship between the early formation of skills and the labour market it is necessary to examine the labour market environment at this time.

Fyle (2002) comments that “...pre-colonial business patterns were... similar to informal sector systems" (p.30). In much of pre-colonial Ghana, particularly in Asante, the social division of labour, petty production, trade and monetisation were advanced (Adebayo, 2002; Dzorgbo, 2001; Iliffe, 1983; Kay, 1972; Kimble, 1963).

In Asante the pre-colonial state played an important role in facilitating indigenous enterprise by enforcing a single currency (gold dust) and by helping to reduce transportation costs by making villages along major routes responsible for their upkeep (Austin, 2005). Indeed the Asante carried out significant trade with North Africa across the Sahara (primarily gold) and with the Europeans (primarily slaves) through their coastal forts. Following the abolition of the slave trade in 1807 the British attempted to establish legitimate trade with the Asante and gold became the main trading medium (Arhin, 1972; Austin, 1995; Kay, 1972). Pre-colonial nonfarm enterprise activity in Asante included artisanal activities (blacksmithing, goldsmithing, weaving/spinning, pottery, carving, leather-craft, canoe-making and bead-making, small-scale gold/bauxite mining) ${ }^{105}$ and trading (food-crops, cooked food and forest products) (Austin, 2005).

\footnotetext{
${ }^{103}$ This Ordinance cannot have been very successful, since in 1908 and 1909 new education reforms again attempted to make the education system more orientated towards work, though again with little success (Kimble, 1963).

${ }_{104}$ The colonial exchange economy refers here to the official transactions taking place within the recognised part of the colonial economy (and concerned with European trade).

${ }^{105}$ See Shaw (1945) for an early account of small-scale bauxite mining.
} 
The labour market in the nineteenth century and the early colonial period was, however, restricted. Outside the emerging colonial economy (on the coast), free labour markets were not the norm and were characterised by slavery and pawnship. In Asante, for example, craft occupations (such as carving, noted above) were often filled by slaves or by free people who were nevertheless kept in villages whose function was to perform specific crafts. A free labour market emerged later, typically involving freed slaves who were also amongst the first to convert to Christianity. Asantes of high birth came late to Christianity and the labour market (see Austin, 2005 on slavery, pawning and the labour market in Asante). In 1874 the Governor of the Gold Coast Colony and Protectorate abolished slavery, slave-trading and pawning, though it largely continued until the British formerly annexed Asante (1902) and the advent of a colonial economy in this area "made traditional forms of involuntary labour expendable" (McSheffrey, 1983: 368; cf. Kimble, 1963).

The colonial exchange economy developed as a result of the activities of the colonial powers and came into direct contact with the pre-colonial trading and bartering activities that existed. In particular it was the development of early cash crops, initially palm oil and palm kernels and later rubber and cocoa, ${ }^{106}$ combined with extractive enterprises, such as gold mining, ${ }^{107}$ and other commercial ventures that contributed to the development of the colonial exchange economy.

In brief the overriding objective of the British in the Gold Coast was to manipulate the economy on the one hand to be suppliers of raw materials for export and on the other to promote consumption of British goods (Arhin, 1979; Fyle, 2002). Though formally neutral in business matters the British administration in its West African colonies had a distinct bias towards expatriate firms (Hopkins 1966 in Olukoju, 2002). Indeed the larger companies exerted a great deal of influence over the colonial administration (Meredith, 1988).

As a result of varying durations of European contact, the development of this colonial exchange economy was unsurprisingly uneven throughout the Gold Coast. The coastal areas, especially the towns, had been subjected to long periods of European contact and had seen a concomitant growth in the exchange economy (even at the beginning of the eighteenth century). The

\footnotetext{
${ }^{106}$ Rubber exports only really got underway in the mid/late-1880s (Arhin, 1972) and cocoa production did not really take off until the start of the twentieth century.

107 The first attempts to develop gold mining with European capital were not made until 1877. Prior to this gold dust was also traded and was the second largest export in the 1850-74 period (after palm oil) (Kimble, 1963).
} 
development of urban coastal towns saw the concomitant development of an increasingly differentiated occupational structure connected with European trade. But,

European expansion was not to lead to any dramatic widening in vocational opportunities open to Africans. During the first half of the nineteenth century these had been confined to a few clerical posts with commercial companies or government. (Foster, 1965a: 89)

The establishment of the Gold Coast Colony in the south in 1874 and the annexing of Asante in 1902 would have facilitated the spread of the colonial exchange economy. By contrast the north retained largely subsistence economies.

The emergence of this colonial exchange economy is likely to have stimulated the development of informal economic activities. With the increasing monetisation of the economy as the colonial period progressed, a problem arose for the indigenous population; how to obtain this new currency. ${ }^{108}$ Where previously socio-economic obligations were either paid in kind or by precolonial currencies, money (British silver) became increasingly required (Adebayo, 2002; Arhin, 1979; Arhin, 1995). This was exacerbated by the increased demand for foreign manufactures. This induced many into artisanal activities and petty trading as a means to obtain cash incomes, since there were too few official jobs in the colonial economy. ${ }^{109}$

As the pre-colonial enterprises (noted above) became monetised, a colonial informal economy developed - comprised of all those earning money outside of the recognised colonial economy. The arrival of missionaries and other Europeans not only brought increasing monetisation to these pre-colonial enterprises, but also new trades (e.g. carpentry and masonry) ${ }^{110}$ and foreign manufactures which led to the demise of some pre-colonial enterprises (e.g. spinning).

Small-scale commercial activities (especially female market trading) boomed during the colonial period (Clark, 1994; Howard, 1978; Rimmer, 1992). In neighbouring colonial Nigeria, "urbanization opened new opportunities to women in the informal sector" (Apena, 1997: 202), and despite female marginalisation in the formal colonial economy, "they controlled the informal economy especially in the supply of food items" (ibid.). The colonial economy led to the

\footnotetext{
${ }^{108}$ By 1889 British silver predominated as the currency of exchange in British controlled areas.

109 The introduction, by the British Treasury, c. 1903 of small denomination coinage "helped considerably to widen the area of internal exchange" (Kimble, 1963: 38).

${ }^{110}$ Colonial documents from the mid-1930s make mention of numerous rural industries (Gold Coast, 1937).
} 
empowerment of men in the colonial recognised sector ${ }^{111}$ and the concomitant empowerment of women in the informal sector (as women moved into previously male dominated spheres, like trading). These unenumerated, unregulated, women traders, and by inference the informal sector more widely, were largely ignored by the colonial government and thought to operate outside of the economy (Aryeetey and Bortei-Doku, 1996); they were not recognised. It is precisely the fact that these sorts of activities in the Gold Coast could operate outside of colonial regulations that they became so widespread (cf. Martin, 1988).

In the Gold Coast, as in other British West African colonies, formal banks were established primarily for expatriate firms and the formal colonial economy (Adebayo, 2002). Africans were largely excluded from these formal mechanisms (Adebayo, 2002; Falola, 1995; Kimble, 1963; Martin, 1988) and the majority of people continued to save and derive the initial capital for their business from the informal financial sector (Adebayo, 2002). ${ }^{112}$ Falola (1995) talks about the existence of the dualistic money market comprised of formal and informal institutions in the colonial period whose clients were predominantly expatriates and Africans respectively. In short most African "entrepreneurs with assets and ideas [had] to fall back on the informal institutions" (Falola, 1995: 169). ${ }^{113}$ The large amount of literature making reference to informal finance mechanisms in existence during this time in West Africa highlights their importance (Austin and Sugihara, 1993; Bascom, 1952; Falola, 1995; Hopkins, 1988; Kay, 1972; Partridge, 1910). Indeed with the monetisation of the economy and the associated increase in income-generating work, the pooling of cash resources in the informal sector rapidly expanded (Adebayo, 2002).

Since the discovery of the informal sector in the early 1970s (chap.2), very little literature has used the same terminology with reference to the colonial period (but see Apena, 1997; Fyle, 2002). Most literature on the colonial economy of the Gold Coast tends to concentrate on the activities of British firms/individuals and the indigenous African bourgeoisie that dealt with them. Frimpong-Ansah (1991) rightly notes that the literature "is rather weak on the economic activities of the rest of the population" (p.55). Even though Hart $(1970,1973)$ discovered the informal sector, as Rimmer (1992) puts it, it "doubtless exist[ed] already" (p.36).

\footnotetext{
${ }^{111}$ E.g. mining, cash-cropping, education, soldiering, trading, government work (including clerks) and missionary activity.

${ }^{112}$ Pre-colonial enterprises in Asante had recourse to three main sources of finance: supplier's credit, retained profits and equity participation (with conjugal or matrilineal family) (Austin, 2005: 135-138).

${ }^{113}$ Many still relied on getting credit informally through the pledging system; either property (e.g. kente clothes, gold ornaments), persons (through the pawning system) or land (e.g. cocoa farms) (Austin, 2005; Kimble, 1963).
} 
Fyle (2002) describes the colonial informal economy in West Africa as "refer[ring] to businesses outside what colonial rule came to establish as formal business operations" (p.29). The recognised colonial economy was pursued at the expense of the informal micro-enterprise (IME) economy: "production and trade not primarily affected by western patterns" (ibid.: 33).

\subsubsection{Summary: the difficulty of establishing TVET during the nineteenth century}

As noted above, both the Basel missionaries and the colonial educationalists made keen attempts during the second half of the nineteenth century to establish TVET in response to the oversupply of academic graduates and doubt over the suitability of general education.

However these early attempts at promoting school-based TVET failed largely due to "a series of factors operating outside the schools themselves" (Foster, 1965a: 57, emphasis added). Prominent among these factors were two aspects of the labour market environment of the period.

Firstly, as early as the mid-nineteenth century it became apparent that wage-employment opportunities for skilled artisans were limited in the Gold Coast. So limited, that some of the early graduates of the vocational Basel programmes, as well as graduates from traditional apprenticeships, migrated across SSA (e.g. to Nigeria, the Cameroons and the Congo) in search of employment and the opportunity to utilise their skills (Foster, 1965a; Quartey-Papafio, 1914). ${ }^{114}$

Secondly, during the nineteenth century the colonial economy's formal occupational opportunities stimulated demand for general academic education. Interest in school-based TVET was marginal. Parents and youth had little interest to go to school only to return to working in agriculture. For parents and children "[e]ducation meant one thing... the opportunity to enter more highly paid posts within the exchange sector of the economy" (Foster, 1965a: 66). Thus the most vocational type of education perceived of at the time was an academic education:

The African did not enter clerical employment because he had been to an academic secondary school; he went to an academic secondary school because it provided the most effective way of entering into such employment. (ibid.: 136)

\footnotetext{
${ }^{114}$ As a consequence of apprentices going to find work abroad, new rules concerning apprenticeship fees emerged (Quartey-Papafio, 1914).
} 
In this sense, Foster argues, academic education was more 'vocational' than vocational education proper. ${ }^{115}$ Moreover, a view emerged among those Africans in closest contact with Europeans that "came to attribute... material advantages to the mystique of... [academic] education" (Kimble, 1963: 62). They also saw that only those Africans that had been educated could hope to access employment as clerks, teachers or higher positions. ${ }^{116}$ Education was viewed as a way of "avoiding the manual labour which was traditionally allotted to slaves" (ibid.).

In fact these two elements of the nineteenth century labour market - the lack of formal jobs for TVET graduates and the preference for academic schooling - persisted throughout the twentieth century. The paradox, therefore, is why from the mid-nineteenth century to 2006, there were further attempts to promote TVET as the response to a growing unemployed school-leaver problem, without also fully addressing other factors in the labour market environment.

\subsection{Gold Coast policies on skills development in relation to the economic and social environments, early twentieth century to 1950s}

After 1901, following the defeat of the Asante Kingdom, the borders of contemporary Ghana were largely defined. ${ }^{117}$ The labour market environment at the beginning of the twentieth century still offered few opportunities in the recognised economy and economic development was negligible: gold mining (using European capital) had commenced in 1877, but its development was very slow; cocoa production did not really take off until the start of the twentieth century, though its advent provided farmers with new opportunities to earn cash incomes; the main exports were still palm oil and palm kernels. However, the emancipation of slaves and pawns (in Asante in 1902) led to the development of a free labour market (Austin, 2005; Kimble, 1963).

\footnotetext{
${ }^{115}$ King (1971) makes a similar point.

${ }^{116}$ In the 1920s, James Aggrey (Aggrey of Africa) was to become a prime case in point. His return to the Gold Coast as the only black member of the 1920s Phelps-Stokes Commission caused a stir among Africans. Aggrey was born in the Gold Coast and had been in the USA for 20 years teaching and studying. His academic educational background made a large impact on those Africans he spoke to about the need to make education more relevant to work. Everyone knew that he had achieved his important position not through TVET but through academic schooling. He thus became, in the minds of many Africans, proof of the value of academic above vocational schooling (see Smith, 1929).

117 The Gold Coast Colony had been established in 1874, but it was not until 1902 that Asante was annexed. In 1918, following the defeat of Germany, part of German Togoland was ceded to the Gold Coast.
} 


\subsubsection{Changes in the labour market and economic environment up to World War One $(W W 1)$}

Between 1898-1919 the colonial government's main economic activity was to develop a railway system in the south (Kay, 1972) to facilitate movement of goods within the colony.

As noted above, the opportunities for employment in the colonial exchange economy at the start of the twentieth century were not great in the southern areas of the Gold Coast. By 1912 it had become apparent that in the Northern Territories too there were not sufficient recognised jobs in the labour market. The acting Provincial Commissioner of the Northern Territories commented at that time that since there were not sufficient job opportunities, education and technical training should not be expanded too quickly, asking: '[w]ill these educated youths go back to work on the farms?" (Wheeler, 1912 cited in Thomas, 1974: 434). He went onto note that

As regards the teaching of carpentry and mason's work; if you teach boys trades you must find them well-paid work locally, or send them to look first elsewhere. How many masons and carpenters would the Navaro [Navrongo] District support? Not many at present. For the time being we can only afford to go very gently with education, both book and technical in my opinion. (ibid.)

A few years later this plea received the support of the new governor of the Gold Coast; Sir Gordan Guggisberg. ${ }^{118}$ Following his arrival in the Gold Coast "emphasis was to be placed on relating education to the rural economy" (Thomas, 1974: 429) in the Northern Territories. Learning from the mistakes of the south (Ashanti and the Colony) "efforts were made to guarantee that the supply of literates did not exceed the new job opportunities in education and the expanding technical departments" (ibid.). ${ }^{119}$

As a result of WW1 the labour market became slightly more open to the indigenous population seeking work in the colonial economy. Killingray (1978) comments that:

The labour shortage and the withdrawal of white artisans and blue collar workers for war service opened up a range of jobs and promotion opportunities for Africans. They became engine drivers on the railways, fitters and mechanics in the mines... (p.53)

\footnotetext{
${ }^{118}$ In 1919 Guggisberg was appointed Governor of the Gold Coast - a position he was to retain until 1927.

${ }^{119}$ See Bening (1990) on the development of education in northern Ghana.
} 
A further consequence of WW1 with regard to skills development was that the Basel Mission effectively stopped functioning; since 36/50 foreign Basel missionaries at the time were German it was suspected of pro-German sentiment and actions (Gannon, 1983). Consequently in 1918 the Gold Coast Government confiscated the Basel Mission properties and its trading company (ibid.). ${ }^{120}$ Guggisberg noted in 1921 that

[t]here can be no doubt that the severest blow dealt by the War to the Gold Coast was the withdrawal of the Basel Mission. The education given by that Mission was practical and good, and it never seemed to lack funds or recruits. (Guggisberg, 1922: 84)

This comment, that Basel education (with its TVET focus) did not lack recruits suggests that there were those Africans that were keen on TVET. This somewhat undermines Foster's prejudice about trade and industrial education - that it was distinctly unpopular. ${ }^{121}$

As noted earlier, the truly traditional apprenticeship activities (e.g. carving, weaving) had been supplemented in the mid-nineteenth century by other trade activities (e.g. carpentry, masonry) as a result of the training provided by the Basel mission (and early government industrial schools). Since the arrival of the first cars in the Gold Coast, around the 1920s, apprenticeships in mechanics became more common, especially in urban areas (Peil, 1970). ${ }^{122}$ Initially these mechanical apprenticeships were undertaken in workshops of the Public Works Department (Guggisberg, 1922), but shortly afterwards this type of training would have spread to the colonial informal sector. ${ }^{123}$ Indeed with the introduction of railways, public works, telegraphs, marine departments, expatriate motor mechanical workshops "a cadre of Africans was trained in technical trades that had no obvious parallels in traditional society" (McLaughlin, 1979: 30).

\footnotetext{
${ }^{120}$ In 1854, in order to provide funds for its missionary activities in the Gold Coast, the Basel Mission had established a trading company which gave part of its profits to mission activities.

${ }^{121}$ However, Guggisberg's opinion over the popularity of the Basel Mission schools was biased, since he was very clearly in favour of school-based TVET (chap.4.2.2).

${ }_{122}$ Motorised trucks were imported into the Gold Coast for carting cocoa some 10-15 years before 1920 .

${ }^{123}$ Other types of apprenticeship, such as radio repairing apprenticeships, were not to be found in the country until the late 1950s/early 1960s (Peil, 1970).
} 


\subsubsection{From Guggisberg's Ten Year Development Plan and renewed push for TVET during the 1920s, to the 1930s-40s depression, retrenchment and war}

Guggisberg's Ten Year Development Plan outlined a large number of development activities he hoped to accomplish between 1919-1929: ${ }^{124}$ the focus being on developing transportation infrastructure (harbour, railways, roads), but also including development of the water supply, drainage, hydro-electric works, public buildings, town improvements, telegraphs/telephones and maps (Bourret, 1949; Kay, 1972). Guggisberg's intention to focus on transportation infrastructure was to expand commerce in the Gold Coast and this is indeed what occurred: total trade 19201926 was almost double what it had been 1913-1919 (Bourret, 1949). The improvements in transportation infrastructure facilitated the spread of cocoa farms and freed large numbers of head-carriers who could then work in the cocoa or mining sectors where demand for labour was high (ibid.). Indeed Guggisberg's focus on developing infrastructure as a means to support private sector development anticipated much later priorities (chap.9).

While the development of transportation infrastructure was high on Guggisberg's agenda, he was also deeply concerned by the importance of education for development, regarding it as the keystone of progress (Williams, 1964). But it is the type of education that is of particular interest to this thesis; throughout Guggisberg's period as governor the basis of education was repeatedly re-orientated towards technical and agricultural subjects - a response to the growing phenomenon of semi-educated youths with a disdain of manual labour (Gold Coast, 1925-6).

In 1921 Guggisberg gave an address to Britain's Royal African Society highlighting what he envisaged as the central role education could play in the "progress [of the "Native Races of the country"] towards the attainment of those conditions of modern civilization which are best suited to the country" (Guggisberg, 1922: 82). Guggisberg bemoaned the focus given to book-work over hand-work in the system of primary schools in 1921:

The general result is that we are turning out annually between six and seven thousand youths who are fitted for employment as clerks and very little else. We are, in fact, being flooded gradually by what can only be described as a semi-educated class of Native. (ibid.: 83$)^{125}$

\footnotetext{
${ }^{124}$ The Ten Year Plan was ended prematurely in 1927 when Guggisberg's position as governor ended (Kay, 1972).

${ }^{125}$ Guggisberg assumed, of course, that academic schooling in some way orientated youths' minds away from manual work and channelled them into wanting jobs like clerks.
} 
Guggisberg later repeated this view that the cause of unemployment was the type of person developed through a particular type of education:

[O]wing to their [semi-educated youths] disdain of manual labour, there is annually less employment... Failing employment in an office, and strongly imbued with an unhealthy dislike to manual labour, they fall a natural victim to discontent and... unhappiness. (Gold Coast, 1925-6) ${ }^{126}$

Guggisberg (1922) noted that part of the government efforts being applied to "the defects of our present system" (p.85) involved providing more opportunities for TVET.

A year before his 1921 address, Guggisberg created a Committee of Educationalists to articulate a comprehensive education policy for the Gold Coast, ${ }^{127}$ which:

strongly advocated a plethora of manual activities such as gardening, woodwork, metal work, and clay work to overcome the 'mere bookishness' of school instruction. (Foster, 1965a: 149)

The committee also recommended the establishment of trade schools offering practical courses. In 1920 four government trade schools ${ }^{128}$ were opened that served to supplement the work of a government technical school established in Accra in 1909 (Kimble, 1963).

The 1920s saw interesting developments regarding TVET in the British colonies which had a profound impact on the way Guggisberg was to attempt to shape education in the Gold Coast. In 1923 the Colonial Office established an Advisory Committee on Native Education in the British Tropical African Dependencies which was to provide the first general colonial educational policies of the British since the 1847 Education Committee. One factor that led to the creation of

\footnotetext{
${ }^{126}$ Gutkind (1969) comments that unemployment can lead to political instability as the unemployed get "agitated and often violent" (p.359). Ghana's draft TVET policy document (GoG, 2004i) comments that without sufficient opportunities the youth will be a threat to peace and stability. Ghana's National Youth Employment Programme (GoG, 2006c) (chap.5), which intends to create over 150,000 jobs 2006/07, states that this will help develop character, lead to self-discipline and patriotism and therefore dispel discontentment.

${ }^{127}$ By the early 1920s, both the former Swiss Basel missionary schools and the German Bremen Mission schools (formerly in German Togoland) had come under the control of the British. At the close of WW1 $60 \%$ of all schools were under government control compared to just $8 \%$ in 1914. This made educational reform easier (Kimble, 1963).

${ }^{128}$ In Yendi, Mampong-Ashanti, Asuantsi and Kibi.
} 
the 1923 committee was the first Phelps-Stokes Report (see Jones, 1922). ${ }^{129}$ This report had the general aim of re-orientating education in the African colonies to meet the needs of African people, "to provide them with elements of good agriculture... and to give them training in simple crafts and home economics" (Brown, 1964: 367).

Guggisberg adopted the Phelps-Stokes Report wholeheartedly and attempted to implement the policies in the Gold Coast to a greater degree than any other governor in any of the British African colonies (Foster, 1965a; Hamilton and Asiedu, 1987). ${ }^{130}$

Guggisberg's Sixteen Principles of Education (Martin, 1976; McWilliam and Kwamena-Poh, 1975; Williams, 1964) announced (though not for the first time) to the legislative council in February 1925, were the product of the Education Committee set up in 1920 and the influence of the Phelps-Stokes Report. ${ }^{131}$ The sixteenth principle was a call on the government to provide trade schools with a "technical and literary education that will fit young men to become skilled craftsmen and useful citizens" (Gold Coast, 1923: 204-205: italics in original).

In 1925 Guggisberg remarked on the "impossibility of either Government or the European trading community giving employment to all those who annually pass through the schools of the Colony" (Gold Coast, 1925: 62). He went on to say that:

There was a period when a clerk of any sort was greatly in demand... but those conditions no longer exist; I doubt very much whether five hundred clerks per annum are required to replace the normal wastage throughout the country. What employment is open to the remainder, roughly four thousand able-bodied and intelligent but wrongly educated youths[?]... Cocoa-brokers? There is a limit to this field of employment, indeed I am not certain that it is not decreasing. Storekeepers? Judging from the number of small stores already existing all over the country... there is not room for more than a small increase in this field of employment. (ibid.: 60, emphasis added)

[However, in] the field of manual labour... there are ample opportunities for the educated product of our primary schools. Mechanics, carpentering, motor driving, engine driving, and other skilled trades are all employment in which educated artisans can do superior and better paid work than the illiterate. (ibid.)

\footnotetext{
${ }^{129}$ The second Phelps-Stokes Report on East Africa was published in 1925 (Jones, 1925). For a critique of the Phelps-Stokes Commissions, see King (1971).

${ }^{130}$ Indeed Martin (1976) noted that Guggisberg was instrumental in getting the grant from the PhelpsStokes Fund that financed the later report (cf. Jones, 1922).

${ }^{131}$ Guggisberg would also have been influenced by his Director of Education who, in 1921, visited the Hampton and Tuskegee Institutes in the United States which had attempted to adapt education to meet the local needs of the economy (Martin, 1976).
} 
... the annual surplus in the supply of educated youths can only be absorbed by private enterprise either in the form of trade or of manual labour. (ibid.: 62)

These comments by Guggisberg are particularly interesting for a number of reasons; first he notes the changing demand for clerks in the formal colonial economy; second he reiterates the view that it is the type of education that impacts on occupational outcomes of youth; third, he comments that in the mid-1920s, there was already a multitude of small-scale trading activities and that new employment opportunities in trading were few; and, fourth, he identified small-scale manufacturing enterprise as the most promising destination for educated youth.

How then did Guggisberg's policies - emphasising school-based TVET as a means to re-orientate the youth towards manual work and hence reduce unemployment - materialise in practice?

On the positive side, Guggisberg's activities in the 1920s certainly provided a "driving force for the development of technical education" (Foster, 1965a: 150); by 1930 more than 55\% of expenditure for all government educational institutions went on trade and technical schools (ibid.). Moreover, as a result of the rapid take-up of cocoa production in Ashanti, purchasing power in the market expanded (Austin, 2005) which might have stimulated nonfarm economic activity, including demand for artisans. Guggisberg's Ten Year Development Plan provided employment opportunities for many artisans in the 1920s, and Guggisberg even complained about a lack of artisans to work on the many infrastructure projects (Kay, 1972; Kimble, 1963).

However, due to a number of significant factors, it soon became apparent that this driving force and demand for artisans could not be sustained.

Firstly, there was staunch criticism from educated African nationalists regarding what they interpreted as an inferior type of education for Africans. ${ }^{132}$ Indeed the early financial support given by Africans ${ }^{133}$ was for establishing academic, western-type, schools - not technical or vocational schools (Foster, 1965a). Guggisberg's attempts to add technical and agricultural subjects into the curriculum of the schools were met with disfavour from leading Africans (Williams, 1964).

\footnotetext{
132 This came both from Africans in the diaspora and indigenous Africans from the Gold Coast, e.g. in the newspaper The Gold Coast Leader (Kimble, 1963: 114).

${ }^{133}$ E.g. the Fanti Confederation pledged, in 1871, to support schools in their areas.
} 
Secondly, as noted above, Africans in the Gold Coast generally had a very keen understanding of labour market opportunities and rightly identified work in the official colonial economy as more financially lucrative than any other type of work. Since entry to these lucrative opportunities was better facilitated through academic education, this type of education was more popular than vocational education.

Thirdly, providing school-based TVET was much more expensive than providing academic education - a cost that was not rewarded in the labour market and ultimately contributed to the demise of school-based TVET in the Gold Coast:

[J] unior trade schools... were very expensive in terms of the cost per student, and were abandoned a few years after Guggisberg left the Gold Coast. Their graduates were not looked upon with favour by expatriate employees, and there is no evidence that anyone else outside the Government looked upon them with particular favour either. (Williams, 1964: 300)

Fourthly, external shocks contributed to a tightening of occupational opportunities in the Gold Coast during the 1920s and 1930s. Martin (1989) notes that there was a broad economic downturn in the Gold Coast as a result of WW1 which, lasting through to WW2, led to declining terms of trade for cocoa and palm oil and thus hit the cash crop sector badly. The worldwide economic slump of the 1930s exacerbated this trend (Bourret, 1949). ${ }^{134}$

Fifthly, at the same time Guggisberg was promoting TVET "there was evidence that unemployment among artisans and technicians was increasing" (Foster, 1965a: 150). Indeed "the fact that technical employment possibilities were even more limited [than academic employment opportunities] during the colonial period is conveniently forgotten" (ibid.: 138). ${ }^{135}$ In 1933 the Director of Education noted in response to a demand for increased TVET that "there was just no demand for technical employees on any scale and that the creation of new technical institutions could not create employment" ${ }^{136}$ This early acknowledgement that training itself does not create employment did not go far enough to counter what had become - and would remain - the underlying assumption of the skills development agenda in the Gold Coast/Ghana: that the

\footnotetext{
134 Government revenue was substantially reduced between $1928-1931$ (from $£ 3.7$ to $£ 2.2$ million), resulting in retrenchment and development project cut-backs (Bourret, 1949; Kay, 1972).

${ }^{135}$ This is somewhat of a generalisation and indeed goes counter to what Guggisberg was saying in the 1920s; that there was a shortage of skilled artisans to work on projects of the Ten Year Development Plan.

${ }^{136}$ Gold Coast Legislative Council Debates, 1933, in Foster (1965a: 151) emphasis in original. A World Bank (2004a) study reiterated this view that "training alone does not create jobs" (p.28).
} 
provision of skills training leads to employment, economic growth and poverty reduction. ${ }^{137}$ By 1935 the employment situation for technical graduates had become so openly bad that the governor was forced to observe that the enrolments into technical training might have to be limited in order to "avoid underemployment among trained artisans" (ibid.: 151). The government drive for school-based TVET had resulted in the unemployment of the graduates of these schools "few of whom attempted to found their own business" (ibid.: 134). Many of those trained in technical or vocational subjects ended up not using their skills due to lack of opportunities and often ended up in different roles altogether. ${ }^{138}$

Sixthly, at the same time as there were insufficient opportunities in the colonial economy for technical graduates, the agricultural labour market environment inhibited the utilisation of skills up to the late colonial period. Unlike the lack of formal employment for those with technical and vocational education, however, there were opportunities available in the cash-crop sector for the products of agricultural schools. But a number of factors meant that these kinds of opportunities were not being taken up (Callaway, 1963; Foster, 1965a; Gutkind, 1969; Nugent, personal communication 18.07.06):

- Better incomes could be achieved outside of farming;

- Undertaking cash-cropping meant residing in rural areas which had inferior amenities when compared to urban areas;

- Since illiterates could also take up cash-cropping, to return to the land was regarded as failing;

- Cocoa production was subject to violent price fluctuations, ${ }^{139}$

- Kin/community obligations in rural areas inhibited efforts to save and increase production through more modern methods;

- Parents perceived schooling not as a means to take their children back to agriculture, but as a means to move out of agriculture;

- Agricultural work, however profitable, was not identified with modernity;

- The lack of security of tenure in the absence of a land register meant that if land could not be found in a person's home village (especially if they were of slave origin) then options

\footnotetext{
137 See chap.9.

138 "By the end of the colonial period the products of technical schools were frequently obliged to find employment in the police force" (Foster, 1965a: 134).

139 Between 1908-1914 prices varied between $£ 38-49 /$ ton. By 1920 prices had risen to $£ 129 /$ ton, but plummeted to $£ 41 /$ ton in 1929 , £20/ton in 1930 and $£ 19 /$ ton in 1933 (Bourret, 1949).
} 
were limited - unless they headed for the cocoa frontier where the risks were offset by the financial rewards;

- Cash-cropping still used very traditional methods.

Perhaps one of the most significant of these points is the last - the agricultural labour market environment remained largely traditional and did not allow school graduates who had learnt about new farming techniques to use them. As noted earlier (chap.3.1.2), skills cannot be utilised effectively without the presence of a supportive environment. ${ }^{140}$ Foster makes this point about skills utilisation:

[M]odern agricultural techniques... may be known to farmers but they may not be utilized unless an institutional framework exists which provides real incentives for them to improve their methods and utilize the land more effectively.

... agricultural education was not likely to be successful until marked changes had already occurred in the agricultural sector. As with technical education the success of agricultural studies was largely dependent upon real opportunities being created in the economic and social environment of the Gold Coast. (Foster, 1965a: 155, emphasis added)

Indeed the real crux of the failure of Guggisberg's renewed push for school-based TVET was that both the economic and social environments at that time were unsupportive to the utilisation of these skills. It had been recognised, as noted above, by the Director of Education in 1933 that skills training itself does not create employment and yet this seems to have been what was expected of it. While Guggisberg's Ten Year Plan markedly improved infrastructure and led to significant increases in trade, apart from creating a short-lived increase in the demand for artisans, it does not appear to have gone far enough towards developing a sustainable demand for skilled labour. This, combined with the external economic shocks which impacted on country's labour market, meant that skills training was unlikely to be a popular option for the youth.

As a last comment on the outcome of Guggisberg's efforts, some twenty years later the Watson Commission $^{141}$ outlined the problem in almost identical terms (Kay, 1972), suggesting that the efforts made in the 1920s had largely failed to impact on unemployment:

\footnotetext{
${ }^{140}$ In the case of farming, these might include, among other things, fertilisers, pesticides, machinery and access to credit.

${ }^{141}$ The Watson Commission was set up to examine the disturbances in the Gold Coast in the late 1940s.
} 
It is realised that literary education alone is doing great harm in the Gold Coast... It is producing a youthful hooligan element in the towns as boys emerge from school to find a glut of clerks and to find themselves disinterested in, or not equipped for, other occupations. It is creating a false sense of values in which the dignity of labour is lost sight of. There must be an immediate expansion of craft, technical and vocational training. (Gold Coast, 1948a: para 374)

\subsubsection{The demise of TVET, the rise of academic schooling and the re-emergence of the unemployed school leaver problem}

The unpopularity of school-based TVET led to curricula becoming increasingly more academic during the 1930s until the period of self-governance in 1951.

By 1951 there were only 23 technical institutions with some 3,300 pupils - less than $1 \%$ of pupils in all types of school (Foster, 1965a). This might lead an observer to regard the neglect of technical education as a characteristic of British policy. The fact was that during the later colonial period the small number of technical and agricultural institutions compared to academic ones was not a result of government policy per se, but rather an outcome of both the unpopularity of school-based TVET among a population who favoured academic schooling, and the few opportunities for TVET graduates in the economy. Indeed during the late colonial period the academic secondary school was the fastest growing sub-sector of the educational system. This occurred in spite of the repeated government attempts, especially during Guggisberg's term as governor, to re-orientate education away from a primarily academic focus by promoting the growth of technical and agricultural schools.

The development of Achimota secondary school during the 1920s is an interesting case. The initial intention was to create a secondary school with a strong agricultural core as part of the curriculum but, as a result of pressure from youth, parents, educated Africans and the press, by 1951 Achimota had become a very academically orientated institution.

For the colonial period there are no adequate statistics regarding unemployment as registering as unemployed at a labour exchange was voluntary. However, the existence of large numbers of unemployed school graduates in the coastal towns of the nineteenth century was, nonetheless, suggestive of a wider problem. During the 1930s "it seems safe to conclude that the proportion of school leavers who got the jobs they desired decreased" (Kay, 1972: 44). 
Guggisberg's view concerning the relationship between academic education and unemployment is a view which remained in the minds of educators despite the failure of TVET during the 1920s. Indeed this view was still prevalent in the mid-1960s (Foster, 1965a) and persists up to 2006 (chap.5).

By the late 1940s as the unemployed school leaver problem was becoming more apparent, ${ }^{142}$ the root cause was again attributed to the academic nature of schooling and again school-based TVET was seen as the solution. But unemployment is largely an economic, not an educational problem. It was the general lack of occupational opportunities in the colonial economy of the Gold Coast, together with the unsupportive or non-existent policies for promoting MSE activities that were the cause of unemployment. The effectively stagnant economic growth from WW1 to 1951 meant that there were insufficient opportunities in any sector of the economy (ibid.) (with the exception of emerging opportunities in the cocoa sector).

At the time of self-government in 1951, 82\% of the labour force was engaged in subsistence/cocoa-farming or petty trading, while $18 \%$ were employed on a wage/salary basis. Two-fifths of those in wage employment were in the public sector (ibid.).

\subsubsection{Traditional apprenticeships and the labour market environment in the first half of the twentieth century}

The literature makes little mention of traditional apprenticeships during the colonial period and, despite the push for school-based TVET during the 1920s, apprenticeship probably remained the largest provider of skills training. The traditional pattern was for a father to apprentice his child to a known master at an early age (Silver, 1981). ${ }^{143}$ However as access to formal schooling became more widespread it became more common for a parent to send their child to school first and then to an apprenticeship afterwards (Quartey-Papafio, 1914). Indeed by the late 1930s apprenticeship had become an established institution (Ninsin, 1991). However, the prospects for apprenticeship graduates entering into entrepreneurial self-employment were low. Access to start-up capital was extremely difficult given the colonial banks' focus towards larger, European, businesses. Those wanting to enter self-employment had to rely on informal finance mechanisms or else try to get

\footnotetext{
${ }^{142}$ This was to a large extent due to the expansion of the educational system during the 1920s and 1930s (Kay, 1972).

${ }^{143}$ Silver (1981) suggests eight years of age was the usual time to start an apprenticeship in the nineteenth century.
} 
some short-term work in the formal colonial economy in order to save money. Ninsin (1991) notes that youth in 1940 who lacked seed capital to establish an enterprise tried to engage in intermittent formal employment to raise this capital. It is likely that most of the self-employed operating in the colonial informal economy were engaged in largely subsistence self-employment (ibid.).

\subsubsection{Summary}

While WW1 increased the opportunities for Africans in the labour market, the expansion of primary schooling during this period soon led to concerns about unemployed school leavers. TVET as a solution to this problem of rising unemployment remained popular among policy makers. Guggisberg vehemently promoted school-based TVET as a means to re-orientate youth towards manual work and hence reduce unemployment. While Guggisberg should be credited for improving the infrastructural environment (and creating associated employment opportunities during the Ten Year Plan), there was no long lasting change vis-à-vis the employment opportunities for academic or TVET graduates. For example, while there were ample opportunities in the expanding cocoa cash-crop sector, farming - of any kind - remained reliant on traditional practices and was not identified with modernity. Moreover pressure from Africans for academic schooling meant that TVET was not a popular option for most. The downturn in the economy in the 1930s tightened occupational opportunities further.

\subsection{Ghana's policies on skills development in relation to the economic, social, historical and political environments, 1951-2000}

In 1951 when the Gold Coast became self-governing under the leadership of Nkrumah's Convention People's Party (CPP), the financial position of the country was sound, with some $£ 200$ million in reserves. However, Nkrumah’s socialist nation-building policies aimed at mass job creation by rapid (import-substitution) industrialisation (Killick, 1978), the mechanisation of agriculture, massive educational expansion, and grandiose public sector projects ${ }^{144}$ meant that these initial reserves soon became exhausted. After Nkrumah's overthrow in 1966, Ghana experienced repeated coups and political instability until a young Flight Lieutenant, Jerry Rawlings, seized power and became president for nearly 20 years, ushering in a more stable

\footnotetext{
${ }^{144}$ E.g. the Akosombo Dam and the building of the headquarters of the new Organisation of African Unity - that ended up being located in Addis Ababa and not Accra.
} 
political period. During these 50 years since independence, Ghana's politicians and policy makers have been continually troubled by youth unemployment and have made repeated attempts to tackle this issue through education reform, though without concomitant support to the primary destination of most school leavers: the IME sector.

\subsubsection{Education, training and the environment in the new Ghana, 1951-1965}

In 1950 the administration of the Gold Coast recorded just 200,000 wage-employees, a fraction of the approximately 2.4 million "of working age" (Rimmer, 1992: 36).

The 1951 Accelerated Development Plan for Education (Gold Coast, 1951) aimed to expand education in all sub-sectors, but with an emphasis on primary and middle schools (renamed senior primary schools). ${ }^{145}$

The subsequent rapid expansion in primary (Ninsin, 1991) and middle school enrolments (19521960) was “accompanied by progressive 'dilution' of the teaching force by untrained teachers" (Foster, 1965a: 186), though the emergency training of teachers eased the situation somewhat. ${ }^{146}$ Despite this quality dilution, in November 1960 the CPP carried educational reform further by making primary schooling compulsory and free starting September 1961. ${ }^{147}$ Again enrolments increased dramatically (Ninsin, 1991; Rimmer, 1992). Nkrumah's policy of rapid expansion of primary education was out of step with the thinking of the colonial administration that had previously shaped educational policy. The colonial administration's ten year education plan (1946-1956), later replaced by Nkrumah's Accelerated Development Plan, had aimed to achieve UPE in 20-25 years (from 1946) (Gold Coast, 1948b). Nkrumah, however, aimed to provide a six-year primary education "as soon as possible... for all children" (Gold Coast, 1952: 33).

The planned expansion of primary education by the colonial administration had been questioned by a report in 1948 from the Watson Commission. It noted that achieving UPE in 20-25 years was

\footnotetext{
${ }^{145}$ At this point, the pre-tertiary school system was comprised of up to seventeen years of education: six years primary, four years middle school, five years secondary school and two years sixth-form. In 1952 primary school fees were abolished.

${ }^{146}$ For a discussion of rapid primary expansion and resulting dilution of quality in Tanzania, see Wedgwood (2005). See also Williams (2005).

${ }^{147}$ It was the same year, 1961, that the Addis Ababa conference on education set the ambitious target to achieve UPE by 1980 . This undoubtedly encouraged Nkrumah to continue with his expansionist policies in primary education.
} 
not a realistic target, one which, moreover, could have adverse effects of not only the post-basic level of education, but on the entire economy (Gold Coast, 1948a). It argued for a "soundly balanced system of education" (ibid.: 64), not one that was unbalanced in favour of one particular sub-sector. The report commented that:

If the material is limited, the alternatives are to build a narrower ladder that, while tapering, reaches the objective, or to build so broad a ladder that it fails to reach anywhere. (ibid.)

In spite of this warning Nkrumah opted to continue building a broad ladder. ${ }^{148}$ Indeed the expansion of education, particularly at the primary level, was to a great extent politically motivated since the "new government was elected to a large extent upon its promises to extend education to a wider proportion of the population" (Foster, 1965a: 184).

The opponents of the plan to expand primary and middle school (due to fears about lowering of quality) ignored the "more significant consequences of mass educational expansion" (Foster, 1965a: 190), namely the unemployment of school leavers from these levels. Increasing numbers of youth were graduating from these schools without a concomitant increase in formal employment opportunities: between 1957-1963 over 100,000 additional formal employment places arose, but over 160,000 left elementary school (Hodge, 1964). ${ }^{149}$

In the late 1950s/early 1960s some attempts were made by the government to tackle the unemployment problem.

Firstly, there was a campaign to encourage school-leavers to return to farming but, without concomitant changes in the agricultural labour market environment which remained largely traditional, this was generally unsuccessful and existed "mostly at the level of rhetoric rather then deliberate policy and action" (Ninsin, 1991: 105).

\footnotetext{
${ }^{148}$ In Tanzania, Nyerere followed a broad ladder approach, focusing on primary education. Indeed, in the 1980s, Tanzania nearly achieved UPE but still remains one of the poorest countries in the world (see Wedgwood, 2005).

${ }^{149}$ For skilled workers there were periodic increases in demand for workers; e.g. the building of Tema in the late 1950s and the Akosombo dam in the 1960s (Peil, 1969).
} 
Secondly, vocational guidance schemes were introduced. However, contrary to popular understanding that this would create jobs, the essential function was to develop better techniques to select graduates for entry into current employment opportunities.

Thirdly, the government set up Workers' Brigades in 1957 which involved the large-scale recruitment of the unemployed for public works in agriculture and construction (GoG, 2004j; Hodge, 1964). ${ }^{150}$ Those working for the Brigades were paid a small wage and subsistence allowance and provided some degree of on-the-job training. However, by the early 1960s the Brigades had became a highly politicised and inefficient extension of the state apparatus, and a drain on national coffers (GoG, 2004j). ${ }^{151}$ The numbers employed in the Workers' Brigades represented only a fraction of the total number of those unemployed and did little to solve the unemployed school-leaver problem. In 1961, for example, only $25 \%$ of the 15,000 recruited into the Brigades were middle school leavers, and since the average output of middle school graduates at that time was about 40,000 per annum, the Brigades had little impact on the total problem ${ }^{152}$ (Foster, 1965a: 205). ${ }^{153}$

Fourthly, technical training institutes were set up (e.g. in Tema) with support from the USSR in some cases. These developed quite good links with industry in the late 1960s/70s, but have been poorly maintained and today suffer from acute delivery problems (Palmer, 2006b). ${ }^{154}$

Nkrumah's policies, aimed at mass job creation by rapid industrialisation, led him towards distinct views concerning employment and informal MSE development in the new Ghana. Nkrumah saw subsistence farmers as backward, favouring instead mechanised agriculture on state farms. Nkrumah saw any part of the economy that was not geared up towards industrialisation, not concerned with the national, state-led, economy as peripheral. The cocoa industry, for example, was seen as a national asset that should be socialised in support of wider developmental

\footnotetext{
${ }^{150}$ Hodge (1964) comments that the Workers' Brigade was the government response to a political crisis of the summer of 1957 during which gangs of unemployed youth roamed the streets of Accra "voicing strong resentment over the lack of work... and expressing disillusion with the honeymoon of independence" (p.114).

${ }^{151}$ Furthermore, in 1961 the Brigades were moved to the Ministry of Defence which led to increased militarisation of Brigade activities (GoG, 2004j).

${ }_{153}^{152}$ At its height the Brigades were responsible for employing some 25,000 people (GoG, 2004j).

${ }^{153}$ For information on the range of other schemes adopted in SSA to solve the primary school leaver unemployment problem (e.g. Botswana Brigades, Kenyan Village Polytechnics and Tanzania's Education for self-reliance) see King (1991).

${ }^{154}$ When Nkrumah was overthrown in 1966, Soviet technicians were expelled and USSR-supplied equipment and curricula in Ghana's public TVET sector was not maintained or upgraded.
} 
objectives (Dzorgbo, 2001) ${ }^{155}$ Those parts of the national economy that could be taxed to support other social projects fell within the formal part of the country's economy. Those that remained separate and un-taxable became part of the informal MSE economy. McLaughlin (1979) notes that after independence MSEs were "written off in official parlance as 'cottage industries' and their workers were lumped together as 'unenumerated' to underscore their unimportance" (p.21).

In 1960 Nkrumah announced that his government would "place far greater emphasis on the development of cooperatives rather than encourage Ghanaians to start private business enterprises" (Legislative Assembly Debates, September 1960, cited in Killick, 1978: 37). Private enterprise had to "stand on their own feet" (ibid.). While Nkrumah saw that encouraging Ghanaian private capitalism would hamper the country's advance to socialism, he could not prohibit private enterprise altogether since much of his support through the 1950s had come from small-scale enterprise owners (Killick, 1978). Nkrumah's solution was to allow the development of smallscale businesses, provided that they had no foreign links and operated within the socialist framework he wished to create (ibid.). Nkrumah planned to increase the opportunities available to Ghanaians to enter the small-scale business sector by excluding foreigners from this activity, though this policy was not implemented until 1969 (by Busia) (Killick, 1978). ${ }^{156}$ In March 1962 Nkrumah announced that, "[i]n future the private small-scale personal enterprise sector will be exclusively reserved for Ghanaians. Foreign concerns already established in this sector will be allowed to continue operation, on condition that they do not expand their present establishment and scale of operations". ${ }^{157}$ Despite limited efforts to assist Ghanaian entrepreneurs in the late 1950s, Nkrumah came to the view that there was little realistic hope of fostering an indigenous entrepreneurial class who could industrialise the country at the speed he was after (Killick, 1978). Nkrumah turned to foreign direct investment as the means to finance industrialisation.

Despite Nkrumah's doubts that rapid industrialisation could not come about through the MSE sector, it was clear that this sector represented by far the most widespread form of occupational opportunities for Ghanaians before and after independence. For example, Hart's study in Nima, a poor urban area of Accra, in the 1960s noted that it was "clear that a very large part of the urban labour force... [was] not touched by wage employment" (Hart, 1973: 62). Furthermore, the 1960 Population Census showed that:

\footnotetext{
${ }^{155}$ In fact the cocoa industry was so heavily taxed by government that this partly led to the demise of the industry.

${ }^{156}$ See chap.4.3.2.

${ }^{157}$ Friedland and Rosberg, 1964, cited in Killick, 1978: 37.
} 
only 16 per cent of the adult population of Accra was employed in what might loosely be described as white-collar jobs, while almost one-third of the adult population were smallscale traders and shopkeepers. (Foster, 1965a: 130).

Despite the rapidly expanding formal education system under Nkrumah, skill acquisition for the majority continued to be in the form of on-the-job apprenticeship training. With the expansion of the primary education system since 1951 and the lack of post-primary formal education and training opportunities, it is likely that from the late 1950s it was no longer just uneducated youth who were going into apprenticeship training, but also the graduates of the primary schools who could not find employment. ${ }^{158}$

CPP policy towards this type of informal training was likely to be neglectful since Nkrumah viewed IMEs as peripheral to the economy. In spite of this neglect, in the mid-1960s informal apprenticeship was very much a "burgeoning system" (Foster, 1965b: 156).

\subsubsection{Education and training policies and practice, 1960s - 1970s: coups, political unrest and education policy repetitiveness in the face of old problems}

On February $24^{\text {th }} 1966$ Nkrumah was overthrown in a military coup by the National Liberation Council (NLC). That same year, the NLC appointed the Kwapong Educational Review Committee which brought about the introduction into the middle schools of two-year prevocational continuation classes (continuation schools) which were based on the perceived industrial and farming needs of the country (Martin, 1976). The continuation schools were created to address the fact that most middle school leavers ( $80 \%$ at the time) could not further their education at formal secondary schools, and hence middle school was terminal for most people. ${ }^{159}$ It was hoped that the vocational classes in continuation schools would better prepare school leavers for the world of work (industry and farming). ${ }^{160}$ However the continuation schools programme suffered serious set-backs which eventually led to its demise. ${ }^{161}$ One major

\footnotetext{
${ }^{158}$ In fact even pre-WW1 it was becoming more common for parents to send their children to formal schooling before an apprenticeship (Quartey-Papafio, 1914).

${ }^{159}$ The majority of youth did not even get as far as middle schools, with primary education being terminal for them.

${ }^{160}$ Subjects included animal rearing, crop and vegetable production, kente weaving, production of sandals, baking and cooking, and needlework.

161 The education reforms in 1987 saw UNICEF financially supporting the revival of the defunct continuation schools under a new name: ICCES (chap.6).
} 
contributing factor was that many pupils in the continuation schools were keen to enter SSS and therefore paid little attention to the vocational and technical subjects of the curriculum. This dual function - as both a continuing and terminal institution - of the continuation schools was a large factor in its demise.

The NLC re-oriented itself to the West for support (Rimmer, 1992) and in May 1966 received support from the International Monetary Fund (IMF). The NLC adopted laissez-faire policies and launched a stabilisation programme with IMF support (Rimmer, 1992). Between 1966-1968 this adjustment programme led to; reduction in overall government expenditure; large scale retrenchment in the public and private sectors; ${ }^{162}$ removal of price-control and subsidies; and devaluation of the cedi by $30 \%$ against the dollar. Following the 1966 coup "total expenditure in education declined, participation rate[s] of school aged children dropped, [and] so did the proportion of trained teachers... [with] this degeneration [continuing] well into the 1980s" (Ahadzie, 2000: 20).

In 1969 the elected Busia government continued relations with the IMF/World Bank, though an agreement was not reached until December 1971 due mainly to Busia's expansionist policies which implied greater pubic spending - that ran counter to the former IMF/World Bank agreement with the NLC.

One of Busia's first actions was to effect a policy that realised Nkrumah's objective of increasing the opportunities available to Ghanaians to enter MSEs; Busia issued an Alien Compliance Order on $18^{\text {th }}$ November 1969 that "gave all aliens [non Ghanaians] without residence permits two weeks to obtain them or else leave" (Peil, 1974: 367; cf. Peil, 1971). As a result more than 200,000 aliens, many of whom were traders, left Ghana within six months (Peil, 1974). ${ }^{163}$ Hart (1970) described this as "the culmination of Ghanaian commercial nationalism" (p.118). However, this did not stem rising unemployment (GoG, 2004j).

Following another coup in 1972, this time led by Colonel Acheampong of the National Redemption Council (NRC), a new government faced with the long-standing youth

\footnotetext{
${ }^{162}$ The NLC expected that the private sector would be able to provide opportunities for those retrenched from the public sector (Ninsin, 1991), and yet opportunities in formal private sector employment also declined.

${ }^{163}$ These included Lebanese, Indians and others from countries surrounding Ghana - principally Nigerians and Togolese (Peil, 1974).
} 
unemployment problem again saw education reform as the panacea. The NRC's Dzobo Educational Reform Committee (GoG, 1972) noted that the graduates of the current middle and secondary school system:

have been found to lack the proper attitude and skills necessary to equip them to work with their hands, and to be willing to take up the type of practical work that is available in our society at the moment. As a result there is a high rate of unemployment and under-employment among middle and secondary school leavers. (ibid.: 3)

Hence the Dzobo Reform suggested the introduction of a Junior Comprehensive Secondary ${ }^{164}$ containing pre-vocational subjects which, it was assumed, would "predispose them [pupils] to working with their hands as well as their minds" (ibid.: 9). ${ }^{165}$

The resulting 1974 education reform introduced the JSS concept on an experimental basis. However, due to economic constraints facing the country from the late 1970s and the lack of interest of those administering it, the JSS programme never survived this experimental stage.

The refocusing by the NRC on creating an educational system that would be of relevance to youth (un)employment issues should be read against the background of the NRC's relationship with external donors. The NRC had, in fact, repudiated all external debts that arose through fraudulent contracts. This antagonised donors and foreclosed any possibility of his regime receiving concessional and long-term bilateral aid. Hence Acheampong adopted a policy of self-reliance, launching 'Operation Feed Yourself' and 'Operation Feed Your Industries'. This also may have encouraged the experimentation with the JSS system that arose from the 1972 Dzobo Reform.

In 1978 General Akuffo took power through another coup. Akuffo reintroduced the structural adjustment policies espoused by the donors - which meant a cut back in public expenditure, including education.

By 1979 school enrolment for 6-14 year olds had fallen to 69.9\% (from a high of $75 \%$ in 1965), and the percentage of trained teachers in schools had dropped from $90.8 \%$ in 1965 to $72 \%$ in

\footnotetext{
${ }^{164}$ Later JSS.

165 Subjects included: woodwork, masonry, metalwork, pottery, commercial subjects, marine science (fishing), automobile practice, craft (basket weaving), home science, beauty culture (including hair dressing), tailoring, dressmaking and catering (GoG, 1972).
} 
1979 (Ahadzie, 2000). On June $4^{\text {th }} 1979$ Akuffo was deposed in coup led by Jerry Rawlings of the Armed Forces Revolutionary Council (AFRC).

One of the AFRC's first acts was to conduct, between June-October 1979, its housecleaning exercise targeted at government officials, formal sector enterprises and informal market traders (Clark, 1988; Robertson, 1983). Rawlings claimed this would eradicate corruption in Ghana's commercial system. ${ }^{166}$ Actions were fast and hard; Accra's Makola \#1 market, well known for wholesaling imported and manufactured items, was raided on the day of the coup, closed down and ultimately dynamited (ibid.). ${ }^{167}$ In Kumasi soldiers took over many of the formal micro- and small-stores and sold off all the provisions at very low prices. Many traders stayed away from the Kumasi market for fear of having their stock confiscated or due to the general violence and thievery (ibid.). Although the first targets were the illegal distribution of imports, the exercise was quickly extended to include local foodstuffs. As a result rural producers kept away from markets for fear of their goods being forcibly sold (ibid.). Rural household incomes plummeted, with many moving back towards subsistence farming and nonfarm enterprises suffered due to decrease in consumer demand (ibid.).

The housecleaning exercise caused huge disruption among informal MSEs and was felt most harshly by those with little or no cash reserves, like market porters and poor traders (ibid.). While some traders were able to switch to artisanal or other informal production work, like sewing or baking, even this came "to a standstill, due to lack of supplies and customers" (Clark, 1988: 67). Furthermore informal finance networks between friends and other traders became "useless... since they faced similar problems" (ibid.).

Haan and Serrière (2002) note that until about 1985, the GoG's policies strongly favoured larger industries - being generally very unsupportive of informal MSEs: "Police harassment of enterprise that had not succeeded to get all of the large number of licenses and permits was common. Financial and other support services were unavailable" (ibid.: 27). However as noted later (chap.4.33\&5.3) many of the government initiatives since the mid-1980s to 2006 have still largely failed to reach the bulk of informal MSEs, especially those in rural areas.

166 Traders (especially female market traders) were blamed for food shortages and were accused by Rawlings of hoarding goods and inflating prices. In reality, Rawlings was merely using them as scapegoats to blame for the economic crisis of the late 1970s (Robertson, 1983).

167 Sekondi, Kumasi and Koforidua and Makola \#2 markets were also destroyed when Rawlings took power again in 1981 (Robertson, 1983). 
On September $24^{\text {th }} 1979$ Rawlings handed over power to an elected president, Hilla Limann (People's National Party), but later, on $31^{\text {st }}$ December 1981 made a second coming, launching a second coup and taking power as head of the Provisional National Defence Council (PNDC).

\subsubsection{Schooling, skills and the environment: from crisis to reform, 1980 s to 2000}

By the time the IMF/World Bank SAPs were adopted by Ghana in 1983 the country was in crisis (Canagarajah and Mazumdar, 1997; Petchenkine, 1993). Not only had the education system been so run down due to repeated political instability and budget cuts, but the economy was in crisis, low-end informal sector activities burgeoned and the infrastructural environment had become run down. ${ }^{168}$

Between 1970-1983 per capita income decreased by 30\% and the cocoa sector, the foundation of export earnings, was devastated: production in 1983 was just 28\% of its level of 1965 (Canagarajah and Mazumdar, 1997). ${ }^{169}$ In spite of falling revenues government spending increased - unconstrained by budgetary considerations. Inflation soured, averaging 58\% (19721982) which depressed real wages in the formal public and private sectors (ibid.). While the public sector protected employment, at the end of 1982 real wages of public employees was no more than 25\% of their 1970 level (ibid.). Canagarajah and Mazumdar (1997: 6) comment that "[i]t is not hard to imagine the dive in efficiency of government services which this must have caused". Many in the civil service, including teachers, were forced to engage in backyard gardening and other income-generating ventures which would undoubtedly have led to a reduction in the quality of education.

Employment prospects in IMEs were equally thin. Honny (1999) comments that most NVTI graduates were finding it hard to enter self-employment at this time.

\footnotetext{
${ }^{168}$ Between 1967 and 1984, real transportation costs increased by as much as 50\% (World Bank, 1985). This increase was due both to the deterioration of Ghana's infrastructure over the previous decade and to decreased government subsidies on petroleum products. In 1983 c.70\% of Ghana's 92,000 heavy-duty vehicles were off the road (Smillie, 1986). The early 1980s also saw frequent power cuts - for as much as half the day in Suame (ibid.).

169 Both the overtaxing of cocoa farmers and the massive overvaluation of the exchange rate led to the demise of the cocoa sector (Canagarajah and Mazumdar, 1997).
} 
The capacity of the trainees to enter into self-employment, even in the most traditional trades, has been constrained by excessive supplies of artisans into those trades (for example, masonry, carpentry), and the lack of linkages... from market and industry. (p.194)

Periods of severe drought (1975-77, 1981-83) (Derrick, 1984), plummeting cocoa prices and increasing oil prices exacerbated poverty and caused an increase in nonfarm informal activities. Moreover, black market activities (kalabule) became widespread during the 1970s and early 1980s (Smillie, 1986).

To make matters worse by the end of January 1983 about one million migrants returned to Ghana after being forcibly repatriated from Nigeria. The large numbers of new entrants into an already saturated economy led to soaring unemployment. Despite these external or natural shocks, some argue that the root cause of Ghana's economic decline can be traced to gross governmental mismanagement, including excessive public spending and over-involvement in economic affairs (Canagarajah and Mazumdar, 1997; Vijverberg, 1995).

The economic crisis of the early 1980s was paralleled by a crisis in education and training. Government financing for education declined sharply 1976-1983, from $6.4 \%$ to $1.4 \%$ of GDP, resulting in the decline of the education system (World Bank, 1996). By the early 1980s, the education system in Ghana was facing huge problems (Ahadzie, 2000; Sawyerr, 1997): lack of trained teachers, lack of materials, books and teaching aids, inadequate infrastructure, low and late pay for teachers, high drop-out rates and low enrolment rates, poor educational management and administration and a general lack of financing for education. By 1983 approximately $50 \%$ of trained primary teachers had left the country (Ahadzie, 2000) due to the deteriorating economic climate and working conditions. ${ }^{170}$ Untrained teachers were employed to avoid disintegration of the education system and the quality of teaching deteriorated. By 1983 the quality of education had reached crisis levels and it became necessary for a serious attempt to be made to salvage it.

In 1987, with World Bank support, ${ }^{171}$ an Educational Reform was started with the objective of improving educational quality and, just as previous reforms had attempted, to make education more orientated to work - a reaction to the massive unemployment problems and economic crisis

\footnotetext{
${ }^{170}$ The Commission for Africa report (2005) discusses the impact brain drain is having on development in Africa today.

${ }^{171}$ For a discussion on World Bank support to the 1987 reforms and after, see Palmer (2005c). For a discussion on aid to education in Ghana since then see Ayamdoo et al. (2006).
} 
facing Ghana in the mid-1980s. The education reform changed the educational system from the 64-5-2-3/4 version, to: six years of primary, three years of JSS, three years of SSS and 3-4 years of tertiary (6-3-3-3/4). This shortened the pre-tertiary education from $17^{172}$ to 12 years (World Bank, 2004c). Basic education consisted of the 6-3 element: six years primary and three JSS (the JSS replaced middle schools).

The 1987 reforms led to comprehensive curriculum reform: while the middle schools were largely academic schools, the JSS curriculum included pre-technical and pre-vocational education (Donge, 2002). Back in 1972 the Dzobo Educational Reform Committee had emphasised that the curriculum should be re-oriented so that graduates were predisposed to work with their "hands as well as their minds" (GoG, 1972: 9). This exact same rationale, manifest in the JSS concept, was taken up and implemented in the 1987 reforms.

In addition to the general subjects, the Junior Secondary School curriculum has been designed to provide opportunities for pupils to acquire basic pre-technical, prevocational, and basic life skills which will enable pupils to... appreciate the use of the hands as well as the mind and make them creative and self-employable. (Republic of Ghana, 1992, cited in McGrath et al., 1995: 22)

Moreover further evidence that the government was keen to manipulate the education and training system so that it better prepared youth for work can be seen in the 1986 revival of the defunct continuation schools programme, albeit under a different name: ICCES (chap.6).

The political environment at the time of the education reform contributed both to its design and to the underlying assumptions of how the reform would impact on the economy. At the time of the reform Rawlings' PNDC, a military government driven by socialist ideology, had made it their objective to make the education system more equitable and responsive to current critical issues, principally unemployment. The argument put forward by the PNDC, which reiterated over a hundred years of previous TVET policy in the Gold Coast/Ghana, was that the education system should:

prepare the youth for work and that providing vocational education at the secondary school level would equip students with the skills for paid and self-employment... [hence] vocationalization [became] widely accepted as one of the key solutions to socioeconomic decline. (Akyeampong, 2002: v)

${ }^{172}$ Six years primary, four years middle school, five years secondary school and two years sixth-form (6-4$5-2)$. 
In addition, the increased attention in the 1987 reform to basic education also had a political basis. At that time Rawlings was seeking political support from rural areas - not from the minority, mainly urban, elite - and a policy of spreading the benefits of education there was dominant (Donge, 2002). The establishment of rural ICCES training centres at this time was likely part of Rawlings' renewed focus on rural areas and rural votes. ${ }^{173}$

Ultimately, however, the 1987 education reform was seen largely as failing to achieve its objectives and resulted in unexpected outcomes.

Firstly, the 1987 education reform failed to inculcate "any meaningful vocational and technical oriented skills into the students" (Aryeetey, Laryea, Antwi-Asare, Baah-Boateng, Turkson, Codjoe and Ahortor, 2005: 133). ${ }^{174}$ The 2004 White Paper on Educational Reforms (chap.5.1) concluded that the 1987 reform "failed to comprehensively equip[...] the youth... with directly employable skills for the world of work" (GoG, 2004a: 4). Indeed the objective of the JSS system to prepare graduates for work has "for years been known to be totally unreal" (ibid.: 7). Akyeampong (2002) suggests that the vocationalisation policy proved to be too ambitious and implementation was hurriedly carried out. The 1987 education reform was initiated without serious consideration given to the associated capital or recurrent costs. It proved difficult, for example, to find sufficient numbers of suitably trained vocational/technical teachers, to finance the construction of JSS workshops or the purchase of essential tools and equipment (Akyeampong, 2002, GoG, 2004i). ${ }^{175}$

A second, related, point is that the expected effect a vocationalised JSS system would have on the labour market - that it would prepare students for (self-)employment and reduce unemployment largely failed to materialise. Almost twenty years after the 1987 education reform youth unemployment is still a critical issue. Van Dijk (1997) argues that “... the strong link between education and employment prospects, a central premise of the post-independence development

\footnotetext{
${ }^{173}$ Indeed new ICCES centres in rural areas were sometimes put in the hands of stalwart PNDC supporters and used as a mechanism to boost support for the party - especially in areas that were traditionally supporters of the opposition (ICCES official, personal communication 10.09.05).

${ }^{174}$ It might be argued that a light-form of vocationalisation took place in the JSS; but lacking equipment and workshops most JSS students will have had very little hands-on practice, with teacher demonstration and pre-vocational/technical theory more predominant.

${ }^{175}$ A further issue which reduced the supply of JSS teachers was that many did not end up teaching at this level, or in fact teaching at all, as the desire among teachers to further their education or to leave their profession was high (Akyeampong and Stephens, 2002).
} 
era in Ghana, has been called into question. It touches all levels and types of training and even extends to formal schooling" (p.107). ${ }^{176}$

Thirdly, an apparently unforeseen consequence of reducing the years of pre-tertiary education from 17 to 12 years was to trigger "the arrival of thousands of young entrants into the labour market at a much younger age" (Honny, 1999: 192).

Fourthly, the expectation that temporary teachers and local craftsmen would be employed to fill in the shortfall in qualified teachers proved unrealistic. Indeed the MoE was fast to change the initial intention of paying these teachers and craftsmen as schools began to present budgets for the cost of hiring teachers to them - budgets which had not been factored into the national budget (Akyeampong, 2002). Moreover the vocationalised JSS concept lost favour among many parents as the "use of local artisans in teaching only reinforced public suspicion that JSS pupils were being trained to become local artisans and carpenters" (ibid.). Additionally the local artisans lacked the required pedagogical skills which served to reduce the quality of the training (ibid.).

In 1983 Ghana launched the Economic Recovery Program (ERP) in reaction to the economic meltdown of the early 1980s with the support of the IMF/World Bank SAPs. The ERP led to improvements in the macro-economic environment, with GDP - which had shrunk by c.16\% 1971-1983 - showing improvements from 1984: in the period 1984-2005, GDP growth has continued to remain positive, averaging $4.9 \%$ per year (table 4.1 ).

\section{Table 4.1. GDP growth rates 1984-2005}

\begin{tabular}{|l|l|l|l|l|l|l|l|l|l|l|l|l|l|l|l|l|l|l|l|l|l|l|}
\hline 1984 & 1985 & 1986 & 1987 & 1988 & 1989 & 1990 & 1991 & 1992 & 1993 & 1994 & 1995 & 1996 & 1997 & 1998 & 1999 & 2000 & 2001 & 2002 & 2003 & 2004 & 2005 & Avr \\
\hline
\end{tabular}

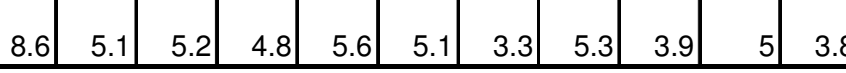

Source: GoG, 2003a: 54; GoG, 2005a: 19; IMF, 2005.

The 2005 figure is an estimate based on data through to August.

However positive macro-economic performance has not brought about overall or balanced economic development.

Firstly, the positive macro-economic performance did not facilitate the structural transformation of Ghana's economy. The over-reliance on primary products (e.g. agriculture, timber, gold) and

${ }^{176}$ As noted earlier (chap.4.1.2), the assumed link between education and employment has not just been a fad of the post-independence era, but goes back to the mid-nineteenth century. 
the massive size of the informal economy has changed little since independence. This lack of structural transformation "constrained the development of new and better employment opportunities and a fuller utilisation of the labour force" (Heintz, 2004: 6). Based on evidence from the late 1990s to early 2000s, some argue that "the structure of employment in the Ghanaian economy has changed quite significantly, with a shift away from agriculture and toward urban activities linked to trade and other services, as well as to manufacturing and construction" (Cavalcanti, 2005: 1). Elsewhere in SSA a shift from farm to nonfarm activities has been observed (Bryceson, 1996; 1997a; 2002a).

Secondly, structural adjustment meant a loss of formal employment, especially in the public sector and the concomitant expansion of the IME sector (Rimmer, 1992). Public sector employment peaked in 1985 with 397,000 people employed, but by 1991 had shrunk to $40 \%$ of the 1985 figure (to 156,000 employees). ${ }^{177}$ Similarly, private sector formal employment shrank from 79,000 in 1987 to less than half that by 1991. Total formal sector employment in 1991 was $40 \%$ of what it was in 1985 (table 4.2).

Table 4.2. Trends in formal sector employment, 1960 to 1991 (thousands)

\begin{tabular}{|l|l|l|l|}
\hline Year & $\begin{array}{l}\text { Public sector formal } \\
\text { employment }\end{array}$ & $\begin{array}{l}\text { Private Sector formal } \\
\text { employment }\end{array}$ & $\begin{array}{l}\text { Total formal sector } \\
\text { employment }\end{array}$ \\
\hline 1960 & 184 & 149 & 333 \\
1965 & 278 & 118 & 396 \\
1970 & 288 & 110 & 398 \\
1975 & 318 & 137 & 455 \\
1980 & 291 & 46 & 337 \\
1985 & 397 & 67 & 464 \\
1986 & 347 & 66 & 414 \\
1987 & 315 & 79 & 394 \\
1988 & 252 & 55 & 307 \\
1989 & 177 & 38 & 215 \\
1990 & 189 & 40 & 229 \\
1991 & 156 & 31 & 186 \\
\hline
\end{tabular}

Source: Gockel, 1998, cited in Adu-Amankwah, n.d.

Teal (2001) presents data on the labour force status of Ghana's population, based on data from four rounds of the GLSS between 1987 and 1999 which were divided into five broad categories:

${ }^{177}$ These figures are small relative to the number of repatriates from Nigeria: estimated at a million. 
wage employees, farmers, the non-agricultural self-employed, unpaid family labour and the unemployed (table 4.3). ${ }^{178}$

Table 4.3. Labour force status: percentages of individuals by category of employment

\begin{tabular}{|l|r|r|r|r|}
\cline { 2 - 5 } \multicolumn{1}{c|}{} & \multicolumn{3}{c|}{ Ghana Living Standards Survey Rounds } \\
\multicolumn{1}{c|}{$1987 / 88$} & $1988 / 89$ & $1991 / 92$ & $1998 / 99$ \\
\hline Wage Employees & 17.3 & 18.1 & 15.4 & 13.2 \\
Government & 8.0 & 7.9 & 7.8 & 5.9 \\
State Enterprise & 1.9 & 2.3 & 1.2 & 0.6 \\
Private & 7.4 & 7.9 & 6.4 & 6.7 \\
Farmer & 58.7 & 54.6 & 56.7 & 55.7 \\
Non-Agricultural & 19.5 & 24.2 & 23.5 & 27.3 \\
Self Employment & & & & \\
Unpaid Family & 2.2 & 1.1 & 1.3 & 0.3 \\
Unemployed & $\mathbf{2 . 2}$ & 1.9 & 3.2 & 3.5 \\
\hline Total & 100 & 100 & 100 & 100 \\
\hline
\end{tabular}

Source: Teal, 2001: 17

Table 4.3 provides some information about the extent of labour market opportunities for the graduates of the schools and skills programmes over this period. Between 1987/88 and 1998/99 the percentage of the population engaged in self-employment activities increased from $78.2 \%$ (58.7\% agriculture, $19.5 \%$ non-agricultural) to $83 \%$ (55.7\% agriculture, $27.3 \%$ non-agricultural). Indeed this period has seen a slight decrease in those engaged in agriculture, while those in nonagricultural self-employment activities have increased from $19.5 \%$ to $27.3 \%$. The percentage of individuals in the wage sector has shrunk from $17.3 \%$ in $1987 / 88$ to $13.2 \%$ a decade later. Formal public wage employment (government and parastatal workers) has shrunk from 9.9\% in 1987/88 to $6.5 \%$ a decade later. Despite the retrenchments in civil servants following the SAPs the public sector remains the largest formal sector employer. It is generally accepted that while employment growth in the formal economy appears to be stagnating, employment growth in the informal economy is still growing.

As noted, Ghana has a massive informal economy accounting for some $86 \%$ of employment (including farm and nonfarm activities) (table 4.4). In rural areas, informal employment accounts for $92 \%$ of all employment, and is predominantly (73\%) agricultural and female in composition

178 These categories disguise much of Ghana's labour market realities (e.g. occupational pluralism) (chap.2.3.1). Moreover the issue of categorising anyone in Ghana as 'unemployed' is highly problematic (chap.2.3). 
(table 4.4). In urban areas, informal employment is largely (75\%) comprised of nonfarm activities.

Table 4.4. Employment and unemployment, by gender and rural/urban (1998/99)

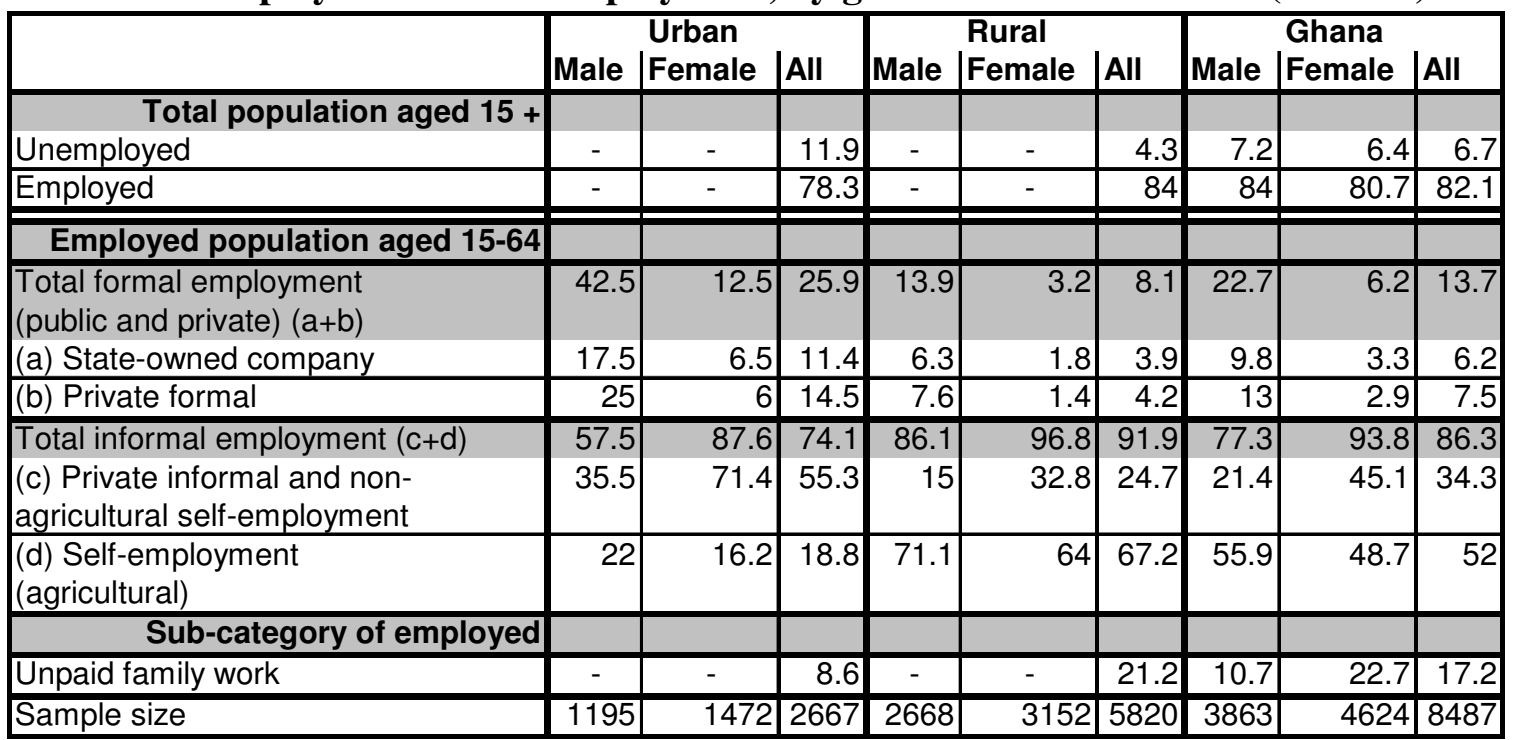

Source: GSS, 2000

Under the SAPs the sustained growth rates failed to improve the employment opportunities for the majority of the working population (Fine and Boateng, 2000). At the same time as formal employment opportunities were declining the majority of opportunities in informal employment continued to consist of low-end activities in both farm and nonfarm enterprise (Heintz, 2004). "Persistent unemployment, underemployment, and growth in precarious forms of employment remained central features of the economy" (ibid.: 6).

The SAPs impacted differently on Ghana's informal MSEs, depending on the enterprise type and whether it was a more entrepreneurial or subsistence-orientated informal enterprise (Dawson, 1993; Osei, Baah-Nuakoh, Tutu and Sowa, 1993; Parker, Riopelle and Steel, 1995; Steel and Webster, 1991). For example Parker et al. (1995) find that the SAPs improved the climate for MSEs in three areas: access to inputs, relative prices, and the ease of doing business. At the same time, however, MSEs faced intensified competition in the post-reform environment. Imports of oburuni waawu ${ }^{179}$ (second hand clothing) and Chinese textiles have had devastating impacts on

\footnotetext{
${ }^{179}$ Literally 'the whiteman is dead'.
} 
informal (and formal) textile manufacturing. Imports of (highly subsidised) foreign farm produce, e.g. rice from the USA, have led to declining farm incomes. ${ }^{180}$

GoG support to IMEs had been neglectful at best prior to the mid-1980s though a couple of MSE agencies existed. ${ }^{181}$ However since the late 1980s a number of agencies have been established which, according to some commentators have "markedly improved [the situation] for the informal sector... with a basic institutional infrastructure [established] to support the sector... [e.g.] the National Board for Small-Scale Industries (NBSSI)" (Haan and Serrière, 2002: 27). However there is strong evidence suggesting that many of these MSE agencies, like the NBSSI, have largely failed to provide support to the majority of IMEs in Ghana and have not markedly improved the situation (Baah-Nuakoh, 2003; Palmer, 2004a; b; chap.5.2-5.3, this thesis). As well as government programmes (since 1970) several donor projects in the mid-1990s have also targeted the MSE sector (fig.4.4).

Financial liberalisation policy has not led to wider access to formal financial mechanisms for the informal MSEs (Steel, Aryeetey, Hettige and Nissanke, 1997), nor have attempts to provide micro-credit been successful in reaching the majority of IMEs (Palmer, 2004a). ${ }^{182}$

According to the GSS, unemployment in Ghana stood at $6.7 \%$ in 2000 though was more acute in urban than rural areas (11.9\% vs 4.3\%) (table 4.4). However 'unemployment' figures in Ghana should be treated with a high degree of caution. Not only do they vary widely according to how 'unemployment' is measured, ${ }^{183}$ but the huge number of working poor (ILO, 1972) in low-end IMEs means that there is a great deal of disguised unemployment or underemployment (chap.2.3).

\footnotetext{
${ }^{180}$ Under the SAP agreements Ghana had to remove subsidies on most farm produce which resulted in many farmers, like rice farmers in the north, going out of business. Meanwhile heavily subsidised rice from the USA was imported into Ghana.

${ }^{181}$ E.g. the Ghanaian Enterprise Development Commission (GEDC) - set up in 1975 as the main credit giving body to small-scale entrepreneurs in Ghana. It merged with NBSSI in 1991.

${ }_{182}$ There are many examples of successful micro-credit initiatives in Ghana but these usually cover a limited geographical area.

${ }^{183}$ Unemployment in 1997 was estimated to be about $25 \%$, or about 2.2 million out of the total labour force of 9 million (Dordunoo, 1994 in Honny, 1999: 191).
} 


\subsubsection{Summary}

Unemployment has remained a major problem in the post-1951 period. During the 1950s-1970s the GoG attempted to tackle this with work creation schemes like the Brigades and by setting up technical institutes and NVTIs. Since the 1960s there have been repeated attempts to reform the education system to make it more orientated towards work. The 1987 attempt to vocationalise the junior secondary level has been officially acknowledged as a failure. Policies concerning small enterprise have largely not been favourable: Nkrumah's socialist policies favoured cooperatives, and the repeated coups during the 1960s/70s led to an unstable investment climate and an economic downturn culminating in the economic nadir of 1983. Rawlings' period brought relative stability and sustained GDP growth but he remained suspicious of private business. Moreover, without any significant change in the structure of Ghana's economy which comprised approximately $90 \%$ informal activities, and without any significant change in the enabling enterprise infrastructure for MSE development, most school and TVET graduates find themselves without formal assistance operating in IMEs and training in traditional apprenticeships.

\subsection{Concluding remarks on 150 years of skills training, work, enterprise and the enabling environment, 1850s-2000}

This chapter has covered the main developments related to skills training, work, and enterprise in the context of changing environments, 1850s-2000. Over this period it is possible to identify themes that have emerged concerning skills, work and MSEs within four types of environment, the:

- political environment;

- policy and legislative environment for skills development;

- policy and legislative environment for work;

- institutional environment for MSEs. ${ }^{184}$

The political environment (fig.4.1) over the last 150 years has shaped quite considerably the whole development of skills and the labour market environment. The formal colonial economy

\footnotetext{
${ }^{184}$ Some of the items in fig.4.1-4.4 have not been previously covered in detail in this chapter. Inevitably, the task of covering 150 years of policy and practice vis-à-vis schools, skills and enterprise means that some items have to be excluded from discussion. Nonetheless, the author considers it valuable to include other dimensions of these four environments in the figures so that the reader can get a fuller picture.
} 
(and the development of a monetised colonial informal economy) spread northwards from the coast as British political rule spread. Formal job opportunities (other than for missions), limited as they were, were largely based around coastal ports and trading posts. Formal job opportunities in the north were few, and MSE activity (including farming) remained more subsistence based than monetised.

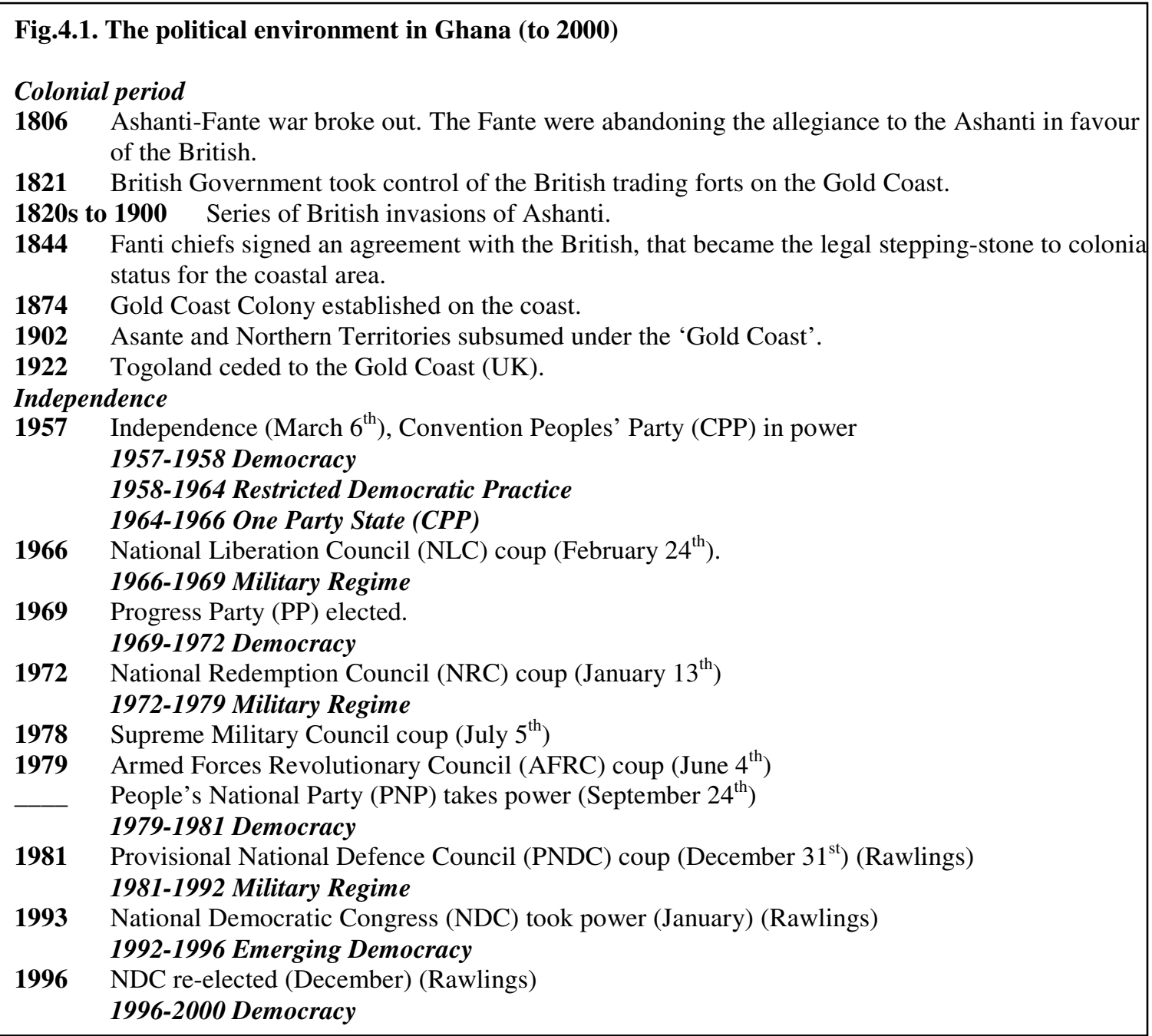

As British political power spread, traditional political power waned - impacting on the traditional labour market and on skills development environments. For example, as the Asante Kingdom declined, the quality of Asante gold deteriorated, the demand for regalia reduced and the need for cash incomes increased. Artisans shifted from producing for largely subsistence needs or for the royal court, to producing goods for cash incomes. 
Since independence, Ghana's political history has not been encouraging for entrepreneurship in general. Between independence and 2000 Ghana has seen almost twenty years of military rule, about twelve years of restricted of emerging democratic practice and some ten years of democracy. Such a history of coups and military rule - and the effects these have had on the macro-economic and labour market environments - have not been conducive to business development. ${ }^{185}$ In the $1970 \mathrm{~s} / 1980$ s military rule drove away many local and foreign entrepreneurs and Rawlings' attitude towards the private sector was "somewhat ambivalent and sometimes openly hostile" (Arthur, 2006: 40).

Moreover, as new post-colonial governments came to power, there has been a tendency to promote new education reforms as each government's contribution to development. For political reasons new governments ushered in new policies so that it would be seen that something new was being done to aid development: in the field of education policy, there were reforms shortly after the 1966 and 1972 coups, Rawlings' second coming and Kufuor taking up office (chap.5). What is remarkable, however, is that these education policies repeatedly espoused the need to promote TVET.

The policy and legislative environment for skills development was been shaped by:

i) the ongoing political and policy concern with youth unemployment. Much effort has been spent in trying to solve this problem but it has remained persistent for the last 150 years.

ii) TVET and education reform being seen as the major solution to this unemployment problem. A key thread running through this chapter has been the remarkable consistency in the way TVET has been revived over the decades from the early colonial period to the present (fig.4.2). ${ }^{186}$

In spite of the repeated attempts to promote school-based TVET and later VTIs and shortduration training (like the World Bank's Vocational Skills and Informal Sector Support Project, fig.4.4), no clear skills development policy had emerged by 2000. In 1990 an attempt was made "to solve the interdepartmental rivalries and bureaucratic constraints that affected the management of training" (King and McGrath, 2002a: 55); the National Coordinating Committee

\footnotetext{
${ }^{185}$ However, the sustained GDP growth during the Rawlings years is impressive (table 4.1).

${ }^{186}$ Yamada (2005) comments on the similarity between TVET policies in the 1920s and those in the 1987 reform.
} 
on Technical and Vocational Education and Training (NACVET) was set up to coordinate a national skills development system ${ }^{187}$ (ibid.; World Bank, 1995). However:

in a decade of existence, NACVET has failed to develop a national policy for skills development and continues to suffer from capacity problems and on-going tensions between the two parent Ministries. (King and McGrath, 2002a: 55)

${ }^{187}$ In particular between providers of skills from the MoE and those from the MoESW. 
Fig.4.2. The policy and legislative environment for skills development in Ghana (to 2000)

Colonial period

1847 Report by the Education Committee of the Privy Council to the Colonial Office - mention of the need to provide practical training in both handicrafts and agriculture to African youth influenced Mission (particularly the Basel) school curricula in the Gold Coast.

1882 Ordinance for the Promotion and Assistance of Education in the Gold Coast Colony tried to establish a series of industrial schools in which pupils were meant to spend no less than 10 hours per week in practical classes

1898 Grants offered by colonial administration to encourage educational establishments to teach technical and agricultural subjects

1908/9 Education Reform Committee (1908) and Education Rules (1909) - planned to introduce hand and eye, industrial and agricultural training into the government schools.

1920s Guggisberg's 'Sixteen Principles of Education' - includes promotion of trade schools.

Self-government

1951 Accelerated Development Plan for Education - aimed to expand education in all sub-sectors, Independence

1957 White Paper on a National Workers Brigade

1960 Education Act (87) - making primary schooling compulsory and free with effect from September 1961 - although it does not define until what age the child should attend school. Established private institutions (many of which offer TVET).

1966 Kwapong Educational Review Committee - introduced continuation schools

1970 The National Vocational Training Institute (NVTI) Act (351) - responsible for the nationwide coordination of all aspects of vocational training including apprenticeship - in both formal and informal sectors.

1972 Dzobo Educational Reform Committee - experimental pre-vocational courses at the junior secondary level.

1986 Evans Anfom Committee - re-introduced the pre-vocational classes at the junior secondary

level

1992 Constitution - introduced Free Compulsory Universal Basic Education (FCUBE)

1990 National Coordinating Committee on Technical and Vocational Education and Training (NACVET) was set up to coordinate a national skills development system.

1995 National development agenda-Vision 2020 - outlines training policy objectives in terms of strengthening and expanding training facilities through; i) improving and expanding the infrastructure for training; ii) increasing opportunities for technical and vocational level training, and iii) strengthening linkages between the training sector and industry.

1995 FCUBE launched

1998 Children's Act (560). Part V, sub-part II on apprenticeship in the informal sector - specifies minimum age of traditional apprenticeship should be 15 years or after completion of basic education (basic education being officially compulsory) (section 98). Sets out masters' responsibilities towards their apprentices regarding training (section 99), the apprenticeship agreement (section 100) duties (section 101) and release (section 102) of apprentice.

Sources: Foster, 1965a; Gold Coast, 1951; GoG, 2004b; 1998; 1995; 1992; 1972, 1970; Guggisberg, 1922; Hodge, 1964

The policy and legislative environment for work has largely been formal sector focused

(fig.4.3) despite the fact that employment and skills acquisition in IME has been the most dominant form of work and training for the majority of the population for the last 150 years. Where the informal sector has been included (like the Children's Act) legislation is often ignored in practice by IMEs. 
Fig.4.3. The policy and legislative environment for work in Ghana (to 2000)

Colonial period

Colonial administration favoured big business. Policies in favour of (British) larger firms.

Independence

1957 Builder's Brigade Board Act (37).

1958 Industrial Relations Act (56) - designed to strengthen the trade unions by giving them legal backing for the first time. The Trade Union Congress (TUC) strengthened (given legal backing); recognised as the sole representative of trade union movement in Ghana.

1960 Civil Service Act - trade union membership compulsory for all civil servants.

1965 Industrial Relations Act (299) (replaced 1958 Act) - every union had to be TUC member.

1966 National Liberation Council repealed section 24 of the 1960 Civil Service Act, which made trade union membership compulsory for civil servants.

1967 Labour Decree (NLCD 157) - established Public Employment Centers to assist job seekers in finding work. It also discusses workers' contracts and agreements and regulates the employment of women, children and young persons. E.g. prohibits employment of children under the age of 15, although the law permits undefined "light" work by children.

1969 Labour Regulations Law (LI 632) provides for the terms and conditions of employment as well as the employment of disabled persons.

1970 Factories, Offices and Shops Act - regulates health, safety and welfare of staff in the workplace.

1971 Industrial Relations (Amendment) Act (383) - (replaced Industrial Relations Act, 299) dissolved the TUC (reinstated by the National Redemption Council in 1972).

1972 Social Security and National Insurance Trust (SSNIT) established to administer the National Social Security Scheme

1981 National Board for Small-Scale Industries (NBSSI) Act (434) - set up to promote and develop the small-scale industrial sector

1987 Workmen's Compensation Law (PNDCL 183) deals with an employer's liability for compensation for a worker's death or incapacity arising as a result of an accident occurring in the course of employment.

1991 Social Security Law (PNDC Law 247) - Voluntary coverage for the self-employed and hence low outreach to the informal sector.

1992 Constitution - right to work under satisfactory safe and healthy conditions.

1998 Children's Act (560). Part V, sub-part I on Child Labour - prohibits employment of children under the age of 15 . Children aged 13 and over can do light work (defined as "work which is not likely to be harmful to the health or development of he child and does not affect the child's attendance at school of capacity of a child to benefit from school work"). Minimum age for the engagement of a person in hazardous work is 18 (defined as work that is a danger to the health, safety or morals of a person - going to sea; mining and quarrying; portage if heavy loads; manufacturing industries where chemicals are produced or used; work in places where machines are used; and work in places such as bars, hotels and places of entertainment where a person may be exposed to immoral behaviour. Children's Act specifically includes the informal sector.

Sources: Anyemedu, 2000; GoG, 1998; 1992

The institutional environment for MSEs has remained weak in practice, despite a number of programmes and projects that have intended to improve the MSE environment (fig.4.4). 
Fig.4.4. The institutional environment for micro- and small-enterprise in Ghana (to 2000): policy and practice

\section{Colonial period}

MSEs not recognised as part of the colonial formal economy. Formal banks favoured big

Independence (foreign) business over small local enterprises.

1950/60s Nkrumah favoured cooperatives over private enterprise, and viewed informal 'cottage industries' as peripheral to his rapid industrialisation goals.

1970 Small Business Loans Scheme - to assist small-scale enterprises to start-up or expand. In practice it was largely formal enterprise that benefited.

1975 Ghanaian Enterprise Development Commission (GEDC) - set up as the main credit giving body to small-scale entrepreneurs in Ghana.

1981 National Board for Small Scale Industries (NBSSI) - set up by the Government as an apex organisation to promote and develop the small-scale industrial sector. However it is poorly funded by meager budget allocations. Part of its function was to manage the PAMSCAD. (The NBSSI did not really function until 1989).

1987 Ghana Regional Appropriate Technology Industrial Service (GRATIS) - set up by the Government to promote small-scale industrialisation and provide employment opportunities, improve incomes and enhance the development of Ghana. GRATIS provides training and technical assistance to artisans through ten Intermediate Technology Transfer Units. GRATIS experiences a high rate of labour turnover in the project as a result of low remuneration and motivation for the workers. There is high level of worker dissatisfaction with poor conditions of employment.

1988 Programme of Action to Mitigate the Social Cost of Adjustment (PAMSCAD) - to assist small-scale industries with a revolving fund of 80 million cedis (1989). PAMSCAD is able to support only a small number of enterprises; its loan amount of 500,000 cedis per applicant has remained constant since 1989 (so that it is worth very little now); repayments are often late which delays loans to others.

1989 Fund for Small and Medium Enterprise Development (FUSMED) - set up by the Bank of Ghana as a credit extension programme with funding from the World Bank to finance the development of private small and medium enterprises (SME) in the productive sectors of the economy. Loans have tended to be 'captured' mostly by urban-based medium sized enterprises.

1990 EMPRETEC Ghana Foundation - organises venture forums where entrepreneurs needing capital are put in touch with investors, and serves as a financial intermediary between SMEs and formal financial institutions. It has a small coverage and excludes informal MSEs.

1990 Informal sector associations supported by Rawlings' PNDC. Ostensibly to act as intermediaries between member enterprises and the government or other supporting bodies, though the establishment of many well-known ISAs had more to do with politics than selfhelp.

1990/91 World Bank project to provide technical assistance and credit facilities to SMEs. However, the conditionalities attached to the credit line rendered them inaccessible from informal MSEs.

1995 Rural Enterprise Project (REP) (IFAD funded 1995-ongoing) - aims to increase rural production, employment and income in order to alleviate poverty through the increased output of small off-farm enterprises. This is being accomplished by: facilitating access to new technology and business advice; promoting easier access to financial services; improving the efficiency of existing small rural enterprises, supporting the creation of new enterprises, and removing communication constraints through feeder road rehabilitation. See GoG/IFAD (2000).

1995 Vocational Skills and Informal Sector support project (VSP) (World Bank funded, 1995-2001) - focused on skills upgrading for 10,000 master-craftsmen and 15,000 traditional apprentices. The VSP did have some success in improving the outcomes of graduates, but experienced a number of problems and did not lead to any significant impact on the wider informal sector. See World Bank (1995).

Source: Author 
As a concluding word it can be said that government efforts to promote TVET have repeatedly been countered by efforts, on the part of civil society, for a more general academic school curriculum. School-based TVET, therefore, has largely failed to materialise as it was envisaged, and skills training in VTIs has remained an unpopular, or at least second, choice for most youth. The preference for academic schooling initially related to the better access it offered to the emerging, if limited, occupational opportunities in the colonial exchange economy. After independence the preference for a stable wage-income (in the public sector) continued to encourage youth to opt for academic schooling. While Gold Coast/Ghana educational policy, therefore, has been very much concerned with the development of TVET, public opinion and demand has shaped an education system that, in practice, remained largely academic at the start of the twenty-first century.

The next chapter will examine skills development and MSE policy and practice from 2001 to 2006. 


\section{Chapter 5: Skills Development and Informal Micro-Enterprise in Ghana's New Political Context, 2001-2006}

\subsection{Introduction: a new chapter in Ghana's political history?}

The election of Kufuor's NPP in December 2000 ushered in a new political context for Ghana: "for the first time a sitting government was ousted from office by means of the ballot box" (Nugent, 2001: 405) and nearly 20 years of Rawlings' rule came to an end. Four years later, in December 2004, Kufuor was re-elected and has now been in power in Ghana for over five and a half years (November 2006).

When Kufuor took up office in 2001 he was faced by formidable un- and under-employment problems particularly among the youth: in fact the NPP had used job creation as a key election pledge (chap.7.2). Apart from the lack of opportunities at the post-primary or post-JSS level, about 1.2 million children of primary school age were still out of school in 2001 (UNESCO, 2004).

The last chapter reviewed the policy and practice of skills development in relation to the changing economic and labour market, social and political environments from the mid-nineteenth century to 2000. This chapter explores skills development and informal micro-enterprise (IME) policy and practice within the new political context, 2001-2006.

This chapter will take the following structure: first it examines the vision and the reality of skills development policy, 2001-2006; second there follows an equivalent analysis of policy and practice concerning IME and youth employment more generally; third it examines a series of critical environments that those entering IME currently face.

\subsection{Skills development policy, 2001-2006: the vision and the reality}

While there is a recognised general absence of skills development in PRSPs (Caillods, 2003; ILO, 2005, 2003a: 8), the World Bank notes that many governments in SSA have put policies in place that emphasise training for the informal sector (World Bank, 2004a: 142), and Ghana is one such country. 
The GPRS I (2003-2005) has a short section on "Skills and entrepreneurial development for the youth" (GoG, 2003a: 104-105). It outlines three groups of young people most in need of support: barely literate young people (due to early drop-out or inability to attend school); those who have completed (a stage of) formal education but are unemployed due to reasons of quality/relevance of education; young people that have acquired some skills but need retraining to enter the labour market. The GPRS I intended to: increase the relevance and coverage of vocational and technical training; develop and expand the traditional apprenticeship system; and promote entrepreneurship among the youth. Similarly the GPRS II (2006-2009) has a section entitled "Training and Skills Development" (GoG, 2005a: 44-45) and also points to these same groups of people as most in need of skills development, but adds a fourth category; young persons with disabilities. The GPRS II calls for the development of skills and entrepreneurial know-how, and sets out a series of priority areas: (i) provide skills and entrepreneurial training in a gender responsive and equitable manner; (ii) promote dialogue between industry and skills/professional training institutions to produce skilled labour required by industry; (iii) strengthen and support human resource training institutions; (iv) promote apprenticeship training; (v) promote the adoption of the National Youth Policy and enactment of the Disability Bill.

However, in Ghana, skills training has traditionally received little practical government focus, despite the rhetoric of the GPRS I and II documents and more than one hundred and fifty years of preoccupation with making education more relevant to the world of work. ${ }^{188}$ It is worth briefly outlining the current state of, and trends in, skills development in Ghana, particularly as it relates to the informal economy.

The structure of public skills development in Ghana is disjointed, with Government programmes spread across no less than nine different ministries (GoG, 2004b: 3).

Formal TVET in Ghana occurs at three levels. Polytechnics, the highest level training institutions beneath universities, are located in regional capitals $(n=10)$ and are followed by the Technical Training Institutes $(n=23),{ }^{189}$ both under the MoESS. Public sector VTIs under the MoMYE

\footnotetext{
188 There were, of course, government efforts to promote school-based pre-technical and pre-vocational courses at the JSS level, though these have largely failed. On this and other attempts to promote schoolbased TVET see chap.4.

${ }^{189}$ In $2005 / 6$ the total student enrolment in technical institutes was 19,241 ; of these only $13 \%$ of students were female (GoG, 2006b).
} 
number about 111 (NVTIs (30), ${ }^{190}$ ICCES (59) ${ }^{191}$ and other VTIs (22)). Other Ministries have vocationally related institutes, for example: the Ministry of Lands, Environment and Forestry has 15 Regional Technology Transfer Units; and the Ministry of Local Government and Rural Development has about 22 VTIs (Botchie and Ahadzie, 2004; NVTI, 2002). Nonetheless, the MoESS and the MoMYE remain the two dominant providers of TVET in Ghana. The MoMYE is more concerned than the MoESS with skills training programmes for the informal economy: e.g. ICCES (chap.6) and short-duration programmes like STEP (chap.7.1).

In addition to public skills provision, there is a huge range of private for-profit and non-profit provision. There are over 450 private training institutions, many of them church-based VTIs with some 10,000 trainees (Botchie and Ahadzie, 2004; GoG, 2004b). ${ }^{192}$ Some of these, for example the Catholic Don Bosco training institutes in Tema/Ashiaman and Sunyani, are probably unequalled in quality anywhere in Ghana, and they have a history of training children from poorer families. International NGO provision is usually concerned with meeting the training needs of poorer children, while much private for-profit provision is beyond the means of poorer parents.

Much of Ghana's public (and, to a lesser degree, private) formal TVET system is characterised by low quality, obsolete equipment, outdated curricula and a lack of relationship with industry and employment (GoG, 2004i). ${ }^{193}$ Moreover, most public and private VTIs are largely out of reach of the poorest individuals (Chant and Jones, 2005). The formal TVET sector in Ghana, as in other developing countries, is largely orientated towards formal rather than informal employment (cf. World Bank, 2004a).

Altogether there are approximately 50,000 students in different formal TVET institutions (public and private) nationwide at all these levels. ${ }^{194}$ Entry requirements for most of the institutes in the TVET system is a Basic Education Certificate (BECE) or Middle School Leaving Certificate (MSLC), and the training period is usually 3 years. Some, like ICCES, do not have any specific entry requirements and cater for both school dropouts and JSS leavers.

\footnotetext{
${ }^{190}$ In 2000 enrolment in NVTIs stood at 3,700 (Botchie and Ahadzie, 2004).

191 Acting ICCES Director, personal communication 28.07.06.

192 Of these there are some 213 private TVET providers recognised and registered by the NVTI (GoG, 2004b: Annex).

193 Though there are obvious exceptions to this. For example the VOTEC centres (c.20) throughout Ghana are comparatively well resourced having received support from the Netherlands 1999-2003.

194 Botchie and Ahadzie (2004) estimate the total enrolment in Ghana's TVET system, excluding apprenticeships, to be 35,000. However, they under-report the number of students in the technical institutes at 4,500. In fact there are nearer 20,000. Correcting for this gives the approximation of 50,000 students.
} 
Another type of skills delivery mechanism has been the short-duration modality. In the mid-1990s the GoG and the World Bank implemented the Vocational Skills and Informal Sector Support Project (VSP) which focused on skills upgrading for master-craftsmen and traditional apprentices (World Bank, 1995). ${ }^{195}$ More recently (2003-2005) a programme, originally termed the Skills Training Employment Placement (STEP) ${ }^{196}$ programme, offered 3-12 months of training to some 27,000 youth with the intention that the STEP graduates would immediately enter selfemployment (chap.7.1).

The 2005 Preliminary Education Sector Performance Report of the MoES acknowledged that the TVET sector has been neglected (GoG, 2005b: 71). This echoes an early comment from the President's Education Reform Committee that skills development sector has been the object of "almost total neglect" (GoG, 2002: 230). Despite a 19\% increase in public TVET enrolments (under MoESS), from 18,001 in 2001-2, to 21,424 in 2004-5 (GoG, 2005b: 72), the numbers that formal public TVET reaches are low when compared to the huge numbers of annual JSS graduates $(\mathrm{c} .300,000) .{ }^{197}$

Government funding for TVET is low: in 2005 MoESS expenditure on TVET was only $1.2 \%$ of the total resource envelope for education (GoG, 2006b: 108); similarly in 2002 the MoMYE allocated $12 \%$ of its budget to the TVET sector under that Ministry (GoG, 2002: 12). In 2003, Heavily Indebted Poor Country (HIPC) funds were released to finance the STEP programme (chap.7.2). ${ }^{198}$

Similarly, external development partner (DP) funding for TVET has never been extensive. For example, DP funding to TVET under the MoESS was only $0.2 \%$ in 2003, 2.3\% in 2004, $0.9 \%$ in 2005 and $1 \%$ in 2006 (GoG, 2004d: 109; GoG, 2005b: 95; GoG, 2006b: 107). ${ }^{199}$

Nonetheless, there have been a number of DPs engaged in TVET-related programmes including: i) the World Bank VSP (1995-01) (World Bank, 1995); ii) the DFID NVTI Centres Support

\footnotetext{
${ }^{195}$ For a summary see Palmer (2005a).

${ }^{196}$ Later renamed the 'Skills Training and Entrepreneurship Programme'.

197 The private VTIs only cater for about 10,000 trainees in total (Botchie and Ahadzie, 2004).

${ }^{198}$ Ghana has been a HIPC member since April 2001.

${ }^{199}$ One senior advisor from a bilateral DP in Ghana suspected that these figures for donor support to TVET would underestimate the real picture by ignoring the proportion of general budget support which goes into TVET (personal communication 23.08.05).
} 
Project, 1996-1998, aimed to reorientate the NVTIs to be more self-employment focused (Honny, 1999); iii) UNICEF support to establishing ICCES, 1987-1992; iv) JICA support in the development of a TVET policy framework (since 1997); other small-scale support to ICCES; and a new Technical Vocational Education and Training Support (TVETS) Project, planned to commence in 2006 (GoG, 2005e); v) German support to technical institutes, e.g. Takoradi Technical Institute, 1977-2005; vi) Netherlands support to 20 VOTEC Resource Centres (19992003) and to the Ghana Industrial Skills Development Centre (GISDC) (2006); vii) IFAD's Rural Enterprise Project (1995-ongoing) that aims to support MSEs (GoG/IFAD, 2000); viii) CIDA support to GRATIS (2000-2009) and to technical training institutes since the 1960s - to develop a secondary focus on providing short skills-upgrading courses for those already working in SMEs (King and McGrath, 2002a; Sawyerr, 1997); ix) Soviet Union support to technical institutes during the 1960s (Sawyerr, 1997); x) EU support (in 2005) to a small vocational training programme in the north; xi) NGO support to ICCES (1986-2006) and other VTIs.

While this support may have improved the quality in individual training institutions it has not had an impact on the national TVET system - partly for the reason that support has targeted individual beneficiary institutions, that TVET provision is spread across numerous different ministries, and that there has been no overall skills development strategy.

Currently DP support to TVET comes largely from JICA, GTZ and various NGOs, but there has not been one large scale project/programme underway, apart from JICA's support to the TVET policy framework, since the World Bank gave support to the VSP. The Bank has no immediate intention of launching any new skills development projects after the unsuccessful nature of the VSP (1995-01). ${ }^{200}$ Indeed DPs in Ghana have tended to prioritise basic education above other sub-sectors, while the GoG has a more holistic view of the education sector (Ayamdoo et al., 2006; Palmer, 2005c; King and McGrath, 2002a).

Government intervention has been focused on pre-employment skills training and there has been very little attention paid to supporting traditional apprenticeships. ${ }^{201}$ But it is clear that the majority of skills training opportunities lie in the informal economy (chap.7.6), with "informal apprenticeship remain[ing] the only real option for a lot of young people for quite some time to

\footnotetext{
200 The VSP was "deemed unsatisfactory at the implementation completion reporting stage in terms of achieving its objectives" (World Bank Ghana education specialist, personal communication 18.11.04).

${ }^{201}$ But this is changing: there are plans underway to intervene in traditional apprenticeship training (see below).
} 
come" (UNDP/ISSER, 2001: 12). However, the scale of the traditional apprenticeship system while acknowledged as being responsible for the bulk of training for those in the informal sector, and as the largest private provider of skills - is clear but unknown. The chairman of the 2002 Education Reform Committee, Anamuah-Mensah, commented that "no one in Ghana knows how many apprentices there are" (personal communication 29.07.06).

An education reform, set to commence in 2007, as outlined in the White Paper on the Report of the Education Reform Review Committee (GoG, 2004a), proposes some quite radical changes to the education and training system in Ghana. ${ }^{202}$ Concerning skills development, the White Paper acknowledges that the vocationalisation of the JSS "has failed to... comprehensively equip [...] the youth... with directly employable skills for the world of work" (GoG, 2004a: 4). ${ }^{203}$ Henceforth the JSS level will have a more general curriculum. Skills training will be emphasised more at the SSS level, which will be extended to four years (from three) and diversified into four streams: vocational, technical, agricultural and general education. Lastly, the White Paper notes that the government faces an "urgent need to restructure the current officially disengaged attitude towards... [those who drop out of primary and JSS and their] subsequent participation in the world of work" (GoG, 2004a: 13). Hence, the government intends to partner with the private sector to promote more formalised apprenticeship training programmes, with government assuming "full responsibility" (GoG, 2004a: 9) for the first year of the programme. The White Paper proposes further to support public and private training institutions, like ICCES and GRATIS, so that they can increase their enrolment capacity, and to constitute a National Apprentice Training Board to regulate and oversee apprenticeship training, including traditional apprenticeship. ${ }^{204}$

The 2004 White Paper (GoG, 2004a), like the previous education reforms (chap.4), is fueled by the assumption that something must have gone wrong with Ghana's education and training system which has resulted in so many unemployed school graduates. Indeed Ghana's Minister of Education and Sports made explicit the connection between the education reforms and unemployment. At a recent (21.04.06) meeting he reportedly:

\footnotetext{
${ }^{202}$ See Palmer (2005c) on the new White Paper reforms.

${ }^{203}$ For more on vocationalised secondary education, see Lauglo and Maclean (2005).

${ }^{204}$ The other key element of the White Paper reform is the expansion of 'basic education' to include two years of KG, making the basic education cycle in Ghana 11 years long ( 2 years KG, 6 years primary and 3 years JSS).
} 
linked youth unemployment problems to lack of proper educational structure hence the need for educational reforms. He expressed concern about the lack of attention given to technical and vocational training and the number of secondary technical educational institutes available as compared to senior secondary schools and said more technical and vocational training were [sic] needed to reduce unemployment among the youth. (GNA, 2006a)

Related to this education reform (GoG, 2004a) is the 2004 TVET Policy (GoG, 2004i) ${ }^{205}$ which complements the White Paper to reform skills training in Ghana. ${ }^{206}$ Prior to this, there has been no comprehensive national TVET policy, and up to now "[a]ctivities and programmes are organized in isolation” (GoG, 2004i: 5).

The GoG recognises the neglect of TVET course content and delivery (Preddey, 2005: 13), and the new TVET policy and the GPRS II are meant to address this situation. The GPRS II emphasises private sector employment creation and skills training as priority areas (GoG, 2005a). The new TVET policy in Ghana broadly defines TVET as taking place in both a formal education environment and a non-formal training environment:

The formal TVET sub-system consists of institutions that provide classroom and workshop-based instruction. They follow written curricula and students take formal examinations for which certificates are awarded... Non-formal TVET covers the traditional apprenticeship system, on-the-job training and all those skills training activities that do not lead to formal certification. (GoG, 2004i: 3-4)

The reformed TVET system will be demand-driven and competency-based in order to help close the currently huge gap between skill acquisition and the employment demands of the world of work. This is a huge task. Unlike the present curricula which stretch back to the ILO and to the Russian advisors, the new intention is that skill competencies and standards shall be "determined by industry groups rather than training providers" (GoG, 2004i: 18). It is also clear that this competency based approach is meant to extend to the traditional apprenticeship system.

\footnotetext{
205 The TVET Framework Document (August 2004) goes back to April 1997, when the consultation process began for reviewing and updating the TVET system of the country. It emerged from the World Bank's VSP. The latest draft of this is August 2004. A slightly earlier version (January 2004) is more lengthy and contains more details on the thinking of the authors of the TVET policy framework. Both documents will be used in this section and referenced accordingly.

${ }^{206}$ The 2002 Anamuah-Mensah report, from which the 2004 White Paper was developed, agreed to adopt the TVET policy document in its 2002 draft form. Hence the White Paper and TVET Policy are complementary.
} 
The TVET policy framework proposes to dramatically expand the formal TVET sector and to include the informal system as part of public provision. However, since budget allocation to the TVET sector is small, even doubling support to this level would only provide 2-3\% of budget allocation to TVET in MoESS.

This renewed focus on skill is being driven by three imperatives (cf. King, Korboe and Palmer, 2006): the "democratic imperative" requires that education and training opportunities should be diversified to serve the needs of all sections of the population; the "poverty reduction imperative" suggests that in a country where the majority of the population survive on less than a dollar a day, "the challenge to reducing poverty can only be met through a wide-scale and continuous provision of relevant productive skills"; but the "economic imperative" makes it necessary in the context of globalisation, "to produce a highly skilled workforce to support industrialisation and make the country more competitive" (GoG 2004i: v, emphasis in the original). Hitherto, the challenge to link skill with poverty reduction has been secured by a series of ad hoc training schemes. With the TVET policy framework in place (COTVET, see below) the expectation is that a comprehensive demand-driven system can be established and financed.

Specifically the TVET policy framework anticipates that "a massive intervention is necessary to modernise and improve productivity of the [informal] sector" (GoG, 2004i: 33). In relation to promoting productivity in the informal sector through TVET, the framework outlines the objectives that should be the focus of policy interventions (GoG, 2004i: 33):

- Reform and strengthen the traditional apprenticeship system by introducing a competency-based training and assessment system;

- Promote technological proficiency by training for skills to produce competitive items for the domestic and international markets;

- Develop training systems and mechanisms to facilitate the articulation of the informal level and standards of skills acquisition with those of the formal TVET system.

Other mechanisms for increasing productivity in the informal sector include: i) encouraging the formation of trade associations as a means of delivering training-related assistance to members; ii) integrate informal apprenticeship training into the proposed National Qualifications Framework (NQF); iii) integrate TVET into poverty alleviation; iv) provide guidelines for NGO activities in informal sector training (GoG, 2004i: 33-34). However, these mechanisms for increasing informal sector productivity appear to refer more to the informal manufacturing sector 
and less to the informal retail sector. Indeed the TVET policy framework makes little mention of the latter.

The TVET policy framework has a separate section on skills development for agriculture and outlines a number of mechanisms by which to improve agricultural productivity through TVET (GoG, 2004i 22-24). These include improving access to training, ${ }^{207}$ extension services ${ }^{208}$ and post-training support, ${ }^{209}$ especially for out-of-school youth and adult men and women (including disabled), and building capacity in agricultural research and technology. Emphasis is on short, intensive training programmes organised at the district level.

As just mentioned, the TVET policy framework notes that a Ghanaian NQF is being planned to achieve the following objectives: "to bring all post-basic occupation-oriented qualifications into a unified qualification framework" (GoG, 2004i: 19); to facilitate access to further education and training for individuals in vocational and technical occupations; to promote and facilitate access to lifelong learning for all, especially operators in the informal sector; and to improve product and service quality by ensuring uniform standards of practice in the trades and professions (ibid.). However, it is unclear how the Ghanaian NQF will meet the skills needs of what McGrath calls very small and micro-enterprises (VSMEs). In South Africa, the NQF was not designed with the needs of VSMEs in mind and has largely failed to understand the skills needs of the sector (McGrath, 2005a).

The inclusion of informal apprenticeship in the definition of TVET (GoG, 2004i: 3-4) is a positive step forward in acknowledging the importance of informal skills acquisition. However, the overall theme of the TVET policy framework - to formalise training in the informal economy - strikes right at the heart of the basic dilemma of informal sector policy. The ILO/JASPA studies back in the mid-1980s noted that "the [informal] sector is efficient because it is informal, but because of its informality it cannot be integrated into development plans" (ILO/JASPA, 1985: $35){ }^{210}$ The ILO/JASPA report asserted that pro-informal sector policies "taken to [the]... extreme... involves the formalization of the informal sector" (ibid.). King further questions the formalisation of the informal economy, and comments that

207 Focused on production and post-production needs, as well as entrepreneurship and business management skills.

${ }^{208}$ The objective is to improve the agricultural extension officer-farmer ratio from 1:1,500 to 1:500.

209 The priority areas are: i) facilitating access to land, tools, equipment, credit, and storage and preservation facilities; ii) provision of extension services; iii) facilitating access to markets.

${ }^{210}$ This basic dilemma of informal sector policy was noted earlier by Steele (1972). 
if what is special and positive about the informal sector has been developed despite total neglect and even active discouragement by the state, then would it not be valuable for government to continue a hands-off approach? (King, 1996: 12)

King (1996) goes on to note that "any attempt to 'formalize the informal sector' could well undermine its robust independence" (p.12).

Nonetheless, both the President's Committee Report and the White Paper pledged that "Government will assume full responsibility for the first year of all approved apprenticeship programmes" (GoG, 2004a: 13). The GoG is referring to the formalisation of the traditional apprenticeships system and payments that are expected to be made directly to masters to cover the cost of an apprentice's first year of training. Surprisingly a figure of US\$500 per apprentice is being discussed - an amount that is many times higher than the cost of the entire three years of the present traditional apprenticeship (chap.7.9.1). The director of technical and vocational education (GES) commented that:

The amount of US\$500 is a budget from the TVET sub-committee of the National Education Reform Implementation Committee as the proposed support to be offered to master craftsmen/women to meet the cost of training one apprentice per year. This proposal has not yet received approval. (personal communication (email) 01.08.06)

It is highly unlikely that this US $\$ 500$ will be approved; the overall costs would be immense. ${ }^{211}$ Nonetheless, while the $\$ 500$ figure will undoubtedly be reduced, a senior figure connected with the 2004 White Paper confirmed that the support of the first year of apprenticeship had the President's blessing (personal communication 29.07.06).

As the World Bank (2004a) notes, the danger of formalising training in the informal economy lies in the possibility of undermining the strengths and sustainability of training in this sector.

In addition to these worries about the formalization of the traditional apprenticeship, there remain larger questions about how the government intends to fund the TVET elements as outlined in both the White Paper and the TVET policy framework. Indeed, it is feared by some DPs that the proposals in the new education reforms, especially the changes at the SSS level, combined with

${ }^{211}$ If just 1000 apprentices were covered, the cost would be half a million dollars. Masters would undoubtedly celebrate this proposal and, what is more, it might lead to a huge surge in the numbers of people claiming to be master-craftspeople! 
unexpected actual expansion of senior secondary and tertiary enrolments (since 2003), will be so costly that this will adversely impact on the funding for TVET (Palmer, 2005c). More worryingly, the current suggestions on how to fund the new TVET policy were all rejected by Ghana's Ministry of Finance (MoF) with no alternative funding modalities suggested (GoG, 2004i: Appendix A1). ${ }^{212}$ According to the local consultants who wrote the TVET policy, the MoF "appears to be indifferent and unsupportive... [and contains] pockets of covert resistance that would confront the implementation of the policy" (GoG, 2004i: Appendix A2).

Another aspect of the TVET policy framework is the establishment of a Council for TVET (COTVET) which will coordinate and oversee all aspects of TVET (GoG, 2004i), across ministries and the broad spectrum of formal, informal and non-formal education and training. On $27^{\text {th }}$ July 2006 the COTVET Bill was passed (GoG, 2006a). Three committees are to be set up under COTVET which will undertake the functions of the council:

1. National TVET Qualifications Committee - the main regulatory authority for the National Qualifications Framework.

2. Training Quality Assurance Committee - ensures training providers and qualification awarding agencies maintain satisfactory standards in the delivery of training and the award of qualifications.

3. Industry Training Advisory Committee - to develop National Occupational Standards or knowledge, skills and work performance standards for the definition and issuance of qualifications.

Of relevance to our interest in skills and IME, the COTVET secretariat will include an Informal Sector Affairs Division which, among other things, is meant to: develop polices to strengthen the informal apprenticeship system; develop and strengthen links between informal sector TVET and the formal TVET system; develop training packages for the informal apprenticeship system; and, integrate reading, writing and numeracy skills into the informal apprenticeships (GoG, 2006e: 12$13)$.

\footnotetext{
${ }^{212}$ Proposals for funding TVET in the policy document included: increasing direct government budgetary allocation of TVET; allocating 10\% of GETFund to TVET; District Assemblies to allocate a minimum of $5 \%$ of total income to support skills training; and, setting up a Skills Development Fund where members would contribute $1 \%$ of pay roll to the SDF (GoG, 2004b).
} 
But there remain some serious challenges to the successful functioning of COTVET. For example, as noted in the previous chapter, COTVET's predecessor (NACVET) failed to develop a comprehensive skills policy for Ghana. Apart from the inter-ministerial rivalries that inhibited NACVET's functioning it never had any legislative backing. It is hoped that COTVET, that does have legal backing, will be more effective.

However, there remain real dangers related to inter-ministerial cooperation. Initially both the MoESS and the MoMYE were involved in COTVET. However, since the judicial process requires that only one ministry propose a Bill, the COTVET Bill was proposed to parliament by the MOESS. Meanwhile the MoMYE is disputing the idea that MOESS should control COTVET. $^{213}$ The precise reasoning as to why MoESS appears to have gained control of COTVET is unknown, but might be to do with accessing funding for TVET from the GETFund. ${ }^{214}$ Under law only institutions under the MoESS can benefit from GETFund - those under other ministries (e.g. MoMYE) could not access it. With COTVET under MoESS therefore, TVET institutions can access the fund. ${ }^{215}$

Of course COTVET is designed to be inter-ministerial, with representatives from the MoESS, MoMYE, MoTIPP and the Ministry of Environment sitting on the Council, itself chaired by someone with "considerable industrial experience" (GoG, 2006a: 4). However, as it was proposed to Parliament by the MoESS there is now a feeling that this Ministry might control its operations. $^{216}$

These inter-ministerial wranglings will be worsened by the fact that current TVET provision is deeply fragmented. Multiple (often conflicting) agendas and politics within each Ministry have the potential of de-railing COTVET, or at least making implementation difficult. Moreover, as noted above, the largest skills training modality is found outside of the Ministries altogether, in the enormous traditional apprenticeship system.

\footnotetext{
${ }^{213}$ Senior NVTI official, personal communication 28.07.06.

${ }^{214}$ The Ghana education trust fund (GETFund) is funded by a $2.5 \%$ levy on goods and service tax and supplements educational funding in Ghana.

${ }^{215}$ Senior MoESS official, personal communication 28.07.06.

${ }^{216}$ To make matters worse, the technical and vocational education division of GES is mooting the idea of moving out of the MoESS building and moving to where the COTVET will be housed (senior MoESS official, personal communication 28.07.06). This is dangerous as it will further appear that COTVET is being run by the MoESS.
} 
Outside the TVET policy proposals and the reach of the ministries a new development in Ghana's skills development system is the GISDC, due to open in Tema in late 2006 (GISDC, 2006a). The GISDC, which operates independently of the MoESS and MoMYE, is a public-private initiative aimed at supplying demand-driven, industry-responsive training to partner industries in the Tema area. ${ }^{217}$ The first training session is due to start in January 2007 and GISDC will have the capacity to take up to 80 trainees at a time on short courses of about a week. Certification will be linked to the Scottish Qualification Authority and not to national bodies. The GISDC is firmly oriented to the formal sector of the economy, and not to the large number of petty producers in the informal sector. Those behind the GISDC initiative have a strong desire to keep the centre autonomous from the ministries; their reasoning is that "it is not easy to teach an elephant [the MoESS] a new thing" (personal communication 27.07.06). Indeed others see the GISDC as a response to the failure of the GoG to deliver TVET reform; one senior DP official commented that the GISDC initiative is "a sign of frustration on the side of the private sector that it has taken ten years [for the TVET policy] to go nowhere" (personal communication 22.07.06).

\subsubsection{Summary}

Since 2001 there has been a renewed government focus on skills development and its relationship with combating unemployment. This renewed focus has been reflected in both the GPRS I and GPRS II documents and has been driven by the democratic, poverty-reduction and economic imperatives. TVET, delivered through public and private schools, VTIs and traditional apprenticeships, continues to be seen as an important link to work. Between 2003-2005 the GoG funded short-duration skills training through STEP - a direct response to government concerns regarding unemployment.

The 2004 education White Paper and the TVET Policy Framework have set a challenging agenda for skills reform in Ghana. Among other things, this involves developing an NQF, scrapping the vocationalisation of the JSS and, instead, diversifying the SSS level and formalising traditional apprenticeships.

\footnotetext{
${ }^{217}$ While it is a public-private partnership, most of the 'public' money is foreign public money. The Dutch (through the EU) are contributing 200,000 euros; the British are contributing technical advice; the GoG is providing land; and the Ghanaian private sector is supplying funding (22 'partner' industries have expressed interest so far and are meant to contribute 10,000 euros each. As of July 2006, 6/22 industries had paid this).
} 
In 2006 skills development has been a priority concern to national policy-makers. In July the Council for TVET (COTVET) Bill, which has been almost 10 years in the making, was passed by Parliament. Its function is to coordinate TVET provision across the formal, informal and nonformal arenas and to harmonize the skills strategies across multiple ministries. This claims it will develop a comprehensive demand-driven skills system for Ghana.

Having briefly examined the current state of skills development policy in Ghana, this chapter now turns to an examination of policy and practice regarding IME and youth employment, 2001-2006.

\subsection{Informal micro-enterprise (IME), youth employment and the enabling environment: policy vision and practical realities}

Ghana is known for its well-developed informal economy (Haan and Serrière, 2002) and, as noted previously, informal employment and agricultural activities account for the majority (c.86-89\%) of employment in Ghana (GSS, 2000; Heintz, 2004; Xaba et al., 2002).

With approximately one million children of primary school age out of school (UNESCO, 2004), and with JSS to SSS transition rates of about 30\% (GoG, 2003b), most schooled and un-schooled youth enter IME. A crucial issue, therefore, concerns GoG policy and practice vis-à-vis IMEs.

Employment/self-employment creation is a priority for both growth and poverty reduction in Ghana (GoG, 2003a; 2005a). However, the government rationale is that before employment/selfemployment can be created, the population need skills and better education. Moreover, since budget constraints mean that the government cannot create formal employment for all, their primary role is twofold: providing education and skills training, and creating an enabling environment for private sector growth.

Both the 2003-2005 GPRS I (GoG, 2003a) and the 2006-2009 GPRS II (GoG, 2005a) see the private sector, both formal and informal, as the main "engine of growth" and poverty reduction (GoG, 2003a: 30; GoG, 2005a: xxiii). The theme of the 2006 National Budget - Investing in People, Investing in Jobs (GoG, 2005c) also underlines the government's focus on jobs. The private sector development strategy 2004-2008 (GoG, 2003c) outlines Ghana's plans to achieve a "golden age of business" (p.4). The strategy underlines the importance of investing in the enabling environment for private sector growth and outlines policies concerning the macro- 
economic environment, financial sector reform, infrastructure development, public sector reform, contract enforcement/debt recovery and the land system and property rights. This concern with developing an enabling business environment cuts across both agricultural and non-agricultural business activities and is also emphasised in both the GPRS I and II documents (GoG, 2003a; GoG, 2005a).

One of the main objectives of the GPRS II is to "achieve accelerated growth through modernised agriculture, led by a vibrant and competitive private sector" (GoG, 2005a: 29). ${ }^{218}$ It therefore sets out priority interventions to create a competitive agricultural private sector (GoG, 2005a: 31-35):

- reform to land acquisition and property rights;

- accelerating the provision of irrigation infrastructure;

- enhancing access to credit and inputs for agriculture;

- promoting selective crop development;

- modernising livestock development;

- improving access to mechanised agriculture;

- increasing access to extension services;

- provision of infrastructure for aquaculture;

- restoration of degraded environment;

- other policies to support agro-based industrial activities.

These are all components of a dynamic agricultural environment which would better enable youth the utilise acquired skills.

In addition, the GPRS II recognises the importance of "strategic support sectors" (GoG, 2005a: 35-37) that would be developed to facilitate improved productivity in agriculture and agroindustry including in the transportation, energy and science and technology sectors.

According to the World Bank, Ghana's business environment for formal private enterprise compares favourably to other countries in Africa and even to China (table 5.1), though important challenges still remain; Ghana was ranked 94 out of 175 countries. Five states in SSA ranked better than Ghana; South Africa (29), Namibia (42), Botswana (48), Swaziland (76) and Kenya

\footnotetext{
${ }^{218}$ The renaming of the 'GPRS' acronym from the 2003 Ghana Poverty Reduction Strategy, to the 2005 Growth and Poverty Reduction Strategy is a clear signal that there is a much more explicit focus on growth in the latest GPRS.
} 
(83). However 32 states in SSA scored worse than Ghana; 14 of the 20 bottom countries were from SSA (World Bank, 2006a).

Table 5.1. Doing business in Ghana, Kenya, South Africa, Tanzania,
(economy rankings out of 175 countries, April 2006)
\begin{tabular}{|l|c|c|c|c|c|c|}
\hline & $\begin{array}{c}\text { South } \\
\text { Africa }\end{array}$ & Kenya & Ghana & Tanzania & China & India \\
\hline Doing Business & $\mathbf{2 9}$ & $\mathbf{8 3}$ & $\mathbf{9 4}$ & $\mathbf{1 4 2}$ & $\mathbf{9 3}$ & $\mathbf{1 3 4}$ \\
\hline Starting a Business & & & & & & \\
Dealing with Licenses & $\mathbf{5 7}$ & 111 & 145 & 127 & 128 & 88 \\
Employing Workers & $\mathbf{4 5}$ & 24 & 83 & 172 & 153 & 155 \\
Registering Property & 69 & 115 & 113 & 157 & 21 & 110 \\
Getting Credit & 33 & 33 & 117 & 117 & 101 & 65 \\
Protecting Investors & 9 & 60 & 33 & 99 & 83 & 33 \\
Paying Taxes & 74 & 127 & 77 & 113 & 168 & 158 \\
Trading Across Borders & 67 & 145 & 61 & 67 & 38 & 139 \\
Enforcing Contracts & 43 & 67 & 50 & 65 & 63 & 173 \\
Closing a Business & 65 & 128 & 94 & 105 & 75 & 133 \\
\hline
\end{tabular}

Source: World Bank, 2006a

The World Bank's 'Doing Business' database provides measures of business regulations and their enforcement, comparable across 175 economies. They indicate the regulatory costs of business and can be used to analyse specific regulations that enhance or constrain investment, productivity and growth. This data is able to provide some measure of what has been termed the 'economic and labour market environment', albeit only referring to the formal and urban sectors. The data is based on businesses operating in the formal sector of a country's most populous city, especially small and medium sized firms. The data refers to businesses with up to 50 employees and a start-up capital of 10 times income per capita at the end of 2005 . The findings, therefore, does not refer to the bulk of the private sector in many developing countries; those operating in micro-enterprises in the informal sector (in both urban and rural areas). See www.doingbusiness.org

While the business environment for formal enterprise is improving, the same is generally not the case for informal enterprise. Indeed as Heintz (2004) argues, there "is no guarantee that creating an "enabling environment" for the private sector in general will address the specific needs of small-scale, informal, or labour-intensive enterprises" (p.23).

In practice, support to private sector growth is largely concentrated in the formal sector with informal enterprises receiving little support from government despite the fact that the informal economy makes up some $90 \%$ of employment activities in Ghana. Policy focus is very much on the education and training system as the solution to un-/under-employment and poverty 
reduction, without the concomitant creation of a supportive pro-poor decent and productive work environment, especially for the informal economy.

Both the GPRS I and II documents have failed to deal adequately with IME. Heintz (2004: 9) comments that the GPRS I did "not adequately analyse the dynamics of the informal economy or present a well-orchestrated approach to poverty reduction for working people in informal employment". The GPRS I discussed the informal economy only in relation to the more dynamic, growth-orientated, manufacturing and urban MSEs, and has less to say about the more subsistence-orientated, retail and rural MSEs. The latter are most likely to be micro-enterprises owned and operated by women. Both the GPRS I and GPRS II documents do, however, discuss the importance of agriculture and stress the need to modernise this sector, but have little to say about farm-nonfarm linkages, or about rural MSEs (ibid.). ${ }^{219}$ Furthermore the emphasis on growth in the GPRS II is likely to mean that the more subsistence-orientated, retail and rural MSEs might continue to receive little support in practice.

Crucially the issue of occupational pluralism (chap.2), a widespread phenomenon in Ghana's rural informal economy, is not recognised in either the GPRS I or GPRS II documents. This, as discussed later, has implications for skills training interventions in Ghana's rural informal economy.

Nonetheless, three developments show that the GoG is starting to focus more on the informal economy: the President's Sessional Address to Parliament in February 2005 acknowledging the critical importance of the informal sector; the decision to establish a unit under MoTIPP which has responsibility for the informal sector; and a nationwide informal sector survey (2006-7).

In February 2005, in his Sessional address to parliament (GoG, 2005d), President Kufuor made specific mention of the critical importance of the informal economy to the country's economic development:

The importance of this informal sector is in the fact that it encompasses a host of activities including agriculture, commerce, manufacturing, construction, music and

\footnotetext{
${ }^{219}$ The GPRS I and II documents do note the importance of promoting agro-processing activities in rural areas. Indeed the development of the agricultural sector and accompanying agro-industries are highlighted in the GPRS II. Further, participatory poverty analysis conducted as part of the GPRS I noted that, among other things, improved access to education and promoting nonfarm employment were crucial to poverty reduction efforts (GoG, 2003a: 29).
} 
entertainment. By far the majority of our national population is captured in this sector. It will therefore be appreciated that the successful reform of the sector should have a major and far reaching impact on the development of our society and economy. Indeed, Mr. Speaker, this is level where the turn-around of the economy must be pursued. (GoG, 2005d: 9)

He went on to stress the need to "to fashion out a plan to discover [sic] and incorporate this part of the private sector into the formal economy" (GoG, 2005d: 8). The stated intention of the government, therefore, is to formalise the informal sector.

In mid-2005 the MoTIPP was tasked with the responsibility for organising informal sector intervention, and in July a Business Development Services Unit (BDSU) was established under MoTIPP with "a mandate to develop an action plan for Ghana's informal sector in collaboration with stakeholders already working in the sector" (GoG, 2006d: 1). This would involve facilitating access to BDS; training, mentoring and various capacity building programs, as well as access to savings and credit (GoG, 2006d). The BDSU has interpreted the President's wish to formalise the informal sector as meaning more than just moving the informal sector into the formal sector, "but also to ensure that the informal sector is aware of the opportunities and resources within the formal economy... and to ensure that the informal sector is regularized in terms of social protection... and the legal framework" (GoG, 2006d: 1).

Furthermore, during 2006/7 the GoG is undertaking a nationwide informal sector survey to understand the characteristics, type, and needs of IME (by region). The objectives are to:

- assess the nature and scale of the informal economy by identifying/estimating the size, causes, constraints and performance;

- feed into the development of a national informal sector policy;

- identify various informal sector groupings as well as individual business operators in each region, and prioritise business support services interventions including training, mentoring and various capacity building programmes as well as access to credit. (GoG, 2006d: 2)

Interestingly, in the light of our earlier discussion (chap.2.2.2), in the President's Sessional address, above, he includes agriculture as part of the informal sector. However, the terms of reference for the informal sector survey that will inform the drafting of the strategy reverts to the 
more traditional view of the informal sector, noting that "all those self-employed outside agriculture will be covered, including retail (petty) trade" (GoG, 2006d, emphasis added).

DP support to informal MSE has not been significant since 2001, but a new Word Bank project, the Micro, Small and Medium Enterprise (MSME) Project (2006-2011) (US\$45million) has the objective of enhancing the competitive and employment levels of Ghanaian MSMEs (World Bank, 2005c). It comprises three mutually reinforcing components:

- Access to Finance - it aims to significantly improve MSME access to finance;

- Access to Markets, Trade Facilitation and Entrepreneurship Development - it aims to reduce operational, technical and regulatory barriers to markets;

- Business Environment - support to the GoG Private Sector Development Strategy.

As noted above, with regard to the promotion of private sector development, the GoG has been very concerned with the development of an enabling environment and with providing skills and education, particularly to the youth. And, while acknowledging that it cannot create employment for all, a new employment programme, the National Youth Employment Programme (NYEP), is being implemented by the government in 2006 which is expected to ease the general unemployment situation in the country by creating over 150,000 jobs in the first year (GNA, 2006c; GoG, 2006c: 10).

The Ghana Youth Job Corps Programme, otherwise known as the NYEP, is located in the MoMYE and arose out of concerns with security, poverty and economic under-development. ${ }^{220}$ Its origins are to be found in the registration of one million unemployed persons in 2001, the STEP programme (2003-2005), and the declaration on employment and poverty alleviation in Africa (African Union, 2004) made by African Union heads of state concerning measures to stem unemployment, especially among the youth.

The NYEP, which was officially launched in October 2006, was initiated on a Presidential directive and has a budget of some 1.1 trillion cedis (US\$105 million). ${ }^{221}$ The President's foreword to the Youth Employment Implementation Guidelines (GoG, 2006c) notes that while the "introduction of the Technical, Vocation [sic] and Education Testing [sic] Policy (TVET) will help to sharpen the technical and vocational skills of our young men and women and make them

${ }^{220}$ NYEP Director, personal communication 01.08.06.

${ }^{221}$ See footnote 220 . 
more competitive... we also desire that they be placed in employment opportunities that are productive and rewarding" (GoG, 2006c: iii). While this is an incorrect reference to the TVET policy framework (chap.5.1), the President is at least indicating the need to link skills training with job creation.

The NYEP is made up of ten-modules covering plans for youth job creation across a wide spectrum of economic activities - from Youth-In-Trades and Vocations, to Youth-In-AgriBusiness and Youth-In-ICT. ${ }^{222}$ The strategy is to set up national, regional and district-level employment task forces to implement the NYEP. The district employment task forces are charged with identifying potential employment promotion areas and then implementing one or more of the NYEP modules.

The NYEP plans to pay the beneficiaries of all these modules a weekly stipend, averaging $ф 50,000$ (US\$5.5). Those engaging in self-employment activities will be given assistance to purchase inputs, the amount dependent on the trade area. ${ }^{223}$ The National Health Insurance Scheme (NHIS) premiums of beneficiaries would also be paid by the NYEP. However, all of these payments to beneficiaries are expected to be paid back to the NYEP once the beneficiaries are settled into employment (GoG, 2006c: 17-22).

The NYEP is intended to be phase one of a two-phase approach to tackling unemployment issues in Ghana; it is initially meant to last about three years and then be phased into a National Employment Policy, Strategy and Action Plan which is meant to "create a sustainable environment for employment generation in the long term" (ibid.: 49).

It is admitted in the introduction of the Youth Employment Implementation Guidelines by the then Minister for the MoMYE that many well-intentioned initiatives in Ghana have not prospered due to implementation difficulties, and lack of "very clear and user-friendly guidelines" (GoG, 2006c: v). It is also admitted that it would have been preferable to have had a national stakeholders' summit from which an employment policy and strategy could have emerged, but the sheer urgency of the youth unemployment situation suggested that some immediate action was required

\footnotetext{
${ }^{222}$ Other modules include: Community protection system; waste and sanitation management corps; rural education teachers assistants; auxiliary health care workers assistants; paid internships and industrial attachments; vacation jobs; and volunteer services (GoG, 2006c).

${ }^{223}$ The Youth Employment Implementation Guidelines also contains a series of specimen forms on which credit applications and disbursements could be filled in by groups of young people.
} 
(GoG, 2006c: 2). It is also likely that the government, mindful of the 2008 elections, did not want to postpone such a programme given that (youth) unemployment is such a politicised topic and that the current NPP government came to power in 2001 with pledges of job creation.

Indeed the NYEP, like the STEP (chap.7.1), appears to be a highly politicised programme. Not only was it initiated on a Presidential directive, but the District Chief Executives (DCEs) have been made directly responsible for the successful implementation of the NYEP. The NYEP guidelines state that the DCEs' "effectiveness as agents of the Presidency at the district level... would be measured by their ability to generate the required number of jobs and self-employment opportunities for the youth" (GoG, 2006c: 6-7). The NYEP director went as far as to comment that the "DCEs [will] be held accountable if [the] NYEP fails" (personal communication 01.08.06).

The Senior Minister, Mr Mensah, was reported by the Daily Graphic as saying that the NYEP carried the risk of maladministration, welfare dependency and eventual unsustainability. Furthermore that the country's economic advisors never liked the initiative, especially its donor partners, but that "the consequences of the alternative of inaction on youth unemployment are much worse" (Daily Graphic, 13.03.06).

\subsubsection{Summary}

The creation of an enabling environment for private sector development (PSD) has been flaggedup in the GPRS I and II documents and the government's 2004-2008 PSD strategy. Since 2001 improvements have been made in the formal business environment and, compared to other countries in SSA, Ghana has come off well in the World Bank's Doing Business survey (though is still halfway down the overall league table). However, there has not been a similar change in the enabling environment for informal enterprise and neither the GPRS I or II dealt adequately with this issue. This being said, in 2005 President Kufuor highlighted the critical importance of the informal sector and, since then, the MoTIPP has been tasked with the responsibility of organising an informal sector policy.

2006 has been an important year for informal sector and employment issues more generally: the country's first nationwide informal sector survey is currently being undertaken, and the National Youth Employment Programme (NYEP) has been launched. The NYEP has added a third 
dimension to the government's job creation strategy. While the provision of skills and education alongside the development of an enabling environment for PSD are still foremost among policy objectives, the GoG is also intending to create formal and informal jobs for 150,000 over the next year. Like the STEP before it, the NYEP also appears to be highly politicized.

Having examined the policy and practice related to skills and employment up to 2006, the next section examines the current state of the transformative context that enables or disables skills acquired being put to use.

\subsection{From skills acquisition to skills utilisation: enabling and disabling contexts in Ghana's informal labour market}

Chapter 3 outlined a number of components that make up the enabling environment for MSEs. This section will examine these components in the Ghanaian context.

Working might be the clearest pathway out of poverty for the poor, but the type of work that people have is critical (cf. Fluitman, 2005). Most of those working in Ghana's IME economy do not work under 'decent' conditions and many are struggling to move from subsistence to growth. In the context of this thesis, it is crucial to examine the context into which skills training programmes are graduating their trainees. To what extent is the enterprise infrastructure around the informal economy enabling or disabling to development outcomes materialising from skills training? This section will briefly examine a series of critical environments that those entering the IME economy face. It will be recalled that we looked briefly at all of these in Chapter three for their relevance across the whole of SSA. These include the:

- economic environment;

- infrastructural environment;

- legal and regulatory environment;

- policy and institutional environment;

- social environment (networks and associations);

- post training environment. 


\subsubsection{The economic environment}

Approximately $90 \%$ of all employment is in the IME economy (including farm and nonfarm enterprises), while formal employment is stagnating (Teal, 2001). Between 1992 and 1999, the percentage of Ghana's population classified as poor reduced from 52\% to $40 \%$ (GoG, 2003a: 15). However, poverty is still pervasive and these averages mask regional and occupational disparities. Poverty is largely a rural phenomenon, with rural poverty running three times as high as urban poverty (Canagarajah and Pörtner, 2003: 61). This rural nature of poverty suggests that poverty is concentrated in the informal economy (which includes agriculture) (GoG, 2003a: 28). Among occupational groups, non-export food-crop farmers and the nonfarm self-employed are still most at risk (GoG, 2003a). The slow growth of formal employment opportunities (resulting in a slow growth in the number of people with reliable salaries), combined with the rural nature of poverty, mean that the IME economy, especially in rural areas, operates as an income-constrained market, and people's buying power is weak overall. This has the double effect of restricting overall demand for products and services and reducing the demand for training (chap.3.2.1).

The importation of cheap foreign manufactures into Ghana, mainly from China, is suppressing demand for certain traditional trades and appears to be leading to problems for some IMEs (e.g. kente-weaving, dressmaking, sandal/shoe-makers).

Price increases for petroleum products have been dramatic. ${ }^{224}$ For example, gasoline (per gallon) tripled in price 2001-2006 from $\phi 10,500 /$ US $\$ 1.5$ (February 2001) to $\phi 20,000 / \mathrm{US} \$ 2.5$ (January 2003 ) to $\notin 36,000 /$ US $\$ 4$ (September, 2006). This has impacted both directly on IMEs through increased transportation costs and hence increased input costs, and indirectly through higher living costs (e.g. everything moved by road has increased in price).

\subsubsection{The infrastructural environment}

Informal economic activities are constrained by the inadequate infrastructural environment: low access to piped water and sewage systems; unreliable/unavailable mains electricity; low quality hospitals/clinics; restricted access to markets, extension and financial services and education and training facilities; unmaintained transport infrastructure and unreliable telecommunications

\footnotetext{
${ }^{224}$ This has been the result of the GoG removing subsidies on the Tema Oil Refinery.
} 
(Arthur, 2006; Heintz, 2004). For example, the lack of electricity in an area means that hairdressers cannot use electric dryers and hence will lose those customers who need to have their hair dried before travelling back to their village (fieldwork, 2005).

While the rail infrastructure remains in a state of disrepair, a series of feeder-road projects have been improving the rural road networks and the main Accra-Bolga highway is being widened and re-surfaced (though at a slow pace). On the telecommunications front, while fixed-line services have remained unreliable the massive growth in mobile phone use since 2001 has revolutionised telecommunications, even in rural areas (and also created job opportunities for space-to-space wireless telephone enterprises). ${ }^{225}$ The growth of internet-cafés has also been rapid since 2001, though connectivity remains slow in most places and cafés are limited to larger settlements. ${ }^{226}$

The GoG has also started to intervene in the health and social security environment that are meant to improve conditions for those in the IME economy. In 2003 a National Health Insurance Bill (GoG, 2003d) was passed which introduced, among other things, a NHIS open to those in the informal sector. The previous system, known locally as cash-and-carry, involved patients being charged immediately before or after treatment; for those in informal activities it was particularly difficult to find sufficient money for treatment. The new NHIS (GoG, 2004k) allows individuals to make annual contributions into a national health fund. Those in formal employment have $2.5 \%$ of their social security contribution used as their NHIS contribution. Informal sector workers pay an annual contribution according to their social grouping. ${ }^{227}$

In 2005 the Social Security and National Insurance Trust (SSNIT) ${ }^{228}$ introduced an informal sector pilot scheme project which is meant to facilitate access to social insurance for these workers. By the end of 2005 the scheme had registered 6,577 people (against a target of 11,536) who had contributed $\phi 1.05$ billion (US\$100,000) to the scheme. ${ }^{229}$ However, the number of informal workers involved in this scheme remains tiny compared to the total number of those in informal employment.

\footnotetext{
${ }^{225}$ See chap.2.2.2.

${ }^{226}$ Information in this paragraph from fieldwork (2001-5).

${ }^{227}$ The NHIS document (GoG, 2004k) identifies six groupings; core poor, very poor, poor, middle income, rich and very rich. The core poor (disabled, elderly) receive free treatment; the very poor and poor have to pay $\notin 72,000$ (US\$8) a year.

${ }^{228}$ The SNNIT aims to provide income replacement schemes to Ghanaian workers and their dependants in the event of old age, permanent disability, or death.

${ }^{229}$ www.ssnit.com
} 


\subsubsection{The legal and regulatory environment}

In Ghana, a key constraint to informal economic activity (and the private sector as a whole) remains the lack of rights over land and commercial assets (GoG, 2003a: 123; GoG, 2005a). While many assets in the informal sector remain dead capital (De Soto, 2001) it is nonetheless possible to informally use some assets, such as the practice of mortgaging cocoa farms to other community members (see Austin, 2005). The difficulty of using assets as legal collateral means that social collateral becomes more important (i.e. the ability to access finance through social relations).

Rising levels of income tax among informal MSEs and utility tariffs, which have increased 300\% since 2001, further disable enterprise activity (Arthur, 2006; fieldwork, 2005).

Constraints arise from the often contradictory nature of District Assembly and central government policy, in relation to tax collection, harassment and official procedures concerning MSE registration and start-up (Palmer, 2004b). Further, standards (e.g. health and safety issues) and social protection $^{230}$ that exist largely ignore the informal economy, especially in rural areas.

The 1998 Children's Act (GoG, 1998) outlines the legislative framework for work for those up to 18 years. ${ }^{231}$ The 2003 Labour Act (651) outlines the legislative environment for labour in Ghana (replacing the 1965 and 1967 Acts). ${ }^{232}$ The new Labour Act amends, consolidates, and extends the laws relating to labour, including the role of employment centres (GoG, 2003e). Enforcing these new laws, however, remains a problem.

\subsubsection{The policy and institutional environment}

While acknowledging the importance of the informal economy, the GPRS I (GoG, 2003a) did not fully cover this issue - having no clear coherent informal economy strategy. Nor was there sufficient attention in the GPRS I on promoting 'decent work' in Ghana's informal economy. Government policy towards the informal economy has been neglectful at best, and disabling at

\footnotetext{
${ }^{230}$ But note above the informal sector pilot scheme of the SSNIT.

${ }^{231}$ Chap.4, figs.4.2, 4.3.

${ }^{232}$ Chap.4, fig.4.3.
} 
worst, but it is hoped that a new informal sector survey (GoG, 2006d) will help to overcome the lack of focus of policies concerned with MSEs recognised in the GPRS II (GoG, 2005a).

In Ghana, there has traditionally been no one ministry that has overall responsibility for the coordination of activities in the informal economy. Instead a number of ministries have programmes related to the informal economy but the lack of coordination between them serves to inhibit a coherent strategy from emerging. ${ }^{233}$ Coordination between the two key ministries concerned with education, skills development and employment, the MoESS and the MoMYE is weak. ${ }^{234}$ Similarly, there is a lack of coordination between government ministries on the one hand, and the private and non-governmental/ civil society sector on the other.

One of the findings of the VSP evaluation (Korboe, 2001a) was the relationship between key government and non-government institutions concerned with skills training and employment start-up was disjointed. This resulted in trained VSP graduates lacking access to an integrated package of services (credit, extension services, post-training support, vulnerability and social protection).

Realising employment objectives involves coordination across Ministries, Departments and Agencies (MDAs); the evident lack of coordination between these groups can hinder the realisation of employment policies (Heintz, 2004: 23).

That the institutional linkages are weak between agencies promoting skills training and those promoting employment should be a key concern in the development of an informal sector strategy, and it is hoped that Ghana's current informal sector survey will cover some of these key issues.

The quality of skills training programmes meant to support IME activity like ICCES and STEP suffer limitations which further disables training outcomes. Moreover, the gender dimension of

233 As noted, in mid 2005 the MoTIPP were tasked with the responsibility for organising informal sector support services.

${ }^{234}$ For example, at a policy dialogue discussion in March 2005 on 'poverty reduction and wealth creation in the informal economy' in Ghana, organised by the ILO and the MoMYE in Accra, there was not one representative of the MoESS. At a workshop in Edinburgh, in May 2005, the Chief Director of the MoES confirmed that coordination between his ministry and the MoMYE could be improved. As a further example, the NYEP Youth employment implementation guidelines (MoMYE), noted earlier in this chapter, had never been seen by the Director of technical and vocational education in GES (MoESS) (personal communication 28.07.06) until after it was finalized. 
skills training means that young women are often restricted to certain, usually less profitable, trades due to socio-cultural restrictions.

But it is not simply a matter of poor coordination; the effectiveness and capacity of:

many government bodies - including MDAs at the national level and district assemblies at the local level falls below what is required to fully implement the policies. Even the most well-developed employment strategies will fail if the capacity to implement them has not been developed. (Heintz, 2004: 11)

Both the financial and non-financial government programmes for MSEs in Ghana are weak, with women disproportionately disadvantaged in this respect. None of the main schemes of the last 1015 years (FUSMED, PAMSCAD, NBSSI or EMPRETEC) ${ }^{235}$ "seem to be of any benefit to rural micro-enterprises, and instead tend to be aimed at the upper-tier of the informal economy or MSEs in the formal sector" (Palmer, 2004b: 20). For example, part of the function of the NBSSI is to serve as a government supported credit intermediation agency and, as such, it manages the small credit component of the PAMSCAD (ibid.: 18-19). However, there appear to be three fundamental problems with PAMSCAD that makes it of limited use particularly for rural IMES. These include: a) limited coverage and urban bias; ${ }^{236}$ b) small loan amount and required equity contribution that excludes the poorest; c) the timing of loan delivery and repayment schedules is bad (ibid.). Further, the NBSSI needs reforming so that it functions as a facilitator agency rather than as a service provider agency as is the case now.

Part of the reason for weak support systems for the IME sector and poor government planning regarding an effective employment strategy is to do with the lack of government information on the labour market and skills programmes (Heintz, 2004: 23).

\footnotetext{
${ }^{235}$ FUSMED: Fund for Small and Medium Enterprise Development; PAMSCAD: Programme of Action to Mitigate the Social Cost of Adjustment; EMPRETEC is a UNCTAD programme that promotes SME development. See Palmer (2004b: sections 2.5-2.6).

${ }^{236}$ For example, in the 2004 GPRS Annual Progress Report it was noted that during the year the NBSSI had succeeded in: incorporating 400 businesses into the formal sector, facilitating the establishment of 120 new businesses, and granting loans totalling $₫ 210$ million to 378 entrepreneurs (GoG, 2004c: 74). These are very small numbers compared to the size of the IME sector.
} 


\subsubsection{The social environment (politics, networks, associations and gender)}

The peaceful conduct of the elections in 2000 and 2004 and the smooth transition between the NDC and NPP in 2001 were significant developments and helped to maintain a stable enterprise environment.

Those in the IME sector suffer from a lack of representation in the policy process and "have no presence in the corridors of decision-making and power" (Adu-Amankwah, n.d: 9). Informal sector associations (ISAs) are not providing MSEs in Ghana with a sufficient voice in the policy process. ISAs in Ghana were set up to act as intermediaries between member enterprises and the government/ other supporting bodies, though the establishment of many well-known ISAs had more to do with politics than self-help. For example, many of the well-known ISAs (e.g. Dressmakers and tailors association, Ghana national association of garages) did not originally emerge from within the informal economy; rather the Rawlings military government sponsored the formation and registration of over 30 ISAs supposedly to serve the interest of their members but in fact with definite political functions in mind (ie. creating groups that would help legitimise PNDC actions) (Ninsin, 1999). In spite of this highly politicised past, ISAs can impart certain benefits to members, including: welfare; bulk-buying materials to offer members cheaper inputs; intermediating in loan applications; regulating traditional apprenticeships (e.g. offering trade association certificates/ the opportunity to register for nationally recognised trade tests); coordinating skills upgrading through formal training centres; and facilitating the development of a new entrepreneur's enterprise and institutional networks. Nonetheless it is not unusual for members to express dissatisfaction with their associations which many see as being primarily a vehicle to facilitate the collection of taxes. Indeed many ISAs are not sufficiently capable or competent to make the voice of their members heard. Korboe (2001b: 25) in an evaluation study for the VSP, argued that "most of the [informal sector] associations identified by the study team only exist in name and are not functioning as mobilisers of the local artisan corps." It is important, therefore, to question whether ISAs are able to communicate good practice of existing informal providers to government - which would help in the development of an informal sector strategy - other than the services they organise. It should be remembered too that many informal MSEs are not members of any registered ISA.

Aside from the organised/registered ISAs, communities all across Ghana have their own informal associations (e.g. for health, funerals, marriage, savings, self-help) which serve to directly or 
indirectly support informal MSEs (Palmer, 2004a, b). Familial, community and ethnic support and connections can be crucial in entering IME in the Ghanaian context. This might relate to obtaining finance (see below) or access to certain trades. For example social barriers to start-up may run along ethnic lines: Hart (1973) noted the existence of ethnic group concentrations that "act as informal rings inhibiting entry into certain commodity trades" (p.73). In the 1970s the whole of the meat (cattle) distribution (from cattle trading to butchering) was dominated by the Islamic Hausa community and non-Muslims had problems accessing this economic area (ibid.). ${ }^{237}$

Women have traditionally been disadvantaged vis-à-vis access to most elements of the infrastructural environment (above) (Ahadzie and Apt, 2002).

Moreover among the Akan, matrilineality has traditionally meant that inheritance has passed from a husband to his sister's son - and not directly to a man's own children or wife. This has, not infrequently, resulted in women and children being ejected from their house, farm and other enterprise on the death of the husband. While the 1985 Intestate Succession Law (PNDC Law 111) was meant to give a larger share of the estate to the spouse and children of the deceased, the implementation of the provisions of the law continuous to face stiff resistance in some areas. Nonetheless, the practice of matrilineal inheritance is weakening and more and more husbands are passing the lion's share of their inheritance to their own wife and children (fieldwork, 2001$5)$.

\subsubsection{The post-training environment}

After receiving skills, either through pre-employment or on-the-job means, youth are frequently faced with the absence of post-training support, especially in rural areas. This is obviously connected to the disabling institutional environment outlined above.

Access to formal credit, especially in rural areas, is difficult in Ghana - as it is in most of SSA (chap.3.2.5). Nonetheless, the introduction of mobile bankers in some rural districts appears to be facilitating easier access to formal savings (and formal credit to a lesser extent) (Palmer, 2004b). ${ }^{238}$ However, most new start-ups still rely heavily on their own savings. Research in rural

\footnotetext{
${ }^{237}$ See Palmer (2004a: section 3.25).

${ }^{238}$ Mobile bankers offer daily door-to-door financial services and are modelled on the traditional door-todoor money collectors (Palmer, 2004b).
} 
Ghana (2003-2005) showed that between 56-77\% of start-up finance came from personal savings (Palmer, 2004b; 2005 fieldwork, chap.8.2). The differential cost of basic equipment has implications for the ease of access into certain trades. For example, in 2006 the cost of purchasing basic equipment needed to start-up in carpentry (carpenter's bench, marking gage, ratchet brace, saws, planes, hammer, chisels, pinch bar) was $ф 700,000$ (US\$70), while in dressmaking (table, sewing machine, scissors, machine oil, thread, thimble, needles, button machine, tape measure, hangers, material) the cost was higher: $\$ 900,000$ (US\$90). In fact the cost of starting a dressmaking enterprise is much higher since they also need to acquire a workplace - unlike carpenters who can set up their bench under a shady tree. Another difference is that it is much easier for a new carpenter to start small and to purchase items along the way than it is for a new dressmaker to do the same: the most expensive of these start-up items for a new carpenter is the bench (US\$25) compared to the dressmaker's sewing machine (US\$50) without which a new dressmaker can do very little. ${ }^{239}$ Similarly, new hairdressers have a similar need for a kiosk to work from rather than working from a temporary location. For both hairdressers and dressmakers it is harder to get apprentices if they are not working from a kiosk.

In addition to problems associated with formal credit, formal savings and insurance programmes are difficult to access by young, often poor, individuals in the rural informal economy.

Provision of non-financial BDS in rural Ghana is weak. Since 2003, however, the NBSSI has opened Business Advisory Centres (BACs) in 102 out of the 138 district capitals to provide business advice to MSEs. These BACs rely on enterprise owners coming to the office in the district capital instead of the advisors visiting the MSEs. This is likely to inhibit their effectiveness. Nonetheless there exist innovative possibilities to extend BDS to rural clients. For example, the GoG could encourage the development of mobile bankers (noted above) by funding training of these mobile bankers who could then deliver door-to-door BDS to IMEs. Having mobile bankers/business advisors would greatly increase outreach and is preferable to having static advisors in an office, inaccessible to the entrepreneurs that need the advice (Palmer, 2004b).

Especially in rural areas, agricultural education, extension and training services are largely ineffective (GoG, 2004b). This contributes to a general lack of access to technology in the rural informal economy which further disables education and skills outcomes.

\footnotetext{
${ }^{239}$ Interview with carpenter and dressmaker, 16.07.06.
} 
The TVET policy framework for Ghana makes it explicit that training for agriculture is not sufficient alone to raise productivity. As noted above, following agricultural training other interventions are envisaged including facilitating access to land, tools, equipment, credit, extension services and markets (GoG, 2005a: 31-35).

But, the TVET framework is not so explicit with regard to the type of post-training needs for those trained in more traditional nonfarm trades, saying only that there should be some allowance made for "post-training support" (GoG, 2004i: 34) for trainees by integrating TVET with poverty alleviation programmes.

\subsubsection{Summary}

Since 2001 there have been some general improvements in the enabling environment for IMEs, notably in transportation and mobile telecommunications infrastructure and in the extension of national health and social security insurance to informal sector workers. Politically there appears to be more support for PSD than there was during Rawlings' time.

However, in general the environment remains disabling. Income tax and utility costs have increased significantly, and agencies concerned with delivering financial and non-financial BDS to IMEs have failed to make significant changes to their operation: access to formal finance, for example, remains out of reach for most.

For the many thousands of youth graduating from skills training schemes, formal post-training support still remains fragmented and inaccessible. Most entrants into the IME sector, therefore, continue to rely on family and other informal networks to assist them in the process of securing resources for start-up.

\subsection{Conclusion}

2006 has been an important year both for skills development (with the establishment of COTVET) and for employment issues (with an informal sector strategy under development and the launching of the NYEP). 
This chapter has examined the current state of, and trends in, both skills development and IME policy and practice in Ghana, 2001-2006. Over this period the tendency for policy makers and politicians in Ghana to link TVET reform to combating unemployment, as noted in chapter 4, remains very strong. While there have been improvements in the formal enterprise environment, similar changes have not been occurring in the IME environment.

The interaction of politics with policy (both formation and implementation) has been all too clear between 2001-2006. The political proclamations of the NPP concerning job creation and election attempts to reach out to the youth resulted in the highly politicised STEP programme (chap.7.1), the education White Paper and more recently the NYEP.

The NPP's first term of office (2001-2004) did not bring about the kind of visible 'positive change' that much of the population expected. Now, mid-way through its second term, the NPP faces significant pressure to noticeably improve living standards and to follow-through on job creation pledges or else risk losing the 2008 elections. The effect such political pressure will have on policy formation and implementation is perhaps already being seen: the launching of the NYEP - with claims that it will create 150,000 jobs in the first year - may be one such manifestation of emerging populist policies.

The following three chapters, drawing on fieldwork between 2004 and 2006, mark a transition point from policy history and policy analysis to the realities of skills acquisition in rural areas. The focus of these chapters will be on the last ' $T$ ' of TVET - training.

Chapters 6 and 7 examine three types of skills training modality in more depth. Chapter 6 looks at skills training at ICCES: this programme, set up in the late 1980s, delivers three-year training courses in formal training centres but has the objective of preparing youth for self-employment in the informal sector. Chapter 7 then looks at enterprise-based training in traditional apprenticeships as well as the STEP, an example of short-duration training for immediate employment creation. Both the ICCES and STEP schemes are unusual in SSA - where skills training programmes directed at IME "hardly exist" (Haan, 2006: xxvi) - and hold the potential to break away from the traditional delivery of skills for wage-sector jobs. These two chapters provide more detail on the operationalisation of the skills agenda just discussed. Chapter 8 then examines the pathways to IME self-employment through retrospective interviews. 


\section{Chapter 6: Institution-Based Pre-Employment Skills Training in Ghana at the Integrated Community Centres for Employable Skills (ICCES): The Training Environment and Pathways to Informal Micro-Enterprise}

\subsection{Introduction}

Typically, training for self-employment is offered outside formal training systems. (King, 1997: 9)

There are very few examples of explicit links between the formal education system and the informal sector. (McGrath et al., 1995: 73)

As these two quotations above underline, training for self-employment - especially in the informal sector - usually does not occur in formal institutions. Moreover, where attempts have been made, this reorientation has proved difficult (Grierson and Mackenzie, 1996). It is interesting, therefore, to examine a further attempt at this from Ghana - the Integrated Community Centres for Employable Skills (ICCES). ICCES is an example of pre-employment long-term skills training that has the principal objective of promoting self-employment, and that provides training within a formal skills training environment. The analysis and information in this chapter has benefited immeasurably from the close contact I have had with the ICCES organisation since January 2001. ${ }^{240}$

ICCES has been mentioned in a number of agency or policy-orientated documents. However, in most cases, this is limited to a few lines (e.g. Aryeetey et al., 2005; World Bank, 2005b), a short section (e.g. Haan and Serrière, 2002; UNESCO, 2003) or is based on information that dates back to the early 1990s (e.g. Boeh-Ocansey, 1995). However, there have been a few field reports written by volunteers working for the ICCES programme (e.g. Brownlee, 2000; Logie, 2004; Palmer, 2001). To the author's knowledge, ICCES has not been discussed at all in the academic literature (but see Palmer, 2005a).

Unlike the Skills Training and Entrepreneurship Programme (STEP) (chap.7.1), which has been high on both the political and policy agenda (2003-2005), ICCES receives little attention within the GoG. ICCES is not mentioned in either the GPRS I (GoG, 2003a), the GPRS II (GoG,

\footnotetext{
${ }^{240}$ Unless otherwise stated, the information in this chapter draws on the author's experience with ICCES 2001-2006 (chap.1.3.3).
} 
2005a), the 2006 budget statement (GoG, 2005c) or the NYEP (GoG, 2006c). However, the 2004 White Paper (GoG, 2004a: 13) does note that there is a need to support TVET institutions such as ICCES. As for documents written by the ICCES Directorate, little material exists of any note that tries to synthesise the current state of affairs (but see ICCES, 2004, 1996).

In accordance with the theoretical framework laid out earlier (chap.3), this chapter analyses both the delivery context of training at ICCES and the transformative context that ICCES graduates experience as they find their pathway to work. ${ }^{241}$ The first section provides background on ICCES, including its aims and objectives, how it relates to GoG strategy, and information on curriculum, enrolments, fees and dropouts. The second section examines the training delivery context. The third section looks at both the further training pursued by ICCES graduates, and at the employment activities of graduates in the labour market. ${ }^{242}$

\subsection{Background}

ICCES is an agency under the MoMYE with a network of, predominantly rural, VTIs offering training in vocational trades and is the offspring of the defunct 1960s Continuation Schools Programme (chap.4.3.2). The creation of ICCES was a further manifestation of the government's desire to prepare youth for work. The intention has been to offer vocational training opportunities for JSS graduates and dropouts. ICCES is essentially designed as pre-employment training for the informal economy and it is expected that trainees will become employed, mostly in selfemployment in enterprises (ICCES, 1996), upon completion of a three year course. ICCES has some similarities to, for example, Kenya's Youth Polytechnics (e.g. see Haan, 2006) or, at one point, the Botswana Brigades. The ICCES Strategic Plan (2004-2007) (ICCES, 2004) outlines the mission statement and objectives of ICCES:

\footnotetext{
${ }^{241}$ While the different components of this transformative context have already been covered (chap.5.3), this chapter provides new data on the employment outcomes of ICCES graduates.

242 The data collected was from seven centres in Ashanti, and is backed up with a very detailed understanding of one particular ICCES centre where I previously worked in 2001/02.
} 
Mission statement: To fill a major gap in employment generation by developing young human resource in line with the poverty alleviation goals of the Ghana Government through the establishment of community-based vocational training centres throughout Ghana.

\section{Objectives}

- To improve upon capacity development, skills training and retraining.

- To promote community involvement in the provision of vocational and viable handicraft training for the youth, particularly JSS and SSS leavers and dropouts at lower academic levels as well as illiterates.

- To support communities, especially rural communities, in mobilising resources within and outside their communities for the establishment and running of the communitybased ICCES Centres and Production Units.

- To support Centres to attain high levels of sufficiency and self-employment for their trainees through entrepreneurial training and the formation of cooperatives.

- To liaise with District Assemblies and other stakeholders to support the various ICCES centres.

- To conduct research and develon plans for the sustenance and expansion of the

\subsubsection{ICCES as part of GoG strategy}

ICCES is meant to have a key role to play in the government's skills drive. According to a former Deputy Minister (MoMYE), the intention is to open ICCES centres in all districts nationwide to offer vocational, agricultural and entrepreneurial training (GNA, 2003a). ${ }^{243}$ Since 1986 ICCES has expanded from 12 to 59 centres (August 2006) but has been beset with problems that seriously hinder quality training provision.

ICCES centres around the country were service providers of STEP, and therefore - at least indirectly - became more important to the government. In 2003 and 2004, ICCES trained 1,369 and 1,500 people respectively under STEP. In 2004 ICCES centres accounted for 43\% (49/114) (Preddey, 2005: 15) of the government training institutions that delivered STEP training in the second phase. ICCES was chosen to deliver STEP due to ICCES' widespread nature (especially in rural areas) compared to other public VTIs under the MoMYE (ICCES has 59 centres compared to about 30 NVTIs). Nonetheless, despite the important function ICCES played in delivering the, much publicised and highly politicised, STEP, ICCES itself still remains a weak institution.

\footnotetext{
${ }^{243}$ In fact the objective of opening up ICCES centres in every district of Ghana was first set in 1996 and was thought achievable in one year (ICCES, 1996).
} 
In addition to delivering STEP, some ICCES centres around the country have been designated as production units. These are meant to generate income "that will provide funds needed to resource the Centres" (ICCES, 2004: 13).

However, despite conducting other activities like the STEP programme and production units, the backbone of ICCES activities centres around the provision of long-term pre-employment vocational training in community-based VTIs.

\subsubsection{Curriculum, enrolments, fees and dropouts}

At the time of writing, the current national enrolment for ICCES was not available; the latest figures available are for 2002, when some 11,800 trainees were enrolled. ${ }^{244}$

Nonetheless, figures are available for Ashanti Region, widely regarded as the most successful region in terms of ICCES development. For the last three years, enrolment in ICCES centres in Ashanti Region has been around 1000 (table 6.1). Enrolment increased significantly in 2002 in part, perhaps, due to the GoG starting to pay the salaries of instructors (chap.6.2.2), which in turn would have led to higher attendance of instructors and therefore, perhaps, higher enrolment. Moreover, STEP might have encouraged enrolment in ICCES.

Table 6.1. Total enrolment figures for ICCES in Ashanti Region, 2001-2006

\begin{tabular}{|r|r|r|r|}
\hline Year & Male & Female & Total \\
\hline 2001 & 267 & 116 & $\mathbf{3 8 3}$ \\
\hline 2002 & 452 & 222 & $\mathbf{6 7 4}$ \\
\hline 2003 & 466 & 260 & $\mathbf{7 2 6}$ \\
\hline 2004 & 690 & 339 & $\mathbf{1 0 2 9}$ \\
\hline 2005 & 596 & 316 & $\mathbf{9 1 2}$ \\
\hline 2006 & 677 & 269 & $\mathbf{9 4 6}$ \\
\hline
\end{tabular}

Source: ICCES Ashanti Regional Coordinator, personal communication (email) 30.03.06

The gender balance in ICCES centres appears not to be equal. For example, in Ashanti Region only 28.4\% (269/946) of all trainees were female (January 2006) (table 6.2). This has remained at about the same level since 2001, but appears to be lower in 2006 than at any time over the last

\footnotetext{
${ }^{244}$ This is in spite of numerous attempts by the author to obtain up to date data. It appears that the ICCES Directorate cannot quickly say how many trainees are currently enrolled.
} 
five years; the percentage of female students has varied from $28 \%$ (2006), 35\% (2005), 33\% (2004), 36\% (2003), 33\% (2002), to 30\% (2001) (table 6.1).

Table 6.2. Enrolment in ICCES centres, by sex, Ashanti Region, January 2006

\begin{tabular}{|l|r|r|r|}
\hline & Male & Female & Total \\
\hline Tetrefu & 112 & 18 & 130 \\
Nerebehi & 142 & 49 & 191 \\
Dwease-Praso & 16 & 4 & 20 \\
Baworo & 66 & 35 & 101 \\
Asiwa & 16 & 6 & 22 \\
Twedie & 44 & 7 & 51 \\
Konkoma & 14 & 17 & 31 \\
Otaakrom & 67 & 35 & 102 \\
Akutuase & 49 & 24 & 73 \\
Amoawi & 61 & 28 & 89 \\
Afoako & 30 & 20 & 50 \\
Ofoase-Kokoben & 55 & 9 & 64 \\
Anyinasuso & 5 & 13 & 18 \\
Kumasi production unit & 0 & 4 & 4 \\
\hline & 677 & 269 & 946 \\
\hline
\end{tabular}

Source: ICCES Ashanti Regional Coordinator, personal communication (email) 27.03.06

There are obviously variations at the centre level (table 6.2), with some centres even having more girls than boys.

ICCES offers trainees a three year vocational course in trades such as carpentry, building/construction, dressmaking, catering, hairdressing, electrical installation, mechanics and batik tie and dye (courses vary depending on availability of instructors). ${ }^{245}$

${ }^{245}$ All of these trade areas in ICCES can also be learnt on-the-job in traditional apprenticeships (chap.7.6). 
Table 6.3. Enrolment in ICCES centres, by trade, Ashanti Region, January 2006

\begin{tabular}{|c|c|c|c|c|c|c|c|c|}
\hline & $\begin{array}{r}\text { Building/ } \\
\text { construction }\end{array}$ & $\begin{array}{r}\text { Carpentry/ } \\
\text { joinery }\end{array}$ & \begin{tabular}{|r|} 
Building/ \\
draftman- \\
ship
\end{tabular} & $\begin{array}{r}\text { Dress- } \\
\text { making }\end{array}$ & $\begin{array}{r}\text { Catering/ } \\
\text { hair- } \\
\text { dressing }\end{array}$ & $\begin{array}{r}\text { Batik, tie } \\
\text { dye }\end{array}$ & $\begin{array}{r}\text { Electrical } \\
\text { installation }\end{array}$ & Total \\
\hline Tetrefu & 49 & 15 & 20 & 15 & 5 & 0 & 26 & $\overline{13}$ \\
\hline Nerebehi & 66 & 8 & 10 & 8 & 40 & 0 & 59 & 19 \\
\hline Dwease-Praso & 10 & 6 & 0 & 4 & 0 & 0 & 0 & \\
\hline Baworo & 31 & 21 & 0 & 23 & 12 & 0 & 14 & 101 \\
\hline Asiwa & 7 & 9 & 0 & 6 & 0 & 0 & 0 & \\
\hline Twedie & 29 & 15 & 0 & 7 & 0 & 0 & 0 & \\
\hline Konkoma & 2 & 8 & 0 & 18 & 0 & 0 & 3 & \\
\hline Otaakrom & 53 & 18 & 0 & 18 & 11 & 0 & 2 & 10 \\
\hline Akutuase & 25 & 24 & 0 & 24 & 0 & 0 & 0 & \\
\hline Amoawi & 31 & 6 & 0 & 19 & 0 & 0 & 33 & \\
\hline Afoako & 12 & 18 & 0 & 20 & 0 & 0 & 0 & \\
\hline Ofoase-Kokoben & 22 & 6 & 0 & 9 & 0 & 0 & 27 & \\
\hline Anyinasuso & 3 & 2 & 0 & 7 & 6 & 0 & 0 & \\
\hline Kumasi production unit & 0 & 0 & 0 & 0 & 0 & 4 & 0 & \\
\hline Totals & 340 & 156 & 30 & 178 & 74 & 4 & 164 & 94 \\
\hline
\end{tabular}

Source: ICCES Ashanti Regional Coordinator, personal communication (email) 27.03.06

In Ashanti region almost 40\% (370/946) of all trainees enrolled are learning building/construction or building/draftsmanship. The next most popular trade areas are dressmaking (19\%, 178/946), electrical installation $(17 \%, 164 / 946)$, carpentry $(16 \%, 156 / 946)$, then catering/hairdressing $(8 \%$, 74/946) (table 6.3). Each trainee pursues one main trade area which leads to an NVTI trade or proficiency certificate. Illiterate/semi-literate trainees have the option of taking a non-written proficiency test (involving a practical and oral examination). Other trainees take the full written trade test. The curriculum also includes English, Maths, Agriculture, Public education and Entrepreneurial Studies. ${ }^{246}$ Training is conducted in the VTI full time, ${ }^{247}$ with an approximate split of $30 \%$ trade theory, $40 \%$ trade practical and $30 \%$ other lessons. A small number of centres (e.g. 1/13 in Ashanti) also offer the City and Guild (C\&G) course, which lasts an additional year and requires an NVTI grade one pass in the full trade test. ${ }^{248}$

Although most trainees are JSS graduates, ${ }^{249}$ trainees must fulfil no specific entry requirement and ICCES is open to both literates and non-literates (ICCES, 2004). However, ICCES is definitely not a first choice for most trainees and certainly comes after SSS, technical institutes

\footnotetext{
${ }^{246}$ Entrepreneurial Studies is not taught in all centres, and mostly only in Ashanti. Public education involves the teaching of general life skills like HIV/AIDs awareness, health education etc.

${ }^{247}$ Some trades (building/construction, carpentry) might spend some time doing on-the-job practical training if the ICCES centre or any of the instructors have contract work to do.

${ }^{248}$ Fees and registration for the $\mathrm{C} \& \mathrm{G}$ are considerably higher: about $\$ 1,500,000$ (US\$150) for the year (2006).

${ }^{249}$ E.g. in Otaakrom ICCES (Ashanti), 126/130 current students had been to JSS (fieldwork, 2005).
} 
and NVTI centres in terms of attractiveness. Most of those that do enter ICCES have very poor aggregate scores at the BECE level, making it difficult to enter into other second-cycle institutions. For example, the 126 trainees ( 85 male, 41 female) in Otaakrom ICCES (Ashanti) had an average aggregate of 30 (same for male and females). ${ }^{250}$

There is no uniform country-wide training fee set. Instead, centre managers usually set their own fees in accordance with the ability of local people to pay. In the absence of any fee guidelines from the ICCES Directorate, a few ICCES centres (though not in Ashanti) have been set up as free-schools in the past (Palmer, 2001). Training fees, therefore, are fairly low. As of July 2006, training fees at ICCES centres in Ashanti ranged from $\not 10,000-100,000 /$ term (US\$1-10.5). In addition, most centres charge for school uniforms, PTA, practicals, sports and other items (table 6.4). These costs, while low in comparison to other VTIs, are still too high for many poorer families (chap.6.2.11).

Table 6.4. Costs of ICCES training in Ashanti Region, July 2006

\begin{tabular}{|c|c|c|c|c|c|c|c|c|c|}
\hline & \multicolumn{4}{|c|}{ One off costs (on entry) } & \multicolumn{5}{|c|}{ Termly costs ( 3 terms/year) } \\
\hline Centre name & $\begin{array}{r}\text { Admission } \\
\text { Forms }\end{array}$ & $\begin{array}{r}\text { Admission } \\
\text { Fees }\end{array}$ & $\begin{array}{r}\text { House } \\
\text { Wear }\end{array}$ & $\begin{array}{r}\text { School } \\
\text { Uniform }\end{array}$ & \begin{tabular}{|r|} 
Tuition \\
Fees \\
\end{tabular} & $\begin{array}{r}\text { Hostel/ } \\
\text { boarding }\end{array}$ & PTA & Practical & Sports \\
\hline Nerebehi & 20,000 & 30,000 & 50,000 & & 92,000 & 5,000 & 10,000 & 5,000 & 10,000 \\
\hline Tetrefu & 20,000 & 100,000 & 45,000 & & 100,000 & 20,000 & 10,000 & 15,000 & 5,000 \\
\hline Otaakrom & 20,000 & 40,000 & & & 65,000 & 15,000 & 20,000 & & 5,000 \\
\hline Baworo & 10,000 & 50,000 & & 50,000 girls & 80,000 & 10,000 & 10,000 & & 5,000 \\
\hline & & & & 100,000 boys & & & & & \\
\hline Dwease-Praso & 10,000 & 20,000 & & & 60,000 & & 10,000 & & 10,000 \\
\hline Twedie & 10,000 & & 40,000 & & 50,000 & & & & 10,000 \\
\hline Konkoma & 5000 & & & & 35,000 & Free & 5,000 & & \\
\hline Akutuase & 10,000 & .. & 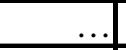 & & 50,000 & $\ldots$ & & & 5,000 \\
\hline Amoawi & 20,000 & & & & 10,000 & Free & 25,000 & 10,000 & 5,000 \\
\hline Ofoase-Kokoben & 20,000 & 20,000 & & 115,000 & 50,000 & 10,000 & 10,000 & & 10,000 \\
\hline Afoako & 10,000 & 120,000 & & & 50,000 & & 8,000 & & 5,000 \\
\hline Asiwa & 5,000 &. & & $\ddot{\ddot{u}}$ & 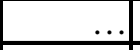 & ... & 5,000 & & \\
\hline Anyinasuso & $\ddot{.}$ & & & &. & & 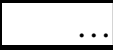 & & \\
\hline
\end{tabular}

Source: ICCES Ashanti Regional Coordinator, personal communication (email) 15.07.06.

Legend: ... - missing data; n/a - not applicable

The average total cost of a three-year course (excluding uniform and hostel fees) at a rural ICCES in Ashanti was $\not 790,000$ (US\$88) in 2006 (calculated from table 6.4). This compares to US\$38-

${ }^{250}$ The BECE aggregate is the aggregate of the best six marks achieved in the BECE. Each subject is graded 1 to 10: grade 5 or below is a pass, making the pass range for the aggregate of the six subjects 6 to 30. A good SSS in Kumasi (e.g. Yaa Asantewaa, Prempeh II) requires entrants to have an aggregate of 610. Otaakrom's local SSS at Nyinahin, not in the same league as Prempeh II or Yaa Asantewaa, requires an aggregate of between 15-30 for entry. About 50\% of all ICCES trainees in Otaakrom achieved less than 30 aggregate and so were theoretically able to access the SSS at Nyinahin (fieldwork, 2005). 
42 total for a three-year traditional apprenticeship (in carpentry or dressmaking) in rural Ashanti (2005) (chap.7.9.1). By contrast, the total cost for three-years training (in carpentry, building/construction or dressmaking) for an NVTI certificate in a good quality private VTI in Kumasi (e.g. Ramseyer) can cost as much as $ф 6,000,000$ (US\$664) in 2006.

Unlike for JSS, dropout rates in ICCES are not routinely calculated. However, data collected from four ICCES centres in Ashanti shows that during 2003-2004, dropout rates were around $20 \%$ for the twelve month period (January to December), improving in 2005 to an average of $12 \%$ (table 6.5). From the four centres where data was available, dropouts appeared highest among building/construction trainees (three yearly average of $21.4 \%$ ); followed by carpentry trainees (three yearly average of 19.5\%); dressmaking trainees (three yearly average of $14.7 \%$ ) (calculated from table 6.5). Out of all those that dropped out over the three year period $(n=111)$, $41 \%$ (46/111) were building/construction trainees, 32\% (35/111) were dressmaking trainees, and $20 \%(22 / 111)$ were carpentry trainees (calculated from table 6.5).

Table 6.5. Dropout rates for Otaakrom, Konkoma, Amoawi and Akutuase ICCES centres, 2003-2005

\begin{tabular}{|c|c|c|c|c|c|c|c|c|c|c|c|c|}
\hline & \multicolumn{4}{|c|}{2003} & \multicolumn{4}{|c|}{2004} & \multicolumn{4}{|c|}{2005} \\
\hline & \multicolumn{2}{|c|}{ Enrolments } & \multirow{2}{*}{$\begin{array}{r}\text { no. of } \\
\text { dropouts }\end{array}$} & \multirow{2}{*}{$\begin{array}{l}\text { \% dropout } \\
\text { in trade }\end{array}$} & \multicolumn{2}{|c|}{ Enrolments } & \multirow{2}{*}{$\begin{array}{r}\text { no. of } \\
\text { dropouts }\end{array}$} & \multirow{2}{*}{$\begin{array}{l}\text { \% dropout } \\
\text { in trade }\end{array}$} & \multicolumn{2}{|c|}{ Enrolments } & \multirow{2}{*}{$\begin{array}{r}\text { no. of } \\
\text { dropouts }\end{array}$} & \multirow{2}{*}{$\begin{array}{l}\text { \% dropout } \\
\text { in trade }\end{array}$} \\
\hline & Jan-03 & Dec-03 & & & Jan-04 & Dec-04 & & & Jan-05 & Dec-05 & & \\
\hline $\mathrm{B} / \mathrm{C}$ & 54 & 37 & 17 & 31.5 & 76 & 60 & 16 & 21.1 & 111 & 98 & 13 & 11.7 \\
\hline $\mathrm{C} / \mathrm{J}$ & 32 & 26 & 6 & 18.8 & 34 & 25 & 9 & 26.5 & 53 & 46 & 7 & 13.2 \\
\hline $\mathrm{D} / \mathrm{M}$ & 59 & 54 & 5 & 8.5 & 84 & 65 & 19 & 22.6 & 85 & 74 & 11 & 12.9 \\
\hline $\mathrm{E} / \mathrm{L}$ & - & & - & & 15 & 20 & 0 & 0 & 29 & 25 & 4 & 13.8 \\
\hline $\mathrm{H} / \mathrm{D}$ & 1 & 1 & 0 & 0 & 1 & 1 & 0 & 0 & - & - & - & - \\
\hline C & 7 & 5 & 2 & 28.5 & 10 & 9 & 1 & 10 & 12 & 11 & 1 & 8.3 \\
\hline Total & 153 & 123 & 30 & 19.6 & 220 & 180 & 45 & 20.5 & 290 & 254 & 36 & 12.4 \\
\hline
\end{tabular}

Source: Calculated by Palmer, based on data from ICCES Ashanti Regional Coordinator, personal communication 27.03.06. B/C: Building/construction; C/J: Carpentry/joinery; D/M: Dressmaking; E/L: Electricals; H/D: Hairdressing; C: Catering.

More detailed work done by the author in Otaakrom ICCES suggests that drop out rates for a particular cohort (2003/4) may be as high as 60\%. More worryingly from a poverty reduction perspective over $70 \%$ of children classified as poor who started in 2003/4 were no longer there in the final year. ${ }^{251}$

\footnotetext{
${ }^{251}$ This was a pilot exercise conducted on 16.07.06 for a DFID-supported research project at Edinburgh University (see Palmer, 2006b).
} 
No data exists on the reasons why ICCES trainees drop out. However, financial problems, followed by pregnancy, are often quoted as the two main factors. ${ }^{252}$

\subsubsection{Summary}

Since ICCES began in 1986 its coverage and form have changed. ICCES has expanded from 12 to 59 centres nationwide and training has become less associated with the labour market and more formalised: the three year courses now take place almost entirely in VTIs and not, as initially happened, mostly with artisans on-the-job. Meanwhile the principal concept has remained the same: to train youth for employment, preferably self-employment in, and around their communities. ICCES remains an important plank in Ghana's TVET system: it is one of the only formal VTIs that does not require a BECE pass and its fees are remarkably low in comparison to other institutions. Nonetheless, the fact that the majority of ICCES trainees are JSS graduates is a signal that ICCES is failing to reach the most vulnerable groups.

\subsection{Training delivery context}

This section examines the different aspects of the delivery context of ICCES training.

\subsubsection{The changing financing environment of ICCES, 1986-2006}

First and foremost, the delivery context of training has been shaped by the changes in the financing environment over the last 20 years.

In 1986 the non-formal education division of the $\mathrm{MoE}^{253}$ with significant financial backing from UNICEF from 1987-1992 (ICCES Director, personal communication 18.11.04), ${ }^{254}$ revived the defunct continuation school programme, under the new name of ICCES, starting with 12 pilot centres around the country. Support was substantial during the UNICEF period, with the agency providing support for salaries, equipment, workshops, transport and follow-up support (ibid.; ICCES, 1996) and financing the "new programme very considerably" (ICCES, 1996: 1). By the

${ }^{252}$ ICCES Ashanti Regional Coordinator, personal communication 01.09.05.

253 Now MoESS.

${ }^{254}$ An earlier ICCES document reports UNICEF funding ending in 1989 (ICCES, 1996). 
early 1990s there were some 45 centres nationwide (Haan and Serrière, 2002), by 1995 there were 67 centres (World Bank, 1995) ${ }^{255}$ and by 2002, 91 centres throughout the country. ${ }^{256}$

After the end of the UNICEF period in 1992, the GoG - lacking the financial resources to continue the level of support UNICEF had provided - turned over the funding of ICCES to the communities, with the Ministry taking on a facilitating role. The ICCES Directorate, nonetheless, was meant to provide some start-up capital to communities opening ICCES centres as well as ongoing support. It was expected that artisans in the community would assist with training at ICCES centres. At this stage, the strategy adopted was to apprentice trainees to a "master craftsman of good standing for 2 years in the trainee's district of residence" (Boeh-Ocansey, 1995: 23), and follow this by a further year in an ICCES institution learning trade theory. Originally no school fees were charged. Instead finance was meant to come from production units (staffed by trainees), chiefs, churches, district assemblies, durbars and communities. In passing the financing of ICCES over to the communities, the GoG stripped back ICCES from its original form: ICCES moved from the provision of training integrated with other support services during the UNICEF-period, to the provision of training alone. Moreover, ICCES training changed from a combination of on-the-job apprenticeship in years one and two, combined with theory training in an ICCES institution during year three, to all three years of training taking place in an ICCES institution. In 1995 ICCES was moved from the Ministry of Education (MoE) to the Ministry of Employment (MoESW). ${ }^{257}$

By the mid/late-1990s ICCES was in crisis: community support had dwindled, local artisans recruited as trainers - were not being paid and National Service Personnel (NSP) were brought in to fill the gap. In practice the expected financial support from the ICCES Directorate, communities and chiefs was not forthcoming and many centres collapsed. Those that survived had some form of external financing and operated effectively independently of the ICCES Directorate. For example, Nerebehi ICCES (Ashanti), among the 12 pilot centres opened in 1986, gained the support of the Ghana Education Service (GES) in the early 1990s who allowed a GES paid teacher to function part-time as the centre manager. Tetrefu ICCES (Ashanti) - also one of the 12 initial centres - has been able to maintain, and sustain, strong community support for

${ }^{255}$ An ICCES document from 1996 noted that in 1994 there were 70 centres active (ICCES, 1996).

${ }^{256} \mathrm{http}: / / \mathrm{www}$.ghana.gov.gh/governing/ministries/social/manpower.php. As of mid-2006, ICCES has 59 active centres (senior ICCES official, personal communication 28.07.06). However, as noted above, in 2002 there were reportedly 91 centres. The difference is likely to be due to centres closing down since 2002 and the higher figure referring to both active and inactive centres.

${ }^{257}$ Now MoMYE. 
ICCES, partly as a result of the dynamic leadership of competent centre managers. Nima-441 ICCES - located in a poor, predominantly Muslim area of Accra (Nima) and one of the very few urban ICCES centres - was also among the 12 pilot centres opened in 1986, but it collapsed in the early 1990s due to lack of financial support. In March 1999 it reopened with support from the Nima-441 Welfare Association and an Iranian NGO.

By 1998 about 40 centres had collapsed (ICCES Director, personal communication 18.11.04). Between 1999 and 2001, ICCES centres around the country were in a very precarious position and, apart from receiving some tools from the directorate (ibid.), very little government support was forthcoming. Since January 2002, the GoG has become more involved by starting to pay the salaries of about 5 instructors per centre: before 2002 all centres had to pay staff costs themselves. Government financing of the salary component of ICCES has helped considerably. However, there is still no central support for investment, tools, equipment, infrastructure or running costs: centres are still expected to cover running costs from fee collection and production units, and infrastructure/equipment costs from the District Assembly (DA) and the community. This remains a major problem.

In fact in 2002 the ICCES Directorate reportedly had the choice of either getting the MoMYE to pay the salaries of instructors or to purchase tools (senior ICCES official, personal communication 23.07.06). The former option was taken as it was considered most urgent, but this left ICCES with no central funding for tools (ICCES, 2004). This either/or approach highlights a lack of government commitment to skills for poverty reduction. ${ }^{258}$

Clearly one of the ways to get most assistance for ICCES nationwide would have been to make it a priority investment area in key policy documents like the GPRS. But, as noted above, most of the main policy documents, with the exception of the 2004 White Paper - which has not yet been implemented, do not make mention of ICCES. Perhaps as a result of this apparently long-running low level of government attention, ICCES is not currently supported to any significant degree by any of the donor agencies operating in Ghana. Indeed, ICCES as an institution is not well known about in Ghana. Brownlee (2000) noted that:

\footnotetext{
${ }^{258}$ Another senior official within ICCES commented that it was ridiculous to have to choose between salaries and equipment since both are needed for training. If he had been in charge he said he would have told the Ministry to close down ICCES altogether since "training without tools is not training at all" (personal communication 23.07.06).
} 
the name of ICCES very rarely makes it into the National newspapers, and when it does it is often as a result of the initiative of some other organisation. (p.17)

Despite being called the Integrated Community Centres for Employable Skills, ICCES as it operates at the moment might be more appropriately called the Independent Community Centres for Employable Skills; centres largely have to rely on their own initiative and skills to generate finance for running costs (other than salaries), equipment and infrastructure. An evaluation of ICCES from a BESO volunteer notes that:

The approach to such funding has been on an "ad hoc" basis, with Centres being responsible for finding the source for their particular projects, and then preparing the presentation to them. Some may get help from the Regional Office, but generally it is done on their own. (Logie, 2004: 27)

Numerous ICCES centres around the country have received ad hoc bilateral support from different organisations including; foreign embassy small grant schemes (mainly from Britain and Japan), ${ }^{259}$ supply of expatriate volunteer teachers (e.g. from Britain's VSO, Japan's JOCV, SYTO and, formerly, the US Peace Corps); ${ }^{260}$ or other bilateral financing from ad hoc overseas trusts/private donations (often linked to the presence of expatriate volunteers), or Ghanaian/International NGOs (e.g. World Vision). A few centres have also received support from the Ghanaian private sector; those ICCES centres that are located close to large mining or logging companies appear to have had most success as these companies frequently have social responsibility agreements with the GoG. Individual ICCES centres are also, increasingly, entering into bilateral partnerships with their local DA. Indeed, the ICCES Directorate assumes that DAs will assist with the provision of infrastructure and equipment through the District Assembly Common Fund (DACF). One factor, however, that hinders ICCES' access to the DACF is that there is no legal framework to this effect: individual centre managers have to negotiate directly with the DA explaining the need for support, rather than there being in place a legal mechanism that states that part of the DACF should be used for ICCES. Consequently in many districts the DA argues that it is already too pressed with other commitments and cannot support ICCES (senior ICCES official, personal communication 29.06.07).

\footnotetext{
${ }^{259}$ Japanese small grants to centres are commonly linked to the presence of a Japanese (JOCV) volunteer at the same centre. Those centres that can successfully get a JOCV volunteer, therefore, have more chance of accessing further support.

${ }^{260}$ SYTO - Student and Youth Travel Organisation.
} 
In some districts, particularly those in Ashanti, DA support has been reasonably good, with Assemblies supplying significant support in some cases (Boateng, 2002). Typical support is in the form of one-off new buildings, building materials or small one-off grants (up to $\notin 10$ million/US\$1,100) from the DACF. However, while very helpful, this support is not sufficient, not reliable, and not a long term solution so long as ICCES is not a part of the revolving budget allocations of the DA. Moreover, the competing pressures faced by the DACF means that allocations to ICCES are in no way sufficient to meet their needs and so ICCES stills ends up lacking basic items. In other districts support and cooperation from the DA has not been good and poses a threat to the survival of some centres (ICCES, 2004).

These bilateral partnerships between individual centres and respective agencies might help to develop individual centres, but do little for the overall development and functioning of ICCES nationally. ICCES remains a very weak and chronically under-funded agency (Logie, 2004).

This lack of funding in the system is, in part, due to the lack of capacity of the ICCES Directorate, their inability to take the lead in coordinating partnership support for ICCES, and the absence of an ICCES governing board that could better vocalise ICCES needs (chap.6.2.14). While it is true that the Directorate does make such appeals from time to time, the fact that they have been largely unsuccessful in these bids - for many years - reflects their lack of capacity to seek external funding. ${ }^{261}$

As a result of the general lack of guidance, support or training from the ICCES Directorate on how to manage relationships with supporting agencies, individual ICCES centres are usually not fully aware of how to manage their bilateral partnerships - if they are lucky enough to get them in the first instance. In particular, ICCES centres are usually not aware of the reporting requirements for grants and this has led to a breakdown in the relationships between ICCES and agencies such as the British and Japanese small grants scheme, as well as with volunteer agencies such as VSO, JOCV and Peace Corps. The sourcing of partnership support by individual ICCES centres is made worse both through the lack of training of centre managers, and the lack of accessible, easyto-follow, guidelines from the agencies themselves. Logie's (2004) evaluation of ICCES comments that:

\footnotetext{
${ }^{261}$ However, in 2004 the ICCES Directorate secured funding from UNICEF for a training workshop for centre mangers (chap.6.2.9).
} 
Clearly some Centre Managers will be familiar with what is required [to seek external funding], or perhaps have a volunteer who can help. Others will be out of their depth, and consequently will miss out on the support that might have been of great value to the Centre. (p.27)

The precarious, and often ad hoc, nature of the partnerships between individual ICCES centres and various agencies does not go far enough to raise the overall quality of ICCES training provision, with many of these partnerships formed for one-off projects which fail to be sustained after the project has ended.

\subsubsection{Salaries and condition of service}

As noted above, since January 2002 the government has been paying the salaries of about 5 instructors per centre. However, salaries are low (ICCES, 2004). ICCES employees are on the Ascale, which provides lower remuneration (by about 20\%) when compared to identically qualified instructors working under the GUSS (Ghana Universal Salary Scale) system of GES (ICCES Director, personal communication 18.11.04). It is therefore very difficult to attract and retain suitably trained and motivated instructors. Moreover, salaries are often delayed, sometimes by many months, leaving instructors less and less motivated and easy to retain (ICCES, 2004) and more likely to seek external informal employment. At a meeting of ICCES centre managers in Ashanti Region (20.01.06), managers complained that salary was still being delayed (ICCES, 2006a). In addition, many centres have more than five instructors and are still expected to pay for these costs (as well as any auxiliary staff, e.g. watchmen) independently of the government.

As of August 2006 there is still no condition of service outlining the appointment of ICCES staff. Among other things this makes it very difficult for staff to know their rights and what they are entitled to claim for (e.g. travel allowances, hospital bills etc.). ${ }^{262}$

In fact the situation regarding salaries and conditions of service has become so bad that the Ashanti Region ICCES Staff Association sent a four person delegation to the ICCES directorate on $27^{\text {th }}$ July 2006 to push the Director to address these issues. The draft resolution (ICCES, 2006b) this delegation took to Accra warned that the problems should be addressed "as soon as possible or we will advice [sic] ourselves" (p. 2). This was a reference to the staff in Ashanti

${ }^{262}$ A document entitled 'Conditions, scheme of service, code of conduct for staff and trainees' is currently (August 2006) being prepared by the ICCES Directorate but there is no indication of when this might be implemented. 
taking these issues directly to the Minister and making their plight public through the media. At the meeting the ICCES Director did not consider this veiled threat appropriate and requested that it should be removed from the resolution. Although the Directorate promised to address these issues raised, it should be remembered that the Directorate's track record over the last five years on delivering on promises and pledges has been, at best, disheartening.

\subsubsection{The rural nature of ICCES}

Since most centres are located in rural areas two main problems arise for the running and sustainability of centres in the light of limited government support.

Firstly, it is an undesirable work place for instructors, most of who are from larger towns or cities, since there is a general absence of amenities, services, entertainment, infrastructure and housing for instructors (ICCES, 2004). Furthermore, there are no incentive packages from the MoMYE to work in rural settings.

Secondly, many of the trainees at ICCES centres come from poor farming backgrounds and often find it hard to pay the fees charged at these centres. In Ashanti, for example, most of the students' families are cocoa farmers who rely on the harvest money as their principal source of income. Since the main harvest is around November each year, families find it hard to pay ICCES fees at other times. ${ }^{263}$ This results in cash-flow problems for ICCES centre and contributes to the deterioration of the quality of teaching and learning - since the fees raised are supposed to pay for all running costs other than salaries.

\subsubsection{Community-supported training and kob\&wo}

The design of ICCES has always assumed community support and involvement. Indeed, the establishment of centres is supposed to be dependent on a strong level of community commitment to the ICCES concept (Logie, 2004). However, as noted above, community support has generally not reached the levels required to sustain many centres, leading to the collapse of dozens of centres over the years.

\footnotetext{
${ }^{263}$ There is, however, a smaller mid-season harvest from June-August.
} 
Centres have largely survived in the past, not because of community support, but rather because of the hard work and self-sacrifice of a limited number of individuals connected directly with the centre - usually the centre manager and staff (Palmer, 2001). ${ }^{264}$ This said, communities often help out with communal labour when a particular centre has a building project, but the GoG's expectation that the communities could pay instructors' salaries or other running costs has proved to be too naïve. ${ }^{265}$

Logie (2004) comments that the level of financial commitment communities are expected to maintain is not understood in the first place, with many communities not realising that it is an "on-going commitment" (ibid.: 3) and some communities promising support but ultimately failing to deliver it (ibid). Logie (2004: 3-4) suggests three reasons why community support often dwindles:

- The people in the community who established it in the first place move on to new activities;

- Pressure from the school is not sustained;

- The local community lose faith in the concept.

But it may be that there is an additional, more fundamental, reason why community support to ICCES has never been strong: this is that community members are often unwilling to assist a centre if they do not currently have one of their children at that centre and, in a given ICCES centre, there is usually a low proportion of ICCES trainees who come from the community the ICCES centre is located in.

Many centres have very high percentages of outsiders - youth training at an ICCES centre who are not from that community. For example, the household survey conducted as part of the fieldwork (2005) in Otaakrom community (Ashanti) where an ICCES centre has been running for the last five years showed that only $2 \%(3 / 147)$ of youth sampled in the community had received training at this centre (Appendix C, table C.6). 95\% of current students at Otaakrom ICCES come from outside of the community ${ }^{266}$ despite the fact that many youth in the community finish JSS and are unable to go onto further studies at the SSS level and there is no other second-cycle

\footnotetext{
${ }^{264}$ This is, of course, not true for all ICCES centres, some of which have very strong community support.

${ }^{265}$ As mentioned earlier, it is still the case that not all salaries are covered by the GoG - though most have been since 2002 .

${ }^{266}$ Otaakrom ICCES centre manager, personal communication 10.09.06.
} 
institution in the community other than traditional apprenticeships. ${ }^{267}$ Honny (1999) also notes that most students at NVTIs do not train in centres located nearest to their place of origin.

This unwillingness of JSS graduates to attend a second-cycle institution in their home community arises from a dislike of what people term kobewo, which signifies a youth's failure. Kobswo, which literally means 'go, come pound (fufu)', refers to something a parent might say to their child - 'go to school, then come home and pound fufu.' 268

Kobswo refers to students who continue their education or training in the same community after completing JSS. The preference, rather, is to pursue training outside of the community "even when the facilities at their place is [sic] better". ${ }^{269}$ Furthermore, kobswo is seen by some as "one of the major problems for low enrolment in rural schools like ICCES" (ibid.). ${ }^{270}$

Where many, or most, of the trainees in an ICCES centre do not come from the community in which the ICCES centre is located, there is understandably a reluctance on the part of community members to contribute financially to the ICCES centre in their community. ${ }^{271}$

\subsubsection{Quality of instruction}

The quality of instruction at ICCES centres is low for a number of reasons.

The first issue relates to the retention of un- and under-qualified instructors in the ICCES system (Logie, 2004). As noted, ICCES instructors were initially comprised of local artisans and prior to 2002 centres had to fund these instructors' salaries independently. Since communities cannot afford very much and centres have problems generating income through the collection of training fees, the remuneration offered to these instructors was typically low. In some centres, especially newer centres, this resulted in few qualified instructors working for ICCES. More established

\footnotetext{
${ }^{267}$ The teachers at this community's JSS estimate that only one in twenty students enter SSS.

${ }^{268}$ It might not literally be pounding fufu (which is usually done by females) but it also refers to general household work that children are expected to do (fieldwork, 2005).

${ }^{269}$ ICCES Ashanti Regional Coordinator, personal communication by email, 18.01.06.

${ }^{270}$ Though, of course, there are many other factors that might inhibit access to rural education and training (e.g. distance to the institution, opportunity costs of learning, poverty etc.).

${ }^{271}$ Kobswo also contributes to the high demand for hostels at ICCES centres due to the high proportion of trainees from outside the community. The difficulty in obtaining finance for infrastructure (chap.6.2.1), such as hostels, contributes to the low enrolment rates in some centres.
} 
centres generally have more highly qualified staff. And yet while technically qualified, most instructors are not trained in pedagogy.

Since 2002, ICCES has been trying to upgrade the quality of instructors in the centres - now that the GoG is paying their salaries. There is, however, still some retention of less qualified instructors who have been in the ICCES system since before the changes in 2002 .

Among the 68 ICCES staff in Ashanti (September 2006), 16 (24\%) are under-qualified (having either an NVTI 1 certificate or a middle school leaving certificate): of these only 5 are artisans. Most instructors $(37 \%, 25 / 68)$ are City and Guild (C\&G) holders. Among all these instructors there are only 3 (4\%) who have been trained how to teach - and all of these have been seconded from GES to ICCES. ${ }^{272}$

This lack of adequately qualified instructors and centre managers in some centres has contributed to the breakdown of an effective training environment. Logie (2004) notes that "[v]isits to Centres revealed extensive indiscipline, with staff missing, students absent, untidiness, poor records, and similar deficiencies" (p.11). Nonetheless, while staff are often un- or underqualified, and in spite of low/delayed salaries and poor working conditions, most are dedicated to their work (Logie, 2004). This being said, salaries are low and the rural nature of ICCES (and lack of incentives) results in problems of finding and keeping qualified instructors. ${ }^{273}$ The low and unreliable salaries means that most ICCES instructors have multiple income-generating activities (e.g. cocoa farming, part-time private contract work) in addition to their ICCES job (fieldwork, 2001-2006).

Secondly, the lack of funding and support from government, combined with the difficulty faced by rural communities in raising funding independently, results in an overall lack of tools, equipment, books, materials and infrastructure (ICCES, 2004). Logie's (2004) field report of ICCES noted that:

None of the 14 Centres visited had a sufficient number of tools for the number of students under instruction. In many cases students had been required to bring their own sewing

${ }^{272}$ The secondment has been done at the District Assembly level. Typically, the GES teacher would be registered in the community's JSS, but would work in the community's ICCES.

${ }^{273}$ This point was reiterated at a 2006 meeting of centre managers (ICCES, 2006a). 
machines to help make up the number, though this still left a significant shortage. Woodwork tools similarly were far too few, and what there were... blunt and weak. (p.5)

This echoed an earlier observation, made in 2001 and based on visits to 9 centres, that "[c]entres receive woefully inadequate amounts of tools, many of which are of inferior quality" (Palmer, 2001: 29).

Indeed a common and ongoing problem at ICCES centres is the general lack of tools. One of the unique aspects of ICCES is that it emphasises practical training to a greater extent than other institutions. However, this means little when centres have pitifully few tools for practical lessons. ${ }^{274}$ In addition to the lack of tools, those few tools that have been supplied by the Directorate are often of inferior quality. Moreover, many pledges made by the ICCES Directorate to provide tools to centres have never been honoured (Logie, 2004). Brownlee (2000) noted that, most ICCES centres in the Central and Western Regions "lack the basic infrastructure required to deliver vocational training effectively" (p.13).

Thirdly, due to shortage of permanent teachers, ICCES has traditionally relied on both National Service Personnel (NSP) and expatriate volunteers to supplement the training staff. While they do bring much benefit to centres, they cannot be relied upon like permanent instructors as their stay is frequently short (typically nine months for NSP, and two-twelve months for expatriate volunteers). Problems with the NSP also include the difficulty in persuading them to live and work in isolated rural localities (Boateng, 2002).

\subsubsection{Pressure for more academic and examination-orientated teaching}

ICCES serves a dual function: it is terminal for many, but the NVTI trade certificates that some graduates gain can be used to enter further formalised education/training. Pupils place a great emphasis on gaining these certificates, and instructors teach aspects of certain trades more with examinations - rather than with self-employment - in mind. Indeed, practical training frequently suffers and often does not get as much attention as was intended in the design of ICCES, and gets passed over for more academic and theoretical subjects useful for the examinations. Hence, the

\footnotetext{
${ }^{274}$ Dressmaking students at ICCES can be particularly disadvantaged. The cost of procuring the standard butterfly sewing machine in 2006 is $\not 450,000$ (US\$50) - a figure out of reach for many. Consequently many of these students learn dressmaking without having their own machine. Some are able to borrow a machine from a friend or family member, others are able to share a fellow-student's machine, others have to rent a machine (at a fee of $\phi 30,000 /$ month (US\$3.30) in 2006).
} 
practical vocational training objective of ICCES is often subverted as a result of pressure from trainees and their parents for more academic and examination-orientated teaching (cf. Middleton et al., 1993). ${ }^{275}$

\subsubsection{Weak centre-level management capacity}

It has been observed that many centres have weak or inefficient centre managers and/or board of governors. The latter is sometimes made up of friends of the centre manager and often does not properly represent a true cross-section of the wider community. Furthermore a few centre managers (e.g. Agomeda, Dodowa) are closely associated with specific Chiefs. Thus when there is a Chieftaincy dispute the ICCES centre suffers.

\subsubsection{Mixing literate and non-literate trainees}

ICCES centres admit not just (supposedly) literate JSS graduates, ${ }^{276}$ but also those who have previously dropped out of school and might be illiterate. This creates problems when ICCES centres place these two groups of people together - as they do. For example, during classroom lessons (e.g. trade theory, entrepreneurial studies, Maths, English), non-literate trainees are usually told by the instructors to ' $k o$ practical', go and do practicals. In some centres, non-literate students are encouraged to participate in these classroom lessons (which are often taught in a mixture of the local language, Twi, and English), but are subsequently teased by literate students. During the practical sessions, both the literate and non-literate students are able to work together.

\subsubsection{General meetings and training of centre managers}

In February 1996 the National Council of ICCES Centres (NACICCES) was formed with the aim of unifying all the ICCES centres in the country. NACICCES was meant to coordinate and support ICCES activities nationwide and comprised of all centre mangers, regional coordinators and directorate staff.

\footnotetext{
275 Interestingly, however, the NVTI exam results (table 6.7) show that the actual outcomes are high pass rates $(90 \%)$ in proficiency exams and $50 \%$ pass rates in the full trade test, the latter of which is needed to continue training.

${ }^{276}$ Many JSS graduates that enter ICCES have performed so badly at JSS that they are effectively illiterate.
} 
However, due to lack of funds NACICCES only met 3 or 4 times between 1996-1999. ${ }^{277}$ In 2002, the defunct NACICCES was replaced by regional groups of centre managers. These are meant to meet every month to communicate needs directly to the directorate, meet the welfare needs of centre managers and organise staff development (ICCES Director, personal communication $18.11 .04) .^{278}$

Combined with the lack of general meetings, training for centre managers has been weak. However, things have started to improve. For example, in 2003 the ICCES Directorate organised a 2-day training workshop to introduce centre managers to the STEP programme.

In June 2004 centre managers in the northern sector (Ashanti, Brong-Ahafo, Northern, Upper East, Upper West) had a training meeting in Sunyani funded by UNICEF. This was the second of two workshops organized by the ICCES directorate to update the knowledge and skills of the participants. The first workshop (January, 2004), sponsored by the MoMDE ${ }^{279}$ was held at Ajumako (Central Region) for participants from the southern sector. Topics treated at the workshops included entrepreneurship, writing of management documents and performance appraisal.

\subsubsection{Poor public perception of vocational training}

Along with other VTIs in Ghana, ICCES shares the poor public perception of vocational training. ICCES, like other VTIs, is seen by parents and students as the poor relative of more academically orientated second-cycle institutions. ${ }^{280}$ This poor perception and negative attitude towards vocational training is acknowledged by the ICCES Directorate (ICCES, 2004).

An apparent paradox, therefore, is why there are so many youth found in traditional apprenticeship (and in lesser numbers in the public TVET system) if vocational training has a bad reputation. But really most youth tend to enter TVET when there is no chance of accessing more

${ }^{277}$ NACICCES ex-president, personal communication 07.09.01.

${ }^{278}$ There is no national information on the frequency of regional centre managers meetings. However, in Ashanti, these meetings usually occur every month.

${ }^{279}$ Now MoMYE.

${ }^{280}$ As noted (chap.4), there has been a history of parents and students favouring more academically orientated institutions as this has always been regarded as the best way to access formal wageemployment. 
academic institutions - either due to direct or opportunity costs, low aggregate scores or other access issues.

This poor public perception of vocational training is exacerbated for ICCES as parents and students are aware of the lack of equipment and facilities at most centres. The ICCES Directorate recognises this and concludes that this makes ICCES "unattractive to prospective trainees and their families" (ICCES, 2004: 12).

\subsubsection{The social composition of ICCES trainees and the centre managers' dilemma}

The question of whether the poor are represented among ICCES trainees is interesting given that its policy is to admit not only JSS graduates, but also "dropouts at lower academic levels as well as illiterates" (ICCES, 2004: 1). It is among these groups that the poor are likely to be most concentrated. But, as noted earlier, since most ICCES trainees are JSS graduates, albeit with poor aggregates, the very poor are unlikely to be found in ICCES.

Nonetheless, a survey by Palmer (2001) of six ICCES centres in Ashanti Region suggested that needy students do get access to training, and comprise of between $12-54 \%$ of the total number of trainees in a given centre (table 6.6). Being needy was defined as those who had difficulty in paying fees (often because these young trainees were responsible for paying their own fees), and/or whose families were known by the centre manger/instructors to be poor. This is likely to be an underestimate of the percentage of needy students since many needy students will have dropped out in year one or two and therefore not be captured by these figures. As noted earlier (chap.6.1.2), $70 \%$ of poor students who started at one ICCES in 2003 were no longer present in 2006. 
Table 6.6. Percentage of 'needy' students in selected ICCES centres in Ashanti Region, according to the centre manager and staff, 2001

\begin{tabular}{|c|c|c|c|c|c|}
\hline $\begin{array}{l}\text { Name of ICCES } \\
\text { Centre }\end{array}$ & District & \begin{tabular}{|c|} 
Total No. \\
of students
\end{tabular} & $\begin{array}{l}\text { No. of needy } \\
\text { students }\end{array}$ & $\begin{array}{c}\% \text { of total } \\
\text { number }\end{array}$ & $\begin{array}{c}\text { Fees/ } \\
\text { year/ } \\
\text { student } / \mathbf{c}\end{array}$ \\
\hline Tetrefu & BAK & 103 & 15 & 15 & 240,000 \\
\hline Otaakrom & Atwima & 85 & 20 & 24 & 150,000 \\
\hline Baworo & Ejusu Juaben & 24 & 13 & 54 & 150,000 \\
\hline Konkoma & BAK & 49 & 15 & 31 & 150,000 \\
\hline Nerebehi & Atwima & 135 & 16 & 12 & 240,000 \\
\hline Dwease-Praaso & $\begin{array}{l}\text { Asante Akim } \\
\text { North }\end{array}$ & 52 & 15 & 29 & 150,000 \\
\hline TOTALS & & 448 & 94 & 28 & - \\
\hline
\end{tabular}

Source: Palmer, 2001

NB. The exchange rate in 2001 was approximately $ф 7,100$ to US $\$ 1$

Despite the policy of admitting youth irrespective of formal educational background (and hence being more accessible to more vulnerable or less-literate youth), ICCES training is not free. ${ }^{281}$ In Ashanti Region, for example, the average yearly fees (July 2006) for training alone was $₫ 150,000$ (US\$16). ${ }^{282}$ And, since there is very little money in the ICCES system, there is no provision for sponsorship of poor students. At the district and constituency level there are limited sponsorship opportunities for needy students (e.g. from the MP) but these opportunities in no way meet the demand.

Centre managers often sack those students that have not paid their fees, and tell them to ko fi, go home, to get the money. The experience of centre managers that do this has been that the poorer students, once sacked, frequently do not return. Centre managers, especially those in deprived communities, are therefore faced with a dilemma: they have usually become centre managers through some desire to help their community and the youth, and not through a desire to make money; ${ }^{283}$ they know that if they sack poor students they will not come back, but equally if they

\footnotetext{
${ }^{281}$ Other than in a handful of free-schools noted earlier.

${ }^{282}$ This ranges from $\phi 30,000-\phi 300,000$ (US\$3-33) a year for training fees only, though many other termly charges apply (table 6.4).

${ }^{283}$ Centre managers do not get paid much and, prior to 2002, were often paid nothing or very little. This suggests that like the original village polytechnics in Kenya these ICCES do operate a bit like NGOs in terms of centre manager commitment.
} 
do not sack non-paying trainees the centre, and themselves, ${ }^{284}$ will be in more financial trouble through lack of fees paid. If the centre manager sets a policy of not sacking trainees that have failed to pay, other trainees - who can afford to pay - start to default on payment and hence the centre is able to collect progressively less and less training fees. What is needed are bursaries for poor, but talented, trainees that are distributed on a means-tested basis (or community peerreview).

For example, at Otaakrom ICCES (Ashanti), the centre manager started in 2001 with a policy of not sacking any students. Otaakrom ICCES had a history of collapsing prior to 2001 and the centre manager was keen to encourage as many of the youth to enrol as possible. The question of fees, therefore, was postponed and those students that were not paying were asked to pay when they could afford to. However, in 2002, when many trainees had still not paid, the centre manger decided to sack trainees until they had paid the fees. Many did not come back. Others were persuaded to return by the centre manager who, on seeing that the needy trainees were not returning, indicated that payment could be made later. By the end of 2005, the situation had reached crisis point with training fees in arrears amounting to some $\phi 19$ million (over US\$2,100). By this time, the centre manger had told trainees that they could not collect their NVTI certificates unless they had paid all the training fees outstanding to the centre. The response of many students was not to come for their certificates. The centre manager, in January 2006, has since adopted a new policy; trainees are not allowed to progress to the next year or take NVTI exams unless they have paid all their training fees.

The progression of the poor through ICCES, therefore, is to some extent dependent on the feepolicy of the centre manger - which is determined not by the national directorate, but by each individual ICCES centre. In the example from Otaakrom ICCES, above, poor trainees have either been unable to collect their examination certificates or have been disallowed from taking examinations in the first place. In the former situation, the poor did receive training, but are not able to get a certificate to confirm this and are hence disabled from entering into some employment opportunities. ${ }^{285}$ In the latter situation, the poor are unable to progress past the first or second years and will, usually, drop-out of their training here.

\footnotetext{
${ }^{284}$ It is not uncommon for centre mangers to use their own resources to finance activities.

285 Employers, even in the informal sector, often prefer trainees to have some kind of certificate that indicates their proficiency. However, ICCES graduates are increasingly commenting that some informal contractors prefer to hire people without certificates as they can pay them less (fieldwork, 2001-2005). For formal employers, having a certificate is usually a prerequisite for employment.
} 
In the absence of gaining access to the limited funding opportunities or being able to delay payment through some informal agreement between the centre manager and the trainee/the trainees' parents, the poor do not get sustained access to training at ICCES centres.

\subsubsection{The gender composition of training}

Overall, there are more male trainees in ICCES than females (table 6.1). The gender composition of training in ICCES programmes follows the gender composition of training activities through Ghana's TVET system more generally; female trainees are clustered in the traditionally female trade areas (e.g. catering, hairdressing, dressmaking); while male trainees are clustered in the traditionally male trade areas (e.g. carpentry, building/construction, electrical installation).

\subsubsection{Regional coordination issues}

The delivery context of ICCES training is hampered by issues at the regional level.

Firstly, regional offices receive very small amounts of money as working expenses from the ICCES Directorate. The Ashanti Regional office, for example, receives $\notin 1$ million (US\$111) per three months (in 2006), or about $₫ 16,000$ (US\$1.8) per working day. ${ }^{286}$ This money is supposed to be sufficient to cover transportation to centres, office supplies, maintenance/repair of the computer/printer, telephone calls and meetings. ${ }^{287}$ This does not go far and allows for little official activity in the region. Indeed the Ashanti Regional office could not afford to pay for any repairs to its computer/printer, which now sits unused, and the phone line has been disconnected as the bills were not paid. Regional Coordinators, like the one in Ashanti, are therefore forced to rely largely on their own resources to do their work, or else not do the work. ${ }^{288}$

Secondly, regional coordinators have no form of ICCES owned transport (ICCES, 2004; Logie, 2004). Consequently their essential job of monitoring, evaluating and coordinating existing

\footnotetext{
${ }^{286}$ ICCES Ashanti Regional Coordinator, personal communication 20.11.05.

${ }^{287}$ In November 2006, two computers and two printers are due to be supplied to the regional office through an Edinburgh-based organisation.

${ }^{288}$ When the author visited the Upper West Regional coordinator in 2001 it was found that he did not even have an office. Instead he came to work each day with his office in his suitcase and looked around the government regional office for a spare room in which to work.
} 
centres, the launching of awareness campaigns in their districts, and conducting feasibility studies for new centres has to be done from a trotro (public transport minibus). Relying on trotros to get around obviously slows the work output of the coordinators considerably. ${ }^{289}$

Thirdly, the ability and commitment of the Regional Coordinators varies massively, and some regions even lack a Coordinator (Logie, 2004).

\subsubsection{National coordination issues}

The delivery context of ICCES training is hampered by numerous issues at the national level. Indeed, one senior official within ICCES went as far as to comment that: "I have the feeling that lack of support from the Directorate is the major factor for the decline of ICCES" (personal communication 15.09.05).

The managerial competency of the ICCES Directorate appears to be weak. National level coordination of ICCES remains poor, with very little support coming from the Directorate to the centres. The Directorate does not have up-to-date information on the centres in the country, sometimes with data being more than a year old. ${ }^{290}$ This lack of up-to-date information held by the Directorate appears to have resulted, among other things, in 'ghost workers' being present on the ICCES payroll. Logie (2004) comments that:

There is evidence of salary payments being made to people with no connection to the Centres, and it is probable that the list of staff attending, and those on the payroll do not agree. (p.11)

The Directorate has too many people doing too little work. Money currently allocated to overstaffing the directorate with secretaries could be more effectively used to cover transport costs of the directorate's programme/technical officers - who currently rarely visit centres outside of Greater Accra. Existing ICCES centres are poorly monitored by the directorate, who appear keener on opening up new centres rather than supporting existing ones. Logie (2004) comments that "pressure to site a Centre in all... Districts works against ensuring that they are properly established" (p.3).

\footnotetext{
${ }^{289}$ ICCES Ashanti Regional Coordinator, personal communication 15.10.05.

${ }^{290}$ Palmer (2001) noted that the official enrolment figures held by the ICCES Directorate often bear little relation to the enrolment figures at the centre level.
} 
Indeed, as noted earlier, it is the intention of the GoG to open up new centres in all districts nationwide. However, when existing centres are so poorly supported, it seems more logical to consolidate on these before expansion. Indeed, this was the recommendation of two previous reports (Brownlee, 2000; Palmer, 2001).

The ICCES Directorate appears to take little action on any recommendations that have appeared in a number of reports written by volunteers working for ICCES. For example, Logie's report (Logie, 2004), submitted in draft in December 2004, never made it to a final report since he received no feedback from the Directorate. In 2006 Logie noted that the ICCES Directorate has apparently taken no action on his recommendations and that the emails from the ICCES directorate have dried up (personal communication (email) 27.01.06). The fact that the ICCES Directorate appears to have ignored a report aimed at highlighting issues of concern and possible ways to improve matters within ICCES is of no surprise: earlier reports (e.g. Brownlee, 2000; Palmer, 2001) have similarly been shelved with no action taken. The findings of all these reports written by volunteers have generally been critical of the ICCES Directorate, and have proposed consolidation of the existing ICCES network before the opening up of new centres. Hence the directorate has not been keen to make these reports known. Moreover, the directorate has been under political pressure to open new centres and expand; an objective that runs counter to the recommendations of all these evaluation reports.

In 2001, two volunteers who had film training even went to the extent of producing a professional, self-financed, documentary about ICCES. This too has never been used by the ICCES Directorate to raise awareness or funding. Indeed that fact that these field reports have effectively been shelved is surprising given one of the stated objectives of ICCES: "To conduct research and develop plans for the sustenance and expansion of the community-based vocational training concept in Ghana" (ICCES, 2004: 2). Lack of funding apart, it appears that the current ICCES Directorate has neither the capacity nor the will to be able to manage and develop the ICCES programme in the country.

Unlike other agencies, ICCES has no Act of Parliament to support it (ICCES Director, personal communication 18.11.04) nor does it have a board of directors. ${ }^{291}$ Instead the ICCES Director reports directly to the Chief Director of the MoMYE. This is a recognised problem:

${ }^{291}$ When ICCES was supported by UNICEF in the late 1980s there was a board of Directors in place (ICCES, 1996). 
Strategic and tactical planning have thus been left in the hands of the management who should have been concerned with the short-term and day-today [sic] running of the organization. The result is the over-stretching of management. (ICCES, 2004: 10)

Logie (2004) further notes that this situation is unsatisfactory and has a number of implications, including: the Ministry is overburdened with other issues and cannot spend the time necessary on ICCES affairs; a board is more likely to induce a stronger sense of purpose than exists at present, and will help raise national awareness of ICCES.

Confidence in the Directorate is further undermined by unfulfilled promises and pledges of assistance received by centres. Logie (2004) notes that " $[\mathrm{t}]$ here is evidence that the Directorate has promised tools, but then failed to deliver them, resulting not only in lack of tools, but also lack of confidence and trust in the Directorate" (p.5). Indeed it is common for the Directorate to attend an opening of a new centre, or a graduation ceremony or commissioning of a building at an existing centre, and to promise support that later does not materialise. ${ }^{292}$

\subsubsection{Summary}

This section has been concerned with trying to understand the nature of the delivery context (chap.3.1.1) for ICCES training. The financing environment of ICCES has had a considerable impact on training quality. ICCES has changed being ostensibly being externally financed (19861992) to being community financed (1993-2001) to being part-supported by government (2002present). Since the GoG took over salary payment there appear to be more trainees in the system, perhaps reflecting increased demand for ICCES and hence signalling an improvement in quality. This being said, the quality of training in many instances is highly questionable and the support centres receive from the ICCES directorate (advice, training and coordination), and from central government (vis-à-vis funding) is woefully inadequate.

\footnotetext{
${ }^{292}$ Senior ICCES official, personal communication 15.02.05.
} 


\subsection{After ICCES, what?}

Each year substantial numbers of youth graduate from ICCES centres around the country. For example, in 2002, 3,022 trainees graduated compared to 2,833 in 2001. ${ }^{293}$ However, just because a trainee graduates it does not follow that they will pass their final NVTI exam nor, if they do, that they will receive their certificate anyway.

Table 6.7. NVTI exam results for Nerebehi, Baworo, Ofuase-Kokoben, Akutuase, Konkoma, Asiwa and Otaakrom ICCES centres, Ashanti Region (May/June 2005)

\begin{tabular}{|c|c|c|c|c|c|c|c|c|c|c|c|c|c|}
\hline \multirow[b]{3}{*}{ Trade } & \multicolumn{6}{|c|}{ GRADE TWO } & \multicolumn{7}{|c|}{ GRADE ONE } \\
\hline & \multicolumn{3}{|c|}{ Proficiency } & \multicolumn{3}{|c|}{ Trade Test } & \multicolumn{3}{|c|}{ Proficiency } & & \multicolumn{3}{|c|}{ Trade Test } \\
\hline & $\begin{array}{l}\text { No. of } \\
\text { students }\end{array}$ & Pass & Fail & $\begin{array}{l}\text { No. of } \\
\text { students }\end{array}$ & Pass & Fail & $\begin{array}{l}\text { No. of } \\
\text { students }\end{array}$ & Pass & Fail & & $\begin{array}{l}\text { No. of } \\
\text { students }\end{array}$ & Pass & Fail \\
\hline Masonry & $\overline{31}$ & 28 & 3 & $\overline{70}$ & 30 & $\overline{40}$ & 13 & 12 & 1 & & $\overline{12}$ & 4 & 8 \\
\hline Carpentry and Joinery & 12 & 10 & 2 & 33 & 15 & 18 & 14 & 7 & 7 & ${ }^{*}(\mathrm{i})$ & 4 & 2 & 2 \\
\hline Building/draughtsmanship & & & & 8 & 4 & 4 & & & I & & 1 & & 1 \\
\hline General electricals & 15 & 14 & 1 & 30 & 5 & 25 & 5 & 5 & & & & - & - \\
\hline Catering & 18 & 15 & 3 & 15 & 5 & 10 & 10 & 10 & & & & - & - \\
\hline Dressmaking & 21 & 21 & - & 24 & 15 & 9 & 19 & 18 & 1 & * & 8 & 6 & 2 \\
\hline Tailoring & 1 & 1 & & & & & & & & & & & \\
\hline Totals & 98 & 89 & 9 & 180 & $\overline{74}$ & 106 & 61 & 52 & 9 & & 25 & 12 & \begin{tabular}{|l|} 
\\
213
\end{tabular} \\
\hline
\end{tabular}

* absent on day of exam

(i) only one of the 7 that failed carpentry proficiency grade one was absent.

Source: ICCES Ashanti Regional Coordinator, personal communication 28.07.06

The NVTI exam results for seven centres in Ashanti Region (table 6.7) show that pass rates for both proficiency grade one and two are reasonably high: ${ }^{294}$ grade two has a $90 \%$ pass rate $(89 / 98)^{295}$ and grade one a $85 \%$ pass rate $(52 / 61)$. However, when it comes to the full trade test the pass rate is low for both grades: grade two has a $41 \%$ pass rate (74/180) and grade one a $48 \%$ pass rate (12/25). The $60 \%$ failure rate for the grade two trade test means that many students repeat year two to retake the exam, but many others drop out. In the final year grade one trade test exams the 50\% failure rate means that many students are leaving ICCES with failure results slips (or else repeating the final year). The good pass rates in proficiency compared to the low pass rates for the trade test underlines the fact that ICCES is more successful in delivering practical

\footnotetext{
${ }^{293}$ http://www.ghana.gov.gh/governing/ministries/social/manpower.php downloaded 25.01.06.

294 The proficiency exam is the non-written exam involving a practical and oral component. The full trade test involves written, oral and practical components. Grade two is taken at the end of the second year and grade one at the end of the third, and final, year.

${ }^{295}$ In fact the only trainees that failed grade two proficiency were absent on the day of the exam!
} 
skills rather than preparing students for further formal training. ${ }^{296}$ It also shows that a combination of low instructor quality, low educational background of most ICCES entrants, and a poor instructional environment result in high failure rates in exams with written components.

For those final year ICCES trainees that do pass their NVTI exams it does not automatically follow that they will be given their results slip/certificate; only those students that have no fees arrears are allowed to collect their certificates in most ICCES centres. Those that pass the exams but are unable to pay these arrears, perhaps due to poverty, cannot collect their certificates. ${ }^{297}$

What about the post-training outcomes of VTI graduates, and ICCES in particular?

A study of $\mathrm{NVTI}^{298}$ graduates in the late 1990s (Honny, 1999) reveals a little about the posttraining activities of VTI graduates in Ghana. He comments that:

Immediately after their training, graduates generally go to their places of origin for about six months to await their examination results. This is usually followed by travel to larger towns and cities for a stay of up to three to four months to look for employment. (p.196)

Honny's survey of graduates from 21 NVTI centres revealed that the most common employers of NVTI graduates were public sector organisations dealing with construction, provision and maintenance of facilities and utilities, and large private construction firms. About $40 \%$ of the NVTI graduates went on to find jobs in the formal or semi-formal sectors within one year of graduation, while a further $10 \%$ went on to further training (Honny, 1999). However "[t]he proportion of those who graduated in the last two or three years employed in this way... has fallen considerably" (Honny, 1999: 196).

There is, in fact, very little evidence regarding the employment outcomes of ICCES graduates. Following the underlying assumption of the Ghanaian skills development agenda, policy makers usually take for granted that the employment objectives of ICCES have been achieved. But with

\footnotetext{
${ }^{296}$ In order to progress to higher education and training post-ICCES, graduates need a pass in the full trade test.

${ }^{297}$ In some ICCES centres this results in large piles of certificates from former graduates that remain locked in cupboards in the centre's office. Those that fail their final exam and want to retake it also need their certificate - which is not released unless fees arrears are paid. This serves as a barrier, inhibiting poorer trainees from retaking exams.

${ }^{298}$ NVTI centres are also under the MoMYE, like ICCES, but have received more support in the past from government and external agencies (e.g. DFID, NVTI Centres Support Project, 1996-1998).
} 
such a catalogue of weaknesses associated with the training delivery context of ICCES, it is crucial to know more about trainees' experiences after ICCES.

One claim posted on the MoMYE website states that "[s]tudies indicate that $62 \%$ of ICCES graduates are self-employed in the rural areas." 299 What is surprising though is that not one official in the MoMYE contacted by the author knows what studies this is referring to. ${ }^{300}$ Indeed it was even suggested by one senior official within ICCES that he was "not surprised about the story posted at the MoMYE/ICCES website... everything there are [sic] false." While this last comment is undoubtedly a gross exaggeration, it does at least suggest that there are those in senior positions within ICCES that doubt the reliability of the ICCES Directorate's claims and data. Assuming that the claim - about $62 \%$ of ICCES graduates being self-employed - is based on a study conducted of ICCES graduates, it still does not tell us what type of self-employment graduates are engaged in. Are they operating more at the survival end of the MSE spectrum, or doing better? Are they working in self-employment activities using their skills acquired at ICCES, or are they working in areas not connected with their training? These, surely, are crucial questions.

After ICCES training it is known that graduates receive no structured post-training support or assisted access to credit facilities - factors deemed necessary to support self-employment creation among VTI graduates in Ghana (Honny, 1999) and elsewhere. ${ }^{301}$ While centre managers, in some cases, have tried to offer advice to graduating trainees, there is no formal mechanism in place to provide follow-up training, support, advice on getting access to finance or information on (the very limited) formal job opportunities.

The difficulty in accessing financing is recognised by the ICCES Directorate, who further comments that this also has a negative impact on enrolment rates:

Unwillingness on the part of financial institutions to grant credit to trainees also poses a threat to the overall objective of training to make them employable notably, selfemployed [sic]. The inability to access start-up capital also dissuades potential trainees from enrolling. (ICCES, 2004: 16)

\footnotetext{
${ }^{299}$ http://www.ghana.gov.gh/governing/ministries/social/manpower.php downloaded 25.01.06.

300 Those contacted included three senior ICCES officials and a former deputy Minister for the MoMYE.

${ }^{301}$ See chap.5.3.6.
} 
ICCES graduates essentially have to fall back on their existing support structures, which consist largely of their family, their family's contacts or other social networks they have been able to develop during their training.

Since ICCES training generally takes place in training institutions out of the labour market, trainees are not exposed to the same opportunities to develop informal social or other business contacts, when compared to those that train in the labour market itself (e.g. in apprenticeships).

However, due to lack of equipment/material at some ICCES centres, some practical training occurs away from the VTI, on-the-job when trainees assist an instructor with a private contract. Other trainees are able to find temporary work during the holidays, and hence have some, albeit limited, opportunity to develop enterprise networks.

Male trainees, especially those in building/construction, are more likely than female trainees to find trade-related vacation work. ${ }^{302}$ Female trainees, who cluster in the traditionally female trades of dressmaking, hairdressing and catering, generally have less opportunity to undertake traderelated vacation work, and consequently have less opportunity to develop the kinds of enterprise networks that might be useful in helping them enter self-employment.

ICCES training, therefore, offers limited opportunity to trainees to develop enterprise networks that are recognised as so helpful to enterprise start-up.

In order to find out about the kinds of post-ICCES activities trainees are engaging in, semistructured questionnaires and focus groups were conducted with ICCES graduates during 2005. The objective was to find out about the graduates first employment activity or about training received after ICCES.

In the first instance information was gathered directly from 60 ICCES graduates (graduating 1999-2004) from three centres (Tetrefu, Baworo, Nerebehi). Questionnaires were sent to graduates of these centres who then completed and returned the forms. Although about 200 forms were sent out only $60(30 \%)$ responded.

\footnotetext{
${ }^{302}$ For final year building/construction trainees the daily market rate (in 2005) for their work ranges from $\notin 25-50$ thousand (US\$2.8-5.5), depending on their experience (focus group 3, below).
} 
In an attempt to compensate for the difficulty of tracking down ICCES graduates who could respond in person, a further method of data collection used was to have discussions with the centre managers and instructors of selected ICCES centres in Ashanti region, and ask them about the current activity of graduates from a specific year. ${ }^{303}$ This method is based on the knowledge that centre managers and/or instructors have very close contact with the communities from which ICCES trainees originate, and are therefore in a good position to comment on their current activities. ${ }^{304}$ Centre managers/instructors from seven centres ${ }^{305}$ were asked about the current activity of all trainees $(n=157)$ who graduated in the summer of 2003. Since this questionnaire was not directly administered to graduates but to VTI staff, the exploration of occupational pluralism was more difficult and respondents were simply asked about the former trainees main activity. Of the 157 ICCES trainees who graduated from these centres in 2003, the centre managers and instructors were able to provide information on 102 of them (or $65 \%$ of the total number).

This data - for 102 graduates of 2003 - was combined with the data collected from the 60 ICCES graduates mentioned above. ${ }^{306}$ This provided information about the current activity (further training or activity in the labour market) for some 162 ICCES graduates, graduating between 2000 to 2004.

In addition, two focus groups ( $n=10$ and $n=14)$ were held with ICCES graduates from Tetrefu ICCES (Ashanti), though most of those available to participate were male (only 4/24 were female) (tables 6.8-6.9). The graduation year of these focus group participants ranged from 1990 to 2005 , providing a whole range of opinion. A further focus group ( $\mathrm{n}=7$ ) (table 6.10) was organised with final year ICCES trainees at Tetrefu ICCES. In addition to general discussions in the focus group, some members of the focus groups were interviewed individually to enrich the data. $^{307}$

Both the interviews and focus group discussions, however, are in no way representative of all ICCES graduates. Since locating graduates of the programme is very difficult (as many are not

\footnotetext{
${ }^{303}$ See Appendix B for the questionnaires.

${ }^{304}$ Despite the fact that most ICCES students come from communities outside the one where the ICCES centre is located, most centre managers/instructors still have a close relationship with surrounding communities and are able to keep track of what most former graduates get up to.

${ }^{305}$ Baworo, Otaakrom, Nerebehi, Ofoase, Twedie, Dweaso Prase and Tetrefu.

${ }^{306}$ Care was taken not to duplicate any responses when merging the two sets of data.

307 The three different focus groups are referred to as FG1, FG2 and FG3.
} 
residents of the community in which ICCES centres are located, and the mobility of graduates appears high) those interviewed comprised those people who were relatively easy to locate (or those $30 \%$, above, who were able to respond to the questionnaire). The findings, therefore, should be interpreted with caution, and used more as a suggestive illustration of the activities of ICCES graduates. It is also important to remember that many ICCES trainees drop-out of the training and hence never complete the full three years. More research is needed to find out about the large numbers of ICCES-trained youth who never make it to final year graduation.

Table 6.8. Composition of focus group 1 (FG1), ICCES graduates, Tetrefu ICCES, 09.10.05

\begin{tabular}{|c|c|c|c|c|c|}
\hline Name & Sex & Age & Trade area & Year finished & $\begin{array}{l}\text { Highest level } \\
\text { of education } \\
\text { before ICCES }\end{array}$ \\
\hline Jusif & $\overline{\mathrm{M}}$ & 28 & Building & 1996 & JSS \\
\hline Constance & $F$ & 26 & Dressmaking & 2001 & JSS \\
\hline Edwood & M & 22 & Building & 2005 & JSS \\
\hline Francis & M & 19 & Building & 2005 & JSS3 \\
\hline Patricia & $\mathrm{F}$ & 20 & Dressmaking & 2002 & JSS \\
\hline Seth & M & 22 & Building & 2003 & JSS \\
\hline Isaac & M & 23 & Building & 2001 & JSS3 \\
\hline Grace & $F$ & 21 & Dressmaking & 2003 & JSS \\
\hline Kusi & M & 25 & Building & 1999 & JSS \\
\hline Yaa & $\mathrm{F}$ & 23 & Dressmaking & 2001 & JSS \\
\hline
\end{tabular}

Source: Author's fieldwork, 2005

Table 6.9. Compostion of focus group 2 (FG2), ICCES graduates, Tetrefu ICCES, 09.10.05

\begin{tabular}{|r|r|r|r|r|r|}
\hline Name & Sex & Age & Trade area & Year finished & $\begin{array}{r}\text { Highest level } \\
\text { of education } \\
\text { before ICCES }\end{array}$ \\
\hline Salisu & $\mathrm{M}$ & 22 & Building & 2005 & JSS3 \\
Alexander & $\mathrm{M}$ & 21 & Building & 2004 & JSS3 \\
Soloman & $\mathrm{M}$ & 30 & Building & 1998 & SSS \\
Frank & $\mathrm{M}$ & 34 & Carpentry & 1990 & MidForm 4 \\
Alex & $\mathrm{M}$ & 33 & Carpentry & 1990 & MidForm 4 \\
James & $\mathrm{M}$ & 34 & Building & 1992 & MidForm 4 \\
Owusu & $\mathrm{M}$ & 33 & Building & 1992 & JSS3 \\
Amankwabo & $\mathrm{M}$ & 27 & Building & 1996 & JSS3 \\
Dennis & $\mathrm{M}$ & 22 & Building & 2001 & JSS3 \\
Patrick & $\mathrm{M}$ & 24 & Carpentry & 2001 & JSS3 \\
Danquah & $\mathrm{M}$ & 25 & Building & 2001 & JSS3 \\
Yeboah & $\mathrm{M}$ & 27 & Building & 1999 & JSS3 \\
Isaac & $\mathrm{M}$ & 32 & Building & 1996 & MidForm 4 \\
Osei & $\mathrm{M}$ & 34 & Carpentry & 1990 & MidForm 4 \\
\hline
\end{tabular}

Source: Author's fieldwork, 2005 
Table 6.10. Compostion of focus group 3 (FG3), final year ICCES trainees, Tetrefu ICCES, 09.10.05

\begin{tabular}{|r|r|r|r|}
\hline Name & Sex & Age & Trade area \\
\hline Peter & $\mathrm{M}$ & 20 & Building \\
Afrifa & $\mathrm{M}$ & 20 & Draftsmanship \\
Collins & $\mathrm{M}$ & 20 & Electricals \\
George & $\mathrm{M}$ & 18 & Building \\
Isaac & $\mathrm{M}$ & 22 & Electricals \\
Emmanuel & $\mathrm{M}$ & 20 & Building \\
Attah & $\mathrm{M}$ & 17 & Building \\
\hline
\end{tabular}

Source: Author's fieldwork, 2005

\subsubsection{Further training}

McGrath et al. (1995), commenting on the fact that "[s]ubject to their performance [in examinations] these [ICCES] trainees may then be admitted into senior secondary school ${ }^{308}$ ...[note that] [i]t is clear... such training may lead to leakages into higher academic institutions rather than bring the advantages of further education to the informal sector" (p.73).

6/7 participants of FG3 (table 6.10) - final year ICCES trainees - mentioned that they planned to go onto do further training. Only Collins indicated that he would not do this - but only because his parents did not have the money to help him further. This small group of trainees seemed generally positive about ICCES, despite listing many problems with their training. ${ }^{309}$ They considered that ICCES would provide them with a skill which can be used to get work:

ICCES is "better than SSS - if you come and don't pass [exams] you can do your own job" (Collins, FG3).

"After ICCES I can do my own job" (Isaac, FG3).

"The moment you complete you can find a job to do... either join someone else or work for self" (Emmanuel, FG3)

Despite this acknowledgement that they could use their skills to be self-employed, the general preference was for wage-employment. As one member of the group noted, "if [you] have [your] own job [you] won't get many [sic] money" (Peter, FG3).

\footnotetext{
${ }^{308}$ The authors were referring to Boeh-Ocansey's Ghana paper written for this synthesis. In fact ICCES graduates at the time of Boeh-Ocansey's study (1993) could not use their certificates to enter SSS (BuduSmith, 1997).

${ }^{309}$ Including: lack of text books, teachers, tools/materials and games equipment.
} 
Moreover, even in this small group there was not agreement about whether ICCES or SSS was better. While Collins, above, thought that ICCES was better than SSS, most of the others considered that ICCES was a second best option compared to SSS and that the job opportunities with ICCES training were worse:

"My parents don't have money to send [me] to SSS, so decided to come [send me] to ICCES. But you get a better job with SSS" (Attah, FG3).

This high desire among ICCES trainees to continue training was also seen in another survey conducted at one ICCES centre in Ashanti Region, which revealed that 79\% (22/28) of current final year ICCES trainees wanted to continue their education/training on completion of the three year vocational course (fieldwork, 2004). ${ }^{310}$

This recognition of the better job opportunities available to those with higher certificates, compared to those with only ICCES training, is undoubtedly the main reason why so many ICCES trainees intend to pursue further training after ICCES.

While final year ICCES trainees show a clear intention to pursue further training, it is interesting to examine how many do this, and what type of training they undertake. As noted above, data was collected from 162 ICCES graduates, who graduated between 2000 and 2004 from seven different ICCES centres in Ashanti Region.

This survey of 162 graduates suggests that many are indeed pursuing further training after they finish ICCES (table 6.11). In fact $42 \%$ (68/162) had pursued further training after ICCES though not, largely, at the SSS level as suggested by Boeh-Ocansey (1993, in McGrath et al, 1995). Of these, $21 \%$ (14/68) had undertaken apprenticeship training, 74\% (50/68) had undertaken $\mathrm{C} \& \mathrm{G}$ or Construction Technician Courses (CTC), and 6\% (4/68) had undertaken other training. ${ }^{311}$ This suggests that there is a view among ICCES graduates that ICCES training alone is not sufficient. The preferred option for further training is for ICCES graduates to follow a more formal education route, e.g. C\&G/CTC, which leads to higher formal education certificates and the possibility of entering yet further education at polytechnic level. More than one in five $(21 \%)$, however, pursue apprenticeship training.

\footnotetext{
${ }^{310}$ About $35 \%$ of trainees indicated that they hoped to become teachers.

${ }^{311}$ Two were in SSS, one was getting training from the police and the other was training outside Ghana.
} 
Out of the 42 female graduates in the sample, 15 (36\%) had undertaken further training: of these the majority pursued apprenticeships and those that did undertake $\mathrm{C} \& \mathrm{G}$ did not continue to CTC level. Out of the 120 male graduates in the sample, 53 (44\%) had undertaken further training: of these the majority had pusued $C \& G$ training (and 1/3 of these had gone on the CTC), while far fewer opted for apprenticeship. Male and female ICCES graduates, therefore, seem to follow two different pathways to further training (fig.6.1 and fig.6.2).

\section{Fig.6.1. Post-ICCES training pathways (male graduates)}

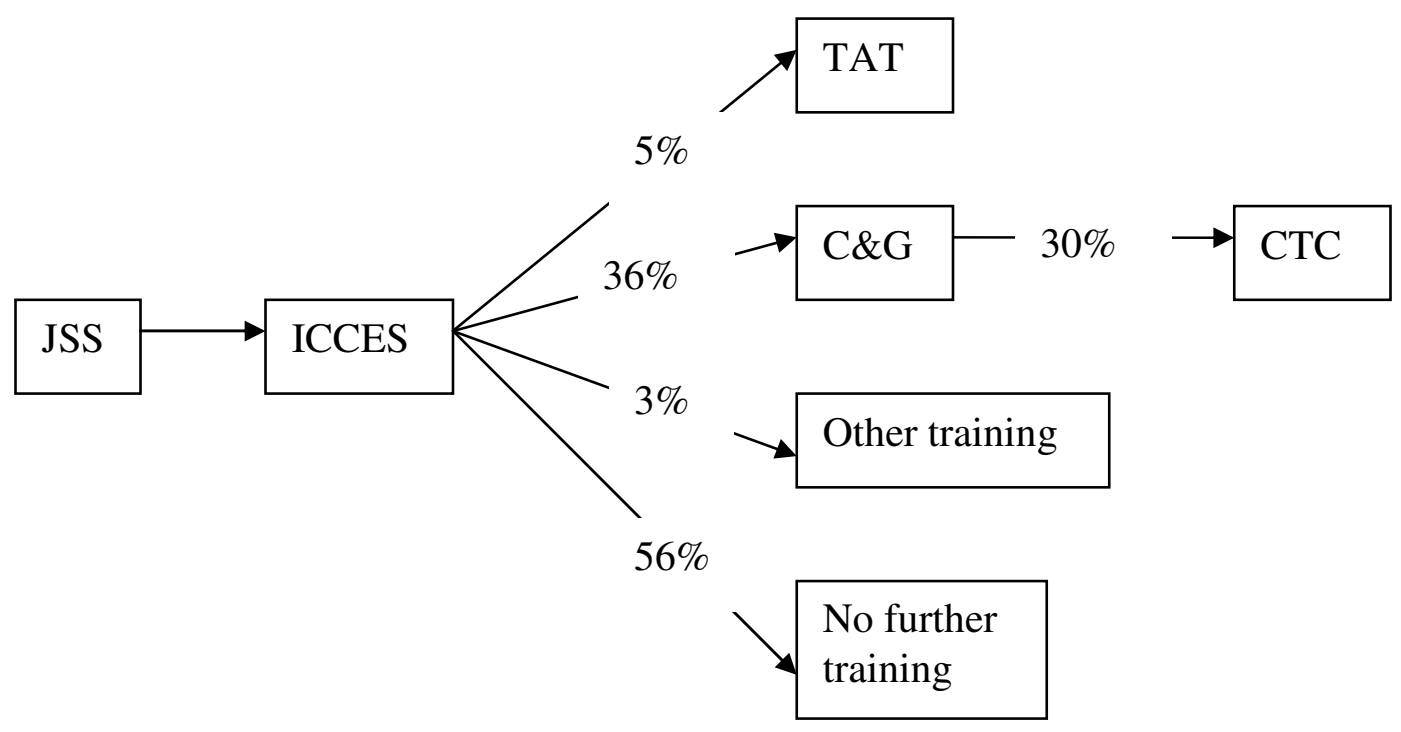


Fig.6.2. Post-ICCES training pathways (female graduates)

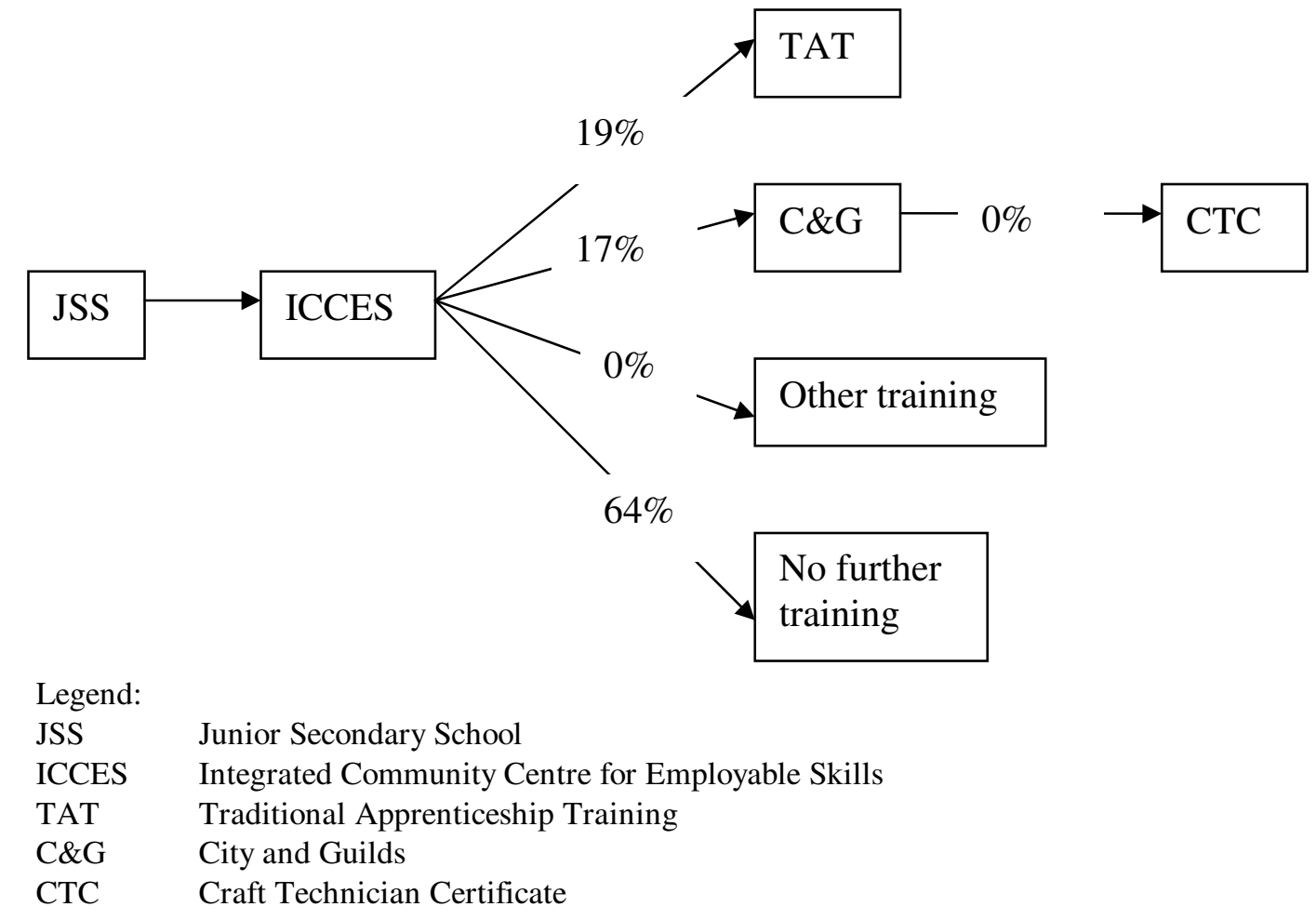

Table 6.11. Further training received by ICCES trainees, from a sample of 20002004 cohorts from Tetrefu, Nerebehi, Bawro, Dweaso Praso, Twedie, Otaakrom and Ofoase ICCES

\begin{tabular}{|c|c|c|c|c|c|c|c|c|c|}
\hline \multirow[b]{2}{*}{$\begin{array}{l}\text { Type of } \\
\text { further training }\end{array}$} & \multicolumn{3}{|c|}{ Male } & \multicolumn{3}{|c|}{ Female } & \multicolumn{3}{|c|}{ Total } \\
\hline & Freq. & $\%$ & $\begin{array}{r}\text { As a \% of } \\
\text { those with } \\
\text { further } \\
\text { training }\end{array}$ & Freq. & $\%$ & $\begin{array}{r}\text { As a \% of } \\
\text { those with } \\
\text { further } \\
\text { training }\end{array}$ & Freq. & $\%$ & $\begin{array}{r}\text { As a } \% \text { of } \\
\text { those with } \\
\text { further } \\
\text { training }\end{array}$ \\
\hline Apprenticeship & $\overline{6}$ & 5 & 11.3 & $\overline{8}$ & $\overline{19}$ & 53.3 & 14 & 8.6 & 20.6 \\
\hline City and Guilds & 30 & 25 & 56.6 & 7 & 16.7 & 46.7 & 37 & 22.8 & 54. \\
\hline CTC & 13 & 10.8 & 24.5 & 0 & 0 & 0 & 13 & 8 & 19.1 \\
\hline Other training & 4 & 3.3 & 7.5 & 0 & 0 & 0 & 4 & 2.5 & 5.9 \\
\hline Those with training subtotal & 53 & 44.2 & 99.9 & 15 & 35.7 & 100 & 68 & 42 & 100 \\
\hline No further training & 67 & 55.8 & & 27 & 64.3 & & 94 & 58 & \\
\hline Total & 120 & 99.9 & & 42 & 100 & & 162 & 99.9 & \\
\hline
\end{tabular}

Source: Author's fieldwork, 2005

It is usually the male graduates (who have taken courses like building/construction or carpentry) that are most likely to continue their training in formal VTIs to achieve higher certificates, with a view of gaining formal employment, often in teaching (FG1\&2). The preference for getting further training and certificates - e.g. at the $\mathrm{C} \& \mathrm{G} / \mathrm{CTC}$ levels - is motivated by the fact that salary 
work is based on qualifications and hence ICCES graduates want to get to the highest level possible (FG1\&2). In order to continue formal training post-ICCES it is not uncommon for graduates to have to work for a number of years to save up for the fees as the following case studies illustrate:

After graduating from a building/construction course (1996), Jusif hoped to continue studying and eventually go to university. However, since his parents could not afford this he ended up working for three years in building projects (per day basis). By 1999 Jusif had saved enough money to attend the local secondary technical school (STS). He considered that an STS certificate would help him get access to university. Since graduating from STS in 2001, he has gone back to working for construction firms on a per day basis and is trying to save money for further study. (FG1)

Kusi finished a building/construction course in 1999 and worked on a per-day basis for two years to save money for tuition fees for further training. He has since completed CTC part 1. (FG1)

Other ICCES graduates, especially female graduates, continue their training by doing a three year traditional apprenticeship course. This pathway suggests that the training that has been received in ICCES is not of sufficient practical orientation to allow graduates to become self-employed. More worryingly, it might suggest that ICCES trainees, as well as customers, recognise the inferior quality of ICCES training, and hence graduates feel the need to get more training. One youth commented that "people prefer apprentice-trained dressmakers instead of ICCES-trained dressmaking graduates as there is poor quality teaching in dressmaking [at ICCES]" (FG1\&2).

The fact that more female ICCES graduates enter apprenticeships, instead of entering more formalised further training, suggests that female graduates have less opportunity than male graduates to continue down this latter path. Individual interviews with three dressmakers from FG1 show that ICCES dressmaking graduates appear concerned that the skills they have received are not sufficient and want to continue further training - in apprenticeships:

After completing a dressmaking course (2003), Grace decided to do an apprenticeship as she considered herself not qualified after finishing the three year course at ICCES. After the apprenticeship, she wants to establish her own enterprise. (FG1) 
Constance graduated from a dressmaking course in 2001 but felt that she had not acquired enough skills during the course and so decided to undertake an apprenticeship. She is now a master dressmaker, but works from her parent's house where she lives, as she cannot afford her own kiosk yet. (FG1)

Patricia finished a dressmaking course in 2002. However, she saw that people prefer to buy things from dressmakers trained through apprenticeship as ICCES trained dressmakers are seen as receiving poor quality training. She is currently doing an apprenticeship. (FG1)

While these focus group discussions suggest that the labour market appears to favour apprenticetrained dressmakers over ICCES-trained dressmakers, the opposite is claimed for the maledominated trades: "in general, ICCES trained C\&J [carpentry and joinery] and BC [building/construction] people do better than apprentice trained people in these areas" (FG1\&2).

The view of this latter focus group - that ICCES graduates are better than apprentice graduates is reinforced in other ways. The ICCES Directorate comment that "[i]t has been generally accepted that ICCES graduates are deft at practicals because of their on the job training orientation" (ICCES, 1996: 7). Similarly centres managers in ICCES Ashanti Region also consider ICCES graduates to be better trained than apprentices (personal communication 20012006). Moreover, the good pass rate for the proficiency NVTI exams (table 6.7) shows that ICCES graduates do perform well practically. ${ }^{312}$ The decision some make to enter apprenticeship after ICCES may have more to do with the need to develop enterprise networks and learn more about the functions of doing business - both aspects which are absent in ICCES training - rather than about learning further practical skills.

\subsubsection{Employment activities of ICCES graduates in the labour market}

From the interviews conducted with the 60 ICCES graduates from three centres during the summer of 2005, it can be said that 37 were currently in the labour market, while a further 23

\footnotetext{
${ }^{312}$ In fact, contrary to the opinions of the dressmakers noted above regarding the low quality of ICCES dressmaking graduates, the NVTI proficiency exam results for dressmaking are particularly high (table $6.7)$.
} 
were in further training. In addition the data collected from the other 110 ICCES graduates revealed that 73 trainees were operating in the labour market, while a further 29 were in further training. Combining both data sets together, while excluding those graduates in further training, provides a sample size of $110(37+73)$.

Out of the 110 graduates in the sample, $85 \%$ were reported to be undertaking some form of paid work (table 6.12). ${ }^{313}$ A further $15 \%$ (5\% of male graduates and as much as $38 \%$ of female graduates) characterised themselves, or were described by the centre managers/instructors, as not working. However, while these individuals might not have been working to earn income, it is very likely - especially for the female graduates - that they were indeed working on their family farm. Support for this proposition came from focus group discussions (FG1\&2).

About 33\% (36/110) of all the ICCES graduates were working in informal self-employment, 36\% $(40 / 110)$ in informal wage-employment and $14 \%(16 / 110)$ in the formal sector. ${ }^{314}$

Out of the women interviewed who were currently in the labour market $(n=34)$, nearly $40 \%$ were characterised as not working and $44 \%$ were working in informal self-employment. ${ }^{315}$

Male graduates seemed more likely to be working in informal wage-employment (in their trade area) than female graduates ( $46 \%$ of male and $3 \%$ of female graduates worked in this area). Male graduates, particularly those in building/construction trades, are more likely to get work on an informal contract basis with construction companies (usually working only part of the year) (FG1\&2). This informal contract work is typically paid on a per-day or per-month basis and might last only 2-4 months of the year. Indeed "it is normal that [only] few of them continue to work [for companies on monthly salaries] since contractors chose to lay off workers at the end of each contract". ${ }^{316}$ Most of the construction companies do not register their workers with the SSNIT, which saves the employer money since they do not have to pay their employees contributions, and makes it easier to lay people off "when the contractor is out of job", though the

\footnotetext{
${ }^{313}$ Note that some of these 110 graduates will have been through additional training after ICCES before entering the labour market.

${ }^{314}$ The majority of those working in formal employment had pursued further formal training after ICCES (e.g. $\mathrm{C} \& \mathrm{G} / \mathrm{CTC}$ ).

${ }^{315}$ However, as noted above, it is likely that many female graduates who were characterised as not working were in fact working on the family farm.

${ }^{316}$ ICCES Ashanti Regional Coordinator, personal communication (email) 29.03.06.
} 
"lucky ones at times get permanent jobs". ${ }^{317}$ Often "contractors want cheap labour so choose to employ people on a daily basis" (FG1\&2). Moreover, depending on the contractor, an NVTI certificate may in fact be a disadvantage in the labour market since "contractors sometimes prefer less qualified people [without certificates] as they are cheaper" (FG1\&2). Construction companies are supposed to pay their workers a monthly salary which is based on the GoG salary structure and varies according to qualifications held. ${ }^{318}$

While this informal per-day wage-employment is popular among building/construction ICCES graduates, it is recognised that this work usually does not pay well and hence there is mobility in and out of this type of work as the following case illustrates:

Seth and Isaac both finished a building/construction course in 2003 and have been doing building work on a per-day basis since then. Seth recently left, however, as the pay was not good and now wants to apply for wage-employment in a company. Isaac, on the other hand, is still doing per-day work but wants to set up his own enterprise as the pay is not good, though he does not know where he will find the money. (FG1)

Getting access to start-up capital prevents many graduates from being able to use their skills on graduation, which is another reason why some enter informal wage-employment (FG1\&2). Honny (1999) identifies the difficulty NVTI graduates face in accessing finance and buying startup equipment.

While it appears more common for male ICCES graduates to find employment in this informal wage sector, there are also opportunities for females in wage-employment. Dressmakers, for example, might find work "for the more endowed fashion designers for monthly salaries which are negotiable". 319

Not an insignificant percentage of the 110 ICCES graduates surveyed were working in formal wage-employment (14.5\%). ${ }^{320}$ Focus group participants identified two main pathways for ICCES graduates to get a formal sector job; i) "to whom you know - It is important to know someone to push you through"; ii) "cold knocking on companies to see if they have a job" (FG1\&2).

${ }^{317}$ ICCES Ashanit Regional Coordinator, personal communication (email) 30.03.06.

${ }^{318}$ ICCES Ashanti Regional Coordinator, personal communication (email) 30.03.06.

${ }^{319}$ ICCES Ashanti Regional Coordinator, personal communication (email) 30.03.06.

${ }^{320}$ As noted, most of these received further formal training post-ICCES. 
On average $14.5 \%$ of graduates (15.8\% of males and $11.8 \%$ of females) were not using the skills acquired through ICCES in their current employment activity (table 6.12). However, if it is assumed that many, if not most, ICCES graduates who were characterised as not working were in fact working on a family farm (as focus group discussions would suggest) the total number of graduates not using their skills acquired through ICCES increases significantly. In this case 30\% of all graduates ( $21 \%$ of male graduates and $50 \%$ of female graduates) were not using their skills in their current employment activity. Many of these ICCES graduates, lacking either the connections or the capital to utilise their skills, go back to the farm and continue to assist their family as before. Female ICCES graduates seem to have less opportunity to continue education/training and less opportunity to start-up their own enterprise. Many female graduates are observed to be not working in the trades that they have trained in, and not a small number go back to farming with their family (FG1\&2).

Table 6.12. Current employment activity of graduates from a sample of 2000-2004 cohorts from Tetrefu, Nerebehi, Bawro, Dweaso Praso, Twedie, Otaakrom and Ofoase ICCES

\begin{tabular}{|l|r|r|r|r|r|r|}
\hline \multirow{2}{*}{ Current activity } & \multicolumn{2}{|c|}{ Male } & \multicolumn{2}{|c|}{ Female } & \multicolumn{2}{|c|}{ Total } \\
\cline { 2 - 6 } & Freq. & $\%$ & Freq. & $\%$ & Freq. & \% \\
\hline Informal self-employed in trade area & 15 & 19.7 & 11 & 32.4 & 26 & 23.6 \\
Informal self-employed not in trade area & 6 & 7.9 & 4 & 11.8 & 10 & 9.1 \\
Informal wage work in trade area & 35 & 46.1 & 1 & 2.9 & 36 & 32.7 \\
Informal wage work not in trade area & 4 & 5.3 & 0 & 0 & 4 & 3.6 \\
Formal wage employment in trade area & 10 & 13.2 & 5 & 14.7 & 15 & 13.6 \\
Formal wage employment not in trade area & 1 & 1.3 & 0 & 0 & 1 & 0.9 \\
Farming with family & 1 & 1.3 & 0 & 0 & 1 & 0.9 \\
Not working & 4 & 5.3 & 13 & 38.2 & 17 & 15.5 \\
Total & $\mathbf{7 6}$ & $\mathbf{1 0 0 . 1}$ & $\mathbf{3 4}$ & $\mathbf{1 0 0}$ & $\mathbf{1 1 0}$ & $\mathbf{9 9 . 9}$ \\
\hline
\end{tabular}

Source: Author's fieldwork, 2005

\subsubsection{Summary}

Many ICCES trainees do not make it to graduation. Of those that do, the pass rate of $85 \%$ for the NVTI one proficiency exam is encouraging, though given what has been said in the previous section regarding the quality of training provision, one has to question exactly what passing NVTI proficiency means vis-à-vis competency levels. For the full trade test only $50 \%$ pass the NVTI one exam. Many ICCES graduates (as much as one-third) are pursuing further formal 
training to the $\mathrm{C} \& \mathrm{G}$ and CTC levels, though males are more likely to take this route. Further training for females is more likely to be through traditional apprenticeships.

Of those that do enter the labour market, most (85\%) appear to find employment in the informal sector, either in wage- or self-employment.

The ability of building/construction graduates to access informal wage-employment (compared to those in other trade areas) may account for the popularity of the building/construction course in Ashanti (as noted earlier, about $40 \%$ of all ICCES trainees in this region are in this trade area).

Some ICCES graduates that have managed to acquire $\mathrm{C} \& \mathrm{G}$ or CTC certificates have been able to access formal employment. Nonetheless about one-third of all graduates (and as much as half of all female graduates) have not been able to utilise the skills they have acquired in ICCES training in the labour market.

\subsection{Conclusion}

First, this chapter has shown that the delivery context of training is both very complex and absolutely crucial: ICCES training suffers from multiple disabling factors which inhibit quality training provision.

Secondly, in examining the current situation of ICCES, an obvious question that emerges is; why do youth want to go to ICCES at all if the quality is so bad? There are probably at least two factors that might explain this: first, most entrants can't access other second-cycle institutions (SSS, NVTIs) due to poor BECE aggregates or higher fees and so 'come-down' to ICCES - the only public formalised training offering certification that does not have official entry requirements (like a specified BECE aggregate) (cf. World Bank, 1991: 58); second, the NVTI certificate that ICCES provides might encourage enrolment: it offers the youth both a chance to access further training after ICCES, and the possibility of using the certificate to access formal employment. This is despite the fact that pass rates for the full trade test (for those that do make it to the final year) appear to be around the 50\% mark. 
Thirdly, from the objectives pursued by ICCES, it is possible to identify a number of underlying assumptions inherent in the design, implementation and expected outcomes of ICCES. It is assumed that:

- Communities will have the managerial and financial capacity, as well as sufficient power and social capital, to be able to keep ICCES centres running and resourced. However, community support is often not sufficient to sustain centres, causing many to close. Most ICCES centres are located in poor areas; to expect, therefore, poor communities to sustain centres is unrealistic. Moreover, kobewo contributes to some ICCES centres only having a small number of trainees from the community training in that centre. This reduces the community's desire to fund the training centres (and also increases the need for investment in student hostels).

- ICCES training helps to empower the most vulnerable groups of society (e.g. youth, illiterates, school drop-outs). While it is true that the poor do get access to ICCES centres, probably to a higher degree than in other formal VTIs, poor trainees still find it hard to pay fees and, depending on the centre manager, might not be allowed take the final exam, continue to the next year if fees for the previous year remain in arrears, or might not be allowed to collect their certificate. Other centre managers simply sack those trainees that have not paid fees and, in so doing, sack the poor from the training centre. The fact that the majority of ICCES trainees have completed JSS3 signals, however, that ICCES has failed to connect with the most vulnerable and disadvantaged groups. What is particularly unfortunate from a poverty reduction perspective, is that the lowest cost public provision of skills for poorer young people in ICCES has been the most neglected by the GoG.

- Providing entrepreneurial studies as part of the curriculum will enable trainees to become entrepreneurs. While the basics of doing business can be taught, it is likely that the most successful entrepreneurs have not been taught such subjects, but have built up their skill from their attitude, from their ambition and from the example of others (Logie, 2004).

- Providing trade-related training will turn out graduate trainees who are not only employable, but who are "preferably self-employed within and around their own 
communities" (ICCES, 1996: 1). The evidence suggests that a high number of ICCES trainees, especially the male graduates, aim to undertake further formal training (usually $\mathrm{C} \& \mathrm{G})$ with a view of getting higher certificates and jobs in the formal sector. The most able and most resourced trainees, therefore, are frequently not taking the advantages of further education into the informal sector (cf. McGrath et al., 1995). Graduates that cannot afford further formal training post-ICCES opt to pursue traditional apprenticeship training - this is especially the case for females. Many students, therefore, are not using ICCES to equip themselves with self-employment skills but, rather, as another pathway to certification and hopes of formal employment. Those who undertake apprenticeship training after ICCES obviously consider ICCES training as insufficient in some way as a precursor for self-employment. Nonetheless, once ICCES graduates move into the labour market, it appears most are finding some kind of employment, predominantly in the informal sector; most commonly in self- or (temporary) wage-employment.

Lastly, fig.6.3 shows how the employment pathways noted above relate to the theoretical pathways identified in chapter 3.3.2. 
Fig.6.3. Post-ICCES pathways to training, employment and enterprise

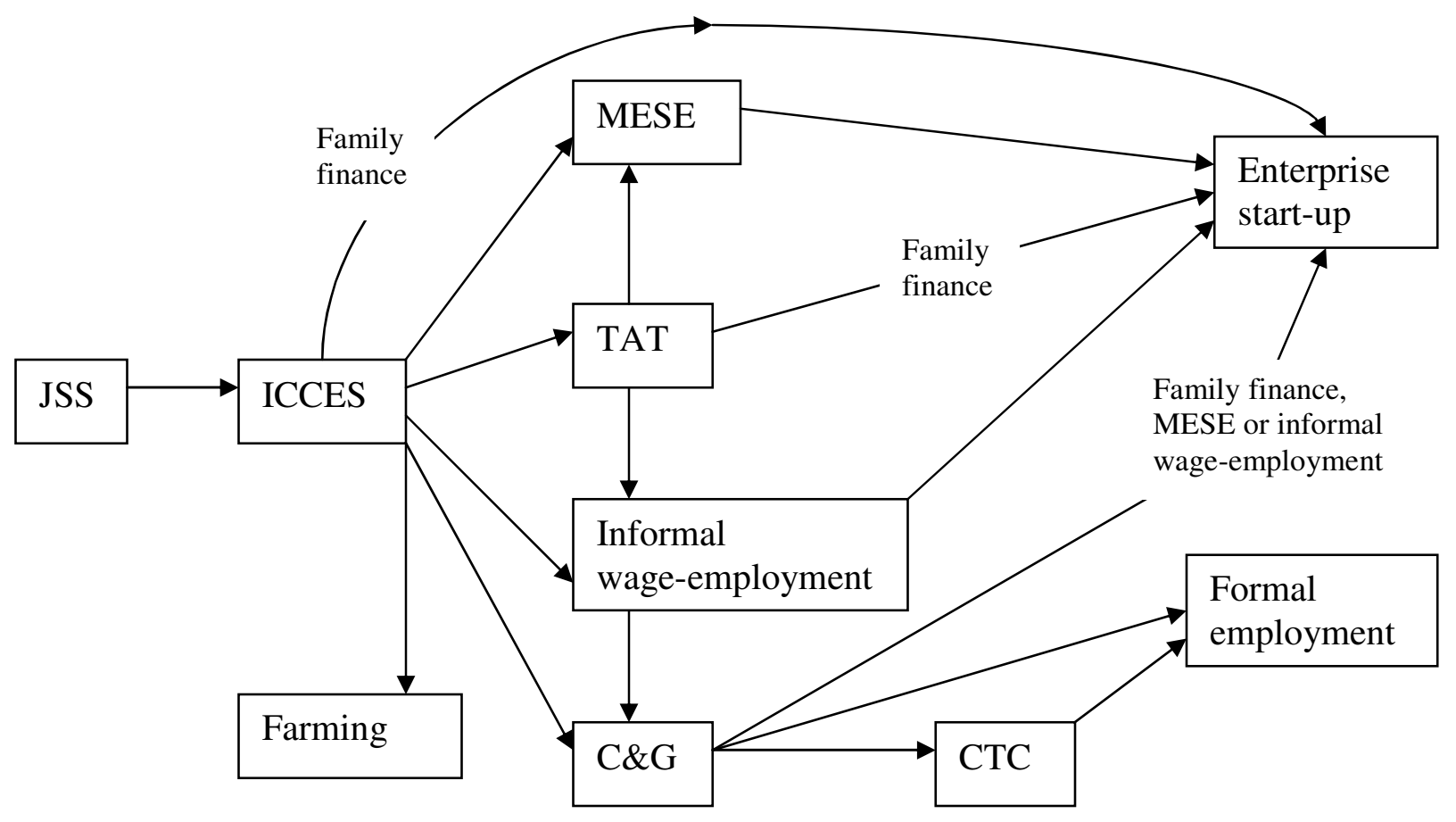

Legend:

MESE Micro-Entrepreneurial Self-Employment

TAT Traditional Apprenticeship Training

C\&G City and Guilds

CTC Craft Technician Certificate 


\section{Chapter 7: Short-Duration Skills Training and Enterprise-Based Training in Traditional Apprenticeships: Training and Post-training Environments in Ghana}

\subsection{Introduction}

This chapter complements the previous chapter - that focused on an example of pre-employment skills training in ICCES - by examining two other types of skills acquisition modalities and presenting new evidence on these programmes.

The first section examines an example of a short-duration skills programme: the Skills Training and Entrepreneurship Programme (STEP) that trained some 27,500 people. ${ }^{321}$ This section will draw on interviews with STEP training providers and government officials conducted between 2003-2006, as well as documents on STEP. The evidence presented will include an analysis of the training and post-training environments as well as the political origins of the programme.

The second section examines informal enterprise-based training (traditional apprenticeships) and draws on fieldwork in rural Ashanti during 2005 which included interviews with 160 apprentices. In addition to an analysis of the training environment, this section presents new evidence on the characteristics of rural apprenticeship, the backgrounds of apprentices and their expectations regarding entry into informal micro-enterprise (IME). ${ }^{322}$

Like the previous chapter the emphasis will be on looking at skills acquisition in rural areas, though the modalities discussed also occur in urban settings. In fact much of the literature on traditional apprenticeship training, in particular, has focused on their characteristics and functioning in urban areas and hence the evidence presented here will go some way to contributing to an understanding of this skills acquisition modality in rural areas.

Like ICCES (chap.6), with the STEP there is an assumed link between skills provision and employment creation; though the intended provision of micro-finance to STEP graduates is

${ }^{321}$ STEP initially stood for 'Skills Training and Employment Placement Programme' when it started in 2003 but was later renamed in the GPRS II as a result of GoG concerns about those trained under STEP expecting employment after training.

${ }^{322}$ The following chapter (8) complements this section: it analyses the findings of retrospective interviews conducted with rural mastercraftspeople - most of whom undertook an apprenticeship prior to entry into IME. 
expected to ease this transition. By contrast, the traditional apprenticeships operate out with the remit of government and training is regarded as being more closely related to employment.

\subsection{Section one: the short-duration skills training modality}

This section will examine an example of short-duration training in Ghana that aimed to link TVET to self-employment creation: the Skills Training and Entrepreneurship Programme (STEP). Between 2003-2005 STEP was very high on both the GoG's political and policy agendas and has since been phased into the National Youth Employment Programme (NYEP). ${ }^{323}$

There has been very little written on STEP to date (mostly internal or consultancy reports, e.g. Preddey, 2005), and not, to the author's knowledge for a wider or academic audience. ${ }^{324}$ And yet it provides some useful lessons about providing training only - STEP was meant to be complemented by micro-finance but this has only materialized for, at most, $10 \%$ of all those trained.

This section takes the following structure: first it examines the background and objectives of STEP; second it looks at the training delivery context; and, last it examines what evidence there is related to the post-training outcomes of STEP graduates and whether or not they are making the expected move into the IME sector.

\subsection{Background and objectives of STEP}

During 2000 when the NPP, led by John Kufuor, was campaigning in the run up to the December election a key pledge made by them was job creation. Indeed the NPP manifesto specifically mentioned the intention was to "create jobs for all persons able and willing to work and to reward each of them appropriately" (NPP, 1996: sect.1.31). Thus the average voter could not be criticised for thinking that if they voted for the NPP, they might be in a better off situation as a result of more jobs being created.

Having won the December election, in early 2001 the Vice-President "[reportedly] gave an assurance that the government will keep faith with its election promises of creating wealth and

\footnotetext{
${ }^{323}$ See chap.5.2.

${ }^{324}$ But see Palmer (2005a).
} 
jobs" (GNA, 2001a). Much was expected of the NPP job creation pledges: during the election campaign one NPP parliamentary candidate had reportedly said the NPP would create 750,000 jobs. ${ }^{325}$ However a few days after the Vice-President's assurance, the NPP "members in Parliament... denied ever making a promise to create 750,000 jobs in the first 100 days of it coming into power" (GNA, 2001b).

In fact it soon became clear that the intention was not to create mass wage-employment for the people, but for the people to create jobs, or mass self-employment, for themselves in the informal economy. ${ }^{326}$ The government's role in job creation would be limited to supporting the development of an enabling environment and the provision of skills training (GoG, 2003a).

From September-December 2001 the NPP government organised a country-wide 'unemployment' registration exercise "which attracted one million unemployed people", mostly aged 15-24 (GNA, 2002) and educated to the basic level or above (GoG, 2004e). ${ }^{327}$ The 2000 Population and Housing Census had estimated unemployment to be $11.2 \%$ of the country's population, or some 2 million people (GNA, 2002; GoG, 2004e). The 'unemployment' registration exercise, therefore, captured about half of those deemed to be 'unemployed'. President Kufuor, in the preface to the Youth Employment Programme brochure, noted that the 2001 unemployment exercise was undertaken "to give us a good understanding of the nature and scope of the unemployment situation among the youth so as to be able to deal with it very effectively" (GoG, 2006c: iii). Arguably the exercise was so politicised and hampered by methodological difficulties, associated with defining and registering the 'unemployed', that it has not provided the government with a good understanding at all. ${ }^{328}$

Those that were registered in the exercise were asked about their aspirations regarding what they wanted to do. Data on the registration exercise from the MoMYE show that only $14 \%$ reportedly

\footnotetext{
325 The promise of 750,000 jobs appears to have come from Kofi Wayo when he was the NPP's parliamentary candidate for the Ayawaso East Constituency during the 2000 election campaign (a constituency he later failed to win).

${ }^{326}$ King (2005b) notes a similar case in Kenya, where in February 2003, the new government under Kibaki, stated it was the government's intention to create 500,000 jobs per year. This was qualified in June 2003, when the government announced that $88 \%$ of these 500,000 jobs were to be created in the informal economy by the people themselves.

${ }^{327}$ Of the 943,212 people registered, 771,000 (82\%) had completed JSS or middle school, a further 77,000 $(8 \%)$ had a post-basic education.

328 There are huge difficulties with 'unemployment' figures in most developing countries, including Ghana (chap.2.3).
} 
requested training (table 7.1). Most respondents, it appears, wanted either assistance in setting up an enterprise (34\%) or a position (wage-employment) in an ongoing project (40\%).

\section{Table 7.1. Responses from the 2001 unemployment registration exercise} (aspirations of respondents)

\begin{tabular}{|l|r|r|}
\hline Option & Freq. & Percent \\
\hline To be trained in a skill/trade area & & \\
To seek apprenticeship training/attachment & 74,100 & 7.86 \\
To be assisted to set up their own enterprises & 61,000 & 6.47 \\
To be placed in ongoing and impending projects & 321,100 & 34.04 \\
To continue general education & 87,012 & 39.97 \\
To be re-integrated into families & 1,000 & 8.91 \\
Other & 25,000 & 0.11 \\
\hline & 943,212 & 100.00 \\
\hline
\end{tabular}

Source: GoG, 2004e

However, these results were used to support the implementation of skills training programmes for the 'unemployed'. The, then, deputy Minister (MoMDE) reportedly said that this exercise "revealed that 60 per cent of the unemployed who registered did not want immediate employment but wanted to be equipped with entrepreneurial skills" (GNA, 2002). This $60 \%$ figure must have come from those that responded they wanted skills training (14\%), those that said they wanted to be assisted to set up an enterprise (34\%) and those that said they wanted to continue general education $(9 \%){ }^{329}$

Therefore, in spite of the fact that most respondents were seeking (self- or wage-) employment and not skills training, as a result of the country-wide unemployment census the MoMDE was mandated to draw up programmes to train the youth to acquire employable skills. This included:

- Competency training for master craftsmen/women;

- Apprenticeship training for the unemployed;

- Opening of ICCES Centres in all 110 districts $^{330}$ (GoG, 20041).

\footnotetext{
${ }^{329}$ An unpublished document from the MoMYE comments that the planned intervention for those who reported that they wanted to be 'assisted to set up an enterprise' was entrepreneurial training and access to micro-credit (GoG, 2004e). The comment from the Deputy Minister was therefore misleading and referred to the MoMYE's planned interventions and not to the responses of those who said they wanted to be 'assisted'. It is very likely that those who responded that they wanted to be 'assisted' to set up an enterprise did not have in mind training but access to start-up capital. Indeed this is what a World Bank report has taken this to mean (cf. World Bank, 2005b).

${ }^{330}$ There are now 138 districts in Ghana (August 2006).
} 
Consequently, the two most visible manifestations of this skills policy became an expanded ICCES network (chap.6), on the one hand, and STEP on the other. While ICCES had been in existence since 1986, STEP was initiated as a direct response to the government promise to tackle youth unemployment if it won political power (Daily Graphic, 18.08.03).

STEP intended to reduce poverty by providing employable skills and other assistance (including micro-finance) to the 'unemployed' enabling them to become productively employed, mainly self-employed in the informal economy. STEP training was delivered through existing service providers, including the ICCES, GRATIS, NVTI and other public and private VTIs nationwide. ${ }^{331}$ Funding was made available by allocations from the HIPC Fund. ${ }^{332}$

The objectives of STEP were (GoG, 2004g) to:

- Offer short, demand-driven competency based vocational/technical training;

- Make trainees self-employable, instead of relying on central Government to offer those jobs;

- Stem the unbridled drift from the rural to urban areas in search of non existent jobs;

- Reduce the endemic poverty and create awareness for wealth creation.

STEP is comprised of three principal components:

- Skills training delivered through vocational training providers: STEP training courses ran for three to twelve months in 58 training areas (fig.7.1). In addition to the main trade skill being taught, STEP trainees were instructed in entrepreneurial and cooperative formation skills. On completion the intention was that they would be able to create employment for themselves in cooperatives.

- Skills enhancement for master-craftspeople and skills training delivered through apprenticeship placements: Master-craftspeople undertook a few days training with GRATIS to make them more effective trainers. Skills training was then delivered by attaching up to 10 trainees to a master-craftsperson to undertake a workshop-based apprenticeship for up to twelve months.

${ }^{331}$ ICCES had an important role to play in the delivery of STEP as noted shortly.

${ }^{332} \phi 11.16$ billion (US $\$ 1.1$ million) was allocated to in 2003 to implement STEP (GoG, 2004c). 
- Micro-finance component: This component, launched in December 2004, intended to provide capital to those trained under STEP to set up their own enterprises. Funding was to be made available from HIPC funds to micro-finance institutions (MFIs) for onlending to qualified trained STEP graduates. Two MFIs participated: the Women's World Banking Ghana (WWBG) and rural bank network under the Association of Rural Banks APEX (ARB APEX).

There were meant to be three training phases to the STEP programme: phase one February-July 2003; phase two November 2003-2005; but phase three, due to commence in September 2005, was discontinued. Indeed in March 2005, when the teams of ministers changed over, the new team decided not to continue with the planned phase three of STEP in its current form. ${ }^{333}$ The MoMYE's Chief Director said in November 2005 that STEP had not been discontinued totally, adding that it would be placed under the new NYEP which is to have skills training and placement components (GNA, 2005a). The NYEP is supposed to absorb STEP graduates who have been trained but not yet placed in jobs or using their skills in self-employment. ${ }^{334}$

\section{Fig.7.1. STEP training courses}

three month courses in 12 training areas including:

Bamboo Processing; Batik, Tie and Dye; Beads Making; Bicycle Repairing; Food Processing; Floral Works; Hospitality and Tourism (10 Weeks); Printing; Rural Craft; Steel Bending; Textiles and Soap Production

six month courses in 42 training areas including:

Ashanti Cloth Designing; Auto Body Repairs; Auto-Engineering; Auto Electrical; Building and Construction; Beautician; Basketry and Beads Making; Cane/Basketry; Carpentry and Joinery; Carving; Carpentry/Furniture Making; Cosmetology; Dressmaking/Tailoring; Electrical; Electronics; Food Processing; Food Processing Technology; Food Processing Materials Packaging; Hairdressing; Jewellery; Information and Communications Technology (ICT); Kente Weaving; Leatherworks; Machining; Painting and Decoration; Multimedia Production; Perfumery/Detergents/Hair care; Plumbing; Pottery/Ceramics; Radio and Television; Photography and Video Production; Production of Concrete; Refrigeration and Air-Conditioning; Tailoring and Apprenticeship Training; Traditional Cloth Weaving; Traditional Footwear Making; Textiles and Printing; Weaving; Wood Processing; Welding and Fabrication.

twelve month courses in 4 training areas including:

Apprenticeship Training Scheme; Draughtmanship and Construction; Foundry; Garment Construction

Source: Preddey, 2005

\footnotetext{
${ }^{333}$ Deputy Minister MoMYE, 2003-05, personal communication (email) 26.03.06.

${ }^{334}$ NYEP Director, personal communication 01.08.06.
} 


\subsection{The training delivery context of STEP}

STEP training occurred in both the formal training environment in public and private VTIs and in the informal training environment in apprenticeship placements.

\subsubsection{Skills training delivered through vocational training providers: the case of ICCES}

One modality by which STEP training was delivered was through vocational training providers including both public and private VTIs. And, as noted in chapter 6, ICCES played a significant role in the delivery of STEP training in the VTIs. In phase one of STEP 37\% (43/117) of all VTIs delivering STEP training were ICCES centres. In phase two ICCES centres accounted for $48 \%$ $(49 / 103)$ of public VTIs delivering STEP and 34\% $(1,369 / 4,052)$ of trainees in the public VTIs (Preddey, 2005). ${ }^{335}$

The mechanism by which training was delivered through ICCES was as follows. ${ }^{336}$ Once the centres were identified that were to deliver the training, details were placed in the national papers to inform those who had previously registered as 'unemployed' during the 2001 exercise that they could register for the training. Centre managers were told to register a maximum of 25 trainees per course per phase, on a first-come first-registered basis, though in many cases substantially more than 25 trainees were enrolled. The government then paid about $\varnothing 555,000$ (US\$61) per trainee to the ICCES centre that provided the training, but only for a maximum of 25 trainees per centre (Logie, 2004). ${ }^{337}$ This was to cover the training fee thus making STEP training free to those enrolled, apart from a nominal commitment fee of $\phi 5,000$ (US\$0.55) payable on registration (GoG, 2004h).

The $₫ 555,000$ per trainee paid by government was allocated as follows: $20 \%$ for ICCES administration; $30 \%$ for tuition, and 50\% for training materials (Logie, 2004). An average ICCES centre, therefore, would receive about $\phi 13$ million (US\$1,440) for 25 STEP trainees (about 3

\footnotetext{
335 In all there were some 244 VTIs in phase two of STEP (103 public and 141 private), training 12,664 people (4,052 in public VTIs and 8,612 in private VTIs). Of all the VTIs providing training in phase two of STEP, ICCES centres were responsible for 49/244 (20\%) of the service provision.

${ }^{336}$ STEP training in other public/private VTIs followed a similar mechanism.

${ }^{337}$ This amount was for a dressmaking course. The amount of fees paid by the government for each course varied slightly; construction courses, for example, were allocated $\phi 800,000$ per trainee (c.US $\$ 88$ ).
} 
million of which was for administration) meaning that, "[t]o some extent... [this] subsidise[d] the rest of the Centre" (Logie, 2004: 19).

The short-duration STEP training delivered through VTIs was meant to be kept separate from the regular (three-year) VTI training. In practice, however, in some cases STEP training delivered by ICCES centres was given to all their students, regardless of whether they were STEP trainees or regular three-year ICCES students. This cross-over had both positive and negative repercussions. One the one hand existing ICCES trainees were able to benefit from STEP training being conducted; e.g. ICCES dressmaking students benefited from learning batik or soap making intended for STEP trainees. ${ }^{338}$ On the other hand, however, it is likely that the training quality was reduced as the centres were only supplied by the government with sufficient materials to cover STEP trainees - and not extra bodies.

A consultant's evaluation of STEP training at ICCES noted that centres liked to deliver STEP training since there was "some benefit to the "normal" students, partly from the funding coming into the school, and partly from the overlap of training and the mixing with older students" (Logie, 2004: 20).

\subsubsection{Skills enhancement for master-craftspeople and skills training delivered through apprenticeship placements}

Apprenticeship training organised by GRATIS either took place in their own facilities - where "adequate" (GoG, 2004f) equipment and machinery existed for the training - or in IMEs with master-craftspeople identified by GRATIS.

Many master-craftspeople that were given apprentices to train by GRATIS could not provide a decent training environment (e.g. protective clothing) and were ill-resourced in tools and equipment (GoG, 2004f). Master-craftspeople complained about receiving insufficient funding to adequately train apprentices: while the GRATIS foundation was being paid $\phi 500,000$ (c.US\$55) per apprentice, the master-craftspeople by contrast received $₫ 300,000$ (c.US\$33). Both GRATIS and the master-craftspeople complained that much of this was spent by them feeding the apprentice throughout the training period (ibid). The duration of training was not considered long

${ }^{338}$ Senior ICCES/STEP official, personal communication 15.05.04. 
enough, especially in trades like welding and carpentry, leading to the creation of "half-baked" apprentices (ibid.: 3). This was especially the case since most apprentices being trained had no prior knowledge of the trades (ibid.). Training was criticised as having a traditional approach to production, one that was not competitive and not productive (Preddey, 2005).

\subsubsection{Lack of demand for these types of skills}

STEP was highly centralized and training providers were required to follow strict rules and procedures leaving little room for training delivery to be tailored to the specific needs of an area (Preddey, 2005).

Skills needs assessments were conducted at NVTI Headquarters in Accra and the choice of skills to deliver appeared arbitrary and decided without the participation of the implementing bodies or the communities involved. There was no real attempt to establish demand for skills and product types at the local level, and District Assemblies sometimes complained about STEP training providers proposing to continue to deliver "useless" courses (ibid.: 22).

A further concern related to the failure of government to conduct any labour market surveys before deciding on which courses to offer was the danger of market saturation and excessive competition; often regular long-term VTIs had been operating for many years in communities and "may have saturated the labour market with their graduates" (ibid.: 24). Moreover, the lack of coordination between local demand for specific products and what STEP trainees learnt led to problems selling the items produced by trainees (GoG, 2003f) (and to problems for STEP graduates later since they were often trained in designs and styles for which there was no local market).

This situation can be illustrated by looking at how one ICCES centre in Ashanti ended up delivering STEP training. The community, the centre's staff (and even the regional coordinator) were not involved in any of the decisions regarding the choice of skills or the implementation. Instead the centre manager was simply told by the ICCES head office to select 'about 30 people' for training in soap making, batik, tie and dye and pomade production. As a result many of those who registered had little idea about what they were doing there and often attended only because the training was free and they thought that they 'may as well take it'. In fact those that were enrolled contained a large number of family and friends of the vocational training centre's staff, 
including the wife of the centre manager. When the training started all the regular ICCES trainees on the three-year course also participated in STEP training (and subsequently continued with their three-year course), thereby diluting the quality of the training for the officially registered STEP trainees since materials were limited to 25 people. Since there had been no market surveys conducted prior to the training some of the products produced could not be sold since there existed no local demand. For example the designs and styles of batik, tie and dye that were taught were not in demand locally and hence it was very difficult to sell them afterwards (the items that STEP trainees produced were supposed to be sold locally to support the income of the centre where the training occurred).

\subsubsection{Lack of coordination and weak management}

STEP suffered from general management problems (Preddey, 2005). In addition those VTIs delivering training were visited irregularly by STEP coordinators which led to poorer performance in some STEP centres (GoG, 2003f). In that case of ICCES this was undoubtedly a direct result of the lack of transport for regional coordinators (chap.6.2.13).

\subsection{The next step: after graduation what?}

Some of you might be asking yourself this question: What next after this graduation?... You will need to start working immediately... but your parents and guardians perhaps do not have means to set you up in business. The government is mindful of this situation and efforts are being put in place to offer you some assistance. In view of the problems which were associated with a similar scheme ${ }^{339}$ organised a few years ago where the majority of people who were given free tools and kits after their training sold them and pocketed the proceeds, only to get back on to the streets. Government is seriously studying the situation to come up with a practicable solution. (Keynote address by the Deputy Minister, MoMYE, at the graduation ceremony of STEP trainees, 17.03 .04 (GoG, 2004g))

There were numerous problems with the implementation of STEP, suggesting among other things, that the expected self-employment creation would not come about as easily as was hoped. Indeed in order to improve implementation of phase two, responsibility for implementing STEP was handed directly by the MoMYE (and not by NVTI which had been responsible for phase

\footnotetext{
${ }^{339}$ This is a reference to the World Bank's VSP.
} 
one). ${ }^{340}$ There have been a number of constraints hindering the outcomes of STEP, one of the largest of which concerns micro-finance provision.

\subsubsection{Micro-finance provision}

Micro-finance represented one of the three main components of STEP: start-up and working capital were meant to be provided to enable those trained to enter self-employment activities. The government pledged early on to provide start-up capital for STEP graduates. It was announced in mid 2003 that:

The government has set aside 10 billion cedis [US\$1.1mill.] out of 50 billion cedis [US\$5.5mill.] of the Youth Fund to support the... STEP. (GNA, 2003b)

Two years later the figure mooted for STEP graduate loans was being reported as $\phi 5$ billion (US\$555,000) (GNA, 2005e).

As noted above, two MFIs were used to channel micro-finance to STEP graduates; the ARB APEX and the WWBG. However both these MFIs have concerns regarding lending to these graduates. While ARB APEX view the capacity of STEP graduates to understand the conditions of lending as inadequate, WWBG expressed concern that the expectations of STEP graduates about their access to micro-finance was unrealistic (Preddey, 2005).

WWBG considered that providing micro-finance to STEP graduates was a social programme and was not commercially viable. The standard loans from WWBG attract interest of $37 \%$ and can only be accessed if the prospective borrower has $50 \%$ of the loan amount deposited with WWBG as collateral and is willing to pay a $2.5 \%$ commitment fee on the loan amount (ibid.). In the case of STEP graduates, the government requested WWBG to charge $25 \%$ interest (to be shared equally with government) and for WWBG to waive the usual requirements of $50 \%$ collateral and the $2.5 \%$ commitment fee (ibid.).

STEP borrowers were seen by WWBG as a higher risk than other borrowers; being new customers with low educational attainment (ibid.) and frequently no credit history. Moreover, in most instances STEP training failed to include guidance on how to put together a proposal for a

${ }^{340}$ Senior STEP official, personal communication 15.06.04. 
loan. Consequently most graduates "lack[ed] the capability to produce viable proposals that would justify loans" (ibid.: 26).

Financial assistance for STEP graduates appears to have been slow in coming in many cases.

An April 2005 consultancy report of STEP noted that representatives of STEP training providers were "unaware of whether any loans had been taken up, and most [were] unaware of the nearest micro-financing institution (MFI) to their own training centres" (ibid.: 25).

At the end of July 2005 the Director of ICCES commented that the loans to STEP graduates who had received their training through ICCES were still delayed (GNA, 2005b). In fact in Ashanti, STEP graduates who trained at ICCES from both phase one and two of the project (that finished in mid-2003 and mid-2004 respectively) had not received any start-up funds by the end of June 2006 (ICCES/STEP coordinator, Ashanti Region, personal communication (email) 28.06.06.). Only the Kumasi production unit STEP graduates, which is loosely attached to ICCES and "has [only] a few trainees has a loan from [sic] rural bank" (ibid.).

In March 2006 it was announced that no start-up funds had been received by phase one and two STEP graduates from Bolgatanga Municipality - who graduated in 2003 and 2004 - though graduates from the Bawku and the Navrongo districts have reportedly been able to access funds (GNA, 2006b).

Indeed anecdotal evidence points towards difficulties in STEP graduates accessing loans. In one case in Ashanti an ICCES centre was asked by the local rural bank to act as a guarantor on loans made to STEP graduates; obviously it was not in a position to do this and STEP trainees still have not had their loans by mid-July 2006 (centre manager, personal communication (email) 11.07.06).

Even when some $\phi 5$ billion has been set aside for STEP graduates, if this were to be equally shared out among all the 27,000 graduates each individual would only get about $₫ 185,000$ (c.US\$20) - hardly sufficient to start-up an enterprise. In fact, "[d]espite expectations to the contrary, not all STEP graduates qualify for micro-finance" (Preddey, 2005: 26). As of April 2005 only 178 individuals had their applications approved, with a further 38 individuals waiting to have their applications considered by WWBG (Preddey, 2005). 
By October 2006, at the official launch of the NYEP, President Kufuor announced that over 3,000 STEP graduates had received loans (GNA, 2006c). This represents about $10 \%$ of all those trained under STEP.

Where micro-finance has been paid out to STEP graduates, the average amount meant for each individual appears to be $\phi 500,000$ (c.US\$56). While this will be a help it is questionable exactly what $\phi 500,000$ per graduate can achieve since this amount is small when compared to the outlays required to start a new enterprise (chap.5.3.6), especially since profits will not come back to the enterprise immediately. This is presumably why the government is encouraging people to form cooperatives so that they can share the cost of initial items.

This delay in micro-credit has not been the result of an unawareness of the need to support STEP graduates financially. Indeed internal reviews of STEP have noted that this delay in micro-credit to STEP graduates will "result [in a]... lack of interest in the skill acquired due to [the] long absence of practice" (GoG, 2005f: 3). It appears that inadequate budgetary planning has left insufficient funds to finance the credit component. Furthermore, the political will needed to drive micro-credit provision has been absent and now the political focus has moved away from STEP to the forthcoming NYEP (chap.5.2).

Apart from the promise of credit, there seems to be very little else planned with regard to other BDS for STEP graduates (e.g. monitoring, advice, tracers). Meanwhile, the institutional framework for MSE support in Ghana, and particularly rural Ghana where most STEP training occurred, is known to be very poor (chap.5.3).

\subsubsection{Employment outcomes unknown}

The government, largely for political reasons, has been very keen to portray the major outcome of STEP as job-creation. However this assumed link between skills training and self-employment creation is largely yet to materialise in reality. It is true that the skills training component of Skills Training and Employment Promotion programme has taken place, albeit with many delivery challenges, but as yet the employment promotion has not occurred. A World Bank (2005b) study on youth employment in Ghana commented that "while [the] STEP program has been successful in providing some skill training to some selected youth, the program has not necessarily enhanced the employment opportunities of the youth" (p.32). 
Indeed the original name of STEP - Skills Training and Employment Promotion - implied to many that STEP had some capacity to place trainees in (waged-) employment. The government saw the political risk this implication held and made efforts to change the public perception of STEP (Preddey, 2005). However it was not until 2005, after much of the training had occurred, that STEP was changed to Skills Training and Entrepreneurship Programme in the GPRS II.

To date (October 2006) there remains a lack of evidence on the employment outcomes of STEP graduates. Indeed, "except for anecdotal evidence, no one really knows what has happened to the substantial number of STEP graduates since the programme's inception" (Preddey, 2005: 23). The indications, from those who implemented STEP at village-level, have been that STEP graduates feel the programme has helped them to acquire useful skills (fieldwork, 2005). However, the ability to use these skills in the labour market appears to be proving difficult. Indeed there is concern that many (if not most) STEP graduates are not faring well in the labour market (Preddey, 2005) and not using the skills they have acquired. There has, however, not been any tracer study of STEP graduates; so concrete evidence is lacking and it was beyond the resources and time constraints of this doctoral work to undertake this tracer.

STEP will not lead automatically into employment creation without a supportive transformative context in the informal economy. The government has announced plans to release loans to STEP graduates but, as noted above, these have been slow in coming. The government wants STEP graduates to form into cooperatives of four or five and to seek loans from the rural banks. Loans are not automatically given, however, and it will be interesting to see how many STEP graduates apply for, and are able to access these loans when they become available. As of October 2006, loans appear to have reached only $10 \%$ of those trained.

\subsection{Concluding comments on STEP: training delivery in a highly politicised environment}

I think STEP is politicised, there is still [a] problem with settling the past trainees by giving them financial assistance to enable them [to] start their own businesses. So on paper so many people have been trained but they are back on the streets selling as usual. (senior official, MoMYE personal communication (email) 29.03.06) 
During the 2000 election campaigns the NPP made special efforts to attract the youth due to Ghana's young population and the fact that the youth vote was "always going to be decisive" (Nugent, 2001: 419). ${ }^{341}$

It was noted earlier (chap.5.2) how the NPP's political rhetoric of job creation for "all persons willing to work" in the NPP manifesto (NPP, 1996: sect.1.31) and election pledges was later translated into providing skills training and support to the development of an enabling environment for the private sector. ${ }^{342}$

Right from the start, STEP, with its origins in the 2001 unemployment registration exercise has been highly politicized. A 2005 evaluation study of STEP commented that "the initial impetus for STEP was political: i.e. a publicly-announced intention to reduce poverty... by eliminating unemployment in the informal economy through skills training and job placements. This worthy intention may have been over-stated" (Preddey, 2005: 27).

It was further noted above that the government has been very keen to present STEP as creating employment for the youth. Indeed it seems that the government has been keen to publicise STEP's success in the media.

For example up to mid 2003, 3,500 people had been provided with skills under STEP (GoG, 2004c). But this was reported in the media as 'Government offers employment to 3,500 people' (GNA, 2003a).

In 2004 the Deputy Minister (MoMYE) again directly reaffirmed the assumed link between STEP and the problem of unemployment. It was reported in the media that 14,611 unemployed youth acquired skills in various trade areas since the commencement of STEP (GNA, 2004). The Deputy Minister (MoMYE), is reported to have said that:

unemployment had been a major concern to the nation and it was against this background that the... NPP government took a bold step to provide a nationwide skills training programme for the youth under the STEP. (GNA, 2004)

\footnotetext{
$34140 \%$ of the population was under 15 years in 2003 (UNDP, 2005).

${ }^{342}$ The enabling environment for the informal private sector remains very weakly developed (chap.5.3).
} 
In May 2005 the Minister (MoMYE) reportedly said that a "total of 27,000 unemployed youth had been trained and assisted with micro-credit to operate on their own under [the] STEP programme" (GNA, 2005d, emphasis added). ${ }^{343}$ But just a day later the same minister was reported as claiming that not only had 27,000 unemployed youth been trained and assisted with micro-credit, but that they were "now self-employed" (GNA, 2005c). Indeed the headline in the article reporting this was '27,000 Unemployed Gets [sic] Jobs' (ibid.).

President Kufuor, in his foreword to the NYEP brochure, also puts a very optimistic political spin on the outcomes of STEP programme. He claims that the: "success of this programme [STEP] can be found in many young men and women who have gone on to start small businesses for themselves while others have been employed by various established organizations" (GoG, 2006c: iii).

Although it has been claimed that young people trained under STEP have started their own businesses or secured employment, it is probably telling that STEP was renamed the Skills Training and Entrepreneurship Programme (in 2005), as it had signally failed to connect with job opportunities the very large number of young people who registered.

While STEP has received much publicity and has been presented by the government as easing unemployment, it should not be forgotten that the total number trained under STEP, about 27,000, is relatively small; over the same two years that the first two phases of STEP operated, about 300,000 JSS graduates finished school, did not enter further formal education or training and found themselves in the IMEs or in informal training, including traditional apprenticeships. Traditional apprenticeships remain the most widespread skill acquisition modality and, having noted earlier the GoG's intention to formalise this system (chap.5.1) it is important to examine this form in depth.

\subsection{Section two: the traditional apprenticeship training modality}

Traditional apprenticeship training has had a long history in West Africa and it is unsurprising, therefore, that today it is so well-developed in this sub-region (Birks et al., 1994; World Bank,

\footnotetext{
${ }^{343}$ From our earlier discussion related to the disbursement of micro-finance to STEP graduates, it was clearly an exaggeration for the minister to claim that all graduates had been assisted with micro-credit.
} 
2004a). ${ }^{344}$ The World Bank (2004a) notes that it is less well developed in eastern and southern Africa but that it is still a major provider of skills for workers in the informal sector. ${ }^{345}$

Despite early recognition in Ghana of the potential of traditional apprenticeship training as a skills delivery mechanism (Foster, 1965a) few policy makers have been interested until the mid1990s. The World Bank now states that for SSA "traditional apprenticeship is the most important source of training for workers in the informal sector" (World Bank, 2004a: 127) and, further, that "[t]raditional apprenticeship training is responsible for more skills development than the offerings of all other training providers combined" (ibid: 129). Others note that more young people acquire competence through informal apprenticeship than it would be possible through more formal educational schemes (Overwien, 1997 in Liimatainen, 2002).

This section takes the following structure: first it outlines apprenticeship training in Ghana; second it presents new evidence on rural apprenticeship drawing on interviews with 160 apprentices; third it analyses the training environment; and, fourth, examines the link to selfemployment.

\subsection{Traditional apprenticeship training in Ghana}

In Ghana apprenticeship training originated as a means to reproduce skills within families or communities, but over the years has been modified to involve more formalised contracts, payments for training and less restrictions regarding access to this training (Silver, 1981; QuarteyPapafio, 1914).

Apprenticeship training is responsible for some $80-90 \%$ of all basic skills training in Ghana, compared to 5-10\% from public training institutions and 10-15\% from NGO for-profit and nonprofit providers (Atchoarena and Delluc, 2001; GoG, 2004b; Haan and Serrière, 2002; Honny, 1999; World Bank, 2004a).

\footnotetext{
${ }^{344}$ For discussions of apprenticeships in Nigeria see Callaway (1963; 1964), Fadahunsi and Rosa (2002); Lloyd (1953); and for Ghana see Ahadzie (2003); Foster (1965a), Frazer (2006); Hakam (1978), Hart (1973), McLaughlin (1979), Peil (1970), Silver (1981), Quartey-Papafio (1914), Valenchik (1995) and Yokozeki (2005). For general overviews of apprenticeship in SSA see Bas (1989), Fluitman (1994), Haan (2001, 2006), World Bank (2004a).

${ }^{345}$ For an early account of informal skills acquisition in Kenya see King (1977).
} 
In Ghana, where about 30\% of JSS graduates are able to enter formal second-cycle institutions and where formal employment opportunities are few, the majority of youth end up either working or acquiring skills in IMEs. Aryeetey et al. (2005) note that traditional apprenticeship training represents the dominant source of skills acquisition for these JSS graduates who cannot access further formal opportunities. Bortei-Doku Aryeetey (2001) adds that "for many people [apprenticeship]... is the only option available for acquiring employable skills" (p.42).

The general features of the traditional apprenticeship training modality are well known. ${ }^{346}$ Briefly stated, in Ghana an aspiring apprentice becomes attached to a master, usually for three years (but this varies by trade/master). ${ }^{347} \mathrm{~A}$ joining fee is usually charged for the training but is sometimes waived if the youth is known to the master. In some trades a contract is signed between the master and apprentice, but in many cases agreements are verbal. ${ }^{348}$ The apprentice largely learns through observation. A new apprentice is initially given simple tasks to perform, often unrelated to the trade (e.g. running errands, doing odd-jobs, cleaning, washing, fetching water, farming) (Bas, 1989). During this initial period the apprentice is also given basic trade-related tasks to perform (e.g. cleaning nuts/bolts or doing simple wood-smoothing work). As the apprenticeship progresses he/she is given progressively more complex tasks under the direction of the mastercraftsperson and other senior apprentices.

\subsection{Traditional apprenticeship training in rural Ashanti (Ghana)}

The GLSS4 (1998/99) generated some macro-data on apprenticeship in both urban and rural areas of Ghana. According to this, most apprentices are to be found in the tailoring/dressmaking (37\%), carpentry $(9 \%)$ and mechanical (8\%) trades (table 7.2). Both male and females are common in tailoring/dressmaking, though many trades are dominated by male apprentices. In rural areas the most popular apprenticeship areas are tailoring/dressmaking (36\%), carpentry (9\%), masonry (7\%) and mechanics (7\%). Male apprentices operate in a more diverse array of trades compared to women who are found mainly in tailoring/dressmaking (68\% of women) (table 7.2).

\footnotetext{
${ }^{346}$ See Fluitman (1994), Haan (2001, 2006), World Bank (2004a).

${ }^{347}$ Unlike in the past (see Silver, 1981; Quartey-Papafio, 1914) entry into traditional apprenticeship training in Ghana today is not really restricted to those from the same community or kin group as the master, though the master is usually known to the parents before being approached to take their child as an apprentice. However, some researchers comment that masters more commonly take on apprentices from their own kin or rural birthplace (Dijk, 1997).

${ }^{348}$ On apprenticeship contracts, see Valenchik (1995).
} 
Table 7.2. Distribution of apprentices by main trade learnt, by sex and locality (\%)

\begin{tabular}{|c|c|c|c|c|c|c|c|c|c|}
\hline \multirow[b]{3}{*}{ Main trade learnt } & \multicolumn{6}{|c|}{ Locality } & \multirow{2}{*}{\multicolumn{3}{|c|}{ Ghana }} \\
\hline & \multicolumn{3}{|c|}{ Urban } & \multicolumn{3}{|c|}{ Rural } & & & \\
\hline & Male & Female & All & Male & Female & All & Male & Female & All \\
\hline$\overline{\text { Carpentry }}$ & 16 & 0.4 & 8.5 & 15.7 & - & 9 & 15.8 & 0.2 & 8.8 \\
\hline Masonry & 8.5 & & 4.4 & 11.4 & -1 & 6.6 & 10.2 & & 5.7 \\
\hline Tailoring & 13.2 & 64.4 & 37.8 & 12.5 & 68.1 & 36 & 12.8 & 66.4 & 36.8 \\
\hline Blacksmithing & 4 & & 2.1 & 3.4 & - & 2 & 3.6 & -1 & 2 \\
\hline Mechanical & 17.2 & 0.3 & 9.1 & 11.2 & 0.4 & 6.6 & 13.6 & 0.3 & 7.7 \\
\hline Electronics/Electrica & 8.9 & - & 4.6 & 5 & -1 & 2.9 & 6.5 & -1 & 3.6 \\
\hline Painting/spraying & 4.8 & 1.1 & 3 & 3.1 & 0.7 & 2.1 & 3.7 & 0.9 & 2.5 \\
\hline Other & 27.5 & 33.7 & 30.5 & 37.7 & 30.8 & 34.8 & 33.6 & 32.1 & 33 \\
\hline All & 100 & 100 & 100 & 100 & 100 & 100 & 100 & 100 & 100 \\
\hline
\end{tabular}

Notes: The GLSS4 report indicates that there were a total of 3,438 trainees in the sample, but did not break this down by rural and urban areas.

Source: GSS, 2000: 13

Fieldwork conducted during 2005 intended to find out more about rural apprenticeship training (nsanodwuma suafuo) in Ashanti. Two approaches were used. The main data collection tool used was to interview 160 apprentices from 114 IMEs in three communities in rural Ashanti. The 114 enterprises had a total of 347 apprentices making the sample size of 160 almost $50 \%$ of the total number of apprentices. ${ }^{349}$ A secondary approach was to use the household survey conducted in one rural community (Otaakrom) (Appendix C) to find out about the training background of youth in that settlement.

The author's interviews (table 7.3) showed a similar pattern to the national figures from the GLSS4: $36 \%$ of apprentices were in the dressmaking/tailoring area (compared to $36 \%$ in the GLSS4); carpentry enterprises trained $19 \%$ of apprentices (9\% in the GLSS4); mechanical enterprises trained $8 \%$ of apprentices (7\% in the GLSS4); and masonry enterprises trained $4 \%$ of apprentices (7\% in the GLSS4). However a significant trade area taking on apprentices, categorized under 'other' trade and so disguised in the GLSS4 figures, was hairdressing: from the author's sample it was found that $20 \%$ of all apprentices could be found in this trade (virtually all female).

${ }^{349}$ See Chap.1.4.4./Appendix A for the methodology. 


\section{Table 7.3. Distribution of rural apprentices, by trade and sex (Ashanti)}

\begin{tabular}{|l|r|r|r|r|}
\hline & Male & Female & All & Percent \\
\hline Dressmaking & 6 & 51 & 57 & 35.6 \\
Haridressing & 1 & 31 & 32 & 20 \\
Carpentry & 30 & 0 & 30 & 18.8 \\
Mechanics & 13 & 0 & 13 & 8.1 \\
Masonry & 7 & 0 & 7 & 4.4 \\
Electronics & 6 & 0 & 6 & 3.8 \\
Shoemaker & 3 & 0 & 3 & 1.9 \\
Welder & 5 & 0 & 5 & 3.1 \\
Artist & 2 & 0 & 2 & 1.3 \\
Vulcanizer & 2 & 0 & 2 & 1.3 \\
Bike repairer & 1 & 0 & 1 & 0.6 \\
Fridge repairer & 2 & 0 & 2 & 1.3 \\
\hline & 78 & 82 & 160 & 100.2 \\
\hline
\end{tabular}

Source: Author's fieldwork, 2005

The household survey conducted in Otaakrom (2005) - that captured data on some 147 youth by wealth category - revealed that almost $40 \%$ of youth had been through an apprenticeship (Appendix C, table C.6). More interestingly, perhaps, is that almost half of all the youth who had been through an apprenticeship came from poor (42\%) or very poor $(6 \%)$ households.

It also appears that migration to nearby towns in order to acquire apprenticeship training is quite a common strategy for youth living in smaller rural settlements. Almost three-quarters (25/34) of youth currently undertaking apprenticeship training in Otaakrom were doing so outside of the village (Appendix C, table C.7).

The following discussion relates to the author's findings from the interviews with 160 rural apprentices (unless otherwise specified).

\subsubsection{Age at start of training}

Of the 160 rural apprentices interviewed the average $e^{350}$ age at the start of the apprenticeship was 19 years (19.7 and 18.6 years for male and females respectively). ${ }^{351} 67.5 \%$ of all apprentices were between the ages of 16-21 at the start of their apprenticeship (table 7.4). This corresponds to the average age reported by others (Haan, 2001).

\footnotetext{
${ }^{350}$ Arithmetic mean.

${ }^{351}$ The youngest was 11 years and the oldest 42 years.
} 


\section{Table 7.4. Age range at start of rural apprenticeship training (Ashanti)}

\begin{tabular}{|l|r|r|}
\hline & Frequency & Percent \\
\hline 15 and below & 22 & 13.8 \\
$16-17$ & 56 & 35.0 \\
$18-19$ & 29 & 18.1 \\
$20-21$ & 23 & 14.4 \\
$22-23$ & 12 & 7.5 \\
$24-25$ & 5 & 3.1 \\
$26-27$ & 2 & 1.3 \\
28 and above & 11 & 6.9 \\
Total & 160 & 100.0 \\
\hline
\end{tabular}

Source: Author's fieldwork, 2005

$14 \%$ of rural apprentices $(n=22)$ were aged 15 or below. Of these eight, or $5 \%$ of the total number, were aged 14 or below and were therefore training illegally; the 1998 Children's Act states the minimum age a child may commence a traditional apprenticeship is 15 years (GoG, 1998). It is clear that this legislation is difficult to enforce.

\subsubsection{Duration of apprenticeship}

Among those interviewed the average duration of training was 3.3 years, but this ranged from 6 months to 10 years. ${ }^{352}$

With respect to trade areas, dressmaking and hairdressing - which are predominantly female in composition - have an average duration of 3 years. The male dominated trades of carpentry, mechanics and masonry have longer, on average, apprenticeship durations of 3.4, 5.5 and 4 years respectively (table 7.5).

\footnotetext{
352 The two individuals interviewed who had been in apprenticeship for 10 years were in the mechanics trade. One of these had received training free of charge (hence the extended period of apprenticeship is normal as the master keeps him on longer to pay for the training).
} 
Table 7.5. Duration of rural apprenticeship training, by trade (Ashanti)

\begin{tabular}{|l|c|c|c|}
\cline { 2 - 4 } \multicolumn{1}{c|}{} & $\begin{array}{c}\text { Mean duration/ } \\
\text { years }\end{array}$ & $\begin{array}{c}\% \text { female } \\
\text { in this } \\
\text { trade area }\end{array}$ & $\mathrm{n}$ \\
\hline Dressmaking & 3 & 89 & 57 \\
Hairdressing & 3 & 97 & 32 \\
Carpentry & 3.4 & 0 & 30 \\
Mechanics & 5.5 & 0 & 13 \\
Masonry & 4 & 0 & 7 \\
\hline
\end{tabular}

Source: Author's fieldwork, 2005

This largely corresponded with the GLSS4 which showed that male apprentices tended to train longer than female apprentices (table 7.6).

Table 7.6. Average length of apprenticeship training, by trade, sex and locality (months) (Ghana)

\begin{tabular}{|c|c|c|c|c|c|c|c|c|c|}
\hline \multirow[b]{3}{*}{ Main trade learnt } & \multicolumn{6}{|c|}{ Locality } & \multirow{2}{*}{\multicolumn{3}{|c|}{ Ghana }} \\
\hline & \multicolumn{3}{|c|}{ Urban } & \multicolumn{3}{|c|}{ Rural } & & & \\
\hline & Male & Female & All & Male & Female & All & Male & Female & A \\
\hline Carpentry & 39.5 & 29.6 & 39.2 & 29.4 & - & 29.4 & 33.4 & 29.6 & 33 \\
\hline Masonry & 31.2 & & 31.2 & 30 & - & 30 & 30.4 & & \\
\hline Tailoring & 37.1 & 29.4 & 30.8 & 31.4 & 26 & 27 & 33.7 & 27.5 & \\
\hline Blacksmithing & 55.5 & & 55.5 & 39.3 & - & 39.3 & 46.3 & & \\
\hline Mechanical & 36.9 & 19.1 & 36.5 & 35.9 & 29.2 & 35.8 & 36.4 & 22.7 & 36 \\
\hline Electronics/Electrical & 36.7 & & 36.7 & 41.7 & & 41.7 & 39 & & \\
\hline Painting/spraying & 32.6 & 16.6 & 29.1 & 37.1 & 23.7 & 35.2 & 35.4 & 20.1 & \\
\hline Other & 35.3 & 24.1 & 28.9 & 29.7 & 21.5 & 26.5 & 31.5 & 22.8 & \\
\hline All & 37.2 & 27.3 & 32.4 & 31.8 & 24.5 & 28.7 & 33.9 & 25.8 & \\
\hline
\end{tabular}

Source: GSS, 2000: 13

\subsubsection{Education level of apprentices}

With respect to the highest level of education achieved, the majority (59\%) of the 160 rural apprentices interviewed had completed JSS, few had SSS and 38\% had less than a basic education (JSS completion) (table 7.7). This makes it very clear that, for most, apprenticeship is now taken after 9 years of education.

Female apprentices had, on average, a lower level of formal education than their male counterparts: $40 \%$ of female apprentices had less than a complete basic education, compared to $38 \%$ of male apprentices; $15 \%$ of female apprentices had no education, compared to $5 \%$ of male apprentices (table 7.7). 
Table 7.7. Education level of rural apprentices, by sex (Ashanti)

\begin{tabular}{|l|r|r|r|r|r|}
\hline & Male & Female & All & Percent & Cumulative \\
Percent
\end{tabular}

Source: Author's fieldwork, 2005

In terms of aggregate levels for the Basic Education Certificate Examination (BECE) achieved for those with complete JSS or higher, the average was 26.5. ${ }^{353}$

Table 7.8. Education level of rural apprentices, by trade (Ashanti)

\begin{tabular}{|c|c|c|c|c|c|c|c|c|}
\hline Apprenticeship & Male & $\begin{array}{l}\text { Tressmaki } \\
\text { Female }\end{array}$ & |Total & Male & $\begin{array}{l}\text { Hairdressi } \\
\text { |Female }\end{array}$ & $\begin{array}{l}\text { |Total } \\
\text { | }\end{array}$ & $\begin{array}{l}\text { Carpentry } \\
\text { (all male) }\end{array}$ & $\begin{array}{l}\text { Mechanics } \\
\text { (all male) }\end{array}$ \\
\hline None & $\overline{2}$ & 12 & 14 & & (c & $\bar{c}$ & $\overline{0}$ & \\
\hline Primary not completed & 1 & 3 & 4 & ( & 1 & 4 & 3 & 0 \\
\hline Primary completed & 0 & 7 & 7 & & 2 & ? & 5 & 2 \\
\hline JSS not completed & 0 & 3 & 3 & & 2 & 4 & 4 & 2 \\
\hline JSS completed & 3 & 26 & 29 & & 23 & 23 & 16 & 7 \\
\hline SSS not completed & 0 & 0 & 0 & & 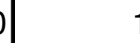 & 1 & 1 & 0 \\
\hline SSS completed & 0 & 0 & 0 & & ( & 0 & 0 & 1 \\
\hline Post JSS vocational school & 0 & 0 & 0 & & 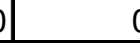 & 0 & 1 & 0 \\
\hline Total & $\overline{6}$ & 51 & 57 & & $\overline{3}$ & 32 & 30 & $\overline{13}$ \\
\hline
\end{tabular}

Source: Author's fieldwork, 2005

Looking at the interview data from my 2005 fieldwork (table 7.8) and data from a 2001 survey of Ghanaian apprentices by Ahadzie (2003) (table 7.9), it can be seen that there appears to be some connection between the level of education of an apprentice and the type of apprenticeship pursued (table 7.10).

\footnotetext{
${ }^{353}$ While 100 apprentices had completed JSS or higher, this average aggregate is based on 69 apprentices as other data was missing. The BECE aggregate is the aggregate of the best six marks achieved in the BECE. Each subject is graded 1 to 10: grade 5 or below is a pass, making the pass range for the aggregate of the six subjects 6 to 30 .
} 
Table 7.9. Educational background of apprentices, by trade (\%) from a 2001 survey in Ghana

\begin{tabular}{|l|r|r|r|r|r|r|r|}
\hline Trade & No School & JSS Dropouts & \multicolumn{1}{c|}{ JSS } & SSS & \multicolumn{1}{c|}{$\begin{array}{c}\text { Tech/ } \\
\text { Voc }\end{array}$} & Other * & \multicolumn{1}{c|}{ Total } \\
\hline Weaving & $\mathbf{3 5 . 3}(6)$ & $\mathbf{2 3 . 5}(4)$ & $\mathbf{3 5 . 3}(6)$ & & $\mathbf{5 . 9}(1)$ & & $\mathbf{5 . 2}(17)$ \\
Leatherwork & $\mathbf{6 0 . 0}(3)$ & $\mathbf{2 0 . 0}(1)$ & $\mathbf{2 0 . 0}(1)$ & & & & $\mathbf{1 . 5}(5)$ \\
Blacksmithing & $\mathbf{3 8 . 4}(5)$ & $\mathbf{3 0 . 8}(4)$ & $\mathbf{3 0 . 8}(4)$ & & & & $\mathbf{4 . 1}(13)$ \\
Goldsmithing & & $\mathbf{3 3 . 3}(1)$ & $\mathbf{6 6 . 7}(2)$ & & & & $\mathbf{0 . 9}(3)$ \\
Gunsmithing & & & $\mathbf{1 0 0 . 0}(2)$ & & & & $\mathbf{0 . 6}(2)$ \\
Welding & $\mathbf{6 . 7}(2)$ & $\mathbf{3 0 . 0}(9)$ & $\mathbf{5 6 . 6}(17)$ & & $\mathbf{6 . 7}(2)$ & & $\mathbf{9 . 4}(30)$ \\
Auto Mechanic & $\mathbf{5 . 0}(2)$ & $\mathbf{3 0 . 0}(12)$ & $\mathbf{5 2 . 5}(21)$ & $\mathbf{7 . 5}(3)$ & $\mathbf{5 . 0}(2)$ & & $\mathbf{1 2 . 5}(40)$ \\
Electrical Inst. & & $\mathbf{3 5 . 0}(14)$ & $\mathbf{6 0 . 0}(24)$ & $\mathbf{2 . 5}(1)$ & $\mathbf{2 . 5}(1)$ & & $\mathbf{1 2 . 5}(40)$ \\
Carpentry & $\mathbf{2 . 5}(1)$ & $\mathbf{4 7 . 5}(19)$ & $\mathbf{4 5 . 0}(18)$ & & $\mathbf{5 . 0}(2)$ & & $\mathbf{1 2 . 5}(40)$ \\
Masonry & $\mathbf{5 . 0}(1)$ & $\mathbf{5 5 . 0}(11)$ & $\mathbf{4 0 . 0}(8)$ & & & & $\mathbf{6 . 2}(20)$ \\
Tailoring & $\mathbf{1 0 . 9}(6)$ & $\mathbf{1 6 . 4}(9)$ & $\mathbf{6 3 . 6}(35)$ & $\mathbf{5 . 5}(3)$ & $\mathbf{3 . 6}(2)$ & & $\mathbf{1 7 . 3}(55)$ \\
Dressmaking & $\mathbf{7 . 3}(4)$ & $\mathbf{4 1 . 8}(23)$ & $\mathbf{4 7 . 3}(26)$ & & & $\mathbf{3 . 6}(2)$ & $\mathbf{1 7 . 3}(55)$ \\
\hline Total & $\mathbf{9 . 4}(30)$ & $\mathbf{3 3 . 4}(107)$ & $\mathbf{5 1 . 3}(164)$ & $\mathbf{2 . 2}(7)$ & $\mathbf{3 . 1}(10)$ & $\mathbf{0 . 6}(2)$ & $\mathbf{1 0 0}(320)$ \\
\hline
\end{tabular}

Source: Ahadzie, 2003: 154 (survey data from 2001)

Legend:

$\begin{array}{ll}* & \text { Commercial Schools } \\ \text { JSS } & \text { Junior Secondary School } \\ \text { SSS } & \text { Senior Secondary School } \\ \text { Tech/Voc } & \text { Technical Vocational Education } \\ \text { Numbers in } & \text { parenthesis }\end{array}$

Table 7.10. Apprentices with less than a complete basic education (\%)

\begin{tabular}{|l|l|l|}
\hline Trade area & $\begin{array}{l}\% \text { with less than } \\
\text { basic education }\end{array}$ & Source \\
\hline Hairdressing & $25 \%(8 / 32)$ & table 7.8 \\
Tailoring & $27 \%(15 / 55)$ & table 7.9 \\
Auto-mechanics & $35 \%(14 / 40)$ & table 7.9 \\
Electrical installation & $35 \%(14 / 40)$ & table 7.9 \\
Welding & $36 \%(11 / 30)$ & table 7.9 \\
\hline Carpentry & $50 \%(20 / 40)$ & table 7.9 \\
Carpentry & $40 \%(12 / 30)$ & table 7.8 \\
\hline Dressmaking & $49 \%(27 / 55)$ & table 7.9 \\
Dressmaking & $49 \%(28 / 57)$ & table 7.8 \\
\hline Weaving & $59 \%(10 / 17)$ & table 7.9 \\
\hline
\end{tabular}

In the female-dominated trades it appears that entry for less-schooled youth into hairdressing apprenticeships may be harder compared to entry into dressmaking apprenticeships. $49 \%$ of dressmaking apprentices had less than a basic education compared to $25 \%$ of hairdressing apprentices (table 7.10). Among the male-dominated trade areas tailoring, auto-mechanics, electrical installation and welding apprenticeships may be harder to enter for less-schooled youth compared to carpentry or weaving apprenticeships (table 7.10). These apparent differences in the 
formal educational background of apprentices in different trades might suggest that some mastercraftspeople in particular trades have a preference for more educated apprentices. Alternatively it might suggest that some apprenticeships are now more popular than others and that mastercraftspeople can be more selective about whom they train - and they are choosing more educated apprentices. For example, hairdressing apprenticeships in rural Ashanti appear to be more popular among the youth compared to dressmaking apprenticeships as the youth perceive there to be more demand for the former trade (fieldwork, 2004-2005) (see chap.8.1).

It has been noted that in SSA, as a result of EFA policies and an increased supply of more educated youth, that apprentices now tend to have had more schooling than their masters (Charmes, 1999; Haan, 2001; Yokozeki, 2005). ${ }^{354}$ Over time, the effect of better schooled apprentices will have an impact on the informal sector with respect to output and productivity (Charmes, 1999; Muskin, 1997). However, having apprentices who have received often substantially more education than their masters who are training them has implications for the effectiveness of the informal training process. Indeed, the consequences of having less- or unschooled master-craftspeople training better-schooled apprentices may well have an adverse effect on the training. Due to issues of respect for master-craftspeople and senior (less-schooled) apprentices, younger (more-schooled) apprentices may feel reluctant to suggest new approaches (Muskin, 1997).

The data collected by the author in 2005 with 114 masters $^{355}$ and 160 of their apprentices in three communities in rural Ashanti did not confirm this emerging trend (table 7.11). Instead it was clear that among those interviewed the masters had higher levels of education than their apprentices: over $10 \%$ of masters had post-basic education, compared to $4 \%$ of their apprentices; $63 \%$ of masters had completed JSS/Middle School, compared to 59\% of their apprentices; less than $1 \%$ of masters had less than a primary education, compared to $15 \%$ of their apprentices. While the trend (of apprentices being more educated than their masters) might be truer in urban areas, where access to education is markedly better than in rural areas, the new data suggests that in rural Ashanti the trend might still be for masters to have more education than their apprentices.

\footnotetext{
${ }^{354}$ However, Yokozeki's findings were based on interviews with just 16 youth in five workshops dressmaking, hairdressing, carpentry, car mechanic, bicycle repair - and so should be treated with caution (personal communication (email) 17.01.06).

${ }^{355}$ For an analysis of the data from the interviews with masters, see chap.8.1. See chap.1.4.4./Appendix A on the methodology.
} 
Table 7.11. Comparison of highest education level of apprentices and their masters in rural Ashanti

\begin{tabular}{|l|r|r|r|r|}
\hline & \multicolumn{2}{|c|}{ Apprentices } & \multicolumn{2}{c|}{ Masters } \\
& Freq. & Percent & Freq. & Percent \\
\hline & 16 & 10 & 1 & 0.9 \\
None & 16 & 5 & 0 & 0 \\
Primary not completed & 8 & 5 & 5 & 4.4 \\
Primary completed & 19 & 11.9 & 23 & 20.2 \\
JSS/MS not completed & 17 & 10.6 & 2 & 63.2 \\
JSS/MS completed & 94 & 58.8 & 72 & 1.8 \\
SSS not completed & 2 & 1.3 & 2 & 6.1 \\
SSS completed & 3 & 1.9 & 7 & 2.6 \\
Post JSS vocational school & 1 & 0.6 & 3 & 0.9 \\
Other & 0 & 0 & 1 & 100.1 \\
\hline
\end{tabular}

Source: Author's fieldwork, 2005

Legend: MS - Middle School

The finding is similar to other research from Ghana (Morton, 2004) which shows that employers are, on average, likely to be more educated than employees, with most employers having some level of secondary education, while the average level of education for employees is only a basic education.

\subsection{The traditional apprenticeship training environment in Ghana}

As a means of skills acquisition, traditional apprenticeship training is well known to have a number of general advantages (fig.7.2) and disadvantages (fig.7.3) with respect to the delivery of training (Ahadzie, 2003; Akyeampong, 2002; Baah-Nuakoh, 2003; Grierson, 1997; GoG, 2004i; UNESCO, 2003; Dijk, 1997; World Bank, 2004a). 


\section{Fig. 7.2. Advantages of the traditional training modality in Ghana}

\section{Relevant to the real world of work and more effective than centre-based training}

On-the-job training:

- Is work-based and practical, and there is a close link between training and production;

- Allows for a gradual building up of informal enterprise networks (e.g. with suppliers, customers, other business owners and apprentice masters), the development of general business-related skills, including customer-relation skills and apprentices are able to "learn the mechanics of being self-employed" (Dijk, 1997: 107);

- Allows apprentices to develop their institutional networks (e.g. with informal sector associations, credit and business support agencies);

- Is more effective than formal pre-employment training as trainees are usually more mature and motivated;

- Offers apprentices the possibility of finding employment with their master on graduation.

\section{Ease of access}

- Entry is relatively easy. Training is not just for literates;

- Serves important target groups (rural populations and urban poor);

- Costs are cheaper than formal training. Parents can pay over time (see also 7.9.1);

- An important source of technical and vocational skills in manufacturing/service trades for those who cannot access formal training institutes.

Functions sustainably with no government intervention

- Low cost and self-financing. No need for subsidies. Costs borne by apprentices and their family. No cost to government or community;

- No need for a training centre or separate tools/equipment for training;

- No tradition of government support, control or supervision. Instead there is a history of sustainability in most countries. 
Fig.7.3. Disadvantages of the traditional training modality in Ghana

Training environment linked to the state of the enterprise environment

- Since training occurs on-the-job, the training environment is intimately linked to the state of the work environment in the MSEs, and evidence suggests that this is generally of low standard in Ghana (fig.7.4, below). According to the 1998 Children's Act it is the responsibility of the craftsperson to provide a safe and healthy environment for the apprentice to train. Legally speaking, therefore, it is clear that most masters are contravening this legislation. Enforcing these legal requirements is clearly a huge problem.

No formal curriculum; what is taught depends on what is produced

- Lack of attention to theoretical aspects;

- Standards vary; there are no common competency-assessment procedures;

- The breadth of training depends on the division of labour within an enterprise;

- Training mostly involves passive learning and observation, not experimentation;

- Traditional technologies are perpetuated (new product designs and production technologies difficult to introduce as technology level and understanding of the master is reproduced in the apprentice);

- Master-craftspeople or enterprise owner frequently lack teaching skills.

Possible screening out of the poor (see also 7.9.1)

- As noted above, where up-front payment is required poor applicants might sometimes be screened-out, or their training delayed. Nonetheless it is clear that some youth are able to access this training free of charge.

Full range of skills often not taught/ risk of competition

- Some masters do not teach the full range of skills for fear of competition from graduated apprentices. Indeed graduated apprentices often start a business in competition with master craftsperson for the same customers.

Risk of exploitation

- Apprentices are sometimes exploited as a form of cheap labour. While some research evidence from Ghana points towards the exploitation of apprentices (Ninsin, 1991; Thomi and Yankson, 1985) others suggest that apprentice arrangements are largely fair - though remuneration and working hours could be improved (Morton, 2004). Moreover the counter argument to the risk of exploitation is that apprentices are gaining a skill from the master in return for their (largely free) work.

\section{Gender biased}

- Apprenticeships are gender biased, with girls learning only traditionally female activities like dressmaking, hairdressing and soap making and boys learning traditionally male activities like carpentry and mechanics.

Economic aspects of business not learnt fully

- Although on-the-job learning helps to develop an apprentice's own enterprise networks - though contact with suppliers, customers and enterprise-owners - some evidence suggests that apprentices still know "virtually nothing... about the economic aspects of the business" (Dijk, 1997: 107) since mastercraftspeople take over this function almost entirely and do not allow apprentices to "deal with customers or delve into accounts" (ibid). Indeed the World Bank (2004a) comments that apprentice graduates lack marketing skills "and other business acumen... [which] poses a serious risk to their success in selfemployment and entrepreneurship" (p.147).

\section{No formal follow-up support}

- Graduates from apprenticeships face the same problems as others entering the labour market vis-à-vis access to formal credit and non-financial BDS (chap.5.3.6).

Integrating apprenticeship training into a formal skills system risks undermining its sustainability

- Until 2006, no one single government ministry had responsibility for it. The COTVET Bill (chap.5) places responsibility for traditional apprenticeship training under the MoESS. Yet responsibility for formal sector apprenticeship training remains with NVTI (MoMYE). But GoG plans are to formalise the system and pay master-craftspeople to train apprentices;

- Interventions like the World Bank VSP project, which tried to link it with the formal education system, were not very successful. 


\section{Fig.7.4. The work environment in Ghanaian MSEs}

An occupational safety and health specialist from the Factory Inspectorate reviewed 50 MSE workplaces on a comprehensive list of safety and health related aspects. The results were as follows.

a) Safety of workplace location: There was no need for action in most of the enterprises. The local restaurants at the Accra Timber Market cluster were, however, exposed to the sources of disease vectors such as flies and mosquitoes.

b) Ventilation: This was not satisfactory in some of the enterprises. Vents provided for fresh air were not adequate and were also improperly orientated.

c) Conditions of floors and work surfaces: The conditions of floors in a few enterprises were slippery or uneven, which could contribute to accidents.

d) Housekeeping: Priority action was needed in most of the enterprises to reduce dust, improve storage of materials and products, so as to prevent people from walking into objects or tripping and to facilitate the flow of products.

e) Frayed, exposed and entangled electric wiring: Electrical wiring in the micro enterprises and to a lesser extent in the small-scale enterprises was frayed, entangled or had worn out or decayed insulations. This could be a source of serious electrical accidents such as electrocution, shock or fire.

f) Lighting: The standard of lighting in some enterprises was not satisfactory and required priority action.

g) Exhaust ventilation systems: The issue of exhaust ventilation was a priority problem in the enterprises. The law was being broken in that it requires workrooms giving off dust, fumes and gases of an injurious nature to have exhaust ventilation to remove such harmful emissions or prevent their accumulation.

h) Hazardous chemicals: There was a problem in some small enterprises in terms of the absence of protective clothing or appliances.

i) Mechanical handling: There was a problem of manual instead of mechanical handling of heavy loads requiring priority attention in the enterprises surveyed.

j) Height of working surfaces, equipment, seats, etc.: The observations indicated that workers were bending and also stretching their bodies and limbs to reach materials, equipment and to transfer objects, or were sitting or standing in uncomfortable positions.

k) Noise and vibrations: Noise was a problem at some of the clusters such as Timber Market, Tema and Adenta/Madina. The use of protective equipment such as earmuffs and ear plugs was totally absent. There was both continuous noise and impulsive noise from use of presses and hand tools such as hammers and chisels. The obsolescent machines in use contribute to the problem.

l) Machine guarding: A pronounced problem was observed in the micro enterprises. Most of the machines in use are obsolete and had changed hands from one enterprise to the other. In the process of transfer, guards had been removed, got misplaced or lost, and were never replaced.

$m)$ Protective clothing and equipment: In most of the enterprises, protective clothing and appliances were either not provided or those provided were not being used. Discomfort was cited as one of the reasons for not using them. In some cases the protective equipment provided was unsuitable.

n) Providing clean water: Apart from the Timber Market cluster where water supply was not available, drinking water had been provided simultaneously with toilet facilities.

o) Separate hygienic place for meals: Most workers took their meals at eating places outside their workplaces. The standard of hygiene in such eating places was not within the control of their employers.

p) First aid: First aid boxes were non-existent in most of the micro enterprises. In the small enterprises where they had been provided, the boxes had not been adequately stocked. In a few cases the first aid boxes had been kept under lock and key, not on the shop floor but in the office of the employer.

q) Fire extinguishers: In some enterprises, these had not been provided. Where they had been provided, they had often been so installed as not to be accessible for use. In some cases, the type of extinguishing agents in the cylinders was not suitable for the type of fire hazard prevalent in the premises.

r) Emergency exit: As a consequence of bad housekeeping and overcrowding, emergency exits had been obstructed by working tables and equipment. Access routes to emergency exits had been used as storage areas for raw materials and finished products. The doors affording means of escape had in some cases been constructed to open inwards.

Source: Morton, 2004: 6-7 


\subsubsection{Access, apprenticeship fees and the poor}

To this discussion of the traditional apprentice training environment must be added the issue of access to this training modality: are the poor ${ }^{356}$ able to gain access to this type of training? It is clear that training fees (nitrinsa) and other costs determine the access of the poor, though some social mechanisms exist that allow at least some poorer youth to access this training modality.

It is usual for a training fee to be charged by a master for the apprenticeship. In Ghana Yokozeki (2005) estimates that apprenticeship fees range from US\$33-100 in 2004/5, but is sometimes waived if the youth is known to the master. Haan and Serrière (2002) estimate that apprentice fees in Ghana range from US\$20-200 depending on the trade, locality and popularity of the master.

Data collected in 2005 from the 160 apprentices in rural Ashanti (table 7.12) reveal that the average apprenticeship fee ${ }^{357}$ was US\$42 (US\$46 for males, US\$38 for females), though this ranged from US\$13-173. ${ }^{358} 78 \%$ (125/160) of apprentices had apprenticeship fees ranging from US\$20-69.

Table 7.12. Cost of training (US\$) for rural apprentices (Ashanti)

\begin{tabular}{|c|c|c|c|c|c|c|c|c|c|c|}
\hline & & \multicolumn{8}{|c|}{ Cost of TAT $/ \$$ range } & \multirow[b]{2}{*}{ Total } \\
\hline & & Free & $\$ 10-19$ & $\$ 20-29$ & $\$ 30-39$ & $\$ 40-49$ & $\$ 50-59$ & $\$ 60-69$ & $\$ 70$ and over & \\
\hline \multirow{3}{*}{\multicolumn{2}{|c|}{$\begin{array}{ll}\text { Sex of } & \text { Male } \\
\text { TAp } & \text { Female } \\
\text { Total } & \end{array}$}} & 18 & 3 & 3 & 24 & 6 & $\overline{16}$ & 5 & 3 & $\overline{78}$ \\
\hline & & 4 & 4 & 22 & 21 & 11 & 12 & 5 & 3 & 82 \\
\hline & & 22 & 7 & 25 & 45 & 17 & 28 & 10 & 6 & 160 \\
\hline
\end{tabular}

Source: Author's fieldwork, 2005

In addition to the training fees, apprentices usually have bring certain items before they can commence training. For example, carpentry apprentices usually have to bring some basic tools

\footnotetext{
${ }^{356}$ The poor here are defined here by a multiple set of characteristics (Appendix C.1).

${ }^{357}$ Excluding those in the sample that did not pay for their training $(n=22)$.

358 The cost of apprenticeship is quoted in US\$ since the apprentices in the survey started their training in different years and the cedi value cited by apprentices as the fee they paid in that year has changed considerably due to changes in exchange rates. In (April) 2005 US $\$ 1=\varnothing 9,025$.
} 
(hammer, chisel, measuring tape) while dressmaking apprentices need to bring their own machine, scissors and tape. ${ }^{359}$

Yokozeki (2005) estimated that apprenticeship training fees were some twenty times or more what it cost to send a child to JSS at the time of her research. ${ }^{360}$ However, given her very small sample size (16 apprentices) this finding should be treated with caution. Moreover, capitation grants (introduced September 2005) have abolished all levies that were previously charged at the basic education level, effectively making schooling cheaper to attend and more accessible.

While it is widely acknowledged that "[t]raditional apprenticeship training can be the least expensive way to get skills training" (World Bank, 2004a: 131), the training fees associated with apprenticeship, combined with the other items apprentices have to bring before training can commence, can serve to exclude the poor. Indeed the World Bank (2004a) comments that:

[i]t is commonly assumed that traditional apprenticeship is open to everyone, or at least to all young men. This is not so. Very poor households typically cannot afford to pay the costs of apprenticeship, particularly for trades that require a high fee or tools and equipment. (p.145)

Bortei-Doku Aryeetey (2001) notes that the costs of apprenticeship in Ghana exclude young people who "cannot find sponsors to register them" (p.42). An earlier study by McLaughlin (1979) notes that the cost of training fees can either serve to delay access to it (while the family saves up) or prevent access altogether. He goes on to note that the only option for some poor youth is to train under a fostering apprenticeship with a kin/lineage related master-craftsperson.

Indeed, of the 160 rural apprentices interviewed by the author, $14 \%(\mathrm{n}=22)$ received their training free of charge, with most (c.80\%) of these being male. ${ }^{361}$ Reasons for receiving free training included: being related to the master (7/22); master not related, but wanted to help (5/22); unspecified (8/22); apprentice works for master on contract work to pay for training $(1 / 22)$; master owes parents of apprentice a favour $(1 / 22)$.

\footnotetext{
359 The standard Butterfly sewing machine, common among dressmaking/tailoring apprentices, costs $\$ 450,000$ (US\$50) (July 2006), representing a sizeable sum of money for a prospective apprentice.

360 Yokozeki does not say how she reached such an estimate and whether it included all the costs (direct, indirect and opportunity costs of training and schooling).

${ }^{361}$ Valenchik (1995) found that about $40 \%$ of enterprises did not charge fees (mid-1990s).
} 
The average cost of rural apprenticeships varied by trade area in the sample. ${ }^{362}$ The average apprenticeship fee ${ }^{363}$ was US\$38, 40, 42 and 50 in dressmaking, hairdressing, carpentry and mechanics respectively (table 7.13). ${ }^{364}$ As noted earlier, male apprentices in the sample were more likely to receive fee free apprenticeships. In the male dominated trades of carpentry and mechanics, $23 \%$ of apprentices in each trade area received free training. This compares to just 5\% and $3 \%$ in the female-dominated trade areas of dressmaking and hairdressing respectively (table 7.13).

Table 7.13. Cost of rural apprenticeship, by trade (Ashanti)

\begin{tabular}{|l|c|c|c|c|}
\hline & $\begin{array}{c}\text { \% who } \\
\text { received } \\
\text { free training }\end{array}$ & $\begin{array}{c}\text { mean fee } \\
\text { in sample (i) } \\
\text { (US\$) }\end{array}$ & $\begin{array}{c}\text { \% female } \\
\text { in this } \\
\text { trade area }\end{array}$ & $\mathbf{n}$ \\
\hline Dressmaking & 5 & 38 & 89 & 57 \\
Hairdressing & 3 & 40 & 97 & 32 \\
Carpentry & 23 & 42 & 0 & 30 \\
Mechanics & 23 & 50 & 0 & 13 \\
\hline
\end{tabular}

(i) average among those that paid for their training

Source: Author's fieldwork, 2005

Often part of the up-front money paid to the master is returned to the apprentice in the form of daily allowance for food (chop money) or with some small gift after the apprenticeship is completed. Indeed the 1998 Children's Act stipulates that it is the responsibility of the craftsperson to provide food for the apprentice unless otherwise agreed.

From the interviews with 160 rural apprentices, it appears that it is in the male-dominated trades that chop money is most commonly received. In dressmaking and hairdressing, $75 \%$ and $81 \%$ respectively of respondents did not receive daily chop money. This compares to $10 \%$ and $21 \%$ of carpentry and mechanic apprentices who did not receive chop money. The amount received as chop money appears to be greatest for masonry apprentices, followed by carpentry and mechanic apprentices (table 7.14).

\footnotetext{
${ }^{362}$ It should be recalled that the traditional apprenticeship fees described here refer to rural Ashanti. Fees vary across the country and between enterprises of differing quality. For example, for three-years training in well-regarded hairdressing enterprises in Accra apprentices can pay up to $\not 1.7$ million (US\$188) in addition to several crates of soft drinks and a gift for the master (fieldwork, 2005).

${ }^{363}$ Excluding those in the sample who received free training.

${ }^{364}$ Haan and Serrière (2002) report the average carpentry apprenticeship fees to be US\$70-85.
} 
Table 7.14. 'Chop money' received by rural apprentices, by trade (Ashanti)

\begin{tabular}{|l|c|c|c|c||c|c|}
\hline \multirow{2}{*}{ Trade } & \multicolumn{3}{|c||}{ All apprentices } & \multicolumn{2}{c|}{$\begin{array}{c}\text { Those that receive } \\
\text { chop money }\end{array}$} \\
\cline { 2 - 7 } & $\mathrm{n}$ & $\begin{array}{c}\text { \% female } \\
\text { in this } \\
\text { trade area }\end{array}$ & $\begin{array}{c}\text { \% who } \\
\text { received } \\
\text { no chop } \\
\text { money }\end{array}$ & $\begin{array}{c}\text { Mean } \\
\text { chop money } \\
\text { (cedis) }\end{array}$ & $n$ & $\begin{array}{c}\text { Mean } \\
\text { chop money } \\
\text { (cedis) }\end{array}$ \\
\hline Dressmaking & 57 & 89 & 75 & 728 & 14 & 2,964 \\
Hairdressing & 32 & 97 & 81 & 1,250 & 6 & 5,000 \\
Carpentry & 30 & 0 & 10 & 3,117 & 27 & 3,463 \\
Mechanics & 13 & 0 & 23 & 2,692 & 10 & 3,500 \\
Masonry & 7 & 0 & 0 & 21,429 & 7 & 21,429 \\
\hline
\end{tabular}

The exchange rate at the time of the interviews was US\$1 $=\varnothing 9,025$ (April, 2005)

Source: Author's fieldwork, 2005

From the total sample of 160 rural apprentices, 77 - mostly female - respondents received no chop money. Out of the total number of apprentices that received no chop money, 87\% (67/77) were female (table 7.15).

Of those that did receive chop money (mostly males) during their training 78\% (65/83) received between $\phi 2,000-6,000$ (US\$0.22-0.66) a day. Given that the average apprenticeship was three years, this finding suggest that male apprentices - even those on the lower band of $\phi 2,000$ a day are able to recoup the cost of the fees paid out to the master at the start of the apprenticeship.

Table 7.15. 'Chop money’ received by rural apprentices, by gender (Ashanti)

\begin{tabular}{|ll|r|r|r|}
\hline \multicolumn{1}{|c|}{ Count } & \multicolumn{2}{|c|}{ Sex of TAp } & \multirow{2}{*}{ Total } \\
\cline { 3 - 4 } & & Male & \multicolumn{1}{|c|}{ Female } & 77 \\
\hline Chop & Nothing & 10 & 67 & 3 \\
money/cedis/day & 1 to 1999 & 2 & 1 & 24 \\
& 2000 to 2999 & 23 & 1 & 15 \\
& 3000 to 3999 & 10 & 5 & 8 \\
& 4000 to 4999 & 8 & 0 & 18 \\
& 5000 to 5999 & 12 & 6 & 3 \\
& 6000 to 9999 & 3 & 0 & 4 \\
& 10,000 to 13999 & 2 & 2 & 1 \\
& 14000 to 17999 & 1 & 0 & 7 \\
Total & 18000 and above & 7 & 0 & 160 \\
\hline
\end{tabular}

US $\$ 1=\not 9,025$ (April, 2005)

Source: Author's fieldwork, 2005 


\subsection{Entering into self-employment after apprenticeship}

\subsubsection{Expected source of start-up capital for apprentices in rural Ashanti}

Part of the transition from graduate apprentice to self-employed artisan involves finding sufficient start-up capital (chap.5.3.6). When the apprentices were asked how they expected to find the main source of start-up capital for their enterprise, $64 \%$ indicated that the family would help them, while $14 \%$ indicated they would self-finance it and $8 \%$ that they were planning to work for their master on graduation (table 7.16).

Table 7.16. Expected source of start-up capital of rural apprentices by gender (Ashanti)

\begin{tabular}{|l|r|r|r|r|r|r|}
\hline Expected source of & \multicolumn{2}{|c|}{ Male } & \multicolumn{2}{|c|}{ Female } & \multicolumn{2}{|c|}{ All } \\
start-up capital & Freq. & Freq. & $\%$ & Freq. & $\%$ \\
\hline Family & 40 & 51.3 & 62 & 75.6 & 102 & 63.8 \\
Self-Employment (informal) & 13 & 16.7 & 9 & 11.0 & 22 & 13.8 \\
Wage-Employment (informal) & 13 & 16.7 & 0 & 0.0 & 13 & 8.1 \\
Wage-Employment (formal) & 3 & 3.8 & 0 & 0.0 & 3 & 1.9 \\
Bank Loan & 1 & 1.3 & 0 & 0.0 & 1 & 0.6 \\
Other & 8 & 10.3 & 11 & 13.4 & 19 & 11.9 \\
\hline & $\mathbf{7 8}$ & $\mathbf{1 0 0 . 1}$ & $\mathbf{8 2}$ & $\mathbf{1 0 0 . 0}$ & $\mathbf{1 6 0}$ & $\mathbf{1 0 0 . 1}$ \\
\hline
\end{tabular}

Source: Author's fieldwork, 2005

However, female apprentices were much more dependent on their family for providing start-up capital than male apprentices were. Three-quarters (62/82) of female apprentices indicated that the family would provide start-up capital, compared to half (40/78) of males. Table 7.16 suggests that, apart from the family, female apprentices might be able to self-finance their enterprise (11\% of female apprentices indicated this), but this is more likely for dressmakers rather than for hairdressers (table 7.17). Male apprentices, however, anticipated greater options with respect to finding start-up capital (table 7.16). 
Table 7.17. Expected source of start-up capital of rural apprentices, by trade

(Ashanti)

\begin{tabular}{|c|c|c|c|c|c|c|c|c|c|c|}
\hline & & \multicolumn{8}{|c|}{ Source of startup } & \multirow[b]{2}{*}{ Total } \\
\hline & & Family & $\begin{array}{c}\text { Formal Wage } \\
\text { employment }\end{array}$ & Self-finance & Bank loan & $\begin{array}{c}\text { Work for } \\
\text { master }\end{array}$ & Other & Don't know & Missing data & \\
\hline \multirow{12}{*}{$\begin{array}{l}\text { Type } \\
\text { of } \\
\text { TAp }\end{array}$} & Dressmaking & 42 & 0 & 10 & 0 & 0 & 1 & 4 & 0 & 57 \\
\hline & Hairdressing & 24 & 0 & 1 & 0 & 0 & 2 & 3 & 2 & 32 \\
\hline & Carpentry & 15 & 1 & 5 & 0 & 6 & 0 & 3 & 0 & 30 \\
\hline & Mechanics & 6 & 1 & 0 & 0 & 6 & 0 & 0 & 0 & 13 \\
\hline & Masonry & 1 & 0 & 3 & 0 & 0 & 1 & 2 & 0 & 7 \\
\hline & Electronics & 4 & 0 & 1 & 0 & 1 & 0 & 0 & 0 & 6 \\
\hline & Shoemaker & 3 & 0 & 0 & 0 & 0 & 0 & 0 & 0 & 3 \\
\hline & Welder & 4 & 0 & 0 & 1 & 0 & 0 & 0 & 0 & 5 \\
\hline & Artist & 1 & 0 & 1 & 0 & 0 & 0 & 0 & 0 & 2 \\
\hline & Vulcanizer & 0 & 1 & 1 & 0 & 0 & 0 & 0 & 0 & 2 \\
\hline & Bike repairer & 0 & 0 & 0 & 0 & 0 & 1 & 0 & 0 & 1 \\
\hline & Fridge repairer & 2 & 0 & 0 & 0 & 0 & 0 & 0 & 0 & 2 \\
\hline Total & & 102 & 3 & 22 & 1 & 13 & 5 & 12 & 2 & 160 \\
\hline
\end{tabular}

Source: Author's fieldwork, 2005

It is interesting to compare the expected main source of start-up capital of these rural apprentices with the actual main source of start-up capital their masters used (table 7.18). ${ }^{365}$ Apprentices appear to expect their families to assist them in start-up to a greater extent than families are actually able to: $64 \%$ of apprentices expected their family to help, compared to $41 \%$ of families actually assisting. Informal MESE (chap.3.3.2) and informal wage-employment ${ }^{366}$ appeared to be a more important source of start-up capital than expected by the rural apprentices.

\footnotetext{
${ }^{365}$ While it would obviously be ideal if these apprentices could be traced longitudinally to see what their own actual (main) source of start-up capital was, there were neither the resources nor the time in this doctoral fieldwork to do this. Nonetheless, comparing the expected source of start-up of the apprentices with the actual source used by their own masters is quite useful.

${ }^{366}$ Informal wage-employment refers to activities where individuals earn a set wage, either on a per day, per week or per month basis, from employment either in an informal enterprise or a formal venture (which does not officially register the labour, hence making these employees informal).
} 
Table 7.18. Expected versus actual sources of start-up capital in rural Ashanti

\begin{tabular}{|c|c|c|c|c|c|c|c|c|}
\hline & \multicolumn{4}{|c|}{$\begin{array}{l}\text { Expected source of } \\
\text { start-up capital (a) }\end{array}$} & \multicolumn{4}{|c|}{$\begin{array}{l}\text { Actual source of } \\
\text { start-up capital (b) }\end{array}$} \\
\hline & Male & Female & Total & Percent & Male & Female & Total & Percent \\
\hline Family & 40 & 62 & 102 & 63.8 & 19 & 28 & 47 & 41.2 \\
\hline Self-Employment (informal) & 13 & 9 & 22 & 13.8 & 31 & 14 & 45 & 39.5 \\
\hline Wage Employment (informal) & 13 & 0 & 13 & 8.1 & 15 & 3 & 18 & 15.8 \\
\hline Wage Employment (formal) & 3 & 0 & 3 & 1.9 & 0 & 0 & 0 & 0 \\
\hline Bank Loan & 1 & 0 & 1 & 0.6 & 0 & 0 & 0 & 0 \\
\hline Other & 8 & 11 & 19 & 11.9 & 4 & 0 & 4 & 3.5 \\
\hline & 78 & 82 & 160 & 100.1 & 69 & 45 & 114 & 99.8 \\
\hline
\end{tabular}

Legend:

(a) Data from the 160 interviews with rural apprentices; (b) Data from the 114 interviews with rural masters. 97\% of all masters interviewed indicated they had been through an apprenticeship prior to entering self-employment. See chap.8 for a detailed discussion.

Source: Author's fieldwork, 2005

\subsubsection{Entry into informal micro-enterprise (IME)}

Traditional apprenticeship training is regarded by some as being the "quickest path to selfemployment" (Liimatainen, 2002: 9). A paper by Frazer (2006) provides some data from the Ghanaian Manufacturing Enterprise Survey (GMES) ${ }^{367}$ on the labour market outcomes of traditional apprentices in Ghana. The GMES data shows the overall percentages of apprentices engaged in different activities (according to their former masters) (table 7.19).

\section{Table 7.19. Activities of apprentices after apprenticeship (\% of former apprentices in different activities)}

\begin{tabular}{|l|r|}
\hline Continued working for the firm & 0.375 \\
Worked for another firm in the industry & 0.152 \\
Worked for a firm in another industry & 0.032 \\
Started their own business & 0.285 \\
School & 0.011 \\
Unemployed & 0.010 \\
Don't know & 0.178 \\
\hline
\end{tabular}

Source: Frazer, 2006: Appendix table 3

\footnotetext{
${ }^{367}$ The GMES was one of nine surveys conducted in African countries in the 1990s as part of the World Bank's Regional Program on Enterprise Development surveys.
} 
The largest percentage, 38\%, of graduate apprentices continued working within the firm they had trained in, while $29 \%$ were reportedly in self-employment. A further $15 \%$ were working for another firm. ${ }^{368}$ According to Frazer's (2006) analysis and interpretation of the GMES data:

apprentices appear highly motivated to pursue self-employment. Of [those]... who had completed apprenticeships, $77 \%$ stated that they would prefer to be self-employed rather than working in their current job. (p.3-4)

This desire for self-employment (as compared to wage-employment with the same or different firm) is explained by Frazer to be a result of the higher returns to self-employment above other employment options. These higher returns, he contests, are the result of the type and value of training received in apprenticeships. Frazer (2006) interprets apprenticeship as training unique to a firm and argues that apprenticeship in Ghana is training in specific human capital - it is more valuable used in the firm where the apprenticeship was taken or in self-employment - rather than taking the skills learnt to work for a wage in a different firm. Frazer (2006) argues that training received in traditional apprenticeships is highly specific to the firm (reflecting a particular firm's technology and business practice) and that while apprentices "are taught by a master how to work the master's craft... the way in which that craft is carried out varies highly from firm to firm" (p.3). Because of this, Frazer concludes, "apprenticeship training cannot be applied to work in other firms, which have their own technology and business practice. However, once the apprenticeship is complete, the former apprentice can use this knowledge to start his own firm and pursue self-employment, replicating the apprenticeship firm" (ibid.). The returns to apprenticeship training, Frazer continues, are highest when apprenticed workers become selfemployed, and lowest when apprentices go to work for a wage in a firm different from where they trained (Frazer, 2006).

However, there are reasons to question some of Frazer's interpretations. Firstly, his calculations for the returns to apprenticeship training do not take into account any of the 'environment' considerations that have been discussed in this thesis. In other words he does not distinguish between apprenticeship training in different training environments, nor does he distinguish between the returns to apprenticeship training in different enabling and disabling enterprise contexts. In very disabling enterprise context do the risks of being self-employed lead graduate

\footnotetext{
${ }^{368}$ Given that the firm owners did not know about the activities of $18 \%$ of the apprentices, these fractions should in all cases (except the case of apprentices continuing to work in the firm) be seen as a lower bound (Frazer, 2006).
} 
apprentices to prefer wage work? If the training quality has been very low might apprentices not have the proficiency to start up by themselves initially, and so prefer to work for a wage? Moreover, it is not uncommon for graduate apprentices to make a conscious decision to work for a wage in a firm different from where they have trained. Apprentices usually explain this as a desire to get more work experience and to obtain different skills before starting out in selfemployment (fieldwork, 2004-2005). Moreover, Frazer's conclusion that “apprenticeship training cannot be applied to work in other firms, which have their own technology and business practice" (2006: 3) seems somewhat of a generalisation and one which most researchers with field experience of Ghana's informal micro-enterprises would take issue with.

It was noted above that access to apprenticeships might be constrained by the inability of poorer families to afford specific items required for the training (particularly dressmakers/tailors due to the high cost of procuring a sewing machine relative to basic carpentry or masoner's tools). For those dressmakers/tailors that do manage to get through apprenticeship training without owning their own machine, either by borrowing or renting a machine, a major constraint to starting up an enterprise is obviously finding capital to acquire their own machine.

The issue of not being able to utilse skills acquired through apprenticeship as a result of an inability to finance the costs of basic tools and equipment is not a new problem. Peil (1970) comments that entry into tailoring/dressmaking in the late 1960s was restricted due to the cost of the sewing machine:

Their chief requirement is a sewing-machine, a substantial capital investment which inhibits widespread entrance to the trade. (p.139)

She notes that, after completing their apprenticeship, "[q]uite a few trained tailors must work at other jobs for several years until they can save enough money to buy a machine" (ibid.).

Referring to traditional apprenticeship graduates, the World Bank (2004a) comments that "[1]ack of access to credit for business start-up and initial operation makes it difficult to use the skills acquired" (p. 147, emphasis added). While this is undoubtedly truer for some trades (which have higher start-up costs, e.g. welding) compared to others, it is also true (see chap.8.2) that aspiring enterprise owners are able to use multiple means to raise the start-up capital required for an enterprise - even if this enterprise starts off considerably smaller than may have initially been envisaged. 


\subsection{Concluding comments on traditional apprenticeship training in Ghana}

Informal skills training serves the informal sector well but is proving too narrowly focused to cope with the increasing challenges of technical change, skills enhancement, and wider markets (Ziderman, 2003). In general since skills development in the informal economy occurs on-the-job then the delivery context for the training is intimately linked to the enabling or disabling enterprise environment of the informal economy itself. Fig.7.4 showed that the work environment for Ghanaian MSEs is generally inadequate. ${ }^{369}$

As noted, the traditional environment in which apprenticeship training is delivered leads to a perpetuation of existing technology. But it also may have other effects on the degree to which schooling is useful in this setting. It might be that, in some trades, the returns to schooling in apprenticeship training will be reduced since education is known to be more useful in dynamic (changing) environments (where there are other inputs which can be used more effectively as a result of some schooling). In static training and working environments, where there is not the availability of new technologies or means of production, experience in that setting might be able to replace any benefits that schooling might have imparted on a youth. Hence it would be interesting for economists to investigate how the returns to schooling vary in different settings, and whether or not the returns to schooling for schooled apprentices and for non-schooled but experienced apprentices are similar in so-called traditional contexts.

Nonetheless, in spite of the recognised limitations of traditional apprenticeship training the general opinion is that it "contributes significantly to upskilling labour force in the [Ghanaian] economy" (Aryeetey et al., 2005: 131). Attempts have been made in the past to overcome the limitations of apprenticeship training in Ghana, though with mixed success. ${ }^{370}$

The discussion in this current chapter on apprenticeship will be complemented by the following chapter (8) which examines, retrospectively, apprenticeship outcomes. In chapter 3 a number of pathways to self-employment were identified. Chapter 8's data will enable us to map out some typical pathways from apprenticeship to self-employment.

\footnotetext{
${ }^{369}$ See chap.5.3 for a discussion of the enabling environment for IME in Ghana.

${ }^{370}$ E.g. the World Bank's VSP (1995-2001), IFAD's Rural Enterprise Project (REP) (1995-ongoing) and the STEP.
} 


\section{Chapter 8: Mastering the Trade - Creating Pathways to Rural Informal Micro- Enterprise}

\subsection{Introduction}

The last two chapters examined case studies of the three main types of skills training in Ghana: informal enterprise-based training (traditional apprenticeships), short-term modular training (STEP), and long-term skills training delivered in a VTI (ICCES).

This chapter is still concerned with the interaction amongst school, skill and enterprise which has been one of the threads of this thesis, but will tackle this issue by analysing data from retrospective interviews with MSE owners already operating in the labour market. In order to find out how MSE owners become established in enterprises it is necessary to conduct retrospective interviews with existing masters to examine how they got to where they are now. ${ }^{371}$

This chapter will integrate what is currently known about how masters in rural MSEs in Ghana enter self-employment with fieldwork: specifically interviews with some 114 rural MSE owners (February-March, 2005). ${ }^{372}$ This will provide further insights into how young people in rural areas create pathways to self-employment through the acquisition of skills and by overcoming both the economic and social barriers associated with self-employment start-up. This will also allow us to reflect on how our various model pathways (chap.3.3.2) appear in practice.

After briefly outlining some of the characteristics of the interviews conducted with rural MSE owners, this section will cover three aspects of the pathway to self-employment:

- becoming skilled and networked - what formal education have masters achieved and what other types of skills have they obtained, and where? How have masters been able to establish and build up social and enterprise networks that are crucial to start-up?

- becoming financed - how have masters been able to overcome the financial barriers associated with start-up?

\footnotetext{
${ }^{371}$ One obvious problem with this approach is that it will miss those youth that have failed to sustain their enterprise activities, and therefore suffers from selection bias.

${ }^{372}$ See Chap.1.4.4./Appendix A for details on the methodology together with some further data on the enterprises. Unless otherwise stated, the discussion in this chapter refers to the author's interviews in 2005.
} 
- becoming established - does the age of start-up vary according to gender or trade area? What ongoing constraints do MSEs face and what strategies are used to sustain selfemployment activities?

The conclusion will discuss some of the main findings of this chapter as well as link back to the earlier discussion on pathways to enterprise.

The interviews with rural MSE owners covered 114 enterprises, predominantly from two small rural towns in Ashanti and Western Regions. ${ }^{373}$ Since these interviews wanted to find out about training enterprises, that offered traditional apprenticeships, the sample was limited to manufacturing and service enterprises, and excluded farming and retail activities where traditional apprenticeship training does not occur. Nonetheless, within these enterprises the issue of occupational pluralism was investigated which does cut across any straightforward exclusion of other enterprise types. The majority of these training MSEs are dressmaking/tailoring, hairdressing and carpentry activities (table 8.1). There is a clear gender distinction in rural MSEs: females are almost exclusively found in dressmaking and hairdressing enterprises, though 10/33 $(30 \%)$ of dressmakers/tailors were male. Males dominate all other trade areas of those interviewed (table 8.1).

Table 8.1. Types of enterprise among those interviewed

\begin{tabular}{|l|r|r|r|r|}
\cline { 2 - 5 } \multicolumn{1}{c|}{} & \multicolumn{2}{c|}{ Sex of MC } & \multicolumn{2}{c|}{} \\
\cline { 2 - 5 } \multicolumn{1}{c|}{} & Male & Female & Total & Percent \\
\hline Dressmaking & 10 & 23 & 33 & 28.9 \\
Hairdressing & 0 & 21 & 21 & 18.4 \\
Carpentry & 24 & 0 & 24 & 21.1 \\
Mechanics & 6 & 0 & 6 & 5.3 \\
Masonry & 4 & 0 & 4 & 3.5 \\
Electronics & 5 & 0 & 5 & 4.4 \\
Shoemaker & 7 & 0 & 7 & 6.1 \\
Welder & 5 & 0 & 5 & 4.4 \\
Artist & 1 & 0 & 1 & 0.9 \\
Vulcanizer & 2 & 0 & 2 & 1.8 \\
Bike repairer & 2 & 0 & 2 & 1.8 \\
Fridge repairer & 2 & 0 & 2 & 1.8 \\
Other & 1 & 1 & 2 & 1.8 \\
\hline Total & 69 & 45 & 114 & 100 \\
\hline
\end{tabular}

Note: male 'dressmaking' refers to tailoring. Where 'dressmaking' appears in the following tables without being disaggregated by gender, it refers to both male tailors and female dressmakers.

Source: Author's fieldwork, 2005

$37390 \%$ of the sample were from the two small rural towns of Bibiani, Western Region, (42\%) and Nyinahin, Ashanti Region, (48\%), while the remaining 10\% came from the village of Otaakrom (Ashanti). 
The majority of the enterprises interviewed were informal micro-enterprises (manufacturing/service). ${ }^{374} 81 \%$ of the enterprises in the sample comprised of $1-5$ people, including the master and apprentices: $24 \%$ of these consisted of only the master-craftsperson. A further 19\% of enterprises had a size of 6 people or more. Overall, 93\% (106/114) of the enterprises interviewed were micro-enterprises (size of 9 or less) (table 8.2). ${ }^{375}$ The majority of enterprises interviewed operated from temporary or simple structures or from the home (table 8.3).

Table 8.2. Size of enterprises among those interviewed

\begin{tabular}{|r|r|r|r|}
\hline $\begin{array}{r}\text { Size of } \\
\text { enterprise }\end{array}$ & Freq. & Percent & $\begin{array}{r}\text { Cumulative } \\
\text { Percent }\end{array}$ \\
\hline Owner-operator & 27 & 23.7 & 23.7 \\
2 & 17 & 14.9 & 38.6 \\
3 & 22 & 19.3 & 57.9 \\
4 & 18 & 15.8 & 73.7 \\
5 & 8 & 7 & 80.7 \\
\hline 6 & 5 & 4.4 & 85.1 \\
7 & 3 & 2.6 & 87.7 \\
8 & 3 & 2.6 & 90.4 \\
9 & 3 & 2.6 & 93 \\
\hline $10-14$ & 5 & 4.4 & 97.4 \\
$15-19$ & 1 & 0.9 & 98.3 \\
20 and over & 2 & 1.8 & 100.1 \\
\hline & 114 & 100 & \\
\hline
\end{tabular}

Source: Author's fieldwork, 2005

Table 8.3. Location of enterprises among those interviewed

\begin{tabular}{|l|r|r|}
\hline & Frequency & Percent \\
\hline Temporary & 19 & 16.7 \\
Under tree & 8 & 7.0 \\
Wooden kiosk & 61 & 53.5 \\
Metal kiosk & 7 & 6.1 \\
Concrete structure & 8 & 7.0 \\
Household & 11 & 9.6 \\
Total & 114 & 100.0 \\
\hline
\end{tabular}

Notes:

'Temporary' included, for example, table-top work places that was taken down at the end of each working day, and enterprises that had no fixed location (such as masoners/carpenters who operate from different on-the-job locations according to what informal contract they are working on). 'Metal kiosks' refer to enterprises established in old metal shipping containers.

Source: Author's fieldwork, 2005

\footnotetext{
${ }^{374}$ See chap.1.2.3.

375 The 114 enterprises had a total of 347 apprentices. 160 of these apprentices were also interviewed (chap.7.6).
} 
Nearly $10 \%(9.6 \%)$ of those interviewed were home-based enterprises, a further quarter $(23.7 \%)$ operated from under a shady tree or other temporary workplace, and about half (53.5\%) operated from wooden kiosks. Only 13\% of enterprises interviewed operated from more permanent structures such as metal kiosks or concrete structures. While most carpenters worked from temporary worksites, most hairdressers, tailors and dressmakers had kiosks (Appendix A, table A.2).

\subsection{Becoming skilled, becoming networked}

The interviews with rural masters revealed that $25 \%$ had achieved incomplete JSS/middle-school or less (17\% of males, $38 \%$ of females), while $75 \%$ had achieved JSS/middle-school completion or higher (83\% of males, $62 \%$ of females) (table 8.4 ). More males (16\%) had post-basic education than females $(2 \%)$.

Table 8.4. Highest education level of master-craftspeople among those interviewed

\begin{tabular}{|l|r|r|r|r|r|r|}
\hline & \multicolumn{2}{|c|}{ Male } & \multicolumn{2}{|c|}{ Female } & \multicolumn{2}{|c|}{ Both } \\
\cline { 2 - 7 } & Freq. & Percent & Freq. & Percent & Freq. & Percent \\
\hline None & 1 & 1.5 & 0 & 0.0 & 1 & 0.9 \\
Primary completed & 2 & 2.9 & 3 & 6.7 & 5 & 4.4 \\
JSS/middle school not completed & 9 & 13.0 & 14 & 31.1 & 23 & 20.2 \\
JSS/middle school completed & 45 & 65.2 & 27 & 60.0 & 72 & 63.2 \\
SSS not completed & 2 & 2.9 & 0 & 0.0 & 2 & 1.8 \\
SSS completed & 6 & 8.7 & 1 & 2.2 & 7 & 6.1 \\
Post-basic VTI & 3 & 4.3 & 0 & 0.0 & 3 & 2.6 \\
Other & 1 & 1.5 & 0 & 0.0 & 1 & 0.9 \\
\hline Total & 69 & 100.0 & 45 & 100.0 & 114 & 100 \\
\hline
\end{tabular}

Source: Author's fieldwork, 2005

Table 8.5 provides a summary of the average education levels of masters in the informal sector of Ghana. In earlier literature, informal sector operators have been regarded as possessing a low skills base and low levels of education (e.g. Hallak and Caillods, 1981). However, it has been recognised that large numbers of much more educated people are entering the informal sector in SSA (Charmes, 1999; Chigunta et al., 2005; King, 1990b; Palmer, 2004a) which is changing the dynamics of becoming a master. That the levels of education among informal sector operators 
and apprentices is rising is most probably as a result of progress towards EFA. ${ }^{376}$ For example, in Ghana a survey in Accra (1990/91) (cited in Baah-Nuakoh, 2003) revealed that $14.2 \%$ of informal sector enterprise owners had not been to school (table 8.5). Later (2003) research in NkawieKuma, a rural town in Ashanti (Palmer, 2004a), recorded a lower figure. ${ }^{377}$ The fieldwork conducted with rural (manufacturing/service) MSEs in 2005 shows that among the masters in Nyinahin and Bibiani, very few had never been to school (0.9\%). The 2003 survey included petty traders which may account for the higher percentage of owners with no schooling. Likewise, the 1990/91 urban data revealed that $36.1 \%$ of operators had completed middle form four, compared to $46.8 \%$ and $63.2 \%$ in the 2003 and 2005 rural studies respectively (averaging 55\% for rural masters). ${ }^{378}$ While the data for rural masters suggests that fewer have no formal schooling, the numbers of masters with incomplete basic education is high in rural areas: $9.2 \%$ and $20.2 \%$ of the masters in the 2003 and 2005 studies respectively had started middle school/JSS but dropped out (averaging 14.7\% among rural masters). This suggests that, while it may have been easier for rural masters to complete primary education, there still remain barriers inhibiting many from completing basic education (JSS3).

\footnotetext{
${ }^{376}$ It may also, in part, be due to the entry of more educated workers from the formal sector into the informal sector - as a result of large scale retrenchment associated with the structural adjustment policies (Chigunta et al., 2005).

${ }^{377}$ It would be better to compare results from urban areas over this time period, instead of having one urban and one rural sample. However, since education in rural areas is almost always less widespread than in urban areas, what this data does indicate is that levels of education in urban areas for informal sector operators are likely to be higher than is suggested by the rural data.

${ }^{378}$ Loosely comparable to JSS3 now. Note that $63 \%$ of the most recent sample (Nyinahin/Bibiani) have about 9 or 10 years of education.
} 
Table 8.5. Highest education level of masters in Ghana: evidence from three studies

\begin{tabular}{|c|c|c|c|c|}
\hline Highest education level completed & \begin{tabular}{r|}
$1990 / 91$ \\
Urban \\
Accra (1)
\end{tabular} & \begin{tabular}{r|}
2003 \\
Rural \\
Nkawie- \\
Kuma (2)
\end{tabular} & \begin{tabular}{r|}
2005 \\
Rural \\
Nyinahin/ \\
Bibiani (3)
\end{tabular} & \begin{tabular}{|r|} 
Rural \\
average \\
(2)+(3)
\end{tabular} \\
\hline $\begin{array}{l}\text { Not been to school } \\
\text { Has not completed primary } \\
\text { Completed primary } \\
\text { Entered middle school / JSS but not completed } \\
\text { Completed middle form four / JSS } 3 \\
\text { Entered secondary but not completed } \\
\text { Completed secondary } \\
\text { Tertiary education } \\
\text { Other }\end{array}$ & $\begin{array}{r}14.2 \\
7.7 \\
7.0 \\
3.3 \\
36.1 \\
4.7 \\
12.1 \\
10.4 \\
5.0\end{array}$ & $\begin{array}{r}9.2 \\
2.8 \\
3.7 \\
9.2 \\
46.8 \\
3.7 \\
15.6 \\
6.4 \\
1.8\end{array}$ & $\begin{array}{r}0.9 \\
0 \\
4.4 \\
20.2 \\
63.2 \\
1.8 \\
6.1 \\
0 \\
3.5\end{array}$ & $\begin{array}{r}5.1 \\
1.4 \\
4.1 \\
14.7 \\
55 \\
2.8 \\
10.9 \\
3.2 \\
2.7\end{array}$ \\
\hline
\end{tabular}

Notes:

(1) data from an Accra survey by Baah-Nuakoh (2003: 119)

(2) data from interviews in the district capital of Nkawie (Ashanti) by Palmer (2004a).

(3) data from the Author's fieldwork, 2005

Percentages do not add up to $100 \%$ due to rounding of fractions.

The JSS replaced the middle school in Ghana. In the table 'middle school' and 'JSS' are assumed to be identical even though middle school was 4 years, while JSS is 3. Primary school in Ghana is 6 years.

Comparing the education levels of masters from the two rural studies, it can be seen that more of those from Nkawie-Kuma had completed secondary or tertiary education than masters from Nyinahin/Bibiani, and hence the percentage of those who had completed middle school/JSS, as their highest level of education attained, was higher among Nyinahin/Bibiani MSE owners (table 8.5). This is not surprising: Nkawie-Kuma is a bigger settlement, only 30 minutes drive from Kumasi, whereas Nyinahin and Bibiani are smaller towns, some 2-2 1/2 hours drive from Kumasi.

The education levels of owners varied according to trade areas, suggesting some kind of selection effect. For example 57\% (12/21) of hairdressers interviewed had less than a complete basic education compared to $18 \%(6 / 33)$ of dressmakers. This suggests that less-educated females tend to cluster in hairdressing, rather than dressmaking, activities. However, in chapter 7.8.3 it was seen that among the apprentices interviewed $(n=160)$ those in hairdressing had a higher level of formal education than those in dressmaking. This seemingly contradictory finding might signal a change over time. When the female hairdressing and dressmaking owners were doing their apprenticeship those with higher educational backgrounds tended to cluster in the dressmaking trade, perhaps because dressmaking was more popular than hairdressing at that time. That current hairdressing apprentices have higher levels of education than current dressmaking apprentices might be a signal that hairdressing has become a more popular trade since the 1990s (and hence masters are selecting apprentices with higher levels of education). 
Indeed interview data supports this view, and suggests that foreign imports of ready made dresses have reduced the demand for locally made wares. Meanwhile hairdressing has increased in popularity among the youth:

dressmaking have [sic]... gone down [in popularity] for the past ten years because of import of outside ware or goods because most women prefer already made goods and the second-hand cloths too are more cheaper [sic]. So if people are not buying more, surely it has to drop and it will no more become attractive.

Fashion is more popular, with regards to hairdressing, women look nice. Whenever with nice hair style, people call them, chat with and whole lot of things I am not worth to mention. In short, it is very very popular. (interview with Otaakrom ICCES centre manager, 27.07.05)

Similarly, of the carpentry masters interviewed $21 \%(5 / 24)$ had less than a complete basic education. Of the carpentry apprentices data reviewed earlier (chap.7.8.3), 40-50\% had less than a complete basic education. This might suggest that a carpentry apprenticeship has become less popular option for schooled youth since the 1990s. ${ }^{379}$ It has been suggested that one reason for the decline in popularity is, paradoxically, the increasing use of carpentry machines. Since carpentry machines are most common in urban areas, and it is unusual to find a rural carpenter with their own machine, rural carpenters' products are generally of lesser quality compared to those with machines. This makes doing a carpentry apprenticeship less popular in rural areas. As one informant put it:

[The] old days of carpentry is different from the present day. With machines it makes it modern with good finishing. How many of workshops have carpentry machine? So it is no more attractive in terms of no machine and to get money to send wood to machine shop is a big problem. The machines are in the cities and how does the rural youth go there get a place to stay and learn or become apprentice to carpentry in the city. Only the few serious ones will stay with somebody, serve the person and get a place to sleep and study. (interview with Otaakrom ICCES centre manager, 27.07.05)

The data also suggests that there might be some relationship between the education levels of masters and the longevity of their enterprise. For example, out of the masters interviewed who had less than a basic education $(n=29)$, the average age of their enterprise was 2.9 years. For those masters with a complete basic education or more, the average age of their enterprise was 6.4

\footnotetext{
${ }^{379}$ These figures are, of course, not directly comparable since the samples are from different sites. But it does suggest, at least, that carpentry apprenticeships are becoming more common among less schooled youth.
} 
years. While there are very many examples of highly successful enterprise owners who are totally illiterate, this data does suggest that there might be a higher chance of an enterprise surviving longer if the enterprise owner has a basic education (or higher) ${ }^{380}$ Of course this data does not prove causation since the relationship between education level and age of enterprise may be spurious: in other words, there may be a third or more variables which cause the correlation. For example, the socio-economic background of a master's household can affect whether or not he/she completes basic education. It is likely that better off families are more able to support their children through basic education and, by being better off, more able to support their child in the initial stages of enterprise start-up (possibly putting their enterprise on a more steady footing and more likely to survive longer).

With regard to the source of skills training, the majority (92\%) of all master-craftspeople interviewed (2005) indicated that they had been through traditional apprenticeship only, while a further $5 \%$ indicated that they had trained in both an apprenticeship and a formal VTI. ${ }^{381}$ Informal enterprise-based training, therefore, seems to be a central ingredient for those who end up selfemployed in rural MSEs: $97 \%$ of rural masters interviewed indicated that they had been through a traditional apprenticeship (table 8.6).

Table 8.6. Source of master-craftspeople training among those interviewed

\begin{tabular}{|ll|r|r|r|}
\hline & Frequency & Percent & $\begin{array}{c}\text { Cumulative } \\
\text { Percent }\end{array}$ \\
\hline Valid & Apprenticeship & 105 & 92.1 & 92.1 \\
& Formal VTI & 2 & 1.8 & 93.9 \\
& TAT and formal VTI & 6 & 5.3 & 99.1 \\
Formal on-the-job & 1 & .9 & 100.0 \\
Total & 114 & 100.0 & \\
\hline
\end{tabular}

Notes: VTI - Vocational training institute. TAT - Traditional apprenticeship training. Source: Author's fieldwork, 2005

\footnotetext{
380 The two longest surviving enterprises in the sample (25 and 28 years old) were both run by SSS graduates.

${ }^{381}$ When asked what their highest level of education was (table 8.4), only 3 master-craftspeople indicated that they had attended a VTI. However, when asked about their training, a total of 8 master-craftspeople indicated that they had been to a VTI. This discrepancy is either because the question was not clear enough - and master-craftspeople did not consider VTI training as education; or, it might have been that some of those interviewed went to a VTI before going onto SSS (or even JSS/middle-school) and hence this is masked in table 8.4 .
} 
The mean duration of apprenticeship training of the master-craftspeople interviewed was 3.2 years, but this varied by trade area (table 8.7).

\section{Table 8.7. Duration of apprenticeship training of the master-craftspeople among those interviewed}

\begin{tabular}{|l|c|c|c|}
\cline { 2 - 4 } \multicolumn{1}{c|}{} & $\begin{array}{c}\text { mean } \\
\text { duration of } \\
\text { training }\end{array}$ & $\mathrm{n}$ & $\begin{array}{c}\% \text { female } \\
\text { in this } \\
\text { trade }\end{array}$ \\
\hline Dressmaking & 3.1 & 33 & 70 \\
Hairdressing & 2.9 & 21 & 100 \\
Carpentry & 3.2 & 24 & 0 \\
Mechanics & 4.5 & 6 & 0 \\
Shoemaker & 2.6 & 7 & 0 \\
All & 3.2 & 111 & 40 \\
\hline
\end{tabular}

Source: Author's fieldwork, 2005

Since $97 \%$ of master-craftspeople interviewed had acquired their training on-the-job in traditional apprenticeships, most would have been well place to develop networks which are known to be important for self-employment.

It was noted earlier (chap.3.2.4) that two distinct types of networks need to be stimulated for selfemployment promotion: i) enterprise networks; and ii) institutional networks (e.g. financial and non-financial BDS institutions) (Grierson, 1997). But given that family and relatives play such a strong function in providing start-up capital for so many new enterprises (see below and Palmer, 2004a), and that ethnic networks are known to be an important in facilitating access to employment or support (chap.5.3.5), it is argued that a third type of network is essential for selfemployment promotion: family and ethnic networks. ${ }^{382}$

If apprentices can establish and maintain contacts with customers, suppliers and enterprise owners during their training, these contacts may well be able to assist them in the start-up phase. As one respondent put it: "apprentices like to meet those people [customers, suppliers] so they can develop connections". ${ }^{383}$ One strategy used to obtain start-up capital is getting suppliers or customers to provide credit. Similarly this supplier or customer credit is also useful to satisfy working capital needs once the enterprise is established (Palmer, 2004a). Hence making enterprise contacts early on (during training) puts aspiring owners at an advantage compared to

\footnotetext{
382 These different networks are, of course, not necessarily mutually exclusive: e.g. a family member or relative might also own an enterprise and hence be in both the family and enterprise networks.

${ }^{383}$ Interview with centre manager of Otaakrom ICCES (VTI), 22.09.05.
} 
those that don't have such connections. McLaughlin's (1979) work on apprenticeship in the late 1970s also led him to note that during apprenticeship youth learn how to deal with customers and build up personal contacts with dealers.

Chant and Jones (2005) comment that "in Ghana... it was identified that employment is frequently a matter of 'know who' not 'know how', with the 'knowing who' involving a complex array of familial, ethnic and religious contacts" (p. 194). Lyon (2000) also highlights the importance of social relations for micro-enterprise survival in Ghana.

\subsubsection{Summary}

Three-quarters of the 114 master-craftspeople interviewed had achieved JSS/middle-school completion or higher, which roughly corresponds with an earlier survey in rural Ghana (Palmer, 2004a). $16 \%$ of male owners had a post-basic education compared to $2 \%$ of female owners. Compared to other data from Ghana, far fewer owners interviewed had never been to school or had dropped out of primary school. While this appears positive, $20 \%$ of those interviewed reported that they had started JSS/middle-school but dropped out.

The education levels of owners varied according to trade areas, suggesting some kind of selection effect. Combined with the earlier data on apprentices (chap.7.8.3) it appears that preference for specific trades has been changing since the 1990s.

The majority of owners (97\%) interviewed had trained through a traditional apprenticeship after school: $5 \%$ of these had also been through a formal VTI. The length of apprenticeship training varied according to trade area, but averaged 3.2 years. During this apprenticeship, masters would have been able to begin to establish valuable networks while gaining experience training on-thejob.

\subsection{Becoming financed: Overcoming the financial barrier to start-up}

Past studies of MSEs in Ghana have revealed that banks are unwilling to finance micro-enterprise start-up (Anheier and Seibel, 1987; Gockel and Akoena, 2002; Palmer, 2004a; Webster and Fidler, 1996) (fig.8.1). 


\section{Fig. 8.1. Reasons why getting access to formal credit is difficult for rural micro-enterprises}

1] Lending to MSEs is considered a higher risk vis-à-vis lending to larger ones; Banks do not have enough information on potential borrowers and fear the lack of predictability surrounding the transaction. Lenders are frequently faced with information asymmetry $(*)$ when compared to potential borrowers and thus "may avoid lending to smaller, less-known clients, or impose strict collateral requirements when they do" (Aryeetey et al. 1994: 7);

2] MSEs lack 'acceptable' collateral;

3] The small size of loan transaction has a high ratio of transaction cost to loan size. "The smaller the SME the more unattractive it is... as financial institutions will always want to recover their costs and make a reasonable profit, which is not always possible with small lendings" (Odei and Hammond 1996: 80).

4] MSEs often produce poor project reports and/or lack of comprehensive project plans;

5] MSEs often do not show managerial competence;

6] The ability of MSEs to repay a loan is not proven;

7] MSEs often lack a clear repayment plan;

8] The weak legal system to enforce repayments or contracts;

9] Suspicion of fungibility of loans disbursed;

10] Physical remoteness of many enterprises, especially in the rural areas;

11] Lack of book keeping is common for MSEs;

12] Mobility of many MSEs;

13] Illiteracy of many MSE owners (**) and the inability to understand what the banks ask of them;

14] MSEs are seen as disorganised.

Notes:

* Asymmetry of information arises when potential borrowers have more information than the lenders are able to accurately obtain about the ability and willingness of the former to repay any loan.

** This assertion is not supported by the research findings from Palmer (2004a) or the field research conducted in 2005 that revealed that most MSE owners interviewed had completed JSS or higher (table 8.4).

Source: Palmer, 2004a: 14

With the difficulty of accessing formal credit, MSEs use personal and relatives' savings as the predominant form of financing enterprise start-up (Anheier and Seibel, 1987; Aryeetey et al., 1994; Baah-Nuakoh, 2003; Buckley, 1997; Kpemlie, 1998; Liedholm, 1991; Meghir, 1991; Thomi and Yankson, 1985). This trend is noted in other developing countries: Liedholm (1991) notes that evidence from Africa indicates over 95\% of initial firm capitalisation is received from family, friends or personal savings. Borrowing from other sources is minimal. When resorted to, it is usually from non-institutional sources such as professional money lenders rather than formal financial institutions (Blunch et al., 2001). Other sources include customer advances and 
suppliers credit (Aryeetey et al., 1994). Some researchers suggest alternative sources. For example, Kpemlie's (1998) research in Ghana revealed that $13.3 \%$ of start-up finance came from churches.

A detailed analysis of how existing rural Ghanaian masters were able to find the start-up capital for their enterprises, and hence overcome the financial entry-barrier contributes to our understanding of how the pathway to self-employment is navigated in rural areas.

Overall, masters interviewed in 2005 mostly obtained their start-up capital for their current MSE activity from their family (41.2\%) (spouse or parents/relatives), from previous periods of informal self-employment (39.5\%) (including small-scale cash-crop farming, MESE activities ${ }^{384}$ or some other form of self-finance), and periods of informal wage-employment (15.8\%) (including working for their previous master or labouring).

The following case illustrates the difficulty of accessing formal finance and the way family finance is sometimes sought:

Thomas completed JSS and went into a shoemaking apprenticeship. After he finished he found it impossible to get a bank loan: 'because I was unemployed nobody [the banks] wanted to give me a loan to start a business'. He turned to his family for support and his grandmother gave him a loan of one million cedis which he is meant to repay with $100 \%$ interest after one year. (interview with shoemaker, 10.02.05)

\footnotetext{
${ }^{384}$ See chap.3.3.2.
} 
Table 8.8. Source of start-up capital for enterprise owners (by sex) among those interviewed

\begin{tabular}{|l|r|r|r|r|r|r|}
\hline & \multicolumn{2}{|c|}{ Male } & \multicolumn{2}{c|}{ Female } & \multicolumn{2}{|c|}{ Both } \\
& Freq. & Percent & Freq. & Percent & Freq. & Percent \\
\hline Spouse & 0 & 0 & 9 & 20 & 9 & 7.9 \\
Parents/other relatives & 19 & 27.5 & 19 & 42.2 & 38 & 33.3 \\
\hline Family & 19 & $\mathbf{2 7 . 5}$ & $\mathbf{2 8}$ & $\mathbf{6 2 . 2}$ & $\mathbf{4 7}$ & $\mathbf{4 1 . 2}$ \\
\hline Farming & 10 & 14.5 & 1 & 2.2 & 11 & 9.6 \\
Starting small & 10 & 14.5 & 3 & 6.7 & 13 & 11.4 \\
Other self-finance & 11 & 15.9 & 10 & 22.2 & 21 & 18.4 \\
\hline Self Employment (informal) & $\mathbf{3 1}$ & $\mathbf{4 4 . 9}$ & $\mathbf{1 4}$ & $\mathbf{3 1 . 1}$ & $\mathbf{4 5}$ & $\mathbf{3 9 . 5}$ \\
\hline Working for master & 9 & 13 & 2 & 4.4 & 11 & 9.6 \\
Labouring & 6 & 8.7 & 1 & 2.2 & 7 & 6.1 \\
\hline Wage Employment (informal) & $\mathbf{1 5}$ & $\mathbf{2 1 . 7}$ & $\mathbf{3}$ & $\mathbf{6 . 7}$ & $\mathbf{1 8}$ & $\mathbf{1 5 . 8}$ \\
\hline Other & 4 & 5.8 & 0 & 0 & 4 & 3.5 \\
\hline & 69 & 99.9 & 45 & 99.9 & 114 & 99.8 \\
\hline
\end{tabular}

Notes:

'Other self-finance' included saving chop money (3), hiring a kiosk (1), Galamsey informal sector gold mining (1), small scale retail trading (2) and other self-finance unspecified (14).

'Labouring' usually referred to 'farm labouring', i.e. getting paid a small per-day wage to weed or do the farm work of other community members.

Source: Author's fieldwork, 2005

Breaking down the components reveals interesting distinctions according to gender.

A higher proportion of female masters (62\%) obtained their start-up capital from their family compared to male masters (28\%). Where male masters obtained start-up capital from their family it primarily came from their parents or other relatives, and not their wife. In contrast, of those women who obtained finance from their family, nearly one third obtained finance from their husband (table 8.8). The high percentage of women receiving start-up finance from their family may be connected with support from maternal uncles (matrilineal system) though, as noted earlier (chap.5.3.5), among the younger generation the matrilineal system appears to be weakening in Ashanti and giving way to the stronger nuclear family system.

Males were more likely to engage in informal self-employment activities to finance start-up, compared to females ( $45 \%$ of men compared to $31 \%$ of women). Male masters were more likely to engage in farming activities or starting their enterprise in a very small way, than their female counterparts (table 8.8).

Similarly, male masters were more likely to use periods of informal wage-employment to finance start-up when compared to their female counterparts ( $22 \%$ of men compared to $7 \%$ of women). 
Male masters had more opportunity, it seemed, to do wage work for their former masters than female masters were (13\% of men compared to $4 \%$ of women) (table 8.8 ).

Table 8.9. Source of start-up capital for enterprise owners according to trade and gender among those interviewed

\begin{tabular}{|c|c|c|c|c|c|c|c|c|c|c|c|}
\hline \multirow[b]{2}{*}{ Sex of MC } & & & \multicolumn{8}{|c|}{ Source of startup } & \multirow[b]{2}{*}{ Total } \\
\hline & & & spouse & $\begin{array}{l}\text { parents } / \mathrm{r} \\
\text { elatives }\end{array}$ & farming & labouring & starting small & $\begin{array}{l}\text { other self } \\
\text { finance }\end{array}$ & $\begin{array}{c}\text { Work for } \\
\text { master }\end{array}$ & Other & \\
\hline \multirow[t]{13}{*}{ Male } & \multirow{12}{*}{$\begin{array}{l}\text { Type of } \\
\text { Enterprise }\end{array}$} & Dressmaking & & 3 & 4 & 1 & 0 & 2 & 0 & 0 & 10 \\
\hline & & Carpentry & & 5 & 1 & 1 & 6 & 4 & 5 & 2 & 24 \\
\hline & & Mechanics & & 3 & 0 & 0 & 0 & 1 & 1 & 1 & 6 \\
\hline & & Masonry & & 0 & 2 & 0 & 2 & 0 & 0 & 0 & 4 \\
\hline & & Electronics & & 2 & 0 & 1 & 0 & 1 & 1 & 0 & 5 \\
\hline & & Shoemaker & & 2 & 2 & 2 & 0 & 1 & 0 & 0 & 7 \\
\hline & & Welder & & 2 & 0 & 0 & 1 & 1 & 1 & 0 & 5 \\
\hline & & Artist & & 0 & 1 & 0 & 0 & 0 & 0 & 0 & 1 \\
\hline & & Vulcanizer & & 1 & 0 & 0 & 0 & 0 & 0 & 1 & 2 \\
\hline & & Bike repairer & & 0 & 0 & 1 & 0 & 1 & 0 & 0 & 2 \\
\hline & & Fridge repairer & & 0 & 0 & 0 & 1 & 0 & 1 & 0 & 2 \\
\hline & & Other & & 1 & 0 & 0 & 0 & 0 & 0 & 0 & 1 \\
\hline & Total & & & 19 & 10 & 6 & 10 & 11 & 9 & 4 & 69 \\
\hline \multirow[t]{4}{*}{ Female } & \multirow{3}{*}{$\begin{array}{l}\text { Type of } \\
\text { Enterprise }\end{array}$} & Dressmaking & 5 & 7 & 1 & 1 & 2 & 7 & 0 & & 23 \\
\hline & & Hairdressing & 3 & 12 & 0 & 0 & 1 & 3 & 2 & & 21 \\
\hline & & Other & 1 & 0 & 0 & 0 & 0 & 0 & 0 & & 1 \\
\hline & Total & & 9 & 19 & 1 & 1 & 3 & 10 & 2 & & 45 \\
\hline
\end{tabular}

Source: Author's fieldwork, 2005

Among female dressmakers, over half $(52 \%, 12 / 23)$ obtained finance from their family, $48 \%$ (11/23) obtained finance from MESE activities and only 4\% (1/23) obtained finance through informal wage-employment (table 8.9). Among hairdressers, nearly two-thirds (71\%, 15/21) obtained finance from their family, 19\% (4/21) obtained finance from MESE activities and only $10 \%(2 / 21)$ obtained finance through informal wage-employment (table 8.9).

In contrast, among carpenters, only one fifth $(21 \%, 5 / 24)$ obtained finance from their family, $46 \%$ (11/24) obtained finance from MESE activities and 25\% (6/24) obtained finance through informal wage-employment (table 8.9). Among male tailors, only 30\% (3/10) obtained finance from their family, 60\% (6/10) obtained finance from MESE activities and 10\% (1/10) from informal wageemployment (table 8.9).

A key issue, perhaps, is how much is needed to start up different enterprises (chap.5.3.6). 
Table 8.10. Main source of start-up capital: A comparison of Ghanaian findings, urban and rural (figures in columns are percentages)

\begin{tabular}{|c|c|c|c|c|c|c|c|}
\hline & $\begin{array}{c}\text { URBAN (1) } \\
\text { Aryeetey et al } \\
1994: 83 \\
(\mathrm{n}=76)\end{array}$ & $\begin{array}{c}\text { URBAN (2) } \\
\text { Buckley } \\
\text { 1997: 1082 } \\
(\mathrm{n}=150)\end{array}$ & $\begin{array}{c}\text { URBAN }(3) \\
\text { Anheier and } \\
\text { Seibel 1987 } \\
(\mathrm{n}=209)\end{array}$ & $\begin{array}{l}\text { URBAN } \\
\text { average } \\
(n=435)\end{array}$ & $\begin{array}{c}\text { RURAL (4) } \\
\text { Palmer } \\
2004 a \\
(n=101)\end{array}$ & \begin{tabular}{|c|} 
RURAL (5) \\
Author's \\
fieldwork \\
$(\mathrm{n}=114)$
\end{tabular} & $\begin{array}{l}\text { RURAL } \\
\text { average } \\
(n=215)\end{array}$ \\
\hline \multirow{5}{*}{$\begin{array}{l}\text { Own savings } \\
\text { Gifts / loan from friend or relation } \\
\text { Loans from an organisation } \\
\text { or someone else } \\
\text { Don't know / can't remember }\end{array}$} & 71 & 56 & 70 & 66 & 77 & 56 & 67 \\
\hline & 15 & 33 & 25 & 24 & 19 & 41 & 30 \\
\hline & 14 & 3 & 5 & 7 & 4 & & 2 \\
\hline & - & 8 & - & 3 & - & 4 & 2 \\
\hline & 100 & 100 & 100 & 100 & 100 & 101 & $\overline{101}$ \\
\hline
\end{tabular}

Notes

The fourth column displays the average of these three urban sites. The author's data is shown in column six.

(1) Aryeetey et al. (1994) study was based on 76 more dynamic micro-enterprises with "good growth potential" (ibid: 1) in the urban areas of Accra, Tema, Koforidua, Kumasi and Takoradi, Ghana. The table only includes the 76 micro-enterprises out of the 133 in the sample (which was made up of micro-, small- and medium-enterprises).

(2) Buckley (1997) study was based on 150 micro-enterprises in the urban areas of Accra, Kumasi and Cape Coast, Ghana.

(3) Anheier and Seibel (1987) study based on 209 small-scale industries (wood- and metal-processing firms)

(size 15 or less) in Kumasi and Accra, Ghana.

(4) Palmer (2004a) study based on 101 micro-enterprises (including manufacturing, retail, food) in Nkawie-Kuma, Ashanti Region.

(5) Data from author's 2005 fieldwork - interviews with 114 rural MSEs (manufacturing) largely from Nyinahin (Ashanti) and Bibiani (Western Region). 93\% (106/114) of enterprises in this survey were micro-enterprises (size 19).

It is interesting, at this point, to compare previous MSE research findings in Ghana with the author's findings from the interviews with rural MSEs in 2005. Four such studies, three urban and one rural based are compared in table 8.10.

Looking at the averages of the three urban studies there appears to be little difference with averages of the rural data. 'Own savings' are still the most important source with gifts and loans from friends and relatives of secondary importance. The data does suggest gifts from family/friends are more common in rural areas (30\%) than urban (24\%). Comparing the results of the 2005 rural MSE interviews with the previous rural study (Palmer, 2004a) indicates that, as in urban areas, there are different patterns of enterprise start-up. The 2005 rural MSE interviews suggested that 'own savings' was a less important source of start-up finance than the previous rural survey suggested (56\% versus 77\%). Moreover, receiving gifts/loans from friends/relatives was more important in the 2005 interviews than in the 2003 survey (41\% versus 19\%). This, 
perhaps is not surprising, and might be a reflection of the different socio-economic contexts of the 2003 and 2005 rural surveys. While the 2003 rural survey was conducted in a well-established rural district capital (Nkawie-Kuma, Ashanti), the 2005 survey was conducted in a very newlyestablished rural district capital (Nyinahin, Ashanti) and a smaller district capital (Bibiani, Western Region). As have noted elsewhere (Palmer, 2004a; 2004b), social and kin obligations are more pronounced in more smaller rural settlements compared to larger, more established, rural towns (or urban areas). ${ }^{385}$ It is therefore perhaps expected that gifts/loans from friends and relatives are more common for rural enterprise start-up. Similarly, it might be argued that, in smaller rural areas there is less opportunity for the young to engage in informal wage- or selfemployment in order to accrue personal savings.

Loans from external organisations are also more common in urban areas (7\%) than rural areas (2\%). Only in the Aryeetey et al. (1994) survey was the percentage of those enterprises getting start-up finance from external organisations of significance (at 14\%). ${ }^{386}$ However, the Aryeetey et al. study is not truly representative of MSEs throughout urban Ghana as these authors concentrated on more dynamic, higher-end MSEs (see Palmer, 2004a). Nonetheless, the author's interview data from Nyinahin/Bibiani does seem to agree in the most part with previous findings.

Palmer (2004a), like others (Aryeetey et al., 1994; Buckley, 1997; Kpemlie, 1998), found that enterprises frequently utilise multiple sources of finance to start-up their enterprise. This is logical, especially in rural areas:

Since informal financing is the predominant source of start-up capital and one of the main problems associated with informal financing is its inability to mobilise a great deal of money, to use multiple sources is logical. (Palmer, 2004a: 33)

One rural survey in Ghana found that $37 \%$ of masters indicated that they had used multiple sources of start-up capital (Palmer, 2004a).

In light of the data discussed above, it is possible to outline a number of strategies that are used in rural areas in order to obtain start-up capital and hence overcome the financial start-up barrier (fig.8.2).

\footnotetext{
${ }^{385}$ See also the 'traders dilemma' in Evers and Schrader (1994).

${ }^{386}$ This was made up of money from pensions (5\%), bank loan (1\%); PAMSCAD (3\%); GEDC (1\%) and other $4 \%$.
} 


\section{Fig.8.2. Strategies adopted to finance enterprise start-up costs in rural Ghana}

\section{Accrue personal savings}

1. Informal self-employment (on an ad hoc and very small-scale basis)

a) Working on a part-time basis on a very small scale periodic basis

for yourself at the same time as continuing to farm to make a living.

Customer or supplier credit is frequently used to avoid the need for capital.

(more common for males, especially in carpentry).

b) Savings from small-scale cash-crop farming (more common for males).

2. Informal wage-employment

a) Working for their previous master (more common for males, especially in carpentry).

b) Labouring for others on a per-day wage basis (more common for males)

\section{Other methods}

a) Apprentices saving 'chop money' given to them by their masters

to buy basic tools (more common for males since females get 'chop money' less frequently)

b) Newly graduated master-craftsmen taking apprentices on and

using the apprentice fees charged to purchase items to start own enterprise.

c) Using profits from existing enterprise activities to invest in another enterprise.

Family (more common for females, especially in dressmaking/hairdressing)

a) Borrow money from a member of the (extended) family either with

or without interest charged.

b) Be given a gift of money by a family member to initiate a business.

Other

a) Getting a loan from the formal financial sector or government credit

programme (not common).

Source: Author's fieldwork (2005) and Palmer (2004a: 37)

\subsubsection{Summary}

Financing for the start-up of their self-employment venture mostly came from family (41\%), previous periods of informal self-employment (40\%), and periods of informal wage-employment (16\%). Women were more likely to obtain start-up capital from their family compared to males. Males were more likely to engage in informal wage- or self-employment activities to finance start-up, compared to females. According to trade areas, the majority of those entering into hairdressing enterprises got finance from their family. Dressmakers used two main strategies: family and starting in MESE activities. Nearly half of carpenters obtained their start-up finance from MESE activities, a further quarter from informal wage-employment, and only $20 \%$ from family. Start-up finance for rural enterprise usually comes from multiple sources and a number of strategies are pursued to access these sources. 
Entry into self-employment in Ghana is constrained by various factors. While Chant and Jones (2005) comment that start-up capital and personal contacts are equally crucial factors, others like Frazer (2006) suggest that youth are "constrained only by capital from becoming apprenticed entrepreneurs" (p. 44). But Frazer appears to be overemphasizing the importance of capital alone, and the author's fieldwork (2004-2005) agrees with Chant and Jones that social networks are absolutely critical for entry into self-employment. However, as noted above, the two are related: access to start-up capital for the majority comes from personal or family contacts and ties. Hence access to financial capital is tied up with access to social capital.

\subsection{Becoming established: strategies for sustaining self-employment activities and ongoing constraints faced by owners}

The MSE owners interviewed were asked at what age they started their enterprise. This can be difficult to determine. For example, where owners have engaged in MESE activities as a means to raise start-up finance, the time at which an enterprise was started (and hence the age of the owner) is muddied: there might not be a distinct start-up time. Furthermore, where MESE activities are in different areas from subsequent enterprise activities (i.e. trade MESE leading to carpentry enterprise) the age at which the owner started their enterprise might not correspond with the age at which they started self-employment ventures per se.

With this cautionary note in mind, the average age given was 23 years, 2 months, though this ranged from 13-38. The average age of women enterprise owners at start-up was slightly higher than it was for men in the sample: 23 years, 7 months, compared to 22 years, 11 months.

Only $9 \%$ of enterprise owners interviewed (11.6\% of men, $4.4 \%$ of women) started their business when they were aged 18 or less. Of those that did, most where men (8/10). 23\% (26/114) started their business between the ages of 19-20 (20.3\% of men, $26.7 \%$ of women); $20 \%$ (23/114) started their business between the ages of 21-22 (21.7\% of men, $17.8 \%$ of women); 18\% (21/114) started their business between the ages of 23-24 (21.7\% of men, $13.3 \%$ of women) (table 8.11). By the age of $28,89 \%$ of all rural masters (101/114) had started their enterprise (88\% of men and $89 \%$ of women). 


\section{Table 8.11. Average age of enterprise owners at start-up according to sex among} those interviewed

Count
\begin{tabular}{|ll|r|r|r|}
\hline & & \multicolumn{2}{|c|}{ Sex of MC } & \multirow{2}{*}{} \\
\cline { 3 - 4 } \multicolumn{1}{|c|}{ Male } & \multicolumn{1}{c|}{ Female } & \multicolumn{1}{c|}{ Total } \\
\hline Age & 18 and below & 8 & 2 & 10 \\
range at & $19-20$ & 14 & 12 & 26 \\
startup & $21-22$ & 15 & 8 & 23 \\
& $23-24$ & 15 & 6 & 21 \\
& $25-26$ & 3 & 6 & 9 \\
& $27-28$ & 6 & 6 & 12 \\
& 29 and over & 8 & 5 & 13 \\
Total & & 69 & 45 & 114 \\
\hline
\end{tabular}

Source: Author's fieldwork, 2005

Of the 72 masters interviewed that had completed JSS/middle school and went no higher, the average start up age was 22 years, 10 months. Assuming that the average master completed JSS/middle school at the usual age of $16 / 17$, and went on to do an apprenticeship averaging 3 years, 2 months (see above), there is a gap of between 3 years, 8 months and 4 years 8 months between completion of formal schooling and apprenticeship training and starting in their selfemployment activity. This period of time seems to be when the young prospective self-employed artisans made their transition from training to self-employment and had to utilise one or more of the strategies outlined above (fig.8.2) to finance the start-up of their enterprise. ${ }^{387}$

There also appears to be some distinction between the start-up ages according to trade area. For example, in the carpentry trade, $88 \%(21 / 24)$ of masters interviewed had started their business by age 24. By contrast, $61 \%$ (20/33) of dressmakers/tailors had started their business by the age of 24. Similarly, 67\% (14/21) of hairdressers had started their business by the age of 24 . Carpenters, therefore seemed to be able to enter self-employment at an earlier age (average 21.8 years), followed by hairdressers (22.2 years average) and then dressmakers/tailors (24.5 years average) (fieldwork, 2005). ${ }^{388}$ This might reflect, in part, the difference in required start-up capital for different trades (chap.5.3.6).

\footnotetext{
${ }^{387}$ Honny (1999) estimates a similar time -5 years after graduation - for trainees of NVTI centres in Ghana to establish themselves in self-employment.

${ }^{388}$ There was little difference between male tailors and female dressmakers.
} 
Most newly graduated apprentices want to take on apprentices as soon as possible. This not only adds prestige to their establishment and allows them to undertake more work, but also, usually, provides the master with a source on income from apprenticeship fees (fieldwork, 2001-2005; see also Valenchik, 1995). Small informal operators may be tempted to use apprenticeship fees as a substitute for capital since they find it so hard to gain access to loans from commercial banks (McLaughlin, 1979). Apprenticeship fees can also be a useful source of working capital for rural enterprises (Palmer, 2004a). ${ }^{389}$ However, taking on apprentices appears to be easier in some trades than others. In dressmaking/tailoring and hairdressing, both female dominated trades, most newly graduated apprentices indicate that they can't take on apprentices until they have a kiosk or other structure to work from - other than the home or from a table-top (fieldwork, 2001-2005). Most newly trained dressmakers/tailors, therefore, work alone from their parents/family house until they can acquire the capital to get their own kiosk and take on apprentices. In contrast, it appears relatively easy for newly trained carpenters to take on apprentices - since most carpenters work under a shady tree or other temporary structure that requires minimal capital outlay. Likewise, newly graduated masonry apprentices can more easily take on apprentices since their worksite is frequently in different on-the-job locations according to the informal contract they might have at the time.

Among those master-craftspeople interviewed, the average number of apprentices per enterprise was three, though this ranged from no apprentices at all to 22 apprentices. ${ }^{390}$ Nearly threequarters of the owners interviewed had 0-3 apprentices (table 8.12): 24\% had no apprentices (27/114), 50\% (57/114) had 1-3 apprentices. Male enterprise owners ( $\mathrm{n}=69)$ had on average 2.4 apprentices, while female enterprise owners $(n=45)$ had on average 4 apprentices.

\footnotetext{
389 In the late 1970s Hakam (1978) and McLaughlin (1979) noted that it was common for mastercraftspeople just starting out to use apprenticeship fees to assist the start-up of their enterprise. A new master's ability to attract a sufficient number of paying apprentices may determine whether he/she is able to purchase particular tools, raw materials and so on. McLaughlin (1979) found that capital from apprentices was likely to be more important for new start-up enterprises than it is for more established enterprises - although he noted that it can still be important for them if they need capital for an investment.

${ }^{390}$ The four largest enterprises (with 12, 17, 20 and 22 apprentices) were all hairdressing ventures. When there are such large numbers of apprentices it might be that the enterprise gets a large proportion of income from being a training provider.
} 
Table 8.12. Average number of apprentices by sex of enterprise owner among those interviewed

\begin{tabular}{|c|c|c|c|c|}
\hline & & \multicolumn{2}{|c|}{ Sex of MC } & \multirow[b]{2}{*}{ Total } \\
\hline & & Male & Female & \\
\hline \multirow{7}{*}{$\begin{array}{l}\text { No. } \\
\text { TAps } \\
\text { range }\end{array}$} & 0 & 19 & 8 & 27 \\
\hline & 1 & 7 & 10 & 17 \\
\hline & 2 & 14 & 8 & 22 \\
\hline & 3 & 13 & 5 & 18 \\
\hline & 4 & 6 & 2 & 8 \\
\hline & 5 & 4 & 1 & 5 \\
\hline & 6 and above & 6 & 11 & 17 \\
\hline Total & & 69 & 45 & 114 \\
\hline
\end{tabular}

Source: Author's fieldwork, 2005

The female dominated trade areas of dressmaking and hairdressing had the greatest number of apprentices. 15\% (5/33) of dressmaking enterprises and 33\% (7/21) of hairdressing enterprises had 6 or more apprentices (table 8.13).

Dressmaking/tailoring enterprises had an average of 2.5 (84/33) apprentices. Male-headed tailoring enterprises had an average of 1.7 apprentices (17/10) compared to an average of 2.9 apprentices (67/23) for female-headed dressmaking enterprises. Hairdressing enterprises had an average of $5.3(112 / 21)$ apprentices. Carpentry enterprises had an average of $2.3(55 / 24)$ apprentices. 
Table 8.13. Average number of apprentices per enterprise by type of enterprise among those interviewed

\begin{tabular}{|c|c|c|c|c|c|c|c|c|c|}
\hline & & \multicolumn{7}{|c|}{ No. TAps range } & \multirow[b]{2}{*}{ Total } \\
\hline & & 0 & 1 & 2 & 3 & 4 & 5 & 6 and above & \\
\hline \multirow{13}{*}{$\begin{array}{l}\text { Type of } \\
\text { Enterprise }\end{array}$} & Dressmaking & 6 & 7 & 8 & 6 & $\overline{1}$ & 0 & 5 & 33 \\
\hline & Hairdressing & 5 & 5 & 1 & 1 & 1 & 1 & 7 & 21 \\
\hline & Carpentry & 4 & 1 & 8 & 7 & 3 & 1 & 0 & 24 \\
\hline & Mechanics & 0 & 0 & 0 & 1 & 0 & 3 & 2 & 6 \\
\hline & Masonry & 2 & 0 & 0 & 0 & 1 & 0 & 1 & 4 \\
\hline & Electronics & 2 & 0 & 1 & 1 & 0 & 0 & 1 & 5 \\
\hline & Shoemaker & 4 & 1 & 1 & 1 & 0 & 0 & 0 & 7 \\
\hline & Welder & 1 & 2 & 1 & 0 & 1 & 0 & 0 & 5 \\
\hline & Artist & 0 & 0 & 1 & 0 & 0 & 0 & 0 & 1 \\
\hline & Vulcanizer & 0 & 0 & 1 & 0 & 1 & 0 & 0 & 2 \\
\hline & Bike repairer & 1 & 0 & 0 & 1 & 0 & 0 & 0 & 2 \\
\hline & Fridge repairer & 1 & 0 & 0 & 0 & 0 & 0 & 1 & 2 \\
\hline & Other & 1 & 1 & 0 & 0 & 0 & 0 & 0 & 2 \\
\hline Total & & 27 & 17 & 22 & 18 & 8 & 5 & 17 & 114 \\
\hline
\end{tabular}

Source: Author's fieldwork, 2005

Respondents were asked what the most important ongoing constraint was for their enterprise. Overall, about $20 \%$ indicated that their enterprise did not have any significant ongoing problems. However, nearly $60 \%$ indicated financial problems to be the most pressing ongoing constraint, and this was similar for both male and female owners. This concurs with other small enterprise literature that shows masters indicate financial problems to be their biggest problem (for Ghana see Aryeetey et al., 1994; Aryeetey, 1996). ${ }^{391}$ Male owners appeared to have more of a problem with ongoing working capital than female owners: $45 \%$ of men compared to $31 \%$ of women indicated that working capital was their biggest problem. Women were more likely to indicate that there was a lack of demand for their type of service/products in the market: $13 \%$ of women compared to $7 \%$ of men said this was their biggest problem (table 8.14).

${ }^{391}$ See chap.3.2.5. 
Table 8.14. Ongoing problems faced by rural MSEs

\begin{tabular}{|c|c|c|c|c|c|c|}
\hline & \multicolumn{2}{|c|}{ Male } & \multicolumn{2}{|c|}{ Female } & \multicolumn{2}{|c|}{ Both } \\
\hline & Freq. & $\%$ & Freq. & $\%$ & Freq. & $\%$ \\
\hline No problem & 13 & 18.8 & 9 & $\overline{20}$ & 22 & 19.3 \\
\hline Lack of working capital & 6 & 8.7 & 2 & 4.4 & 8 & 7 \\
\hline Problems with clients paying & 10 & 14.5 & 8 & 17.8 & 18 & 15.8 \\
\hline Lack of fixed capital & 10 & 14.5 & 11 & 24.4 & 21 & 18.4 \\
\hline Lack of fixed and working capital & 15 & 21.7 & 4 & 8.9 & 19 & 16.7 \\
\hline All working capital problems & 31 & 44.9 & 14 & 31.1 & 45 & 39.5 \\
\hline All fixed capital problems & 25 & 36.2 & 15 & 33.3 & 40 & 35.1 \\
\hline All financial problems & 41 & 59.4 & 25 & 55.6 & 66 & 57.9 \\
\hline Lack of customers/market & 5 & 7.2 & 6 & 13.3 & 11 & $\overline{9.6}$ \\
\hline Availabilty of parts/ material & 5 & 7.2 & 0 & 0 & 5 & 4.4 \\
\hline Other problem & 5 & 7.2 & 5 & 11.1 & 10 & 8.8 \\
\hline & 69 & 99.8 & 45 & 99.9 & 114 & 100 \\
\hline
\end{tabular}

Notes:

According to the respondents; 'problems with clients paying' included: 'clients don't pay for good workmanship'; 'the client don't [sic] pay regularly'; 'clients don't come for their item on time'; 'people refuse to pay money after work is done'; 'inability of customers to pay for charges'. 'Other problems' included: 'luck at getting job and problems with so many taxes'; 'apprentices are undisciplined'; 'too many bills'; 'electricity bill and income tax'; 'want to help poor to acquire a trade, but limited to help them'; 'problem with writing'; 'do not have electricity'; 'land to establish my shop'; and, 'Family pressure'.

Source: Author's fieldwork, 2005

Another survey conducted with MSE owners in rural Ghana in 2003 (Palmer, 2004a) also showed financial problems as ranking high among the concerns of owners (table 8.15). In this survey, respondents were asked to rank different factors on a 5-point scale from 'no problem to 'major problem', and were not just asked about the main problem they faced. 
Table 8.15. Factors considered as 'major ongoing problems' by rural MSE owners in Ghana (multiple responses)

\begin{tabular}{|l|c|}
\hline & $\%$ \\
\hline Profits too small to reinvest & 34 \\
Lack credit to buy large item & 32 \\
Too much competition & 30 \\
Problems with equipment & 21 \\
Cost of credit & 13 \\
Lack of working capital & 25 \\
Access to raw materials & 19 \\
Low purchasing power & 15 \\
Lack of demand & 10 \\
Other markting problems & 15 \\
Community obligations & 13 \\
Family obligations & 11 \\
Getting title to land & 18 \\
Poor Infrastructure & 15 \\
Other government regulations & 16 \\
Lack of electricity/water & 13 \\
Uncertain about future & 11 \\
Managerial ability of owner & 3 \\
Lack of training for owners & 5 \\
Availability of skilled labour & 8 \\
\hline
\end{tabular}

Source: Palmer, 2004a: 58

The difficulty of accessing finance has repercussions for the scale of business that can be achieved. For example, two hairdressers interviewed (fieldwork, 2005) commented that their inability to afford a hair-dryer was a big problem as, without it, they find it hard to attract customers who want their hair dried the same day and they are forced to reduce their charges to attract customers

Looking again at the results of the 2005 rural MSE interviews, it is clear that among the three trades of dressmaking, hairdressing and carpentry, carpenters appear least likely to have no problem: $24 \%$ of dressmakers, $14 \%$ of hairdressers and $8 \%$ of carpenters indicated they were not constrained by ongoing problems. For carpenters, working capital constraints were by far the most pressing issue and appeared to be more so than in the other two trade areas: $54 \%$ of carpenters, compared to $33 \%$ and $30 \%$ of hairdressers and dressmakers respectively mentioned working capital problems. Lack of demand was felt most by hairdressers (19\%) and carpenters (17\%) (table 8.16). 
Table 8.16. Ongoing problems faced by rural MSEs (by selected trade area)

\begin{tabular}{|c|c|c|c|c|c|c|}
\hline & \multicolumn{2}{|c|}{ Dressmaking } & \multicolumn{2}{|c|}{ Hairdressing } & \multicolumn{2}{|c|}{ Carpentry } \\
\hline & Freq. & $\%$ & Freq. & $\%$ & Freq. & $\%$ \\
\hline No problem & 8 & 24.2 & 3 & 14.3 & 2 & 8.3 \\
\hline Lack of working capital & 1 & 3 & 1 & 4.8 & 2 & 8.3 \\
\hline Problems with clients paying & 7 & 21.2 & 3 & 14.3 & 3 & 12.5 \\
\hline Lack of fixed capital & 8 & 24.2 & 5 & 23.8 & 3 & 12.5 \\
\hline Lack of fixed and working capital & 2 & 6.1 & 3 & 14.3 & 8 & 33.3 \\
\hline All working capital problems & 10 & 30.3 & 7 & 33.3 & 13 & 54.2 \\
\hline All fixed capital problems & 10 & 30.3 & 8 & 38.1 & 11 & 45.8 \\
\hline All financial problems & 18 & 54.5 & 12 & 57.1 & 16 & 66.7 \\
\hline Lack of customers/market & 2 & 6.1 & 4 & 19 & 4 & 16.7 \\
\hline Availabilty of parts/ material & 0 & & 0 & 0 & 2 & 8.3 \\
\hline Other problem & 5 & 15.2 & 2 & 9.5 & 0 & 0 \\
\hline & 33 & 100 & 21 & 100 & 24 & 99.9 \\
\hline
\end{tabular}

Source: Author's fieldwork, 2005

Given that working and fixed capital problems represent the most pressing constraints to rural MSEs - according to the owners - what strategies are adopted to help ease this situation?

Evidence from rural Ghana suggests that MSE owners use multiple strategies to compensate for the lack of working capital in their enterprises (fig.8.3). One survey indicated that: nearly a quarter of owners obtain financial advances from customers in order to complete an order; $11 \%$ acquire working capital from suppliers; $10 \%$ acquire working capital from apprenticeship fees; $12 \%$ from labouring work; $8 \%$ from farming work; and 15\% from Rotating Savings and Credit Associations (ROSCAs) (Palmer, 2004a). ${ }^{392}$

\section{Fig. 8.3. Strategies adopted to finance working capital costs}

a) Retained profits from previous sales (might be saved in ROSCAs or rural bank for example).

b) Total advance payment from customer

- either in cash and/or materials.

c) Partial advance payment from customer

- either in cash and/or materials.

d) Loan from friends / relatives.

e) Cross-financing from other owned enterprises, pawning of labour or farming work.

f) Credit from suppliers.

g) Use of apprentice fees.

Source: Palmer, 2004a: 44

${ }^{392}$ ROSCAs are a widely used, effective and cheap savings mechanism in Africa (Ardener and Burman, 1996). 


\subsubsection{Occupational pluralism among rural masters}

Undertaking other informal self- or wage-employment in order to complement a main enterprise activity therefore appears a logical option in rural Ghana. Indeed, as noted earlier, occupational pluralism - owners operating multiple enterprises - in rural Ghana is widespread and growing in importance (chap.2.3). Research from rural Ghana suggests that nonfarm enterprises are more likely to be used to finance the start-up of a new enterprise rather than contribute to the working capital needs of existing nonfarm enterprises (Palmer, 2004a). Buckley (1996) suggests that one reason that owners might have for shifting money from one enterprise to another is to 'conceal' their wealth from family and community members who might otherwise act as a drain on the business (cf. Palmer, 2004a). However, with respect to cash-crop farming, the evidence from rural Ghana suggests that a two-way cross-financing does occur between farming enterprises and the working capital needs of nonfarm enterprises (Palmer, 2004a). Undertaking cash-crop farming at the same time as a main nonfarm enterprise, therefore, appears to be important for the survival of some rural enterprises.

Table 8.17 shows that $40 \%$ (46/114) of all masters interviewed indicated that they worked in an additional income-generating enterprise activity: $25 \%$ small-scale farming, ${ }^{393} 9 \%$ retail activity and $6 \%$ other. $^{394}$

\section{Table 8.17. Primary additional income-generating enterprise activity of master- craftspeople}

Count
\begin{tabular}{|ll|r|r|r|r|r|}
\hline & \multicolumn{4}{|c|}{ Pluri-activity } & \multirow{2}{*}{ Total } \\
\cline { 2 - 5 } & \multicolumn{1}{|c|}{ None } & Farming & Retail Ent & \multicolumn{1}{c|}{ Other } & \multicolumn{1}{|c|}{69} \\
Sex of & Male & 34 & 25 & 4 & 6 & 45 \\
MC & Female & 34 & 4 & 6 & 1 & 114 \\
Total & & 68 & 29 & 10 & 7 & 7 \\
\hline
\end{tabular}

Source: Author's fieldwork, 2005

Male masters were more likely to have additional income-generating enterprise activities than women. $50 \%$ of all men (35/69), compared to $24 \%$ of all women (11/45), reported an additional

\footnotetext{
393 'Farming' here refers to small-scale cash crop farming, not subsistence agriculture or 'chop crops' as they are known.

${ }^{394}$ Other included: driving; renting out sewing machines; composing songs; vehicle body repair; painting; renting a room.
} 
(farm or nonfarm) enterprise activity. This figure is likely to be an underestimate of additional activities done by the masters, particularly the female masters. Respondents were asked to report on additional income-generating enterprise activities that they undertook in addition to their trade activity. Women, in particular, engage in numerous forms of subsistence or non-paid work or activities that contribute directly to the overall wellbeing of their households, even though no income is generated per se. Table 8.18. Primary additional income-generating enterprise activity, by trade and
sex, among those interviewed

\begin{tabular}{|c|c|c|c|c|c|c|c|}
\hline \multirow[b]{2}{*}{ Sex of MC } & & & \multicolumn{4}{|c|}{ Pluri-activity } & \multirow[b]{2}{*}{ Total } \\
\hline & & & None & Farming & Retail Ent & Other & \\
\hline \multirow[t]{13}{*}{ Male } & Type of & Dressmaking & 5 & 5 & 0 & 0 & $\overline{10}$ \\
\hline & Enterprise & Carpentry & 12 & 8 & 1 & 3 & 24 \\
\hline & & Mechanics & 3 & 1 & 1 & 1 & 6 \\
\hline & & Masonry & 1 & 2 & 0 & 1 & 4 \\
\hline & & Electronics & 4 & 1 & 0 & 0 & 5 \\
\hline & & Shoemaker & 2 & 3 & 2 & 0 & 7 \\
\hline & & Welder & 4 & 0 & 0 & 1 & 5 \\
\hline & & Artist & 0 & 1 & 0 & 0 & 1 \\
\hline & & Vulcanizer & 0 & 2 & 0 & 0 & 2 \\
\hline & & Bike repairer & 1 & 1 & 0 & 0 & 2 \\
\hline & & Fridge repairer & 2 & 0 & 0 & 0 & 2 \\
\hline & & Other & 0 & 1 & 0 & 0 & 1 \\
\hline & Total & & 34 & 25 & 4 & 6 & 69 \\
\hline \multirow[t]{4}{*}{ Female } & Type of & Dressmaking & 21 & 0 & 2 & 0 & 23 \\
\hline & Enterprise & Hairdressing & 13 & 4 & 3 & 1 & 21 \\
\hline & & Other & 0 & 0 & 1 & 0 & 1 \\
\hline & Total & & 34 & 4 & 6 & 1 & 45 \\
\hline
\end{tabular}

Source: Author's fieldwork, 2005

Table 8.18 suggests that the need for additional income-generating activities is higher in some trade areas than others. In carpentry and tailoring, 50\% (12/24 and 5/10 respectively) of respondents have second income enterprises, compared to 38\% (8/21) of hairdressers and just $9 \%$ $(2 / 23)$ of (female) dressmakers. The small number of masters in other trade areas makes any generalisations difficult, but the data suggests that artists, vulcanizers, shoemakers and builders (masonry), as well as carpenters and tailors rely on secondary income activities to a greater degree than do dressmakers, hairdressers, welders or electronics repair enterprises. Among carpenters in the survey, $33 \%(8 / 24)$ were engaging in small-scale cash-crop farming in addition 
to their carpentry enterprise. Given the working capital problems faced by carpenters (table 8.16) and the evidence that farming activities are often used to support nonfarm activities in rural areas (Palmer, 2004a), it is likely that many of these farmers in the survey are using their farming in this manner too - to financially support their carpentry activities.

The interviews with MSE owners (2005) appears to suggest that the way an enterprise was financed in the start-up phase has an effect on whether the owner engages in other incomegenerating activities later on (table 8.19).

Table 8.19. Source of start-up capital and later incidence of occupational pluralism (\%'s refer to \% of those with a particular source of start-up capital)

\begin{tabular}{|c|c|c|c|c|c|}
\hline \multirow{2}{*}{$\begin{array}{l}\text { Occupational pluralism } \\
\text { Source of start-up }\end{array}$} & \multicolumn{2}{|c|}{ No other income } & \multicolumn{2}{|c|}{ Other income activity } & \multirow[b]{2}{*}{ Total } \\
\hline & Freq. & $\%$ & Freq. & $\%$ & \\
\hline $\begin{array}{l}\text { Spouse } \\
\text { Parents/other relatives }\end{array}$ & $\begin{array}{r}7 \\
26\end{array}$ & - & $\begin{array}{r}2 \\
12\end{array}$ & $\overline{-}$ & $\begin{array}{r}9 \\
38\end{array}$ \\
\hline Family & 33 & 70.2 & 14 & 29.8 & 47 \\
\hline Farming & 2 & - & 9 & - & 11 \\
\hline Starting small & 8 & - & 5 & - & 13 \\
\hline Other self-finance & 16 & - & 5 & - & 21 \\
\hline Self-Employment (informal) & 26 & 57.7 & 19 & 42.2 & 45 \\
\hline Working for master & 4 & - & 7 & - & 11 \\
\hline Labouring & 3 & - & 4 & - & 7 \\
\hline Wage Employment (informal) & 7 & 38.9 & 11 & 61.1 & 18 \\
\hline Other & 2 & - & 2 & - & 4 \\
\hline & 68 & F- & 46 & $\overline{-}$ & $\overline{114}$ \\
\hline
\end{tabular}

Source: Author's fieldwork, 2005

Table 8.19 suggests that masters whose start-up finance came from their family were less likely to be undertaking other income generating activities. Conversely, masters that financed their enterprise start-up through informal self- or wage-employment were more likely to be undertaking other income generating activities after start-up. ${ }^{395}$ Of those masters that obtained their start-up capital from their family (47/114), only 30\% were pursuing some other form of income generating activity at the time of interview. In contrast, of those masters that obtained start-up capital through informal self- or wage-employment, $42 \%$ and $61 \%$ respectively were pursuing some other form of income generating activity at the time of interview.

\footnotetext{
395 This relationship does not necessarily imply causation.
} 
The interview data with the MSE owners suggests that - if one measure of a successful enterprise is its longevity - more successful enterprises commonly practice occupational pluralism: only $29 \%(23 / 80)$ of those enterprises aged five years or less reported undertaking additional income generating activities, compared to 68\% (23/34) of those enterprises aged above five years (table $8.20)$.

Table 8.20. Pluri-activity (occupational pluralism) of owners by age of their enterprise

\begin{tabular}{|c|c|c|c|c|c|c|}
\hline & & \multicolumn{4}{|c|}{ Pluri-activity } & \multirow[b]{2}{*}{ Total } \\
\hline & & None & Farming & Retail Ent & Other & \\
\hline \multirow{20}{*}{$\begin{array}{l}\text { Age of } \\
\text { Ent/years }\end{array}$} & 0 & $\overline{5}$ & 0 & 0 & 0 & 5 \\
\hline & 1 & 16 & 5 & 2 & 0 & 23 \\
\hline & 2 & 6 & 3 & 0 & 0 & 9 \\
\hline & 3 & 12 & 3 & 2 & 0 & 17 \\
\hline & 4 & 8 & 1 & 3 & 2 & 14 \\
\hline & 5 & 10 & 2 & 0 & 0 & 12 \\
\hline & 6 & 0 & 3 & 0 & 0 & 3 \\
\hline & 7 & 2 & 0 & 1 & 1 & 4 \\
\hline & 8 & 1 & 3 & 0 & 0 & 4 \\
\hline & 9 & 1 & 2 & 0 & 1 & 4 \\
\hline & 10 & 3 & 1 & 0 & 0 & 4 \\
\hline & 11 & 0 & 0 & 0 & 1 & 1 \\
\hline & 14 & 0 & 0 & 1 & 0 & 1 \\
\hline & 15 & 3 & 1 & 0 & 1 & 5 \\
\hline & 18 & 0 & 1 & 0 & 0 & 1 \\
\hline & 20 & 0 & 2 & 0 & 0 & 2 \\
\hline & 21 & 1 & 0 & 0 & 0 & 1 \\
\hline & 24 & 0 & 1 & 0 & 0 & 1 \\
\hline & 25 & 0 & 1 & 0 & 0 & 1 \\
\hline & 28 & 0 & 0 & 1 & 1 & 2 \\
\hline Total & & 68 & 29 & 10 & 7 & 114 \\
\hline
\end{tabular}

Source: Author's fieldwork, 2005

\subsubsection{Summary}

Over $60 \%$ of owners interviewed started their self-employment activities between the ages of 1924. Only a few (9\%) started self-employment at age 18 or less. Carpenters seemed to enter selfemployment at an earlier age than other trade areas (nearly $90 \%$ had started by age 24), implying that entry is easier into this trade area, probably related to the differential costs of start-up for different trade areas. 
Once self-employment commenced, masters did their best to attract apprentices to their enterprise. Taking on apprentices, however, appears to be easier for carpenters and masons than it is for dressmakers and hairdressers. Owners interviewed revealed that financial problems were their biggest problems. Multiple strategies are adopted to overcome working capital needs. One strategy involves entering into other forms of self-employment - engaging in occupational pluralism. In the interviews, $40 \%$ of owners indicated that they undertook another income generating activity. Those that had been financed by the family, mainly women and hairdressers, were least likely to have additional income generating activities. In contrast, those that had to find start-up capital principally from their own resources were more likely to be engaging in multiple activities. For example, $50 \%$ of carpenters interviewed indicated that they had other income generating activities.

\subsection{Conclusion: typical pathways to self-employment in rural Ghana}

The pathways to self-employment identified through the interviews are related to the typical pathways noted earlier (chap.3.3.2) but are, usually, much more complex. It is not the intention to list all the possible pathways identified but, rather, to show some of the more common routes.

The first pathway relates to Model B: enterprise-based training followed by wage-employment, followed by self-employment (fig.8.4). This is illustrated in the following two cases:

Akua did not complete middle school. She trained in a hairdressing apprenticeship for two years under her sister's guidance who had her own enterprise. After her apprenticeship, Akua went to work for a different hairdresser for one year to 'test if [she] can be self-employed'. The money she saved during this year was used to start up her own hairdressing store in Otaakrom. (interview, 29.01.05)

After JSS, Victor trained in an electronic repair apprenticeship for $2 \frac{1 / 2}{2}$ years. After the apprenticeship, he did labouring for 2 years to save up money to start up his enterprise. (interview, 12.03.05) 


\section{Fig.8.4.}

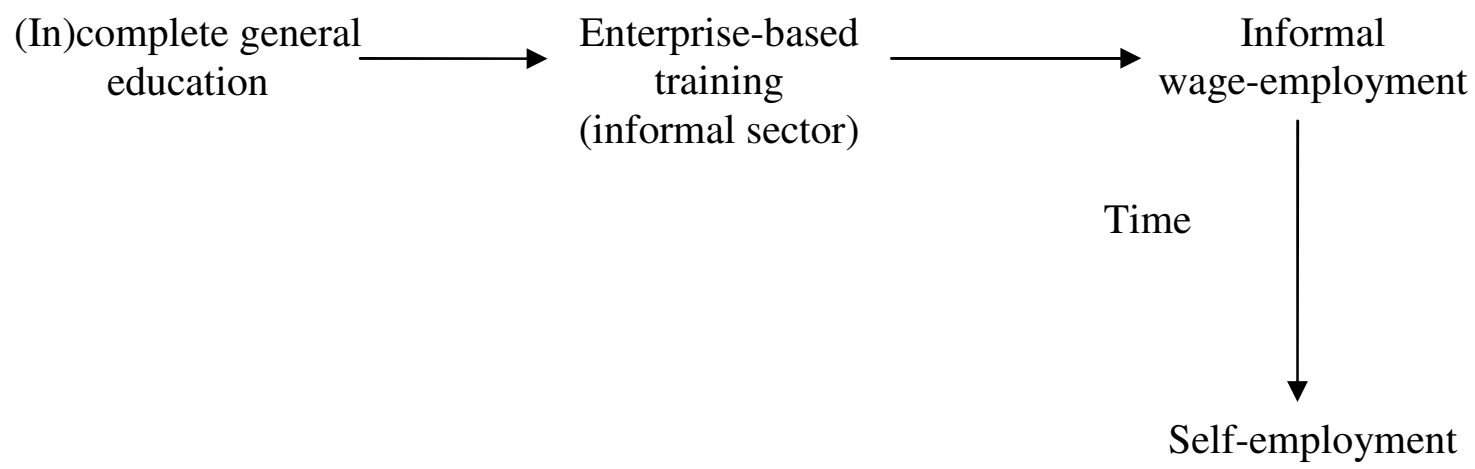

The second pathway (fig.8.5 \& 8.6) combines Models B + C, but also highlights the common practice of engaging in informal wage-employment (usually labouring or weeding) in order to save money to do an apprenticeship or pay for schooling. Among the apprentices interviewed (chap.7.6), while the average education level was a complete basic education (ending at age 16/17), the average age of starting an apprenticeship was 19 years: part of this 2-year gap between completion of JSS and starting apprenticeship may be filled with earning money to finance an apprenticeship, as well as waiting for the BECE results and, perhaps, trying to gain admission into formal second-cycle institutions, including SSS. After the apprenticeship both (in)formal wage-employment and MESE activities are used to raise start-up capital. This is illustrated by the following two cases:

After finishing JSS in 1991, David did day labouring for two years to earn money for a tailoring apprenticeship. After his apprenticeship he did more day labouring as well as small-scale ad hoc tailoring work in order to start-up his business. (interview, 10.01.05) 
Fig.8.5.

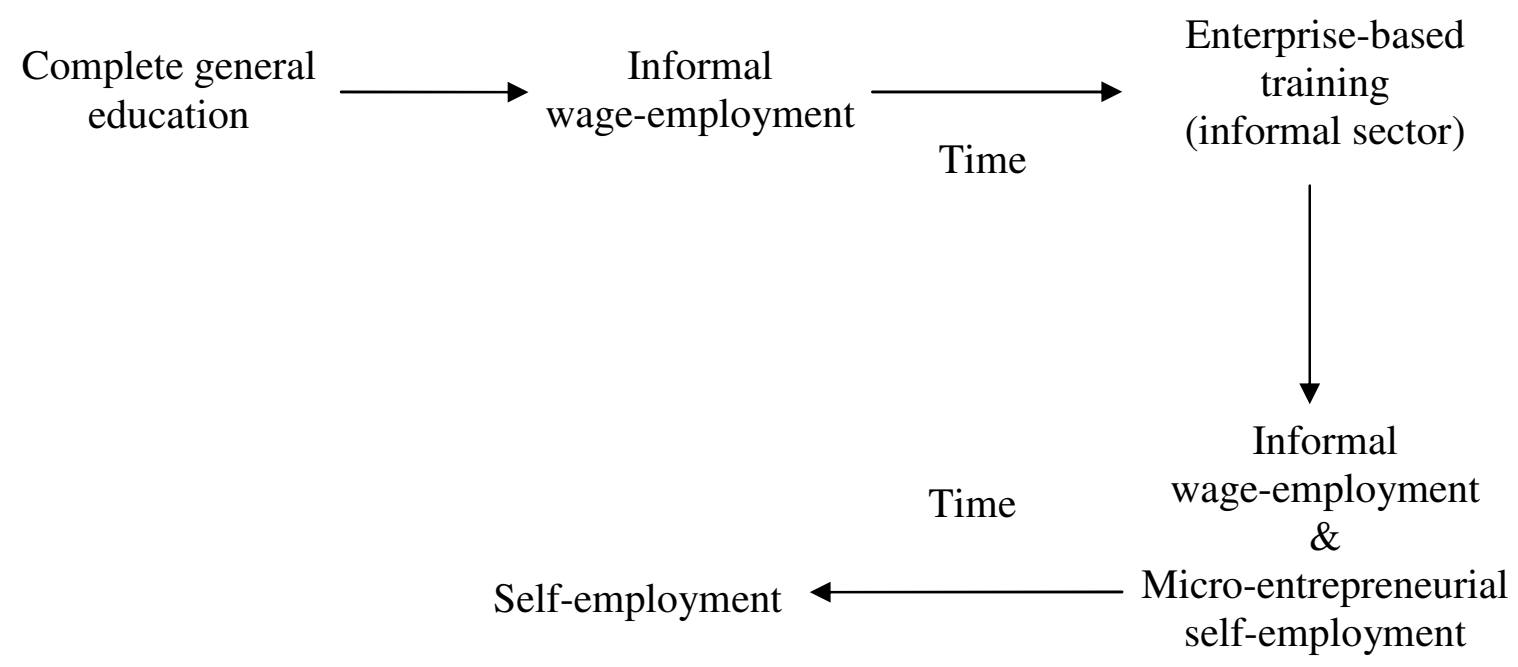

Anthony, an old rural tailor, describes his pathway to self-employment:

When I was five I saw some children going to school so I followed them, but I could not get help [to afford school], so I went to some cassava farmers and asked them if I could weed for them to get money. I did this until I was about nine years. In 1965 I finished middle school, and stayed idling until about 1969 before I know that they [parents] cannot help me so I should help myself. So I went to a certain tailor to learn from him. Before that he realized I am learning it was about three months. I used to make notes how to sew. The first day I was there I opened his measurement book and learnt something the measurement he was using to cut one shirt or one trouser. So I write. After three months I know that I am qualified, so I went to Kumasi Ministry and asked a certain man to give me appointment letter to go and teach. I was a supply teacher. So through teaching I got some money, and went to a certain man to buy this [sewing] machine. It was from these Lagos people [Nigerians] who they were driving from Ghana [with the Alien Compliance Order]. I taught for about one year four months. When I worked [on tailoring] in the holidays and saw the money that I could get I stopped the teaching. (interview, 17.07.03) 
Fig.8.6.

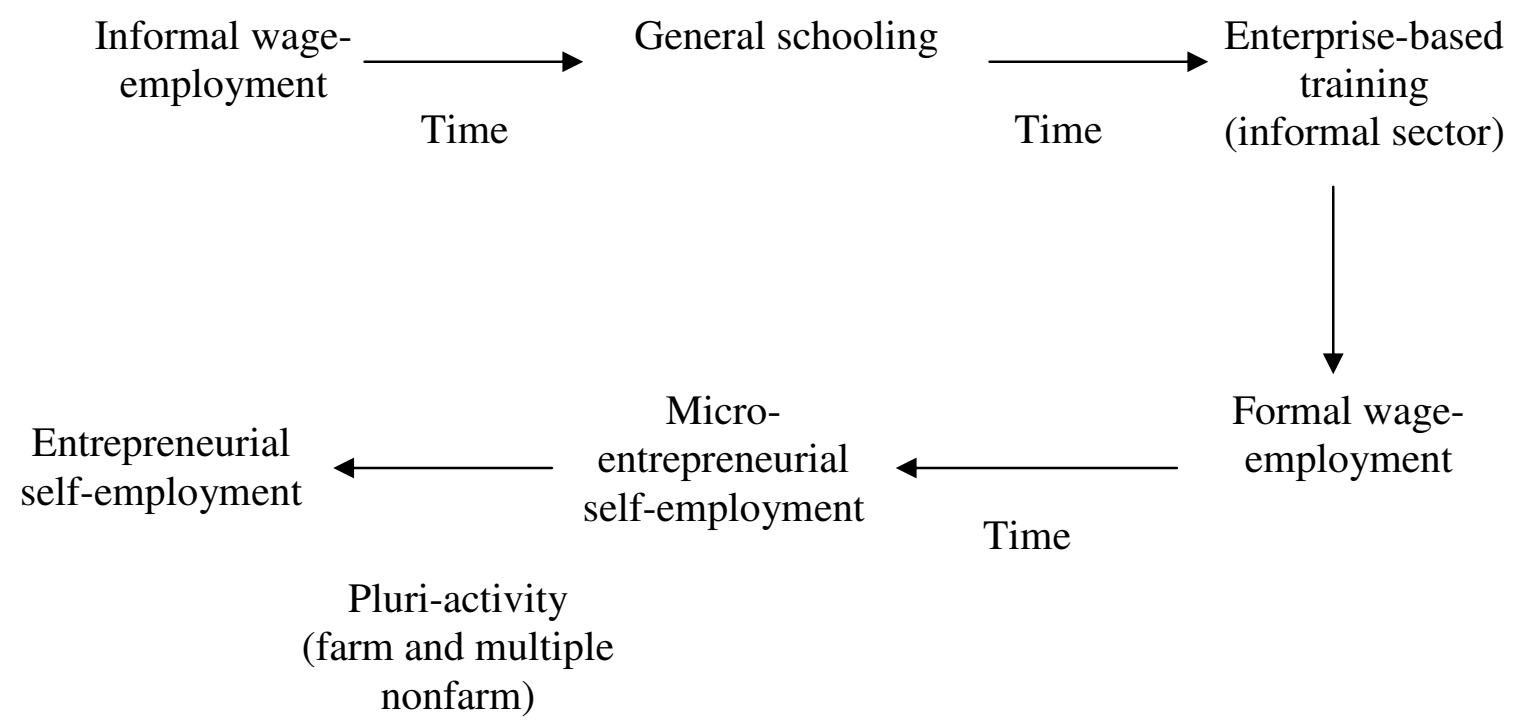

The third pathway (fig.8.7) is similar to Model C: informal enterprise-based training followed by MESE activities to finance start-up costs. This is illustrated below:

Isaac finished JSS and then undertook a three year carpentry apprenticeship, during which he saved his 'chop money ${ }^{, 396}$ so that he could purchase tools. 'After I had the tools, people brought the jobs [with an advance] and I could do the work'. Six months after he finished his own apprenticeship he took on apprentices to train and used the fees that they paid to buy more materials. (interview, 11.01.05)

${ }^{396}$ Daily food money (chap.7.9.1). 


\section{Fig.8.7.}

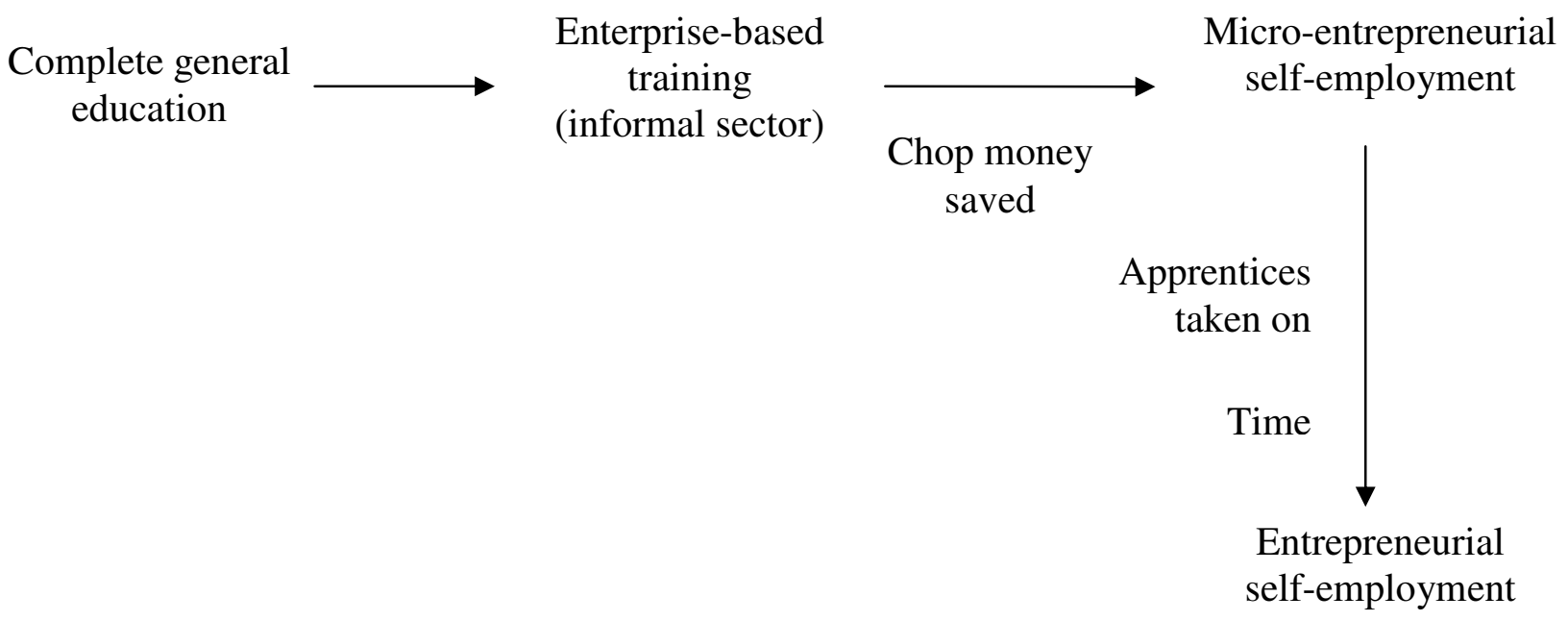

The fourth pathway, anticipated in Model $\mathrm{H}$ involves acquiring skills from multiple sources prior to self-employment. The first case (fig.8.8) involves combining VTI-based training with informal enterprise-based training and also highlights the importance of family support in the post apprenticeship period. This is illustrated below:

After completing JSS, Alima went to the village ICCES centre to learn hairdressing, but dropped-out after one year as the hairdressing instructor left and was not replaced. She did a hairdressing apprenticeship for 8 months. She did not get any certificates from her training and continued to work with her former mistress for just over a year until her mistress left the village in 2004. Alima then started out on her own, with support from her mother, and took over the 'pitch' and customers of her mistress, but gradually lost most of them as she no longer had access to a hair-dryer (her mistress took it with her when she left, and Alima can't afford to buy her own). (interview, 03.03.05)

After JSS Issah started to learn dressmaking in the village ICCES centre, but dropped-out after about 2 years of the course as she did not think the practicals were very extensive and the ICCES lacked instructors. After leaving ICCES she did labouring for three months to earn enough money to do a dressmaking apprenticeship in a nearby town. On completion she started her own dressmaking enterprise from her family's house using her dead mother's sewing machine (interview, 03.02.05). 
Fig.8.8.

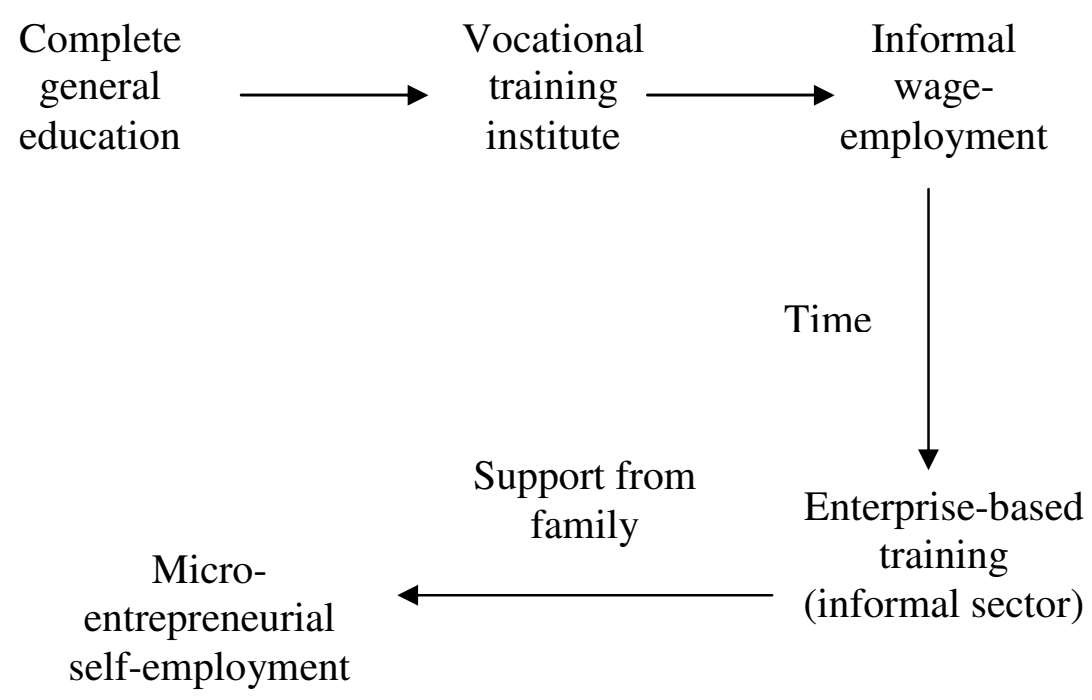

The second case (fig.8.9) involves acquiring skills through multiple informal enterprise-based training:

Doris did not complete middle school. She trained as a hairdresser for five years in three different places so as to acquire a wider understanding of hairdressing from different sources. After her apprenticeship, she worked for an established hairdresser for four years and was able to save money so she could start her own business. Her main problem at the moment is how to acquire her own store from which to conduct business from. At the moment she works from the house. She says that it is difficult to get apprentices without having your own store. (interview, 29.01.05) 
Fig.8.9.

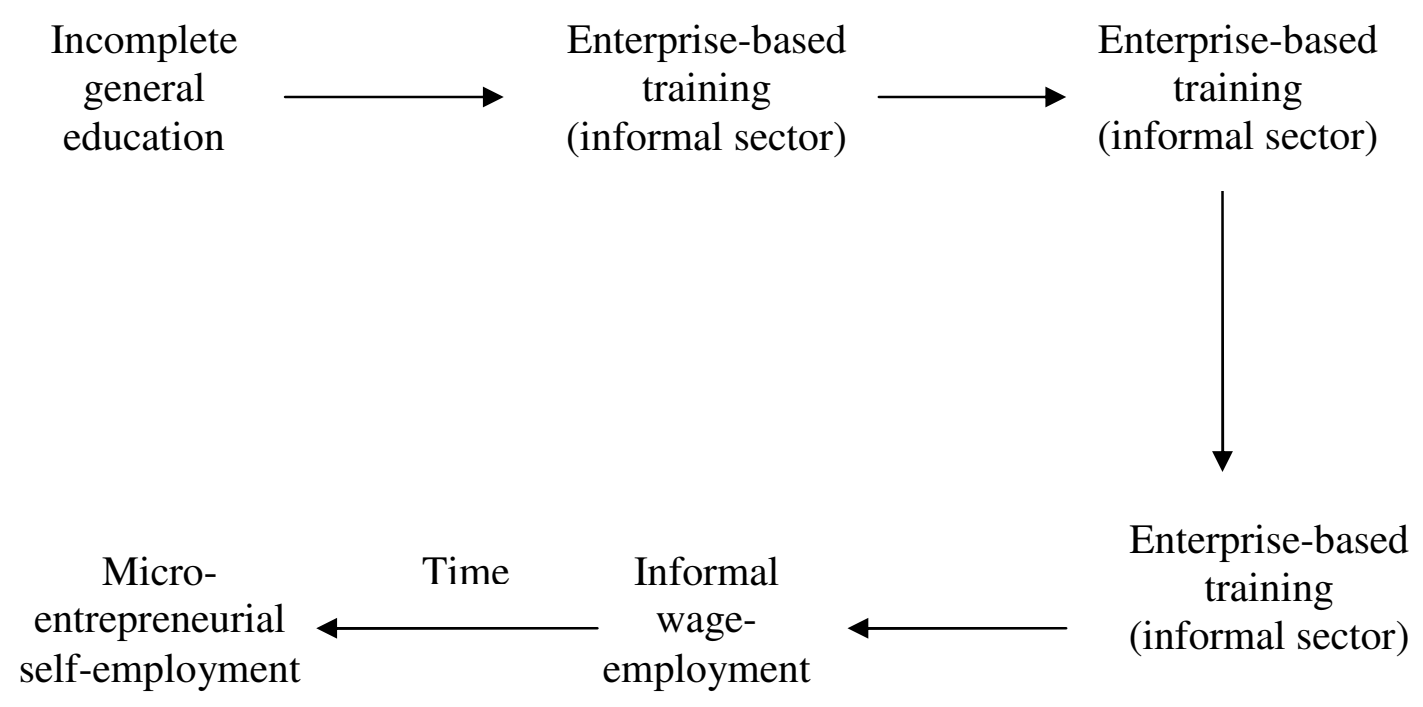

These illustrations (figs.8.4-8.9) highlight three important points concerning the pathway to selfemployment for these masters. First, for the vast majority of all masters interviewed the acquisition of skills through formal training was either minimal or absent: most had acquired their skill in traditional apprenticeship training. Second, it is quite common for youth to self-finance this apprenticeship training through a period of prior informal wage-employment. Third, the issue of time appears crucial, particularly post-training: for most youth the pathway to self-employment is drawn out. Multiple strategies are used to find the required start-up funds, including working for periods in informal wage-employment, MESE activities or sourcing start-up support from the family.

Based on the discussions from this chapter and chapter 7 it is also possible to map out some typical pathways to self-employment for specific trade areas in rural Ashanti: hairdressing and dressmaking for females and carpentry and tailoring for males (figs.8.10, 8.11, 8.12, 8.13) 


\section{Fig.8.10. Typical pathway to self-employment in a rural hairdressing enterprise (females)}

TIME

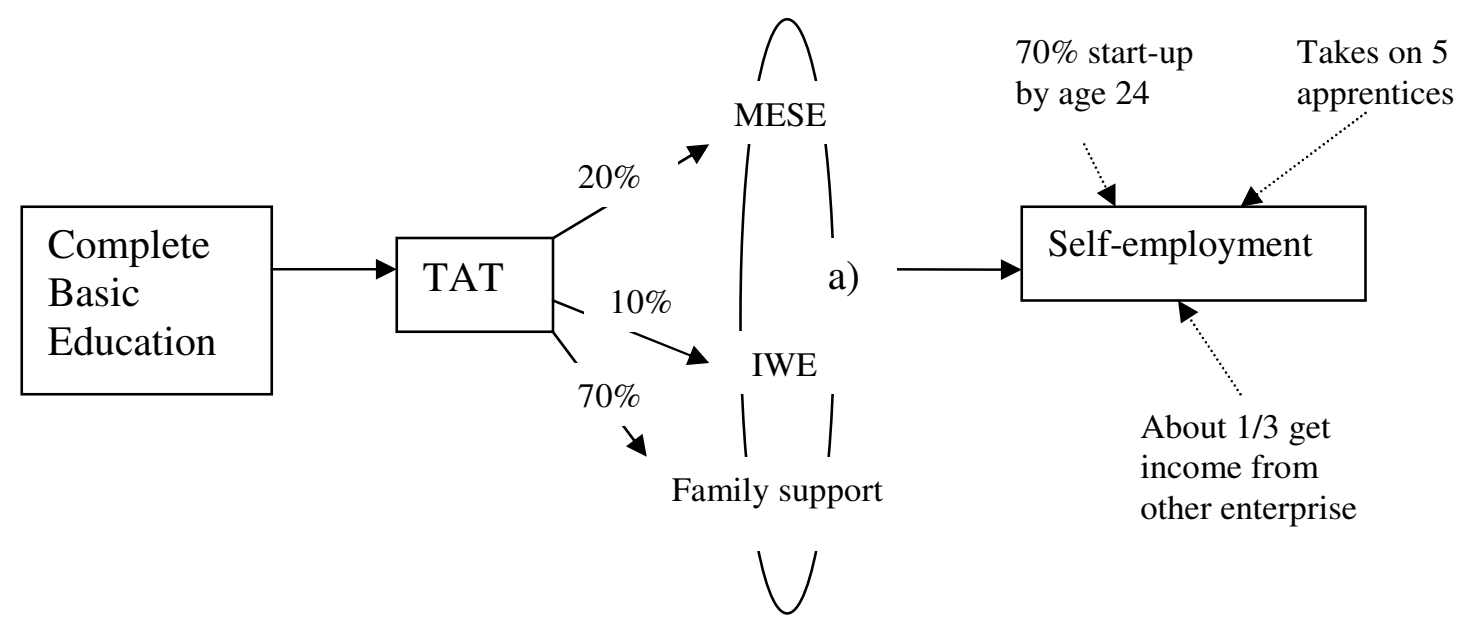

Legend:

TAT - traditional apprenticeship training

MESE - micro-entrepreneurial self-employment

IWE - informal wage-employment

a) Usually starts out working from home

A typical route to hairdressing in rural Ashanti involves a female completing basic education (9 years of schooling) by age 16/17. After about 2 years, during which time the girl waits for her BECE results (about 6 months) and then either tries to seek admission to other second-cycle institutions and/or tries to earn some money to pay for an apprenticeship, a three-year apprenticeship commences.

After finishing the apprenticeship there is a gap of about 3 years during which the graduate apprentice seeks support to start the enterprise. Most (70\%) get support from their family, while others get support from MESE activities (20\%) or informal wage-employment. ${ }^{397}$

About $70 \%$ will be able to start-up by age 24 and gradually take on apprentices to a maximum of about 5. After a couple of years of business about one-third of new enterprises start other enterprises to supplement their income.

\footnotetext{
${ }^{397}$ These categories are not mutually exclusive. Multiple sources of start-up are common. This applies also to figs.8.11, 8.12 and 8.13.
} 


\title{
Fig.8.11. Typical pathway to self-employment in a rural dressmaking enterprise (females)
}

\author{
TIME
}

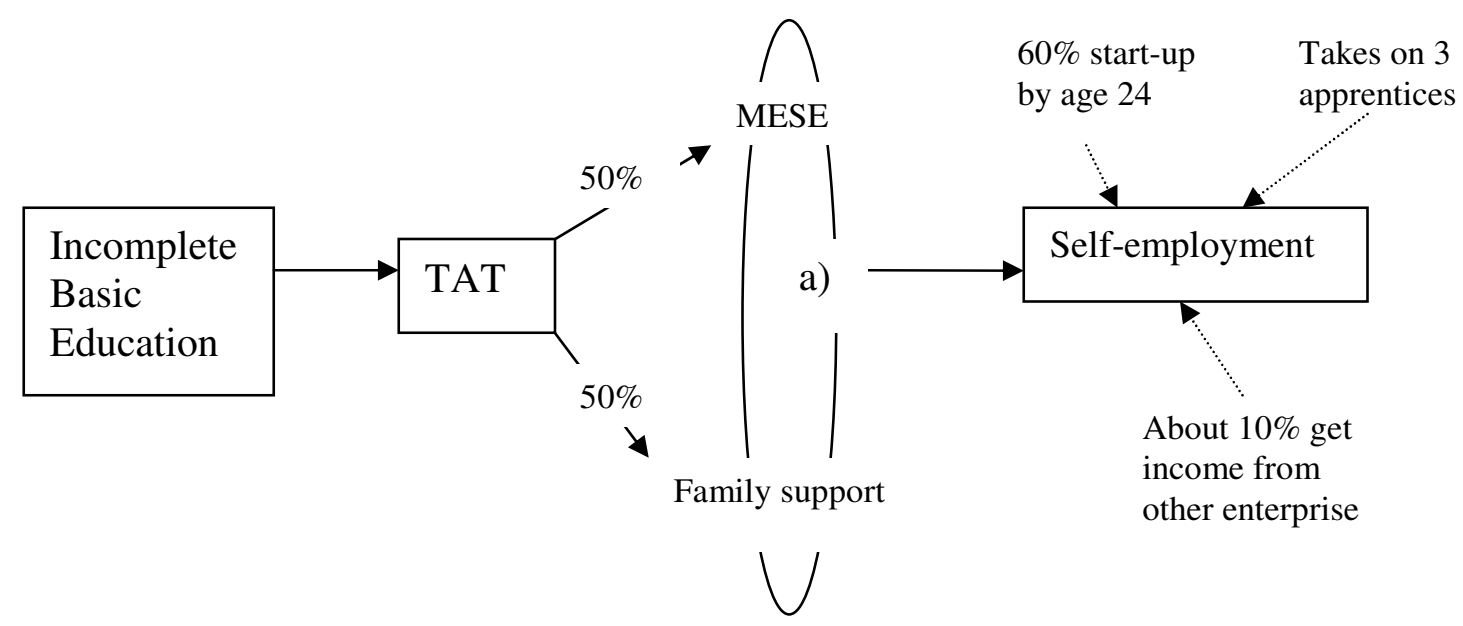

Legend:

TAT - traditional apprenticeship training MESE - micro-entrepreneurial self-employment

a) Usually starts out working from home

A typical route to dressmaking in rural Ashanti involves a female not completing basic education. At the age of about 17, perhaps after having earned money to pay for the fees, a three-year apprenticeship commences.

After finishing the apprenticeship there is a gap of about 4-5 years during which the graduate apprentice seeks support to start the enterprise. Half get support from their family, while the other half save money through MESE activities.

About $60 \%$ will be able to start-up by age 24 and gradually take on apprentices to a maximum of about 3. After a couple of years of business about one-tenth of new enterprises start other enterprises to supplement their income. 


\section{Fig.8.12. Typical pathway to self-employment in a rural tailoring enterprise (males)}

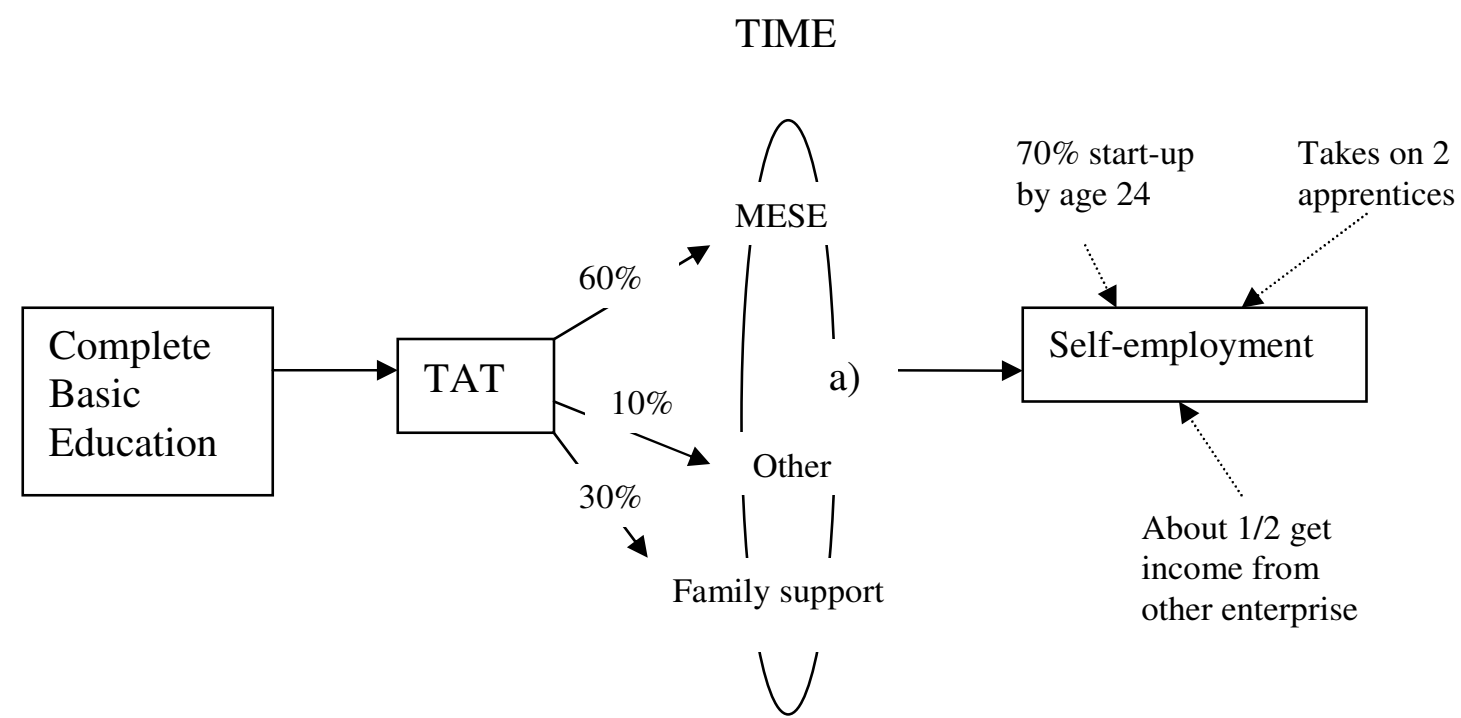

Legend:

TAT - traditional apprenticeship training MESE - micro-entrepreneurial self-employment

a) Usually starts out working from a temporary worksite (e.g. under a shady tree)

A typical route to tailoring in rural Ashanti involves a male completing basic education by age 16/17. After about 2 years, a three-year apprenticeship commences.

After finishing the apprenticeship there is a gap of about 2-3 years during which the graduate apprentice seeks support to start the enterprise. Most (60\%) get support from MESE activities, while about $30 \%$ get support from their family.

About $70 \%$ will be able to start-up by age 24 and gradually take on apprentices to a maximum of about 2. After a couple of years of business about one-half of new enterprises start other enterprises to supplement their income. 


\section{Fig.8.13. Typical pathway to self-employment in a rural carpentry enterprise (males)}

TIME

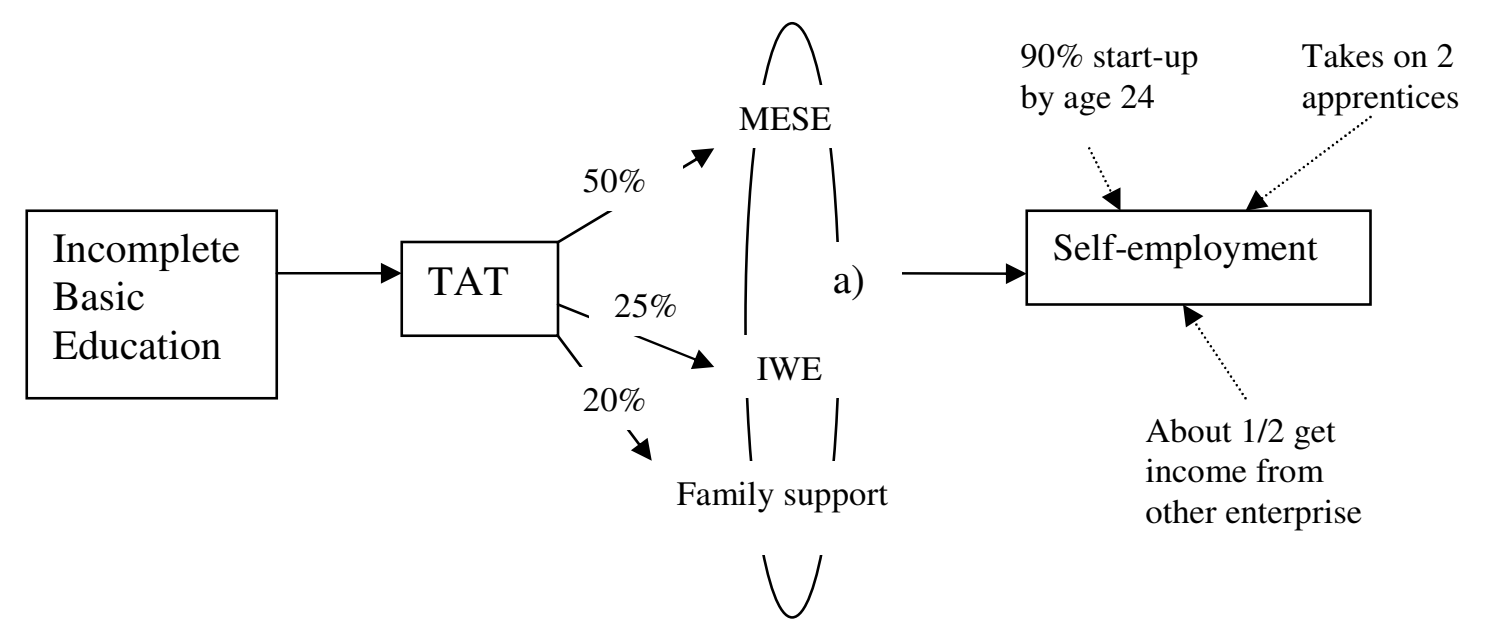

Legend:

TAT - traditional apprenticeship training MESE - micro-entrepreneurial self-employment

IWE - informal wage-employment

a) Usually starts out working from a temporary worksite (e.g. under a shady tree)

A typical route to carpentry in rural Ashanti involves a male not completing basic education. At the age of about 17, perhaps after having earned money to pay for the fees, a three-year apprenticeship commences.

After finishing the apprenticeship there is a gap of about 4 years during which the graduate apprentice seeks support to start the enterprise. Half save money through MESE activities, while a quarter do so through informal wage-employment. One-fifth get support from their family and a further $5 \%$ from elsewhere.

About $90 \%$ will be able to start-up by age 24 and gradually take on apprentices to a maximum of about 2. After a couple of years of business about one-half of new enterprises start other enterprises to supplement their income.

These four diagrams above (figs.8.10-8.13) highlight a number of aspects of the school-skillenterprise relationship. In all cases there is a time component in this relationship; both before 
apprenticeship training, but especially after completing apprenticeship. Females are more likely to receive support from their families, especially if they are also able to see these girls through a complete basic education, when compared to males. While males are more reliant on their own initiative vis-à-vis finding start-up capital, they are also more likely to start enterprises earlier than females. Females in dressmaking and hairdressing take on more apprentices but engage less in occupational pluralism than males in carpentry and tailoring. 


\section{Chapter 9: Skills Development, Enabling Environments and Informal Micro- Enterprise in Ghana}

\subsection{The study's contribution to knowledge}

This study has been concerned with rethinking education, skills training and the informal sector in relation to their enabling environments. It has examined the history of the interaction amongst school, skill and enterprise (chap.3) as well as the history of the concept of the informal sector, and of pluri-activity (chap.2). It has sought to make a contribution to the understanding of the transition from training to self-employment and is the first treatment of the world of skills that takes seriously the perspective of the enabling/disabling environment; in both its delivery and transformative contexts (Palmer et al., 2007) (chap.3). It has examined the repeated and assumed link between TVET and unemployment (chap. 4, 5, 6, 7 and 9.2.1).

This present study also contributes to our understanding of rural development in three ways. ${ }^{398}$ Firstly, by emphasising occupational pluralism and highlighting the blurred nature of the farm/nonfarm divide - which still remains in much of the policy and (some) academic literature (chap.2). ${ }^{399}$ Secondly, it marries the livelihoods and enterprise diversification literatures with the literature on the relationship between schooling and farm outcomes and schooling and nonfarm outcomes (chap.3). Thirdly, it contributes to our understanding of how individuals are accessing these nonfarm enterprises (through skills training and other means) in rural areas (chap.3, 6, 7 and $8)$.

Finally, it has sought to contextualise all these issues, for example by contributing to the understanding of the rural informal sector and the policy history of school, skill and enterprise in Ghana (chap. 4 and 5), and by examining the three main types of skills training modality in the country (chap.6 and 7).

\footnotetext{
${ }^{398}$ For many 'rural' and 'agriculture' are synonymous. This traditional notion of 'rural' sees agriculture as the main sector for employment creation in rural areas. But it is increasingly being acknowledged that there has been, and still is, a transformation of rural labour markets marked by a rise in the importance of nonfarm rural employment.

${ }^{399}$ Though the livelihoods and enterprise diversification literatures, noted in the second point, do recognise occupational pluralism, much of the economics of education literature still discusses farm and nonfarm separately.
} 
This conclusion will cover three major issues: first, it examines the limitations of the study and issues of generalisability; second it re-examines the assumptions of the Ghanaian skills development agenda (chap. 4 and 5) and positions this both in relation to access and equity issues, but also to the larger macro-economic dynamics; third, it comments on the skills development programmes and pathways to rural informal micro-enterprise identified in chapters 6,7 and 8 ; lastly, it outlines some theoretical concerns arising from the study (particularly in relation to chap. 2 and 3). Throughout the conclusion references will be made to supporting evidence in the main body of the thesis.

\subsection{Limitations of the study and generalisability}

How generalisable are the findings of this study to other developing countries and SSA in particular?

In developing countries, like Ghana, where formal job growth is limited, demand for technical and vocational education (TVE) remains weak and yet there is still frequently the false assumption that the provision of skills (without concomitant improvements in the MSE environment or in the formal labour market) will reduce unemployment. But in countries like South Korea, China and Mozambique, where job growth has been sustained in recent years, demand for TVE has been strong (Adams, 2006); hence the link between skills and employment would be stronger and the assumption more true.

All of the three types of training modality examined in this study (pre-employment long term, short term and on-the-job apprenticeships) are to be found in similar forms in other countries in SSA and developing countries in general. However, while traditional apprenticeship training is common in West and Central Africa, it is less prevalent - though still important - in Eastern and Southern Africa (Haan, 2006, King, 1996). In these countries, and others like India, the pathway to IME appears less likely to be dominated by this type of skills acquisition strategy. Nonetheless learning on-the-job, often through casual work, does still appear to be the key method of skills acquisition in many of these countries, though this is not as formalised as it is in Ghana's traditional apprenticeships. More research that examines the transition from training to selfemployment in other countries, particularly those that do not have a history of traditional apprenticeship like Ghana, is needed. 
How generalisable are the findings within Ghana?

The bulk of the information collected during the fieldwork for this study was undertaken in one district of Ashanti (the district capital of Nyinahin and a smaller settlement, Otaakrom). Data from another district capital, Bibiani, was also used. Although Bibiani is technically in the Western Region, it is located right on the boundary of Ashanti and Western Regions, a few kilometres from Nyinahin and Otaakrom. Data was also collected from a total of 7 ICCES centres, all in Ashanti Region. What limitations are placed on the findings of this study, therefore, and how generalisable are the findings to other parts of Ghana?

Ashanti Region is the largest in terms of population in Ghana and, while there are pockets of poverty throughout the region (particularly amongst non-export food crop farmers and others in nonfarm informal employment), it is better off with regards to average poverty levels when compared to all the other regions apart from Greater Accra and Western Region (GoG, 2003a). The rural forest-belt areas of Ashanti had a lower incidence of poverty (21\%) compared to the rural coastal (28\%) or rural savannah areas (59\%) in 1999 (GoG, 2003a). In much of Ashanti cash cropping of cocoa is widespread (unlike in other regions) which offers households increased livelihood opportunities.

Had the data been collected in a district in one of the three northern regions (Upper East, Upper West, Northern Region) - the three poorest regions in Ghana - there might have been differences in the pathways to self-employment. Firstly, when compared to Ashanti, more youth never attend school or drop out early in the three northern regions. It would be less common, therefore, for a pathway to self-employment to include a period of complete basic (or even primary) education. Secondly, there might be differences in the way youth were able to acquire start-up capital for ventures. Outside the cocoa belt of Ashanti there might be less opportunity for youth to earn a wage (informally) doing farm work in the cash-crop sector. Moreover, higher poverty levels might mean that families would be less able to support their children financially vis-à-vis a proposed enterprise venture. With less opportunity to acquire support from their family or from informal wage employment, other avenues to raising capital (e.g. starting small in microentrepreneurial self-employment) might be more important and there may well be a longer period of time required to save sufficient capital than is seen in Ashanti. Furthermore, the higher incidence of poverty would suggest that markets are more constrained in the three northern regions compared to Ashanti. 
What about the specificity of ICCES in Ashanti Region? Where ICCES is concerned, Ashanti Region is widely regarded as the most successful region in terms of organisation and number of (comparatively) developed centres. Indeed, apart from a few notable exceptions from other regions (e.g. Agomeda ICCES in Greater Accra has almost 200 trainees) many other centres in other regions remain under-developed and under-populated. Reports (Brownlee, 2000; Palmer, 2001; Palmer, 2006b) suggest that ICCES in regions other than Ashanti experience similar or worse disabling training conditions when compared to centres in Ashanti. For example, visits by the author to three ICCES centres in the Upper West Region in 2001 revealed a slightly worse state of affairs than was seen in Ashanti at the same time. Centres were desperately short of equipment and infrastructure and the regional coordinator at the time did not even have a permanent office to work from. Detailed fieldwork by the author in Agomeda and Nima 441 ICCES, both in Greater Accra Region, in July 2006 revealed a general lack of equipment and government support (Palmer, 2006b).

Indeed, how comparable is ICCES to other VTIs in Ghana? In many regards ICCES is quite similar to other public (e.g. NVTIs) and private VTIs; many VTIs in Ghana, particularly the public ones, suffer from a lack of equipment and materials (Palmer, 2006b). But there are some noticeable differences. Firstly, ICCES differs from other VTIs in not having a minimum formal education qualification required for entry (though in practice most entrants to ICCES are JSS leavers) (chap.6.1.2). Secondly, the fees charged at ICCES are substantially less than those charged in other types of VTI (chap. 6.1.2; Palmer, 2006b). Thirdly, the organisational structure of ICCES as a whole appears to be significantly weaker than other training agencies like NVTI. For example, there is no board to oversee the affairs of the Directorate, and the Directorate itself appears to lack managerial capacity. The lower cost and different entry requirements, therefore, make ICCES the most likely destination for poorer trainees seeking formal training. In this regard, it is particularly disturbing that ICCES appears to have been so neglected by the government. A total reform of the leadership of ICCES is required.

What of the generalisability of the findings regarding traditional apprenticeship in rural Ashanti? While the general features and characteristics of traditional apprenticeship are similar to other regions of Ghana (and, indeed, elsewhere), differences are likely to be evident vis-à-vis apprenticeship types and fees. Apprenticeship studies in the north, for example, might pick up different kinds of trades not so common in Ashanti (e.g. while the weaving of Kente cloth is 
common in Ashanti, the weaving of smocks is common in the north). Training fees in rural Ashanti are likely to be slightly lower then those charged in urban Ashanti (e.g. Kumasi) or other urban (particularly southern) areas of Ghana. As noted earlier, some apprenticeships in Accra can cost significantly more than the US\$42 average seen in rural Ashanti (chap.7.9.1): e.g. three-years training in well-regarded hairdressing enterprises in Accra cost up to $\not 1.7$ million (US\$188) in addition to several crates of soft drinks and a gift for the master. Though these costs are still significantly lower than the US\$500 subsidy the GoG is proposing to give to masters (chap.5.1).

\subsection{The Ghanaian skills development agenda}

\subsubsection{Underlying assumptions of the Ghanaian skills development agenda}

In Ghana there has been a long history of attempts to vocationalise education and to provide skills for employability (chap.4 and 5). The underlying assumption of the Ghanaian skills development agenda - that skills provision will lead to a reduction in unemployment - has taken a central role in repeated government attempts to promote technical, vocational and agricultural education and training in the country. Over the last century and a half the GoG, and the Gold Coast administration and missionaries before that, have repeatedly tried to make education more relevant to the world of work. During the nineteenth century the underlying assumptions referred to school-based technical and vocational education (TVE) (the 'TVE' of TVET). The colonial period saw the advent of the ' $\mathrm{T}$ ' (training) in formal TVET with training delivered through public works departments, government trade schools and technical institutes. It was not until the 1960s/70s with the Workers Brigades, expansion of Technical Institutes and (N)VTIs, that the 'T' of formal TVET became more widespread in Ghana. This being said, the largest provider of training has always been in the informal apprenticeships.

What is clear is that the argument that vocational education is superior to general education as a preparation for work has received considerable support in Ghana.

Indeed, internationally, the beneficial results of skills development - improved productivity, higher income, service/product diversity - perpetuate the assumption that skills training leads to economic growth and poverty reduction (cf. WGICSD, 2002: 16). But the empirical basis for linking skills development to these kinds of outcomes is limited (King and Palmer, 2006b). 
Similarly, while this assumption is popular in Ghana it is backed up with little evidence. For example, Akyeampong (2005) comments that he:

did not find empirical studies conducted in Ghana that support the economic benefit argument of vocationalization of the secondary school curriculum - for preparing students for paid and self-employment. Many simply assume this to be the case - an assumption which is firmly imbedded in the discourse of TVE in Ghana at both school and policy level. (Akyeampong, 2005: 9, emphasis added)

The research, monitoring and evaluation evidence from Ghana for the impact of skills development on informal micro-enterprise is weak. King and McGrath (2002a: 55) note that "[e]vidence of where students go for employment [after training] is typically weak, save where there is a dominant local employer, such as the Volta River Authority". Those programmes that have been evaluated were externally funded - like the World Bank VSP (World Bank, 1995) and the IFAD/GoG Rural Enterprise Project (GoG/IFAD, 2000). In contrast to these donor-evaluated projects, GoG skills development programmes that target the informal sector - like ICCES (chap.6) and STEP (chap.7) - have been little evaluated. The MoMYE does not really know what happens to ICCES or STEP graduates; it is simply assumed that objectives are reached and that these programmes have a positive impact on their target clients, the unemployed poor or rural youth. Indeed, their very names suggest some kind of semi-automatic link between skills and employment: the Integrated Community Centres for Employable Skills (ICCES) and the Skills Training and Employment Placement Programme (STEP). ${ }^{400}$

The over-riding assumption of the Ghanaian skills development agenda, therefore, is that unemployment among the bulk of the population could be solved through the provision of TVET. But it is possible to break down this assumption into three components:

1. That the provision of pre-vocational subjects in the curriculum, or the creation of VTIs would generate a demand for such an education;

2. That the expectations of parents and students regarding the potential functions of schoolbased TVET and VTIs were congruent with those of the policy makers and politicians;

3. That technical, vocational and agricultural education was the key to economic development as it is more orientated towards the world of work.

\footnotetext{
${ }^{400}$ It was noted earlier (chap.7) that STEP was renamed in 2005.
} 
However, as has been suggested throughout this thesis, each one of these three assumptions - and hence the over-riding assumption - is misleading.

Firstly, simply expanding school or VTI-based TVET will not generate a demand for this kind of education. Only when parents and, more crucially, the youth see sufficient (formal) labour market demand for these skills, and a wage structure that has similar remuneration levels comparable to those that have an academic education, will demand for TVET increase.

The second assumption is related to the first. An issue concerning much vocationalisation policy in Ghana is that policy makers have expected such institutions (e.g. the continuation schools in the 1960s and the vocationalised JSS and ICCES in the late 1980s) to have dual functions; on the one hand they are meant to prepare the youth for (self-)employment by equipping them with skills and, on the other hand, to prepare youth for further study. However, parents and students often use VTIs, not as ways to obtain skills training for work, but, rather as a means to obtain certificates for further education (and hoped for access to better paid jobs in the formal sector). Hence the expected outcomes of TVET promotion from the government's side - the provision of employable skills to the youth so they can enter self-employment - are, to a large degree, subverted by those that enroll in TVET courses. While there will be those with a genuine interest in TVET, many youth enroll in TVET institutions not so they can learn technical and vocational skills per se, but rather because they could not get access to SSS, and TVET institutions provide an alternative pathway to formal employment. That youth and parents are using TVET institutions in this manner not only subverts the original objectives of policy makers, but also gradually transforms schools with a TVET focus into more academic schools, and encourages VTIs to focus more on theory for examinations, rather than practical classes. Hamilton and Asiedu (1987) comment that:

subtle political pressure... tend[s] to transform these [technical] schools progressively into academic institutions, and... in most cases, students did not regard their courses as terminal, leading to artisan work; rather, they saw them as "stepping stones" to enable them to enter professional courses. (p.353)

Akyeampong (2002) also argues that it is nearly impossible to achieve a dual purpose: "TVE subjects come under the strong influence of general education goals that might lead to a corruption of the goals of vocationalization" (ibid.: 45). This is of course particularly a challenge with the weak version (chap.1.2.1) of vocationalisation. 
Lastly, the third assumption about TVET being more orientated to the world of work fails to acknowledge that: i) from the youth's perspective an academic education is often a better preparation for the world of (formal) work and is, in this sense, more vocational than vocational education; and, ii) training itself does not create jobs and the acquisition of skills (in schools, VTIs on on-the-job) in an environment largely unsupportive of enterprise development will not encourage the utilisataion of these skills and hence impede economic growth.

\subsubsection{The Ghanaian skills development agenda: access and equity}

Ghana's formal education system is generally not pro-poor (Palmer, 2005c). For example, research by Addae-Mensah (2000) shows that over $60 \%$ of entrants into the five publicly funded universities are from just 18 SSSs - considered to be elite public boarding schools. Meanwhile, the Ghanaian elite tend to send their children to good quality private primary and JSSs so that their children are better able to access the publicly funded elite senior secondary boarding schools (Palmer, 2005c). Furthermore, while the methodological problems of these studies should be acknowledged, economics of education research from Ghana is increasingly showing that the returns to education are lowest at the primary level and that it is at the post-basic level that returns are now highest (Palmer, 2006a); hence access to the highest paying formal wage jobs increasingly requires SSS education or higher.

With the removal of subsidies at the SSS and tertiary levels in the 1987 reform, combined with an inadequate bursary system and increased competition for places, the poor appear much less likely to get to, for example, the University of Legon than they did at the time Foster was writing his monograph in the mid-1960s. Given that access to the highest levels of Ghana's education system appears to be getting increasingly more difficult, and the better-off segments of society are more able to compete for these places, it is interesting to ask to whom do the underlying assumptions of Ghana's skills development agenda (chap.9.1.1) relate?

It appears that the assumptions of the skills development agenda - concerned with VTI-based, modular and informal on-the-job training - do not appear to be particularly relevant to the elite; this minority is very much focused on formal academic education (to the highest possible level) and generally not found acquiring skills training (other than through the current supposedly vocationalised JSS or at higher levels in polytechnics and universities). 
The Government's proposed skills agenda is wide and includes increasing the global competitiveness of Ghana's human resources, but it is also concerned with the relationship between skill and poverty. Hence, while the assumptions of the skills development agenda appear to relate less to the better-off segments of society, there are questions concerning who is getting access to this training; are the poor and marginalised excluded, or rather do they rapidly drop out, as some anecdotal evidence suggests?

In the formal TVET system the fee structure means that the poor find it hard to access this training. Even ICCES, which has the lowest fees among the public VTIs still find it hard to reach the very poor, and large numbers of poor students (as much as $70 \%$ of a cohort) appear to dropout from some centres (chap.6). While some of the private non-profit VTIs (e.g. Don Bosco) do appear to be successfully targeting and retaining the poor (Palmer, 2006b), other for-profit VTIs appear to offer far fewer opportunities for them.

Hence, while it is probably true to say that the poor are significantly more represented in the formal post-basic TVET system than they are in the formal post-basic academic system, many of the poor (and larger numbers of the very poor) are still not getting access to institution-based skills training. Since large numbers of the poor are not to be found in formal VTI-based training, the assumptions of the skills development agenda relating to the formal TVET system do not apply.

It is the largest private provider of skills training in Ghana - the traditional apprenticeships - that appears able to serve the poor most effectively (though not all and probably not the poorest) (chap.7.9.1). And it is this area that the government is increasingly becoming interested in formalising (see below and chap.5.1).

\subsubsection{The skills development agenda in relation to larger macro-economic dynamics}

During Nkrumah's time, Ghana was very much a "developmental state" (Mkandawire, 1999); it was believed that economic development would come about through a large and active statesector (chap.4). During the later 1960s and the 1970s, "there was a lot more continuity than diminution in the role of the state" (Killick, 2004: 4) as subsequent governments were unsure about whether to oust the Nkrumah model (ibid.). To some extent there was a break from this 
state-led model with the introduction of the SAPs in the early 1980s, and subsequent privatization programmes and reductions in the size of the public sector. In spite of this, however, the state is still responsible for some $50 \%$ of all formal sector jobs (chap.4, table 4.3), and Killick (2004) suggests that this large public sector reflects "faith in a development process led by the state" (p.5).

With the advent of Ghana's new political context following the election of the NPP in 2000 (chap.5), the government has put in place strategies to promote private sector development (PSD) - in trade, industry and the agricultural sectors - as the engine of growth (e.g. GoG, 2005a, 2003c). In parallel to this renewed focus on promoting PSD, the government is in the process of implementing other strategies aimed at stimulating growth and development, for example in: infrastructure (energy, water, roads, communications), ICT, science and technology and health (GoG, 2005a), and reforms in education and TVET (chap.5). Indeed, these kind of parallel strategies for PSD, education, health, infrastructure etc. appear to be in line with much of the international literature regarding the need for large multi-sectoral investments to kick-start sustainable development (Commission for Africa, 2005; UN Millennium Project, 2005; see also chap.3.1.2, this thesis). The realization of these inter-connected strategies is crucial if the acquisition of skills in school, VTIs or on-the-job are to be translated into utilization of these skills in productive employment on the farm, in a trade or in a salaried job.

It is precisely the degree to which these policies can be successfully implemented that will dictate the extent to which assumptions about skills provision leading to employment can be realized (i.e. the link between skills acquisition and skills utilization). With regard to the implementation of the PSD strategy, while the government has made some progress in creating an enabling environment for the formal business sector (chap.5.2), challenges remain (Killick, 2004). More worryingly, the enabling environment or transformative context for the IME sector has changed little and remains disabling; for example, prohibitively high interest rates and a scarcity of capital are very practical constraints faced by entrepreneurs. But it is hoped that the 2006/07 informal sector survey will contribute to the development of a better strategy (chap.5.2).

Indeed, Killick (2004) argues that, "thus far there seems to have been a marked gap between [GoG]... desire to improve the business environment and its actual achievements" (p.6). It also appears that the government is starting to move beyond just developing an enabling environment for PSD and into creating the jobs directly. For example, the national youth employment 
programme (NYEP), launched in October 2006 (chap.5.2), will allegedly create new employment opportunities but will also add more people to the public sector payroll at a time when public sector reform is attempting to streamline this area. What will be interesting to track, however, will be the extent to which this job creation pledge refers to formal jobs or the government assisting in the creation of jobs in IMEs; which would take the government back to its role in developing an enabling environment for informal PSD.

Moreover, there appear to be government moves to promote the formalization of part of the informal sector; for example the government intention to assume responsibility for the first year of traditional apprenticeships (chap.5.1). The process of formalising the traditional apprenticeship would be beset with problems. Some of these came to the fore when the GoG paid some mastercraftspeople to train youth under the STEP (chap.7.3.2), while other issues might be expected based on experience elsewhere (e.g. the Nigerian Open Apprenticeship System, see Adam, 1993 and King, 1990c).

\subsection{Skills development and pathways to informal micro-enterprise (IME) in rural Ghana}

A 2006 review of IME in SSA (Haan, 2006) noted that the transition from training to selfemployment "remains unclear" (p.3). As noted, this study has contributed to the understanding of this transition to manufacturing IME in rural Ghana.

Skills development provision for Ghana's IME sector, as it does elsewhere in SSA, generally takes two forms:

i) skills development for IME - this includes both longer-duration IME-targeted preemployment training in VTIs, such as ICCES (chap.6), and short-duration training for immediate self-employment in IME, such as STEP (chap.7.1).

ii) skills development in IME - this enterprise-based training includes traditional apprenticeships (chap.7.6), trade- and farm-related training (Palmer, 2005a).

Pathways to IME in rural Ghana do not commonly include training in formal VTIs, including ICCES. Furthermore, the STEP programme trained comparatively few $(27,000)$ when compared to the large numbers of JSS graduates (and dropouts from earlier stages of schooling) entering the labour market every year. 
This study confirms the importance of traditional apprenticeship training as a component of many rural entrepreneurs' pathways to manufacturing IME (chap.8) (cf. Haan, 2006). It has also stressed the complexity of these pathways including: combining formal schooling with (in)formal skills training, acquiring skills from multiple sources, and the movement to and within the IME sector and beyond (chap.6, 7 and 8) (summarised in fig.9.1). The incidence of multiple skills pathways to the labour market (fig.9.1) represents one area in need of further investigation in Africa's IMEs.

Movement into different activities in the labour market is strongly affected by the transformative context in which youth find themselves post-school or post-training (chap.5.3). More research is required - at a country level - into determining the most critical elements of such a transformative context for Ghana's IMEs (see also 9.3.3 below).

While most rural youth graduate into what can only be described as a "constrained environment" (Kodithuwakku and Rosa, 2002: 431), some appear more entrepreneurial than others with regard to furthering their education and training, or accessing resources required for start-up. For example, it appears that many youth (e.g. JSS, ICCES graduates) are using periods of informal wage- or self-employment to finance further education and training (chap.6.3). This highlights the determination of many youth to acquire further training, particularly that which leads to formal certification. Once youth enter the labour market multiple strategies are adopted to find the required start-up funds, including working for periods in informal wage-employment, MESE activities or sourcing start-up support from the family (chap.8.2).

For the most part, the types of transitions that have been presented in this study (chap.6, 7 and 8) appear to be the kinds of pathways likely to be pursued by the poor. While it has been noted that many of the poor don't get access to, or drop out of, ICCES (chap.6.1.2) and apprenticeship training (chap.7.9.1), these skills acquisition modalities do appear open for at least some of the poor. It would be interesting for further research to map out the transitions to urban IMEs (or in different rural areas like the north) in Ghana, as well as examining the types of transitions experienced by Ghana's elite. In the case of the latter, it has been suggested above that one such transition is from private basic education to (good quality) public SSS to university. But there are, undoubtedly, many different variations. 


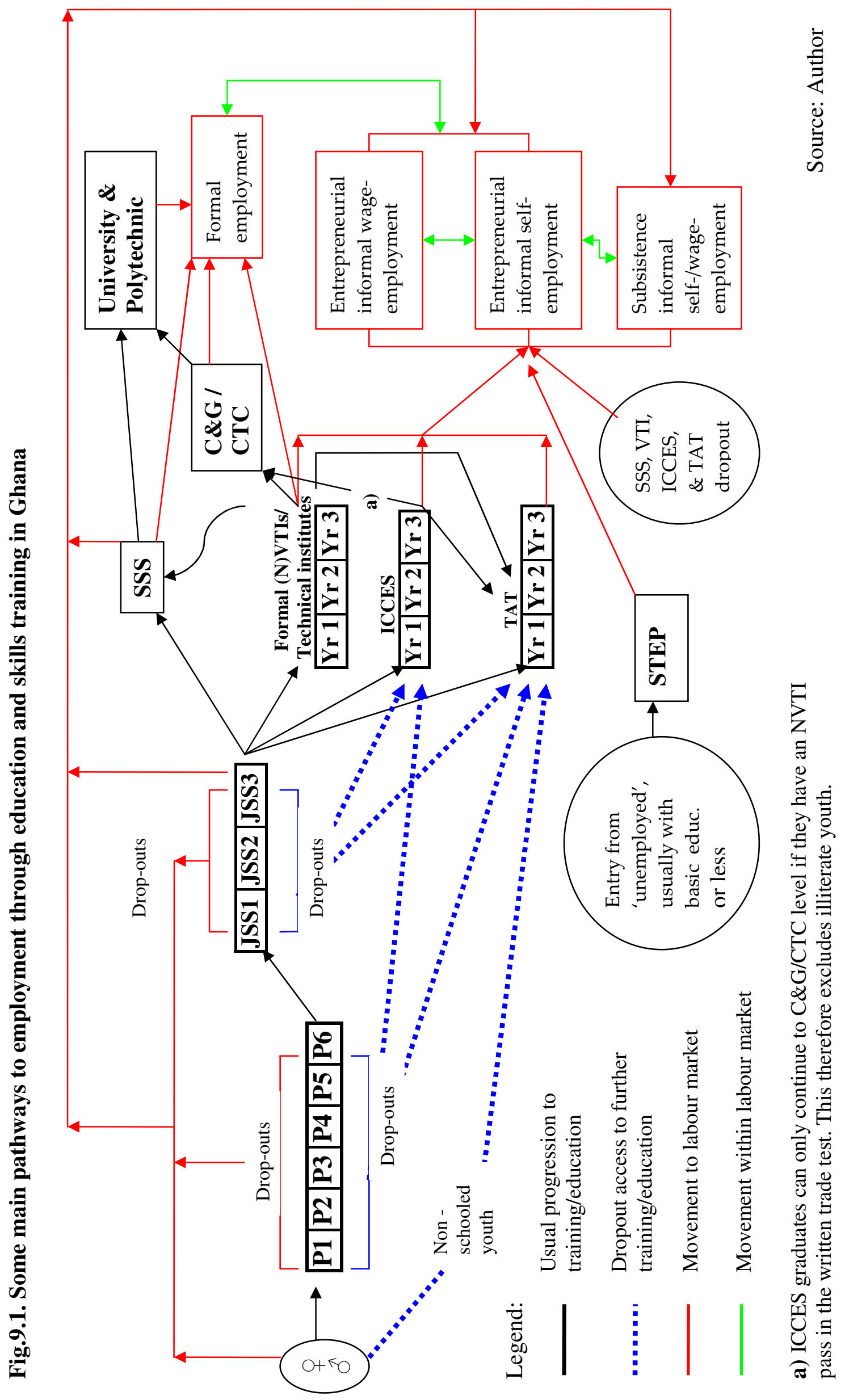




\subsection{Theoretical concerns arising from the study}

The fieldwork strategy was driven by several theoretical concerns with the conceptualisation of informal economy and of the interaction amongst school, skill and work which have gone relatively unchallenged for almost 35 years.

The impact of education, and particularly primary education, on poverty reduction (increased productivity etc.) has held sway in the economics of education literature for the last twenty-five years (cf. Palmer et al., 2007). But the way that many of these quantitative studies link school to employment outcomes oversimplifies the complex reality of many people in developing countries.

This thesis has shown that the complexity of the school-skill-enterprise interaction has been oversimplified in both academic and policy discourse as a result of misunderstanding four important aspects of this relationship. Firstly, as noted above, the link between skill acquisition and skill utilisation in enterprise is to some degree seen as almost semi-automatic (chap. 4, 5, 6, 7 and 9.2.1). Secondly, the standard years of schooling variable does not account for the complementarities between schooling and skills training, nor does it account for the variable quality and complexity of the delivery context (see chap.3). Thirdly, the dichotomous occupational classification (e.g. farm/nonfarm, self-/wage-employment, formal/informal) commonly used fails to represent the occupational pluralism of increasing numbers of SSA's population (chap.2). Fourthly, too little emphasis has been given to examining the school-skillenterprise relationship in different enabling and disabling contexts (chap.3).

\subsubsection{The years of schooling variable}

The quantitative measurement of the impact of schooling on developmental outcomes usually focuses on the formal schooling of owners as measured by a years of schooling variable. This variable says nothing about the kind of school (e.g. academic, vocationalised) that these years of schooling have been in. But this thesis has also shown that there are implications - vis-à-vis using this variable - arising from: i) combining schooling and vocational skills acquisition, and ii) the concept of the enabling environment. 
This study has shown that many IME owners and youth in rural Ghana are combining (a period of) formal schooling with informal apprenticeship training (and/or, less commonly, with formal VTI training) (chap.6, 7, 8). But the years of schooling variable says nothing about the complementarities and interaction between formal education and informal/formal skill acquisition. Indeed there appears to be a lack of research that examines the synergies between skills development, particularly informal skills training, and education that youth receive prior to the training.

There are also new methodological challenges related to the concept of the enabling environment. The years of schooling variable fails to account for the type of delivery context (or quality) of the schooling or training delivered. Indeed acknowledgement of this is leading some economists to use different education variables, like test scores (cf. Jolliffe, 1998), to measure human capital. But this still only goes part of the way to capturing all the elements of the education and training delivery context (chap.3.1.1) or the specific delivery challenges for vocational training in VTIs (e.g. chap.6.2), modular training (e.g. chap.7.3) or in traditional apprenticeship training (chap.7.9).

\subsubsection{Occupational classifications: interrogating the farm-nonfarm and formal- informal dichotomies}

There has been a bias in both the academic and policy literatures since the early 1970s towards the urban informal sector (chap.2), and when the term informal sector was finally used to refer to rural areas, there was a strong tendency for it to refer only to nonfarm activities. Only since the early 2000s have small farms also been considered small firms in SSA's informal sector. Nonetheless, both sets of literatures still hold on to the farm-nonfarm divide which oversimplifies the multiple occupational realities, or occupational pluralism, of many of those in SSA (chap.2.3). Increasing numbers of people in SSA are operating multiple IMEs (multiple farm, multiple nonfarm or multiple farm and nonfarm!): this blurs the neat farm-nonfarm divide. Moreover, the large number of links and shared characteristics between formal/informal economies (Palmer, 2004b) also blurs the relationship between the formal and informal. For example: where formal sector employees (e.g. teachers) have informal sector sidelines (straddling); where there is movement from the formal to informal areas of the economy and hence movement of formal backgrounds, up-to-date information and access to formal support mechanisms for enterprise; or where informal activities are used to finance a period of formal sector training. 
While acknowledging the blurred nature of these categories, it is not suggested that the farmnonfarm and formal-informal categories are done away with altogether. It is, for example, useful for policy makers to know about the relative importance of farm and nonfarm activities within the IME sector. But it is crucial that the growing incidence of multiple employment be captured in employment statistics, instead of classifying a worker as simply self- or wage-employed, and assuming that one person has one 'job'. Indeed, a number of countries are already starting to collect data on secondary activities (Charmes, 2005).

Therefore, researchers examining quantitatively the impact of schooling on farm and nonfarm enterprises need to take occupational pluralism more into account. Rate of return studies have been criticized for largely focusing on wage-employment (Bennell, 1996a) and not being of relevance for the majority of developing countries with large informal sectors characterized by self-employment in IMEs and occupational pluralism. Other quantitative studies are normally based on distinct occupational catergorisations (e.g. public/private wage job, non-agricultural self-employment, farmer - see Teal, 2001), or distinct job types (carpenter, mechanic, food-crop farmer, export farmer etc.). Many studies simply examine either farm or nonfarm activities and do not account for multiple farm or multiple nonfarm enterprise behaviour. One exception to this is Jolliffe (1996, 1998, 2004) who "argues that the estimated returns to education need to incorporate the effect that human capital has on all sources of income" (1996: iii). Jolliffe's examination of the impacts of schooling on farm, nonfarm and total income would have been better, however, if he had been able to disaggregate the farm and nonfarm categories further. Since there is a whole spectrum of farm and nonfarm work, much of which is very subsistence orientated, it would have been useful to know more about the type of activity.

\subsubsection{The transformative context}

Most quantitative studies of this sort also fail to account for the transformative context, or the different types of environment into which school, VTI or apprenticeship graduates emerge. Usually, the generic returns for different levels of education or different types of occupation are simply stated. But research (e.g. Lockheed et al., 1980) and commonsense would suggest that the returns to education and skill acquisition are markedly higher where there are other supportive measures in place (chap.3.1.2). For example, in an econometric study of the returns to apprenticeship in Ghana (Frazer, 2006), no attempt was made to make a distinction between more 
and less dynamic enterprises or more and less dynamic enterprise environments. It was noted earlier that one such early attempt by Lockheed et al. (1980) to distinguish between different types of environment - they used modernizing and traditional (chap.3.1.2) - showed that schooling has an impact on agricultural productivity only in a modern environment (where complementary inputs - e.g. fertilizers - are present). It is likely that the same is true for Frazer's apprentices: that the returns would be higher for those in more dynamic, more urban enterprises who have better access to (formal and informal) resources (social, financial and physical), compared to those in tiny, more-subsistence orientated, more rural enterprises whose access to any type of resource is poor. This type of evidence would be far more useful and have far more significant implications for policy than simply saying that apprentices in Ghana have returns of $\mathrm{x}$, or that farmers have average returns of $\mathrm{y}$ - with no indication of the type of environment for which these returns hold true. Research, therefore, is needed that examines the differential impact of schooling and skills in disabling and enabling contexts. Given what has been said above, it would be interesting to investigate the degree to which the wider environment, particularly the labour market environment, impacts on education and training outcomes.

Related to this point above is the methodological challenge of how such an environment might be measured. Indeed, given the complexity of the transformative context for IMEs (chap.3.2 and 5.3), this is not an easy task - and was beyond the scope of this current study. But it would be interesting for research to examine what a list of indicators might look like that could be used to measure the transformative context for informal micro-enterprise. Undoubtedly much can be learnt from how the formal enterprise environment is measured in developing countries, for example in the World Bank's 'Doing Business' surveys, ${ }^{401}$ its Regional Programme on Enterprise Development (RPED) data on investment climates, ${ }^{402}$ or its enterprise surveys. ${ }^{403}$ This being said, the formal enterprise environment is very different from the kinds of informal micro-enterprise contexts discussed in this study.

In 2005 DFID commissioned a number of new five-year programmes of education research and three consortia of researchers are examining issues of educational access, quality and

\footnotetext{
${ }^{401}$ http://www.doingbusiness.org/

${ }^{402} \mathrm{http}: / / \mathrm{www} 1$.worldbank.org/rped/index.asp?page=overview

${ }^{403}$ http://www.enterprisesurveys.org/
} 
outcomes. ${ }^{404}$ By chance all three consortia are working in Ghana and the author is involved with the Centre of African Studies (Edinburgh) in this process. It is hoped that this project will be a chance to explore a new frontier in the worlds of skills, poverty and growth.

\footnotetext{
${ }^{404}$ Further information on each of the three consortia on educational access, quality and outcomes can be found at the following websites: ACCESS (CREATE) http://www.create-rpc.org/; QUALITY (EDQUAL) http://www.edqual.org/; OUTCOMES (RECOUP) http://www.educ.cam.ac.uk/RECOUP/index.html
} 


\section{APPENDIX A: Background on master-craftsperson and apprentice interviews}

\section{A.0. Introduction}

Between February and March 2005 in-depth interviews were conducted by the author in 114 rural MSEs in three rural communities of Ghana; Otaakrom and Nyinahin in Ashanti Region and Bibiani in the Western Region (chap1, fig.1.2). The objectives were to: i) conduct retrospective interviews with the owners to find out how they were able to establish themselves (and in particular about their education and training backgrounds) and; ii) to interview rural apprentices in their workshops to get a better sense of this form of skills acquisition in rural areas.

Since the theme of the thesis is an examination of skills development, it was decided to conduct interviews only in MSEs that were seen to, or thought to, deliver training to traditional apprentices. Skills acquisition through traditional apprenticeship is known to be the most widespread modality of skills acquisition available to Ghana's youth, the poor in particular. ${ }^{405}$

\section{A.1. Background data on enterprises}

Most enterprises were to be found in the larger rural settlements of Bibiani and Nyinahin, both rural district capitals (table A.1).

\section{Table A.1. Location of enterprises}

\begin{tabular}{|l|r|r|}
\hline & Frequency & Percent \\
\hline Bibiani & 48 & 42.1 \\
Nynahin & 55 & 48.2 \\
Otaakrom & 11 & 9.6 \\
Total & 114 & 100.0 \\
\hline
\end{tabular}

Source: Author's fieldwork, 2005

In the three localities, enterprises were mapped with the assistance of local VTI instructors. These local actors were able to point out the majority of store, street and home-based enterprises. Since there was neither sufficient time nor resources to systematically map all the MSEs in these three communities and then randomly sample from among these, the interviews were conducted on a

\footnotetext{
${ }^{405}$ Though as we noted earlier (chap.7.9.1), the poor are often excluded from traditional apprenticeship training - due to direct or opportunity costs.
} 
non-random basis. Nonetheless, each of the communities were roughly divided into four zones and MSE owners were interviewed in each of these areas so an attempt to capture a representative population of masters was made. The in-depth qualitative interviews with masters used, as a starting-off point, a short semi-structured questionnaire (see section A.2, below) which was followed by the more qualitative work. The interviewing exercise was conducted with a research assistant who acted as translator in most cases. But since this research assistant was also from one of the three communities, he knew many of the masters personally which facilitated the interview process. He was also able to identify 'hidden' enterprises (e.g. in households) that would not have otherwise been included among those interviewed. Interviews with the masters took approximately thirty minutes.

Most of the rural MSE owners interviewed were dressmakers/tailors (29\%), carpenters (21\%), hairdressers $(18 \%)$, shoemakers $(6 \%)$, mechanics $(6 \%)$, electronics repairers $(4 \%)$ and welders $(4 \%)$. Of those masters interviewed $61 \%(n=69)$ were male and $39 \%$ female $(n=45)$. Female owners were clustered in the dressmaking and hairdressing enterprises (chap.8., table 8.1).

One third (38/114) of enterprise-owners interviewed were operating from non-permanent enterprises. ${ }^{406} 10 \%$ of those interviewed operated 'hidden' enterprises within households. Most of those interviewed (54\%) were operating from a wooden kiosk and a sizeable minority (13\%) had more permanent structures (of metal or concrete) (chap.8., table 8.3).

\footnotetext{
${ }^{406}$ This included temporary enterprises set up in a collapsible table, enterprises set up under a shady tree and those operating from inside households or compound areas.
} 
Table A.2. Structure of enterprises, by type of enterprise and sex of master

\begin{tabular}{|c|c|c|c|c|c|c|c|c|c|}
\hline \multirow[b]{2}{*}{ Sex of MC } & & & \multicolumn{6}{|c|}{ Enterprise structrure } & \multirow[b]{2}{*}{ Total } \\
\hline & & & Temporary & Under tree & Wooden kiosk & Metal kiosk & $\begin{array}{l}\text { Concrete } \\
\text { structure }\end{array}$ & Household & \\
\hline \multirow[t]{13}{*}{ Male } & Type of & Dressmaking & 1 & 0 & 5 & 0 & 3 & 1 & 10 \\
\hline & Enterprise & Carpentry & 5 & 8 & 9 & 1 & 1 & 0 & 24 \\
\hline & & Mechanics & 0 & 0 & 4 & 2 & 0 & 0 & 6 \\
\hline & & Masonry & 4 & 0 & 0 & 0 & 0 & 0 & 4 \\
\hline & & Electronics & 0 & 0 & 4 & 0 & 0 & 1 & 5 \\
\hline & & Shoemaker & 2 & 0 & 3 & 0 & 0 & 2 & 7 \\
\hline & & Welder & 2 & 0 & 3 & 0 & 0 & 0 & 5 \\
\hline & & Artist & 0 & 0 & 1 & 0 & 0 & 0 & 1 \\
\hline & & Vulcanizer & 0 & 0 & 1 & 0 & 1 & 0 & 2 \\
\hline & & Bike repairer & 0 & 0 & 2 & 0 & 0 & 0 & 2 \\
\hline & & Fridge repairer & 0 & 0 & 2 & 0 & 0 & 0 & 2 \\
\hline & & Other & 0 & 0 & 1 & 0 & 0 & 0 & 1 \\
\hline & Total & & 14 & 8 & 35 & 3 & 5 & 4 & 69 \\
\hline \multirow[t]{4}{*}{ Female } & Type of & Dressmaking & 4 & & 15 & 1 & 1 & 2 & 23 \\
\hline & Enterprise & Hairdressing & 1 & & 11 & 2 & 2 & 5 & 21 \\
\hline & & Other & 0 & & 0 & 1 & 0 & 0 & 1 \\
\hline & Total & & 5 & & 26 & 4 & 3 & 7 & 45 \\
\hline
\end{tabular}

Source: Author's fieldwork, 2005

Looking at the structure of enterprises by type of enterprise and sex of the owner reveals some interesting patterns (table A.2).

Most carpenters (all male) worked from basic non-permanent workshops; one third (8/24) simply worked under a shady tree, while a further $21 \%$ used temporary structures (5/24). More established carpenters were operating from wooden kiosks (38\%) or from metal (4\%) or concrete structures (4\%).

Most dressmakers/tailors (61\%, 20/33) worked from wooden kiosks, 15\% (5/33) from temporary structures, $12 \%$ (4/33) from concrete structures and 9\% (3/33) from their household.

Over $70 \%$ of hairdressers (15/21) operated from kiosks, compared to about a quarter $(5 / 21)$ working from the home.

For both dressmaking/tailoring and hairdressing there appears to be less of a possibility of working from a temporary enterprise structure, suggesting that entry into these trades might be more difficult than entry into carpentry where new owners can simply set up a bench under a tree. 
Fig.A.1. Age of enterprises interviewed

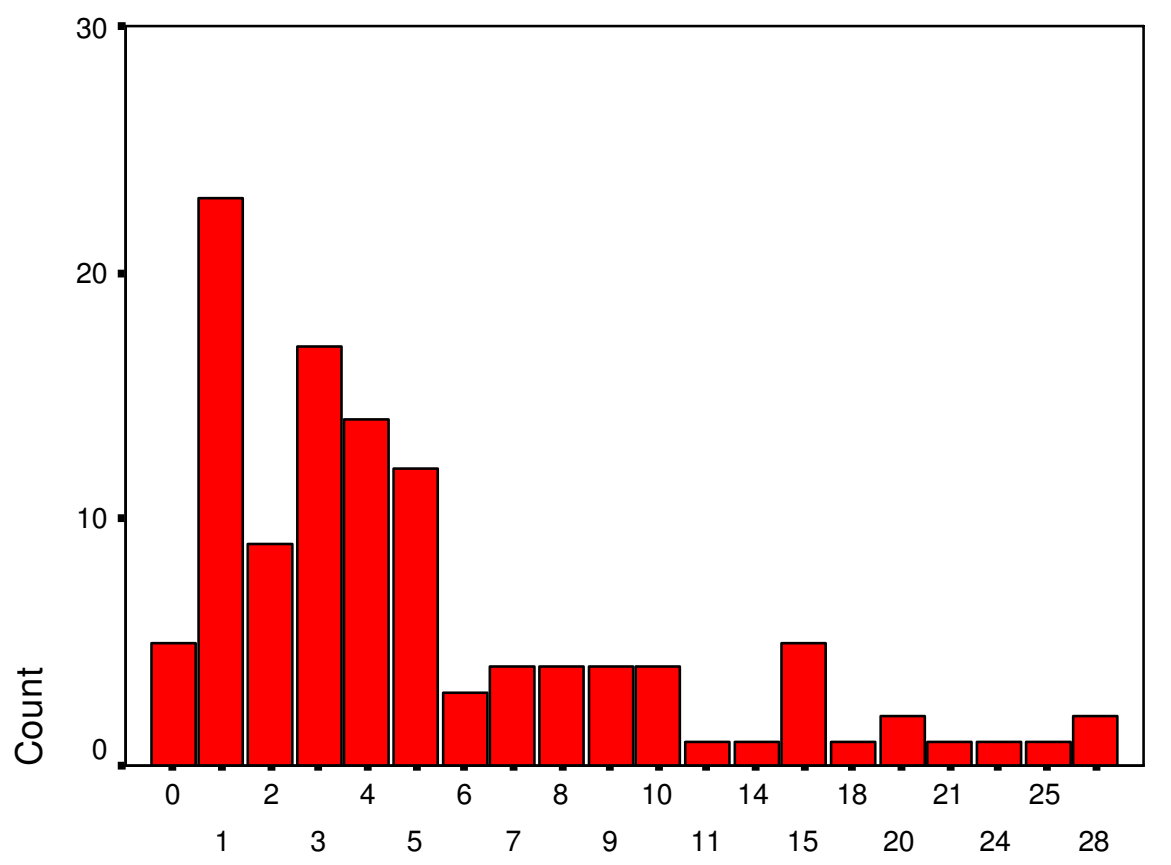

Age of Ent/years

Source: Author's fieldwork, 2005

The majority $(70 \%, 80 / 114)$ of those enterprise owners interviewed had been in business for five years or less, though some had been operating for nearly 30 years (fig.A.1). ${ }^{407}$ This suggests that many enterprise ventures are short-lived and that turnover is high in the informal micro-enterprise sector (cf. Liedholm and Mead, 1999). Only 13\% (6/45) of female owned enterprises were older than five years, compared to $41 \%$ (28/69) of male owned ventures (author's fieldwork); suggesting either that women owners find it harder to survive in the labour market and/or that women are more likely to enter into short term business ventures than men - perhaps to smooth over a lean time in the household income.

\section{A.1.1. Occupational pluralism}

Overall $40 \%$ (46/114) of owners reported to be undertaking additional income generating activities, mostly in farming enterprises (chap.8., table 8.17).

\footnotetext{
${ }^{407}$ Only five enterprises had opened up in 2005 , compared to 23 in 2004 but this is not surprising as the interviews were conducted during February and March 2005.
} 


\section{A.1.2. The apprentices}

Of the 114 masters interviewed, 87 had apprentices they were training at the time of the interview. Of these 87, 17 had only one apprentice; and all 17 were interviewed. Of the remaining 70 enterprises visited two apprentices from each enterprise were interviewed making a total of 160 apprentices interviewed. ${ }^{408}$

The 114 enterprises had a total of 347 apprentices making the sample of 160 almost $50 \%$ of the total number of apprentices.

Again a semi-structured questionnaire was used to start the more in-depth interview process (see section A.3 below). This allowed for additional questions and for probing to occur. Each interview lasted approximately twenty minutes per apprentice.

${ }^{408}$ In a few enterprises there were very many apprentices (over 20), and in these cases more than two apprentices were interviewed, making the total of 160 apprentices. 
A.2. SEMI-STRUCTURED QUESTIONNAIRE FOR MASTERS (starting point for more in-depth interview - see A.1 above)

Date and time of interview:

Location of Enterprise:

1. Name of Master

2. Sex (please circle) M / F

3. Age

4. Type of Work

5. Size of Enterprise (master, apprentice, other)

6. What year was you enterprise started?

7. What is the highest level of education you completed? (INCLUDE AGGREGATE FOR JSS)

No schooling

Primary not completed

Primary completed

JSS / Middle school not completed

JSS / Middle school completed

SSS /STS not completed

SSS / STS completed

Other

8. a] What type of training did you do to learn your trade?

8. b] If apprenticeship, what was the length of this training? months

8. c] Why did you choose this type of training?

9. What was the main source of start-up capital for your enterprise?

10. Do you have any other source of income generation? If so, what is it?

11. What is the structure of the enterprise? (please tick)

Temporary structure

Work under tree

Wooden kiosk

Metal kiosk

Other (please describe)

12. Do you have a bank account? (please circle)

YES / NO

12. b] IF YES, when was the last time you made a deposit? months

13. Do you keep financial records for you enterprise? (please circle) YES / NO

14. What is the main problem that your enterprise faces? 


\section{A.3. SEMI-STRUCTURED QUESTIONNAIRE FOR APPRENTICES: (starting point for more in-depth interview)}

Date and time of interview: Location of Enterprise:

1. Name of Apprentice

2. Sex (please circle) M / F

3. Age

4. Type of Apprenticeship

5. What is the highest level of education you completed? (INCLUDE AGGREGATE FOR $\underline{\text { JSS })}$

No schooling

Primary not completed

Primary completed JSS / Middle school not completed

JSS / Middle school completed SSS /STS not completed

SSS / STS completed Other

6. Why did you choose to do an apprenticeship?

7. What is the duration of your apprenticeship? (years, months)

8. What is the cost of your apprenticeship when you started? cedis

9. What year did you start your apprenticeship?

10. Do you receive daily chop money from your master? IF YES, how much do you currently get?

cedis

11. What do you think will be the most important source of start-up capital for you to start your own enterprise when you finish this apprenticeship? 
APPENDIX B: ICCES questionnaires

\section{B.1. ICCES TRACER QUESTIONNAIRE (06.01.05) - filled in by graduates themselves}

Please check the below details and amend any error where necessary.
A. Year passed out
B. Centre
C. Name
D. Sex
E. Years of Study
F. Course followed
G. Certificates obtained

1. What is your current address

2. Mobile / contact telephone number if available

\section{EDUCATION RECEIVED BEFORE ICCES}

3. What is the highest level of education you completed BEFORE ICCES? (please tick)

No schooling

Primary completed

JSS / Middle school completed

SSS / STS completed
Primary not completed

JSS / Middle school not completed

SSS /STS not completed

Other

\section{ABOUT YOUR TRAINING AT ICCES}

4. What grade did you obtain in the final examination?

5. What was the quality of teaching like? (please tick)

$\underline{\text { Excellent }} \underline{\text { Good }} \quad \underline{\text { Average }} \quad \underline{\text { Poor }} \quad \underline{\text { Very poor }}$

6. What was the availability of tools/equipment? (please tick)
Excellent
Good
Average
Poor
$\underline{\text { Very poor }}$ 
7. What was the availability of teaching and learning materials for your theory lessons (eg text books)? (please tick)
Excellent
Good
Average
$\underline{\text { Poor }}$
$\underline{\text { Very poor }}$

8. What was the availability of teaching and learning materials for your practical lessons (eg. Timber, blocks, brown papers etc)? (please tick)
Excellent
$\underline{\text { Good }}$
Average
$\underline{\text { Poor }}$
$\underline{\text { Very poor }}$

9. What was the availability of buildings like (eg classrooms, workshops)? (please tick)
Excellent
$\underline{\text { Good }}$
Average
$\underline{\text { Poor }}$
$\underline{\text { Very poor }}$

10. Were you taught Entrepreneurial Studies? $\underline{\text { Yes }} / \quad$ No

11. Were you able to pay all your fees during the course duration?

Yes

GO TO QUESTION 12]

$\underline{\text { No }}$

$$
\text { GO TO QUESTION 11. b] }
$$

11. b] If No, why not?

Parents can't pay Other reason (please state)

\section{EDUCATION AND TRAINING AFTER ICCES}

12. Did you continue your education and/or training AFTER FINISHING at ICCES? (please tick all that apply)

Apprenticeship training

City and Guild Intermediate

City and Guild Advanced

CTC 1

CTC 2

None

\section{CURRENT EMPLOYMENT ACTIVITY}

13. Are you working now? $\underline{\text { Yes }}$

No

14. What type of work are you doing?

15. Please tick the box below that best describes your current work situation

Salary worker $\quad \square \quad$ - GO TO QUESTION 16 
Self-employed $\quad \square \quad$ - GO TO QUESTION 17

Both self-employed and a salary worker $\quad$ - PLEASE ANSWER BOTH QUE 16 AND 17

\section{QUESTION 16. FOR THE SALARY WORKER}

16. Please describe as best you can the type of work you do (e.g. where it is, if it is full-time or part-time, salary) QUESTION 17. FOR THE SELF-EMPLOYED

17. a] Are you now working in your hometown?

$\underline{\text { Yes }} / \quad$ No

17. b] Please describe as best you can the type of work you do (e.g. where it is, if it is full-time or part-time, earnings)

\section{FOR BOTH SALARY WORKERS AND THE SELF-EMPLOYED}

18. What is the address and location of your employment?

19. In addition to either being self-employed or a salary worker, do you have any other source of income generation? (eg. Farming) (please tick all that apply)

No other source of income

Small scale Farming for chop

Small scale Farming for cash-crops

Large scale Farming for cash-crops

Trading

Other (please state)

20. Please use this space to tell us anything else you want to about your experience DURING ICCES OR AFTER ICCES. 


\section{B.2. ICCES questionnaire for centre managers and instructors regarding the current activity of 2003 graduates}

\section{Subject: Current Activity of ICCES trainees who graduated in 2003}

Please look at the form below. We would like you to look at your list of students who graduated in 2003 and to write down the current activity of these graduates - according to the following options:

- Further training apprenticeship - they are currently doing an apprenticeship;

- Further training City and Guild - they are currently doing a city and guild course;

- Further training CTC - they are currently doing a CTC course;

- Other further training - they are currently doing some other type of training or education, like SSS;

- $\quad$ Self-employed in trade area - they are currently self-employed in the trade area that they learnt. E.g a carpentry graduate is self-employed as a carpenter;

- Self-employed not in trade area - they are currently self-employed NOT in the trade area that they learnt. E.g a carpentry graduate is self-employed as a tailor or trader;

- Per-day wage employment in trade area - they are currently employed on a 'per day' basis in the trade area they learnt in - e.g. a masonry graduate is working on a per day basis doing building/construction work;

- Per-day wage employment not in trade area - they are currently employed on a 'per day' basis NOT in the trade area they learnt in - e.g. a masonry graduate is working on a per day basis doing trading work;

- Formal wage employment in trade area - they are currently employed on a continuous basis in a waged job; e.g a carpentry graduate is employed as a carpentry teacher or instructor;

- Formal wage employment not in trade area - they are currently employed on a continuous basis in a waged job; e.g a carpentry graduate is employed as a masonry teacher/ instructor, or as a soldier, policeman etc;

- Farming with their family - they are currently working in farming helping their family;

- Not working at all - they are currently doing nothing at all. 
If you do not know the current activity of a trainee, record it as 'don't know'. If they are doing something which is not in the list above, record it as 'other activity' and write down the activity they are doing. 


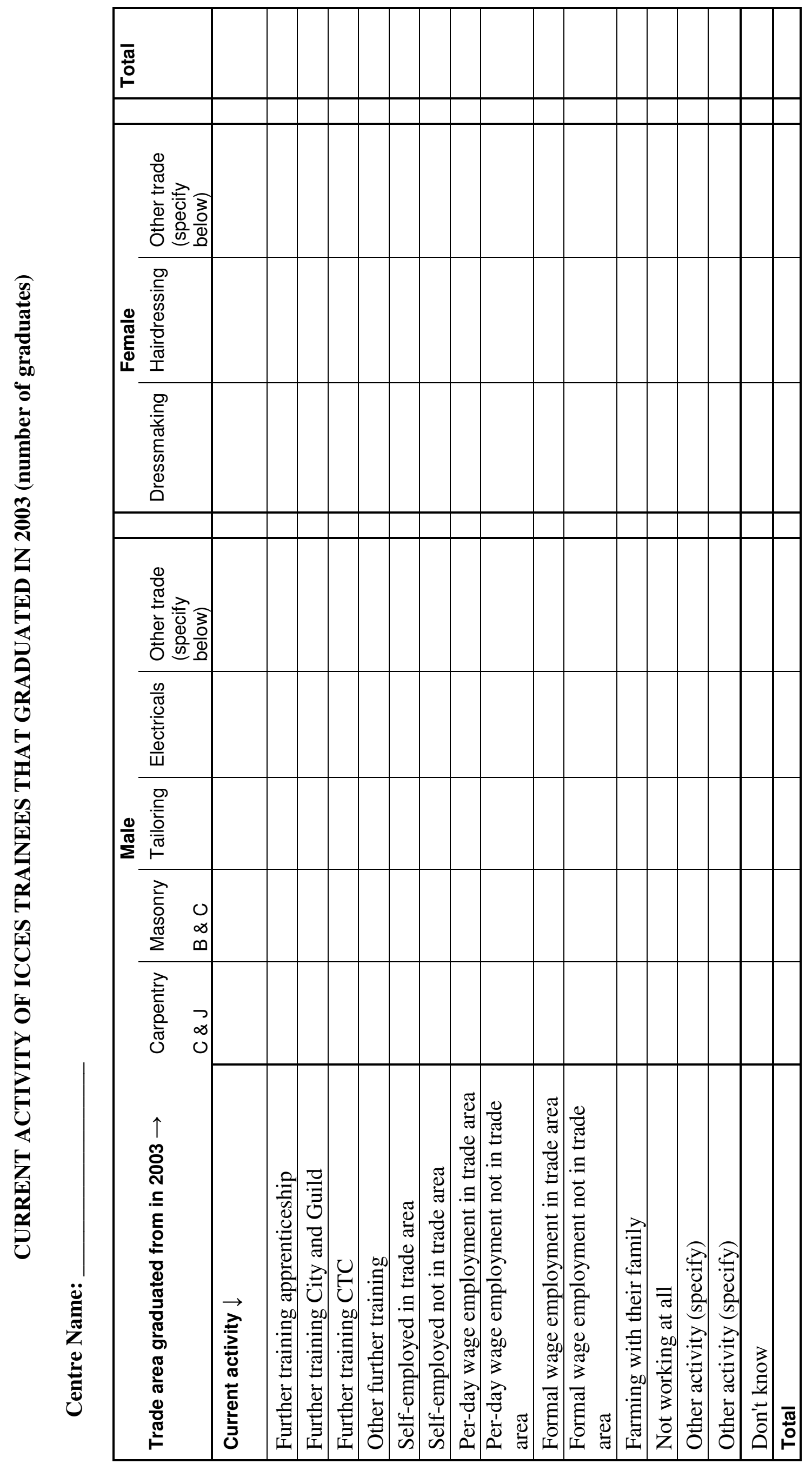




\section{APPENDIX C: Household survey in Otaakrom village. Methodology and background data}

\section{C.0. Introduction}

Objectives of the survey:

- To get information on youth in Otaakrom (aged 14-25) regarding their education and skills background and their current activities;

- To get information on occupational pluralism of households in Otaakrom;

- To be able to categorise the households into different poverty/wealth categories in order to look for trends.

This survey in Otaakrom village in Ashanti Region was conducted between October 2005 to January 2006 (for further details about Otaakrom see chap.1.3.2).

A multi-stage approach was used to select the youth in the sample. It was decided to map all the households in the community and then to select at random a number of households in the community to interview in order to obtain information on the youth and occupational pluralism issues.

\section{C.1. Poverty classification and the wealth ranking exercise}

Before the household mapping exercise could occur, however, I needed a way of categorising households into different wealth/poverty groupings.

Within international development literature and policy there appear to be two major trends with regard to defining and measuring the concept of poverty. On the one hand there is a reasonable consensus (at least among policy-makers and development agencies) on the importance of a multidimensional understanding of poverty that recognises the complex inter-relations between social and physiological aspects (see Shaffer, 1998; Thin, 1999; World Bank, 2000). Elaborate systems have been established which seek to capture these multiple dimensions, such as the Human Development Index and the Human Poverty Index (UNDP 2005). On the other hand, in policy and practice there is a tendency to categorise poverty simplistically in terms of the 
minimum income required to satisfy basic needs (food, accommodation, services), i.e. income poverty. This is often reduced to measuring the population living on less than $\$ 1$ or $\$ 2$ a day. While this measurement may indirectly take into account various aspects of poverty, it can become a simplistic label which obscures interesting nuances in how poverty is perceived in different countries. ${ }^{409}$

The literature on poverty and poverty classification in Ghana is fairly extensive (e.g. Ashong and Smith, 2001; Canagarajah and Pörtner, 2003; Coulombe, 2004; GoG, 2003a: section 3.3; GoG, 2000; Kunfaa, 1999; Kunfaa and Dogbe, 2002; Norton, Bortei-Doku Aryeetey, Korboe and Dogbe, 1995) and is generally in line with the international literature in identifying the multidimensional nature of poverty. Much of this literature recognizes the inadequacy of income poverty measures (and the difficulty in measuring income anyway) and discusses participatory poverty classification, including wealth ranking, as a means to access local knowledge about poverty. These "local, or self-definitions of poverty provide a vital insight into physical, economic, human and social conditions of the poor" (Ashong and Smith, 2001: 5).

Broader interpretations of poverty present a more accurate picture of who the poor are (e.g. defined in terms of income/ consumption, low achievements in education and health, vulnerability, exposure to risk and voicelessness / powerlessness, material/ non material assets, gender and ethnic equality, and freedom/security) and question the precision of poverty lines defined only in terms of income or expenditure (Ashong and Smith, 2001; World Bank, 2000).

However, in practice, the Ghana Government uses an economic index to measure poverty. The Ghana Living Standards Surveys (GLSS), which are used by the government to collect economic and social indicators, characterizes the poor as those subsisting on a per capita income of less than two-thirds of the national average. The 'hard core' poverty line is defined as income below one third of the mean. In monetary terms these two poverty lines translated as $\$ 700,000$ per adult per year (approximately US\$100) and $\not 900,000$ (approximately US\$129) in 1998/99.

In order to obtain a more multi-dimensional understanding of poverty, therefore, it was decided that a simple wealth ranking exercise was needed in order to be clear about possible poverty/wealth categories that would be used in the household mapping exercise.

${ }^{409}$ This paragraph draws on Palmer et al., 2007. 
Moreover, getting accurate data on incomes is difficult, not least due to occupational pluralism and the fact that most households keep no financial records.

The concept of wealth ranking is based on using local knowledge about people's levels of wealth. Local people who live and work in the same village and who can observe others over a long time period are normally a better judge of levels of wealth than an outsider. In a wealth ranking exercise, key informants from the local communities rank their fellow villagers into wealth categories. The informants decide on their own definitions of wealth and wealth categories. The wealth ranking exercise therefore helps to bring out the complexities and realities of wealth and poverty, rather than using definitions predetermined by the researchers (Jeffries, Warburton, Oppong-Nkrumah and Fredua Antoh, 2001: 3-4).

Firstly I had lengthy discussions with two well-known community members who were to assist me with the mapping exercise. ${ }^{410} \mathrm{I}$ had explained to them what I wanted to do - to think about possible poverty/wealth categories before conducting a household mapping exercise. What made this exercise easier was that one of the community members assisting me had just finished conducting an assessment of 'social groupings' for the local district assembly to determine how much each household had to pay under the new national health insurance scheme (NHIS). Under the NHIS, households were classified as either core poor, very poor, poor, middle-income or rich (Table C.1). While a start, the NHIS classifications were not totally satisfactory since the descriptions of each category was still very employment- and income-centric. Moreover, the terms 'unemployed' and 'employed' are problematic in the Ghanaian context, particularly in rural areas (chap.2.3.1). Hence in order to find out what such classifications mean it was necessary to conduct a qualitative exercise to establish what factors should be included when thinking about a household's wealth status. ${ }^{411}$

\footnotetext{
${ }^{410}$ One used to be the local assembly person (lowest official in district assembly hierarchy), has lived in the community all his life (he is aged about 50 years) and I have known him since January 2001. Having known this person for almost five years meant that we had a strong rapport and I was able to freely access information about the village in the knowledge that he would not give me a guarded response. The other was a teacher in the local ICCES centre who had been in the village for the last two years.

${ }^{411}$ This was intended to capture the multi-dimensional nature of poverty.
} 
Table C.1. Social groupings in the informal sector according to the National Health Insurance Scheme

\begin{tabular}{|l|l|}
\hline Core poor & $\begin{array}{l}\text { Adults who are unemployed and do not receive any } \\
\text { identifiable and constant support from elsewhere for } \\
\text { survival }\end{array}$ \\
\hline Very poor & $\begin{array}{l}\text { Adults who are unemployed but receive identifiable } \\
\text { and consistent financial support from sources of } \\
\text { low income }\end{array}$ \\
\hline Poor & $\begin{array}{l}\text { Adults who are employed but receive low returns for } \\
\text { their efforts and are unable to meet their basic needs }\end{array}$ \\
\hline Middle income & $\begin{array}{l}\text { Adults who are employed and able to meet their } \\
\text { basic needs }\end{array}$ \\
\hline Rich & $\begin{array}{l}\text { Adults wo are able to meet their basic needs and } \\
\text { some of their wants }\end{array}$ \\
\hline Very rich & $\begin{array}{l}\text { Adults who are able to meet their basic needs and } \\
\text { most of their wants }\end{array}$ \\
\hline
\end{tabular}

Source: GoG, 2004k

The following list emerged through discussions:

The source of a household's income (degree to which family members are employed, unemployed or underemployed, what types of income-generating activities they pursue and how successful these activities are); clothing/shoes; food eaten (including number of meals a day); type of housing (materials used, type of toilet, water and fuel source); whether the children were at school; the type of medical care the household usually has; whether the household owns any farmland or livestock; what kinds of 'luxury' items a household owns (e.g. TV, radio, fridge, bicycle, car); the extent to which a household contributes/participates in to social and community obligations/associations (e.g. funeral or church/mosque donations, and membership of informal health and savings groups); household misfortune (including disease, death in the family and funeral obligations etc); household vulnerability (how easily could they fall into poverty?); education and training background of household members and ability of household to educate their children; family structure (including divorced or widowed women, old people with no family support).

We decided that we would categorise households into five types: very poor, poor, average (middle-income), well off, very well off bearing the above proxy indicators of poverty/wealth in mind. Discussions with the community member who had previously been involved in the NHIS revealed that virtually no-one in the community had been classified as core-poor. Hence we 
decided to merge 'core-poor' and 'very poor' together as simply 'very poor'. At the other end of the scale we decided to expand 'rich' into two categories to distinguish between those seen as asikafoo (rich people) or meyeyie / meya ayeyie (on the way to becoming rich) and those seen as sikawur ('owner of money') (see below). To get a better idea of what constitutes a household in each of these categories we made visits to 21 households in Otaakrom community over a five day period; talking informally to the household members and making an assessment of the household, their assets and their capabilities. The following descriptions represent the typical households in each of the five categories.

Very poor - ohiabubroo (miserably poor); ohia ye edam bo (poverty is madness); oteneho ('I live on my own')

- Poor house structure (mud as principal building material);

- Usually has about 3 rooms in their house;

- Uses a communal toilet;

- Cooks with firewood;

- Might not own a radio;

- Does not own a TV;

- Can't meet normal requirements, e.g.:

- Does not eat three meals a day;

- Clothing is old and very poor quality;

- Children often do not attend school;

- Prefers not to go to hospital due to costs and can't afford the national health insurance scheme (NHIS);

- Is not a member of community associations and either makes little or no contribution at church/mosque;

- Often does not attend funerals as can't afford to make a donation;

- Has very little influence over community affairs/decisions.

Poor - ohiafoo / ohiani (the poor)

- Poor house structure (mud as principal building material);

- Usually has no more than 4-5 rooms in their house;

- Uses a communal toilet;

- Usually owns a radio;

- Usually can't meet normal requirements, e.g.: 
- Finds it tough to get three meals a day;

- Clothing is old and poor quality;

- Finds it hard to send children to school (e.g. due to cost of school uniform);

- Prefers not to go to hospital due to costs and can't afford the NHIS;

- Usually a member of community associations but often is late paying contributions;

- Makes small contributions at funerals;

- Has little influence over community affairs/decisions.

Average - adantemo

- Adequate shelter: usually mud block house often with concrete plastering;

- Usually has no more than 9 rooms in their house;

- Might have access to a private or shared KVIP toilet; ${ }^{412}$

- Owns a radio and might own a TV;

- Is a member of community associations and makes contributions on time;

- Has some influence over community affairs/decisions;

- Able to afford adequate clothing and food for family;

- Able to send children to school, but has difficulty sending them to post-basic education (e.g. sending a child to SSS is a big problem, but not impossible).

Well off-asikafoo (rich people); meyeyie / meya ayeyie (on the way to becoming rich)

- Good shelter: strong house structure (concrete clock, plastering, burglar bars);

- Often many rooms;

- Has a private KVIP toilet;

- Might cook with gas;

- Owns a radio and TV;

- Probably owns a mobile;

- Is a member of a number of community associations and makes contributions on time;

- Has quite a lot of influence over community affairs/decisions;

- Able to afford good clothing and food for family;

- Able to send children to school, including to post-basic institutions.

Very well off - sikawur ('owner of money'), odefuo

- Lives in a well-built large house;

- Cooks with gas, has own toilet;

${ }^{412}$ KVIP - 'Kumasi ventilation improved' toilet: a single pit latrine with a ventilation tube. 
- Can meet and surpass all requirements regarding clothing and food;

- Owns a TV, radio, mobile, fridge/freezer, cooker and often a car/vehicle;

- No problem sending children to the best schools at any level;

- Very influential in the community.

These categories above could then be used in the household mapping exercise.

\section{C.2. Household mapping exercise}

Next the household mapping exercise was conducted over a seven day period, during which a map of all households in Otaakrom was drawn up with the assistance of the two community members mentioned above.

This consisted of two main activities:

\section{Identification of different households}

The two community members were able to identify different economic family units; in some instances more than one family lived in the same household, or some families had more than one household. The definition of a 'household' for the purpose of this survey was taken to be the household economic unit; people were considered to be in the same household if they contributed to the economic welfare of that unit and/or ate from the same (re)source. This was decided by the two community members who were guiding the household mapping process.

\section{Categorisation of household according to poverty/wealth indicators}

The two community members were asked to consider the multiple proxy indicators of wealth/poverty - which we had determined previously - for each household. I asked them to consider not only the situation the households found themselves at the time we saw them, but how representative the households current situation was in relation to how the household normally is over the space of the last year. ${ }^{413}$

\footnotetext{
${ }^{413}$ The household mapping exercise was conducted about the same time as households were starting to receive income from cocoa (November/December harvest). Hence households tend to have more disposable income at this time of year.
} 


\section{C.3. Random sampling and questionnaires}

After the household and wealth mapping exercise was complete, a random sample of 81 households was taken from the list of all households in Otaakrom $(n=235)$, representing a 35\% sample of all households in the village. Resources were not available to increase the sample size, but the author considers it to be fairly representative of all households in the community.

Each household was then visited and a simple questionnaire was administered to the household head, asking principally about the youth aged 14-25 in the household (see C.5, below, for the questionnaire). However, while the principal focus was on collecting data on youth, I considered that it would be interesting to ask a question about the income generating activities of the households at the same time; to get a sense of the degree of occupational pluralism at the household level.

Each questionnaire took approximately 30 minutes with the household head being the principal respondent. In many instances other family members were present at the interviews and were able to contribute and clarify aspects of the household head's response. The household head, along with the family members present at the time of the interview were relied upon to provide information about their children. Since it was known that many of the youth raised in Otaakrom are not currently present in Otaakrom it was considered more effective and less time consuming not to interview the youth directly. Hence information of the youth was obtained from the household head and other family members present at the time the questionnaire was administered. Using this approach meant that some information was missing as parents or other family members could not tell exactly what some of their families' youth were currently doing outside of the village, but it also meant that data on a significant proportion of non-resident household members was able to be collected.

In the household interviews I was assisted by a teacher from the village vocational centre who acted as a translator, but who later took over the data collection exercise acting as a research assistant. Approximately half the questionnaires were undertaken with both myself and the teacher. Later on, however, as my time in Ghana was coming to a close, the teacher took over the data collection exercise and posted the remaining questionnaires to me in the UK. Since we had done approximately 40 household interviews together, I considered that he had sufficient experience to continue alone. 


\section{C.4. Analysis: some background data on the survey}

Once all the 81 questionnaires were completed, the data was inputted into SPSS and then analysed. Below is some background data on the household heads and youth in the sample. The three principal data tables from this exercise can be found in chapter 2 (table 2.1 on occupational pluralism) and in this appendix (tables C.6 and C.7 on skills training).

\section{C.4.1. Household heads in the survey}

Questionnaires were administered in 81 households ( 45 households were headed by men and 36 by women). The age of the household head ranged between 28 and 78 years, with the average age of household heads at 50 years.

A third of all household heads had no formal schooling. A further $10 \%$ had primary or less. $31 \%$ had completed middle school/JSS (table C.2).

Table C.2. Education level of household heads in the survey

\begin{tabular}{|l|r|r|r|}
\hline & Frequency & Percent & $\begin{array}{c}\text { Cumulative } \\
\text { Percent }\end{array}$ \\
\hline None & 27 & 33.3 & 33.3 \\
Primary not completed & 6 & 7.4 & 40.7 \\
Primary completed & 2 & 2.5 & 43.2 \\
JSS/MS not completed & 9 & 11.1 & 54.3 \\
JSS/MS completed & 25 & 30.9 & 85.2 \\
SSS not completed & 1 & 1.2 & 86.4 \\
SSS completed & 6 & 7.4 & 93.8 \\
PB Vocational & 1 & 1.2 & 95.1 \\
Univ/poly & 1 & 1.2 & 96.3 \\
other & 3 & 3.7 & 100.0 \\
Total & 81 & 100.0 & \\
\hline
\end{tabular}

Source: Author's fieldwork, 2005

Legend: JSS - Junior Secondary School; SSS - Senior Secondary School; MS - Middle School; PB - Post-basic

\section{C.4.2. Youth in the survey}

The survey consisted of 205 youth (101 males, 104 females) aged 14-25 from the village of Otaakrom in Ashanti Region (table C.3). At the time of the survey (October 2005 -January 2006) 
$53 \%$ of the youth were resident in Otaakrom, while a further $47 \%$ were living elsewhere, mostly in Kumasi (table C.4).

\section{Table C.3. Age of youth in Otaakrom survey}

\begin{tabular}{|r|r|r|r|}
\hline & Frequency & Percent & $\begin{array}{c}\text { Cumulative } \\
\text { Percent }\end{array}$ \\
\hline 14.00 & 35 & 17.1 & 17.1 \\
15.00 & 11 & 5.4 & 22.4 \\
16.00 & 25 & 12.2 & 34.6 \\
17.00 & 25 & 12.2 & 46.8 \\
18.00 & 26 & 12.7 & 59.5 \\
19.00 & 13 & 6.3 & 65.9 \\
20.00 & 21 & 10.2 & 76.1 \\
21.00 & 4 & 2.0 & 78.0 \\
22.00 & 13 & 6.3 & 84.4 \\
23.00 & 5 & 2.4 & 86.8 \\
24.00 & 12 & 5.9 & 92.7 \\
25.00 & 15 & 7.3 & 100.0 \\
Total & 205 & 100.0 & \\
\hline
\end{tabular}

Source: Author's fieldwork, 2005

Table C.4. Location of Otaakrom's youth at time of survey (Oct.05-Jan.06)

\begin{tabular}{|l|r|r|}
\hline & & \\
& Frequency & Percent \\
\hline Otaakrom & 109 & 53.2 \\
Another village $\mathrm{nr}$ & 4 & 2.0 \\
Otaakrom & 1 & .5 \\
Bibiani & 5 & 2.4 \\
Nyinahin & 1 & .5 \\
Nkawie-Toase & 44 & 21.5 \\
Kumasi & 17 & 8.3 \\
Accra & 10 & 4.9 \\
Northern town/city & 14 & 6.8 \\
Southern town/city & 205 & 100.0 \\
Total &
\end{tabular}

Source: Author's fieldwork, 2005

From the sample of 205 youth, 55 were still in school, 3 gave no response and 147 had already left school. The highest educational level of those youth who had left school is shown in table C.5; while the majority of youth (52\%) had completed JSS, over $25 \%$ of youth had less than a complete primary education (including $10 \%$ with no schooling at all). 
Table C.5. Highest formal education level of youth that have left school

\begin{tabular}{|l|r|r|}
\hline & Freq. & Percent \\
\hline None & 15 & 10.3 \\
Primary not completed & 22 & 15.1 \\
Primary completed & 2 & 1.4 \\
JSS not completed & 27 & 18.5 \\
JSS completed & 76 & 52.1 \\
SSS completed & 4 & 2.7 \\
\hline & $\mathbf{1 4 6}$ & $\mathbf{1 0 0 . 1}$ \\
\hline
\end{tabular}

Source: Author's fieldwork, $2005^{414}$

\section{C.4.3. Youth training}

Of the 205 youth aged 14-25 in the Otaakrom sample, 55 were still in school and 3 gave no response. Out of the remaining 147 youth, 37\% (55/147) had engaged in apprenticeship training, $61 \%(89 / 147)$ had received no further training and only $2 \%(3 / 147)$ had been to a vocational institute. The fact that only $2 \%$ of the youth in the survey had been to a vocational institute is remarkable given that there has been a vocational training centre (an ICCES) in the village since 2001. This underlines the fact that youth do not like to pursue further institution-based training in the same village as they went to JSS. This compares to nearly $40 \%$ of Otaakrom youth who have gone through apprenticeship training.

Furthermore, table C.6 shows that the 'poor' are able to participate in apprenticeship training; nearly half of all Otaakrom's youth who had been through an apprenticeship were from 'poor' or 'very poor' households (26/55).

Table C.6. Percentage of youth in Otaakrom engaged in post school skills training

\begin{tabular}{|c|c|c|c|c|c|c|c|}
\hline & \multicolumn{2}{|c|}{ Apprenticeship } & \multicolumn{2}{|c|}{ Vocational school } & \multicolumn{2}{|c|}{ No further training } & Total \\
\hline & $\mathrm{n}$ & $\%$ & $\mathrm{n}$ & $\%$ & $\mathrm{n}$ & $\%$ & $\mathrm{n}$ \\
\hline Very poor & 3 & 5.5 & 0 & 0 & 6 & 6.7 & 9 \\
\hline Poor & 23 & 41.8 & 1 & 33.3 & 26 & 29.2 & 50 \\
\hline Average & 29 & 52.7 & 2 & 66.6 & 56 & 62.9 & 87 \\
\hline Above avr. & 0 & 0 & 0 & 0 & 0 & 0 & 0 \\
\hline Well-off & 0 & 0 & 0 & 0 & 1 & 1.1 & 1 \\
\hline Total & 55 & 100 & 3 & 99.9 & 89 & 99.9 & 147 \\
\hline
\end{tabular}

Source: Author's fieldwork

\footnotetext{
${ }^{414}$ Total of youth completing formal education was 147 , but missing data means that the total in this table is 146 .
} 


\section{C.4.4. Schooling, training and migration}

Poor households in the sample were more likely to send their children outside of Otaakrom village for apprenticeship training; 15/17 youth from poor households currently doing apprenticeships were not currently resident in the village. On the other hand, youth from slightly better off households doing apprenticeships, while still showing a great deal of mobility to receive training, appeared more likely to reside in the village during the training period (table C.7). Kumasi was the most popular destination to undertake an apprenticeship with 56\% (19/34) of youth travelling here. 9\% (3/34) travelled to Accra, while 26\% (9/34) stayed in Otaakrom village to do their apprenticeship (author's fieldwork). ${ }^{415}$ The situation became reversed, however, with regards to those youth still in school; those from poor households were more likely to be currently residing in Otaakrom (16/23), compared to those from average households (9/23). Again Kumasi proved the most popular destination for youth to attend school outside of Otaakrom; While 59\% (36/61) of sampled youth were still at school in Otaakrom, 20\% (12/61) were in Kumasi and 7\% (4/61) in Accra (author's fieldwork).

${ }^{415}$ However, just because an apprentice lived in Otaakrom village during his/her apprenticeship it might have been that they travelled daily to a nearby town (Nkawie or Bibiani) to actually undertake the apprenticeship. 


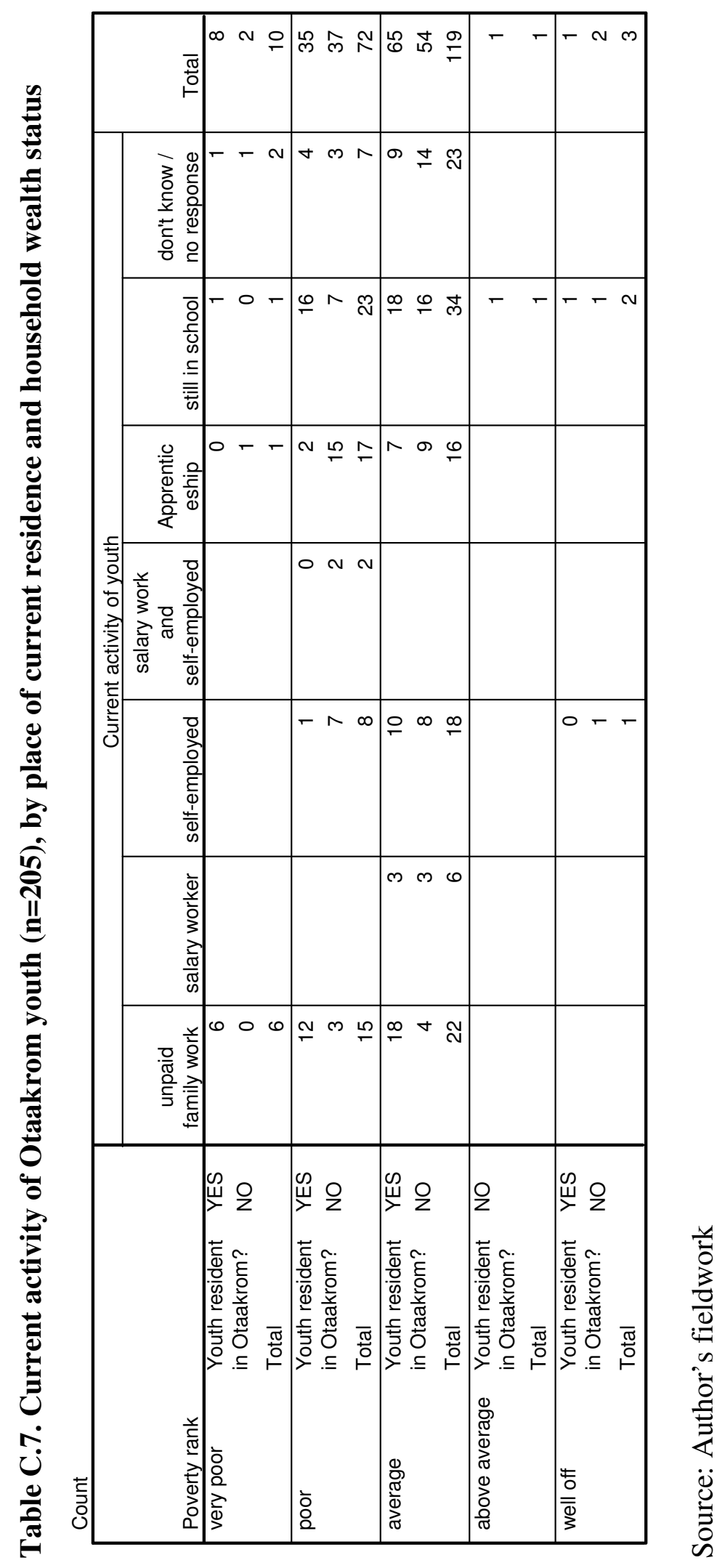




\section{C.5. HOUSEHOLD QUESTIONNAIRE: OTAAKROM}

Date:

Poverty code:

Location code:

Q.1. Name of Household head

Q.2. Sex (please circle)

MALE / FEMALE

Q.3. Age

Q.4. What is the highest level of education you have completed? (circle)

No School

Primary not completed

SSS not completed

Primary completed

SSS completed

JSS not completed

Other (please state below)

JSS completed

Q. 5. Please tell us about any income generating occupational activity (eg farming, trading etc) that your HOUSEOLD engages in at any time in the year.

i)

iii)

vi)

Q.6. How many children do you have aged:

a] UNDER five (5) years old?

b] five (5) years old to thirteen (13) years old? ii)

iv)

vii)

\section{ABOUT YOUR CHILDREN AGED 14-25}

The next series of questions are about all your children aged 14 to 25 inclusive. We want to find out about where they are and what they are doing now. 


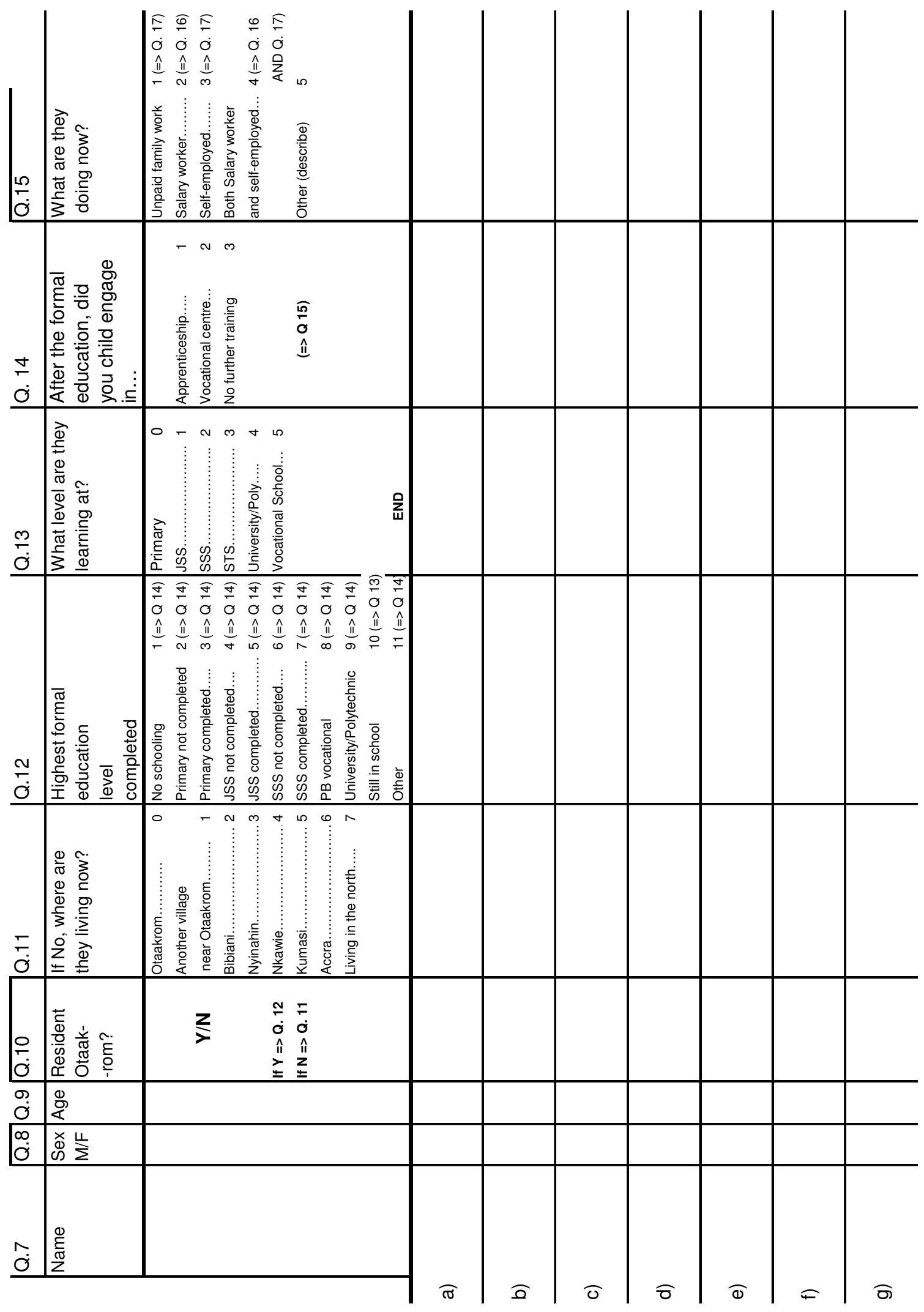




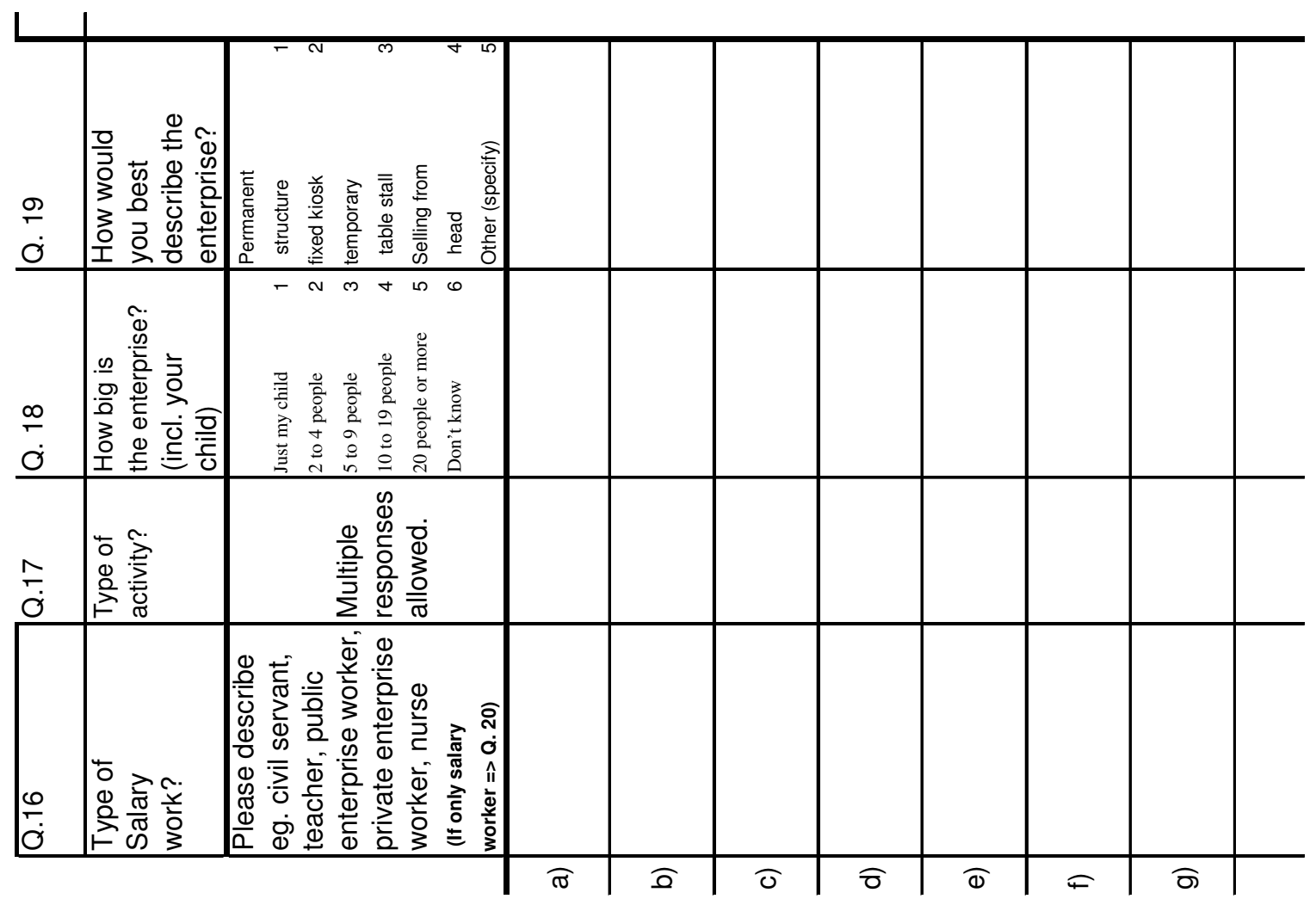




\section{APPENDIX D: Methodological choices, approach and considerations}

\section{D.0. Introduction: the research design}

Chapter 1 outlined the methodological approach used and the research sites chosen in this study. It is useful, however, to examine further the choices, approach and considerations that shaped this research.

Since the mid-1990s, academic research into MSEs has been characterised by its transdisciplinarity, where research is driven not by the traditions of a particular discipline, but by the research problem (Gibbons, Nowotny, Limoges, Trow, Schwartzman and Scott, 1994). The examination of the relationship between school, skill and enterprise in this thesis required that two main sets of literature were drawn together. On the one hand the education and skills development literature (including the literature on traditional apprenticeships), and on the other hand the literature concerned with the informal sector, rural livelihoods and MSE development (including the literature examining pathways to enterprise and the literature that discusses the challenges faced by enterprises). This research therefore took this multi-disciplinary approach as a starting point from which to construct a research design.

The research design provided the "framework for the collection and analysis of [the] data" (Bryman, 2001: 29) and was important since it maximised the chance of producing research results that would be seen as credible by particular audiences. In this way the author is able to gain a greater awareness and understanding about the information collected (cf. Blaike, 2000). This can also feed back positively into future designs (cf. Kvale, 1996). ${ }^{416}$ From the outset I was intentionally very reflexive about my design and allowed it to constantly change as both my ideas and thoughts evolved and as certain unforeseen constraints arose. Indeed, it is to be expected in any piece of research spanning a number of years that research questions, theoretical approaches and methods will develop.

\footnotetext{
${ }^{416}$ Although Kvale in his article was actually referring to the need for reflexivity with respect to interviews (and not research designs), in the sense that by critiquing the strengths and weaknesses of particular questions or interview methods this would feed back positively into future interviews. The same principle is suggested here for 'research designs'.
} 


\section{D.1. Choices made: why Ghana, why this research and why this approach?}

\section{D.1.1. Why investigate skills development and MSEs in Ghana's informal economy?}

Chapter 1 explained the case and rationale for investigating skills development and MSEs in Ghana's informal economy. This will not be repeated here. Instead I will briefly re-state the reasons for choosing the three types of skill modality examined in chapters 6 and 7 .

Chapter 6 examined the Integrated Community Centres for Employable Skills (ICCES). This was chosen for a number of reasons. First, my prior knowledge of, and contact with this programme (since 2001) made access very easy. Second, it is a useful example of formal training, delivered in a VTI over three years, which has the specific intention of training youth for self-employment in the informal sector. Third, it has not been examined previously in the literature.

Chapter 7 (section 1) examined the Skills Training and Entrepreneurship Programme (STEP). This was a useful example of short-duration modular training that had the intention of promoting self-employment through the provision of skills and micro-credit. STEP has been very high on the policy and political agenda recently (2003-2005) which further made it an interesting choice. Other short duration skills programmes, like the World Bank funded Vocational Skills and Informal Sector Support Project (VSP) (1995-2001) (Korboe, 2001a, b; World Bank, 1995) or the IFAD Rural Enterprise Project (REP) (1995-ongoing) (GoG/IFAD, 2000) have already been extensively evaluated and discussed in the literature.

Chapter 7 (section 2) examined traditional apprenticeship training. As the largest provider of skills training for the informal micro-enterprise sector, this had to be examined. However, the rural focus of my research should complement other research done on apprenticeship in Ghana that usually examines urban settings.

\section{D.1.2. Why look at the rural informal economy?}

Chapter 2 highlighted the urban bias associated with the informal sector literature. This study intended to contribute to the wider understanding of Ghana's informal sector by examining it in rural areas. 


\section{D.1.3. What is rural?}

It is not always clear exactly what a 'rural settlement' is defined as, and thus the term itself needs clarifying. Some define it numerically, as being less than 2000 people (Mead, 1999: 62), less than 5000 people $^{417}$ or less than 15,000 people (Aryeetey, 1994: 14). However as Livingstone (1991: 652) rightly notes, to denote a place as 'rural' by how big it is, is to a great extent arbitrary. The Ghana Statistical Service defines rural areas as having the following characteristics: ${ }^{418}$ the majority of the population are engaged in primary economic activities (farming, fishing, hunting); an area where the per capita income is significantly lower than the national average; an area with a general lack of basic social amenities. For this research rural is defined more by characteristic than size and is taken as meaning an area where the predominant activities are or concerned with agricultural activities.

\section{D.1.4. Where in rural Ghana?}

During the research design phase, I initially intended to have three rural research sites in different parts of Ghana: one in Ashanti and two in Upper Volta Region. I had visited all these sites before as Schatzman and Strauss (1973, in Hammersley and Atkinson, 1995: 37-38) advise:

[The researcher should] case possible research sites with a view to assessing their suitability, the feasibility of carrying out research there, and how access might best be accomplished.

However, as my research design developed I made the decision to focus on a smaller area, with three sites closer together: Otaakrom and Nyinahin in Atwima Mponua District (Ashanti Region) and Bibiani in Bibiani-Anhwiaso-Bekwai District (Western Region). This was because, prior to commencing the PhD fieldwork, I had some 16 months experience working in this area: 14 months working in a VTI and living at village-level, and 2 months doing MSc research on rural MSE financing. I decided that it would be better to take advantage of the prior knowledge and excellent contacts and access I had in this locality.

\footnotetext{
${ }^{417}$ Ghana Statistical Services, 1995, in Kpemlie, 1998: 7.

${ }^{418}$ Ghana Statistical Services, 1995, in Kpemlie, 1998: 7.
} 


\section{D.2. Methodological approach}

As noted in chapter 1, six main approaches were used to collect data: i) retrospective interviews with 114 masters in rural manufacturing enterprises; ii) interviews with 160 traditional apprentices; iii) questionnaires, interviews and focus groups with 162 graduates from 7 vocational training centres; iv) a basic household survey ( 81 households) in one rural community (involving a wealth-ranking and mapping exercise) that captured data on 165 youth; v) interviews with other key informants (e.g. village, district and national officials, as well as development partner officials); and, vi) informal (participant) observation of education, skills and enterprises in rural communities. Having covered the first four approaches earlier (chap.1.4 and Appendices A, B and C), it would be useful to say a few words on the last two approaches.

\section{D.2.1. Interviews with other key informants}

The names of key informants are not included in this thesis deliberately to protect their identity.

During the fieldwork, interviews were undertaken at the three main ministries related to the theme of this thesis: education (MoESS), manpower (MoMYE) and private sector development (MoTIPP). In each of these ministries there were different agencies whose head offices in Accra were also approached for information, for example ICCES, STEP, Ghana Education Service (GES), National Vocational Training Institute (NVTI), National Board for Small-Scale Industries (NBSSI), National Youth Employment Programme (NYEP).

Key individuals in the development partner (DP) community in Accra were also approached (e.g. education/TVET advisors, economists, rural livelihood specialists, private sector development advisors), for example in the ILO, World Bank, DFID, USAID, JICA. In a number of instances I was able to interview senior agency individuals who were visiting Ghana for research (e.g. in the case of the ILO). In addition, while doing interviews in the World Bank (Washington) and UNDP (New York) as part of DFID-funded work (see Palmer et al., 2007) I was also able 'piggy-back' questions specifically related to my $\mathrm{PhD}$. In this way I was able to access very senior individuals within these agencies.

The academic and research consultancy community in Accra was also approached to find out about current research being conducted and/or to have discussion related to my thesis. For 
example, visits were made to the University of Ghana (Centre for Social Policy Studies, Institute of Statistical, Social and Economic Research) (Legon), the Private Enterprise Foundation (Legon) and Associates for Change (Accra).

At the regional level, I was able to follow-up on national level interviews with agencies like ICCES, STEP, NBSSI. At the district level, interviews were conducted with assembly officials.

Some of the most valuable information, however, arose from countless informal discussions I had with those involved in education and skill delivery at the village level. Many of these individuals I have known for five years and count as friends. Our discussions led to the very detailed understanding of ICCES and STEP in particular, but also to TVET and rural MSE development more widely.

\section{D.2.2. Informal (participant) observation of education, skills and enterprises in rural communities}

While doing the doctoral fieldwork I was able to continue to do some work for ICCES (teaching, administration, planning etc.) which updated my first hand experience previously gained in 20012002. A further strategy adopted was to observe master-craftspeople, who I knew from the village, in their enterprises.

\section{D.2.3. The case study approach and issues of triangulation}

In effect there are multiple levels of case studies involved in this research. First, and foremost, Ghana is used a case study to illustrate the interaction amongst school, skill and enterprise. Second, the three main locations chosen (Otaakrom, Nyinhin and Bibiani) represent case studies of particular localities. Third, the three types of skills training programmes chosen (ICCES, STEP and apprenticeship) are all case studies of particular types of training modality (long-duration preemployment, short-duration modular and on-the-job respectively). Fourth, those interviewed in more detail (e.g. master-craftspeople and ICCES graduates/trainees) are themselves micro-level case studies.

The case study approach has a number of advantages and disadvantages. On the one hand: a) the emphasis on an intensive examination of a contextualised single case reveals the complexity and 
unique nature of the phenomenon (Yin, 1994); b) the use of a variety of data collection techniques allowing multiple triangulation should provide a rich depth of data (Bryman, 2001; Hakin, 2000; Stake, 1998); c) the use of multiple case studies allow for comparison and contrasting to occur (Hakin, 2000); d) the confidence in the general significance and robustness of research findings will increase with more case studies (Sudman, 1976 cited in Hakin, 2000).

However, the principle weakness is that the results can be strongly shaped by the interests, perspective and 'brought-self' of the researcher (Hakin, 2000; Reinharz, 1997). Moreover this method has been criticised for its lack of rigour and generalisability (Bryman, 2001).

Inherent in the case study approach is the use of multiple tools (in this case questionnaires, semistructured interviews, interviews with key informants and impromptu discussions) that serve as a cross check. In addition, since different information arises from different tools a more holistic view is obtained overall.

Triangulation itself has a number of strengths and weaknesses that should be noted. On the one hand, triangulation can help to mitigate personal bias associated with a single methodological approach since the use of a collection of methods is thought to reduce the effect of the peculiar biases of each one (Webb et al., 1966 in Blaikie, 2001). On the other hand, however: a) practical constraints relating to time and money will mean that any triangulation that does occur will be limited in time, depth, space and professionalism (of researcher multi-tasking); b) Mathison (1988: 14 in Blaikie, 2001: 267) points to ontological considerations, noting that different methods may tap different ways of knowing different realities; c) since triangulation rarely (if ever) leads to convergence the researcher still has to subjectively interpret the results. However, Blaike (2001) notes that provided the methods used follow a common research strategy, ontological problems are not an issue since all methods are interpreted within a consistent ontology.

\section{D.3. Considerations}

\section{D.3.1. Epistemological considerations}

In terms of the epistemological considerations that underpin the theory, the aim of the research to understand the situation from the perspective of the informants, not to 'discover' knowledge, 
but to see how informants socially construct it - is consistent with a constructionist epistemology (Crotty, 1998). The interpretivist theoretical perspective followed sees meaning as 'situated' in specific contexts (LeCompte and Schensul, 1999: 49). It is thus clear that the proposed methods of semi-structured interviews, the use of case studies, non-directive questioning use of impromptu discussions are consistent with these theoretical and epistemological underpinnings. Indeed Stake (1998) notes that researchers using case studies can "assist readers in the construction of knowledge" (p.95).

\section{D.3.2. Pragmatic considerations}

The initial design accepted that pragmatic considerations such as travel costs, contacts and access to information would be very important in the choice of location (Hammersley and Atkinson, 1995), but noted that these considerations would also directly affect the choice of research questions, methodology and theoretical approach. Main considerations include the issues of time, money and the comparative advantages the author has for conducting this type of research.

Firstly, it was necessary to adopt a feasible approach given the time-frame. Probably the most effective way of analyzing the school-skill-enterprise relationship would have been to organize longitudinal tracer studies with different groups of youth (e.g. those that had never been to school, those that had completed primary but not entered JSS, those that had completed JSS, those that had completed an apprenticeship or a VTI course). This would have required at least 5 years to do since it would be necessary to trace individuals into the labour market (or into skills training) for some time. Within the constraints of doctoral fieldwork this was not possible. Instead, I tried to do the next best thing: to get information from VTI graduates on their first destination (training or in the labour market) and, perhaps more usefully, to conduct retrospective tracers with those already working in the labour market.

Secondly, financial constraints directly affected the methods. While I was able to hire a full-time local research assistant to help with the interviews and questionnaires, it was not possible to have full-time assistance for the duration of the fieldwork.

Practical considerations arose from the author's various strengths and weaknesses related to personality and personal skills. The fact that I have spent sixteen months in rural Ghana before was a great help as it meant I already had a firm grasp of the culture and could more or less 'hit 
the ground running', not wasting (valuable) time settling in or being misled or confused because of cultural misunderstandings.

I was also able to judge much better what was and what was not feasible in the given time frame. Moreover, the many existing contacts in Ghana the author has from village to Ministry level were utilised. The research was also greatly assisted by the fact that I could demonstrate previous insider status as this allowed me to gain greater access to individuals (trust, rapport), situations, events, places or documents (cf. Agar, 1996). My dual position of being able to demonstrate previous insider status, while at the same time remaining an outsider, was advantageous since culture members are "often not conscious of the fundamental presuppositions that shape their vision" (Hammersley and Atkinson, 1995: 9). Although I cannot speak fluent Twi (the local language) I speak enough to be able to break down initial barriers and get informants laughing at my attempts. Obviously it would have been better if I could conduct all the interviews in Twi myself, since some information may be lost or mixed up in translation. Further, reliance on a translator can mislead the researcher since the translator can steer the research in the wrong direction or can lead the researcher to get either a good or bad impression of an informant depending on how they translate and what the personal interaction is like between them and the informant they are talking to. The Ghanaian proverb, Obrofotefo na oma obruni ye aye (It is the one who hears English [the interpreter] who directs the white man whom to praise), neatly sums this up.

\section{D.3.3. Ethical and power considerations}

The power relations between the researcher and the researched created a number of ethical problems concerning the knowledge generated. For many micro-enterprise owners, apprentices and VTI teachers, oburunis (lit. 'white men') in Ghana are associated with money and power (among other things), meaning that for me it was hard to escape a 'powerful' big-man image when interviewing these type of people. Some of those interviewed initially thought that I represented a bank, an NGO or development agency. However, for the interviews conducted with owners and apprentices I was accompanied by residents of that community - who were also my friends - and hence these local actors were able to legitimize my position and dispel rumors that I was able to provide financial support to these people. My working connection with ICCES at village level since 2001 also helped to legitimize my position and often an interview started with a discussion of the local ICCES. 
This power asymmetry also relates to the fact that the researcher defines the topic, situation and course of the interview (Kvale, 1996: 126), although I attempted to mitigate this in the in-depth interviews by encouraging respondents to talk of issues concerning them (while loosely keeping within my research parameters).

Another ethical issue connected to power relations I was aware of was that of the foreign researcher going into a developing country and extracting information for use abroad, so-called 'academic colonialism'. In order to counter this, the intention is for me to rewrite and substantially shorten some of the chapters in this thesis in collaboration with some individuals in Ghana - like the one on ICCES - so that the information can be used by these individuals to raise awareness of their situation.

These problems created by the perceived and actual power imbalance could only be minimized to an extent since certain derived characteristics of the researcher cannot be changed.

\section{D.4. PhD timetable}

1. October 2003 - September 2004: Literature reviews and research design constructed (methodology outlined, questionnaire designed, research questions formulated, choices made).

2. October 2004 - November 2005: Ghana fieldwork,

3. December 2005 - October 2006: Analysis and write up. 


\section{APPENDIX E}

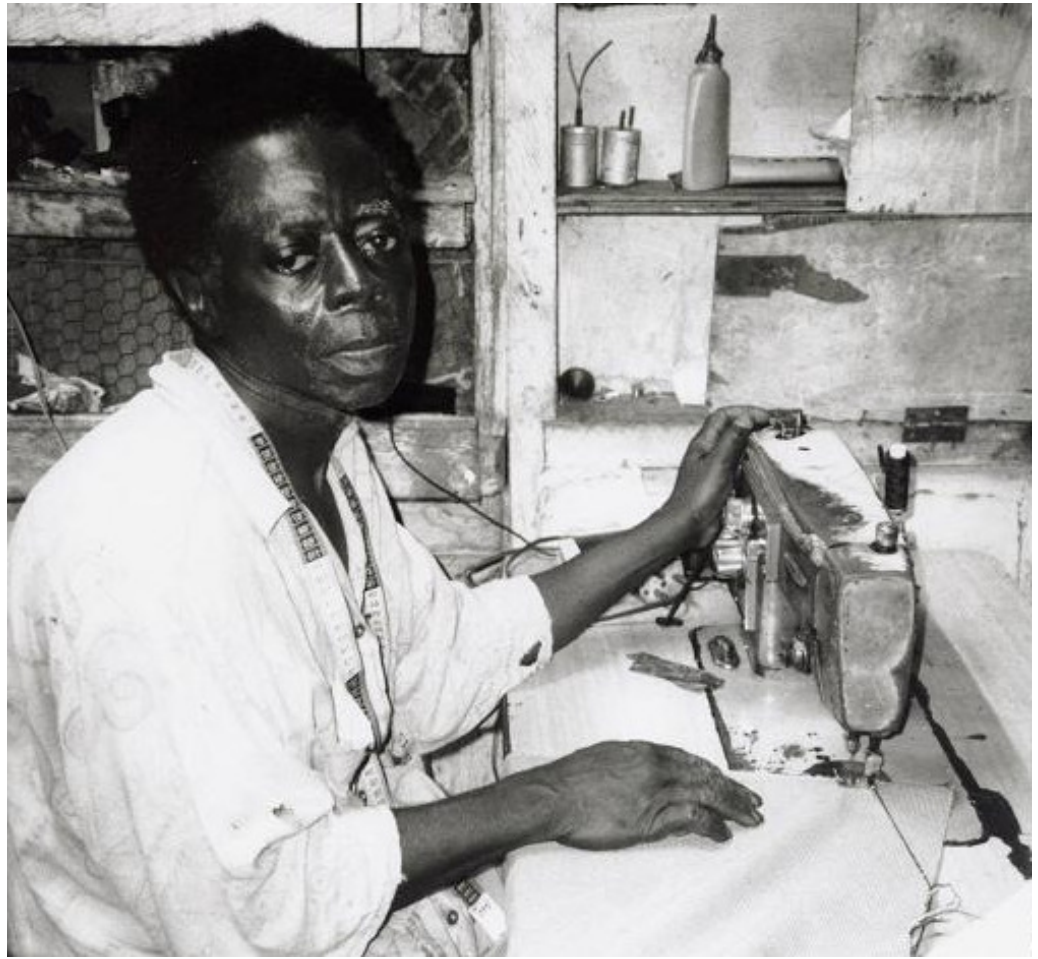

Photo 2: Papa Anthony, who described himself as 'the colonial man' (due to his age), a tailor, farmer and all round entrepreneur, NkawieKuma, Ashanti Region (July, 2003).

'For me, I don't like loan. At first I was just making poultry, so I borrowed money from somebody, later the money went away, the cocks died and I went myself into debt, so I don't like this loan business... at all koraa!' (Papa Anthony)

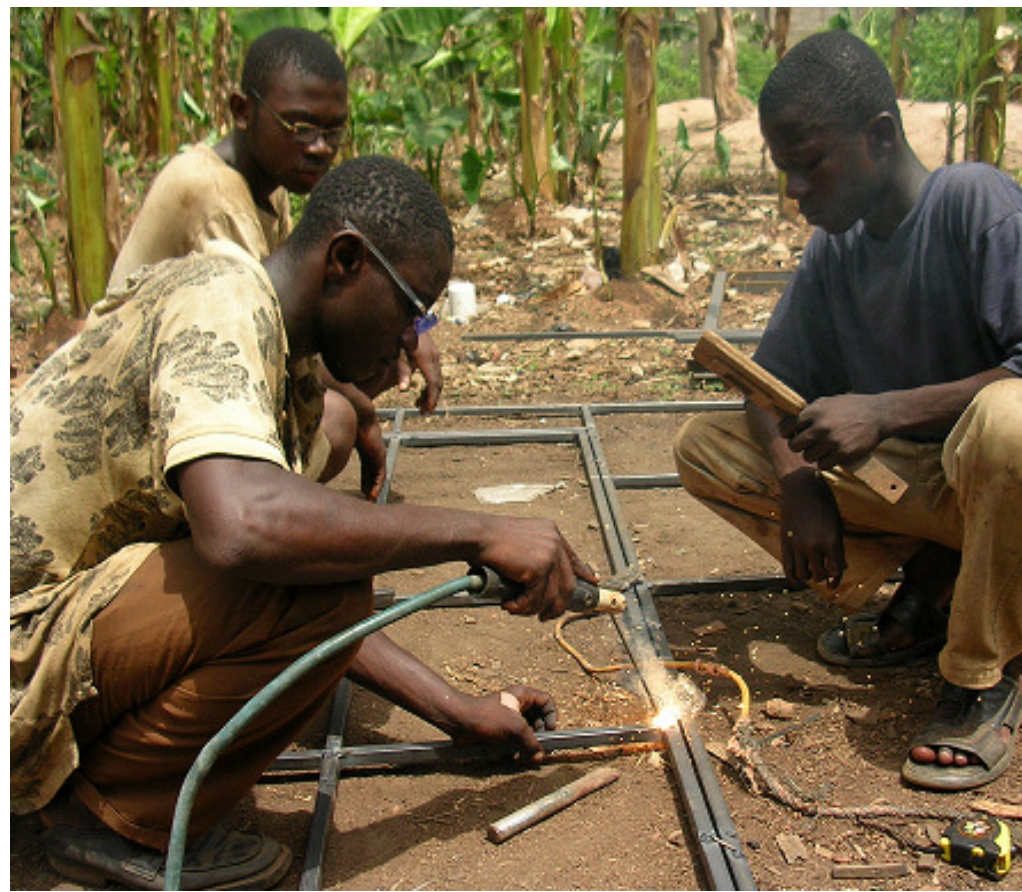

Photo 3: Welders working outside in Nyinahin. Note the lack of proper eye protectors and the use of sun-glasses as a substitute (July, 2005). 

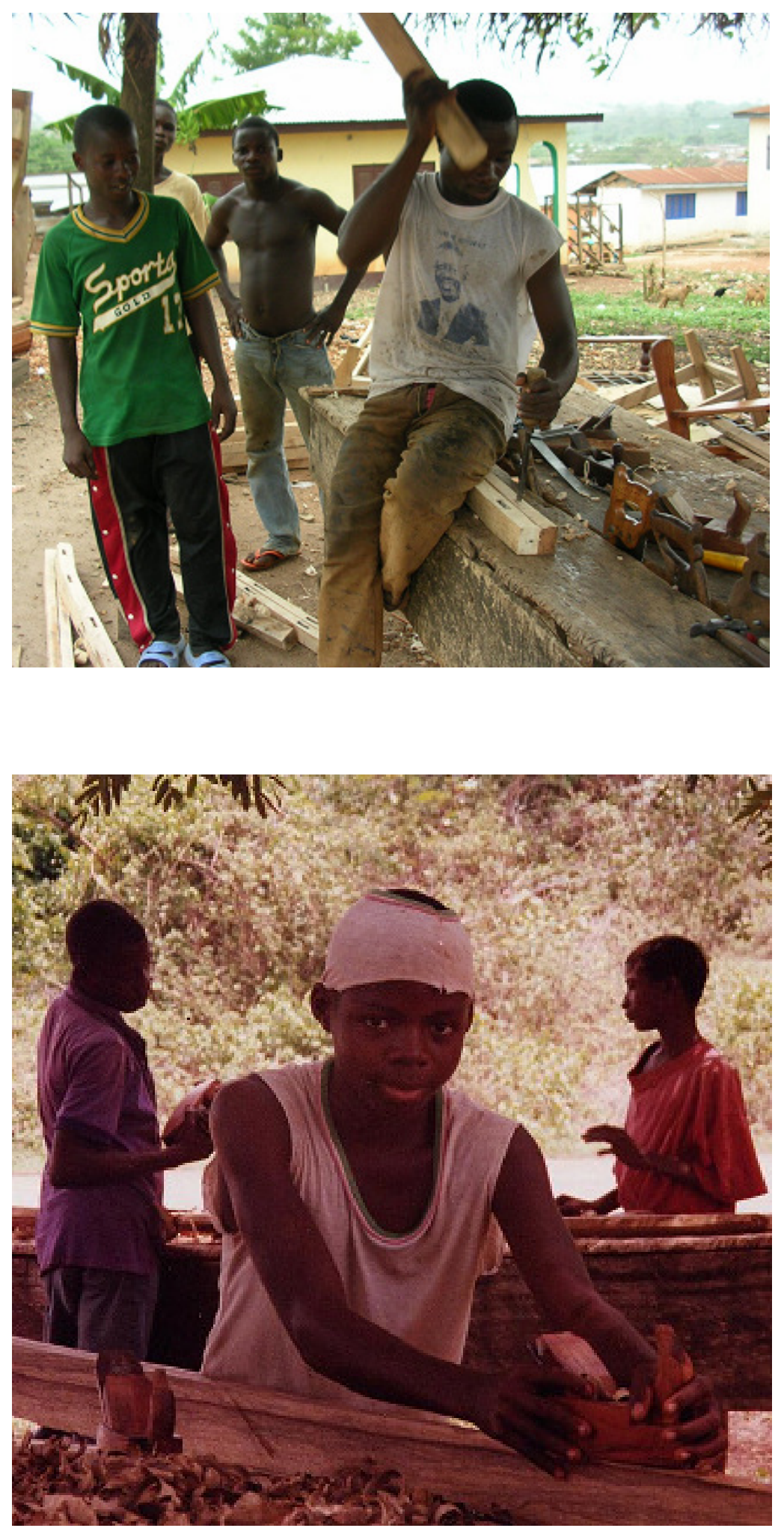

Photo 4: The master shows them how it is done in this carpentry enterprise. Note the outside location, the basic hand tools used and the lack of a wood clamp (so the master has to sit on the wood while chiselling).

Photo 5: Carpentry practical class at Otaakrom ICCES (2001). Note the similarities with the apprentices above: no uniform, lack of tools (e.g. clamp), training outside. 

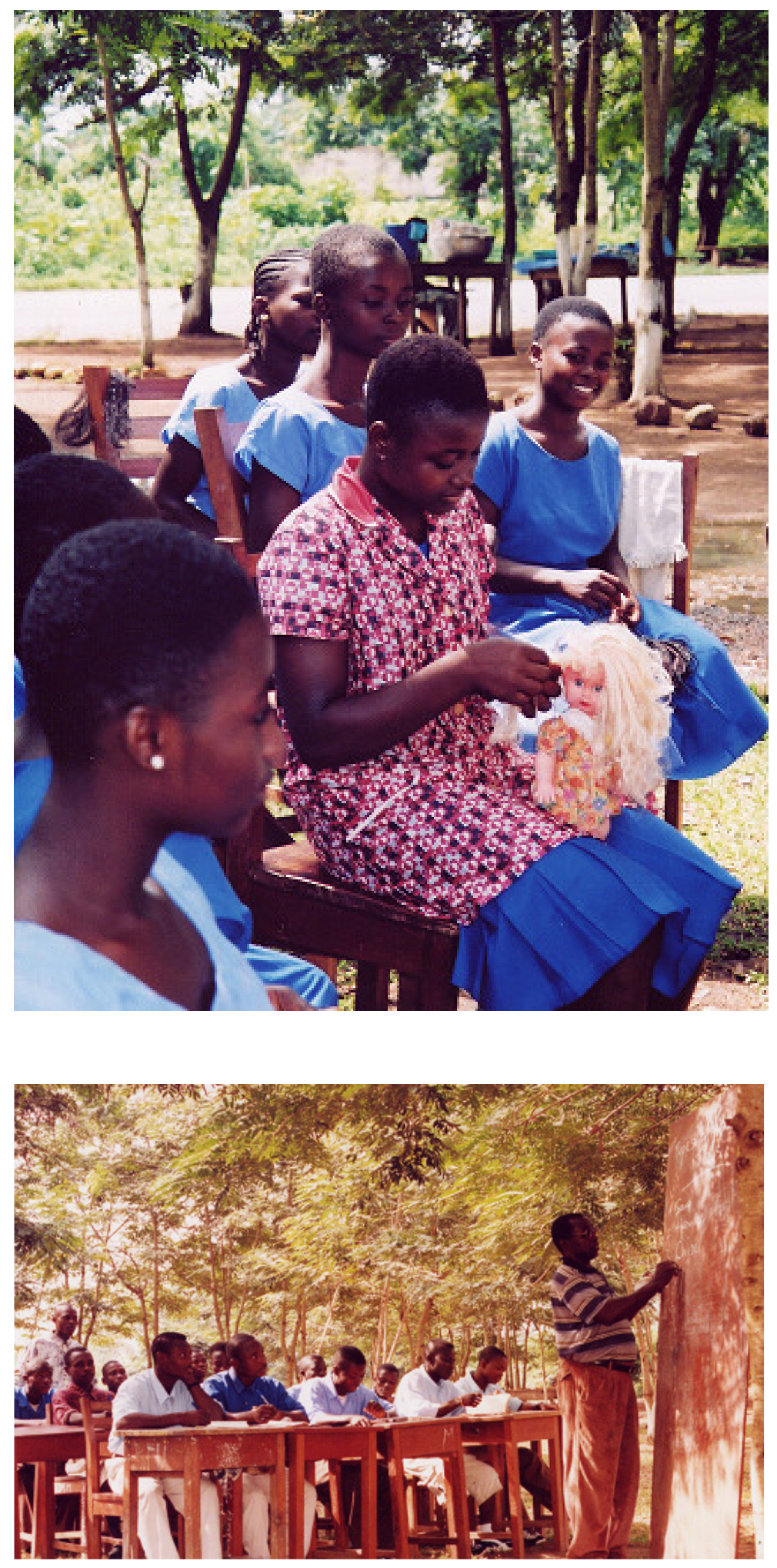

Photo 6: Hairdressing at Otaakrom ICCES (2003). Note that there is only one practice doll so while one girl learns hands-on, the other apprentices learn through observation similar to apprentices.

Photo 7: Under the sun: lack of classroom space in many ICCES centres means that classes often occur outside in the dry season. 

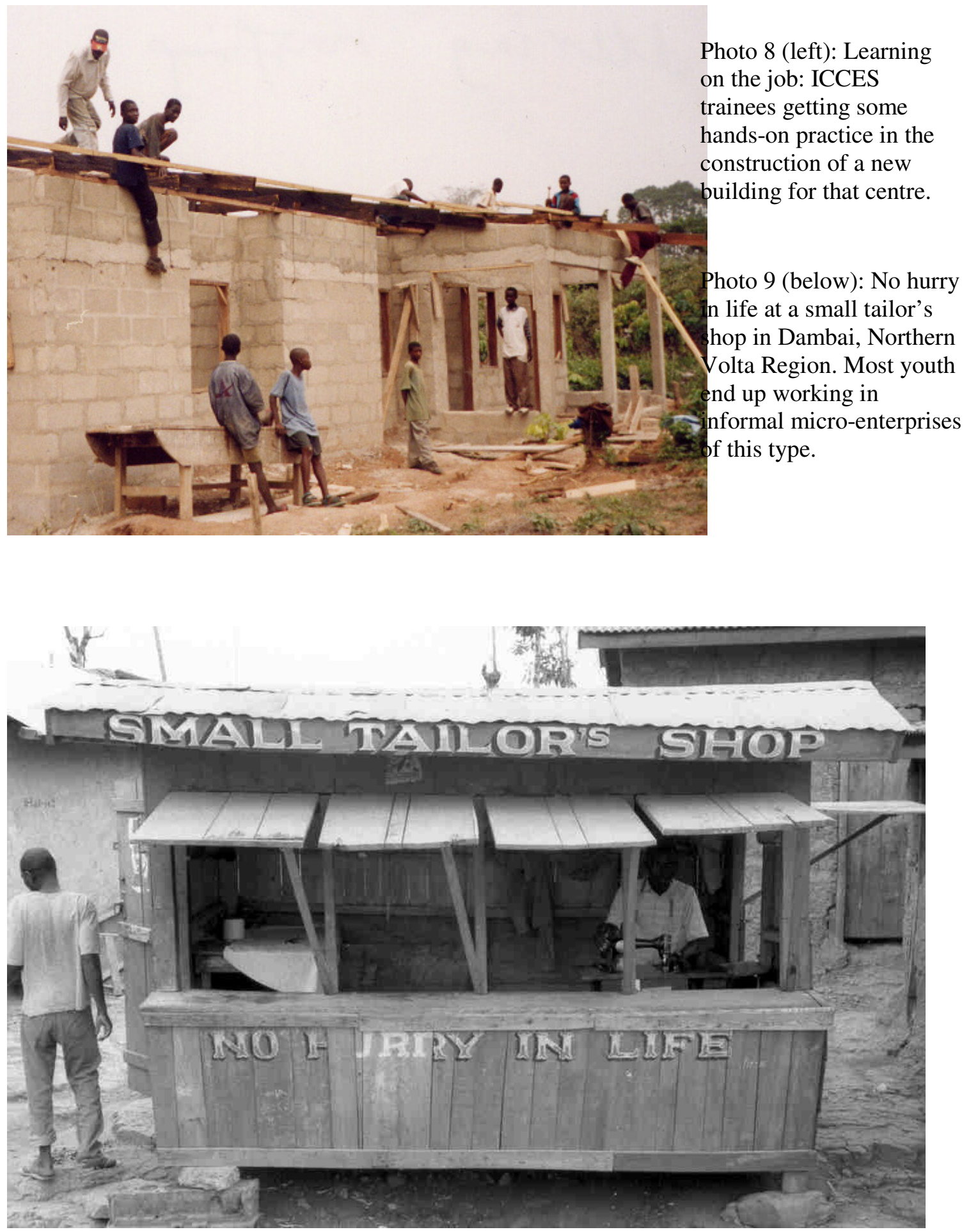


\section{REFERENCES}

(Mimeo refers to unpublished documents)

Aboagye, A. and Gozo, K. (1986) The informal sector: a critical appraisal of the concept, in ILO/JASPA, The challenge of employment and basic needs in Africa, OUP: Nairobi.

Adam, S. (1993) Review of the National Open Apprenticeship System (Nigeria), Norrag News 14: 58-61.

Adams, A. (2006) The role of skills development in the transition to work: a global review (draft of July $25^{\text {th }}$ 2006), background for the World Development Report 2007.

Adams, D. and Von Pischke, J. (1992) Microenterprise credit: Déjà vu? World Development 20 (10): 1463-70.

Addae-Mensah (2000) Education in Ghana: A tool for social mobility or social stratification, J. B. Danquah Memorial Lectures: Accra.

Adebayo, A. (2002) Money, credit and banking in colonial and postcolonial West Africa, in Falola and Jalloh (2002).

Adu-Amankwah, K. (nd) Trade unions in the informal sector. Downloaded 05.06.06 from http://www.streetnet.org.za/english/ghana.htm

Afenyadu, D., King, K., McGrath, S., Oketch, H. Rogerson, C. and Visser, K. (1999) Learning to compete: Education, training and enterprise in Ghana, Kenya and South Africa, DFID Education Research, No.42. DFID: London.

African Union (2004) Declaration on employment and poverty alleviation in Africa, Assembly of the African Union, third extraordinary session on employment and poverty alleviation 08.09.04-09.09.04, Ouagadougou.

Afrisat (1997) Observatoire economique et statistique d'afrique subsaharienne, Proceedings of the seminar on the informal sector and economic policy in sub-Saharan Africa (10.03.9714.03.97), Afrisat: Bamako.

Agar, M. (1996) The professional stranger. An informal introduction to ethnography ( $2^{\text {nd }}$ Ed.), Academic Press: London.

Agbodeka, F. (1992) An economic history of Ghana, Ghana Universities Press: Accra.

Ahadzie, W. (2003) Non-formal training: a study of the traditional apprenticeship. system in Ghana, doctoral thesis (mimeo), University of Ghana: Legon.

Ahadzie, W. (2000) Ghana's education reform: equalising opportunities or marginalising the poor? Social Policy. Journal of the Centre for Social Policy Studies 1(2): 18-33.

Ahadzie, W. and Apt, A. (2002) Women's access to rural infrastructure in rural Ghana; how real? (mimeo) Centre for Social Policy Studies, University of Ghana: Legon.

Akpalu, W. and Bhasin, V. (2001) Impact of micro-finance enterprises on the efficiency of microenterprises in Cape Coast, IFLIP Research Paper 01-5, ILO: Geneva.

Akyeampong, A. (2005) Preparing students for work in Ghana: is vocationalization of secondary education working? $8^{\text {th }}$ Oxford International Conference on Education and Development, 13-15.09.05, New College: Oxford.

. (2002) Vocationalization of secondary education in Ghana, a case study, Regional Vocational Skills Development Review, World Bank: Washington.

Akyeampong, K. and Stephens, D. (2002) Exploring the backgrounds and shaping of beginning student teachers in Ghana: toward greater contextualisation of teacher education, International Journal of Educational Development 22: 261-274.

Altman, M. (2003) Jobless or job creating growth? Some preliminary thoughts, Paper presented at the TIPS/ DPRU annual forum 8-10.09.03, HSRC.

Anheier, H. and Seibel, H. (1987) Small-scale industries and economic development in Ghana: Business behavior and strategies in informal sector economies, Verlag breitenbach: Saarbrucken. 
Anyemedu, K. (2000) Trade union responses to globalization: case study on Ghana, Discussion papers DP/121/2000, ILO: Geneva.

Apena, A. (1997) Colonization, commerce, and entrepreneurship in Nigeria: the Western Delta, 1914-1960, Peter Lang: New York.

ApT (1993) The informal sector: state of the art review, ApT: Moreton-in-the-Marsh.

Ardener, S. and Burman, S. (Eds.) (1996) Money-go-rounds. The importance of rotating savings and credit association for women, Berg: Oxford/Washington.

Arhin, K. (1995) Monetization and the Asante State, in Guyer (1995).

. (1979) West African traders in Ghana in the nineteenth and twentieth centuries, Longman: London/New York.

. (1972) The Ashanti rubber trade with the Gold Coast in the eighteen-nineties, Africa: Journal of the International African Institute 42(1): 32-43.

Arthur, P. (2006) The state, private sector development, and Ghana's "Golden Age of Business", African Studies Review 49(1): 31-50.

Aryee, G. (1976) Effects of formal education and training on the intensity of employment in the informal sector: a case study of Kumasi, Ghana, World Employment Programme 2-18, Working Papers 14. ILO: Geneva.

Aryeetey, E. (1996) (Ed.) Small enterprise credit in West Africa, British Council: London and Accra.

. (1994) Financial integration and development in Sub-Saharan Africa: a study of informal finance in Ghana, Working Paper No. 78. ODI: London.

Aryeetey, E., Baah-Nuakoh, A., Duggleby, T., Hettige, H. and Steel, W. (1994) Supply and demand for finance of small enterprises in Ghana, World Bank Discussion Papers 251, World Bank: Washington.

Aryeetey, E. and Bortei-Doku, E. (1996) Mobilizing cash for business: Women in rotating susu clubs in Ghana, in Ardener and Burman (1996).

Aryeetey, E., Laryea, A., Antwi-Asare, T., Baah-Boateng, W., Turkson, E., Codjoe, E. and Ahortor, C. (2005) Globalization, employment and poverty reduction: a case study of Ghana, ISSER, University of Ghana: Legon.

Ashong, K. and Smith, D. (2001) Livelihoods of the poor in Ghana. A contextual review of Ghana-wide definitions and trends of poverty and the poor with those of peri-urban Kumasi, Centre for the Development of People: Kumasi / Natural Resources Institute: Chatham.

Assad, R. (1993) Formal and informal institutions in the labour market with applications to the construction sector in Egypt, World Development 21(6): 925-39.

Atchoarena, D. and Delluc, A. (2001) Revisiting technical and vocational education in SubSaharan Africa: an update on trends, innovations, and challenges, IIEP/Prg.DA/01.320, IIEP: Paris.

Atwima District Assembly (ADA) (2003) The district at a glance, Atwima District Assembly: Nkawie, Ghana.

Austin, G. (2005) Labour, land and capital in Ghana. From slavery to free labour in Asante, 1807-1956, University of Rochester Press: Rochester.

- (1995) Between abolition and Jihad: the Asante response to the ending of the Atlantic slave trade, 1807-1896, in Law, R. (Ed.) From slave trade to 'legitimate' commerce. The commercial transition in nineteenth-century West Africa, University Press: Cambridge.

Austin, G. and Sugihara, K. (1993) Local suppliers of credit in the third world, 1750-1960, Macmillan Press: London.

Ayamdoo, C., Casely-Hayford, L., Palmer, R. and Thompson, N. (2006) Aid and donor partnerships' in the Ghana education sector: a critical review of the literature and progress, Improving the Outcomes of Education for Pro-Poor Development, Working Paper, CAS: Edinburgh/AFC: Accra. 
Baah-Nuakoh, A. (2003) Environment, informal sector and factor markets. Studies on the Ghanaian economy Vol. 2, Woeli Publishing Services: Accra.

Bagachwa, M. (1997) The rural informal sector in Tanzania, in Bryceson and Jamal (1997).

Bangasser, P. (2000) The ILO and the informal sector: an institutional history. Employment Paper 9, ILO: Geneva.

Barrett, C, Reardon, T. and Webb, P. (2001) Nonfarm income diversification and household livelihood strategies in rural Africa: concepts, dynamics, and policy implications, Food Policy 26: 315-331.

Barwa, S. (1995) Structural adjustment programmes and the urban informal sector in Ghana, Issues in development, Discussion Paper 3, ILO: Geneva.

Bas, D. (1989) On-the-job training in Africa, International Labour Review 128: 485-496.

Bascom, W. (1952) The Esusu: a credit institution of the Yoruba, Journal of the Royal Anthropological Institute of Great Britain and Ireland 82(1): 63-69.

Bauer, P. (1954) West African trade. A study of competition, oligopoly and monopoly in a changing economy, Cambridge University Press: Cambridge.

Bening, R., (1990) A history of education in northern Ghana 1907-1976, Ghana University Press: Legon.

Bennell, P. (1999) Learning to change: skills development among the economically vulnerable and socially excluded in developing countries, Employment and Training Papers 43, ILO: Geneva.

. (1996a) Rates of return to education: does the conventional patten prevail in SubSaharan Africa? World Development 24(1):183-199.

. (1996b) General versus vocational secondary schooling in developing countries: a review of the rates of return evidence, Journal of Development Studies 33(2): 230-247.

Beveridge, M., King, K., Palmer, R. and Wedgwood, R. (Eds) (2005) Reintegrating education, skills and work in Africa, CAS: Edinburgh.

Birks, S., Fluitman, F., Oudin, X. and Sinclair, C. (1994) Skills acquisition in micro-enterprises: evidence from West Africa, OECD: Paris.

Blaike, N. (2000) Designing social research. The logic of anticipation, Polity: Oxford.

Blunch, H., Canagarajah, S. and Raju, D. (2001) The informal sector revisited: a synthesis across space and time, Social Protection Discussion Paper Series, No. 0119, World Bank: Washington.

Boapeah, S. (1996) Financing small rural enterprises through informal arrangements: a case study of the Ahanta West District of Ghana, in Aryeetey (1996).

Boateng, A. (2002) ICCES: Ashanti region annual report, mimeo: Kumasi.

Boeh-Ocansey, O. (1997) Ghana's microenterprise and informal sector... bedrock for national development? Perspectives in education, training and other support services. Anansesem Publications: Accra.

. (1995) Education and training for the informal sector: Ghana country study, in Leach, F. (Ed.) Education and training for the informal sector, Vol 2, Country Studies, Education Research Paper 11, DFID: London.

Bortei-Doku Aryeetey, E. (2001) Human capital development for socio-economic transformation, ISSER, University of Ghana: Legon.

Botchie, G. and Ahadzie, W. (2004) Poverty reduction efforts in Ghana; the skill development option, mimeo CSPS/ISSER, University of Ghana: Legon.

Bourret, F. (1949) The Gold Coast. A survey of the Gold Coast and British Togoland, 1919-1946, Oxford University Press: London.

Bromley, R. (1978) The urban informal sector: why is it worth discussing? World Development 6(9/10): 1033-1039.

Brown, G. (1964) British educational policy in West and Central Africa, The Journal of Modern African Studies 2(3): 365-377. 
Brownlee, A. (2000) Making ICCES work: an action plan for change, Western and Central Region, mimeo.

Bryceson, D. (2004) Poverty policies or policy poverty: paradoxes of economic reform and occupational displacement in Sub-Saharan Africa, seminar presented at CAS' seminar series (mimeo), 14.01.04 Edinburgh.

. (2002a) The scramble in Africa: reorienting rural livelihoods, World Development 30(5): 725-739.

. (Ed.) (2002b) Alcohol in Africa. Mixing business, pleasure and politics, Heinemann:

Portsmouth.

- (2002c) Multiplex livelihoods in rural Africa: recasting the terms and conditions of gainful employment, Journal of Modern African Studies, 40(1): 1-28.

. (1997a) Deagrarianisation in Sub-Saharan Africa: acknowledging the inevitable, in Bryceson and Jamal (1997).

. (1997b) Deagrarianisation: blessing or blight? in Bryceson and Jamal (1997).

(1996) Deagrarianisation and rural employment in Sub-Saharan Africa: a sectoral perspective, World Development 24(1): 97-111.

Bryceson, D. and Jamal, V. (Eds.) (1997) Farewell to farms, Ashgate: Aldershot.

Bryman, A. (2001) Social research methods, Oxford University Press: Oxford.

Buckley, G. (1997) Microfinance in Africa: is it either the problem or the solution? World Development, 25(7): 1081-1093.

. (1996) Superstitions, the family and values in microenterprise development, Small Enterprise Development, 7(4): 13-21.

Budu-Smith, J. (1997) Vocational and technical education, in Boeh-Ocansey (1997).

Caillods, F. (2003) Do the poverty reduction strategy papers get to the root of EFA problems? Results of an IIEP/DFID review of 18 papers, IIEP Newsletter XXI(4), IIEP-UNESCO: Paris.

. (1993) Reforms in the organisation of vocational education and training: convergences and divergences, Workshop on new trends in training policy, 18-20 October, ILO, Geneva.

Callaway, A. (1964) Nigeria's indigenous education: the apprentice system, Odu: University of Ife Journal of African Studies 1(1), 62-79.

. (1963) Unemployment among African school leavers, Journal of Modern African Studies, 1(3): 351-371.

Canagarajah, S. and Mazumdar, D. (1997) Employment, labor markets, and poverty in Ghana, World Bank: Washington.

Canagarajaha, S. Newman, C. and Bhattamishra, R. (2001) Non-farm income, gender, and inequality: evidence from rural Ghana and Uganda, Food Policy 26: 405-420.

Canagarajah, S. and Pörtner, C. (2003) Evolution of poverty and welfare in Ghana in the 1990s: achievements and challenges, Africa Region Working Paper Series No. 61, World Bank: Washington.

Carter, S. and Rosa, P. (1998) Indigenous rural firms: farm enterprises in the UK, International Small Business Journal 16(4): 15-27.

Cavalcanti, C. (2005) Ghana: recent trends in growth and poverty reduction. Downloaded 20.06.06 from http://www.isser.org/69\%20Cavalcanti.pdf

Chambers, R. (1983) Rural development. Putting the last first, Prentice Hall: London.

Chant, S. and Jones, G. (2005) Youth, gender and livelihoods in West Africa: perspectives from Ghana and the Gambia, Children's Geographies 3(2): 185-199.

Charmes, J. (2005) Rethinking Africa's ordinary economies: the informal/formal and the farm/non-farm divides, in Beveridge et al. (2005). 
Charmes, J. (1999) Micro-enterprises in West Africa, in King, K. and McGrath, S. (Eds.) Enterprise in Africa, between poverty and growth. Intermediate Technology: London.

Chen, M. (2001) Women in the informal sector: a global picture, the global movement. SAIS Review 11(1): 71-82.

Chen, M., Sebstad, J. and O'Connell, L. (1999) Counting the invisible workforce: the case of home-based workers, World Development 27(3): 603-610.

Chigunta, F., Schnurr, J., James-Wilson, D. and Torres, V. (2005) Being "real" about youth entrepreneurship in Eastern and Southern Africa., Draft SEED Working Paper No. 72, ILO: Geneva.

Clark, G. (1994) Onions are my husband. Survival and accumulation by West African market women, University of Chicago Press: Chicago/London.

(1988) Price control of local foodstuffs in Kumasi, Ghana, 1979, in Clark, G. (Ed.) Traders versus the state. Anthropological approaches to unofficial economies, Westview Press: Boulder/London.

Coulombe, H. (2004) Construction of the census-based Ghana poverty map, paper presented at ISSER-Cornell International Conference on Ghana at the Half Century, Accra, July 2004.

Commission for Africa (2005) Our common interest: report of the commission for Africa, DFID: London.

Crotty, M. (1998) The foundations of social research. Meaning and perspective in the research process, Sage: London.

Cruise O'Brien, R. (1972) Urban unemployment in Africa, Journal of Modern African Studies 10(1): 109-112.

Daniels, L. (1999) The role of small enterprises in the household and national economy of Kenya: a significant Contribution or a Last Resort? World Development 27(1): 55-65.

Davies, R. (1979) Informal sector or subordinate mode of production? A model, in Bromley, R. and Gerry, C. (Eds.) Casual work and poverty in third world cities, John Wiley and Sons: Chichester.

Dawson, J. (1997) Beyond credit: the emergence of high-impact, cost-effective business development services, Small Enterprise Development 8 (3): 15-25.

. (1993) Impact of structural adjustment on small enterprises sector: a comparison of the Ghanaian and Tanzanian experiences, in Helmsing, A. and Kolstee, Th. (Eds.), Structural adjustment, financial policy and assistance programmes in Africa, IT Publications: London.

Derrick, J. (1984) West Africa's worst year of famine, African Affairs, 83(332): 281-299.

De Soto, H. (2001) Dead capital and the poor, SAIS Review 11(1): 13-43.

DFID (2006a) The importance of secondary, vocational and higher education in development, Briefing paper July 2006, DFID: London.

. (2006b) Eliminating world poverty. Making governance work for the poor, White Paper on International Development, DFID: London.

. (2000) Eliminating world poverty: Making globalisation work for the poor, White Paper on International Development, DFID: London.

Dingwall, R. (1997) Accounts, interviews and observations, in Miller, G. and Dingwall, R. (Eds.) Context and method in qualitative research, Sage: London.

Dijk, van, M. (1997) Economic activities of the poor in Accra, in Bryceson and Jamal (1997).

Donge, van, J. (2002) Into the black box of Ghanaian education: why do increased inputs not lead to better educational outputs? Preparatory Study for the Operations Evaluations Department of the World Bank. Mimeo.

Dore, R. (1976) The diploma disease, Unwin: London.

Duggleby, T., Aryeetey, E. and Steel, W. (1992) Formal and informal finance for small enterprises in Ghana, Industry Series No. 61, World Bank: Washington. 
Dzorgbo, D. (2001) Ghana in search of development. The challenge of governance, economic management and institution building, Ashgate: Aldershot.

Ellis, F. (2000) The determinants of rural livelihood diversification in developing countries, Journal of Agricultural Economics 51(2): 289-302.

Ellis, F. (1998) Household strategies and rural livelihood diversification, Journal of Development Studies 35(1): 1-38.

Evers, H. and Schrader, H. (Eds.) (1994) The moral economy of trade. Ethnicity and developing markets, Routledge: London/New York.

Fadahunsi, A. and Rosa, P. (2002) Entrepreneurship and illegality: insights from the Nigerian cross-border trade, Journal of Business Venturing 17(5):397-429.

Falola, T. and Jalloh, A. (Eds.) (2002) Black business and economic power, University of Rochester Press: Rochester.

Falola, T. (1995) Money and informal credit institutions in colonial Western Nigeria, in Guyer (1995).

FAO (1998) The state of food and agriculture. Part 3: Non-farm income in developing countries. Downloaded 14.03.06 from www.fao.org/docrep/w9500e/w9500e12.htm

Fine, B. and Boateng, K. (2000) Labour and employment under structural adjustment, in Aryeetey, E., Harrigan, J., and Nissanke, M., (Eds.) Economic reforms in Ghana: the miracle and the mirage, Africa World Press: Trenton.

Fluitman, F. (2005) Poverty reduction, decent work, and the skills it takes or: towards correcting a partial view of training needs in African development, in Beveridge et al. (2005). . (2001) Working, but not well. Notes on the nature and extent of employment problems in Sub-Saharan Africa, Occasional papers ITC/ILO: Turin.

. (1994) Traditional Apprenticeship, in Husén, T. and Postlethwaite, T. (Eds.) International encyclopedia of education ( $\left.2^{\text {nd }} \mathrm{Ed}\right)$, Pergamon: Oxford. . (1989) Training for work in the informal sector, ILO: Geneva.

Fluitman, F., and Haan, H. (2002) Informal sector training, in World Bank study on Vocational skills development in Sub-Saharan Africa. Debates In Skills Development, Paper 7, WGICSD, ILO/NORRAG/SIDA: Edinburgh.

Foster, P. (2002) Commentary. The vocational school fallacy revisited: Education, aspiration and work in Ghana 1959-2000, International Journal of Educational Development 22: 27-28.

. (1975) Dilemmas of educational development: what we might learn from the past, Comparative Education Review 19(3): 375-392.

. (1965a) Education and social change in Ghana, Routledge and Kegan Paul: London.

. (1965b) The vocational school fallacy in development planning, in Anderson, C. and Bowman, M. (Eds.) Education and economic development, Aldine: Chicago.

Frazer, G. (2006) Learning the master's trade: apprenticeship and human capital in Ghana, Journal of Development Economics, 81(2): 259-298.

Frimpong-Ansah, J. (1991) The vampire state in Africa. The political economy of decline in Ghana, James Currey: London.

Fyle, M. (2002) Indigenous values and the organisation of informal sector business in West Africa, in Falola and Jalloh (2002).

Gannon, M. (1983) The Basle mission trading company and British colonial policy in the Gold Coast, 1918-1928, Journal of African History 24(4): 503-515.

Gibb, A. and Ritchie, J. (1982) Understanding the process of starting a small business, European Small Business Journal 1(1): 26-46.

Gibbons, M., Nowotny, H., Limoges, C., Trow, M., Schwartzman, S. and Scott, S. (1994) The new production of knowledge: the dynamics of science and research in contemporary societies, Sage: London. 
Ghana Industrial Skills Development Centre (GISDC) (2006a) Short project outline (March), mimeo: Accra.

Glewwe, P. (2002) Schools and skills in developing countries: education policies and socioeconomic outcomes, Journal of Economic Literature 40(2): 436-482.

Ghana News Agency (GNA) (2006a) National employment policy in the offing, General News 21.04.06.

. (2006b) No seed money for STEP graduates in Bolga, General News 27.03.06.

. (2006c) Govt to create 155,000 jobs, Business News 03.10.06.

. (2005a) Govt trains 27,000 people in 46 trades, Business News 24.11.05.

. (2005b) Ministry to introduce agriculture training into STEP, General News 28.07.05.

. (2005c) 27,000 Unemployed gets jobs, General News 19.05.05.

. (2005d) Govt to start Ghana youth employment programme, Business News 18.05.05.

. (2005e) Government support STEP graduates, General News 17.04.05.

. (2004) STEP programme trains 14,611 in various vocational skills, General News

22.11.04.

. (2003a) Government offers employment to 3,500 people, General News 05.11.03.

. (2003b) Government sets aside 10 billion cedis for skills training, 01.08.03.

. (2002) Ghana's unemployment rate is 11.2\% - Ministry, General News 05.08.02.

. (2001a) Government will honour election promises, General News 05.03.01.

. (2001b) NPP denies promising to create 750,000 jobs, General News 08.03.01.

. (2001c) Registration of unemployed extended, General News 16.11.01.

Gockel, A. and Akoena, S. (2002) Financial intermediation for the poor: credit demand

by micro, small and medium scale enterprises in Ghana. A further assignment for financial sector policy? IFLIP Research Paper 02-6 ILO: Geneva.

Gold Coast (1952) Annual report on the Gold Coast for the year 1951, His Majesty's Stationary Office: London.

. (1951) Accelerated development plan for education, 1951, Government Printing Department: Accra.

. (1948a) Report of the commission of enquiry into disturbances in the Gold Coast 1948, Report No.231, His Majesty's Stationary Office: London.

. (1948b) Annual report on the Gold Coast for the year 1947, His Majesty's Stationary Office: London.

. (1937) The Gold Coast handbook, West African Publicity: London and Accra.

. (1925-26) Gold Coast legislative council. The post-war Gold Coast: A review of the events of 1923 (minutes) Public Record Office, U.K., 98/45b.

. (1925) Guggisberg, G., The Gold Coast. A review of the events of 1924-1925 and the prospects of 1925-1926. Government Printer, Accra.

. (1923) Guggisberg, G., The Gold Coast. A review of the events of 1920-1926 and the prospects of 1927-1928, Government Printer, Accra.

Government of Ghana (GoG) (2006a) The council for technical and vocational education and training act, Government Printer: Accra.

. (2006b) Preliminary education sector performance report June 2006, MoEYS: Accra

- (2006c) Youth employment implementation guidelines (Ghana youth job corps programme) (March), MoMYE: Accra.

. (2006d) Terms of reference for a regional informal sector survey, Draft (May), MoTIPP: Accra.

. (2006e) Discussion paper on the implementation of the national qualifications framework $(N Q F)$, prepared by the COTVET preparation technical committee (CPTC) task force, draft of July $28^{\text {th }}, 2006$. MoESS/MoMYE: Accra. 
Government of Ghana (GoG) (2005a) Growth and poverty reduction strategy (GPRS II). The coordinated programme for the economic and social development of Ghana (2006-2009), (November), NDPC: Accra.

. (2005b) Preliminary education sector performance report July 2005, MoEYS: Accra . (2005c) The budget statement and economic policy of the Government of Ghana for the 2006 Financial Year, Ministry of Finance: Accra.

. (2005d) State of the Nation Address, delivered by President of Ghana J.A Kufuor on 03.02.05.

. (2005e) Project document for the pilot CBT project for TVET in Ghana (final draft, August), GoG/JICA: Accra.

. (2005f) Review of the STEP programme, internal review (mimeo), MoMYE: Accra.

. (2004a) White paper on the report of the education reform review committee, GoG:

Accra.

. (2004b) Draft TVET policy framework for Ghana (January), MoEYS: Accra.

. (2004c) Ghana poverty reduction strategy 2003 annual progress report, NDPC: Accra.

. (2004d) Preliminary education sector performance report 2004, MoEYS: Accra

. (2004e) The skills training programme (STEP), mimeo, MoMDE: Accra.

- (2004f) Preliminary report on monitoring Gratis foundation apprenticeship/STEP

programme, memo from the STEP monitoring officer to the deputy minister, MoMDE, $29^{\text {th }}$ October: Accra (mimeo).

. (2004g) Keynote address by the Deputy Minister (MoMDE), on the $2^{\text {nd }}$ Graduation ceremony of STEP programme at the City Educational Complex Bohyen (17.03.04), mimeo: Accra.

. (2004h) MoMDE STEP memorandum of understanding, MoMDE: Accra.

. (2004i) Draft TVET policy framework for Ghana (August), MoEYS/MoMDE: Accra.

. (2004j) The national reconciliation commission report, volume 4 (October).

. (2004k) National health insurance scheme. What you must know! Ministry of Health:

Accra.

. (2004l) Address the Ashanti Regional Minister at the graduation ceremony of STEP

programme at the City Educational Complex Bohyen (17.03.04), mimeo: Kumasi.

. (2003a) Ghana poverty reduction strategy (GPRS) paper. An agenda for growth and prosperity 2003-2005, IMF Country Report No. 03/56

. (2003b) Education strategic plan 2003 to 2015. Volume 1, Policies, targets and strategies, MoE: Accra.

. (2003c) National medium term private sector development strategy 2004-2008. Vol. 1

\& 2. GoG: Accra.

. (2003d) National health insurance bill, Government Printer: Accra.

. (2003e) Labour act, Government Printer: Accra.

. (2003f) Minutes of the first phase STEP review meeting (11.09.03) for Ashanti Region, mimeo: Kumasi.

. (2002) Meeting the challenges of education in the twenty first century. Report of the President's committee on the review of education reforms in Ghana (October, 2002):

Accra.

. (2000) Poverty trends in Ghana in the 1990s. Ghana Statistical Service: Accra.

. (1998) Children's act, Government Printer: Accra.

. (1995) Ghana - vision 2020 (The First Step: 1996-2000), Government Printer: Accra.

. (1992) The constitution of the Republic of Ghana, Government Printer: Accra.

(1972) Report of the education advisory committee on the proposed new structure and content of education for Ghana, Government Printer: Accra.

. (1970) National vocational training institute act, Government Printer: Accra. 
GoG/IFAD (2000) Rural enterprises project, Republic of Ghana, Interim evaluation, Report No.1097, IFAD.

Grierson, J. (1997) Where there is no job. Vocational training for self-employment in developing countries, SKAT/SDC/CAS: Switzerland.

Grierson, J. and Mackenzie, I. (Eds.) (1996) Training for self-employment through vocational training institutions, ILO: Turin.

GSS (2000) Ghana Living Standards Survey: report of the fourth round (GLSS 4), GSS: Accra.

Guarcello, L., Manacorda, M., Rosati, F., Fares, J., Lyon, S. and Valdivia, C. (2005) School-towork transitions in Sub-Saharan Africa: an overview, ILO/UNICEF/World Bank (November draft).

Guggisberg, G. (1922) The goal of the Gold Coast, Journal of the Royal African Society, 21(82): 81-91.

Gutkind, P. (1969) Tradition, migration, urbanization, modernity, and unemployment in Africa: The roots of instability, Canadian Journal of African Studies 3(2): 343-365.

Guyer, J. (1995) (Ed.) Money matters. instability, values and social payments in the modern history of West African communities, James Currey: London.

Haan, H. (2006) Training for work in the informal micro-enterprise sector: fresh evidence from Sub-Sahara Africa, Springer: Dordrecht.

. (2001) Training for work in the informal sector: fresh evidence from eastern and southern Africa, ITC/ILO: Turin.

Haan, H. and Serrière, N. (2002) Training for work in the informal sector: fresh evidence from western and central Africa, ITC/ILO: Turin.

Haggblade, S., Hazel, P. and Brown, J. (1989) Farm-nonfarm linkages in rural Sub-Saharan Africa, World Development 17(8): 1173-1201.

Haggblade, S. and Liedholm, C. (1991) Agriculture, rural labor markets, and the evolution of the rural nonfarm economy, GEMINI Working paper No. 19.

Hakam, A. (1978) Technology diffusion from the formal to the informal sector: the case of the auto-repair industry in Ghana, ILO: Geneva.

Hakin, C. (2000) Research design: successful designs for social and economic research, Routledge: London.

Hallak, J. and Caillods, F. (1981) Education, training and the traditional sector, IIEP: Paris.

Hamilton, E. and Asiedu, K. (1987) Vocational-technical education in tropical Africa, Journal of Negro Education, 56(3): 338-355.

Hammersely, M. and Atkinson, P. (1995) Ethnography: principles in practice (2 ${ }^{\text {nd }}$ Ed.), Routledge: London.

Harbison, F. (1967) The generation of employment in newly developing countries, in Sheffield, J. (Ed.) Education, employment and rural development, East African Publishing House: Nairobi.

Harper, M. (1984) Small business in the third world, John Wiley and Sons: Chichester.

Hart, K. (1976) The politics of unemployment in Ghana, African Affairs 75(301): 488-497. . (1973) Informal income opportunities and urban employment in Ghana, Journal of Modern African Studies 11(1): 61-89.

. (1970) Small-scale entrepreneurs in Ghana and development planning, Journal of Development Studies 6(4): 104-120.

. (1969) Entrepreneurs and migrants - a study of modernization among the Frafras of Ghana, $\mathrm{PhD}$ thesis (mimeo), University of Cambridge: Cambridge.

Heintz, J. (2004) Elements of an employment framework for poverty reduction in Ghana, Working Paper No. 85, Political Economy Research Institute University of Massachusetts: Amherst.

Hettige, H. (2006) When do rural roads benefit the poor and how?: an in-depth analysis based on case studies, Asian Development Bank: Manila. 
Hodge, P. (1964) The Ghana workers brigade: a project for unemployed youth, British Journal of Sociology 15: 113-128.

Honny, L. (1999) Reshaping vocational training: hopeful signs from a Ghanaian experience, in King and McGrath (1999a).

Hopkins, A. (1988) An economic history of West Africa, Longman: New York.

Hoppers, W. (1994) The promotion of self-employment in education and training institutions: perspectives in East and Southern Africa, ILO: Geneva.

House, W. (1984) Nairobi's informal sector: dynamic entrepreneurs or surplus labor? Economic Development and Cultural Change 32(2): 277-302.

Howard, R. (1978) Colonialism and underdevelopment in Ghana, Croom Helm: London.

Hugon, P. (1990) The informal sector revisited (in Africa), in Turnham et al. (1990).

ICCES (2006a) Minutes of centre managers meeting for 2005/2006, Regional Secretariat, Kumasi, 20.01.06 (mimeo).

. (2006b) A resolution of Ashanti Regional ICCES staff association, mimeo, 18.07.06. . (2004) ICCES: strategic plan (2004-2007), mineo (August), ICCES Directorate: Accra. . (1996) ICCES: background information, mimeo, ICCES Directorate: Accra.

ICLS (1993) 15th ICLS, Resolution II.

IDB (2000) Vocational and technical training: a strategy for the IDB: Washington.

IFAD (2004) Rural enterprise policy, IFAD: Rome.

Iliffe, J. (1983) The emergence of African capitalism, Pitman Press: Bath.

ILO (2005) Vocational training and skills development in the Poverty Reduction Strategy Papers: a preliminary review, ILO: Geneva.

. (2004) Summary report of the 17th ICLS for the statistical commission (02-05.03.04),

ILO: Geneva.

. (2003a) Working out of poverty, ILO: Geneva.

. (2003b) Decent Work Pilot Programme: country briefs, ILO staff seminar, Turin (July). . (2002) Women and men in the informal economy: a statistical picture, ILO: Geneva.

(1998) World Employment Report, 1998-1999: employability in the global economy, how training matters, ILO: Geneva.

. (1990) The promotion of self-employment, ILO: Geneva.

. (1988) Rural and urban training in Africa, ILO: Geneva.

. (1985) Rural and urban vocational training, ILO: Geneva.

(1972) Employment, incomes and equity: a strategy for increasing productive employment in Kenya, ILO: Geneva.

ILO/JASPA (1985) Informal sector in Africa, JASPA: Addis Ababa.

IMF (2005) Ghana: staff assessment of qualification for the multilateral debt relief initiative, prepared by the African Department (08.12.05) IMF: Washington.

Jain, B. (1991) Returns to education: further analysis of cross country data, Economics of Education Review 10(3): 253-58.

Jeans, A. (1999) Technology, NGOS \& small enterprise: securing livelihoods through technical change, in King and McGrath (1999a).

Jeffries, D., Warburton, H., Oppong-Nkrumah, K. and Fredua Antoh, E. (2001) Wealth ranking study of villages in peri-urban areas of Kumasi, Ghana, University of Greenwich / Kwame Nkrumah University of Science and Technology, Ghana.

Johanson, R. (2005) Knowledge and skills for agricultural productivity in Sub-Saharan Africa, World Bank, AFTHD, Draft 3.1.

Jolliffe, D. (2004) The impact of education in rural Ghana: examining household labor allocation and returns on and off the farm, Journal of Development Economics 73: 287-314.

. (2002) Whose education matters in the determination of household income? Evidence from a developing country, Economic Development and Cultural Change (50): 287-312. 
Jolliffe, D. (1998) Skills, schooling, and household income in Ghana, World Bank Economic Review 12(1): 81-104.

. (1996) Schooling, cognitive skills and household income: an econometric analysis using data from Ghana, $\mathrm{PhD}$ thesis (mimeo), Princeton University: Princeton.

Jones, J. (1922) Education in Africa: A study of West, South and Equatorial Africa by the African education commission, Phelps-Stokes Fund: New York.

. (1925) Education in East Africa, Phelps-Stokes Fund: New York.

Jones, P. (1992) World Bank financing of education: lending, learning and development, Routledge: London.

Kay, G. (Ed.) (1972) The political economy of colonialism in Ghana, Cambridge University Press: Cambridge.

Kerr, S. (2006) The Tanzania teachers union: pay, politics, and performance, $\mathrm{PhD}$ thesis (mimeo), CAS: Edinburgh.

Kilby, P. (1969) Industrialization in an open economy: Nigeria, 1945-1966, Cambridge University Press: London.

Kilby, P., Liedholm, C. and Meyer, R. (1984) Working capital and nonfarm rural enterprises, in Adams, G. and Pischke., v. (Eds.) Undermining rural development with cheap credit, Westview Press: Boulder.

Killick, T. (2004) What drives change in Ghana? A political-economy view of economic prospects, mimeo, ODI: London.

. (1978) Development economics in action. A study of economic policies in Ghana, Heinemann: London.

Killingray, D. (1978) Repercussions of World War 1 in the Gold Coast, Journal of African History 19(1): 39-59.

Kimble, D. (1963) A political history of Ghana. The rise of Gold Coast nationalism, 1850-1928, Clarendon Press: Oxford.

King, K. (2005a) Education, skills, knowledge and work on the world's development agenda, 2005, in Beveridge et al. (2005).

. (2005b) Re-targeting schools, skills and jobs in Kenya: quality, quantity and outcomes, International Journal of Educational Development 25(4): 423-435.

. (2001) Africa's informal economies: thirty years on, SAIS Review 11(1): 97-108.

. (1997) Introduction, in Grierson (1997).

. (1996) Jua Kali Kenya. Change and development in an informal economy 1970-95, James Curry: London.

. (1991) Aid and education in the developing world, Longman: Harlow.

. (1990a) Research, policy and the informal sector: African experience, in Turnham et al. (1990).

. (1990b) Emerging trends in Africa: a briefing note for new studies, in Turnham et al. (1990).

- (1990c) Training and structural adjustment: images from Ghana and Nigeria, Occasional Paper 29, CAS: Edinburgh.

- (1987) Evaluating the context of diversified secondary education in Tanzania, in Lauglo, J. and Lillis, K. (Eds.) Vocationalising education, Pergamon: Oxford.

. (1980) Education and self-employment, in IIEP, Education, work and employment, Vol.

2. IIEP: Paris.

. (1977) The African artisan. Education and the informal sector in Kenya, Heinemann:

London.

. (1971) PanAfricanism and education, Clarendon Press: Oxford.

King, K., Korboe, D. and Palmer, R. (2006) Technical and vocational education and training for employment: policy frameworks and practical realities in Ghana. Policy brief (mimeo). 
King, K. and Martin, C. (2002) The vocational school fallacy revisited: education, aspiration and work in Ghana 1959-2000, International Journal of Educational Development 22: 5-26.

King, K. and McGrath, S. (Eds.) (2002a) Learning-led competitiveness: education, training and enterprise in Ghana, Kenya and South Africa, Occasional Paper No. 93, CAS: Edinburgh. . (2002b) Globalisation, enterprise and knowledge, Symposium Books: Oxford.

(Eds.) (1999a) Enterprise in Africa, between poverty and growth, Intermediate Technology: London.

. (1999b) Enterprise in Africa: new contexts; renewed challenges, in King and McGrath (1999a).

King, K., McGrath, S., Nugent, P. and Trudell, B. (Eds.) (2002) Africa's young majority, Centre of African Studies: Edinburgh.

King, K. and Palmer, R. (2006a) Skills, capacities and knowledge in the Least Developed Countries: new challenges for development cooperation, background paper for the 2006 UNCTAD Least Developed Countries Report, CAS: Edinburgh.

. (2006b) Skills development and poverty reduction: the state of the art, Post-Basic Education and Training Working Paper no. 7, CAS: Edinburgh. See http://www.cas.ed.ac.uk/research/projects.html.

. (2006c) Education, training and their enabling environments: a review of research and policy, Post-Basic Education and Training Working Paper no. 8, CAS: Edinburgh. See http://www.cas.ed.ac.uk/research/projects.html.

King, K., Palmer, R. and Hayman, R. (2005) Bridging research and policy on education, training and their enabling environments, Journal of International Development 17(6):803-817.

King, K. and Postlethwaite, T. (1975) Curriculum development for basic education in rural areas, in Planning Problems in Rural Education, IIEP, UNESCO: Paris.

Kodithuwakku, S. and Rosa, P. (2002) The entrepreneurial process and economic success in a constrained environment, Journal of Business Venturing 17(5): 431-465.

Korboe, D. (2001a) Government of Ghana: vocational skills and informal sector support project, Project Evaluation Report (draft, 30.06.01).

. (2001b) Ghana: VSP beneficiary impact assessment, consultancy report for NACVET/World Bank.

Kpemlie, F. (1998) Small scale industries and rural development in Ghana. A case study of small-scale industries in South Tongu and Akatsi Districts in the Volta Region, MA thesis (mimeo), ISSER, University of Ghana: Legon.

Kunfaa, E. (1999) 'Consultations with the poor' Ghana country synthesis report. Report Commissioned by the World Bank for the Voices of the Poor study.

Kunfaa, E. and Dogbe, T. (2002) Empty pockets, in Narayan, D. and Petesch, P. (2002) Voices of the poor from many lands, World Bank: Washington.

Kvale, S. (1996) Interviews: an introduction to qualitative research interviewing, Sage: London.

Lanjouw, J. and Lanjouw, P. (2001) The rural non-farm sector: issues and evidence from developing countries, Agricultural Economics 26: 1-23

Lauglo, J. and Maclean, R. (Eds.). (2005) Vocationalization of secondary education revisited, Netherlands: Springer.

Lecompte, M. and Schensul, J. (1999) Designing and conducting ethnographic research. Ethnographer's toolkit 6, Sage: London.

Lewis, A. (1954) Economic development with unlimited supplies of labour, Manchester School of Economics and Social Studies 22: 139-191.

Leys, C. (1973) Interpreting African Underdevelopment: Reflections on the ILO Report on Employment, Incomes and Equality in Kenya, African Affairs 72(289): 419-429.

Liedholm, C. (1991) Dynamics of small-and micro-scale enterprises and the evolving role of finance, GEMINI Working paper No. 26. 
Liedholm, C. and Mead, D. (1999) Small enterprises and economic development: the dynamics of micro and small enterprises, Routledge: London.

Liimatainen, M. (2002) Training and skills acquisition in the informal sector: a literature review, ILO: Geneva.

Livingstone, I. (1997) Rural industries in Africa: hope and hype, in Bryceson and Jamal (1997). . (1991) A reassessment of Kenya's rural and urban informal sector, World Development 19(6): 651-670.

Lloyd, P. (1953) Craft organisations in Yoruba towns, Africa 23: 30-44.

Lockheed, M., Jamison, D. and Lau, L. (1980) Farmer Education and Farm Efficiency: a Survey, in Economic Development and Cultural Change 29(1): 37-76.

Logie, B. (2004) ICCES performance analysis 2004, draft report by a BESO volunteer to the ICCES directorate and MoMDE (09.12.04) mimeo: Accra.

Long, N. and Richardson, P. (1978) Informal sector, petty commodity production, and the social relations of small-scale enterprise, in Clammer, J. (Ed.) The new economic anthropology, Macmillan Press: London.

Lyon, F. (2000) Trust, networks and norms: the creation of social capital in agricultural economies in Ghana, World Development 28(4): 663-681.

Mamman, A. (2003) Skills needs of small and medium-sized enterprises: an investigation of the interface between labour market and vocational education and training in Nigeria, IDPM: Manchester.

Marris, P. and Somerset, A. (1971) African businessmen. A study of entrepreneurship and development in Kenya, Routledge and Kegan Paul: London.

Martin, C. (1976) Significant trends in the development of Ghanaian education, Journal of Negro Education 45(1): 46-60.

Martin, S. (1989) The long depression: West African export producers and the World economy, 1914-1945, in Brown, I. (Ed.) The economies of Africa and Asia in the inter-war depression, Routledge: London/New York. . (1988) Palm oil and protest. An economic history of the Ngwa Region, South-Eastern Nigeria, 1800-1980, Cambridge University Press: Cambridge.

McGrath, S. (2005a) Spreading the South African skills' revolution? in Beveridge et al. (2005). . (2005b) (Ed.) Skills development in very small and micro enterprises, HSRC press: Cape Town. . (1995) From PhD to consultancy: an alternative career path, Norrag News 18.

McGrath, S., Jedrej, C., King, K. and Thompson, J. (Eds.) (1997) Rethinking African history: interdisciplinary perspectives, CAS: Edinburgh.

McGrath, S., King, K., Leach, F. and Carr-Hill, R. (1995) Education and training for the informal sector, DFID Education Research, No.11. DFID: London.

McLaughlin, S., (1979) The wayside mechanic: an analysis of skill acquisition in Ghana, Centre for International Education, University of Massachusetts: Amherst.

McSheffrey, G. (1983) Slavery, indentured servitude, legitimate trade and the impact of abolition in the Gold Coast, 1874-1901: a reappraisal, Journal of African History 24(3): 349-368.

McWilliam, H. and Kwamena-Poh, M. (1975) The development of education in Ghana, Longman: London.

Mead, D. (1999) MSEs tackle both poverty and growth (but in differing proportions), in King and McGrath (1999a).

Mead, D. and Morrisson, C. (1996) The informal sector elephant, World Development, 24(10): 1611-1619.

Mead, D., Mukwenha, H. and Reed, L. (1993) Growth and transformation among small enterprises in Zimbabwe, GEMINI Working Paper, Maryland/PACT Publications: New York. 
Meghir, R. (1991) Formal and informal financial support for small and micro-enterprises, Journal of the Society for International Development 1: 102-108.

Meredith, D. (1988) The colonial office, British business interests and the reform of cocoa marketing in West Africa, 1937-1945, Journal of African History 29(2): 285-300.

Middleton, J., Ziderman, A. and Adams, A. (1993) Skills for productivity. Vocational education and training in developing countries, Oxford University Press/World Bank: New York.

Mkandawire, T. (1999) Developmental states and small enterprises, in King and McGrath (1999a).

Molony, T. (2006) Food, carvings and shelter: the adoption and appropriation of information and communication technologies in Tanzanian micro and small enterprises, $\mathrm{PhD}$ thesis (mimeo), CAS: Edinburgh.

Moock, P., Musgrove, P. and Stelcner, M. (1990) Education and earnings in Peru's informal nonfarm family enterprises, LSMS Working Paper No.64, World Bank: Washington.

Morton, P. (2004) Job quality in micro and small enterprises in Ghana: field research results, SEED Working Paper No. 68, ILO: Geneva.

Moser, C. (1978) Informal sector or petty commodity production: dualism or dependence in urban development? World Development 6(9/10): 1041-1064.

Mureithi, L. (1973) Non-farm economic activities in rural areas, in Child, F. and Kempe, A. (Eds.) Small scale enterprise, IDS, University of Nairobi, Occasional Paper no. 6, Nairobi: Kenya.

Muskin, J. (1997) Becoming an independent entrepreneur in the informal sector of northern Cote D'Ivoire: what role can primary schooling play? International Journal of Educational Development 17(3): 265-283.

Newman, C. and Sudharshan, C. (2000) Gender, poverty, and nonfarm employment in Ghana and Uganda, Policy Research Working Paper 2367, World Bank: Washington.

Ninsin, K. (1999) Informalization and Ghanaian politics, in Lauer, H. (Ed.) Ghana: changing values / changing technologies. Ghanaian Philosophical Studies, II. Cultural Heritage and Contemporary Change. Series II, Africa, Volume 5.

. (1991) The informal sector in Ghana's political economy, Freedom Publications: Accra.

Norton, A., Bortei-Doku Aryeetey, E., Korboe, D. and Dogbe, D (1995), Poverty assessment in Ghana using qualitative and participatory research methods, PSP Discussion Paper No. 83, World Bank: Washington.

NPP (1996) Development in freedom, agenda for change. Manifesto of the New Patriotic Party, 20.09.96.

Nugent, P. (2001) Winners, losers and also rans: money, moral authority and voting patterns in the Ghana 2000 elections, African Affairs 100(400): 405-29.

NVTI (2002) NVTI in perspective, NVTI: Accra.

Oketch, H. (1993) Education and training for the informal sector: Kenya. Kenya rural enterprise programme (K-REP), in McGrath et al. (1995).

Olukoju, A. (2002) The impact of British colonialism on the development of African business in colonial Nigeria, in Falola and Jalloh (2002).

Osei, B., Baah-Nuakoh, A., Tutu, K. and Sowa, N. (1993) Impact of structural adjustment on small-scale enterprises in Ghana, in Helmsing, A. and Kolstee, Th. (Eds.) Small enterprises and changing policies. Structural adjustment, financial policy and assistance programmes in Africa, Intermediate Technology: London.

Palmer, R. (2006a) Education, training and labour market outcomes in Ghana: a review of the evidence, Improving the Outcomes of Education for Pro-Poor Development, Working Paper No.1. (mimeo) CAS: Edinburgh. 
Palmer, R. (2006b) The social composition of skill acquisition and its labour market outcomes in Ghana: report of the southern fieldwork, Improving the Outcomes of Education for ProPoor Development (mineo), CAS: Edinburgh.

. (2005a) Skills for work?: from skills development to decent livelihoods in Ghana's rural informal economy, International Journal of Educational Development (article in press, available in 2007). See http://www.cas.ed.ac.uk/research/projects.html.

. (2005b) Beyond the basics: the need for a balanced education and training system in developing countries, Journal of Education in International Development 2(1): 1-21.

. (2005c) Beyond the basics: post-basic education and training and poverty reduction in Ghana, Post-Basic Education and Training Working Paper Series No. 4, CAS: Edinburgh. See http://www.cas.ed.ac.uk/research/projects.html. . (2004a) The financing of rural micro-enterprises: evidence from Nkawie-Kuma, Atwima District, Ghana, Occasional Paper No. 96, CAS: Edinburgh.

. (2004b) The informal economy in Sub-Saharan Africa: unresolved issues of concept, character and measurement, Occasional Paper No. 98, CAS: Edinburgh.

. (2001) ICCES: the way forward. An evaluation report for Integrated Community Centres for Employable Skills (ICCES) Ghana, mimeo.

Palmer, R., Wedgwood, R., Hayman, R., King, K., Thin, N. (2007) Educating out of poverty? A synthesis report on Ghana, India, Kenya, Rwanda, Tanzania and South Africa, Researching the Issues, No.70, DFID: London.

Parker, R., Riopelle, R. and Steel, W. (1995) Small enterprises adjusting to liberalization in five African countries, World Bank: Washington.

Partridge, C. (1910) Native laws and custom in Egbaland, Journal of the African Society 10: 422433.

Peil, M. (1974) Ghana's aliens, International Migration Review 8(3): 367-381. . (1971) The expulsion of West African aliens, Journal of Modern African Studies 9(2): 205-229.

. (1970) The apprenticeship system in Accra, Africa: Journal of the International African Institute 40(2): 137-150.

. (1969) Unemployment in Tema: the plight of the skilled worker, Canadian Journal of African Studies 3(2): 409-419.

Petchenkine, Y. (1993) Ghana, in search of stability, 1957-1992, Praeger: Westport.

Preddey, G. (2005) Skills training and employment placement (STEP): the programme document and performance appraisal, and proposals for enhancement, ILO: Geneva.

Preston-Whyte, E. (1991) Mere survival or the road to accumulation? Petty trading in Umgababa, in Rogerson, C. and Preston-Whyte, E. (Eds.) The South African informal economy: past, present and future, Oxford University Press: Johannesburg.

Psacharopoulos, G. (2006) World Bank policy on education: a personal account, International Journal of Educational Development 26: 329-338.

Psacharopoulos, G. (1980) Returns to education: an updated international comparison, in King, T. (Ed.) Education and income, Staff Working Paper No.402, World Bank: Washington.

Psacharopoulos, G. and Loxley, W. (1985) Diversified secondary and development: evidence from Colombia and Tanzania, Johns Hopkins Press: Baltimore.

Psacharopoulos, G. and Patrinos, H. (2002) Returns to investment in education: a further update, World Bank Policy Research Working Paper 2881, World Bank: Washington.

Quartey-Papafio, A. (1914) Apprenticeship amongst the Gas, Journal of the Royal African Society 13(52): 415-422.

Reardon, T. (1997) Using evidence of household income diversification to inform study of the rural nonfarm labor market in Africa, World Development 25:735-747.

Reardon, T., Berdegue, J. and Escobar, G. (2001) Rural non-farm employment and incomes in Latin America: overview and policy implications, World Development 29(3): 395-409. 
Reardon, T., Crawford, E. and Kelly, V. (1994) Links between non-farm income and farm investment in African households: adding the capital market perspective, American Journal of Agricultural Economics 76: 1172-1176.

Reinharz, S. (1997) Who am I? The need for a variety of selves in the field, in Hertz, R. (Ed.) Reflexivity and voice, Sage: Thousand Oaks.

Rhyne, M. and Otero, M. (1994) Financial services and microenterprises: principles and institutions, in Rhyne, M. and Otero, M. (Eds.) The new world of microenterprise finance. Building healthy financial institutions for the poor, IT Publications: London.

Rimmer, D. (1992) Staying poor: Ghana's political economy 1950-1990, Pergamon Press: Oxford.

Robertson, C. (1983) The death of Makola and other tragedies, Canadian Journal of African Studies 17(3): 469-495.

Rogerson, C. (2001) In search of the African miracle: debates on successful small enterprise development in Africa, Habitat International (25): 115-142.

Saint, W. (2005) Who understands African agriculture? Too few! Working Group for International Cooperation for Skills Development meeting 10-11.11.05, Rome.

Sawyerr, H. (1997) Country-led aid coordination in Ghana, ADEA: Paris.

Scott, A. (1979) Who are the self-employed?, in Bromley, R. and Gerry, C. (Eds.) Casual work and poverty in third world cities, John Wiley and Sons: Chichester.

Scott, J. (1976) The moral economy of the peasant. Rebellion and subsistence in Southeast Asia, Yale University Press: New Haven and London.

Shaffer, P. (1998) Poverty reduction strategies: a review, UN: New York.

Shaw, C. (1945) Bead-making with a bow-drill in the Gold Coast, Journal of the Royal Anthropological Institute of Great Britain and Ireland 75(1/2): 45-50.

Sievers, M. and Vandenberg, P. (2004) Synergies through linkages: who benefits from linking finance and business development services? SEED Working Paper No. 64, ILO: Geneva.

Silver, H. (1981) Carving up the profits: apprenticeship and structural flexibility in a contemporary African craft market, American Ethnologist 8(1): 41-52.

Simon, D. (1984) Urban poverty, informal-sector activity and intersectoral linkages: evidence from Windhoek, Namibia, Development and Change 15(4): 551-576.

Smillie, I. (1986) No condition permanent. Pump-priming Ghana's industrial revolution, IT Publications: London

Smith, E. (1929) Aggrey of Africa, Ayer Co. Publishers: London.

Stake, R. (1998) Case Studies, in Denzin, N. and Lincoln, Y. (Eds.) Strategies of qualitative enquiry, Sage: London.

Start D. (2001) The rise and fall of the rural non-farm economy: poverty impacts and policy options, Development Policy Review 19(4): 491.

Steele, D. (1972) Hindrances to the programme to encourage the rise of African entrepreneurship in Kenya resulting from the theory of the dual economy, in Developmental trends in Kenya, CAS: Edinburgh.

Steel, W., Aryeetey, E., Hettige, H. and Nissanke, M. (1997) Informal financial markets under liberalization in four African countries, World Development 25(5): 817-830.

Steel, W. and Webster, L. (1991) Small enterprises under adjustment in Ghana, World Bank Technical Paper No. 138, Industry and Finance Series, World Bank: Washington.

Teal, F. (2001) Education, incomes, poverty and inequality in Ghana in the 1990s, CSAE WPS/2001-21: Oxford.

Tellegen, N. (1997) Rural enterprises in Malawi: necessity or opportunity? African Studies Centre: Leiden.

Thin, N. (1999) Evaluation of poverty reduction literature reviews and annotated bibliography, Edinburgh: University of Edinburgh for OECD Development Assistance Committee, Working Group on Evaluation. 
Thomas, R. (1974) Education in northern Ghana, 1906-1940: a study in colonial paradox, The International Journal of African Historical Studies 7(3): 427-467.

Thomi, W. and Yankson, P. (1985) Small scale industries and decentralisation in Ghana, University of Ghana: Legon.

Trager, L. (1987) A re-examination of the urban informal sector in West Africa, Canadian Journal of African Studies, 21(2): 238-255.

Tribe, M. (1995) Rural small-scale industrial development in Ghana: an exploration of issues, Science, Technology and Development 13(1): 55-62.

Tripp, A. (1997) Changing the rules. The politics of liberalization and the urban informal economy of Tanzania, University of California Press: New York.

Turnham, D., Salome, B. and Schwarz, A. (Eds.) (1990) The informal sector revisited, OECD: Paris.

UN (2005) 2005 World summit outcome, draft resolution (20.09.05), World Summit, UN: New York.

UN Millennium Project (2005) Investing in development: a practical plan to achieve the Millennium Development Goals, Earthscan: London/New York.

UNDP (2005) Human development report 2005, UNDP: New York. . (2004) Unleashing entrepreneurship making business work for the poor, UNDP: New York.

UNDP/NDPC (2004) District Human Development Report 2004, Atwima District, UNDP/NDPC: Accra.

UNDP/ISSER (2001) Ghana human development report 2000, ISSER/UNDP, Worldwide Press: Accra.

UNESCO-IIEP (2004) Promoting skills development, UNESCO-IIEP: Paris.

UNESCO (2004) Education for all: The quality imperative, Education for all global monitoring report, UNESCO: Paris. . (2003) Synthesis of main findings from two case studies carried out in Ghana and Zambia on private TVET (Phase II), IIEP: Paris

. (2000) The dakar framework for action, education for all: meeting our collective commitments, Dakar, 26-28.04.00, UNESCO: Paris.

Valenchik, A. (1995) Apprenticeship contracts, small enterprises, and credit markets in Ghana, World Bank Economic Review 9(3): 451-475.

Vijverberg, W. (1999) The impact of schooling and cognitive skills on the income from non-farm self employment, in Glewwe, P. (Ed.) The economics of school quality investments in developing countries, St. Martins: New York.

. (1995) Returns to schooling in non-farm self-employment: an econometric case study of Ghana, World Development 23(7): 1215-1227.

WCEFA (1990) Meeting basic learning needs: a vision for the 1990s, Background document for the WCEFA, Jomtein, Thailand, WCEFA: New York.

Webster, L. and Fidler, P. (1996) The informal sector and micro finance institutions in West Africa, World Bank: Washington.

Wedgwood, R. (2005) Post-Basic Education and Poverty in Tanzania, Post-Basic Education and Training Working Paper Series No. 1, CAS: Edinburgh.

Weeks, J. (1973) Does employment matter? in Jolly, R., de Kadt, E., Singer, H. and Wilson, F. (Eds.) Third world employment, Penguin: London.

Williams, T. (1964) Sir Gordan Guggisberg and education reform in the Gold Coast 1919-1927, Comparative Education Review 8(3): 290-306.

Williams, P. (2005) Universal Primary Education - for the $2^{\text {nd }}$ time - in Anglophone Africa, in Beveridge et al. (2005). 
Working Group for International Cooperation in Skills Development (WGICSD) (2002) World Bank study on vocational skills development in Sub-Saharan Africa - a working group review, Debates in Skills Development, Paper 7. WGICSD: Edinburgh.

World Bank (2006a) Doing business database (www.doingbusiness.org) . (2006b) World development report 2007. Development and the next generation, World Bank: Washington. . (2005a) Education sector strategy update. Achieving education for all, broadening our perspective, maximizing our effectiveness (December), World Bank: Washington. . (2005b) The youth and prospects for quality jobs in Ghana (final draft, December), World Bank: Washington. . (2005c) Project appraisal document for a micro-small and medium enterprise project, World Bank: Washington. . (2004a) Skills development in Sub-Saharan Africa, World Bank: Washington. (2004b) World development report 2005. A better investment climate for everyone, World Bank: Washington. . (2004c) Books, buildings, and learning outcomes: an impact evaluation of World Bank support to basic education in Ghana, Operations Evaluation Department, Report No. 28779, World Bank: Washington.

. (2003) Reaching the rural poor, World Bank: Washington.

. (2002) Constructing knowledge societies: new challenges for tertiary education, World Bank: Washington.

- (2001) Implementation completion report on a loan/credit/grant to Ghana for an education and training project, draft internal document, World Bank: Washington. . (2000a) Can Africa claim the 21st century? World Bank: Washington. . (2000b) Attacking Poverty: World Development Report 2000/01, Washington: World Bank. . (1996) Basic education sector improvement program, staff appraisal report, Republic of Ghana, World Bank: Washington.

. (1995) Vocational skills and informal sector support project, Staff Appraisal Report No.13691-GH, World Bank: Washington.

. (1991) Vocational and technical education and training: a World Bank policy paper, World Bank: Washington.

. (1985) Ghana agricultural sector review, World Bank: Washington.

Xaba, J., Horn, P. and Motala, S. (2002) The informal sector in Sub-Saharan Africa, Working Paper on the Informal Economy, ILO: Geneva.

Yamada, S. (2005) Socio-moralist vocationalism and public aspirations: secondary education policies in colonial and present-day Ghana, Africa Today 52(1): 71-94.

Yin, R. (1994) Case study research: design and methods, Thousand Oaks: London.

Yokozeki, Y. (2005) Education for sustainability in Africa, in Beveridge et al. (2005).

Ziderman, A. (2003) Financing vocational training in Sub-Saharan Africa, World Bank: Washington. 